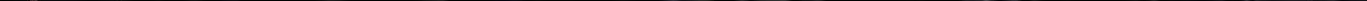




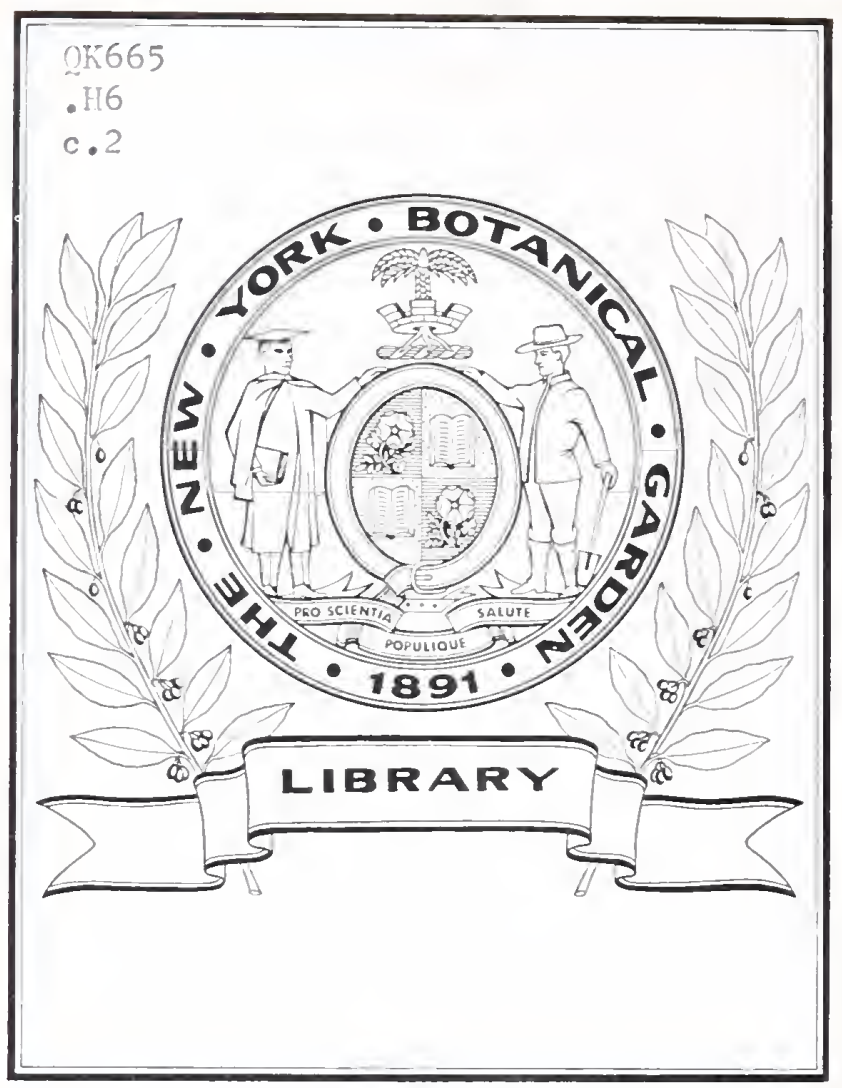






\section{W. HOFMEISTER,}

MITGIAED DER RÖ.VGL. SÄCHS. GESELLSCIAF' DER WISSENSCHAFTEN

\section{NEUE BEITRÄGE}

ZUR

\section{KENNTNISS DER EMBRYOBILDUNG}

DER

\section{PHANEROGAMEN.}

1.

MIKTYLEDONEN MT URSPRUNGLICH EINZELLIGEM, NUR DURCH ZELLENTHEILUNG WACHSENDEM ENDOSPERM.

MIT' 27 'TAFELN.

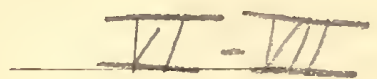

Aus den Abhandlungen der mathematisch-physischen Classe der Königlich Säcbsischen

Gesellschaft der Wissenschaften.

\section{LEIPZIG}

B E I S. H I R Z E L.

1859. 


\title{
ABHANDLUNGEN
}

DER

KÖNIGL. SÄCHSISCHEN GESELLSCHAFT DER WISSENSCHAF'TEN

\author{
ZU LEIPZIG.
}

ERSTER BAND: Abhandlungen der mathe matisch-phy s $\mathrm{c}$ hen Classe. Erster Band. Mit 3 Tafeln. hoch 4. 1852. broch. Preis 4 Thlr. 16 Ngr.

In halt:

A. F. MÖBIUS, über die Grundformen der Linien der dritten Ordnung.

$21 \mathrm{Ngr}$

P. A. HANSEN, allgemeine Auflösung eines beliebigen Systems von linearischen Gleichungen. - Ueber die Entwickelung der Grösse $\left(1-2 \alpha H+\iota^{2}\right)-\frac{1}{2}$ nach den Potenzen von $\alpha$.

$12 \mathrm{Ngr}$

A. SEEBECF, ïbcr die Querschwingungen elastiscber Stäbe.

$10 \mathrm{Ngr}$.

C. F. NAUMANN, über die cyclocentrische Conchospirale und üher das Windungsuesetz von Planorhis Corneus.

$10 \mathrm{Ngr}$.

IV. WEBER, elektrodynamische Maassbestimmungen (Widerstandsmessungen), I'Thlr.

F. REICH, neue Versuche mit der Drehwage.

M. IV. DROBISCH, Zusätze zum florentiner Problem.

W. WEBER, elektrodynamische Maassbestimmungen (Diamagnetismus.)

$20 \mathrm{Ngr}$.

$16 \mathrm{Ngr}$.

$20 \mathrm{Ngr}$.

ZWEITER BAND: Abhandlungen der philologis $\mathrm{ch}-\mathrm{h}$ is tor is chen Classe. Erster Band. Mit einer Karte. hoch 4. 1850. broch.

Preis 6 Thlr. In h a I :

A. WESTERMANN, Untersuchungen über die in die attischen Redner eingelegten Urkunden. 2 Ahhandlungen.

1 Thlr.

F. A. UKERT, über Dämonen, Heroen und Genien.

$24 \mathrm{Ngr}$.

TH. MOMMSEN, üher das römische Münzwesen.

1 Thlr. $20 \mathrm{Ngr}$.

E. v. WIETERSHEIM, der Feldzug des Germanicus an der Weser.

I Thlr.

G. HARTENSTEIN, Darstellung der Rechtsphilosophie des Hugo Grotius.

$20 \mathrm{Ngr}$.

TH. MOMMSEN, über den Chronographen vom Jalıre 3j4. Mit einem Anhange uher die Quellen der Clironik des Hieronymus.

1 Thlr. $10 \mathrm{Vgl}$.

DRITTER BAND: Abhandlungen der philologisch-historischen Classe.

Zweiter Band. Mit 3 Tafeln. hoch 4. 1857. broch. Preis 7 Thlr. 10 Ngr. In h a l t :

W. ROSCHER, zur Geschichte der Englischen Volkswirthschaftslehre im sechzehnten und siehzehnteu Jahrhundert $18 j 1$.

1 Thir.

Nachträge. 1852.

J. G. DROYSEN, Eherhard Windeck. 1853.

$8 \mathrm{Ngl}^{\circ}$.

TH. MOMMSEN, Polemii Silvii laterculus. 1853.

$24 \mathrm{Ngr}$.

$16 \mathrm{Ngr}$.

Volusii Maeciani distrilutio partium. 1853.

6 Yarr.

J. G. DROYSEN, zwei Verzeichnisse, Kaiser harls V. Lande, 'seine und seiner Grossen Einkünfte und anderes betrelfend. 1854 .

$20 \mathrm{Nor}$.

TH. MOMMSEN, die Stadtrechte der latinischen Gemeinden Salpensa und Malaca in der Provinz Baetica. 18 jう.

Nachträge. 1855.

1 Tulr.

$16 \mathrm{Ngr}$.

FRIEDRICH ZARNCKE, Die urkundlichen Quellen zul Geschichte der Universität Leipzig in den ersten $150 \mathrm{Jahren}$ ihres Bestehens. 1857. 3 Thlr.

VIERTER BAND : Abhandlungen der mathematis $\mathrm{ch}-\mathrm{phy}$ is $\mathrm{che}$ h Classe.

Zweiter Band. Mit 19 Tafeln, hoch 4. 1855. br. Preis 6 Thlr. 20 Ngr.

In halt:

M. W. DROBISCH, über musikaliscbe Tonbestimmung und Temperatur. 1852 . I Thlr.

IV. HOFMEISTER, Beiträge zur Kenutniss der Gefässkryptoganen. Mit 18 Tafeln. 18j2. 


\section{AB H A NDLUNGEN}

SEGHSTER B $\Lambda$ ND. 
Digitized by the Internet Archive in 2017 with funding from IMLS LG-70-15-0138-15 


\section{ABIIANIDLINGEN}

\section{DER KÖNIGLIC'II SÏCIISISA' IIES}

\section{GESELLSCIIAFT DER WISSENSCHAFTEN.}

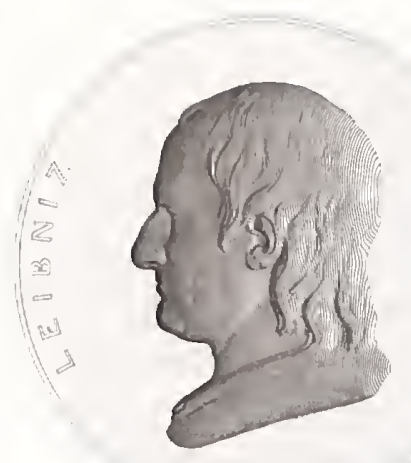

SECISTER BAND.

MIT NEL NUEWIVZG TAEEL

\section{LEIP'ZIG}

BSEI S. II I RZEL.

$18 \% 9$. 


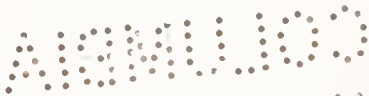

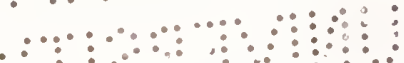

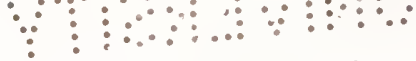

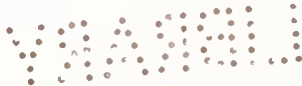




\section{N II A L T.}

P. A. Hansen, Auseinandersetzung einer zweckmiissigen Methode zur Berechnung der absoluten Störungen der kleinen Planeten. Zweite $\mathrm{Ab}$ handlung . . . . . . . . . . . . . . . . . . .

W. G. IhNkel, Elektrische Untersuchungen. Zweite Abhandlung, über die thermo-elektrischen Eigenschaften des Boracites . . . . . . . - 149

Derselbe, Elektrische Untersuchungen. Dritte Abhandlung, über Elektricitaitserregung zwischen Metallen und erhitzten Sazen . . . . . . . . - 253

P. A. Hunsen, Theorie der Sonnenfinsternisse und verwandten Erscheinungen. Mit 2 Tafeln. . . . . . . . . . . . . . -303

G. T. Fecuner, Ueber ein wichtiges psychophysisches Grundgesetz und dessen Beziehıng zur Schätzung der Sterngrössen . . . . . . . - 453

Wilnely Hofyeister, Neue Beitriige zur Kenntniss der Embryobildung der Phanerogamen. 1. Dikotyledonen mit ursprünglich einzelligem, nur durch Zellentheilung wachsendem Endosperm. Nit 27 Tafeln. . . . . - 533 
Indem die mathematisch-physische Classe der Königlich Sächsischen Gesellschaft der Wissenschaften den vierten Band ihrer Abhandlungen herausgiebt, ist sie verpflichtet mit Dank der kräftigen Unterstützung der Fürstlich Jablonowskischen Gesellschaft zu gedenken, ohne welche es ihr nicht möglich gewesen sein würde innerhalb des Zeitraums, in welchem es geschehen ist, die erschienenen Bände zu veröffentlichen. 


\section{NEUE BEITRÄGE}

ZIK

\section{KENNTNISS DER EMBRYOBILDUNG}

DER

\section{PIIANEROGAMEN}

vox

\section{WILHELM HOFMEISTER.}

I.

DIKOTYLEDONEN MT URSPRUNGLICH EINZELLIGEM, NUR DURCII ZELLENTHEILUNG WACHSENDEM ENDOSPERM. 


$$
\text { Botang ir. II }
$$


Die heiner phanerogamen Pllanze völlig fehlende, die Entwickelung des Embryo begleitende Zellenbildung im befruchteten Embryosacke, welche im Raume desselben in vielen Fällen einen umfangreichen Körper aus geschlossenem Zellgewelse erzeugt, in den hinein der heranwaclisende Embryo dringt; - und die auch da, wo sie am spärlichsten auftritt, in dem vorübergehenden Erscheinen einzelner freier Zellen oder doch Zellenkerne in der Flussigkeil des Embryosackes zum Wenigsten in einzelnen Individuen der betreffenden Pflanzen sich :aussert*): - diese Zellbildung erscheint bei den Pflanzen einiger Verwandtschaftskireise in einer eigenthümlichen Modification. Es bildet sich im eben befruchteten Embryosacke eine einzige, verlältnissmässig grosse Zelle, welche einen beträchtlichen Theil des Raumes desselben vollständig ausfültt, in der Art, dass gleich beim ersten Sichtbarwerden dieser Zelle ihre Seitenwände der Innenwand des Sackes dicht anliegen. Diese Zelle theilt sich durch eine Scheidewand in zwei Tochterzellen; ein Vorgang der in den Theilzellen stetig sich wiederholt, bis die volle Zellenzahl des Endosperms erreicht ist. Die so sich verhaltenden Pflanzen gehören folgenden Familien an:

Loranthaceen, Santalaceen, Aristolochieen, Asarineen, Cytineen, Balanophoreen ; -

Orobancheen, Scrophularineen, Bignoniaceen, Acanthaceen, Labiaten, Verbenaceen, Selagineen, Globulariaceen, Lentibularieen, Gesneriaceen, Hydrophylleen, Plantagineen; -

Ericaceen, Epacrideen, Pyrolaceen (mit Einschluss der Monotro* peen), Droseraceen; -

Campanulaceen, Loasaceen, Bartonieen.

*) So bei Tropaeolum, Trapa, Najas, Zostera, Ruppia, Canna, Orchideen. 
Der ganze Innenraum des Embryosaclis verhält siclı als Anfangszaile des firosperms bei den Asarineen, Aristolochiaceen, Balanophoreen, Prolaceen, Nonotropeen; die erste Theilung des Sackes erfolgt durôn jho in zwei ziomlich gleiche Halften scheidende Wand, deren jede einen Zellenkern einschliesst, und deren jede mindestens noch einmal Tochterzellen bildet. - Dagegen nimmt die Anfangszelle des Endosperns das obere Ende des Embryosacks ein; - es erscheint der eben befruchtete Embryosack durch eine Querwand in zwei Hälften geschieden, deren obere durch eine Reihe ron Zweitheilungen zum Endosperm sich umwandelt, während in der unteren keine solche Zellentheilung stattindet, bei Viscum, Thesium, Lathraea, Rhinanthus, Mazus, Melampyrum, Globularia. - Sie füllt die Mittelgegent des Embryosacks aus bei Veronica, den Labiaten, Nemophila, Pedicularis, Plantago, Campanula, Loasa; - das untere Ende desselben bei Loranthus, Acanthus, Catalpa, Hebenstreitia, Verbena, Vaccinium. Die angedeuteten Unterschiede in der Entwickelungsweise des Endosperms lassen sich schärfer und richtiger ausdrüicken. wenn man - wie dies anch die consequente Anwendung der bekannten Regeln der Zellbildung verlangt, - in allen Fällen den ganzen Embryosack als liutterzelle des Endosperms betrachtet; seine zwei ersten Theilhäften schon als erste Endospermzellen auffasst, und dann die Intensitait der weiteren Vermehrung der Endospermzellen in den verschiedenen Gegenden des Embryosacks bezeichnet. Unter diesen Voraussetzungen ordnen sich die Thatsachen in folgender Weise.

A. Die Endospermzellen vermehren sich sämmtlich; die Intensităt der Vermehrung nimmt von beiden Enden des Embryosacks gegen dessen Mitte hin allmälig ab.

Aristolochia, Balanophoreen. Pyrola, Drosera, Bartonia (bei letzterer abgesehen rom scheitelständigen Auswuchs des Embryosacks, der hier schon vor der Befruchtung durch eine Querwand vom ursprünglichen Raume geschieden wird).

B. Die eine der beiden ersten Tochterzellen des Embryosacks rermelırt sich gar nicht; alle Zellenvermelırung findet nur in deren schwesterzelle statt.

«. Nur die untere der beiden Tochterzellen vermehrt sich

Loranthus, Lepidoceras, Catalpa, Acanthus.

8. Nur die obere theilt sich fernerhin. 


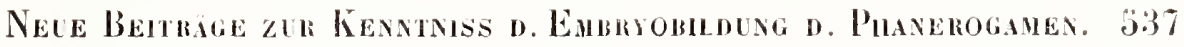

1. Hhre Vermehrung ist allseitig gleichmaissig in dem Sinne wie unter a:

\section{Viscum. Thesium. Asarum.}

2. Die den Scheitel des Embryosachs ausfullenden Tochterzellen halten weit fruher in der Vermehrung inne, als die übrigen.

a. Der Theilungen der äussersten, die Keimblischen einschliessenden Scheitelzelle sind nur eine, oder $1 \times 1$ :

Lathraea. Mazus. Veronica hederacfolia und triphyllos. Rhinanllus. Melampyrum. Plantago. Globularia.

b. Die äusserste Scheitelzelle bleibl ganz und gar ohne Theilung durch Längswände:

Pedicularis. Veronica hederaefolia und Buxbauniii. Nemophila. AcanIhus. Catalpa. Lamium. Prostanthera. Hebenstreitia, Campanulaceen. Loasa.

So scharf auch diese Eigentlumblichkeit des Entwichelungsganges des Endosperms bei den genaunten Pllanzen hervortritt, so schwierig ist es doch, die Gränze zwischen den Phanerogamen mil nur durch Zelltheilung wachsendem Endosperm, und denen deren Endosperm durch freie Zellbildnng angelegt wird, mit Genauiglicit zu ziehen.

Auch bei einigen Pllanzen aus anderen Familien kommt ein einzelliger Zustand des Eudosperms vor. Das obere Eude des Embryosachis erscheint sehr bald nach der Befruchtung durch eine Querwand ron dessen übrigem Raume abgeschieden; und nur in jenem oberen, auch die Keimbläschen einschtliessenden Theile fundet die weitere Bildung von Tochterzellen statt. So ist es unter den Dikotyledonen bei Nymphaca, Nuphar, Ceratophyllum, unter den Monokolyledonen bei Anthurium longifolium. Aber ein wesentlicher Unterschied zwischen den vorgenannten und diesen letzleren findet darin stall, dass hier das bleibende Endosperm durch eine, innerhall, der oberen Theilhälfte des Embryosaks eintretende freie Zellenbildung angelegt wird. Es bilden sich in seiner einzigen Mutterzelle gleichzeilig mehr als zwei freie Zellenkerne. Un diesellsen entstehen Zellen, welche bei ihrem ersten Erscheinen die Mutterzelle noch nicht völlig ausfillen. Dies ist sehr deutlich bei Anthurium; schwer erkennbar bei Nuphar, insofern die Zahl frei entstehender Zellkerne in der Regel dhei nicht ubersteigt.

Den Pllanzen, deren Endosperm durch forgesetzte Zwoillieilung einer einzigen Mutterzelle entsteht, ist es gemeinsam, dass der Embryo- 
sack besonders lebhafte Wachsthumserscheinungen, und eine hohe Entwickelung seiner Membran zeigt. Schon vor der Befruchtung äussert der Embryosack ein ungewöhnliches Längenwachstlıum bei den meisten der hierher gehörigen. Nach erfolgter Befruchtung treibt er häufig seitliche, oder grundstaindige, in einzelnen Fällen sellsst gipfelständige Aussackungen, blinddarmartige Anhänge, welche zerstörend in die benachbarten Gewele weit eindringen. Seine Haut ist überall derb, besonders stark verdickt namentlich in der Scheitelgegend. In jeder Beziehung verhält sich der Embryosack hier selbstständiger, in seinen Lebenserscheinungen minder gebunden an die der angränzenden Gewebe, als bei anderen Phanerogamen.

Die weit überwiegende Mehrzahl der ìchten Parasiten gehört zu dieser grossen Gruppe*). Sie begreift nur dikotyledone Gewächse; unter diesen năchst den ächten Parasiten vorwiegend solche, deren Vegetation durch einen sehr humusreichen Boden bedingt wird (z. B. die nicht parasitischen Rhinanthaceen und Scrophularineen, die Monotropeen, Pyrolaceen, Ericaceen, Asarineen, u. s. w.).

Die Anordnung, Grösse und Festigkeit der Wände der Endospermzellen der Pflanzen aus diesen Familien machen sie zu besonders geeigneten Gegenständen der Erörterung, ob die Endospermbildung auch beim Unterbleiben der Befruchtung, in Embryosäcken, in welchen kein Embryo aus dem Keimbläschen sich entwickelt, eintreten könne. Aus dem Ergebniss der zahlreichen Untersuchungen folgt die entschiedene Verneinung dieser Frage.

*) Auszunehmen ist nur Cuscuta, deren Endosperm durch freic Zellbildung spät, ersl geraume Zeit nach der Befruchtung, entstcht. 
l.

\section{Loranthaceen.}

Loranthis europaens $\mathrm{LL}_{\text {. }}$ ).

Taf. I-IV.

Die Blüthenknospen des Loranthus europaeus werden in dem, der Blühe um ein Jahr vorausgehenden, Frühlinge angelegt. Mitte Juni erscheint der junge (weibliche) Blüthenstand als ein schlanker Spross, der vier bis acht Pare decussirter, kurzer, fleischiger Bracteen trägt. In der Achsel jeder Bractee steht eine abgeplattet warzenförmige "Zellgewebsmasse, nahezu von Form eines umgekehrten gestutzten Keģels (T. I. F. 1). Sie ist die Anlage einer Bläthe.

Einen Monat später haben auf der Sclıcitellaiche dieser Zellgewelssmasse zwei dreigliedrige Kreise von mit einander alternirenden Blatlorganen sich erhoben: nach der Mitte der Blithe zu ühergeneigte kurze dicke Platten aus Zellgewebe von dreiseitigem Umriss (T. I. F. 2, 2"). Sie sind die Perigonialblätler. - Der Rand der Scheitelfäche der Knospe hat sich zu einem gleichhohen Ringwulste entwickelt, und stellt so den sogenannten Calyculus dar.

Auf Längsdurchschnitten solcher Knospen erkennt man, dass innerhalb der zwei dreigliedrigen Kreise von Perigonialblattern noch zwei, ebenfalls dreigliedrige, je mit dem nächstvorentstandenen äusseren abwechselnde Kreise von Blaltorganen entstanden sind (T. 1. F. 3). Sie sind die Anlagen der Staubfidden. Die Rückenfläche jedes derselben verwächst auf eine geraume Strecke mit der Vorderfläche des von ihm nach aussen stehenden Perigonialblattes. - In der Mitte der Blüthenknospe steht das fortentwickehngsfähige Ende ihrer Achse, von Form eines sehr flachen Kegels. Auf dieser Stufe der Ausbildung der Bluithenknospe tritt die Winterruhe ein.

*) Ich verdanke das Naterial zur Ůntersuehung der Bläthen- und Embryoentwickelung dieser interessanten Pflanze Herrn Professor Fenzl, weleher die Guite hatte, wïhrend des Frülulings und Sommers 1852 von etwa 10 zu 10 Tagen frisch abgesehnittene Zweige beider Gesehleehter derselben von Wien aus mir zu übersenden. 
Ende Aprils des nächsten Frühlings lıat um das Centrum der Bluithenknospe ein füfter Kreis von drei Blattorganen sich erhoben, die Carpelle. Sie stehen aufrecht; sind geraume Zeit nach ihrem Auftreten völlig frei von einander, von Form gleichseitiger Dreiecke (T. I. F. 4, 6). Der Mittelpunkt der Blüthe erscheint jetzt als eine tiefe Einsenkung zwischen ihnen. Die Anordnung der Zellen dieses zu noch weiterer Entwickelung bestimmten Endes der Blïthenaclıse erinnert, auf Längsdurchschnitten gesehen, an die der Terminalknospe von Ophioglossum * ${ }^{*}$. Senkrecht unter ihm, in geringer Tiefe, besteht eine meniskenförmige Stelle des Gewebes der Blithenachse aus besonders kleinen würfeligen Zellen mit engen lufterfüllten Intercellularräumen. Dieses Gervebe, welches auf Längsdurchschnitten bei durchfallendem Licht als dunkler Ialbmond sehr auffällig hervortritt, entspricht in seiner Zusammensetzung (und, wie die Folge zeigen wirl, in seiner Lage) der Chalaza eines Eychens (T. I. F. 4, ch). Es bleibt im heranreifenden Samen sehr lange kenntlich.

Gegen Nitte Mai erscheint das Ende der Blüthenachse aufs Neue zu einem flachen Kegel umgewandelt (T. I: F. 7 u. 8). Die drei CarpelJen, mit ihren Seitenrändern inzwischen röllig verwachsen, stellen einen die Mitte der Knospe ausfüllenden, bis zur Höhe der Staubfadenrudimente reichenden gestutzten Kegel dar, auf dessen Scheiteltläche ein axiler, auf das Ende der Blüthenachse zuführender, enger Kanal, der Griffelkanal, sich öfnet.

Von jetzt ab entwickeln sich die Blüthentheile sehr rasch in dic Länge. Schon in der letzten Häfte des Mai reicht die Spitze des Griffels bis in die Innenwölbung des Scheitels der Knospe. Sein Wachsthum geschieht zunächst durch apicale, später durch intercalare Zellvermehrung, die in der breiten Basis des Griffels ihren Hauptsitz hat. Die Zellvermehrung in den Perigonialblältern ist ausschliesslich intercalar, auf die Gegend dicht iber ihrem Grunde beschränkt. Die Rudimente der Staubfäden werden dadurch hoch empor geholsen (T. I. F. 12, s). Auch in der Blüthenachse dicht unterhalb der Einfügung der Perigonialund Carpellarblatter findel eine noch lebhaftere intercalare Vermehrung der Zellen statt, durch welche die bis dahin halbkugelige Gewebsmasse langgestreckte Eyform erhält, und - der gewöhnlichen Entwichelungs-

a Yergleiche in Bd. Y. math. phys. Cl. Bd. IlI. dieser Abhandungen T. XI. F. 1 $^{\text {b }}$. 


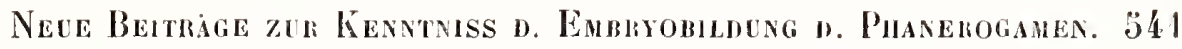

weise unterständiger Fruchtknoten gemäss, — das Ende der Blithenachse tief zwvischen ihre rasch emporwachsenden peripherischen Theile versenkt wird.

Während dieser Vorgänge verwächst das tlach kegelfïrmige Ende der Blüthenachse - das einzige, aufrechte nackle Ey des Loranthus vollständig mit den Innenwinden der Iöhlunģ innerhalls der zum Fruchtknoten verschmolzenen Carpelle. Die intercalare Zellvermelırung dieser, hicr am Iebhaftesten, ibberträgt sich auch auf einen Theil der wenigen Zellen des Eyclıens, die in rasch wiederholter Folge durch Querwände sich theilen. In anderen, der Mlehrzahl dieser Zellen erfolgt diese Theilung nur sparsam; sie werden bei dem starken Laingenvadisthum der umgebenden Gewebe betrachtlich in die Länge gestreckt. Kurz vor dem Aufbrechen der Blithenknospe erscheint der axile Theil des jetzt eine solide Zellgewebsmasse darstellenden Fruchthnotens - ein durch grrössere Durchscheinendheit von den übrigen Geweben desselben aullällig unterschiedener spindelförniger Zellenkörper (T. I. F. 12, die Region um die mit $e$ bezeichnete Stelle) — zusammengeselzt aus einer Anzahl kurzer, fast wüfeliger, und aus minder oder mehr gestreckten Zellen (T. I. F.10, T. II. F. 12, T. III. F. 1). Die am lingsten gestreckiten dieser Zellen (meist drei im Kreis stehend, doch ist auch die Zweizahl häufigg,) sind die Enbryosticke: meistens von cylindrischer Form, mit etwas erweiterten oberen und unteren Enden (T. III. F' 1-3, 5); bisweilen aber auch sonderbare Krümmungen und Auswiichse zeigend (T. II. F. 11, 12). Der Griffelkanal ist jetzt geschlossen; die ihn begrünzenden Zellen sind nicht eigentlich verwachsen, nur papillös geworden und eng verfilzl, mechanisch trennbar (T. I. F. 12, T. III. F. 3).

Die Entwickelung der männlichen Blïthen stimmt in den Hauptzügen mit der der weiblichen überein. Die Unterschiede bestehen, ausser in der Entwickelung der Staubkolben an den Slaubfäden, in weit stärkerer Ausbildung des Calyculus, und im Unterbleiben der starken intercalaren Zellvermehrung in der Horizontalebene unterhalls der Einfugung der Perigonialblätter. In Folge letzteren Umstandes erscheint der verliümmernde Fruchtknoten oberständig (T. IJ. F. 8, 9). Der Bau der Antheren ist der der grossen Nehrzahl der Phanerogamen gemeinsame. Sie sind ursprünglicli vierfächerig, zweiklappig aufspringend, der Triger kurz und dick (T. II. F. I, 3-6). Auch die Entwickelung und die Gestalt des Pollens haben nichts Ungewöhnliches (T. II. F. \%). 
Die Keimbläschen sind im unbefruchteten Embryosảcke nur in Zweizahl vorhanden, lang gestreckt (T. I. F. 13), mit zarter, äusseren Einwirkungen wenig Widerstand leistender Membran. Gegenfüsslerzellen derselben sind nicht vorhanden. Das Längenwachsthum des Embryosacks ist mit ihrer Anlegung noch nicht beendet. Er drängt sich in dem durch verfilzte Zellen verschlossenen Griffelkanal etwa um ein Viertheil der Länge desselben aufwärts (T. III. F. 7).

Hier trifft auf seinen Scheitel der dünne Pollenschlauch, der diese Stelle beim beginnenden Welken der Perigonialblatter erreicht. Sein stumpfes Ende legt sich bald dem Scheitelpunkte, bald einer der Seiten des oberen Embryosackendes an; krümmt sich bisweilen auch nicht unbeträchtlich ruickwärts (T. III. F. 5, 6, 8). Die Membran des Scheitels des Embryosacks ist gleichmässig und nicht unbedeutend verdickt.

Nach Ankunft des Pollenschlauchendes am Embryosachscheitel er-scheint eines der Keimbläschen sehr bald zu einer langen dünnen Rölıre, einem Embryonalschlauche, gestreckt, welcher die volle Länge des Embryosackes rasch durchläuft. Das andere Keimbläschen verschwindet bald. Hat die Spitze des Embryonalschlauchs dem unteren Ende des Embryosackes sich genähert, so bildet sich in ihr eine quere Scheidewand (T. IlI. F.2). Die so vom cylindrischen oberen Raume abgetrennte lıalbkugelige Endzelle des nun zweizelligen Vorkeims streckt sich ebeufalls zum langen Cylinder, bis sie den Grund des Embryosackes erreicht.

In diesem erweiterten unteren Ende des Sackes ist inzwischen das Endosperm angelegt worden: ursprünglich eine cinzige, dasselbe völlig ausfïllende grosse Zelle (T. III. F. 2). Zur Zeit, da das Ende des Vorkeims hier anlangt, hat sie sich durch zweimalige Theilung mittelst kreuzweis gestellter Längswände in einen Körper aus vier in einer Ebene liegenden Zellen verwandelt (T. III. F. 4, כ̈). Zwischen die Berührungskanten dieser vier Zellen drängt sich das Ende des Vorkeims; zunächst nach mühsamer Ueberwindung eines Widerstandes, wie aus den lä̆ufigen starken Krümmungen des Vorkeims über dieser Stelle hervorzugehen scheint (T. III. F. 4).

Der Endospermkörper vermehrt die Zahl seiner Zellen zunächst vorwiegend durelı wiederlolte Quertheilung der vorhandenen vier. Die ersten Querwände entstehen nahe dem unteren Ėnde einer jeder lieser Zellen; die unteren der neu gebildeten Tochterzellen unterscheiden sich durch geringeren Unfang, wie auch durch grössere Concentration des 
Inhalts auffallend von den oberen (T. III. F. 6). Die Zellenvermehrung ist auch weiterhin am unteren Ende des Endosperms weit lebhafter, als am oberen. Bis gegen die Reife hin sind an unteren Ende die Zellen kleiner, mit dichterem Inhalt gefiiltt (T. III. F. 10, T. IV.F.3, 4, 7). - Aus der urspriinglichen, gestreckt eiförmigen Gestalt (T. III. F.9, T. IV. F. I) gehıt der Endospermkörper bald durch Zellvermehırung nach allen drei Riclıtungen des Raumes in eine melır breit gezogene über (T. III. F. 10, T. IV. F. 3, 4.).

Während dieser Zunahme der Zellenzahl des Endosperms dringt die Spitze des Vorkeims immer tiefer in dasselbe cin. Sie erreicht dessen untere Grainze, und triftt auf die Membran des Grundes des Embryosacks meist sclıon zu der Zeit, in welcher der Endospermkörper noclı die gestreckt-ciförmige Gestalt besitzt (T. III. F. 9, T. IV. F. 1, 2); seltener langt er erst dann hier an, wenn der Umriss des Eiwcisses bereits der Kreisform sich nähert (T. III. F. 10). Auf der Innenwölbung des Embryosacligrundes angeliommen, schwillt das untere Ende der Endzelle des Vorkeims beträchtlich an, und gliedert sich bald durch cine Querwand vom oberen, cylindrischen Raume ab (T. IV. F. 1, 2). Nicht selten erlangt die Endzelle bei dieser Anschwellung cine unregelmïssige, gelappte Form (T. IV. F. 2). Sie theilt sich entweder sofort durch eine Längswand (T. IVe F. 2), oder es geht dieser Theilung die durch eine schrage Querwat voraus (T. IV. F, 3). In den parallelen Zellen, aus welchen jetzt das Ende des Vorkeims besteht, tritt balıl eine neue Laingstheilung durch auf den zuvor entstandenen rechtwinklige Wandungen ein. Die verdickte spitze des Vorkeims ist jetzt aus vier parallelen Längsreihen von Zellen zusammengesetzt (T. IV. F. 4, 4'), den noch nicht zerfallenen Vorkeime einer Abietinee sehr áhnlich.

Je in den Endzellen jeder dieser vier Längsreihen erfolgen gleichmaissig noch einige Quertheilungen (T. IV. F. 4.b). Dann hört in dreien derselben die fernere Zellvermehrung auf, während in der Endzelle der vierten eine Zellvermehrung nach allen Richtungen des Raumes beginnt (T. IV. F. $\left.5^{b}\right)$. Bald streclien sich die Zellen des so entstandenen parenchỹnatischen Körpers in die Länge, und stellen fortan allein den unteren Theil des sehr massig werdenden Vorkeims dar; dic Zellenreihen der oberen Uälfte des Vorkeims, in welchen die Zellenbildung erlosch, zur Seite drängend. Einzelne derselben können noch am Träger des in der Entwickelung weit vorgeruickten Embryo deutlich erkannt werden (T. IV. 
F. 7, bei $x$ ). Bis zu diesem Zeitpunkte - Anfang Augusts - hält das Längenwachsthum des Endosperms eben nur Schritt mit demjenigen des Vorkeims. Das stumpfe untere Ende dieses ragt fortwährend ein Wenig aus der Basilarflảche jenes hervor, auf der als Chalaza bezeichneten Gewebspartie ruhend, und nur durch die etwas nach aussen gestülpte Nlembran des Embryosackgrundes ron ilı getrennt (T. IV. F. 4 bis 7). Nur dic — sehr spärliche - Vermehrung und Dehnung der Zellen des Scheitels des Endospermkörpers überwiegt gewöhnlich einseitig schon während dieser früheren Entwickelungszustände der Frucht die Längsstreckung des oberen, dünnfädlichen Theils des rom Endosperm eingeschlossenen Vorkeims. In Folge davon wird die obere, dünn cylindrische, zellenleere längere Hälfte des Embryosacks meistens etwas zur Seite gedrängt, und erscheint jetzt dem Endospermkörper wenig unterhall) dessen Scheitels schief angesetzt (T. IV. F. 4, ̈̈). Das oberste Ende dieses zellenleeren Theils des Embryosacks fällt mit dem Griffel ab, in dessen Kanal es hinein reicht, wenn dieser durch Umwandlung einer horizontalen Gervebschicht seines Grundes in korkähnlichés Gewebe von der jungen Frucht sich abgliedert. Die Oeffnung des abgebrochenen Embryosackendes wird durch das Auftreten eines Propfes von in durchfallendem Lichte braunrother körniger Substanz, und unterhalb desselben auch noch durch Zusammendrückung, hervorgebracht durch quere Dehnung der von aussen angränzenden Zellen, geschlossen.

Beim Auftreten des Embryokügelchens, — des aus kleinen würfeligen Zellen mit blaugrünlichem Inhalte zusammengesetzten Gewebes am unteren Ende des massigen Vorkeims, aus welchem die bleibenden, gegen die Samenreife hin mit assimilirten Stoffen sicli füllenden, nicht vertrocknenden Theile des Embryo sich entwickeln, - steigert sich die Lebhaftigkeit der Zellvermehrung im unteren Theile des Eiweisskörpers sehı beträchtlich. Diese Zellenmasse überwächst, gewöhnlich zuerst einseitig (T. IV. F. T) die Spitze des jungen Embryo, die jetzt einer lippenförmigen Hervorragung der unteren Fläche des Endospermkörpers lualb eingebettet erscheint. Indem eine Steigerung der Zellenvermehrung in gleichem Maasse bald auch auf die übrigen, den Scheitel der Embryuanlage umgebenden Zellen dieser Basilarflaclıe des Eiweisses sich erstreckt, wird dieses Ende des Embryo zunächst in eine cylindrische Vertiefung des Gewebes des Endosperms eingesenkt, dcren Wände bei 
weiterer Vermelırung und Dehnung der sie zusammensetzenden Zellen rasch vor und unter dem Embryo sich vereinigen und verschliessen, so dass dieser vom Endosperm überwallt und in dessen Masse eingeschlossen wird (T. IV. F. 8); gànz in der Weise wie die blosgelegte absterbende Gewebsmasse im Grunde der einem dikotyledonen Stamme beigebrachten Wunde durch die endliche Verschmelzung der wulstig anschwellenden Rinder derselben. - Fortan ist der Embryo allseitig vom Endosperm umhiillt, und bleibt es bis zur Keimung. Der Theil des Endosperms unterhalb seines Scheitels nimmt gegen die Samenreife noch belletitend an Länge und Umfang zu.

Während des IIeranwachsens des Endosperms sind die Zelten der ihm angränzenden Gewebe des Fruchtknotens in lebhafter Vermehrung begriffen. Insbesondere gilt dies von dem Parenchym neben und unter der Chalaza. Der früher von zalılreichen Körnchen getrübte Inhalt dieser Zellen wird während deren Vermehrung klar und durchsichtig (T. IV. F. 6, der mit $y$ bezeichnete lichte laum). Diese Gewebsmasse ist es vorzugsweise, auf deren Kosten das Endosperm an Umfang zunimmt. Ihre Zellen, soweil sie jeweilig dem Endospermkörper angränzen, werden von diesem abgeplattet, bis zum Verschwinden der Zellhöhle zusammen gedrickt (T. IV. F. 4), und entschwinden endlich der Beobachtung. Das Parenchym der Chalaza erhält sich während dieser Vorgänge lange Zeit unversehrt. Aus dem Zusammenhange mit dem von unten her ihm angränzenden, breiig werdenden Gewebe tretend liegt es wic ein todter Körper in demselben, unverändert. Beim Herausheben des Eiweisskörpers aus dem Fruchtknoten bleibt es gewöhnlich jenem anhaften (T. IV. F. 7, 9).

In den Zellen der Fruchtknotenwand, welche zwischen dem äusseren und dem inneren Gefässbündelkreise desselben liegen, und welche friihe schon eine strahlige Anordnung zeigen (T. IV. F. 6), beginnt Mitte Juni die Bildung von Viscin. In jeder Zelle erscheint ein in ihrer Mitte frei schwimmender Ballen zäher, fadenziehender, das Licht stark brechender Substanz. Später, von Mitte August an, tritt dieselbe Bildung auch in den Zellen des axilen Theiles des Fruchtknotens ober- und unterhalb des Endospermkörpers auf (T. IV. F. 6; die viscinhaltigen Gewebe sind durch dunklere Schattirung bezeichnet). Ende August erweichen sich auch die Wandungen der viscinhaltenden Zellen, nachdem der Ballen von Viscin in ihrem Innern sich bis zur völligen Ausfuil- 
lung desselben vergrösserte. Die dünne Gewcbeschicht ausserhalb des ausseren Gefássbuindelhreises ( $z$ in T. IV. F, 6) wird zur Wand der Beere.

Die Anfang August halbkugelige Embryoanlage erlangt gegen Ende dieses Monats liugelform. Anfang September sprossen neben ihrem flach kegelförmigen Scheitel die beiden Kotyledonen hervor, welche mit ihren oberen Fläclıen dicht an einander liegend, später auch haftend, bis Mitte September schon ihre volle Länge erreichen. Jetzt wird im dicken kugeligen Wurzelende des Embryo, an welchem der Rest des vertrocknenden Embryoträgers noch kenntlich ist, die Anlage des Würzelchens sichtbar $(r$, T. IV. F. 10). Auch die Haube desselben ( $h$ derselben Figur) ist tief im Innern des Gewebes des Embryo eingeschlossen. Loranthus europaeus ist ganz in der nämlichen Weise eine endorhize Pflanze, wie diejenigen Palmen, deren erste Wurzel in der Verlängerung der Längsachse des Embryo liegt, Sabal Adansoni z. B. *).

*) In den reifen Samen von Loranthus europaeus, die mir zur Untersuchung vorlagen, war das Gewebe des Endosperms von mehlartiger Beschaffenheit, leicht zerreiblich. Die Zellen desselben vereinzelten sich ohne Weiteres, wenn dünne Schnitte in Wasser gebracht wurden. Die Pulpa dieser Beeren war während des Transports in saure Gährung übergegangen. Ich lasse unentschieden, ob die Zerreiblichkeit des Endosperms durch den Einfluss dieser Gährung in benachbartein Gewebe hervorgerufen war, oder ob sie eine normale Erscheinung ist.

Damit man noch auf anderem Wege, als durch Yergleichung der beigegebenen Ahbildungen, die vorstehenden Mittheilungen über Entwichelung von Blülhe und Frucht des Loranthus europaeus controliren könne, mögen hier die Angaben der Maasse und Zellenzahlen der wichtigeren Entwickelungsstufen folgen.

1) Anlage der weiblichen Blüthe, Mitte Augusts vor der Blüthezeit (abgebildet T. I. F. 3).

Entfernung ron dem einen Rand des Calyculus zum anderen 499, 238 M.M.M. *)

Hoble des Blürhenbodens 106,762 M.M.M., Zellenzahl 14 .

Verticale Eutfernung des Rands des Calyculus ron der Blïthenstandsachse 259,332 M.M.M.

2) Blähhenknospe, Ende Aprils des nächsten Jahres, entsprechend der Abbillung T. II. F. 4 .

Querdurchmesser des Calyculus 184,786 M.M.M. Zellenzahl in dieser Richtung 6 - $\quad$ (grösster) eines

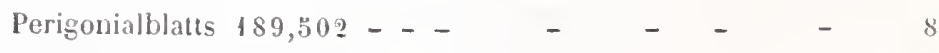

- eines Carpells $230,817 \ldots \ldots$ - $\quad$ - $\quad$ - 21

- d.Blüthenbodens $866,012 \ldots$ - $\quad$ - $\quad$ - $\quad$ - 33

- 1 Mikro-Millimeter $=0,001$ M.M. 


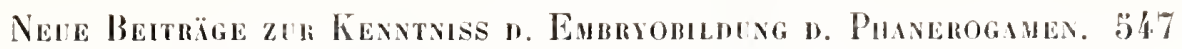

So abenteuerliche Abweichungen von der Entwickelungsgesehichte des Embryo anderer Phanerogamen die des Loranthus europaeus zeigl;

Verticale Distanz der Spitze eines Perigonialblatts von der Einfügung der Rückenflïehe desselben in den Blïhrenhoden 239,946 M.M M. Zellenzalıl 11

Lïnge der Rüchenfliiche eines der Carpelle $\quad 198,818 \ldots$

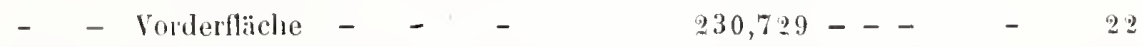

Höhe des Blitltenbodens (verticaler Abstand der Achsel der Bractec rom liefsten

Punkte der Einsenkung zwisclsen den Carpellen) 573,664 M.M.M.; Zellenzahl 31

3) Knospe, 3 Wochen vor dem Aufblülıen

(Anfang Mai), wenig weiter entwickelt als der T. I. F. 9 abgebildete Zustand.

Hölıe des Germen 324,344 M.M.M.

- - Griflels 284,074 - -

Grösste Entfernung der Gefissbündel in der Gegend der Chalaza von einander 280,767 M.M.M.; Zellenzalıl 28.

4) Knospe, unmittelbar vor dem Aufblühen (am 20. Mai); Enlwickelungsstufe der T. I. F. 12 abgebildeten.

Grösste Entfernung der inneren Gefüssbïndel des Germen von einander, in der Gegend der Embryosäcke 474,376 M.M.M.; Zellenzahl in dieser Richtung 40.

Entfernung zwisclıen den innern und äusseren Gefässbündeln des Germen an der nämlichen Stelle 85,498 M.M.M.; Zellenzahl 5.

Entfernung von den äusseren Gefässbündeln bis zur Epidermis des Germen 320,441 M.M.M.; Zellenzahl 42.

Hölıe des Germen I M.M., 963,696 M.M.M.

Ganze Länge des längsten Embryosacks774,989 M.M.M. (wovon ein Stück von 82,9 4

M.M.M. Länge in den Griffelkanal reicht).

5) Befrucliteter Embryosack, Entwickelungsstufe wie T. III. F. 5.

Ganze Länge 1 M.M., 332,11 \& M.M.M.

6) Junge Frucht, in der Entwickelung soweit vorgerïkt, wie die T. IV. F. 4 abgebildeten Theile darstellen.

Länge des Germen 3 M.M.

- des Embryosacks 1 M.M., 356,936 M.M.M.; wovon auf den Eiweisskörper kommen 83,498 M.M.M.

Entfernung der innern Gefässbündel des Germen vom Embryosack:

a. Durchsichtige Schicht 209,608 M.M.MI.; Zellenzahl 11.

b. Viscinhaltige Schicht $212,366 \ldots$ - 7 . 7 .

Entfernung der inneren Gefässbündel von einander 854,99 M.M.M.; Zellenzahl, einschliesslich des für 1 Zelle gezählten Embryosacks 39.

Entfernung zwischen den inneren und äusseren Gefüssbündeln des Germen 278,598 M.M.M.; Zellenzahl 6.

Entfernung zwischen den äusseren Gefissbündeln und d.Epidermis 3:35,784 M.M.M.;

Zellenzahl 44 .

7) Eiweisskörper, Entwickelungsgrad wie T. IV. F. "3.

Grösste Länge 208,781 M.M.M.

- Breite 212917 - - 
- sie werden noch iiberbolen von derjenigen einiger ostindischer Loranthaceen, deren Beschreibung wir G riffi th verdanken*). Die genauere Kenntniss der Embryoentwickelung von Loranthus europaeus, wie sie jetzt vorliegt, erlaubt die zahlreichen Liicken der Darstellung Griffith's zu ergänzen, und ein anschaulicheres Bild des Herganges der Samenbildung dieser interessanten tropischen Formen zu entwerfen.

Griffith erkannte bei allen den Arten von Loranthus, welche er untersuchte (L. Scurrula, globosus, bicolor), dass auf den früheren Entwickelungsstufen der Blithe eine deutliche, mit dem Griffelkanal in offener Verbindung stehende Höhlung des Ovarium vorhanden ist, die erst bei weiterer Ausbildung der Frucht undeut lich wird und verschwindet ${ }^{*}$ ). Vom Grunde dieser Hölılung erhebt sich ein flach kegelförmiges Wärzchen von Zellgewelse (, a nipple-shaped process"); - dieses ist das von mir als Eychen gedeutete Gebilde. Bei Loranthus bicolor hat Griffith auch die von mir als Chalaza bezeichnete Gewebspartie unterhalls

8) Junge Frucht, von der Entwickelung der T. IV. F. 6 dargestellten. Länge des Germen $: 5,5$ M.M.

Entfernung der inneren Gefïssbündel desselben rom Embryosack:

a. Durchsichtige Schicht 63,431 M.N.M.; Zellenzahl 6

b. Viscinlaltige - .281,316 - - $\quad 16$.

(Entfernung der inneren Gefässbündel von einander 1 M.M., 203,155 M.M.M.; Zellenzahl, den Embryosack $=1$ gerechnet, 46).

Entfernung zwischen den inneren und äusseren Gefässbündeln

727,112 M.M.M. Zellenzahl 17

Von da zur Epidermis . . . . 339,234 - - $\quad 13$

Breite des Eiweisskörpers . . 510,897 - -

- des Vorkeims . . . 290,693 - -

9) Nahezu reifer Embryo (wie T. IV: F. 10).

Länge der Kolyledonen . • . . . 2 M.M., 986,914 M.M.M.

Verticale Distanz des Gipfels des Achsenen-

les vom unteren Ende der im Radicularende

des Embryo eiugeschlossenen Wurzel . . . . 379,18

Yon da bis zum Radicularende selbst . . . . 612,276

Ganze Länge des Embryo . . . . 4 M.M., 178,37 M.M.M.

Grösste Breite der Achse desselben . . 1 - - 169,392 - -

*) Griffith's erste Ablıandlung, am 21. Juni 1836 der Londoner Linnéschen Geellschaft vorgelesen, steht abgedruckt in Bd XVIII, der Verhandlungen dieser Gesells.chaft, (erschienen 1841) p. 71 ff.; die zweite (gelesen 1843) findet sich im XIX. Bande derselben Sammlung (1845) p. $17 \mathrm{fr}$.

**) a. a. O. vol. XIX, p. 178. 
thes Eychens erkannt und abgebildet*). Die Embryosiclie (Ovules nach Griffilh's, an Decaisne sich anschliessender Ausdrucksweisc) sind geraume Zeit vor der befruchtung von ihm gesehen: in der liegel in Mehrzahl; bei L. bicolor bis zu sechsen. Dass sie atus dem Eychen hervolsprossen, vermochte Griffith zwar nicht zweifellos zu ermilleln**). Nach den, was von L. europaeus bekannt ist, kann jedoch daran nicht gezweifelt werden. Bei Loranthus bicolor reichen die Enbryoşcke in Grilfellianale weit aufwarts, bis nahe an die Narbe. Der Gritchianal bleibt bei den ostindischen Arten un Vieles deutlicher und offener, als bei der europaischen. - Nachdom Pollen auf die Narbe gelangt war, fand Griffit Pollenschlauchenden an den Scheitch der Embryosiache laften, und das Innere derselben der gauzen Lange nach durchzogen von farlenförmigen Zellen. Der Dirchmesser derselloen ist am grössten mahe dem Scheilel des Embryosacls; weiter ahwaits verjügen sie sich betrichtlich, ohne jedoch so dimn zu werden wie die Pollenschliüche ausserhall, des Sackes. Diese fädlichen Zellen, welche Grifli lı unter dem Einflusse der irrigen Angaben Schleiden's für Pollenschlauche lialt, welche in den Embryosack eingedrungen seien, sind olme alle Frage die befuchteten und zu Embryonalschläuchen gestreckten Keinblaschen. Merkwirdig genug - und dies ist die grösste Abweichung in der Entwickelung der indischen Formen von der in unserem Vaterlande vorkommenden — ist jeder Embryonalschlanch doppelt. Jeder besteht aus zwei parallelen, mittelst der planen flächen in innigsler Verbindung stehenden halbeylindrischen Zellen. Selu wahrschenlich ist eine fribe, der Längsstreckung noch vorusgehende Längstheilung des befruchleten liemblaschens die Ursache dieser aufiallenten Erscheinung. - Das offenbar nicht minder trüh, als bei L. europracus auftetende Eudosperm von L. bicolor und L. globosus wird, ganz wie dort, von Vorkeime rasch durchwachsen, der dann aus dem unteren Ende des Endosperms hervor tritt. Bei L. bicolor auf heine sehr weite strecke; selbst das noch selı junge Embryolingelchen ist immer zum Theile wenigstens vom Endosperm umsclılossen ${ }^{\text {*xt }}$ ). Ganz anders bei Loranthus globosus. Dic weit aus dem Endosperm hervorwarhsenden

\footnotetext{
a. a. O.T.XX.F. I.

*: a. a. O. p. 178, Anmerkung.

+t) a. a. 9. p. 179.

Abhandl. d. li. S. kins. d. Missenseh. IT.
} 
Vorkeime nehmen hier schraubenlinige Lagerung an; ähnlich wie im Eyweisshörper der Coniferen nach dem Hervorbrechen aus den Corpusculis. - Es ist bei beiden Arten Regel, dass mehrere Embryosäche befruchtet werden. Nicht allein die so entstehenden mehreren EndospermMassen, sondern auch die aus deren unteren Enden hervorgetretenen Vorkeime pflegen unter einander zu verwachsen, olne dass jedoch aus der Zellenmasse, zu welcher die Enclen der Vorkeime zusammen treten, bei L. bicolor melır als ein einziger Embryo sich zu entwickeln pflegt. Bei L. globosus dagegen zeigt sich eine ,,Tendenz zur Wiedertrennung" der vereinigten Vorkeime darin, dass aus jenem Zellenkörper häufig zwei, noch mit besonderen Trägern versehene Enibryonen hervorsprossen. - Gegen die Samenreife hin umwächst und überwallt das Endosperm den oder die Embryonen, ganz wie bei L. europaeus. Der Vorgang hat bei L. globosus nur durch die beträichtiche Entfernung des Embryo vom Endosperm etwas sehr sonderbares. - Die dritte ron Griffith untersuchte Art der Galtung, L. scurrula, scheint dem L. europaeus in Bezug auf letzteren Punlit sich ganz ảhnlich zu verhalten*).

Eine ron Decaisne in seiner berihnten Arbeit über Viscum album gegebene Bemerkung über den Bau des jungen Samens ron Loranlhus aphyllus*; zeigh, dass hier der Strechung des befruchteten Keimhasschens zu dem die ganze Länge des Embryosacks durchziehenden Vorkeime noch weit zahlreichere und complicirtere Zelltheilungen rorausgehen missen, als sie bei Loranthus globosus zu vermuthen sind. Decaisne fand im Scheitel des rom Endosperm bereits völlig ausgefülten Embryosacks (des Eylierns, nach seiner Terminologie,) eine konische Masse aus Zellgewebe von grösserer Dichligheil als die des Endosperms, von deren Basis vier dimne, leicht von cinander zu trennende röhrige Zellen in schraubenlınigen Windungen durch die ganze Länge des Endospermkörpers sich zogen. Die unteren Enden dieser Röhren standen in festem Zusammenhange und trugen eine homogene Zellgewebsmasse (une espèce de petit sac ou de mamelon charnu, sur lequel on ne peut découvrir aucun indice d'une strie). Spätere Zuslände zeigen, dass aus dem unteren Ende dieses zelligen Körpers der Embryo sich

*) a. a. 0. v. XYIII, p. 72. Die Untersuchung zeigt am entscheidenden Punkte eine Lücle.

**) Nour. mém. de l'acad. Roy. de Bruxelles, 1. XVIII. (1841) p. 32. 
cutwichelt. Er sellst gehört noch zum Embryotüiger: das Würzelchen des Vorkeins ragt noch in ihn hincin. Waluscheinlich wird es ungeben von einer kransentörmigen Wucherung des Vorkeims, etwa wie bei Tropacolum, oder in starlister Ausbildung bei Trapa.

Ka rsten hat in einer Arbeit uber die Entwickehngegeschichte der Loranthaceen aucli den Blithenbau und die Embryobildung ciner milledancrikanischen Art von Loranthus behandelt, die er mit dem Namen Passowia odorata belegte* $)$. Karsten lat die Bildung des Grillels aus cinem Kreise verwachsender Blattorgane nicht eskamt; er nimmt all, dass der miltlere Theil der Bliilhenknospe sich nach oben wäbe: und last zur Länge der ülnigen Blühontheile sich verlingere. Die Bildung des Embryosackes stellt er so dar, dass die Querwinde der axilen Zellreihe des Markgrewebes der weiblichen Bhithe resorbirt werden. Dieser Embryosack soll schon vor der Befruchtung nit Zellgewebe sich fuillen, bis auf einen axilen, engen Intercellulara!n, in welehen später der Pollenschlauch eindringe, bis nahe an den Grund des Sackes herahsteige, wo dann sein Ende zur Anlage des liinfligen Enhbryo sich ausbilde. - Ich stehe nicht an, meine Ueberzeugung von der Irrthümlichkeit dieser Ingaben auszusprechen. In den Beobachtungen Kál's le n's, soweit sie durch die seiner Abhandlung beigegebenen Zcichnungen controlint werden kïnnen, ist cine bedeutende Lücke zwischen dem Zustand Ier Blithe, wo die Staubfiden eben wur angelegl sind, und der Entwickelungsstufe derselben, welche dem Aufhluilen unmitlelbar vorausgehl. Was Karsten über Entwickelung des Griflels und Embryosachs behaupted, ist ofrenlsar nicht direct beobachtet, sondern aus Beschallenlıcit der fertigen Zuslainde rückwärts erschlossen. Die Carpelle mögen bei der miltelanerikanischen Art noch friber und vollstandiger verschmelzen, der Embryosack noch rascher sich dehnen, als bei der eurojäischen; - aber es liegt kein Grund vor, an der wesentlichen Ueber_ cilstimmung des Enlwichelungsganges zu zweifeln. Der vom Endosperm erfulle Embryosack ${ }^{*}$ ) ist zuverlassig cin bereits befiuchleter; der als Intercellularraun gedeutete axile Cylinder in demselben das zum Embryonalschlauch entwichelie, bereits bis hieher herabgestiegene befruchtele Keiublaschen.

Bot. Zeil. 1832. S. $30 \%$.

$\cdots$ abgebildei a. a, O. T. IV, F. II. 
Die Auffassung der Loranthaceen als der Classe der Gymnospermen angehöriger Gewächse sei nur als geschichtliche Thatsache erwähnt*). Es erscheint nach dem Vorausgeschickten die Erörterung (lieser Ansicht mir ebenso wenig nöthig, als die eingehendere Erwähnung der irrigen Behauptung älterer Systematiker, welche den Loranthaceen haingende Eychen andichten.

\section{Lepidoceras Kingii Hook. fil. **)}

Taf. IX. F. 1-6.

Weit rollständiger als bei den bisher untersuchten Arten ron Loranthus erscheinen die einzelnen Organe der weiblichen Geschlechtstheile von Lepidoceras und verwandten Formen von emander geschieden.

Iom Grunde der Ovariunhöhle von Lepidoceras Kingii erhebt sich ein schlank kegelförmiger Körper, aus gestreckten engen Zellen zusammen gesetzt, der in scinem lnnern einige weitere. ebenfalls lang gestreckite Zellen birgt. Die Spitze dieses Körpers berührt den Scheitel der Wölbung der Ovariumhöhle. Die Deutung dieser kegelförmigen Zellenmasse als Eychen, der grösseren Zellen in ihrem Innern als Embryosicke wird nach dem, was über die Entwickelung der weiblichen Blïthe von Loranthus behannt ist, als völlig berechtigt erscheinen. Der Raum zwischen der Aussenfläche des Eychens und der Innenseite der festen, bleibenden Fruchtlinotenwand ist mil grosszelligem, zartwandigem Gewebe ausgefullt (F. 1). So in Fruchthnoten von 1//2 M. M. Länge, deren Perigon offenbar vor Kurzem erst abfiel.

In dem weiter entwickelten, etwa un die Iiălfte lianger, un das Dreifache dicker geworlenen Fruchtlinoten ist das lockere Gewebe aus grossen Zellen verschwunden, welches den Raum zwischen Eychen und Fruchthnotenwand ausfullt. Das untere Ende eines der Enibryosäche - des befruchteten - hat sich stark in die Breite gedehnt und ist ron bereits vielzelligem Lindosperm ausgefullt (F, 4): In der Scheitelansicht

*) Schleiden in Wiegmanns Archiv Bd. I. S 253 (1839); — Meyen, über Polyembryonen. Berlin is $40, \mathrm{~S}$. 41 .

*) Nach Herbarienexemplaren, von King auf Chiloë gesammelt, deren Mittheilung ich der Güte Herrn Prof. Grisebach’s verdanke. Vergleiche dessen „,Bemerkungen zu den Pflanzensanml. Philippi's und Lechler's" in Ah. der K. Gesellsch. d. Wiss, zu Göltingen, I1, S. 21 u. 43 . 


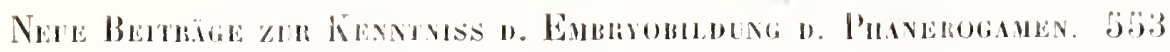

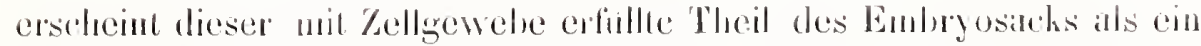
slumpl dreiseiliger hörper. J)ie grössere, zellenteene obere llablfe des

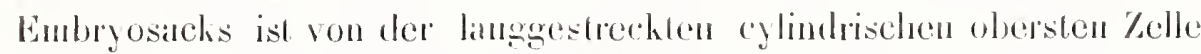
des limbiyolrigers durchzosen. Lis ron ihr getragene, wenigzellige Embryokïgelehen (F. \&, $i$ ) betinded sich in Millelpunlite des flachen Ejucisshorpers.

Das Gewebe der Fruchlholemwand hat sich zu drei anthillig verschicdenen Schichten diflerenzirt. Die innerste derselben (T.IX. F. 3, a) besteht aus einer einfachen Lage taliellörmiger Zellen von geringen Quer-, und elwa viermal grösseren längsdurchmesser. Auf diese folgt eine sehicht selı enger, quergestreckter Zellen $(\mathbf{l} .3, b)$, an welche die átsserste Zellschicht der Fruchlhnotenwand, eine dicke Plalle derbivandigen Pancenchyns, sich anschliesst.

In der nahezn reifen Fruch erlingl die nitlere dieser Zellschichten cine sehr betrachlliche Lutwickelıng. indem namentlich im oberen Theile der Fruclıt ihre Zellen stark in die länge waclisen, und dalsei, dureh die äusserste Schicht der Fruchelinotenwand an freicr Iusdehnung gehindert, einen geschlangelten Verlauf anmehmen $(\mathbf{F} . ;), b)$. Da, wo eine dieser ey lindrisch und von ihren seillichen Nachbarzellen völlig frei gewordenen \%ellen mit einer der tafelfirmigen dickwandigen \%ellen der innersten Zellsehich der liruchlholenivand zusammonhägl, zeigl die Wand dieser Zelle cinen Tiuplel (F. $\mathbf{b}, \boldsymbol{a})$. Die Anssenwand des Fruchlknotens ist in iluen ïussersten Zelschichten theischig geworden; im getrochnelen Zustande rmzelig (F. ö). Der lnnenraun des Frucht-

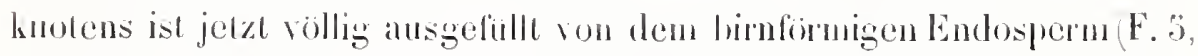
6 , ed, welches selbst bis aul zwei bis drei Zellschichlen rom grossen, grunen Embryo, mil seln entwickeltem Wurzelende und zwei umfangreichen, plall an cinander liegenden Kolyledonen verdrangt ist.

\section{Viscum alloum L.}

Tar. V-VIII.

In zeiligen Frïlijahre, vor dem Erwachen der Vegelalion (Mufang

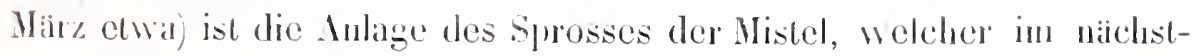

* Der Raum zwischen diesen Zellen ist mit einer zähen, fadenzichenden Substanz (Viscin) erfitllt. 
folgenden Jahre zur Blüthe gelangen wird, vollständig verborgen in der durch eine Anschwellıng des Blattstiels geschlossenen Achselhöhle der Laulhbätler unterhalb der zum Blühen im laufenden Jahre bestimmten Inllorescenz (T. V. F. 1, x). Der Spross hebt an mit zwei schuppigen, rechts und links stehenden Vorblïttern (T. V. F. 2, a), auf welche, durch cin bereits etwas in die Länge entwickeltes Stengelglied von ihnen gefrennt, die zwei gegenständigen Laubblätter des sprosses (dieselbe Figur, b) in zu den vorigen gekreuzter Stellung folgen. Diese Laubbläter haben bereits eine niclıt unbeträchtliche Länge. In der Achscl eines jeden findet sich die Anlage des zur Entfaltung im zweitnächsten Jahre bestimmten Sprosses, von Gestalt eines flachen Wärzchens aus zartem Zellgewebe (seine Lage ist bei erwähnter Figur durch den punktirten Freis $x$ angedeutet). - Das̉ Sprossende zwischen den Laubblättern zeigt noch ein Paar von Hochblättern (Bracteen); der decussirten Blattstellung der Pflanze gemäss mit den Laubblättern gekreuzt (T. V.F. 2. c ) Zwischen ilnen erhebt sich der Vegetationspunlit als ein flacher liegel aus wenigen grossen Zellen (T. V. F. 2b).

Encle Aprils tritt noch ein Paar von Bracteen oberhalb der eben erwáhnten am Sprossende auf (T. Y. F. 3, 4, d). In den Achseln der unteren erscheinen die Anlagen von Knospen (T. V. F. 3,y); sie sind die Anfänge der seillichen Blüthen der Inflorescenz. Die Achseln des oberen Bracteenpaares blieben an den von mir untersuchten Pllanzen in der Regel steril. Das Sprossende zwischen den obersten Bracteen wandelt sich zur Terminalblüthe um. Zunächst (bei der weiblichen Blithe, deren Entwickelung vorerst uns beschäftigen soll) durch stärkcre Entwickelung der peripherischen Theile, in: fleren Folge das Knospenende flach vertieft erscheint (T. V. F. 3). So wird der Calyculus angelegt; kein Kreis von Blattorganen, sondern eirie blosse Parenchymwucherung.

Mitte Juni hat sich aus der Mitte dieser Einsenkung der Vegelationspunkt wieder kegelförmig erhoben (T. V. F. 3). An den seitlichen Bliithen der Inflorescenz, deren Entwickelung derjenigen der terminalen in dieser Periode etwas rorauseilt, sind hereits die beilen :iusseren, rechts und links yon der Bliithenaclsse stehenden Perigonialzipfel aufgetreten (T. V. F. $\ddot{g}^{\mathrm{b}}$ ), denen bald die leiden inneren folgen.

Von jetzt al, geht die Entwickelung um Vieles schneller. Schon cine bis zwei Wochen später finden sich auf dem Scheitel der flachen Anlage der Endblithe zwei zweigliedrige Blattkreise, die Perigonialblat- 


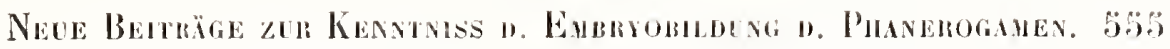

ter, deren beide áussere sehr deullich zu den obersten Bracteun in Kreuz stehen (T. VI. F. 1). An den seitlichen, ron oben und unten her stark zusammengedrickten Bluthen, deren Entwickelungr von jetzt ab) hinter der der terminalen etwas zuruckbleibt, tritt dieses Verhälniss minder schart hervor.

Männliche Blüthenslande und Blaithen entwickehn sich bis hieher den weiblichen in allen stucken gleich. Mhr morphologischer Aufbau ist damit beendet; - es differenziren sich unter der oberen Flache der Perigonialb)atter cinzehe Zellgruppen zu Pollenmutterzellen; neue Blattorgane werden fortan nicht mehr in der männtichen Blithenknospe angelegt (T. VI. F. 2).

In den weiblichen dagegen erscheinen Mitte Juli vor den ausseren Perigonialblattern zwei wenig vorspringende Blattorgane vom Umriss cines Viertel-Kreises (T. VI. F. 3). Diese liugelig ins Innere der Bluthe vorspringenden zwei Polster aus Zellgewebe sind die Carpelle. Bah herühren sie sich mit ilıren sich abptattenten Vorderflichen, nur einen engen Spalt zwischen sich lassend (T. VI. F. 4). Die Gruppe von sehr wenigen Zellen aut dessen Grunde (T, VI. F. 4.) muss als das Eychen der Mistel betrachtet werden. Schon Anfang August ist anch der enge Spalt zwischen den, in tebhafter Zellvermehrung begriffenen Carpellen bis zur Verwischung der spur firulierer Trennung verwachsen. Die Carpelle und der Blithenboden stellen eine homogene Masse mit abgestutzt kegelförmigg zwischen den Perigonialblittern enpor ragendem Schcitel da: (T. VI. F. $\ddot{3}^{\mathrm{b}}$ ).

Die Zellenvermelırung, welche in den Carpellen eintrilt - vorzugsweise eine oft wiederholte Quertheilung, während deren die Grmplen aus einer Mntterzelle hervorgegangener Tochterzellen noch lange deren Umrisse erkennen lassen (T. VI. F. 4) - selzl sich lief in den Blüthenboden hinab fort, dessen dicht unter der Einfügung der Perigoniallbatter gelegener Theil durch diese intercalare Zellbildung in den mnterstindigen Fruchtlinoten sich umwandelt. Schon Anfang August besteht das axile Zellgewebe desselben aus in parallete Längsteihen geordneten wirfoligen Zellen. Yon dieser Zellvermehrung sind nur wenige, zwei schr solten drei, Zellen ausgenommen, deren Lage dem Punkte entspricht, an welchem der, jetzl geschlossene, enge spalt zwischen den Carpellen nacls unten endete. Diese Zellen strecken sich unter mancherdei Kriminungen, wilhend ihre Nachbarzellen in stelig wiederholler Folge ques. 
sich theilen; - unt zwar erfolgt diese Streckung, abweichend von Loranthus, zum Theil auch nach unten hin. Die sich verlängernden Zellen dräingen sich mit verjüngten Enden auch abwärts zwischen die Parenchỵmellen der Fruchtknotenachse. Sie sind die Embryosaicke(T.VI.F.6, S).

Es könnte auf den ersten Blick ersclıeinen, als sei die Stellung der Embryosäcke von Viscum eine Ausnahme von der Regel, welche ich früher aussprach**), dass es stets Zellen des axilen Zellstranges des Eychens seien, welche zu Embryosäcken sich entwickeln. Indess ergiebt die Untersuchung bald, dass zwei Stellen der beiden Embryosảcke von Viscum stets in derselben Verticalen liegen; in einer Verticalen. welche mit der Längsachse der Blüthe zusammenfält. Diese Stellen sind diejenigen Punlite, an welchen die Embryosäcke am engsten sind, etwa um ein Sechstheil ihrer Länge rom untercn Ende entfernt. (In ler beigegebenen Zeichnung, welche Embryosäcke in natürlicher Lage darstellt, T. VI. F. T, trill dieses Verhältniss aus dem Grunde nicht hervor, dass die frei gelegten unteren, so zu sagen verschlungenen Enden der Embryosäche auf eine horizontale Fläche projicirt dargestellt sind; so wie sie naclı dem Auflegen mit dem Decliglas erschienen. Eine perspectivische Abbildung witre verworren erschienen.) Nichts steht der Annahme entgegen, dass diese, mil der Kreuzung der Richtung der Embrỹosäcke zusammen fallende engsten Stellen derselben den Ort der ursprünglich in Grösse von den Nachbarzellen nicht verschiedenen Gewebezellen bezeichnen, welche zu Embryosäcken dadurch sich entwickelten, dass die eine anfwärts mit seitlicher Abweichung nach rechts und zugleich abwärts mit seitlicher Ablenkung nach links, die andern aufroärts, nach links seillich abgelenkt, und zugleich abwärts, nach rechts abweichend auswuchs.

Schon Anfang Octobers sind die Keimbläschen und deren Gegenfüsslerzellen gebildet. Der Embryosack sowohl, als seine Tochterzellen sind jelzt noch zartwandig. Die Keimbläschen, meist zu zweien, seltner zu dreien vorlanden, haften mil breiten Ansatzflächen an der Innenwand des Tubryosacks. Diese Ansatzllächen sind bisweilen eine Strecke von einander entfernt (T. YII.F.4, T. YIII.F. 11). Die Keimblitischen sind kurz birnförmig, mil blassem schwach contouritem Kern T. VI. F. Tb, Die

W Berichte der K. Sïchs. Ges. d. Wiss. 18̈36, s. so; und Pringsheim Jahrbücher L. 178 . 


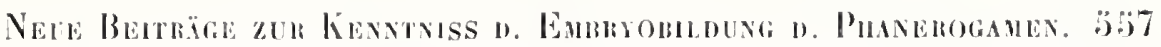

Zalıl ilner Antipoden sehwankt zwischen oiner und zweicon. Nielıt sellen felılen sie völlig.

Wihrend des Winters chalten der Embryosack und seine Tochterzellen fostere Menhranen. Die des Sackes selbst wie die aler Gegrenlïsslerzellen der Keimblaschen, enlangt cine ungewöhnliche Dicha/T. VI. F. 8, b c). und zeigt deutlich Schichtung (T. VII. F. 5, 6). Jie Ilaut der Keimblaschen bleibl düner. lisst aber sehr entschieden alle Eigenthümlichkeiten einer Cellulosenembran erkenuen (T. VI. F. 9; T. VII. F. ?). So erscheinen die, Embryosicke Endo Marz, zn welcher Zeit es nieht schwer hialt, sic unerletzt aus dem umschliessenden l'arenchyn herauszuschälen. Nach solcher Freilegung zeigt die Membran der Scheitclgegend des Embryosacks eine, bisher bei keiner anderen Pllanze beobachrete Eigenthimmlichkeit. In ter verdichten Membran befmelen sich eine bis zwei eng umgräinzte, unverdickt geblicbene Stellen; walue Tiipfel. Selı hïulig ist die diinne Membran, welche diese Tiipfel verselıliesst, mach aussen vorgestulpt (T. YII. F. 1, 4-6; T. VIII. F. 3, 5). Diese Tiipfel stehen bald auf den Ansatzflachen von Keimblaschen, bald neben densclben. Sie finden sich nicht an allen Embryosticken*).

Nit dem Wiedererwachen der Vegetation tritt teullicher eine bisher nur schwach (T. VI. F. 6) angententele Sonderung der Wand oles unterstindigen Fruchthnotens in vier Gervebschichten verschicdener Beschaffenheil hervor. Die äusserste, das Epicarpium, von den Gefissbiindeln durchzogen die zu den Perigonialbättern gehen, ist mässig reich an Chlorophyll, die Wande der Zellen etwas dicker und derber als die chlorophy llarmen der naiclsstfolgenden Schicht, des zunächst nur dimmen Mesocarpium. Das Endocarpium endlich, dic Achse des Fruchtknotens ausfüllend, von Flaschenform, ist ibberreich an Chlorophyll. In seinem Innern aber findet sich eine Gruppe von chlorophyllarmen, protoplasmareichen Zellen, welche die Eubryosacke einschliesst. Dass die Bildung der vier schichten nur auf dem verschiedenartigen Verhalten

*) Die Tüpfel der Embryosackhaut ron Viscum erscheinen dann nicht mehr als cin völlig vereinzeltes Vorkommen, wenn un erwägl, dass die Membran der Scheitelsegend der Embryosïcke sehr vieler anderer Phanerogamen in ilıer lerdickung hinter der der übrigen Embryosackhat beträichllich zurüch bleibt. Allerolings sind diese Stellen minder eng umgrïnzt, und minder scharf von den dickeren Theilen der Haut abgeselal; vielmelır allmälig in diese übergehend. So z. B. dic Scheitelıegion des Emlug̣osachs bon Crocus, von Citlypanula, von Viola u. A. 
der Zellen eines und desselben zusammenhängenden Gewebes beruht, zeigt nicht allein die Entwickelungsgeschichte, sondern auch der ganz allmablige Uebergang besonder's der zweiten in die dritte.

Das Verstauben des Pollens der Mistel erfolgt bei uns gewöhnlich in der ersten Hailfte des April ${ }^{*}$ ). Die Zeit, deren die Pollenschläuche zu ihrer Entwickelung, und bis zum Vordringen zu den Embryosäcken bedürfen, ist sehr reränderlich; offenbar in hohem Grade von der Gunst der Witterung abhängig. Die Bertihrungr von Pollenschlauch und Embryosack erfolgte $183 ̈ 1$ erst gegen Ende des Mai; 18322 schon Anfangs desselben Monats; $1830 \%$ und 36 Mitte Mai. - Der Pollenschlauch bahnt sich seinen Weg durch das Parenchym des Narbenkörper's, ohne dass sein, oft sehr geschlungener Lauf die Richtung der einstigen Spalte zwischen den Carpellen einhielte. Es gelingt nur schwer, grössere Stüchen desselben frei zu legen(T. VIII. F. 8). Seine Wandung erhält schon während des Herabsteigens durch den Narbenkörper beträchtliche Dicke. - DerAussenseite des Embryosacks legt er sich mit stumpfen Ende an. Oft trifft er genau auf einen der Tüpfel des Embryosacks (T. VII. F. 6; T. VIII. F. 7); eben so häufig haftet er aber auch neben einem solchen an der Aussenwand des Sackes (T. VIII. F. 3, 6, 7). In einem Falle ist beobachtet, dass das Pollenschlauchende eine Gabelung zeigte; der dünnere, spitzer endende Arm haftete an einer Tüpfelstelle des Sackes; der dickere stumpfe Arm kroch eine kleine Strecke an der Aussenwand des Embryosackes hin (T. VII. F. 4, $a, b, c)$. Nicht selten haftet der Pollenschlauch am Embryosack nur lose, so dass beide bei der Freilegung sich leicht trennen (T. VII. F, 3; T', VIII. F. 9).

Schon beim Auftreffen des Pollenschlauchs auf den Embryosack ist gewöhnlich nur eines der Keimbläschen, das dem oberen Ende des Sackes ferner der Innenwand desselben anhaftende, noch intact (T. VII. F. 3-6; T. VIII. F. $\left.1-8,9-12 k^{\prime}\right)$; das oder die anderen sind ver-

*) Viscum album fehlt der Umgebung Leipzigs völlig. Ich verdanke den Stoff zu meiner Untersuchıng der Güte einiger Freunde, welche of wiederholt frische Zweige mir zusandten: Prof. G. Reichenb a ch aus TharandI, Prof. Schnizlein aus Erlangen, Hr. Röse aus Schnepfenthal am Thüringer Wald. Die Standorle der Pflanzen, auf welche Obiges sich bezielıt, sind beIrächrlich hoch über dem Neere gelegen: Wald über Tharand nicht unler $900^{\prime}$; Hügel bei Schnepfenthal nicht unter $1100^{\prime}$. Dies mag die Unterschiede meiner Zeilangaben ron den auf das unilde Klima Bonns sich beziehenden bei Treviranus erklären. 
schrumplt, ihr Inhalt eine grumöse, weissliche in durchlallenden Lichte brimnliclggelloe) Masse (in denselben Figuren, $h$. Selten ist ihre Membran moch deutlich volhanden (T. VII. F. 6, \%, Ig); latufiger ist die Zelle zu einen Körper aus körniger Masse verwandelt, oft von Wurnform (T. MII. F. 3, T. VIII. F. 3, 7), oft auch noch den Umliss des Keimblaselicus zeigend (T. VII. F. 4, 6); minder oft von unbestimnten Inmissen (T. VIII. F. 2, 4, 11). Noch seltener ist im vor Kurzem erst vou Pollenschlauch erreichten Embryosick jede Spur der unbefruchted gebliebenen Keinblischen verschwunden (T. VII. F. 6). - Die Hembran des erhaltenen, befruchleten Keimbläschens daggegen erscheint jetzt um vieles dicker und derber, als vor Ankunft des Pollenschlauchs an Sack. Der Zellenkern in Innern des Keimblaschens ist häufigr nicht unchr walızunehmen (T. VII. F. 3, 6); in andern Fallen lassen scine Unursse nur schwierig sich erkennen (T. VII. F.3); in noch anderen treten sie mit grösster Deullichkeil hervor (T. VII. F. 4; T. VIII. F. 7, 9, 10, 12).

Die erste wesentliche Veranderung, welche im Embryosacke nach Anlangen des Polleuschlauches an dessen Scheitel hervortritt, ist das Erscheinen zweier, im llittchaume desselben frei schwehender grosser Zellenkerne, durch Bänder oder strahlige Faden kernigen Schleimes mit dem Wandbelege aus ähnlichem Schleime verbunden. Dem Auftreten dieser lierne folgt sofort die Bildung einer den Embryosack quer durelsetzenden Scheidewand zwischen beiden Kernen, welche den Sack in eine, gewöhnlich lingere untere und kiurzere, aber geräumigere, obere Haifte theilt (T. VII. F. 4). Dass diese Scheidewand die Beruibrungsflaclıe zweicr rollstandiger, jede cine Hälfte des Embryosacks ausfïllender Zartwandiger Zellen isı, wirk sehr wahrscheinlich durch das vereinzelte Vorkommen von Fällen, in welchen die Zelle unterhall, der Scheidewand das verjingte Ende des Embryosackes nicht vollstindigg ausfiillı, sondern mit stumpfem Ende in dasselbe linein ragl (T. VIII. F. I0). In diesem Falle füllte die cinzige grosse Mutlerzelle des Endosprerms den Embryosack nur zum Theil aus; sic reichte nicht bis in sein engeres unteres Ende.. Bei dem gewöhnlichen Torgange erscheint der ganze Innenraum des Sackes als die Urmutterzelle des Endosperms, wir diirfen uns vorstellen, dass die zarte llaut dieser der Innenwand des Sackes, der Aussenwand der Keimbläsclsen und deren Gogenfüsslerzellen aul allen Punkten dicht anliege.

Die untere der so entstandenen zwei Endospermzellen vermehrt 
sich entweder gar nicht weiter, oder nur noch durch einige Quertheilungen. In der oberen dagegen beginnt, nach einigen Quertheilungen, Vermehrung nach allen Richtungen des Raums, bald früher (T. VIII. F. 10, 12) bald später (T. VII. F. 9), die binnen etwa vier Wochen nach rer Befruchung den oberen Theil des Embryosacks zu einem aus schon vielen Zellen zusammen gesetzten Endospermkörper umwandelt.

Die Zellvermehrung im befruchteten Keimllaischen ist währenddem eine ungemein langsame. Noch vier bis fiun Wochen nach dem Verstäuben des Pollens ist es meistens eine, einfache Zelle, unverändert. Anfang Juni erst erfolgt seine erste Theilung durch eine Querwand. Beide so gebildete Tochterzellen pflegen durch Längswände sich zu theilen; die mntere früher (T. VIII. F. 13) und öfter als die olere. Auch die fernere Zellvermehrung ist zunächst nur langsam; Anfang Juli ist die Embryoanlage ein sehr kleiner, aus sechs bis acht Zellen bestehender Körper, eingeschlossen im oberen Ende des schon umfangreichen Endospernkörpers (T. VIlI. F. 14, 10̈). Erst Ende Juli wirl die Entwickelung lehhaft. Aus dem unteren Ende des kurzen, massigen. zum Embryoträger werdenden Vorkeims sprosst rasch der immer tiefer ins Endosperm ein(lringende Embryo herror*).

Viscum album ist eine der am öftersten in Bezug auf Entstehung und Ausbildung des Samens und des Embryo untersuchten Pflanzen. Es sind insbesondere zwei Arbeiten uber die Entwickelmngsgeschichte der Mistel, welche einen weilgreifenden Einfluss in der Wissenschaft ausgeibt haben: die eben erwähnte von Decaisne, und eine lileine, aber inhaltreiche Schrift ron Me y en ${ }^{*}$ ).

Decaisne nimmt das (in allgemeinem Umriss flaschenförmige,) lichtere innere Gewebe der dicken Fruchthnotenwand von Viscum album fiur das Ovarium, die Embryosticlie fur die Eychen. Die frulıesten Entwickelungszustände von solchen, die ihm (Anfangs Juni) zu Gesicht liamen, waren bereits befruchtete. durch mehrere Querscheidewände ge-

*) Ueber die weiteren Entwickelungszustände bis zur Samenreife, namentlich über das Verwachsen mehterer im nïnlichen Fruchthnoten zu Endospermkörpern entwickelten Embryosäcke, und die Polyembryonie vergleiche Decaisue in Memoires de l'acad. d. Bruxelles, T. XIII. (1841) p. 29 11., und besonders Treviran us, über Bau mud Eutwickelung der Eychen unil Saamen der Mistel, in Abh. k. Baỵr. Akad. It. Cl. Vil.

*) Mém. de l'acad. d. Bruxelles, T. XIII. p. 34. 


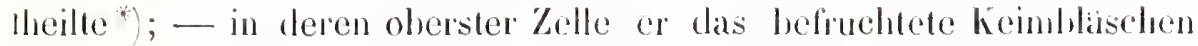
ïbersah. Neben solchen Embryosichen hat er auch lehlgeschlagene, unbefiuchtel gebliebene cinzellige gesehen. Embryonen erkinnte Decaisne crst Anfangs Juli, an denen er Tragger und Embryoliugelchen seliarl' unterscheidet.

bie um ein Jihr fiuher verölientlichten Beobachtungen Me yen's sind ungleich vollstandiger. Er begann seine Untersuchumg Anfangs April, fand bereits zu dieser Zeil die Embryosicke, in denen or indess die Keimblasehen nicht zu linden vermochte. In befiuchteten Embryosicken, welche in wenige, vier bis sechs Endospermzellen gretheilt waren, channte Meyen ganz richtig das befruchtete Keimblaschen, in einzelnen Fallen das unbefruchtet gebliebene neben diesem. Sonderbar genug ist es ihm nicht mogglich gewesen, rom Dasein von Pollenschliuchen sich zu überzeuren. - In der Deutung der Blühenorgane stimmt Me yen, wie schon oben beiLoranlhus erwahnt, völlig mits chleiden uherein: die Nanbe ist ihm die Keimwarze des nacklen Eychens, auf dem ohne Weiteres die Perigonialblatter stehen. - In einer neuerdings erschicnenen Mbhandhug hat Treviran us $\mathrm{s}^{*}$ ), neben einer treflichen Schilderung der späteren Entwichelungszustande des Embryo und der Unbildung der bluthe zur Frucht, cine überkünstelte Deutung der Bluthentheile der Mistel gregeben. Ton ter alteren, durch die Entwickelungsgeschichte wilerlegten Aullassung der Entstehungsweise unterslandiger Fruchtknolen ausgehend, nenut er das Epicapium die angewachsene lleischige Röhre der Blithendechen; das Mesocarpiun den Fruchthoten (, Eyerstoch."; das Endocarpium das cinzige Integunent des aufrechten Eys; das lichte Gewebe im Innem desselben den Eykern. Den Embryosack erkennt er als solehen an (als Ammios); er zeichnet in der obersten der in ihm eingeschlossenen Endospermzellen das befruchtcte, noch einzellige liemblaschen**a ; nimmt aber unbegreillicher Weise den Zellenkern dieses kemublasehens lur eiuen zelligen Körper und fur , ,len Anfung derjenigen Substanz, welche im reilen Samen als Mlbunen sich zu

") Heyen, noch einge Worte aber den Befruchtungsiht und die Polycmbryonie bei den höheren Pllanzen. 8. Berlin $18: 0$.

* Veber Bau und Entwickelung der Eychen und Samen der Mistel. Ablaand. k. Bayr. Akad. II. Cl. VII. (18:33).

a. a. O. T. H. F. 10, I 1, 13, 1 i. 
erkennen giebt." Dieser Anschauung gemäss lasst Treviranus das den Embryosack (Ammios) erfïllende Gewebe bis Anfang Juli völlig verschivinden und durch das Albumen ersetzt werden, den Embryo erst zu dieser Zeit sichtbar werden - Annahmen die alles Grundes entbehren.

Schach t hat beiläufigr $\left.{ }^{*}\right)$ Fruchtknoten und Embryosäcke von Viscum album abgebildet: - Zeichnungen die, noch unter dem Einflusse der Horkel-Schleiden'schen Theorie entstanden, in Bezug auf das Verhältniss des Pollenschlauchs zun Embryo sảmmtlich unrichtig sind, und im Uebrigen kein Verhältniss erläutern, das nicht seit Decaisne schon bekannt wäre.

Die Embryobildung ostindischer nicht näher benannter Arten von Viscum hat G riffith besprochen*** ${ }^{*}$. Die eine der von ihm untersuchten Formen (Species aus Mergui) ist indess, den Abbildungen nach ${ }^{* * *}$ ), offenbar von Viscum generisch und weit verschieden; ist eine Santalacee. - Bei der Art vom Himalaya tritt die Verwachsung der einzelnen wesentlichen Organe der weiblichen Blüthe später und minder vollständig ein, als bei der deutschen.

Die Ansicht D eca is ne's von der nahen Verwandtschaft der Loranthaceen mit den Santalaceen $f$ ), neuerdings von der Mehrzahl der Systematiker adoptirt, wird auch durch die genauere Kenntniss der Entwickelungsgeschichte bestätigt. Im Baue der weiblichen Organe beider waltet nur der eine wesentliche Unterschied ob, dass bei den Loranthaceen das einzige, mehrere Embryosäcke erzeugende Ey aufrecht auf dem Grunde der Fruchtknotenhöhle steht, während bei den Santalaceen hier eine centrale, freie Placenta eingefügt ist, die an ihrer Spitze eine Mehrzahl hängender Eychen, jedes mit nur einem Embryosacke erzeugt $\overbrace{}^{*})$. Ein

*) Das Mikroskop, 2. Aufl. Berlin 1855. F. 6-9.

**) Transact. Linn. Soc. XVIII. (1841), p. 74. XIX. (1845), 181.

***) a. a. O. XVIII. T. XI. F. 1, 3, 4 .

†) Nouv. Mém. de l'acad. d. Bruxelles XIII., 29.

$\left.\leftarrow^{*}\right)$ Dies als Unterscheidungszeichen zugegeben gehört Myzodendron zu den Santalaceen, wo auch von ihm die Rede sein soll. 


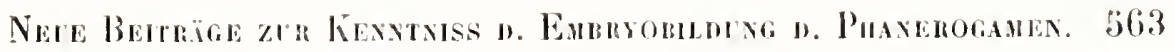

nur gradweiser, melır in mnserer Terminologie als in dem Entwickelungsgange liegender Unterschied $\left.{ }^{*}\right)$. Die heiden Fimilien zeigen dabei einen gewissen Parallelismus in der Enbryobildung. Osyris, Thesium ăhneln in dieser Bezichung Viscum, Santalum steht nither an Loranthus.

\section{II.}

\section{Santalaceen.}

\section{Thesium alpiumm L. Ind Th. intermedium Schuad.}

Tisf. X. F. 1-6.

Die vom Scheitcl der limgen, cylindrischen grundstandigen Placenta der Thesien schrig nach unten gerichtet herah)hingenden drei nackten Eychen sind vor der Befruchlung gestreclit eyfömige Massen kleinzelligen Gewebes, deren Längsachse eine enge cylindrische Zelle, ziemlich ron der limge des Eychens, einnimmt. Sie ist der Embryosack. Er ist rugs von Zellen eingesclilossen; seine scheitelgegend nur von einer einzigen Zullschichı. Narlı dem Grunde hin ist er von mehreren Zellenlagen ungeben. In der scheilehwölbung haften zwei verhällnissmissig klane, kurz birnförmige Zellen, die Keimblischen (T. X. F. 1).

Die von der bestaublen Narbe schnell, und meist in grosser Anzahl in die Fruchtlinotenhöhle herabsteigenden Pollenschläuche bilden in dieser einen vieffach verschlungenen, lockeren Filz. Einzelne Potlenschlänche zeigen bisweilen betrichthiche hasige Anschwellungen von unregelmässigem Umriss (T.X. F. 6). Dje Eychen bleiben so lange ohne

* Er waire sclınell gehoben, wenn man das von mir als Ey bezeichnele Organ von Loranthus für die Placenta dieser Pflanze nehmen wollte. Ich kann mich nicht dazu entschliessen, der Anwesenheit der einer Chalaza gleichenden Gewebsmasse unterhalb dieses Eyes wegen. Eher, glisube ich, möchte dem Samentriger der Santalaceen der Charakler einer Placenta zu bestreiten sein. So gut wie die zusammengesetzten (verästelten) Antheren, die Pay er bei Mesembryanthemum und anderwärts kennen lehrte, sind auch verzweigte Eysprossen denkbar. 
nerkliche Verïnderung, his das Ende eines Pollenschlauchs zwischen die Zellen der den Scheitel des Embryosacks eimes der Eychen deckenden Zellschicht sich drängt, und so auf die Aussenwand des Embryosackes trifft. In allen beobachteten Fällen ist die Stelle dieses Auftreflens des Sclılanches auf den Sack an der inneren, dem Samenträger zugewendeten Seite des Eỵchens gelegen.

Unmittelbar nach Ankunft des Pollenschlauchs beginnt ein lebhaftes Flächenwachsthum der Membran des Embryosacks an dessen äusserer. dem Samentriiger abgewendeter Seite dicht unter der Spitze. Seine Haut wölbt sich hier nach aussen, drängt die - in Vermehrung begriffenen - Zellen der umhüllenden Schicht auseinander, und tritt blasig hervor (T. X. F. 2). Die Form des Embryosacks wird dadurch vollständig verzerrt. Während seine innere Seite in ursprünglicher Kürze verharrt, verlängert sich die äussere zu èiner, in der Durchschnittsansicht zunächst halbkreisförmigg, bei weiterem Wachsthum elliptisch gekrümmt erscheinenden Fläche. Der ursprüngliche Scheitelpunkt des Sackes, die Anlıeftungsstelle der Keimbläschen, ersclıeint dadurch an die innere Seite desselben weit hinabgerückt (T. X. F. 2, 3).

Die Keimbläschen strecken siclı währenddem in der Richtung der grössten Auschwellang des Sackes. Zunächst erscheinen sic in, zur Lingsachse des Embryosacks rechtwinkliger Richtung verlängert (T. X. F. 2). Die Streckung des einen übertrifft leträchtlich die des anderen; dieses letzlere wird bald aufgelöst, und verschwindet. Nahe unterhall, der Keimbläschen hat sich inzwischen eine Querwand im Embryosacke gebildet, welche den gestreckten, im Gewebe des Eychens eingeschlossenen unteren Theil des Sackes von dessen halbkugeligem, in die Fruchtlinotenlı̈̆lle ragenden oberen abscheidet (T. X. F. 2). - Jener untere Theil bleibt während der ganzen ferneren Entwickelung des Samens eine einfaclue Zelle. Sein unteres Ende verlängert sich zu einem lang gezogenen Schlauche, welcher zunächst in das Gewebe des Eychens; nach dessen Durchbohrung spitzwinklig umbiegend und senkreclıt herab steigend noch tief in das des Samenträgers eindringt (T. X. F. 3-6. Die obere Hälfte des Embryosachs wandelt sich durch eine lange Reihe cinander rasch folgender Zweitheilungen in den Endospermiörper um. der, in demselben Sinne fortwachsend wie der eben befruchtete Enbryosack, zu einer tief in die Fruchthnotenhöhle herein hängenden eyförmigeu Masse sich nmwandelt. 


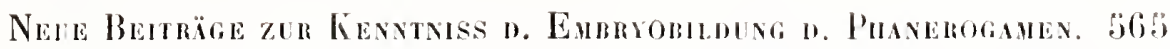

Die Entwickelung des befruchteten Keimblaschens zum Vorkeim und Embryo erfolgt auch hier (der fast allgemein giiltigen Regel gemaiss) nach der Richtung hin, in welcher das Endosperm am stirksten sich ausbildet. Da diese Richtung bei Thesium der Linie vom oberen zum unteren Ende des unbefruchteten Embryosacks nahezu diametral entgegen gesetzt wird, so biegt sich das weiterwachsende Ende des Vorheims, oft schon in friihester Jugend (T.X.F.4; angerleutet sogar schon in der einseitigen Anschwellung des befruchteten Keimbläschens der F. 3) nach dem Grunde der Fruchılinotenhöhtle hin um. In sciner Krimmung stellt der Vorkeim die schriltweise Ablenkung der Entwicliclungsrichtung des Embryosicks von Thesium von der der Mehrzahl der Plaanerogamen dar (hier entgegengesetzt der Entwickelungsrichtung des Eychens, bei Thesium ihr gleichsinnig). - Die Endzelle des Vorkeims theilt sich nur wenige male durch horizontale Wände, bevor Zellvermehrung nach allen Richtungen hin in ihr eintritt. Ein kiteiner Theil des so entstehenden massigen Zellgewebes geht noch in Bildung des Embryotragers ein, welcher vom dicken Wurzelende des Entbryo nur ganz allmälig sich absetzt.

Während der Entwickelung des Eyweisskörpers erhalten sich viele der Pollenschlauche in der Fruchthnotenhöhle noch tebenslirtiftig. Oft heften sich einzelne derselben mit ihren Seitenfliachen der Aussenseite des von der Embryosackhaut überzogenen Endospermkörpers an (T. X. F. 2, 6), und zwar so fest, dass dic Tremnung ohne Zerreissung nicht möglich ist.

Die unbefruchtet gebliebenen Eychen (nie fand ich mehr als cines befruchtet) nehmen während der Entwickelung des befruchtelen an Umfang zu, indem in den den Embryosack umhüllenden Zellsehichten, wie dort, eine lebhafte Zellvermelirung eintrilt. Nic aber tritt der Embryosick dieser Eychen aus der ihn deckenden Zellenlage hervor.

Die Entwickelung des Samens von Osyris scheint sich, nach dem Wenigen, was wir durch Griffith dartiber wissen*), der von Thesium ganz áhnlich zu verhalten. Der Embryosack wächst aus der Kernwarze des nackten Eys herror, und streicht durch dasselbe bis zur Basis. Der

*) Griffith, Notes on the Orulum of Santalum, Osyris, Loranthus and Viscum, in Transact. Linn. Soc. XIX, p. 171. 
Pollenschlauch adhärirt sehır fest der Membran des Embryosacks. Griffith's Ansicht, dass das Endosperm nicht im Embryosack gebildet, sondern der Aussenwand desselben verhältnissmässig spät aufgelagert werde*) - cine Ansicht, welche an die Schleiden's rom Verbältniss des Prothallium der Rhizocarpeen zu der Membran der Malirospore erinnert - beruht zuverlissig, wie diese, auf dem Uebersehen friiherer Entwickelungszustände, auf welchen die Membran, welche das Endosperm rom zellenleeren Theil des Sackes abgränzt, noch nicht nach aussen convex, die einzelnen Endospermzellen noch nicht nach aussen gewölltt waren. - Die Umkehrung der Entwickehungsrichtung des Embryo ist bei Osyris insofern minder vollstindig. als bei Thesium, als bei Osyris der reife Embryo mit der Längsachse des Eychens einen ziemlich weit geöffneten Winkel bildet.

Die Angaben, welche Schacht über die Entwickelungsgeschichte des Samens von Thesium veröffentlicht hat**), beruhen in der Hauptsache auf irrthimlicher Beobachtung. Die Richtung des Embryotrigers, die Art seiner Anheftung an die Wand des Embryosacks beweisen streng, dass eine Lage des befruchteten Keimblaischicns, wie sie Schacht für sein ,,in den Embryosack eingedrungenes Pollensclulauchende" abbildet, gar nicht vorkommen kann.

* Das Endosperm soll entstehen: ,from the deposit of minute and laxly formed cells on the surface" of the protruded part of the embryonary sac", a. a. 0, p. 176.

${ }^{*}$ ) Schacht, Entwickelungsgescluichte des Pflanzenembryon S. XII ; T. 19,20. F. 96. 


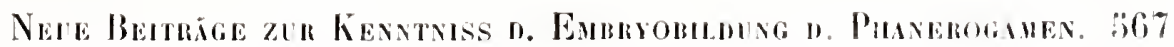

\section{III.}

\section{Aristolochieen.}

\section{Aristolochia Clematilis $\mathbb{L}$.}

Taf. X. F. 7, 8 .

Die Eychen von Aristolochia Clematitis Laben in der Ansicht von vorn die Form eines Dreiceks $(\mathbf{F} .7$ b), in der Scitenansicht die cines Parallelogramms. Die Raphe, sehr stark entwickeh, macht die Hauptmasse des unbefruchteten Eys aus. Der Eykern, von zwei dünnen Integumenten iiberzogen. ist an der Vorder- und Ilinterflache stark abgeplattel; der in seiner Längsiclise liegende, rings von Gewebe umschlossene Embryosack schlank keulenförmig.

Bevor nach erfolgter Befruchtung die Keimblaischen sich irgend veriindern, wird der Embryosack wiederholt durch Querwinde getheilt. Zur Zeit des Welkens des Perigons erscheint er auf Längsdurchischnitten, welche durch die Raphe gelegt sind, als eine Längsreihe von fiunf bis sieben Zellen, ailunlich dem befruchteten Embryosacke von Viscum album (F. 7). Die ersten Längswände, welche in diesen frühesten Zellen des Endosperms entstehen, sind simmtlich der Ebene des erwähmten Schnittes parallel. Das Endosperm wächst zunächst nur in die Breite, nicht in die Dicke. Zwei Wochen nach dem Fall des Perigons frei praiparirl, erscheint es als eine llache Hasse aus einer cinzigen Schicht grosser Zellen bestehend, deren jede einen wandstindigen Zellenkern enthialt (F. 8). Das eine der Keimblaischen ist jelzt verschwunden; das andere. befruchtete, ist nur wenig verindert; dickwandiger als vor und lurz nach der Befruchtung, aber noch eine einfache, kurz birnförmige Zelle, die mil breiter Ansatzlliche an der Innenwand des Sackes haflet (F. S R). Auch die fernere Entwickelung des Embryo ist sehr langsam und gering. ibereinstimmend mit der von $A$ sarum. 


\section{IV.}

\section{Asarineen.}

\section{Isarum europaeum L. und canalense L.}

Taf. X. F. 9-16.

Die Eyclıen der beiden genannten Arten von Asarum haben nicht die plattgedrickte Form derer von Aristolochia, stimmen im Uebrigen aber in ihrem Baue mil jenen überein. Schon frülıe, noch vor der Befruchtung, macht sich eine vorwiegende Entwickelung der Rückseite der Raphe bemerklich. Sie erfolgt dadurch, dass die Zellen der Zellschicht zunächst nnter der Epidermis sich selir bedeutend ausdelınen, wălırend die der Epidermis selbst, in Richtung der Tangenten sich stark vermehrend, als sehr kleinzellige Schicht jene sehr herangervachsenen Zellen bedecken (F. 9, x).

Der keulenförmige Embryosack liegt in der Achse des Eykerns, rings von dessen Gewebe eingeschlossen; auch auf dem Scheitel von drei Zellschichten (F. 12, 17) bedeckt. Die Keimbläschen, verhältnissmässig klein, von kugeliger Form, zu zweien, seltener zu dreien vorhanden, haften mit kleinen Ansatzflächen an der Innenwand seiner Scheitelwölbung. Der grosse, abgeplattet ellipsoïdische primäre Kern des Sackes liegt in dessen Mittelgegend der Seitenwand an, im Mittelpunkte strahliger Stränge aus körnigem Protoplasma. Die Gegenfüsslerzellen der Keimbläschen, drei an der Zahıl, von beispielloser Grösse, füllen dicht an einander gedrängt die ganze untere IIäfte des Embryosacks (F. 9, 12). Bei Asarum europaeum fand ich sie beständig, bei Asarum canadense in der Regel so beschaffen. Bei letzterer Art kommen indess auch Ausnahmen vor: das Vorhandensein von melır als drei, in verschiedener Höle befindlicher, scheinhar ein Parenchym bildender Gegenfüsslerzellen (F. 10), und auch das vollständige Fehlen derselben (F. 11).

Nach Ankunft des Pollenschlauchendes am Embryosackscheitel theilt sich der Embryosack durch eine Querwand in zwei den ganzen Raum oberhalb der Gegenfiisslerzellen der Keimblischen ausfiillende Tochterzellen. IVo diese Zellen fehlen, erscheint die untere der neu gebildeten 


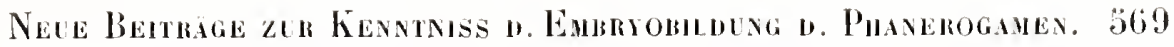

Zellen vom Chalaza-Ende des Embryosackes durch eine Wand alogegranzt (F. 11); - eine Andeutung allseitiger Nembranbildung an diesen Tochterzellen. In einem Falle wurde deutlich beobachtet, dass diese Zell,jildung in Embryosack eintrat, bevor das Pollenschlauchende, noch auf seinem Wege durch die vor ilım lıer sich rerflüssigenden Zellen der Kernwarze begriflen, den Scheitel des Embryosackes erreicht hatte (F. 11)*). Die Tochterzellen des Embryosacks fahren fort, durch Quer-, Längs- und schräge Wände sich zu theilen; das Endosperm wird rasch zu einem vielzelligen, Anfangs cylindrischen (F. 12), dann bauchig anschwellenden Körper. Während dieser Vorgảnge bleilsen die Keimbläschen und ilıre Gegenfüsslerinnen lange Zeit unverändert (F. I 2). Endlich verschwindet das eine Keimbläschen; aber noch bleibt das andere, das befruchtete, eine einfache Zelle. Erst wenn das Endosperm beinahe seine volle, während der Reifung des Samens nicht mehr zunchmende Grösse erreicht hat, beginnt eine Reilıe von Thıilungen im befruchteten Keimbläschen. Zunächst eine Quertheilung, welcher bald die wiederholte Quertheilung der sich streckenden unteren Tochterzelle folgt. Die junge Embryoanlage erscheint nun als kurzer eyförmiger Zellkörper, der an seinem freien Ende im Querschnitt vier, weiter aufwärts zwei Zellen zeigt, und mit einer einzigen Trägerzelle an der Innenfläche des Embryosacks lose haftet (F. 14). Später erfolgt eine Längstheilung auch der Trägerzelle (F. 10̈). Auch im völlig reifen Samen ist der Embryo ein sehr kleiner länglicher Körper von fast viereckigem Umriss (an der Spitze nicht breiter als an der Basis), aus einer nur geringen Zahıl von Zellen zusammen gesetzt, die von der Anheftungsstelle gegen die Spitze an Grösse ab-, an festem Inhalt zunehmen (F. 16).

*) Diese Beobachtung lässt sich allerdings auch so erklären, dass ein zweiter Pollenschlauch in das Ey gedrungen und durch den Schnitt entfernt worden sein könnte. Doch wurde in keinem Falle bei Asarum das Eintreten von mchr als einem Pollenschlauche in die Mikropyle eines Eychens gesehen. 


\section{V. \\ Cytineen.}

\section{Cytinus IIypocistis L. ${ }^{*}$ ). \\ Taf. X. F. 19-25.}

Die acht Placenten des unterständigen Fruclttknotens von Cytinus stehen auf der Innenwand desselben als vorspringende Längsleisten, in ihrer Anordnung dem Verlaufe der Gefässbündel entsprechend, welche durch die Fruchtknotenwand je zwei zu einem der vier Perigonialzipfel gehen. Die Placenten ähneln in ihrer Form vollständig denen der Orchideen: sie erscheinen sowohl auf Längs- als auf Querschnitten dendritisch verzweigt $(\mathrm{F}, 17,18)$. Kein Ast der Gefässbündel tritt in die Placenten ein. Die letzten Enden der zalılreichen dichtgedrängten Verzweigungen der Placenten sind die selır kleinen, völlig durchsichtigen Eychen.

Auf den frühesten beobachteten Zuständen (etwa acht Tage vor dem Aufbrechen des Perigons) erscheint das Ende jedes Eysprosses als eine schlank-keulenförmige Zellenmasse, bestehend aus einer axilen Zellreihe und einer einzigen, diese umwindenden Zellschicht. Dieser Theil des Eys ist der künftige Eykern. Rings um seinen Grund erhebt sich aus dem Gewebe des Eyträgers eine Ringwulst, welche durch wiederholte Theilung ihres Kranzes von Scheitelzellen mittelst geneigter, dem Eykern wechselnd zu- und abgewendeter Scheidewände zu einer den Eykern eng umschliessenden, aus einer Doppellage von Zellen gebildeten Hülle emporwächst: dem einzigen Integument des Eyes (F. 19). Nach seiner Anlegung sprossen aus dem Eyträger, tiefer abwärts, schuppenförmige Anhängsel hervor, welche keine beträchtliche Länge erreichen und, auch bei voller Entwickelung vereinzelt bleibend, einen unrollständigen und unregelmässigen Kranz am oberen Theile des Eytrïgers darstellen (F. 20, 22-24). Die axilen Zellen des Eyträgers theilen sich öfter durch Längswinde, als die peripherischen; diese öfter durch

- Den Stoff zur Untersuchung dieser Pflanze verdanke ich Herrn Podestà Tommasini in Triest, welcher die Güte hatte, Ende Aprils 1853 lebende Exemplare mir zu sender. 
Querwände als jene. Der Eyträger, auf den früheren Zuständen aus gleichartigem Zellgewebe aufgebaut $($ F. 19, 20) erscheint bei voller $\Lambda$ usbildung als ein centraler Strang aus engen, langen Zellen, der von einer einfachen Schicht liurzer Zellen berindet ist (F. 22-24).

Die oberste Zelle des axilen Zellstranges des Eylierns nimmt fruhzeitig vorwiggend an Grösse zu (F'. 19). Während das Integument den Eykern einhüllt, vergrössert sic sich um das Zwanzigfache. Die sic umhiullenden Zellen folgen ihrer Dehnung, mehr und mehr sich abplattend, und durch Laings- und Querwände, welche auf den freien $\Lambda$ ussenflaichen rechtwinklig stehen, sich theilend und vermehrend. Jene rasch lieranwachsende Zelle ist der Embryosack. Scin grosser primäıer Kern, auf den frühesten Entwicliclungsstufen inmitten des die ganze Zelle erfüllenden körnigen Protoplasma schwebend (F. 19), erscheint später, wo im Mittelraume der Zelle eine immer grösser werdende Vacuole auftrilt, dem Wandbeleg aus Protoplasma eingebettet, welcher da wo der Zellkern der Seitenwand der Zelle anliegt, am dicksten ist und von dieser Ansammlung aus in strahligen Streifen an der Wand hin verläuft. Es ist dieselbe Umwandlung der Lagerungsverhältnisse des Zellinhalts, wie sie bei cler Grössenzunahme einer ursprüglich von Protoplasma ausgefuillten Zelle ganz allgemein ist $\left.{ }^{*}\right)$, und wie sie namentlich im Entwickelungsgange der Embryosäche durchweges gefunden wurde, sorveit meine Beobachtungen reichen.

Ausser der Protoplasma-Ansammlung um den primairen Zelliern häufen deren im jungen Embryosacke noch zwei sich an: die cine in der Wölbung des Scheitels, die andere in der des Grundes. In beiden entstehen freie Zellkerne (zuerst kernkörperchenlose Küigelchen das Licht schwächer als das ungebende Protoplasma brechender Substanz) in der ersteren meist zwei (F.21), in der letzleren drei, un welche sphärische Zellen sich bilden. Die ersteren sind die Keimblaschen, die letzteren ihre Gegenfüsslerinnen. Die Bildung dieser ist früher beendel als die jener. Die Keimblaischen erhalten bald Birnenform, und hiingen, mit breiter Ansatzllache der Innenwand des Embryosaclis angeschmiegl, in dessen Raum lıcrab. Die Gegenfüsslerzellen werden bei weilerer Entwichelung (Anschwellung) des Eys mehr und mehr abgeplattel (F. 22, 23).

*) Hofmeister in Bot. Zeitung 1848, S. 657. A. Braun Verjüngung S. 2ác. 
Dicse Stufe der Entwickelung erreichen die Eychen bei dem Aufblühen des Perigons. Die Zellen der den Embryosack umgebenden Zellschicht sind jetzt zwar stark abgeplattet, aber noch kenntlich (F. 22, 23). Wahrend des Blühens tritt aber eine starke Anschwellung des Eyes, insbesondere auch des Embryosacks ein, wobei die Hohlräume jener Zellen vollständig verschwinden, so dass die Membran des Embryosacks der Innenfläche des Integuments unmittelbar anzuliegen scheint (F. 24).

Künstlich auf die Narben gebrachter Pollen trieb nach sechs bis zwölf Stunden Schläuche (F.23a,b). Bevor dieselben die Fruchtknotenhöhle erreichten, ereilte auch den Parasiten des Cistus der Tod, welchen die Nährpflanzen, aller aufgewendeten Sorge zum Trotz, schon einige Tage fruiher erlitten hatten. Die Untersuchung konnte nicht weiter fortgesetzt werden.

Der Bau der reifen Samen von Cytinus ist durch Rob. Brown beschrieben worden*); - mir haben keine zu Gebot gestanden. Den zelligen Körper innerhalb der Samenschale, welchen R. B r. als homogenen Embryo deutet, halte ich für Endosperm, in dessen Innerem der Embryo zu suchen ist.

\section{VI.}

\section{Balanophoreen.}

\section{Cynomorium coccincum Mich.***).}

Taf. XI.

Eine nicht genau bestimmte Zahl von Gefissbündeln, zwei bis fünf, meist drei, tritt in die Basis der weiblichen Blithe ron Cynomorium ein. In der Einfügungsstelle des Fruchthnotens in die keulenförmige Achse der Inflorescenz stehen sie so dicht bei einander, dass sie ein einziges Bündel zu bilden scheinen. Ihre Zahl scheint mit der gleichfalls verän-

*) Transact. Linı. Soc. XIX, 229.

**) Nach einer bei Murcia aufgenommenen, in Weingeist aufbewahrten Infloresccnz, welche Prof. Rossmässler von einer spanischen Reise mir mitzubringen die Güte hatte. Bekanntlich zeigen dic Dichasien, welche in den Achseln der grossen Bracteen der Hauptachse des Blüthenstandes von Cynomorium sich entwickeln, sehr verschiedene Entwickclungszustände von Blüthc und Frucht neben einander. 
derlichen der Perigonialblatter in Bezichung zu stehen. Wo diese ganz fehlen oder uur eines rudimentar vorhanden ist, treten nur zwei Gefissbündel in die weibliche Bliathe: so bei denen, welche dic letzten Verzweigungen der Dichasien darstellen. Ihr Verlauf innerhall, der Wand des hall, unterstindigen fruchtinotens ist nicht genau senkrecht; sie weichen oft betrichtlich rechts gewendet*) von der Verticalen ab. In jedes vollstindig entwicliclte Perigonialblatt zweigt sich von dem ilm nächsten Gefissbiundel der Fruchtknotenwand ein Ast ab, welcher in der Langslinic des Blattes verlaufend, nahe unter dessen Spitze mit einer Gruppe ron Spiral - und Netzfaserzellen endet (F. 6). Der ubrige Theil des Bündels jedes Perigonialblattes, wie die Bündel des Germen, bestehen aus Spiralgefissen. Nahe der Ursprungsstelle des Griffels vereinigen sich die Gefiissbiindel, wenn deren mehrere als zwei vorhanden, zu zweien, die in den Griflel eintreten, hier vertical aufsteigen (bei der sehr häufigen Drchung des Griffels in Rechtswendung um seine eigene Achse, cine Drehung die in der Anordnung der langgestrecliten Zellen seiner Epidermis sofort hervortritt, steil ansteigende rechtsumbiufige balbe Schraubenwindungen beschreibend; - so bei F. I) und enden nahe unter der kummetförmigen Narbe, zu beiden Seiten des tief herab grehenden Längsspalts dessclben (F. 1). Ein enger, aber deutlicher Langshanal durchzieht die Achse des Griflels und mindet in die Fruchtknotenlıölıle (F. 1, 2, 6).

Dicht unter der Innenmündung des Griftelkanals lıängt an kurzem Funiculus das kurz ellipsoüdische, fası kugelige Ey von der Fruchtknotenwand in die Höhle des Fruchthnotens herab, welche es völlig ausfüllt. Der Anheftungspunkt des Eys faillt zwischen die beiden Eintrittsstellen ron Gefässbiindeln in den Griffel; bald genau in clie Milte, bald dem einen Bündel näher. Beide Bündel entsenden Abzweigungen in den Funiculus, die dicht iber dem Ursprung desselben sich vereinigen und bis zur Chalaza verlaufen. Der Funiculus ist Sförmig schwach gelirümmt (F. 1, 2, 6).

Der von cinem einzigen, dicken Integument umhüllte, abgeplatlet ellipsoüdische Eyliern macht mit dem Funiculus einen stumpfen Winkel von beilaufig $120^{\circ}$ (F. 1). Die horizontale Richtung des Eys entspricht

*) Bestimmung der Richtung wie bei der der Wendung der Blattstellung, den Beobachter in die Längsachse des Objects gedacht. 
genau derjenigen der Narbenspalte: eine durch Chalaza und Mikropyle gelegte Ebene schneidet auch jene Spalte, und geht mitten durch zwischen beiden Gefässbündeln des Griffels; - wobci selhstverständlich etwaige Torsionen des Griffels wegzudenken sind. - Eykern und Mikropylekanal sind durchaus ungekrümmt.

Das Integument bestelıt seiner Hauptmasse naclı aus polyedrisclien, mässig grossen Zellen, die gegen die Mikropyle lin stetig kleiner werden. Diese Zellen sind von Amylumkörnem dicht vollgestopft. Die innerste Lage von Zellen des Integuments besteht aus stark abgeplattelen tafelförmigen Zellen. Aelınliche Zellen kleiden den Mikropylekanal aus (F. 3). - Zartwandige, etwas gestreckte Zellen setzen den Eykern zusammen. In Uebereinstimmung mit dem Baue des Eykerns der grossen Mehrzahl der Phanerogamen ist ilhre Anordnung so, dass sie von der Chalaza aus aufwärts allseitig strahlen (F. 1, 2). Ins Innere dieses Gewebes ist der Embryosack eingeschlossen. auch auf seinem Scheitel von zwei Zellschichten bedeckt (F. 1, 2, $, 3,8)$; - eine grosse keulenförmige Zelle, die beinahe die ganze Längsachse des Eykerns cinnimmt. In ihrer Scheitelwölbung haften in unbefruchteten Eychen zwei kurze, mit breiter Fliche der Embryosackhaut ansitzende Keimbläschen, welche der festen Zellhaut entbehren. In der Mittelgegend des Sacks liegt dessen grosser primärer Kern der Wand an (F. 1). Zellenkerne und Protoplasma des Zellinhalts zeigten sich bei den (in Alkohol gelegten) untersuchten Exemplaren von Cynomorium, wie bei allen anderen in Flüssigkeiten aufbewahrten Balanophoreen von dunkelgelber bis rothbrauner Färbung - ohne Zweifel eine Folge der Aufspeicherung der von der Aufbewahrungsflüssigkeit gelösten Farbstoffe in der porösen Substanz der Zellenkerne und des geronnenen Protoplasmas.

Der früheste aufgefundene Entwickelungszustand eines befruchteten Embryosackes zeigte denseliben von vier grossen Endospermzellen ausgefullt, zu zweien paarweise neben einander geordnet (F. 3). Ohne Zweifel entstanden diese Zellen durch zweimalige Zweitheilung des ganzen Raumes des Sackes. In der Scheitelwölbung des Embryosacks war nur noch ein Keimbläschen sichtbar, jetzt mit einer Zellstoffhaut bekleidet; das andere war spurlos verscliwunden.

In weiter vorgerükten jungen Fruchten hat die Zahl der Endospermzellen sich betrïchtlich vermehrt; vorzugsweise in dẹr oberen Ilialfte des limbryosackes der immer ausgepriagtere Keulenform anuimmt 
(F. 4, 5). Ilier folgt die Anordnung der neu gebildeten Tochterzellen allen drei Richlungen des Raumes, willsend in der unteren, engeren Hälfte des Embryosackes geraume Zeit hindurch keine anderen, als Quertheilungen der Endospermzellen vorkommen (F. 4). Dąs Ende des Pollenschlauches findet man häufig der Aussenwand des Sackes anhaftend (F. 4, э. 8). Das befruchtete Keimblisschen theilt sich friih durch eine Querwand (F.4.). Die obere beider neu gebildeter Zellen stellt für siclı allein den Embryoträger dar; schon ihre Schwesterzelle wird durch Theilung mittelst nach verschiedenen Richtungen hin gestellter Scheidewainde zum Embryokügelchen (F.7,8,9). Die Trägerzelle bleibt meistens ganz kurz (F. 8); die Fälle sind selten, in welchen sie lïnger erscheint als ihre Querdurchmesser (F.9).

Ilier endet meine Untersuchung; das mir zu Gebote stehende Material zeigte lieine späteren Entwickelungszustände. - Aus den übereinstimmenden Angaben L. C. Richard's*), Weddell's**) und J. D. Hooker's***;) geht hervor, dass bis zur völligen, bis jetzt allein von Il o o ker untersuchten Samenreife keine andere wesentliche Veränderung in der Frucht vor sich geht, als die Verdrängung des Eykerns und des grössten Theiles der Gewebe des Integuments durch den an Umfang immer mehr zunehmenden und endlich Kugelgestalt erlangenden Endospermkörper. - Der liugelige Embryo, der erste und lange Zeit der einzige bei irgend einer Balanophoree gesehene, ist seit 1822 durch Rich a r bekannt $\psi$ ). Seine einseitige, schräg abwärts gerichtete konische Verlängerung ist von ihrem Entdecker, J. D. Hooker, als das Wurzelende gedeutet worden * $\left.^{*}\right)$; - ohne alle Frage vollkommen rich-

*) Ann. du Huseum VIII, p. 426; T. 21, F. $O, P$.

**) Ann. sc. natur. III. Seric T. 14 p. 180.

***) Transact. Linn. Soc. XXII, p. 36.

t) Wunderlich genug ist Richard's Analyse nicht ohne Anfechtung gcblicben. Endlicher hat ihre Richtigkeit in Zweifel gezogen und die Ansicht gcäussert, Richard luabc sich bci der Untcrsuchung von vorgefassten Mcinungen leitcn lassen (Meletcmata, Fasc. 11, p. 9). Der Vorwurf prallte vollstïndig auf Endlicher selbst zurück, der offenbar in seinem Widerspruch gegen Richard von dem Vorurt'seil ausging, dic Balanophoreen könnten und dürften kcine Embryoncn haben, seien nebst den Rafflcsiaceen in ihrer Organisation die Mitte zwischen Pilzen und Planerogamen haltende Pflanzen, mit Samen die von ,sporenfülırender Masse“ erfüllt scicn. (Verglciche auch Griffith in Transact. Linn. Soc. XIX, p. 307$)$.

$\left.\dagger^{*}\right)$ Transact. Linn. Soc. XXII, T. I., wo auch von den hicr zur Sprache gebrach- 
tig, da die Richtung jener Verlängerung genau auf die von mir aufgefundene Mikropyle zu weiset.

Nur als eine Sonderbarkeit ist nach dem Vorausgeschickten zu erwăhnen, dass Weddell*) auch dem Cynomorium seine Lehre von der Nacktsamigkeit der Balanophoreen aufzuzwängen versucht, und die Fruchtknotenwand desselben als Testa gedeutet hat. Ein Unternehmen, von dem die ganz richtig von ihm erkannte Lage des Embryo ihn billig hätte abhalten sollen; -- sie zu erklären ist er zur Annahme eines unmässig langen Embryoträgers gezwungen, der den (aufrecht gedachten) Embryosack seiner ganzen Länge nach durchstreichen soll.

\section{Langsdorflia hypogaea Mart. $\left.{ }^{*}\right)$. \\ Taf. XII.}

Wie bekannt, stehen die cylindrischen weiblichen Blüthen von Langsdorffia dicht gedrängt auf der Oberflache der in der Jugend halbkugeligen Blüthenachse. Im oberen Drittheil sind die Blüthen unter einander fest verwachsen; der säulenförmige sechsseitige untere Theil, obwohl die Nachbarblüthen unmittelbar berührend, ist völlig frei****). Die Blüthen sind zur Zeit, da sie bereit sind die Bestäubung durch den Pollen zu empfangen, etwa 1, 3 M.M. lang, den Griffel nicht mitgerechnet. Der weit vorragende Griffel ist von einem engen Kanale durchbohrt, welcher sich seitlich, in der Mltte des papillösen oberen Theiles des Griffels, nach aussen öflnet (F.2). Dieser Kanal streicht durch die ganze Länge der Blume, um in die sehr hleine, dicht über der Einfügung derselben in die Blüthenachse befindliche, eyförmige Fruchthnotenhöhle zu

ten Verlıältnissen der Gefässbündelverlaư im Griffel und das Integument des Eỵs (aber nicht dessen Mikropyle) erörtert sind.

*) a. a. 0 .

**) Die jüngeren Zustände nach einem von Dr.J. D. Ilooker mir mitgetheilten Theile einer in Essig aufbewahrten Inflorescenz. Einen Fruchtstand mit reifen Samen verdanke ich der Güte des Prof. Mettenius.

***) Richard (Ann. du Museum VIII, T. 22) und Martius (Nova Gen. ac sp. T. III. Tf. 298) stellen übereinstimmend den unteren Theil der Blüthe viel dünner dar, als den oberen angewachsenen. Wahrscheinlich Folge einer Formweränderung, welche das Object durch Wasserentziehung (Trocknen oder Aufbewahrung in Alkohol) erlitten hatte. 
miinden (F. I). Die Wand dieser IJöhle hesteht aus hexagonal-lafelförmiggen Zeltchen mit sehr protoplasmareichen Inhalte. In der Ungebung der Höhle und so weit aufwirts, als der Fruchthnoten frei, nicht mit den benachbarten verwachsen ist, besteht dessen relativ dicke Wand aus engen, langgestreckt prismatischen Zellen, welehe leicht aus dem seillichen Zusammenhange sich lösen. Ihr Inhalt ist wässerig, enthailt ausser dem Zelliern nur wenige feste Bildungen. Von der Stelle an anfivairts, wo die Verwachsung des oberen Theils der Bliithen anlıebt, ist das Gewebe derselben um Vieles grosszelliger, die Zellen nur mässig gestreckit, der Inlaalt derselben die Zellen fast ausfïllende feste liörnige Missen, deren IIaupthestandtheil Wachs ist. In der Achse dieses Gewebes verläuft ein diinner Cylinder von engen langen Zellen, in ihrer Beschaffenheit denen des unteren Theils des Fruchthnotens ähnlich. Dieser Cylinder gelıt unmittelbar in das Gewebe des freien Griffels iiber; in seiner Achse verlikuft der Griffelkanal (F. 2). Zwischen den wachshaltiggen Zellen des oberen Theils der Blüthe sind einzeln gestrecktere, prosenchymatische Zellen eingestreut, deren Wande zum Theil schon jetzl, in dieser frühen Zeit, stark verdickt und eng getiipfelt sind (F. 2, y). Andere der prosencliymatischen Zellen sind jetzt noch dünnwandig (F. 2, x). Die Prosenchymzellen stellen einen weder ganz regelmässigen noch vollstiandigen, mit dem Griffelkanal concentrisehen Cylindermantel dar.

Um die Basis des freien Griffels verliuft eine, aus ungleich gestalteten Zellenwucherungen zusammengeselzte Ringwulst (F. 1, z), die wohl als Andeutung eines Perigons genommen werden mag. Die Aussenflachen ihrer Zellen, wie die der Zellen des Scheitels der Blithe ïberhaupt sind mit einer netzlinig stark gertmzelten Cuticula behleidel, der :ilnnlich die auf den lieulenförmigen Seitensprossen der Blïthenachse der Balanophoren, sowie auf den oberen Enden der Spreuschuppen der Ifelosideen und der nimlichen Inflorescenzen der Langsdorflia selbst sich findet.

In einem Theile der untersuchten Blüthen war die Fruchthnotenhöhle von einer einzigen, verlıälınissmässig grossen Zelle nahezu ausgefüllt. Sie hïngt free in die Fruchtknotenhöhle herein, nur seitlich dicht unter ihrem Scheitel an ciner kurzen Stickzelle befestigt (F. 3, 4). Diese Zelle mit ilıren Traigern muss als das Ey der Langstorflia betraclıted werlen. Es ist, nebst dem ron Sarcophyte, nicht nur das hleinste 
(Länge 1/11 M.M., Breite 1/15 M.M.) aller mir bekannten Eychen von Phanerogamen, sondern auch; weil einzellig, das einfachst gebaute. - Bei der :iussersten Einfachheit seines Baues stellt es, wie aus der Lage des Embryo hervorgeht, die reinste denkbare Form eines anatropen Eyes dar, insofern es keinem Zweifel unterliegt, dass die Richtung der grossen, Ey und zugleich Embryosack darstellenden Zelle ursprünglich der Richlung der Stielzelle gleichsinnig nach unten ging, und dass nur die überwiegende einseitige Entwickelung des schliesslich als untere Hälfte erscheinenden Theils den Scheitel des Embryosacks nach oben riickte.

Einzelnheiten der Organisation des Inhalts des jungen Embryosacks vermochte ich nicht zu erkennen. In den meisten Fällen war derselbe zu einer unförmlichen Masse zusammen geschrumpft (F. 3). In anderen, dem nämlichen Blïthenstand entnommenen Fruchtknoten konnte ein, verhältnissmässig kleiner, der Wand des Embryosackes anliegender Zellkern wahrgenommen werden (F. 4). Keimbläschen wurden nicht beobachtet.

Die Fruchtknotenhöhle anderer, in Minderzahl vorhandener Blithen aus derselben Inflorescenz war von einem Körper sehr abweichender Beschaffenheit ausgefüllt. In seiner Form glich er im Allgemeinen dem eben beschriebenen Embryosacke; auch haftete er, gleich demselben, an der Fruchtknotenwand mittelst einer seitlich, dicht unter seiner Spitze, ihm ansitzenden Stielzelle. Im Uebrigen war er ohne organischen Zusammenhang mit der Wand des Germen, aus welchem er sich leicht lösen liess. Er war zusammengesetzt aus einer zwischen acht und zwölf schwankenden Zahl in vier Längsreihen geordneter, dicht mit Oeltropfen erfiilter Zellen. Bei Quetschung flossen die kleinen, punktförmigen Oeltropfen zu grösseren Massen von gelber Farbe zusammen. In einer der vier Zellen des Scheitels des Zellenkörpers fand sich regelmaissig eine Zelle von Form eines cylindrischen Schlauches, welche mit breiter Ansatzfläche an der freien Aussenwand der sie einschliessenden Zelle befestigt war. Wenig entfernt von diesem Punkte haftete in den meisten Fällen an derAussenseite des Zellenkörpers eine fadenförmige, dickwandige Zelle, unzweifelhaft das Ende eines Pollenschlauchs (F. 5, 6). Die Querwände, welche die einzelnen Zellen jeder Längsreihe von einander trennen, schiessen stark nach innen ein. Der Zusammenhang derZellen unter sich ist nur locker (wahrscheinlich Folge langer Aufbewahrung des Blïthenstandes in concentrirtem Essig); ein gelinder Druck auf das Deckglas, 
eine unvorsichtige Beriilırung mit der Nadel lüsen den \%elliörper in eine Gruppe beiderseits zugeschärfter, nahezu spindelförmiger Zellen aul: Dann wird eine, die vereinzelten Zellen einschliessende Haut zerrissen sicliblor.

In den wesentlichen Zijgen seines Baues entspricht dieser Zelliörper vollstảndig einem vor nicht langer Zeit befruchteten, in wenige Endospermzellen getheilten Enbryosacke, der in einer der obersten Endospermzellen das befruchtete lieimblaschen (jene Zelle von Gestalt eines cylindrischen Schlauches) hirgt. Zwei Umstinde becintrichtigen indess die Wahrscheinlichlieit dieser Deutung: der Reichthum der Inhaltshlissigkeit der Zellen an Oeltropfen, und die Kleinheit der Zellen des Endosperms, verglichen mit denen des reifen Samens. Die zweite dieser Erscheinungen, wenn auch im übrigen Pllanzenreiche nirgends so aulfällig vorhanden, findet sich aber bei anderen Balanophoreen wieder; so bei der nalıe verwandten Sarcophyte sanguinca, bei Balanophora. Der Oelgehalt des sehr jungen, einer mächtigen Entwickelung entgegen gehenden Endosperms, so einzig in seiner Art nach dem bisher Beliannten er auch erscheint, wird für Langsdorflia durch die, im Uebrigen von den meinigen weit abweichenden, Abbildungen Karsten's*') bestätigt, der Langsdorffia hypogaea lebend zu untersuchen Gelegenheit hatte. Es ist diese Ersclıcinung aber vielleicht eine sehr weit verbreitete; die feinen, durch ilıre Klcinheit der directen Untersuchung sich entzichenden Körnchen des Protoplasma sind vielleicht in sehr vielen Fällen Oeltropfen. Einen völlig sicheren solchen Fall werde ich weiterhin bei Lathraea squamaria nachweisen. Diese Gründe bestimmen mich, dic Vermuthung fallen zu lassen, dass die fraglichen Zellkörper missgebildete, dem Absterben nahe befruchtete Embryosäcke seien, und sie für normale Entwickelungszustionde zu halten.

Es sind die besprochenen Körper die nämlichen, welche J. D. II o o ker als Eychen von Langstorflia deutete $\left.{ }^{*}{ }^{*}\right)$, und durch deren genaue Beschreibung er ein glänzendes Muster für feinste phytotomische Untersuchungen hinstellt. - Zwischenzustande von dieser Entwickelungsstufe und reifen Samen haben mir nicht zu Gebot gestanden.

*) N. A. A. C. L. XXVI, P. II. T. IV. F. 3, 7.

**) Transact. Linn. Soc. Y. XXII, p. 41, Anmerkung. - Mir stand ein Stück einer der Inflorescenzen zu Gebote, welche J. D. Hooker erwälnt. 
Der reife Fruchtstand iibertrifft den Blïthenstand im Querdurclimesser etwa um dås Fünffache: im Ucbrigen ist er wenig veränder\%. Die freien Enden der Griffel sind abgefallen; die ihren Grund umgebende Ringwulst hat sich - es scheint nur durch Dehnung ihrer Zellen beträchtlich erhoben und nach innen zusammengeneigt (F. 7). Eine spitze, von einem blinden Längskanal durchzogene Warze bezeichnet auf der Aussenfläche des Fruchtstands die Lage jedes im Innern verborgenen Samens. Im oberen wachshaltigen Theile der Fruchthnotenwand hat sich die Zahl der stark verdickten, spindelförmigen Zellen beträchtlich gemehrt. Sie bilden jetzt einen langen, den obliterirten Griffelkanal einschliessenden Cylinder. Der untere Theil des Fruchtknotens, so weit er zur Blüthezeit frei, und aus lang prismatischen, weichen, lockerverbundenen Zellen zusammengesetzt ist, wird jetzt fast vollständig vom Samen und dessen nächster Hülle eingenommen. Diese Hülle, eine Steinschale, dem Putamen der gemeinen Steinfrüchte in allen Stücken vergleichbar, besteht aus zwei Schichten stark verdickter, getüpfelter Zellen, die an den Seitenwänden der Schale lang gestreckt, auf ihrer breiten Scheitelfläche fast würfelig sind (F. 7). Der Same entbehrt, seiner Entwickelung aus einem nackten Embryosacke gemäss, aller ihm eigenen Integumente. Er ist ein, locker in der Steinschale liegender, aus der geöffneten leicht herausfallender*), Körper von langgezogener Eyform (F. 7, 8), zusammengesetzt aus grossen dünnwandigen Zellen, die angefüllt sind mit einer Mengung aus viel Oel und wenig eyweissartiger Flüssigkeit. Aus den angesclinittenen Zellen viele Jahre trocken aufbewahrter Herbarienexemplare tritt das Oel flüssig heraus, zu grossen Tropfen zusammenfliessend. - Dieses Zellgewebe ist Endosperm. Im oberen Viertheile dessellsen befindet sich in der Längsachse der kugelige, kleinzellige - Embryo, mittelst eines diinnen cylindrischen Trägers, einer einfachen Zellreihe, an der Innenwand des Embryosacks nahe an dessen Scheitel befestigt (F. 7, 8).

Der innere Bau des Fruchtknotens von Langstorffia war bis auf die neueste Zeit, bis auf die oben angefihrten Beobachtungen J. D. Hooker's, völlig unbekannt. Weddell hat das Dasein der Fruchtknotenhöhle

*) J. D. Ilooker's Abbildung von Samen, die dicht unter ihrem Scheitel mit einem Stiel an der Fruchtknotenwand hängen (a. a. 0. T. II. F. 21, 22) bezieht sich ohne Zweifel auf einen etwas früheren Zustand. 
Neue Beitrïge zer Kenntniss d. Embryobledeng d. Pianenoganex. 381

nicht nur ühersehen, sondern ausdrücklich verncinen zu können geglaubt* $)$. Die denen H o o ker's nachfolgenden Angaben Karsten's ${ }^{*} *$ ) differiren weniger von jenen und den meinigen, als sie minder vollstaindig sind. Karsten nimmt den Embryosack für in allseitig organischem Verbande mit der Fruchtknotenwand; die ganze Blüthe, Weddell's abenteuerlicher Anschauung folgend, für ein nacktes Ey. Seine F. 6 der vierten Tiffel, Pollenschlauch mit Embryoanlage in angeschwollenen Ende darstellend, kann recht wohl ein frei gelegter Embryosack mit anhaftendem Pollenschlauche in einer Lage sein, in welcher Sticlzelle oder Scheitel des Embryosacks die Endigung des Pollenschlauchs verdeckten. Den Träiger des Embryo hat auch Karsten nicht erkannt, wie denn meine Mittleilungen über dieses Verhältniss für die Balanophoreen überhaupt die ersten in die Oeffentlichkeit gelangenden sind. Dic Feststellung der Richtung des Embryo der Balanophoreen ist damit erst jetzt ermöglicht.

\section{Sarcophyte sanguinea Sparrm. $\left.{ }^{* * *}\right)$.}

Taf. XIII.

Die weiblichen Blithen von Sarcoplıyte, Fruchlknoten, die jeder Blüthenhülle entbehren, sind bekanntlich zu kugeligen Köpfehen vereinigt, dic an den Aesten einer lockern Rispe zerstreut stehen; jede Bliathe seitlich mit ihren Nachbarinnen fest verwachsen, nur in oberen Theile frei.

Der Fruchtknoten hat die Gestalt einer niedrigen Flasche mit kurzcm Ilalse und brcitgerandeter Mlundıng. Dieser Rand ist die Narbe; ilıre Oberfläche ist mit kurzen halbkugeligen Papillen bedeckt, denen an den untersuchten Exemplaren bisweilen schlauchtreibende Pollenkörner anhafteten. Im Mittelpunkt der Narbe öflnet sich der enge Griffelkanal, der senkrecht abwärts in die kleine kugelige Fruchtknotenhöhle führt (F. 1). Zahlıreiche, concentrisch schalig geordnete Sclichten dünnwan-

*) Ann. sc. nat. III. S. T. XIV. Tf. 11, F. 36.

**) N. A. A. C. L. XXVI. p. II. p. 906 if.

***) Eben befruchtete Blüthen verdanke ich Dr. Hooker, reife Früichte Prof. Mettenius. Jene sind von Dr. IIarvey gesammelt; wahrscheinlich von Jerselben Ernte stammend, von deren Ertrag Griffith untersuchte. 
diger Zellen mit trübenı, graureissem Inhalte umgeben zunäclıst die Fruehtknotenhöhle. Eỉe dünne Lage älınliehın Gewebes umschliessı den Griffelkanal. Die Hauptmasse der Fruchtknotenwand besteht aus ziemlich grossen, ficlıerig-strahlig angeordneten. derbwandigen, flach getuipfelten Zellen mit (an in Essig aufbewahrten Exemplaren) braunrothem Inhalte und Wïnden. Die fürLangsdorffia und für viele Helosideen charakteristisclıen verknöcherten Zellen der Fruchtknotenwaud fehlen Sareophyte völlig, Auch trägt kein Theil ihrer Blülıen odler eines Organs in deren Nähe die zierliel gefelderte Cutieula, wie sie auf der Oberseite des Fruchllinotens von Langsdorffia, auf den keuligen Zellgewebsmassen zwischen den Fruchılinoten von Balanophora, auf den Spreuschuppen der Helosicleen vorkommt.

Seitlieh in der Scheitelwölbung der Fruchtlinotenlı̈hle der ror Kurzen bestäubten Bliuthen, nahe an der Innenmindung des Griffellianals, ist mittelst einer scheibenförmigen Stielzelle ein kugeliger oder kurz eyförmiger Körper befestiğ, der frei in die Höhlung herein laảngend etwa ein Drittel derselben ausfüllt. Er besteht aus einer grossen, durch wenige Scheidewände in zwei bis vier Tochterzellen getheilten Zelle F. $1 b, 2)$. Die unteren der Tochterzellen sind dicht mit Protoplasma erfüllt, in welehem meistens ein grosser, kugeliger Kern liegt. Die oberste, der Innenmündung des Griffelkanals näehste dieser Zellen ist ärmer an Protoplasna. In ihrer Seheitelwölbung lıaften zwei kurz birnförmige, fast hallskugelige Zcllchen. Die Aussenwand der sie einsehliessenden Zelle zeigt an den Anheftungsstellen derselben strahlig geordnete, vorspringende Leistehen, denen ähnlich, die bei Crocus und Sorghum auf der Aussenfläche des Embryosackscheitels vorkommen*). In der Năhe dieser Stelle haftet eine fädliehe Zelle, welche bis in den Griffelkanal sich verfolgen lässt (F. I $b, 2)$.

Es ist in dem eben besehriebenen Zellhörper das nur aus dem Embryosacke und der ihn tragenden Stielzelle bestehende, hängende analrope Ey der Sareophyte, ganz nach dem Typus desjenigen von Langsdorffia gebaut, nicht zu rerkenuen. Der Embryosaek ist in wenige

*) Hofmeister in Pringsheim's Jahrbüchern I. p. 134, 161. Aehuliche Bildungen hat Schachı (der sie früher, bei Gladiolus, lïr integrirende Theile der Keimblisschen hielı) bei einer Anzahl anderer Phanerogamen beschrieben, ihnen ohne thatsächliche Gründe eine Rolle bei der Befruchtung zuschreihend (dieselbe Zeilschrift, p. 193 ff.). 


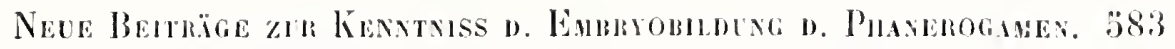

Endospenmzellen getheilt. Die birnfümigen zollen in der Schoitelwölbung der obersten derselben (F. I b, 2 $i$ ), sind die Keimblaschen; die firlliche dem Embryosack von aussen anlaftende \%elle (F. 1 6. 2/ ist der Pollenschlauch.

Zalılreiche andere Blïthen der nämlichen Intlorescenzen zeigen einen wesentlich abweichenden inmeren Rau. Der Griftellianal führt hier in cincu engen liaum von Form einer Querspalte im Innern des Gewebes. Von unten luer ist dieser Raum hegrinzt durch einen breit herzförmiggen Körper aus kleinen, protoplasmareichen \%ellen (an den untersuchten, in Essig aufbewahrten Blïtıen nit brauncm Inhalt). Seillich und nach unten steht dieser Körper mit lem weichen, concentrisch schalig geordncten Gewebe der Fruchılnotenwand in organischem Zusammenlang. In seinem Innern sind zwei excentrische, lang-eyförmige IlolılI’ume, jeder ziemlich ausgefüllt von einer grossen, einfachen, seilich unter dem Sclıeitel befestigten Zelle. Dic Höhlungen communiciren durch enge Kanảle mit dem spaltenförmigen Holılraum, in welchen der GriffelLanal nuindel (F. 3). - Diese Form der Bliithen stellt einen zweifächerigen Fruchtknoten, in jedem Fache mit cinen hägonden auf den Embryosack reducirten Ey dar. Wahrscheinlich entsteht das Germen von Sarcophyte, gleich dem von flelosis, aus zwei Carpellen, die nach Art in kappiger Knospenlage befindlicher Blitter mit den Rändern sich berühren, und zu einem einfïcherigen Germen verwachsen. Die Entwickelung nur eines haingenden Eys mag der normale Hergang sein. Haufig aber mögen abnormer Weise zwei haingende Eyer, von jedem Carpelle aus cines, entwickelt werden, und dann durch Wucherung der zellen dor Fruchulinotenwand deren Höhlung ausgefüllı, scheinbar zweifucherig werden. Der Umstand. dass der Bau des reifen Samens sich leicht auf den des einfächerigen Fruchthnolens zuruck führen lässt, während die zalılreichen felılschlagenden Samen ungezwungen als Endzustande der Eulwickelung zweificheriger Germina betrachtet werden kömen, veranlasst mich jene als die regehechten Bildungen, diese als Missbildungen zu deuten.

An der reifen Frucht ist die Narbe und der obere Theil des Fruchtknotens, soweit er aus den derbwandigen Zellen mit rothem Inhalte besteht, kaum repindert. Die Stelle des weichen Gewebes, welches die Fuchthnotenlıöhle umgab, ist dagegen rom Samen und einer ihn unschliessenden Sleinschale cingenommen. 
Die Steinschale besteht normal aus zwei Zellschichten: einer ausseren aus etwas radial gestreckten Zellen mit sehr stark verdickten, bald mehr (F. 10) bald minder reichlich (F,9) getuipfelten Wänden, und einer inneren aus tafelförmigen Zellen mit mässig dicker, glatter Haut. Stellenweise ist die äussere dickwandige Zellenlage doppelt; es haben noch einige der Hauptschicht anliegende Zellen des ursprünglich weichen Gewebes an der: Verholzung Theil genommen (F. 9).

Der von dieser Steinschale eingeschlossene Same besteht nur aus dem grosszelligen Endosperm, und dem in ihm centralen kleinzelligen Embryo. Die Gestalt des Endospermkörpers ist mannichfaltig : gewöhnlich ist er platgedrickt, zweischneidig, von breit eyförmigem Linriss; das breite Ende meist nach oben gekehrt (F.4), doch kommt auch, wiewohl nur vereinzelt, das Gegentheil vor (F. 5). In seltneren Fảllen ist der Same stumpf dreikantig, ein Iänglicher Körper (F. 8), dessen Querdurchschnitt ein gleichseitiges Dreieck darstellt**). Die Zellen des Endosperms sind weich- und dünnhäutig, gefüllt mit Tropfen dünnflüssigen fellen Oels.

Der Embryo ist in den von mir untersuchten, der nämlichen Inflorescenz angehörigen Früchten sehr verschiedenartiger Ausbildung; in einigen Fällen eine sehr kleine (F.6) in anderen eine grössere (F. 4, 5, 8) kugelige oder gestrecht ellipsoïdische Masse kleiner Zellen; in anderen ist er von weit beträchtlicherem Unfange und zeigt aufs deutlichste die Anlagen zweier liolyledonen (F.7). Sein Träger ist nach oben gerichtet, mit schwacher seitlicher Ablenkung (F. 6, 7). Es gelang nicht, ihn weiter zu verfolgen als bis zu der des Embryo gleich kommender Länge; es scheint, lass das Stick ron hier bis zur Innenwand des Embryosacks durch die starke Ausdehnung der Endospermzellen völlig zum Verschwinden gebracht wird.

Die grosse Mehrzahl, mindestens neun Zehntel der untersuchten Früchte zeigen statt der normalen Entwickelung des Samens eine auffallende Misshildung. Es findet sich im Innern der Frucht, an der Stelle der Steinschale des normalen Samens, ein ähnlich gestalteter, jedoch kleinerer, und im Querschnit stets kreisrunder, Korper, der aber kein Endosperm mit Embryo einschliesst, sondern seiner IIauptmasse nach

*) So bildet Weddell ihn ab: Ann. sc. nat. III. S., T, XIV. Tf. 10, F. 36. 


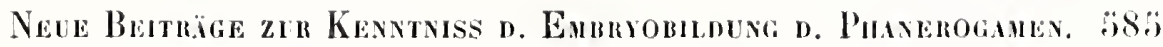

aus verholzten, dickwandigen, getijpfelten Zellen besteht, denen ähnlich, welche die :iussere Schicht der normalen Steinschale zusammen setzen. Im Mittelpunkte dieses ,Holzkerns" fintel sich entweder eine unregelmissig gestaltete Gruppe duinnwandiger Zellen, oder eine his zwei, auffillend grosse dünnwandige Zellen (F. 11). Ich bin geneigl, diese für fehlgeschlagene Embryosäcke zu halten, und anzunehmen, dass der holzige Scheinsame durch Verlinöcherung der Zellen entsteht, welche in den zweificherigen Fruchtknolen das brame Gewelse im Centrum der Blïthe, innerhalb der hohlkugeligen Schicht aus concentrisch schaligg geordneten weichen Zellen zusammen setzen. Solche missrathene Frichte sind es, welche Griffith ausschliesslich untersucht hat, und deren Zergliederungy ihn zu dem Nusspruche führte, der Samenkern oder Embryo sei homogen und bestehe durch ind durch aus , gepanzerten" Zellen *).

Die nahe Verwandtschaft der Sarcophyte mit Langsdorflia in Fruchtknotenbau und Samenbildung liegt nach dem hier Migetheilten so deutlich auf der Ifand, dass es nicht nöthig sein wird, die Ansicht Griffith's zu erörtern, der Sarcophyte von den Balanophoreen ausschliessen will **). Jie Angaben desseltsen Forschers über den Bau der Blüthe, obwohl sehr unvollständig, stehen mit den meinigen nicht im Widerspruche.

\section{Balanophora dioüca R. Br.; \\ fulyandra Grifl,; involucrata Hook. f.; fungosa Forst. ****). Taf. XIV; XV.}

Dic juingsten weiblichen Blüthen, - wie bekannt, Fruchthnoten ohne jede Spur cines Perianthium, - von Balanophoren, welche zur Untersuchung mir vorlagen; 9 M.M. langen, vollständig von den Deck-

*) Transaet. Linn. Soc. $\mathrm{XIX}, 346$.

**) a. a. 0.3 \&1.

*x) Nach in Essig aufbewahrten Exemplaren, deren Mittheilung ich der Gïte Mr.

J. D. Hooker's verdanke. Die Untersuchung wurde so geführt, dass ich mögliclıst zarte Längsselınitte aus dem Blüthenkolben herstellte, und an diesen Präparaten die Germinil aussuchte, welche durch den Schnitt nahezu halbirt oder, was noelı besser, beiderseitig gestreift waren. Gelungene Sehnitte erlueht ich an Iläuligsten aus denjenigeı Fruchtknoten, welehe nicht auf den Stielen der birnföruigen Seitensprossen der Hauptachse des Blïthenstands, sondern zwischen denselben standen. 
schuppen noch eingeschlossenen Kolben ron B diö̈a entnommen, sind flaschenförmige Körper, aus wenigen Zellen zusammengesetzı (T. XIV. F. 1, 2). Der Ulalstheil ist der in Entwickelung begriffene Stylus, ein aus vier Längsreihen von Zellen bestehender Cylinder, am Scheitel vollig geschlossen. In seiner Längsachse schliessen die ihn zusammensetzenden Zellen dicht an einander. Die Zellen seines Scheitels sind noch in Vermehrung begriffen. Vergleichung mehrerer Oljjecte zeigt, dass diese Vermehrung durch Theilung einer einzigen Scheitelzelle mittelst nach verschiedenen Richtungen geneigter Scheidewinde erfolgt (T.XIV.F. I3). Am oberen Ende des bauchigen Theiles des Zellenkörpers befindet sich in seinem Inneren ein eyförmiger Hohlraum, von einer einzigen Schicht Zellen umschlossen. Er wird von einer grösseren Zelle beinahe vollständig ausgefüllt. An Fruchtknoten, welche durch einen sie streifenden Längsschnitt in günstiger Weise zufällig geöffnet worden sind, erkennt man, dass diese grössere, angeschwollene Zelle mittelst einer kurzen, scheibenförmigen Stielzelle an der Seitenwand des Fruchthnotens, nahe unter der Scheitelwölbung, befestigt ist, und in die Fruchtknotenhöhle frei herabhängt, unter sich einen nicht unbeträchılichen Raum frei lassend (T. XIV. F. 1). Bei Balanophora dioïca fand ich die Fruchthnotenhöhle, auch an den jüngsten mir zu Gesicht gekommenen Entwickelungszuständen, stets allseitig vollständig geschlossen. Ebenso bei Balanophora polyandra, von welcher Fruchtinoten ungefähr gleich geringer Ausbildung, doch minder wohl erhalten, mir vorlagen*). Bei den weit massigeren, aus zàhlreicheren Zellen zusammengesetzten Fruchtknoten der Balanophora fungosa dagegen erkannte ich in der Seitenwand des jungen Germen einen kurzen Lăngsspalt, welcher den Einblick in die Fruchtknotenhöhle und auf die, in dieselbe vorragende gestielte Zelle gestattete (T. XIV. F. 4).

Diese Beobachtung scheint zu dem Schlusse zu berechtigen, dass die Entwickelung des Fruchtknotens von Balanophora dem Typus folge, welchen Duchartre bei den Nyctagineen kennen lehrte ${ }^{*}$ ), und dessen

*) Uebereinstimmend mit diesen sind die Beobachtungen von Göppert in N.A.A. C. L. T. XVIII. Suppl. Tf. i 1. F. 40-51. - Was Göppert für Samen nimmt, sind deutlich noch unbefruchtete, an der Spitze geschlossene Germina. Daraus erklärt sich ohne Weiteres die Abwesenheit von Embryonen.

**) Ann. sc. vat. III. S. IX, 263. 


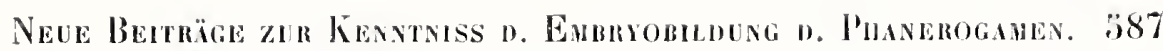

ausgedehntes Vorkommen auch bei Urticeen P'a y er später nachwies*). Nachdem die ungeschlagenen Ränder des einzigen Carpells bis auf cine seitliche Oeflnung verschmolzen, wächst die Spitze desselben (der oberhalb des oberen Endes der Oeflnung befindliche Theil) zur einem cylındrischen Fortsatz, dem Griflel aus, in dessen Längsachse durch Auseinindertreten der Zellen ein in die Fruchtknotenhöhle führender Kanal entsteht, waihrend die seitliche Oefinung dieser Höhle spurlos sich schliesst.

Selır hảufig findet man neben dem Grunde junger Fruebtknoten cine lileine, flache, aus wenigen Zellen zusammengesetzte Schuppe, welche am Germen băngen zu bleiben pllegt, wenn man dasselbe vom Blithenboden ablöst (T. XIV. F.2). Vielleicht ist dieses Verhallniss eine Andeutung davon, dass auch bei Balanophora der Fruehtknoten Iypisch alus zwei Carpellen besteht, von denen das eine in der Regel selır früh, noch vor der Verwachsung der Carpelle, fehlschlägt.

Die nächst weit entwickelten, mir zu Gebote stehenden weiblichen Bliithen einer Balanophora gehören der Balanophora involucrata Hook. f. an. Die Wand der Fruchtknotenhöhle ist jetzt eine Doppelsehicht von Zellen. Der Griffel ist bereits an der Spitze geöflnet, und seiner ganzen Lïnge nach von eincm axilen, in die Fruchtknotenhöhle und nach aussen geöfhneten engen Intercellulargange durchzogen. An der unverainderten scheibenförmigen Stielzelle, welche seitlich in der Scheitelwölbung der Fruchthnotenhöhle sitzt, hăngt jetzl ein mehrzelliger Körper, bestehend in einigen Fällen aus nur vier, in eine und dieselbe Längsdurehschnittsebene fallenden Zellen; in anderen aus einer grösseren Zilhl, die dann so geordnet sind, dass zwei grosse, nahezu kugelige Zellen die Stielzelle und einander auf kleinem Raume berijhren, und ein Kranz von vier bis sechs kleineren Zellen die tiefe Einkerbung zwischen ihnen ausfiullt (T. XIV. F. 6, 7). Es ist einleuchtend, dass dieser wenigzellige Körper aus der wiederholten Zweihlheilung der frimher von der Stielzelle getragenen kugeligen Zelle hervorging; Theilungen, bei welchen zuerst die beiden grossen Zellen entstanden, und dann von ihnen die einen Kranz. um den Aequator des sphärischen Körpers darstellenden Zellen abgeschieden wurden. Der in Rede stehende Zellenkörper ist das hängende Ey der Balanophora. Die uberwiegende Ausbildung seines unteren Thei-

*) Organogénie végétale, $\mathrm{Tr}, 60,62$. 
les gielut zu erkennen, dass es als ein anatropes aufzufassen ist. Die weiteren Entwickelungsvorginge werden dies noch deutlicher zeigen.

In etwas weiter vorgerückten Fruchthnoten, zunächst der B. involucrata, hat das Ey an Grösse soweit zugenommen, dass es die Fruchtknotenhöhle fast ausfüllt. Die untere der beiden grossen polaren Zellen desselben hat sich nicht wesentlich verändert. Ihr Zellenkern ist, wie bisher, verhältnissmässig klein geblieben. Der Kern der anderen grossen Zelle dagegen ist beträchtlich gewachsen. Die Zelle ist an Protoplasma um Vieles reicher geworden. In ihrer Scheitelwölbung haften zwei scharf umschriebene, dunkle Massen sehr dichten Protoplasmas, mit breiter Fläche der Innenwand der Zelle angesetzt (T. XIV. F. 8). Diese Massen sind offenbar die Keimbläschen, die Zelle, welche sie einschliesst, ist der Embryosack. Er erscheint jetzt von einer einfachen Schicht tafelförmiger Zellen berindet. Wie es scheint, sind diese eine ringförmige Sprossung des äquatorialen. Zellenrings zwischen den zwei grösseren Zellen des Eys; - ist diese Muthmaassung iiber ihre Entstehung richtig, so würde ihre Entwickelung einigermaassen an die eines Integuments erinnern.

Ganz ähnlich beschaffen, wie die eben beschriebenen Eychen aus einem Blüthenstand der Balanophora involucrata, in welchem keines der zahlreichen der Untersuchung unterworfenen Germina als befruchtet sich erwies, zeigten sich die Eychen in vielen Fruchtknoten aus Kolben von Balanophora polyandra, in denen die Mehrzahl der weiblichen Blüthen theils seit längerer, theils seit kürzerer Zeit dem Einfluss des Pollens unterworfen gewesen waren*). Bisweilen konnten hier die Kerne der Keimbläschen erkannt werden (T. XV. F. 1). In einzelnen Fällen war die Berindung des Embryosacks unvollstảndig, selbst gar nicht rorhanden (T. XV. F. 1). Die Fruchtknotenwand war hier uberall durch Bildung ron, den freien Aussenwänden parallelen, Scheidewänden in ihren Zellen zu einer Doppelschicht von Zellen geworden. Aehnliche Scheidewandbildung setzt sich eine Strecke weit in den Griffel aufwärts fort.

Sehr häufig findet man der Spitze des Griffels von Balanophora

*) Balanophora steht auch in der Beziehung in der Mitte zwischen Cynomorium und den Helosideen, dass die Entwickelung der Blüthen zu Früchten weit minder gleichzeitig erfolgt, als bei letzteren. Ein Blick auf T. XIV. F. 9 wird dies veranschaulichen. 


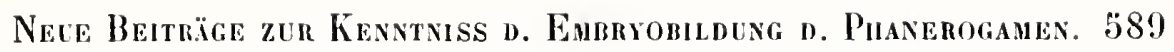

polyandra Pollenkïrner anlaften ${ }^{*}$ ). Den Austritt des Pollenschlauchs aus der Exine und seinen Eintritt in den Griflelkanal lrabe ich aufs Deutlichste erkannt (T. XVI. F. 10). Der Sehlauch erseheint stellenweis von einem das Licht der Zellenwand gleichartig brechenden Stoff, stellenweis voll witsseriger Fliissigkeit erfuillt.

Mehrmals wurde bei Balanophora polyandra und fungosa cine fadliche Zelle, mit dis Licht stark brechendem Inhalte, in Berührung mit dem oberen Theile des Embryosacks beobachtet (T. XV. F. 3, 4, 5, 8,9). In einzelnen Fàllen konnte auch ihr Verlauf weit aufwärts im Griffelkanale verfolgt werden. Kein Zweifel, dass sie das Ende des Pollensclılauchs ist. Ueberall, wo sie wahırgenommen wurde, war nur noch eines der Keimblischen vorhanden, — in der Form unverandert, aber mit eincr festen, durch die Einwirkung der Aufbewahrungsflüssigkeit nicht zusammengezogenen Haut umkleidet, - und der ganze Raum des Embryosacks in mindestens zwei Tochterzellen getheilt. Diese zwei ersten Zellen des Endosperms werden durch das Auftreten einer Liingsscheidewand gebildet, welche auf einer durch die Längsachse des Eys gedachten, dasselbe in zwei symmetrische Hälften theilenden Ebene rechtwinklig stehen würde. Jede Zelle enthält einen der Scheidewand anliegenden, abgeplattet ellipsoïdischen Kern, von dem strahlige Protoplasmastränge ausgehen (T. XV. F. 2, 3). Dieser ersten Theilung folgt sofort die durch auf der zuvorgebildeten rechtwinklige Längs-, dieser die durch Querwände. In den acht Zellen des Endospermkörpers treten darauf verschieden geneigte Wandungen auf (T. XV. F. 4-10). Aber auch wenn die Zahıl der Endospermzellen schon eine ziemlich hohe geworden, liisst sich in ihrer Anordnung der Verlauf der erstentstandenen Scheidewand noch leicht erkennen. - Der Endospernkörper von Balanophora polyandra behält, während seiner Entwickelung, die länglich ellipsoïdische Gestalt des Embryosacks. Der von Balanophora fungosa erscheint meist beträchtlich in die Breite gezogen, selbst abgeplattetellipsoïlisch.

Das befruchtete Keimbläschen verảndert sich zunächst nicht erheblich; es streckt sich kaum merklich in die Länge. Die Zellwände, wel-

*) Wie schon Griffith heschrieb und abbildete: Transact. Linn. Soc. XX. T. T F. 13, 16. Vergl. auch D. Hooker in denselben Gesellschaftsschriften, XXII. T. 5. F. $13-17$. 
che die Wandungen des Griffelkanals zusanmmensetzen, schliessen sich, bald nach dem Durchgang des Pollenschlauchs. durch quere Dehnung wieder fest aneinander, so dass der Griffelkanal völlig obliterirt. Darauf verdicken sie ihre Wände nicht unbetsächtlich, welche tief braune Färbung annehmen. Diese Verdickung der Zellwände rückt vorerst nicht bis auf die Zellen der Fruchtknotenwand herab.

Die den Embryosack unschliessenden übrigen Zellen des Eys lösen sich schon während der ersten Theilungen des Sackes aus dem festen Verbande mit diesem und unter einander. Ihre Wände werden runzelig; sie schrumpfen mehr und mehr zusammen. Beim Durchschneiden einzs Germen werden sie gewöhnlich zum grösseren oder geringeren Thei'e vom Messer mit hervorgerissen. Die Fruchtknotenhöhle erscheint ¿ann oft fast leer, soweit nicht der Endospermkörper ihren Raum ausfiullt (T. XV. F. 8). Immer aber bleibt der Zusammenhang des Embryosacks mit der, mehr und mehr sich abplattenden, Stielzelle des Eychens ein ziemlich fester. Durch sie wird in der Regel der Endospermkörper in der ursprünglichen Lage des Embryosacks fest gehalten.

Der Reife nahe und reife Samen haben von keiner anderen Art der Gattung mir zu Gebote gestanden, als von Balanophora diö̈ca. Wie bekannt, verändern sich Form und Grösse der Fruchtknoten nicht merklich von der Befruchtung bis zur Reife. Auch die Veränderungen im Innern sind nicht sehr beträchtlich. Die zwei Zellenschichten der Fruchtknotenwand verdicken ihre Wände: die der inneren, deren Zellen hinter denen der äusseren im Querdurchmesser um etwa das Dreifache, in der Höhe und Breite häufig um die Hälfte zurückbleiben, allseitig; die Zellen der äusseren Schicht sehr stark an ihrer nach innen gewendeten Fläche, schwächer an den Seitenwänden, gar nicht an der Aussenwand. Sämmtliche Wandverdickungen sind von Tüpfeln durchsetzt, am zahlreichsten die der Wände, welche beide Zellschichten trennt. Diese Verdickungen treten schon dann sehr deutlich hervor, wenn der Endospermkörper die Fruchtknotenhöhle um etwa zu zwei Drittheilen ausfüllt (T. XV. F. 11). Später gewinnen sie noch an Mächtigkeit, während das an Umfang wachsende Endosperm die Zellen der innern Schicht der Fruchtknotenwand bis zum Verschwinden des Lumens zusanmen driickt. Am reifen Samen sinken die diinnen Aussenwände der oberflächlichen Zellen beim Austrocknen des Inhalts ein; die dicken Seiten- 
wände stehen dann hervor, und geben der Oberflàche der Früchtchen ein wabiggrubiges Ansehen.

Im heranwachsenden Endosperm verlängert sich das befruchtete Keimbläschen zu einem bis nahe an den Mittelpunkt des Zellenkörpers wachsenden Embryonalschlauche, dicht über dessen Ende dann eine Querwand entsteht (T. XV. F. 11, 12). Bisweilen, doch nicht immer, wiederholt sich diese Querwandbildung in der unteren Zelle des zweizelligen Vorkeims. Die Umbildung seiner Endzelle zum Embryokügelchen wurle nur in solchen Früchten beobachtet, in denen das Endosperm die Fruchtknotenhöhle völlig ausfüllte und die alle Zeichen der vollsländigen Reife trugen. Hier erschien die Endzelle des Vorkeims durch übers Kreuz gestellte Längsscheidewände in vier Zellen getheilt (T. XV. F. 13), - ein Zustand, dem ähnlich, zu welchem der Embryo von Oenothera $z$. B. binnen acht Tagen nach der Bestäubung der Narbe gelangt, und von dem bei Balanophora anzunehmen ist, dass seine Weiterentwickelung erst beim Beginne des Keimens eintritt*).

Von früheren Untersuchungen der weiblichen Blüthentheile von Balanophoren habe ich insbesondere derer von Griffith, J. D. Hooker und Weddell zu gedenken. Griffith** ${ }^{*}$ ) erkannte bereits den interessanten Zug in der Entwickelungsgeschichte der Germina, dass die Enden der Griffel ursprünglich geschlossen seien. Das Endosperm, dessen Bau und dessen Verhältniss zur Fruchtknotenwand er übrigens völlig richtig beschreibt, nahm er für den Embryo, ein Irrthum, in welchem auch die späteren Forscher ihm gefolgt sind $\left.{ }^{* * *}\right)$. Mit dem Thatsächlichen der Angaben J. D. Ho o ker's stimmen meine Beobachtungen vollständig, nicht so vollstandig indess unsere Deutungen des Gesehenen. Den Gegenstand, welchen Hooker als einen jungen Embryosack mit zwei Endospermzellen von Balanophora involucrata auffasst $t$ ), nehme ich für ein junges Ey, in der Entwickelung zwischen meine, T. XIV. F. 1 und F. 6 abgebildeten Präparate zu stellen. Seine Abbildung eines weiter

*) Bekanntlich giebt es einen noch einfacheren phanerogamen Embryo: den von Monotropa Hypopitys, welcher wie ich nachgewiesen (Entst. des Embryo S. 36 ; T. XII. F. 16) aus nur zwei durch eine Querwand getrennten halbkugeligen Zellen besteht.

*) Transacl. Linn. Soc. XX. p. 93 ff.

***) J. D. Hooker indess mit wohl begründetem Zweifel: a. a. O. XXII. p. 23.

t) a. a. O. T. V. F. 11, 12 . 
vorgeriickten Zustands*) entspricht selır wohl der äusseren Ansicht einer Entwickelungsstufe, welche der von mir T. XIV. F. 6 abgebildeten kurz vorausgehen würde. Hooker's Darstellungen vom Eintrilt der Pollenschläuche in den Griffelkanal und ihrem Herabsteigen durch denselben, und die meinigen von den gleichen Vorgängen bestätigen und ergänzen sich gegenseitig.

Um so entschiedeneren Widerspruch muss ich gegen die Schilderungen Weddell's **) erheben, - Angaben, bei deren Kritik ich meine Beobachtungen an Balanophora diö̈ca unbedenklich zu Grunde legen darf, da die von Weddell untersuchte Balanophora indica Wall. nach J. D. II o o ke r's gewichtiger Meinung von B. diö̈ca wahrscheinlich nicht einmal specifisch verschieden ist. Der wesentlichste Unterschied zwischen Weddell's und meiner Darstellung liegt darin, dass jener das Endosperm für den Embryo nimmt, und das Vorhandensein eines zum Theil transitorischen kleinzelligen Endosperms behauptet, von dem aber selbst im reifen Samen ein nicht unbeträchtlicher Theil noch vorhanden sein soll. - Der Vergleich meiner Abbildungen mit denen Wed dell's (a. a. O. F. 14, 16, 21) wird die absolute Unvereinbarkeit unserer Auffassung zeigen. Ich glaube den Beobaclitungsfehler zu errathen, welcher Weddell zu seinen ganz unmöglichen und widernatülichen Abbildungen führte. Er mag mehr mit dem Compressorium, als mit dem Messer untersucht haben. Bei nicht zureichender Vertrautheit mit der Bedeutung bei stärkeren Vergrösserungen erlangter Bilder hat er dann da die Tïpfel der verdickten Zellen derFruchtknotenwand für Zellchen genommen, und auf diese Wahrnehmung seine Theorie vom Vorhandensein eines den Endospermkörper umgebenden Albumens gebaut. Ein Vergleich seiner F. 13 mit meiner Zeichnung T. XV. F. 12 und mit der Natur lässt keinen Zweifel an der Richtigkeit dieser Vermuthung.

Eine von der meinigen weit abweichende Auffassung des Baues der weiblichen Blüthe von Balanophora hat neuerdings auch Karsten, nach Ansicht Sch a ch t'scher Praparate ausgesprochen****). Das angebliche Pistill sei ein nackter Eykern. Bei B. globosa soll in der Scheitelwölbung des Embryosacks eine kugelige Zelle frei schweben. - Diese

*) a. a. O. T. V. F. $13,14$.

**) Ann. sc. nat. III. Série t. XIV, p. $168 ;$ T. 9.

***) N. A. A. C. L. XXVI. p. II, 923. 
Néue Beiträge zur Kenntniss d. Embryobildung d. Pinanerogamen. 593

kugelige Zelle ist unzweifelhaft der Embryosack; was Karsten wunderlich genıg den Embryosack nennt, ist die Fruchtknotenhöhle. Dass der Embryosack nicht frei in der Fruchtknotenhöhle liegt, ist an jedem angeschnittenen Germen deutlich zu sehen.

\section{Helosis mexicana Liebm.; guyanensis Rich. *). Taf. XVI. F. 1-5.}

Sehr junge weibliche Blüthen von Helosis mexicana stellen schlanke, verkehrt kegelförmige Zellenmassen dar, auf deren Scheitelfläche die Anlagen der beiden Carpelle und der zwei bis drei Perigonialblätter stehen (F. 1). Die Bläthen sind eingesenkt zwischen den dicht gedrängten, zahlreichen Spreuschuppen; lang keulenförmigen, seitlich abgeplatteten Zellenmassen, aus vier parallelen Längsreihen von Zellen zusammengesetzt, deren oberes Ende von einer, zur Zeit noch glatten, Cuticula umhüllt ist. Unter dem Einflusse verdïnnter Säuren (so des zur Aufbewahrungsflüssigkeit der untersuchten Exemplare benutzten Essigs) hebt sich diese Cuticula nicht selten als grosse, weit abstehende Blase von den Zellen ab, welche sie umkleidet****). In den Antheren der zwischen die weiblichen eingestreuten männlichen Blüthen ist der Pollen bereits ausgebildet; H. mexicana unterscheidet sich in dieser Beziehung sehr auffällig von H. guyanensis und deren, durch Richard bekannten ${ }^{* * * *}$ ), sehr späten Entwickelung der månnlichen Blüthen. Die Oberfläche der Blüthenkolben ist jetzt noch völlig verhüllt durch die dicht gedrängten, schildartig angehefteten, sechsseitig pyramidalen fleischigen Bracteen.

Zarte Längsdurchschnitte durch solche junge weibliche Blüthen zeigten, dass der Blüthenstiel noch die Hauptmasse derselben ausmacht. Er besteht aus zartwandigen, hexagonalen Parenchymzellen. Seine Längsachse wird von einem dünnen Strange prosenchymatischer Zellen eingenommen. Die Höhle des Fruchtknotens erscheint, in Bezug auf das

*) Nach in Essig aufbewahrten Exemplaren, welche Dr. J. D. Hooker mir mitzutheilen die Güte hatte.

***) Dies der Grund der Erscheinung, welche J. D. Hooker sehr auffällig war (a.a. 0., S. 60). Es ist der nämliche Vorgang, welcher an der Cuticula jugendlicher Pflanzenorgane überhaupt schon seit längerer Zeit bekannt ist (Cohn, de Cuticula, in Linnaea 1850 , S. 18 des Aufs.; T. II. F. 5, 18.

***) Mém. Mus. VIII, 416 . 
noch ganz rudimentäre Perianthium (F. I $p$ ) bereits völlig unterständig. Sie ist von oben her bedeckt durch die zwei, mittelst ihrer Seitenränder bereits verwachsenen, Carpelle. Die Spitzen derselben (F. I $c$ ) sind noch frei; sie beginnen zu den Griffeln auszuwachsen, indem sie zu cylindrischen, im Querschnitt aus acht Zellen (vier peripherischen und vier axilen Längsreihen) bestehenden cylindrischen Fortsätzen sich entwickeln. Zwvischen diesen Anlagen der Griffel befindel sich eine breite, offene Spalte, mittelst deren die Fruchtknotenhöhle mit der äusseren Luft in unmittelbarer Verbindung steht.

Vom Grunde der Fruchtknotenhöhle erhebt sich mit breiter Basis eine stumpf kegelförmige, die Höhlung beinahe ausfüllende Zellenmasse (F. 1, o). Die Anordnung ihrer Zellen erscheint im oberen, freien Theile fächerartig strahlig, an ihrer Einfügungsstelle in den Blüthenstiel concentrisch schalig; - in Folge hier oft wiederholter Quertheilung mittelst Wandungen, die zu einer durch das Organ gelegten Kugelfläche tangental, und in der Nachkommenschaft je einer Mutterzelle unter sich parallel sind. Die Bildung dieser Gewebspartie hat grosse Aehnlichkeit mil dem Bau der sogenannten Chalaza der Eychen anderer Pflanzen. Das Folgende wird zeigen, dass die eben besprochene Zellenmasse das einzige, aufrechte Ey der Helosis ist.

Der nächste meiner Untersuchung dargebotene Entwickelungszustand von Helosis mexicana sind Inflorescenzen, deren Bracteen grossentheils abgefallen sind, in denen die Griffel der weiblichen Blüthen völlig entwickelt sind, und papillöse Enden zeigen (denen indess keine Pollenkörner anhaften). Diese Blüthen sind offenbar eben zur Befruchtung bereit.

Der innere Bau derselben erscheint nur insoweit wesentlich verändert, als die in die Fruchtknotenhöhle führende Spalte zwischen den Griffeln sich geschlossen, und eine Zelle des Eychens zum Embryosacke sich entwickelt hat. - Der Bliithenstiel, früher die Hauptmasse der Blume, nimmt jetzt nur noch ein Drittheil von der Länge derselben ein. Der in seiner Achse verlaufende Strang prosenchymatoser Zellen hat sich zu einem Bündel von Spiralgefässen umgebildet (F. 2), die als letzte Endungen der in der dickfleischigen Spindel des Blüthenstands zahlreich verlaufenden Gefassbündel sich darstellen. Das Eychen fuillt die Fruchtknotenhöhle völlig aus, es liegt der Innenwand derselben auf allen Punkten dicht an, in manchen Fällen bis zu völliger Verwachsung, während 
in anderen die Loslösung des Eychens von den Seitenwänden und aus der Scheitelwöllsung der Fruchtknotenhı̈hle ohne Zerreissung der sich berührenden Gewebsmassen möglich war. Die Hauptmasse des Eys besteht aus langgestreckt prismatischen, seitlich nur lose verbundenen Zellen, die nach unten hin plötzlich iı die concentrisch angeordneten quer gestreckten Zellen jenes Gewebes iibergehen, welches oben mit der Chalaza verglichen wurde. Dieses Gewebe unterscheidet sich durch die Zartheit der Wände wie durch die Anordnung seiner Zellen auffällig von dem des Blüthenstiels, und gränzl das Ey an seiner Anheftungsstelle sehr scharf ab (F. 2 ch). Nach dem Scheitel des Eychens hin werden dessen Zellen rasch um Vieles kleiner, nahezu würfelig. Sie umschliessen hier, mit zwei Zellschichten sie bedeckend, eine sehr grosse, derbwandige Zelle, den Embryosack (F. 2 c). Dieser lässt sich mit leichter Mühe aus dem ihn umgehenden Gewebe lösen, und unverletzl freilegen. Man erkennt dann sehr deutlich in seinem Mittelpunkte eine grosse dunkelgefärbte Kugel, - den centralen primären Kern des Sakkes; von ihr strahlig ausgehende Bänder und Strảnge einer durchscheinenden, zahlreiche Körnchen enthaltenden Substanz: - unter dem Einfluss der Aufbervahrungsflüssigkeit erhärtete Protoplasmaströme; endlich in der Scheitelwölbung des Sackes zwei halb ellipsoïdische, mit breiten Flächen an dessen Innenwand haftende, scharf umgränzte dunkle Massen: - zwei unbefruchtete Keimbläschen (F. 3).

Die Spalte zwischen den Griffeln ist jetzt spurlos verschwunden. An ihrer Stelle ist die Wölbung der Fruchtknotenhöhle durch eine dicke, aus sechs Zellenlagen bestehende Schicht kleinzelligen Gewebes verschlossen. Dagegen hat sich in jedem Griffel ein dessen Längsachse durchziehender, offen in die Fruchtknotenhöhle mündender Intercellulargang - Styłuskanal - gebildet (F. 2 s). Die Zipfel des Perigons, aus einer einfachen Schicht schräg aufwärts gestreckter grosser Zellen zusammen geselzt, haben eine Länge erreicht, welrhe einem Sechstlıeil der ganzen weiblichen Blithe gleichkommt. Ihre Cuticula zeigt zierliche, schwach wellenlinige Längsstreifen; die der oberen Enden der Spreuschuppen jelzt zahlreiche Querrunzeln, welche ein Netzwerk aus quergezogenen Maschen darstellen (F. 2 x).

Spätere Zustände von Helosis mexicana fehlen mir. Dagegen konnte ich reife Samen von Helosis guyanensis untersuchen. Der nur zivei Centimeter lange Blüthenstand zeigte sehr schön die von L. C. Ri- 
chard*) bereits beschricbene merkwürdige Erscheinung des Hervorbrechens münnlicher Blüthen erst nach der Samenreifung mit ihnen auf demselben Blüthenboden stehender weiblicher. Die Früchte sind schwach zusammengedrückte, walzliche Körper, mit Einschluss des ihren Scheitel krönenden, vertrockneten dünnhäutigen Perianthium von 1,75 M.M. Länge. Die Frucht besteht aus einer Doppelschicht kurzer Zellen mit stark verdickten, braunrothen Wänden (F. 4). Die Zellen der äusseren Schicht sind tafelförmig, die der inneren würfelig. Den Scheitelpunkt der Schale nimmt eine Gruppe kleiner Zellen, mit ebenfalls verdickten Wänden ein. Sie bezeichnen die Stelle, an welchér die abgefallenen Griffel sassen. Die Höble des Fruchtknotens ist vollständig ausgefüllt durch das Endosperm, einen länglich ellipsoïdischen Körper aus dünnwandigen Zellen, die neben viel Eyweiss und weniger Oel auch etwas Amylum in Form kleiner, kugeliger Körner enthalten. Der Spitze des Endospermkörpers isst der verhältnissmässig kleine, kugelige Embryo eingelagert. Er haftet durch einen fädlichen, kurzen Träger, eine einfache Zellreihe, an der Innenwand des Embryosacks (F. 4, 5). Seine Zellen enthalten feinkörniges, dichtes Protoplasma, jede einen deutlichen grossen Zellkern, aber kein Amylum.

Man hat bisher Helosis und den ihr verwandten Gattungen ziemlich allgemein hängende Eychen zugeschrieben, auch diese, der klaren Entwickelungsgeschichte gegenüber unhaltbare Auffassung durch Abbildungen versinnlicht***) - ähnlich wie bei Loranthus. - Innerer Bau des Samens und Beschaffenheit des Embryo waren völlig unbekannt.

Phyllocoryne jamä̈censis Hook. f. Corynea crassa Hook. f.; Rhopalocnemis phalloïdes Jungh.

Taf. XXI. F. 6-9. Taf. XVi1. F. $7,8$.

Von jeder der in der Ueberschrift genannten Arten***) habe ich je nur einen einzigen Entwickelungszustand der weiblichen Fortpflanzungsorgane untersuchen können. Die Uebereinstinmung derselben

*) Mém. Mus. VIII, p. 416 .

**) J. D. Hooker, a. a. O. Tf. XVI. F. 17.

***) Gleich der Mehrzahl meines Materials von Balanophoreen verdanke ich Stücke in Essig aurbewalırter Inflorescenzen auch dieser Formen der Güte Dr. J. D. Hooker's. 
unter sich und mit Helosis ist aber so gross, dass über die Deutung der geschenen Organe kein Zweifel obwalten kann.

Völlig entfaltete, aber noch unbefruchtete Blülsen sah ich von Corynea crassa. Sie sind denen von Helosis mexicana ganz ähnlich beschaffen; nur ist die Verwachsung des Eychens mit der Fruchtknotenhöhle auf allen Punkten eine ganz vollsłändige. Der Embryosack lässt sich eben so leicht frei legen, wie bei Helosis. Er ist noch reicher an Protoplasma als dort. Unter dem Einfluss der Aufbewahrıngsfliissigkeit vollstándig erhärtet, liess dasselbe nicht allein die Strömungsfäden sehr deutlich erkennen, welche vom grossen centralen Kerne ausgehen; sondern es liess sich aucli der fest gewordene Wandbeleg der Zelle aus Protoplasma vollständig, in Form einer geschlossenen Blase, aus der zerrissenen Zellhaut horaus nehmen (T. XVI. F. 9). Interessant ist dabei der Umstand, dass die Keimbläschen von dieser, die Form der Zelle nachahmenden Proloplasmaschicht ausgeschlossen erscheinen. Sie haften fest an der Zellwand.

Von Phyllocoryne jamaïcensis Hook. f. untersuchte ich junge Frichte, deren Griffel bereits alygefallen waren. Die zahlreichen Spreuschuppen, von denen die Früchte dicht umstanden sind, zeigten eine Besonderheit des innern laues. Dic von einer, aus vier Längsreihen zusammengesetzten, einfachen peripherischen Zellschicht umhüllten axilen Zellreihen (zwei bis drei) des oberen Theils der Schuppen haben stark verdickte, geschichtcte und getüpfelte Wände (T. XVII. F. 8). Ein Mantel aus ähnlich gebildeten Zellen befindet sich im Innern des obereu Theiles der Fruchthnotenwand. Er beginnt im Innern der langen Zipfel des Perianthium mit einer umfangreichen, dicht unter den gestreckten Oberhautzellen der Zipfel gelegenen Gruppe besonders dickwandiger kurzer solcher Zellen, an welche in die Länge gezogene sich anschliessen, um so gestreckter und dünnwandiger, je weiter abwärts von jener Gruppe; bis endlich, etwa in der Hälfte der Höhe des Germen, die verdickten Zellen unmerklich in die dünnwandigen der Fruchılinotenwand ubergelıen (T. XVII. F. 8). Jene umfangreichcre Masse dickhäutiger Zellen erinneri an das ähnliche Vorkommen bci Scybalium. Ohne Ziveifel nimmt, wie dort, die Wandverdickung der Zellen der Fruchtwand von ihnen ihren Ausgang, und führt endlich zur Bildung einer rings geschlossenen, allseitig die Frucht umgebenden Steinschale.

Im Uebrigen weicht der Bau des Fruchtknotens nicht von dem der 
Helosis mexicana ab. - Die Abgränzung des aufrechten Eychens vom Gewebe der Fruchtknotenwand ist allseitig besonders scharf, auch an der Einfügungsstelle im Grunde. Die Zellen der Kernwarze sind auffällig klein und dicht gedrängt; uber ihr eine sehr deutliche Lücke; hier gar kein Zusammenhang der Aussenfläche des Eys mit der Innenwand der Fruchtknotenhöhle, während seitlich Verwachsung beider eintritt. Der Embryosack hat die Form eines abgeplatteten Ellipsoïds; seine Jlembran ist dunkelgell, auf beiden Flächen mit kleinen Körnchen besetzt, sehr brüchig. In allen der Zergliederung unterworfenen Früchten befand sich in ilın Endosperm, das aber in der Mehrzalıl der Fälle zusammen geschrumpft erschien und, zu einem rundlichen Klumpen gebaltt, auf dem Grunde des Embryosacks ruhte, nur etwa zwei Drittheile der Höhlung desselben ausfullend. Andere Embryosäcke dagegen waren von geschlossenem Gewebe prall erfült und in offenbar normalem Zustande. Sie waren verschiedener Entwickelung: die mindest ausgebildeten zeigten auf dem Durchschnitt nur eine mässige Zahl von Endospermzellen, in welche hinein, vom Scheitel des Sackes her, ein aus einer einfachen Lảngsreihe von zwei bis drei Zellen bestehender Vorkeim ragt (T'XVII. F. 7). Die Zellen des letzteren unterscheiden sich von denen des Endosperms durch dichteren, aber feiner körnigen Inhạt. - In den weitest entwickelten Früchten fand sich im Mittelpunkte des Endosperms ein relativ grosser abgeplattet kugeliger Finbryo, mittelst eines zweizelligen cylindrischen Trăgers an der Embryosackhaut liaftend (T. XVII. F. 8). Auch diese, schın einen weit vorgeriickten Embryo enthaltenden Embryosäcke nahmen erst einen kleinen Theil des Eychens ein, während doch ohne Zweifel im reifen Samen der Endospermkörper die ganze Fruchthöhle ausfüllen wird. Wahrscheinlich ist Phyllocoryne eine Form mit sehr grossem Embryo, gleich der zunächst zu besprechenden Gattung.

Von Rhopalocnenis phalloïdes Jungh. (Plıaeocordylis areolata Griff.) lagen reife Früchte zur Untersnchung mir vor. Sie sind, wie durch Griffith bekannt, seitlich stark abgeplattete, von den breiten Flächen gesehen breit eyförmige Körper, deren dünne, aus verholzten, dunkelbraunvandigen, abgeplatteten Zellen bestehende Schate einen weisslichen Samen von hornartiger Festigkeit einschliesst. Dieser Same, bisher für eine homogene Zellmasse erklärt*), erweist sich, auf dünen

*) So von Griffith und Hooker a. a. O. 


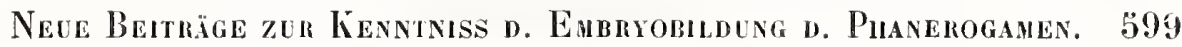

Durchschnitten unter Behandlung mil Jodwasser untersucht, als aus zwei verschiedenen Theilen zusammengesetzt. Die Mitte des Samens nimmt ein Körper ein, dessen Form mit der der Frucht (in verkleinertem Maasse) genau übereinstimmt. Er besteht aus zienılich grossen, im Allgemeinen langgestreckten Zellen, die reichlich grobkörniges Amylum enthalten. Mit einer seinem Scheitelpunkte angesetzten Stielzelle haftet er an der den Samen umschliessenden Membran. Dieser Körper ist der Embryo. Er ist rings umschlossen von einer fast durchweges einfachen Schicht kürzerer dünnwandigerer Zellen, die sehr wenig feinkörniges Amylum, aber sehr viel eyweissartige Substanz enthalten. Diese Gewebschicht ist Endosperm. - Lässt man zarte Durchschnitte von Früchten zwischen Glasplatten langsam eintrocknen, so pflegen sich an den Beruibrungsflächen von Endosperm und Embryo deutliche Spalten zu bilden (Taf. XVI, F, 6, 7, 8).

\section{Scybalium fungiforme Schott 8 ; Endl. *)}

Taf. XVII. F. $1-6$.

Ein besonderes Interesse knüpft sich an Scybalium durch den Umstand, dass in Innern seines Fruchtlnotens zwei Em!)ryosäcke (von fruheren Autoren als Eychen aufgefasst***) vorkommen. Im Uebrigen ist der Bau des Fruchtknotens im Wesentlichen übereinstimmend mil dem anderer Helosideen. Das Germen ist minder schlank, als das von Helosis, seitlich zusammengedrückt; die Griffel um Vieles länger; die der Peripherie der kreisförmigen Gruppen, zu denen die weiblichen Blüthen auf dem flachen Blüthenboden geordnet sind, stark nach einwärts gebogen. Die Griffel bestehcu, gleich denen von Helosis, aus vier peripherischen, weiten, und vier axilen, den Griffelkanal umgebenden sehr

*) Untersucht an zwei Blüthenständen, einem unbefruchteten und einem $\mathrm{Ab}$ schnitt eines der Fruchtreife nahen, welche Prof. Fenzl aus denı Wiener Museum mir mitzutheilen die Güte hatte. - Bekanntlich sind die dort aufbewahrten Exemplare die einzigen vorhandenen; die Pflanze ist seit ihrer Entdeckung von keinem Sammler wieder gefunden worden.

**) Endlicher gen. pl. 44 ; Meletemata p. 3, t. 2. Ich citire den Text des letzteren Werks nach dem Gedächtnisse, die Abbildungen nach Copieen. Endlicher liess dies Buch beklagenswerther Weise in einer ăusserst geringen Zahl von Exemplaren abdrucken. Es ist mir nicht zur Hand; auch nirgends käuflich. 
engen Längsreihen von Zellen. Eine kranzförmige Gruppe von in Langsschnitt je vier Zellen, welche unter der Einfügung des rudimenIåren Perianthium verläuft, hat schon im unbef'uchteten Germen stark verdickte, getüpfelte Wände (F.1, 2). - Die Spreuschuppen bestehen in der Regel aus vier Läıgsreihen von Zellen, von denen sich indess nicht selten einige axile Zellreihen abscheiden (F. 4, \& b, Querschnitle), eine Andeutung an den bei Phyllocoryne regelmassigen zusammengesetzteren Bau.

Die Höhle des Fruchtknotens ist völlig ausgefüllt von einem Körper, der auf den ersten Blick dem aufrechten Ey von Helosis vollständig ahnelt. Gleich diesem steht er im festen Verbande mit dem Grunde der Höhlung des Germen und lässt er sich von deren Seitenwänden nur schwer und unvollständig, leicht und vollkommen dagegen aus der Scheitelwölbung desselben lösen. Er besteht im unteren Theile aus lang gestreckten dünnwandigen Zellen, die nach oben zu in kürzere äbergehen; die des Scheitels sind nicht länger als breit. - Im Innern dieses scheinbar homogenen Zellkörpers befinden sich zwei Embryosticke; in der Art angeordnet, dass ein, parallel den längeren Seiten des Germen und durch die Einmündungsstellen beider Griffelkanäle in die Fruchthnotenhöhle geführter Schnitt beide Embryosäcke halbirt (F.4,3). Auf solchen Durchschnitten erscheinen die Embryosäcke stark einwärts gegen die Längsachse des Germen geneigl. Auf zu diesem Schnitt rechtwinkligen Längsschnitten er'scheinen ihre Seitenflächen den breiten Seiten des Germen parallel (F. 2). Die Membran der Embryosücke steht in festem Zusammenhange mit den ihr angränzenden, tafelförmigen, in zwei bis drei concentrische Schichten geordneten Zellen des umhüllenden Gewebes. Die Embryosackhaut lässt sich nur stückweis ablösen. Der Inhalt des Embryosacks ist eine halbflüssige, von zahlreichen Körnchen tief getrübte schleimige Substanz, in welcher der grosse Zellkern des Sackes bald mehr, bald minder deutlich erkannt werden kann. In der obern Wölbung der Embryosäcke haften zwei scharf umgränzte, abgeplattete Protoplasmamassen an der Wand: die Keimbläschen (F. 1, 2).

Genauere Betrachtung lässt eine, der Mitte der beide Embryosảcke einschliessenden Zellenmasse entlang verlaufende, besonders dunkle Commissur zweier Längsreilien von Zellen erkennen $(\mathrm{F} .1 x)$. Es ist hier zwischen den Zellwänden eine hörnige, in durchfallendem Lichte 
bräunliche, Substanz in äusserst geringer Menge vorhanden. Dieselbe Trennungslinie tritt an Querdurchsehnitten hervor, wenn auch minder deutlich $(\mathbf{F} .2 x)$. Es gelingt nicht, die dureh diese Linie getrennten beiden Uälften der die Fruehtknotenhöhle ausfüllenden Zellenmasse unverletzt von einander zu lösen. Gleiehwohl möchte ich vermuthen, dass bei Seybalium zwei, die Fruehtknotenhöhle völlig ausfüllende, an der dureh gegenseitigen Druek abgeplatteten Berührungsfläehe fest verwachsene, aufrechte, ungekrümmte naekte Eyehen vorhanden sind. Die Annahme, dass die beiden Embryosäeke einem und demselben Ey angehören, ist unvereinbar mit dem bisher überall zutreffenden Erfahrungssatze, dass eine axile Zelle des Eys zum Embryosaeke sieh entwickelt*).

Unter den der Reife nahen Früchten des anderen Blüthenstandes fand sich eine in der Entwickelung zurück gebliebene. Der eine Embryosaek derselben erscheint um etwa das Vierfaehe des Durehmessers gewaehsen (so dass er jetzt den Umfang von beiläufig einem Drittel der Fruchtknotenhöhle hatte), und von vielzelligem Endosperm ausgefüllt, welches einen zweizelligen Vorkeim einsehliesst (F. ̈̈). Die muthmaassliche Trennungslinie der beiden Eychen ist um Vieles schärfer ausgeprägt, als auf frülıeren Zuständen. Der zweite Embryosack ist gewelbleer, verschrumpft, von dem herangewachsenen Nachbar zusammengedrückt; — auch das ihn einschliessende unbefruchtet gebliebene Eychen von dem anderen beträchtlich zur Seite gedrängt. Die beiden der Innenfläehe der Fruchtknotenwand angränzenden Zellschichten derselben zeigen getïpfelt verdickte, braun gefärbte Wände. An jene Gruppe verdickter Zellen unter der Einfügung des Perianthium sich ansehliessend, auf deren Nachbarzellen die Wandverdiekung inzwischen

*) Entscheidenden Aufschluss wird nur die, zur Zeit unzugängliche, Entwickelungsgeschichte gehen können. Ohne die Kenntniss dieser können auch die Fälle des Vorkommens mehrerer Embryosäcke aus und auf demselben Ey (? - vielleicht Placenta ?) bei tropischen Loranthusarten nicht als güllige Beweise gegen die oben ausgesprochene Ansicht hingestellt werden. Das Untereinandergreifen der zwei Embryosäcke von Viscum album (vergleiche S. 556, u. T. VI F. 7) zeigt, dass auch in der Familie der Loranthaceen die Mehrzahl der Embryosäcke auf die Aushildung mehrerer, bei der Längsentwickelung an einander vorbei wachsender Zellen des axilen Zellstranges des Eys zurück geführt werden kann; ganz wie bei Rosa und bei Cheiranthus Cheiri. 
auch sich erstreckt hatte, stellen sie bercits eine vollständige Steinschale dar.

Diese Steinschale hat in den übrigen Früchten des nämlichen Fruchtstandes an Härte und Festigkeit noch zugenommen. Der herangewachsene, sehr grosszellige Endospermkörper erfüllt den weitaus grösseren Theil der Fruchthölıle, in deren Grunde nur noch ein kleiner Rest vom Gewebe des Eychens sich erhalten hat (F. 6). In anderen Früchten war auch dieser verschwunden. Die Zellen des Endosperms sind dünn - und weichwandig, ihr Inhalt (unter dem Einflusse der Aufbervahrungsflüssigkeit - Alkohol - zu einem die Zellhöhle nur zu zwei Dritteln erfüllenden Ballen zusammengeschrumpft) cin dicker Wandbeleg aus Protoplasma, in dem zahlreiche Oeltropfen*) und cin Zellenkern. Etwas seitlich vom Scheitel des Endosperms ist an der Innenfläche der dasselbe umschliessenden Embryosackhaut der Embryoträger mit breiter Ansatzfliche befestigt. Er besteht aus drei cylindrischen Zellen, deren letzte den Embryo, einen gestreckt eyformigen Körper aus wenigen, nicht eben kleinen Zellen trägt (F. 6, 6 b).

Die vorstehenden Untersuchungen ergeben, dass bei den Balanophoreen zwei verschiedene Entwickelungsformen des Eychens vorkommen: hängende Eychen, hemitrop bei Cynomorium, anatrop bei Balanophora, Langsdorffia und Sarcophyte; - und aufrechte atrope Eychen bei den zweigriffeligen Formen; - Unterschiede, die nicht ausreichend sind, die überhaupt polymorphe, aber doch in vielen der wichtigsten Beziehungen gleichartige Familie in zwei, beziehendlich drei (etwa Cynomorieen, Langsdorffieen und Helosideen) zu zerspalten. Verschiedenartig vertheilt, finden siclı innerhalb der Familie schrittweise Uebergänge in dem Grade der Vollkommenheit des Baues der weiblichen Blüthe und des Samens. Von der einfachsten Form der Eychen bei Langsdorffia und Sarcophyte bildet Balanophora den Uebergang zu den vollkommenen

*) Herausgedrückte und zu grösseren Massen zusammengeflosscne Tropfen solchen Oeles haben zweifelsohne den Anlass zu Endlicher's Annahme gegeben, das Gewebe im Innern der Balanophoreenfrïchte sei ,,sporenführende Masse.“ 
von Cynomorium. Der Embryo, wenigzellig bei Balanophora, ist entwickelter bei Langsdorffia, Helosis; noch weiter ausgebildet bei Rhopalocnemis, Cynomorium; endich mit Andeutungen des Cotyledonen versehen bei Sarcophyte, mit grösseren Cotyledonen bei Mystropetalon. Die Steinschale der Frucht, fehlend bei Cynomorium, nur angedeutet bei Balanophora, vom übrigen Gervebe der Fruchtwand nicht gesondert bei Helosis guyanensis und bei Rhopalocnemis, findet sich in vollständigerAusbildung bei Langsdorffia, Sarcophyte, Phyllocoryne, Scybalium.

Dic genatuere Kenntniss der Entwickelung von Samen und Embryo bestätigt vollkommen die von J. D. Hooker*) dargelegte Auffassung der systematischen Stellung der Balanophoreen als zunächst verwandt mit Hippuris. Zwei Punkte sind dabei noch hervorzuheben: dass Hippuris eine der wenigen Pflanzenformen ist, deren Ey, gleich der grossen Mehrzahl der Balanophoreen, den Loranthaceen und Santalaceen der Integumente enthehrt, und dass auch bei Hippuris das Endosperm durch Theilung des ganzen Innenraums des Embryosacks gebildet wird ${ }^{*}$ ).

*) In Lindley, veget. kingdom III. ed. p. 89, 90; und in Transacl. Linn. soc. XXII.

**) Es bilden zwar sowohl Unger (Bot. Zeit. 1849, T.III. F. 12) als Schacht (Entw.Gesch. d.Pflanzenembryon, Tr. XXVI. F. 1-3,7) im jüngst befrucbteten Embryosack von Hippuris in grosser Anzahl frei schwimmende Zellchen ab. Doch unterliegt es keinem Zweifel, dass diese Bildungen Vacuölen sind, denen äbulich welche bei Bartonia aurea vor der ersten Quertheilung des befruchteten Embryosacks in dessen Inhaltsflüssigkeit auftreten (Hofmeister Entst. d. Embryo, Tf. III. F. 3). Bei meinen Untersuchungen von Hippuris, die im Uebrigen denen vou Tulasne (Ann. sc. nat. III. Série,) nichts Wesentliches hinzufügen (abgesehen davon, dass ich, gleich Unger und Schacht, im unbefruchtelen Embryosack die Keimbläschen deullich erkannte), sah ich junge Zustände des Endosperms, in welchen dasselbe aus vier in eine Längsreihe geordneten, den Embryosack ausfüllenden Zellen bestand, deren oberste und unterste weiterhin sich nicht vermehren.

Ob auch in embryologischer Beziehung Uebereinstimmung zwischen den Balanophoreen und Gunnera, Haloragis u. A. von Hooker angezogenen Formen obwaltet, kann ich zur Zeit nicbt beurtheilen. Die von mir bisher untersuchten lebenden Exemplare der eben genannten brachten nur taube Früchte. 


\section{VII.}

\section{Orobancheen.}

Lathraea squamaria.

Taf. XVIII, XIX.

Das Eychen der Lathraea squamaria ist halbumgewendet* ${ }^{*}$. In der frühen Jugend desselben, hevor der schlanke Eykern von dem sehr dicken Integument überzogen wird, erkennt man jenen zusammengesetzt aus einer kurzén axilen Zellreilhe, die von einer einzigen Zellschicht umgeben wird $\left.{ }^{* *}\right)$ - der Bau des jungen Eykerns, welcher den Familien gemeinsam ist, die im Folgenden uns beschäftigen werden. Die oberste, grösste Zelle des axilen Zellstranges entwickelt sich zum Embryosack. Sie durchbricht die umbüllende Zellschicht am Scheitel des Eykerns, und wäclıst hinein in den, rom jungen Eykern bei weitem nicht ausgefüllten Hohlraum des Integuments. Gegen die Blüthezeit hin ist nur der kleinere untere Theil des Embryosacks von der peripherischen Zellschicht des Eykerns umhüllt. Seine grössere obere Hälfte ragt aus dieser hervor (T. XVIII. F. 1) und liegt auf allen Punkten der Innenfläche des Integuments an. Diese besteht aus einer Schicht quergestreckter, langprismatischer Zellen nit in durchscheinendem Lichte gelblichem, fein körnigem Inhalte. Das ubrige Gewebe des Integuments besteht aus isodiametrischen Zellen, vollgestopft mit groben Amylumkörnern. Am Scheitel des Embryosacks pflegt dessen Membran eine betrachtliche Verdickung zu zeigen (T. XVIII. F. 1-10, T. XIX. F. 8); - bisweilen ist diese verdickte Stelle nach aussen hin, in den Nikropylekanal hinein, zu einem kurzen, geraden (T. XIII. F. 20), oder gekrümmlen (F. 8) Stachel verlängert $\left.{ }^{* * *}\right)$. Auf der Aussenfläche des verdickten Theiles der

*) Vergleiche Schleiden, Wiegmanns Archiv B. I. (1837) T. 8, u. Gesammelte Aufsätze T. 5 F. 62. Schacht, Entw.-Gesch. d. Pflanzenembryon S. 121, T. 18. Hofmeister, Flora 1851 . S. 449, T. X.

**) Siehe Hofmeister a. a. 0 .

***) Diese Anhängsel sind von Schacht irrthümlich als den Embryosack anbaftende Pollenschlauchenden gedeutet worden (Pflanzenzelle, T. XX. F. 17; Mikroskop, 2.Aufl., T. III. F. 20). 
Neqe Beiträge zur Kenntniss d. Embryobildung D. Phaneroganen. 605

Wand des Embryosackscheitels erkennt man bei Anwendung kräftigster Vergrösserung zarte, nach der Spitze des Sackes convergirende Längsstreifen (T. XIX. F. 8).

Unterhalb dieser verdickten Stelle der Haut des Embryosackscheitels haften an deren Innenfläche schon mehrere Tage vor dem Aufblühen, in Knospen deren Corolle und Antheren noch gänzlich geschlossen sind, die bereits völlig ausgebildeten Keimbläschen; in der Regel zwei an der Zahl: birn- oder eyförmige Zellen, von zwar sehr zarten, aber festen Zellstoffhäuten unhüllt, mit breiter Ansatzfläche der Membran des Embryosacks angeschmiegt, das eine etwas höher als das andere. Ihre Innenwand ist ausgekleidet mit einem Ueberzug körnigen Protoplasmas, in welchem, nahe dem unteren Ende der Zelle, der verhältnissmässig grosse Kern mit einzigem Kernkörperchen liegt. Diese Verhältnisse des Inhalts der Keimbläschen treten deutlich hervor an Präparaten, bei welchen durch zwei Parallelschnitte durch das Eychen der Embryosack blos gelegt wurde. Sie sind schwerer wahrzunehmen an völlig frei präparirten Embryosäcken, bei deren Hervorziehen aus dem Integument der Inhalt der Keimbläschen in seiner Lagerung gestört, oft auch aus den berstenden Zellen ausgetrieben wird. Sind die Keimbläschen auf solche Weise ihres festen Inhalts beraubt worden, so bedarf es der Anwendung von Instrumenten ersten Ranges, um die höchst zarten Umrisse der festen Cellulosemembranen der Keimbläschen zu erkennen. Mikroskope, die nicht ganz so viel leisten, zeigen deutlich nur die Berührungskanten der Keimbläschenhaut mit der Innenfläche des Embryosacks in Gestalt rundlicher, oder (im Profil gesehen) dreiseitiger Figuren (vergleiche F. 1-6). Diese sind die Anschauungen, welche bei verwandten Pflanzen Tulasne zu seiner Ansicht von der Entstehung des Keimbläschens aus einer Spaltung der Embryosackhaut, parallel der Fläche derselben führten*). Nahe unterhalb der Keimbläschen liegt in

*) Tulasne in Ann. sc. nat. III. Sér. Bot. T. XII. Was hier von unbefruchteten Keimbläschen gesagt wird, gilt auch von eben befruchteten, auf welche Tulasne sich bezieht. Auch deren Nembran erhält erst einige Zeit nach der Befruchtung grössere Dicke und leichtere Erkennbarkeit. Ich gab diese Deutung der Anschaung Tulasne's bereits 1855 (Flora 38 Jahrg., S. 258); und glaube damit auch den letzten derGründe widerlegt zu Laben, weiche den trefflichen französischen Forscher veranlassten, die Anwesenheit der Keimbläschen im Embryosacke vor Ankunft des Pollenschlauchs zu bestreiten. Radlkofer ist etwas später bei Untersuchung von Euphrasia serotina zu Er- 
unbefruchteten Embryosacke dessen primärer Kern; ein abgeplatteter Körper von ovalem Umriss, mit einem oder zwei grossen Kernchen (F. 1, 3, 5). Gegenfüsslerzellen der Keimbläschen sind niclıt immer, und oft nur in Einzahl vorhanden (F. 3).

Bei warmer Wilterung findet man schon drei bis vier Stunden nach künstlicher Bestäubung der Narbe Pollenschläuche bis in die Mikropylen der Eychen vorgedrungen. Es geschieht nicht häufig, dass mehrere Pollenschläuche in denselben Eymund eintreten. Die Pollenschläuche sterben ziemlich rasch von oben her ab. Der Inhalt wandert während ihres Ilerabwachsens nach dem unteren Ende hin; die leere Membran des oberen Theils wird schnell dünner und blässer, und endlich dürr. Eine scharfe Abgliederung des fortwaclısenden Endes vom leeren Theile ist nicht wahrzunehmen, so lange die Schläuche nicht in Eychen eingedrungen sind. - Bei der ersten Ankunft deș Pollenschlauchendes am Embryosack ist die Haut des Schlauches, so weit die zahlreichen Beobachtungen gehen, stets dünn und zart. Der Inhalt des Schlauches ist ein das Licht stark brechender, bei durchfallender Beleuchtung gelblicher Schleim, wenig getrübt von sehr kleinen Körnchen, in welchem einige etwas grössere feste Körper, vön rundlicher, seltner länglicher Gestalt, eingebettet sind (F. 8, 9, 14, 16, 18). Bald indess erscheint in den meisten Fällen (wiewohl. keineswegs regelmässig) der Pollenschlauch in seinem Aussehen sehr verändert: er gleicht einem Stabe aus das Licht gleichartig brechender Substanz, in dessen Achse nur hier und da Reihen oder Stränge des körnigen Inhalts noch zu erkennen sind (F. 12, 13). Diese Veränderung beginnt am hinteren, aus dem Eymunde hervorhiıngenden Theile des Pollenschlauchs, dessen Ende durch eine Art von Propfenbildung vom leeren oberen Theile schroff abschliessend; und schreitet von dieser Stelle gegen die Spitze des Schlauches hin vor. Es ist nicht unwahrscheinlich, dass sie auf dem Aufquellen der Innenfläche der Nembran beruht.

Die Stelle, an welcher dås Pollenschlauchende auf die Aussenfläche des Sackes trifft, ist sehr veränderlich, und offenbar von Zufälligkeiten abhängig; namentlich davon, ob der Embryosack bei Ankunft des Pollenschlauches die Höhle des Integuments mehr oder minder prall aus-

gebnissen gekommen, welche mil den meinigen rollständig übereinslimmen. (Befruchtung der Plianerogamen, Lpz. 1836, S. 12.) 
füllt. Der häufigste Fall ist der, dass das Pollenschlauchende eine kurze Strecke (etwa bis zur oberen Gränze der Ansatzlläche des unteren Keimbläschens) zwischen Embryosackhaut und Integument sich drängt (F. 4. 12, 14, 19). Selten wischst er weiter hinab (F. 11). Es verdient Beachtung, dass kein Fall aufgefunden werden konnte, in welchem der Pollenschlauch der Stelle des Embryosacks sich anlegte, an welcher innen das untere (wie das Folgende zeigen wird fertile) Keimbläschen haftet. Ebensowenig ist beobachtel, dass der Pollenschlanch nur mit der stark verdickten Spitze der Embryosackhaut in Berührung getreten war. Oft zeigt sein Ende starke Krümmungen seitwärts (F. 14, 18) oder riickwärts (F. 13, 20).

Das Pollenschlauchende haftet bald ziemlich fest an der Aussenfläche des Embryosacks, bald nur so lose, dass eine leichte Berührung zur Trennung beider genïgt. Der letztere Fall ist auf den früheren Entwickelungszuständen entschieden der häufigere (F. 8-10, 17), kommt aber auch auf späteren noch vor; - ebenso wie der erstere auf sehr frïhen. Eine beide Organe verkittende Substanz konnte ebensowenig beobachtet werden, als Oeffnungen in der Haut des einen oder des anderen.

Die ersten Veränderungen, welche nach Ankunft des Pollenschlauchs im befruchteten Embryosacke sichthar werden, sind das Verschwinden des primären Kerns desselben; das Erscheinen zweier neuer Kerne an dessen Stelle (F. 6) und das Anftreten einer Querscheidewand zwischen diesen, welche den Sack in eine grössere untere und kleinere obere Halfte theilt (F. 7, 10). In der ersteren findet keine weitere Scheidewandbildung statt. Die letztere dagegen theilt sich baid und wiederholt aufs neue durch Querwände (F. 9, 11); die Tochterzellen darauf durch Längswände (F. 11, 12), welche in der Regel in einer durch die Raphe gelegten, das Ey in zwei symmetrische Halften theilenden Ebene liegen, so dass auf blossen Durchschnitten diese Wände niclıt sichtbar werden; es bedarf dazu der Freilegung des Sackes*). Diese Längswände treten früher in den unteren, scheibenförmigen Zellen des in der Bildung begriffenen Endosperms auf, als in der obersten kegelförmigen,

*) Dieser Umstand ist der Grund der in diesem untergeordneten Punkte irrthümlichen Darstellung meines Aufsatzes in Flora $18 \% 1$, welche das junge Endosperm als eine einfache Längsreihe von Zellen schildert. 
in welche die Keimbläschen herein hängen (F. 11). Die Längsscheidewand in dieser geht sehr häufig zwischen beiden Keimbläschen mitten durch (F. 12, 13, 16, 17, 19); ganz regelmåssig ist die Längswand einer der Seiten des unteren Keimbläschens dicht angeschmiegt (F. 13-24).

Die Zellen der jungen Endosperms sind reich au Protoplasma, welches zum Theil als dicker Beleg die Innenwand iberzieht, zum Theil in Stränge geordnet ist, welche vom jener Schicht eingelagerten Zellenkern aus durch den Zcllraum strahlen. Dieses Protoplasma ist von zahılreichen, unmessbar kleinen Körpern getribt, deren chemische Natur an frischen Endospermzellen, ihrer Kleinheit wegen, nicht erkannt werden kann. An Präparaten aber, welche mehrere Jahre lang in Chlorcalciunlösung aufbewahrt wurden, erscheinen jene Kügelchen zu grossen Tropfen das Licht stark brechender, gelblicher Flüssigkeit zusammengeflossen. Diese Flüssigkeit ist $\mathrm{Oel}$; seine Masse ist beträchtlich, beträgt etwa 1/25 des Volumns der Zellen.

Das freie Ende des unteren Keimbläschens verlängert sich allmälig zu einem kurzen cylindrischen Schlauche, wetcher - wie bemerkt der Längsscheidewand der obersten Tochterzelle des Embryosacks angeschmiegt, - nach den scheibenförmigen Zellen des Endosperms zu wächst (F. 14-18, 20, 23). Selten biegt das untere Ende dieses Embryonalschlauchs von der Scheidewand ab (F.19). Das obere, sterile Keimbläschen verschwindet entweder unterdessen, zuerst die Membran, späler der zu einem Klumpen grobkörnigen Schleimes geballte Inhalt (F. 15, 16, 20) - oder aber es erhält sich lange Zeit, wenig verändert, nur dass seine Membran sich verdickt (F.11-13,18, 19, 22). Bisweilen erscheint es etwas in die Länge gestreckt (F. 14).

Die Vermehrung der scheibenförmigen Zellen des jungen Endosperms ist am lebhaftesten etwas über der Mitte des kurzen Cylinders, welchen sie zusammensetzen. Von dieser Stelle nimmt die Vermehrung nach oben rasch, nach unten hin allmäliger ab. In den obersten, die Spitze des Embryosacks einnehmenden, die Keimbläsclıen einschliessenden Zellen findet keine Zellheilung weiter statt. In den übrigen zunächst um Quertheilungen (F. 19): später erst, von der Zeit an, zu welcher das zum Embryonalschlauche verlingerte befruchtete Keimblisschen zwischen die in Vermehrung begriffenen Zellen des Endosperms einzudringen beginut, auch Theilung durch zur Längsachse des Eyweisskörpers stark geneigt, endlich auch durch ilire parallele Wande (F. 21). 
Diese Zelltheilungen, oberhalb der Mitte des Endosperms am öftersten sich wiederholend, wandeln dasselbe zu einem birnförmigen Zellkörper um (T. XIX, F. 3, 4), - bis an dessen dickste Stelle der Embryonalschlauch hinabdringt, hier durch eine Querwand dicht über seinem Ende sich theilt, und nach ein- oder zwcimal wiederholter Quertheilung der Endzelle diese, durch Entstehung wechselnd von Längs-, Quer- und später auch schrägen Wänden, zum Embryokügclchen umbildel (T. XIX. F. 3, 5, 6, 7)*). Dabei tritl sehr deullich hervor, dass das Embryokügelchen in alten Fällen zunächst aus vier in einer HorizontalEbene liegenden Zelten, von Form der Quadranten eines am oberen Ende gestutzten Ellipsoïds besteht (T. XIX. F. 3, 5, 6). Nach einer oder zweien Quertheilungen dieser vier Zellen beginnt dic (nach unten gerichtete) Scheitelzelle einer der so entstandenen vier Längsreihen eine, die ihrer Nachbarzellen weil überwiegende Entwickelung, in Folge deren sie auf den Scheitelpunkt des Embryokügelchens rückt (T. XIX. F. 7), dessen Zelle ersten Grades sie fortan darstellt.

Die untere, ursprünglich grössere Hälfte des Embryosackes, wie auch die obersten, dessen Scheitelgegend ausfüllenden, aus den frühesten Theilungen der Urmutterzelle des Endosperms hervorgegangenen Zellen, in denen allen keine Zellentheilungen statt haben, entwickeln dafür umfangreiche Ausstülpungen ihrer Membranen; blinddarmähnliche Fortsälze, welche nach dem Anheftungspunkt des Eychens hin strcbend, tief in dessen Gewebe zerstörend eindringen. Von der Seilenfläche des unteren, zellenleeren Endes des Embryosackes aus entwickelt sich ein solcher, meist sehr weiträuniger und langer, cylindrischer solcher Fortsalz (F. 19), der nicht selten, von seiner ursprünglichen Richtung (nach der Anheftungsstelle des jungen Samens) ablenkend, seitwairts aus dem Gewebe desselben hervorbricht**). Von den beiden obersten Zellen des Endosperms, deren eine das befruchtete Keimbläschen einschliesst, entwickelt in der Regel nur eine (T. XVIII. F. 14, 16, 23, T.XIX. F. 1), seltener beide (F. 19) eine derartige Ausstülpung; zunächst eine halbkugelige Auftreibung (F.14) der Membran, die später sich zu einem schlauchförmigen Anhange umbildet (T. XIX. F. 3, 4). Sehr häufig geht

*) Vergleiche Flora 1800 I, S. 40 4.

**) Vergleiche Schieiden a. a. O.; Schacht, Entw.-Gesch. d. Pflanzenembryo. T. XYIIL. F, 19, 20. 
in diesen Ausstiilpungen die Bildung transitorischer Zellenkerne und freier Zellen vor sich (T. XVIII. F. 19).

Die Membran des Embryosacks zeigt bisweilen ein etwas stärkeres Flächenwachsthum in der nächsten Umgebung der Ansatzfläche des befruchteten Keimbläschens, als auf dieser Fläche selbst. Es ereignet sich in Folge dieses Umstands, dáss die Aussenseite der Ansatzstelle des Keimbläschens von einem flaclıen, mehr oder minder vollständigen Ringwulste umgeben erscheint (F. 21, 22), in dessen Mitte bisweilen die der oberen Endfläche des Keimbläschens angewachsene Embryosackhaut nach aussen sich wölbt (F. 22). Dies die Erscheinungen, in welchen Schacht früher*) den Beweis für die Abstaminung des Embryonalschlauchs von ausserhalb des Embryosacks zu finden glaubte.

\title{
VIII.
}

\section{Scrophularineen.}

\author{
Pedicularis sylvatica L. \\ Taf. XIV. T. XV. F. 1-7. \\ Pedicularis comosa L. \\ Taf. XV. F, 8-11.
}

Die Entwickelung des Samens und des Embryo der Scrophularineen nichıt allein, sondern auch der weiterhin zu erörternden Familien ihres weiten Verwandtschaftskreises stimmt in wesentlicheren Punkten so vollstäntlig mit denen von Lathraea überein, dass eine kürzer gefasste Besprechung derselben genügen wird.

Das halbgekrümmte Ey von Pedicularis (T. XIV. F. 3) haftet mit dunnem Funiculus an der Placenta. Der Bau des Integuments gleicht dem von Lathraea, nur dass die Zellen des Parenchyms desselben mehr in die Länge gestreckt, und minder reich an Stärkemehllkörnern sind. Der vom Integument umschlossene Hohlraum ist der Krümmung des Eys entsprechend gebogen. In der Jugend des Eychens iuberragt er weit den auf seinem Grunde stehenden E yliern, welcher freigelegt als

*) Flora 1835 , S. 148; das Mikrósko p, II. Aufl. (Berlin 1855) S. 140. 
Neqe Beiträge zer Kexntniss d. Embryobildung d. Phanerogayen. 611

eine gerade, keulenförmige Zellenmaśse sich erweist, zusammengesetzt aus einer axilen, und einer einzigen peripherischen Zellschicht (T. XIV. F. 1). Die oberste der axilen Zellen, der junge Embryosack, ist bereits von bedeutendem Umfang, aber noch bedeckt von den Zellen der peripherischen Schicht, aus deren Anordnung und der verschiedenen Dicke der Wände derselben es leicht erkenntlich ist, dass die ursprünglich wenigen einzelnen Zellen derselben durch oft wiederholte Quertheilung mittelst anf den freien Aussenflächen senkrechter Wände sich beträchtlich vermehrt haben. - Etwas später durchbricht der Embryosack, plötzlich sich beträchtlich verlängernd, die seinen Scheitel deckenden Zellen der peripherischen Zellschicht des Eykerns, und wächst frei in den weiten Hohlraum linein, welchen das Integument umschliesst (T. XIV. F. 2). Im oberen Ende des Sackes zeigen sich zu dieser Zeit zwei (selten drei) freie Zellkerne, eingebettet einer die Scheitelwölbung des Sacks ausfüllenden Anhäufung von Protoplasma. Diese Zellkerne siind es, um welche die Keimbläschen sich bilden werden.

In Embryosäcken, die frei präparirt wurden aus Eychen, entnommen geschlossenen Blüthenknośpen mit geschlossener kaum gefärbter Corolle und geschlossenen Antheren, erscheinen die Keimbläschen als bauchige, mässig gestreckte Zellen mit sehr dünner aber fester Mentbran, welche mit kleiner Ansatzfläche der Scheitelwölbung der Embryosackhaut in verschiedener Höhe angeheftet, frei in dessen Raum herabhängen. Ihre Zahl überschreitet nur selten zwei (T. XIV. F. 4-7). Der Inhalt der Keimbläschen - ein Wandbeleg aus Protoplasma, in welchem, in der unteren Wölbung der Zelle, ein linsenförmiger Zellkern eingebettet ist - wird bei Freilegung des Embryosacks gewölınlich ausgetrieben oder in seiner Anordnung zur Unkenntlichkeit gestört. 'An gelungenen-Schnitten ist er leicht sichtbar*). Der Scheitelpunkt der Embryosackmembran, noch oberhalb der Ansatzflächen der Keimbläsclıen, ist häufig beträchtlich verdickt (T. XIV. F. 7). Im unteren Theile des langen Embryosackes, meist àn der Stelle seines grössten Querdurchmessers, liegt dessen umfangreicher primärer Kern.(T. XIV F. 3):

Schon 6 bis 10 Stunden nach künstlicher Bestäubung der Narbe sind Pollenschläuche bis zu den oberen Enden der Embryosăcke vorge-

*) Siehe meine Abbildung in Flora 1851 , T. X. F. 2 (unten). 
drungen. Hhr Verhalten hier stimmt im Wesentlichen mit denen der Lathraea völlig übercin. Auch hei Pedicularis konnte in keinem Falle beobaclıtet werden, dass der Pollenschlauch genau auf die Aussenseite der Ansatzfläche des unteren, zur Entwickelung des Vorkeims und Embryos bestimmten Keimbläschens trifft. Am häuligsten legt er sich bloss dem Scheitel des Sackes an, und nur selten dringt er zwischen Integument und Aussenseite des Embryosackes weiter abwärts, als bis zur Gränze der Ansatzfläche des oberen Keimbläschens (T. XIV. F. 8, 10, 11, 13, 15, 17). Das Aufquellen der Innenfläche seiner Membran, seine Verwandlung in einen Cylinder aus das Licht gleichartig brechender Masse, ist weit seltener als bei Lathraea, und wo es eintritt auf die untere Extremität des Pollenschlauchs beschränkt (T. XIV. F. 13). In der Regel bleibt der Pollenschlauch ziemlich dünnwandig, sein Innenraum deutlich hohl, gefüllt mit schleimiger Flüssigkeit, in welcher kleine kugelige Körner sclıweben. Krümmungen und kurze, knotig anschrvellende Verástelungen des Pollenschlauchendes sind häufig (T. XIV. F. 13-1 5, T. XV. F. 3, כ.,9); in einem Falle wurde eine beträchlliche Anschivellung des unteren Pollenschlauchendes beobachtet. In der Mitte der das geschwollene Ende füllenden Protoplasmamasse befand sich eine kugelige Vacuole (T. XIV. F. 9). Die Verbindung zwischen Pollenschlauch und Aussenfläche des Sackes ist noch lockerer als bei Lathraea; die unverletzle Lösung beider ron einander ein bei der Freilegung des Sackes sehr gewöhnlich eintretender Fall, namentlich auf fruheren Zuständen (T. XIV. F. 9, 11, 12, 14); bisweilen auch auf späteren (T. XV. F. 5). Auch hier, bei einer Grösse der Theile, welche die von Lathraea erheblich übertrifft, konnte nie eine Oeffnung, weder am Ende des Pollenschlauchs, noch an Scheitel des Embryosacks wahrgenommen werder. Auf der Aussenseite der Embryosackhaut, von welcher das PollenschIauchende abgelöst ward, liess sich an manchen Präparaten eine beide verkittende Substanz erkennen; auf früheren Entrvickelungsslufen von körnig-schleimiger Beschaffenheil (T. XIV. F. 11), auf späteren von glasülnnlicher Durchsichtigkeit (T. XV. F. 5); anderwärts, in der Mehrzahl der Fälle, fehlte diesellse spurlos.

Das untere Keimblasschen zeigt sehr bald nach Ankunft des Pollenschlauchs ein Wachsthum der Membran seines freien halbkugeligen Endes, welches sich zu einer zitzenförmigen Spitze verlängert (T. XIV. F.8-16. Oft ist bei Beginn dieser Verlängerung der primăre Kern des 
Keimbläschens noch vorhanden (T. XX. F. 11, 14), meistens indess bereits verschwunden. Die Verlängerung des vorgezogenen Endes schreitet rasch weiler vor; das Keinblaschen wird zu einer lang gestreckten Zelle, deren cylindrischer unterer Theil nach oben in die bauchige Form des Keimblischens vor der Befruchtung ubergeht (T. XX. F. 17, T. XXI. F. 1, 2, 4, 5, 9). Kaun irgendwo anders zeigl der Augenschein so deutlich, wie bei Pedicularis, die Identität des befruchteten Keimbläschens, des jungen Embryonalschlauches, mit dem unteren der unbefruchteten Keimbläschen. Das obere, sterile Keimbläschen erlaăl sich in der Regel währenddem lange unverändert (T. XX. F, 8, 10-14, 17, T. XXI. F. 1-3, 5, 9): - das frühe Verschwinden, zuerst seiner Membran (T. XX. F. 9), später auch der Reste seines Inhalts (T. XXI. F. 15,16$)$ ist Ausnahme.

Gleichzeitig mit dem Beginn des Spitzenwachsthums des befruchteteu Keimbläschens tritt die Mutterzelle des Endosperms auf: eine Zelle von verhältnissmässig geringem Längsdurchmesser, welche den Embryosack dicht unterhall, der Stelle seiner grössten Dicke querüber ausfïllt. Ihre erste Theilung" geschieht durch eine Längswand (T.XX. F. 8); beide Tochterzellen theilen sich zunächst durch Querwande(T.XXI. F. 3). Die Quertheilungen wiegen fernerhin vor; das Endosperm verwandeli sich in einen spindelförmigen Körper aus grossen, nahezu kubischen Zellen, mit sehr weichen, leicht zerfliessenden Wänden, die um eine axile Laingsreihe geordnet sind (T. XXI. F. 6). Die Zellen der innersten, dem Endosperm angränzenden Schicht des Integuments schwellen dabei blasig an, füllen sich mit feinkörnigem Schleime, und erscheinen so einer, die Wand des Embryosackes einer Pflanze mit freier Endospermbildung auskleidenden ersten Schicht dieses Gervebes sehr ähnlich*). Während dieser Vorgänge hat sich das befruchtete Keimbläschen soweit verlängert, dass sein Ende das Gewebe des Endosperms erreichte und in dessen axile Zellreihe eindringt. Aus der Seitenfläche des oberen. zellenleeren Theils des Embryosacks ist ein blinddarmförmiger Ast hervorgesprosst, der in das Gewebe des Integuments, nach der Raphe hin eindringt. In diesem schlauchförmigen Zellenaste bildet sich das von

*) Das der Anlass zu cincr irrigen Darstellung Schacht's (Entw.-Gesch. d. Pflanzenembryo T. XV. F. 3 und irrthümlichen Auffassung meiner selbst (Flora 1831, S. 4.53 ; T. X. F. 4). Schacht stell jene Zellen als spliärisch und frei dar; ich sie als der Innenfläche des Integuments angesetzt. 
Schachı entleckte*), interessante System strahlig geordneter veristelter Querbalken aus Zellstofi, das bei Plantago in ganz ähnlicher Weise, bei Veronica in einer lehrreichen Modification sich wiederfindet. - Im oberen Drittheil des Eyweissliörpers angelangt, entwickelt der Enbryonalschlauch, nach wiederholter Bildung von Querscheidewänden dicht oberhalb seines fortwachsenden Endes, aus seiner Endzelle das Embryokiigelchen (T. XXI. F. 6, 7). Die Membran des Embryosacks zeigt währenddem in der nächsten Umgebung der Anheftungsstelle des Vorkeims ähnliche Wachsthumserscheinungen, wie oben (S. 610) bei Lathraea geschildert; - Formånderungen die, wie die bei jener Pflanze beobachteten, von den Vertheidigern der Schleiden'schen Embryobildungslehre als Beweismittel aufgegriffen worden sind : - Erörterungen auf die jetzt, nach allseiliger Erkenntniss der Irrthümer der Pollinisten zuriickzukommen nicht mehr nöthig ist ${ }^{*}$ ).

Die ersten Theilungen der beim Beginn der Bildung des Embryokuigelchens kugelig anschwellenden Endzelle des Vorkeims geschehen durch verticale Wände. Die Endzelle theilt sich durch cine Längswand, beide Tochterzellen darauf aufs Neue durch Längswände, welche zu der zuvor entstandenen rechtwinklıg sind. Die Anlage des Embryokügelchens besteht aus vier Zelten von Form am oberen Ende gestutzter Quadranten eines Ellipsoïds (T. XXl. F. 6 b $b$ ). Nur in einer dieser vier Zellen findet dauernde Zellenvermehrung stall. Sie theilt sich durch eine nach aussen geneigte Wand. In der dem Scheitel der EmbryoAnlage nächsten neu gebildeten Zelle (der Zelle ersten Grades des Embryo) erncuert sich, stetig wiederholt, die Theilung durch nach verschiedenen Richtungen geneigte Wande. Die anderen drei jener vier Zcllen werden durch die Zunahme des Umfanges des Complexes von Tochterzellen der vierten mehr und mehr zur Seite geschoben. Jene Zelle ersten Grades nimmt immer ausgeprägter den Scheitelpunkt der Embryo-Anlage ein (T. XXI. F. 7). Es ist der nämliche Vorgang, wie er allerwärts hervortritt, wo der Vorkeim eine einfache Reihe von Zellen ist, aus deren Endzelle das Embryoliigelchen hervorgeht (um nur einige Beispicle ausser den Scrophularineen und den ihnen nächst verwandten Familien

*) Beiträge zur Anatomie, Berlin 4854, S. 259.

**) Vergleiche Schacht in Flora $1 \$ 55$, S. 154 , und das Mikroskop, 2. Aufl. S. 141 und Entgegnungen von mir in Flora 1855, S. 262 ; ferner Tulasne in Ann. sc. nat. IV. Série, Bot. T. IV. p. 109, und Radlkofer, Befruchtung der Phanerogamen, S. 25. 
zu nennen, Ranunculaceen, Caryophyllaceen, Aenthereen, Compositen, Solanaceen, Cyperaceen, Orchideen). Unverkeninbar, dass die dem ersten Blick so auffällige Erscheinung der Entwickelung der Endzelle nur einer der vier Lingsreihen von Zellen des Vorkeims von Loranthus europaeus (S. 543) nur eine Steigerung des nämlichen Verhältnisses ist; zugleich eine Art von Uebergang zu der Entwickelungsweise der Coniferen, bei denen jede der parallelen Längsreihen von Zellen des Vorkeims die Anlage eines Embryo hervorzubringen wenigstens vermag.

\section{Mazus rugosus Lour.}

Taf. XXI. F. $14-16$.

Der unbefruchtete Embryosack dieses Pflänzchens ist nur mässig gestreckt; fast eyförmig, das Mikropyle-Ende desselben rasch verjingt Dic. zwei Keimbläschen haften hier in verschiedener Höhe, das obere der Scheitelwölbung ausfüllend, mit sehr breiten Ansatzflächen. Unmittelbar nach Ankunft des Pollenschlauchs an der Aussenfläche des Embryosacks theilt sich derselbe durch eine Querwand in zwei ungleiche Hälften. Die kleinere unterc (welche die, nicht immer und wenn, nur einzählig vorhandene) Gegenfüsslerzelle der Keimbläschen einschliesst (F. 15), vermehrt sich nicht durch weitere Zellentheilung, wächst aber späterhin zu beträchtlicher, die obere vom Endosperm ausgefüllte Hälfte des Embryosacks weit übertreffender Länge heran (F.16). — Die obere, die Keimbläschen einschliessende Theilhälfte des Sackes wird zunïchst nochmals durch eine Querwand, beide Tochterzellen darauf wiederholt durch Längswände getheilt (F. 14). Das junge Endosperm besteht jetzt ans vier Längsreihen von je zwei Zellen. In der Innenkante ciner der Zellen des oberen Doppelpaares wächst das untere, befruchtete Keimbläschen herab, zu einem kurzen Embryonalschlauche sich entwickelnd (F.14, 15). Das obere, unbefruchtet gebliebene, verschwindet bald früher (F. 14), bald später (F. 15). Das Pollenschlauchende haftet währenddem nur lose an der Aussenfläche des Sackes, von der es bei dessen Freilegung fast ausuahmslos sich zu trennen pflegt.

Nur in dem unteren Doppelpaar von Zellen des jungen Endosperms findet fernere Zelltheilung statt; zunächst sehr vorwiegend durch zur Längsachse des Sackes rechtwinklige Wände (F. 15, 16). Während das Ende des Embryonalschlauchs gegen die Mittelgegend des an Unfang 
zunehmenden Endosperms vordringt, wachsen die vier Endospermzellen, welche den Scheitel des Embryosacks ausfüllen, zu ziemlich langen, tief in das Gewebe des dicken lnteguments dringenden Ausstülpungen aus (F. 16); nicht ganz gleichzeitig; eine eilt den andern voraus (F, 15).

\section{Rhinanthus minor und hirsutus L.}

Taf. XXII. F. 1-כ。

Auch der Embryosack von Rhinantlus ist im Vergleich mit dem von Pedicularis von nur mässiger Länge, im iubrigen jenem in allen Stiicken ähnlich, nur dass der primäre Kern dem Keimbläschen sehr nahe zu liegen plegt (F. 1, 4). Ganz wie bei Mazus theilt sich der Embryosack, gleich nach Ankunft des Pollenschlauchs, durch eine Querwand in zwei Hälften, deren untere von Anfang an grössere zwar an Umfang noch zunimmt (F. 3, 引), aber zellenleer bleibt (nur ausnahmsweise kommt die Bildung weniger bald wieder verschwindender Zellenkerne in ihr vor; F. 3). Die obere Hälfte des Sackes dagegen wird durch eine Reihe rasch einander folgender Theilungen zu einem aus vier Liängsreihen von Zellen zusammen gesetzten Körper.

Das obere keimbläschen verschwindet früh. Das untere - sein Verhailtniss zum Pollenschlanchende wie bei Pedicularis - entwickelt siclı langsam zum, im Vergleich mit Pedicularis, Euphrasia, Veronica, sehr kurzen Embryonalschlauche. Während dieser gegen die Mittelregion des Eyweissliörpers hin vordringt, hilden sich auf den vier obersten, den Scheitel des Embryosacks ausfüllenden Zellen des Endosperms kurze, krause Ausstülpungen der Wand desselhen; anfangs nur einige wenige (F. 5), dann rasclı melı (F. 2), endlich ein ganzer, den inzwischen selır verbreiterten Scheitel des Sackes bedeckender Wald davon (F.3). An der unteren Gräinze der von diesen Auswüchsen bedeckten Gegend sprosst aus der Seitenwand des Embryosacks gegen die Raphe hin uur umfangreiche Aussackung hervor (Fragment derselben F. 3 bei $a^{*}$ ).

*) Vergleiche hierüber, und über allgemeine Form des Eychens, auch Schachıt (in Entwickelungsgesch. d. Pflanzenembryon, Amsterdam 1830, T. 16) der auch hier, wie bei allen diesen seinen früheren Untersuchungen die Beobaclıtung der freigelegten Embryosackspitze unterliess, und so jene sehr in die Augen fallenden krausen Auswïchse völlig übersah. 


\section{Melampyrum nemorosum $\mathbf{L}$.}

Taf. XXIIl. F. $1-6$.

Gleich dem Melampyrum pratense ${ }^{*}$ ) zeigt auch (lie in der Ueberschrift genannte Art im nämlichen Fruchtknoten Eychen von zweierlei Richtung: halbgekrümmte deren Mikropyle dem Dissepiment des Ger-men zugekehrt ist (diese sind die höher stehenden) und stäı ker gebogene, deren Eymund der Wand des Fruchtknotens sich zuwendet. Bei beiden Formen ist der freie Theil des Funiculus von einer Länge, welcher der des übrigen Theiles des Eyes gleichkommt (F. 1); bei beiden beschränt sich Krïmmung und Beugung des Eys auf Funıculus und Chalazaregion; der Eykern ist streng gerade, ebenso der Mikropylekanal und der Embryosack auf allen Stufen seiner Entwickelung (F. 1, 2); - eine bedeutende Abweichung vom Bau der Eychen anderer Scrophularineen.

In Eychen aus eben aufbrechenden Blüthen ist der Embryosack kurz eyförmig, mit plötzlich verjüngtem Grunde. Nur dieser letztere Theil ist von der periphorischen Zellschicht des Eykerns umhüllt; der übrige, bei weitem grössere Theil des Sackes berührt unmittellbar die Innenfläche des dicken Integuments (F. 1). Der Keimbläschen sind in der Regel zwei, das untere stärker entwickelt; Gegenfüsslerzellen derselben nur eine (F, 2).

Nachelem das Pollenschlauchende bis zur Aussenseite der Embryosackspitze vcrdrang, verbreitert sich diese, schon vorher von nicht eben schlanker Form, noch beträchtlich, so dass das obere Ende des Embryosacks eine ebene Fläche darstellt (F. 3). Gleichzeitig entsteht im Em-bryosacke, nur wenig unterhalb der freien unteren Enden der Keimblasschen, eine Querwand, welche den Sack in eine sehr grosse untere und kleine obere Hälfte theilt. Die erstere bleibt zellenleer; die letztere verwandelt sich durch Quer-und Längstheilungen in einen, zunächst nur weinzelligen Körper (F. 4), das Endosperm. Die obersten, den Scheite I de Embryosacks einnehmenden Zellen desselben, vier bis fünf an der Zahl, deren eine das befruchtete Keimblaschen einschliesst, vermelıren auch bei Melampyrum sich nicht durch fernere Theilungen.

*) Vergl. Tulasne in Ann. sc. nat. III. Sér. T. XII. (1849) P. 46; Tf.4 F. 8-45 
Dafür treiben sie, wie bei Rhinanthus, Lathraea u. A., Auswüchse in das Gewebe des Integuments. Diese Auswiichse sind aber hier von sehr ungewöhnlicher Form. Es erhebt sich die Membran der flachen Scheitelgegend des Embryosacks wallförmig im Umkreise der Anheftungsstelle der Keimblaschen, nach oben hin sich ausstülpend. Zunächst einseitig (F. 3), aber bald immer weiter im Kreise vorschreitend, und weit aufwärts in das Gewebe des Integuments dringend. Dieses Gewebe besteht, in der nächsten Umgebung des Mikropylekanals, aus einer cylindrischen Schicht gestreckter, gegen den Nikropylekanal einwärts geneigter Zellen (F. 3, 4), deren feste Wande nach erfolgter Befruchtung sich verdicken und gelbe Farbe annehmen; - weiter hin aus lockerer verbundenen, polyedrischen Zellen, mit dünneren, weicheren Wänden. Diese werden von der nach aufwärts wachsenden Ausstiulpung des Embryosackscheitels verdrängl, und verflüssigt. Die cylindrische Zellschicht der Wand des vom Pollenschlauch durchzogenen Mikropylekinales dagegen erhält sich. Ihr legt sich die Ausstülpung des Embryosackes zuvörderst einseitig dicht an (F, 3), umfasst sie dann mehr und mehr, je mehr ihre Form der eines Ringwalls sich nähert (F. 4), und schliesst sie endlich fast vollständig ein (F. 5). Das Letztere geschieht erst, nachdem das zum kurzen Embryonalschlauche entwickelte Keimbläschen in das, inzwischen zu sehr beträchtlicherem Umfange entwickelte Endosperm weit vorgedrungen ist, wo dann, nachdem der Embryonalschlauch durch wiederholte Scheidewandbildung dicht iber seinem unteren Ende zu einem, aus einer einfachen Reihe von 6 bis 8 Zellen bestehenden Vorkeim mit langer Trägerzelle sich umbildete, die Endzelle desselben zum Embryokïgelchen anschwillt (F. $5,5 b$ ). Inzwischen haben aus den obersten Zellen des Endosperms auch seitliche Ausstülpungen sich entwickelt: aus jeder der vier bis fünf Zellen eine umfangreichere, von nur mässiger Länge, an der Spitze wiederholt verästelt; und unregelmässig vertheilt einige kleinere (F. 5 b Seitenansicht, F. 6 Ansicht von unten, nach Abtrennung von dẹ Hauptmasse (les Endosperms). Das Zellgewebe des Endosperms, welches zuvor der zellenleeren Hälfte des Embryosacks mit völlig ebener Fläche anģänzte (F.4), wird unterdess, während der bedeutenden Zunahne seiner Masse, an der unteren Fläche stark concav (F. 5); - zum kleinen Theil nur durch Vermehrung, hauptsächlich durch slarke Dehnung der Zellen seines Randes. - In die halbkugelige, später sogar parabolische Höhlung 
ragt der nur von klarer Flüssigkeit (die gegen die Samenreife hin vertrocknet) erfiillte weite Raum der unteren Embryosackhalfte tief hincin, scillich umbiillt von nur einer cinfachen Lage von Endospermzellen, deren unterste, den Saum des Randes des Endospermgewebes darstellende die grössten sind (F. 5).

\section{Veronica Buxhaumii; hederacfolia; triphyllos $\mathbf{L}$.}

T. XXII. F. $6-15$.

Der Embryosack der hemitropen Eychen von Veronica Buxbaunii zeigt schon friihe, zu ciner Zeit wo das knospende Perigon noch farblos, cine Anschwvellung des Mikropyle-Endes, in dessen Scheitelwölbung dic zivei, jetzt noch ziemlich kugeligen Keimbläschen haften (F. 3 ). An der Stelle, wo der Sack siclı verengt, liegt der abgeplattete primäre Kern desselben der Scitenwand an; strahlige Stränge körnigen Schleims gehen von ihm aus durch den mit wässeriger Fluissigkeil erfüllten Innenraum des Sackes. Gegen die Blüthenzeit hin nähert sich die Anschwellung des oberen Endes des Sackes mehr und mehr der Kugelform. In seinem Innern, besonders in der Nähe des Kernes, erscheinen zahlreiche Amylumkörnchen. Die Kcimbläschen werden gestreckter. Endlich, kuř vor dem Verstäuben des Pollens, schwillt auch das untere Ende des Sackes beträchtlich an (F.6, 7). Bei den anderen oben genannten Arten der Gattung sind diese beiden Erweiterungen des Sackes minder scharf ausgepragl.

Das Pollenschlauchende erreicht dic Aussenfläche des Embryosackscheitels gleichzeitig mit dem Abfallen der Corolle. Sofort nehmen die Anschwellungen des Embryosacks an Umfang beträchtlich zu, besonders die untere. In der Mittelgegend des Sackes entsteht gleichzeitig (ohne Zweifel durch zweimalige Bildung von Querwänden) dic Mutterzelle des Endosperms (F.12), bei V. Buxbaumii in einer jetzt crst hier gebildeten Erweiterung des sehr engen Sackes gelegen (F. 8, 9); einer Erweiterung, deren Entsteliung sichtlich eine stärkere Wölbung (Folge localer Zellvermehrung) und ein durch sie bedingtes Auseinanderweichen der Innenwände des Integuments vorausgeht : - man findet bisweilen, dass die nittlere Anschwellung des Embryosacks, mit der von ihr eingeschlossenen, bereits in Tochterzellen getheilten Anfangszelle des Endosperms dic örtliche Erweilcrung des Hohlraums im Integumente nicht 
völlig ausfüllt (F. 9). Die ersten Theilungen der Mutterzelle des Endosperms geschehen durch Querwände, denen Längswände bald folgen (F. 8, 9, 13). Während derselben verschirumpft und verschwindet das obere Keimbläschen (F.12); das untere (von dessen eng umschriebener Ansatzlläche das Pollenschlauchende stets eine Strecke, oft eine sehr bedeutende, entfernt bleibt,) verlängert sich zum Embryonalschlauche und wächst zum Endosperm herab (F. 8, 9, 12, 13), zwischen dessen, inzwischen zahlreicher gewordene Zellen das freie Ende des Embryonalschlauchs eindringt (F. 10, 14); um, in der Mitte des Endosperms angelangt, nach wiederholter Bildung von Querwänden über seinem Ende die Endzelle zum Embryokïgelchen umzubilden (F. 10, 11).

Die obere und untere Anschwellung des Embryosacks nehmen während dieser Vorgänge noch an Umfang zu; bei V. Buxbaumii und triphyllos ziemlich gleichmässig allseilig, ihre Form nur wenig ändernd; bei V. hederaefolia dagegen einseitig, nach der Raphe hin (F. 12, 13), ähnlichı wie bei Lathraea squamaria. Die untere Anschwellung bleibt völlig zellenleer, soweit die Beobachtung reicht; nur dass in cinzelnen Fällen ein Zellkern in ihr auftritt, von welchem Fäden körnigen Schleimes ausstrahlen (F.8). In der oberen dagegen erfolgt häufig die Bildung freier Zellenkerne und sell)st Zellen (F. 8, 9, 11), die aber wieder vergehen, ohne zu bleilsendem Gewelse sich zu vereinigen. Nur bei Veronica triphyllos sah ich dic Erweiterung in der Regel durch eine Längswand in zwei Zellen getheilt. Der Embryonalschlauch erschien dieser Scheidewand licht angeschmiegt (F.14; F. 15 ist ein ähnliches Präparat, um $90^{\circ}$ gedreht gesehen, wo diese Scheidewand, parallel der Ebene des Objectträgers gelegen, nicht sichtbar wird).

Auf späteren Entwiclielungsstufen, nach Anlegung des Embryoliügelchens, erscheint die obere Anschwellung des Embryosachs von Veronica triphyllos durchsetzt von einem vielfach verästelten Flechltwerk aus ungleich dicken, nach allen Richtungen strahlenden Strängen zäher Gallerte (F. I \& b, c), die durch Quetschung sich breit drücken lassen. Die Sulsstanz derselben bricht das Licht nur wenig sturker, als die Fliissigkeit in den kleinen isodiametrischen Hohlräumen zwischen ihnen. Die Gallerte ist gegen die kurz dauernde Einwirkung selbst concentrirter Lösung von Salzen und Alkalien, sowie von Mineralstauren sehr unempfindlich. Die Erscheinung ist offenbar den Zellstoffbalken in der Aussackung des Embryosacks von Pedicularis analog. Bei monatelangem Liegen der 
Neqe Beiträge zur Kenntniss d. Eubriobildung D. Pilaneroganen. 621

Präparate in concentrirter Glycerinlösung löset sich dieses System von Gallertsträngen stellenweise von der Wand des Embryosackes ab, und zicht sich auf kleineren Raum zusammen (F. 15 b). In älteren, der Reife nahen Samen sind die Stränge dagegen völlig starr, und mil der Emhryosackhaut fest verbunden.

In Betreff der ferneren Entwickelung des Samens, namentlich der Verdringung des Gewebes des Integuments durch das Endosperm, verweise ich auf die Mitlheilungen Tulasne's*).

\section{IX.}

Acanthaceen.

Acanthus spinosus.

Taf. XXIII. F. 8, 9 .

Das dicke Integument des Eys von Acanthus**) umschliesst emen spitzwinklig gekrümmten schlanken Eykern; die Raphe dagegen ist völlig gerade (F. 8). Der Embryosack verdrängt früh die ganze Substanz des Kerns. Zur Blüthezeil ist er fadenförmig cylindrisch, an Chalaza-Ende schwach angeschwollen. In dieser Anschwellung bildet sich nach dem Antreten des Pollenschlauchs ans Mikropyle-Ende Endosperm, zu welchem von diesem Ende, des Sackes her der ungemein lange Embryonalschlauch herabsteigt, rasch bis in die Mitte des Endosperms vordringend. Vom oberen Ende des Embryosackes aus entwickelt sich gegen die Raphe hin eine seilliche Ausstülpung, von nur mässigem Umfange (F.3). Das Endosperm erlangt im halb reifen Samen ein beträchtliches Volumen, wird aber gegen die Samenreife hin vom schnell heranwachsenden Embryo wieder verdrängl.

*) Anu. sc. nat. III. Sér. T. XII. p. 17 đr.

**) Vergleiche auch Planchon in Ann. sc. nat. III. S. T. IX. p. 72. 


\section{$\mathbf{x}$. \\ Plantagineen.}

\section{Plantago lanceolata L. $\left.{ }^{*}\right)$ \\ Taf. XXV. F. $8-13$.}

Form und Bau des Eychens des Wegbreits zeigen mehrere auffalIende Aehnlichkeiten mit denen derAcanthaceen. Das aufrechte schildförmige Ey, von einem einzigen sehr dicken Integument (dessen Gewebe, wie bei Acanthus, durch und durch gleichartig, weich, von weisser Farbe isl) ist umgewendet, sein Kern und Mikropylekanal in einem Bogen von beiläufig $50^{\circ}$ gekriummt (F, 8). Die sehr bedeutende Entwickelung der Seite des Integuments, welche der Raphe abgewendet ist, in der Umgebung der Mikropyle lässt das Ey bei oberflächlicher Betrachtung nur halbgewendet erscheinen. Geraume Zeit vor dem Aufblühen hat der Embryosack die übrigen Zellen des Eykerns völlig verdrängt; er allein erfüllt den vom Integument umschlossenen verhältnissmässig kleinen IIohlraum. Bei im Allgemeinen schlank kegeliger Gestalt zeigt er eine beträchtliche Ausbauchung an der der Raphe abgewendeten Seite; die Ansicht seines Längsdurchschnitts ist nahezu dreieckig (F. 8 b). Die Keimbläschen, zwei an der Zahl, haften im Mikropyle-Ende des Sacks der Innenwand desselben in verschiedener Höhe an. Der primäre Kern des Sackes liegt in der Nittelgegend des Sackes innerhalb derselben die Innen vand auskleidenden Protoplasmaschicht. Von Gegenfüsslerzellen der Keimbläschen ist nur eine vorhanden (F. 8 b).

*) Die Schildform der Eychen von Plantago macht die Herstellung feincr Durchschnittc scnkrccht auf den grössten Querdurchmesser im höchsten Grade schwierig, wenn man nach der gewohnten Methode verfährt, das cinzelne Eychen zwischen Daumen und Zeigefinger der linken Hand zu fassen. Plantago lanceolata ist deshalb die der Untersuchung am bequemsten sich darbietende Art der Gattung, weil hier die Eychen, nur eines in jedem Fruchthnotenfachc, von bestimmter, äusserlich am Fruchthnoten erkennbarer Lagc sind. Fertigt man Durchschnitte durch den ganzen Fruchthnoten, indem man das Mcsser parallel eincr durch die Mlittellinie beider Ficher gelegten Ebene führt, so hält es nicht allzu sehwer, hlare Bilder zu crlangen. 
Nach der Ankunft des Pollenschlauchendes an der Aussenflichc des Embryosackscheitels, welche sehr bald nach Bestäubung der Narben erfolgt, wird der Embryosack, nach Verschwinden scines primären Kerns, durch cine Querwand, dicht oberhalb jener der Raphe abgewendeten Ausweitung in zwei Tochterzellen getheilt. Dieser Theilung folgt sehr bald eine neue Theilung derjenigen beider Tochterzellen, welche das Wikropyle-Ende des Embryosackes ausfillt, durch eine auf der vorher entstandenen rechtwinklige, in Beziehung auf das gebogene miliropylare Ende des Sackes ebenfalls quere Wand (F.9). Gleichzeitig nimmt die Ausweitung des Sackes an Umfang noch zu.

Von den beiden Tochterzellen des Embryosacks, welche dessen Mikropyle- und Chalaza-Ende ausfüllen, vermehrt fortan die Erstere sich nur durch einige wenige Theilungen, die letztere gar nicht, sie bleibt bis zur Samenreife zellenlcer. Die mittlere der Tochterzellen dagegen, diejenige welche jene der Raphe abgewendete Ausweitung ausfültt, verhailt sich als Mutterzelle der Hauptmasse des Endosperms. Durch eine Reihe einander rasch folgender Zweitheilungen, während deren in ihrer die Keimbläschen einschliessenden Schwesterzelle nur noch eine Längsund Quertheilung zu erfolgen pflegt, verwandelt sich jene in einen umfangreichen Zcllenkörper (F. 10, 11), der zunächst vorzugsweise in die Dicke; in zum Längsdurchmesser und zum grössten Querdurchmesser des Eyes rechtwinkliger Richtung wächst (F. 12). Das junge Endosperm erscheint als ein abgeplattetes Ellipsoïd, dessen kleine Achse mit der Längsachse des Eys zusammenfällt.

Das untere Keimbläschen ist inzwischen zu einem Embryonalschlauche von mässiger Länge ausgewachsen, der bis etwas unter den Mittelpunkt des Eyweisskörpers herabsteigt, und hier durch eine sehr nahe über dem stumpfen Ende entstehende Querwand sich theilt (F.10, 11). Die halbkugelige Endzelle theilt sich noch einigemale durch Querwände; die Schlusszelle der kurzen Reihe wirl durch fortgesetzte, nach allen Richtungen hin crfolgende Zwveitheilungen zum Embryokügelchen.

Jetzt ändert sich die Richtung der grössten Lebhaftigkeit der Zellvermehrung und des Waclusthums des Endosperms. Dasselbe nimmt fortan in Richtung der Länge und Breite des Eys rasch an Umfang zu, dic Zellen des Integuments bis auf die ausserste Zellenlage desselben verdrängend und verfliissigend. Noch ehe am Embryokügelchen die Anlagen der Kotyledonen sichtbar werden, hat das Endosperm, nur von 
einer dünneren Lage von Zellen überzogen, die Löffelform des reifen Samens (F. 13). - Die Membran, welche - als Rest des Integuments - das Endosperm umkleidet, besteht zu äusserst aus der Epidermis desselljen, unter welchem eine diunne, bei der Samenreife tief gebräunte, Schicht von schwer zu entzifferndem Baue liegt: die bis zum Verschwinden des Inhaltsraumes zusammen gepressten, etwas verdickten Wände einer grossen Anzahl von Zellen des Integuments*).

Sclıon beim Beginn dieser Entwickelung des Endosperms in Länge und Breite sprossen aus den, dem Embryosaclischeitel nächsten, nichıt mit assimilirten Stoflen sich füllenden Tochterzellen der oberen der ersten drei Zellen in welche der Embryosack sich theilte, blinddarmförmige Auswiichse hervor (F. 12), deren eine aufwairts, die andere abwirts in das der Placenta angewachsene Gewebe des Integuments dringt; oft wunderlich gekrummt (F. 12, 13). In diesen im Allgemeinen cylindrischen A usstülpungen entsteht, noch vor dem Sichtbarwerden der Kotyledonen am Embryo, ein Netzwerk vielverästelter Querbalken aus Zellhautstoff, von dem bei Pedicularis sylvatica vorkommenden nur durch grössere Dünne der Balken verschieden.

\section{XI.}

\section{Labiaten.}

\section{Lamium purpureum und maculatum L.; Prostanthera violacea.} Taf. XXIV.

Stellung und wesentliclıste Züge des inneren Baues der Eychen sind bei allen untersuchten Gattungen der grossen Familie in Uebereinstimmung. Die Eychen stelıen einzeln an den eingeschlagenen Rändern der zwei Carpelle, welche den Fruchtknoten zusammensetzen; zwei Eychen also in jedem der beiden Fächer dessellsen. Jedes Fach ist durch eine falsche Scheidewand getheilt, der Fruchthmoten scheinbar vierfä-

*) Vergleiche meine Darstellung des Baues dieser Schicht bei l'lantago Psyllium in Berichten K. Sächs. Ges. d. Wiss.: Math. phys. CI. 1838. 
cherig(F.17).*) Die Eychen sind aufrecht, mehr oder minder gewendet und gekrümmt; dabei auch seitwär's abgelenkt. Eine durch den Eykern und den Mikropylekanal gelegte Ebene macht mit dem Spalt zwischen den Carpellen einen Winkel von etwa 45\%. - Das einzige, selır dicke Integument uberzieht einen aus wenigen Zellen zusammengesetzten Eykern, aus welchem schon sehr früh der Embryosack hervor bricht, der im Laufe seiner Entwickelung die Zellen der Rindenschicht des Eykerns bis zum Verschwinden zusammendrückt.

Untergeordneter Formenverschiedenheiten zeigen die Eychen verschiedener Gattungen eine lange Reihe, als deren Endpunkte die in der Ueberschrift genannten Gattungen betrachtel werden können. Das Eychen von Lamium erhebt sich, auf verhältnissmässig schlankem, freiem Theile seines Funiculus vollständig über seine Anheftungsstelle; das Ey ist nicht gebogen, nur der Eykern gekrummt; die Raphe ist völlig gerade (F. 1, 15). Aehnlich vertalten sich Galeopsis, Stachys, Dracocephalum**). Bei Prostanthera dagegen ist das Ey im Halbkreise nach abwärts gebogen; - eine Krümmung die so gut wie ausschliesslich von der Raphe beschrieben wird. Der Embryosack ist fast gerade (F. 15). Eine Miltelform zwischen beiden stellt Ajuga dar (F. 20). Die Aussenfläche des Eychens von Lamium purpureum trägt nicht selten Haare: eine Zellenreihe mit stark angeschwollener Endzelle (F.1, 16 ); ein nirgend anderswo bemerktes Vorkommen.

Aehnliche Mannichfaltigkeit waltet ob in der Form der Embryosäcke. Der von Prostanthera hat die keulige Gestalt, wie sie der grossen Melızahl der Phanerogamen eigen ist (F, 16). Der von Ajuga ist gegen das Mikropyle-Ende hin kugelig angeschwollen (F. 20). Zivei solcher Anschwellungen, die eine am Miliropyle-Ende, die andere (oft von sehr beträchtlichem Umfange) an der Stelle der starken, spitzwinkligen Beugung des Saclics zeigt der von Lamium (F. 3, 8, 9, 12, 13) und verwandten Gattungen*****); daneben auch häufig, nicht regelmässig, noch vor dem Eintritt der Befruchtung, lurze Ausstülpungen veränderlichen Ortes und Umfangs; - grössere nahe am Chalaza-Ende (F.3); kleinere,

*) Vergleiche über diesen Gcgenstand Schleiden, Grundz. II. Aufl. Bd. II. S. 310 Payer, Organogr. T. 114. F. 14-18, 22.

**) Vergleiche Tulasne in Ann. sc. nat. IV. S. T. 4, Tf. 7 u. ff.

***) Tulasne a. a. O. 
der Aussenwand des Embryosacks dicht angedrückt, mit körnigem Protoplasma völlig erfüllt, an der oberen Ausweitung des Embryosackes $\left.(\text { F. } 3,5)^{*}\right)$.

Im Nikropyle-Ende des Embryosackes haften die Keimbläschen: zarte Zellen mit leichtzerfliessender Wand; bei Lamium (wo nie mehr als zwei beobachtet wurden, F. 2, 3, 12,13) und bei Ajuga (F. 20) nur wenig gestreckt; bei Prostanthera (F. 16) mehr in die Länge gezogen. Der Kern des Embryosacks liegt bei den letztgenannten nahe unter den Keimbläschen; bei Lamium ihnen fern, an der Stelle der Umbiegung des Embryosacks (F. 3, 12,13); 一 in allen Fällen der Wand des Sackes angeschmiegt und der Millelpunkt mehr oder weniger zahlreicher Stränge körnigen Schleimes. Gegenfüsslerzellen der Keimbläschen fehlen entweder oder sind nur in Einzahl vorhanden (F. 9, 12, 16).

Der Pollenschlauch erreicht das Mikropyle-Ende des Embryosacks von Lamium purpureum und maculatum noch wăhrend der Frische der Corolle. Die Wand des Pollenschlauchs erscheint gleich bei seiner Ankunft hier stark verdickt; der Inhalt auf einen selır engen cylindrischen Raum zusammengedrängt (F. 4-9). Das eine der Keimbläschen — das der Raphe nähere, dem Scheitelpunkt des Embryosackes fernere, streckt sich sofort in die Länge, meist indem es seine Spitze zitzenförmig verlängert (F.5, 7), während das andere mehr oder weniger rasch zu einem Ballen grumöser Substanz zusammensinkt (F. 4, 7), und endlich verflüssigt wird. Durch schnell weiter fortschreitende Verlängerung des unteren Endes wird das befruchtete Keimblaischen zum Embryonalschlauche ungebildet. Diesem Längenwachsthum geht aber häufig (keineswegs immer) die Bildung einer Querwand im befruchteten Keimbläschen, dicht über dem unteren Ende, voraus (F. 4,5). Beide Tochterzellen, die an festem Inhalt ärmere obere, wie die inhaltreichere untere, enthalten Zellkerne. In dem noch ungetheilten, aber bereits etwas gestreckten Keimbläschen wurden in einen Falle zwei Kerne beobachtet (F. 7). Diese frühe Quertheilung des befruchteten Keimbläschens von Lamium purpureum ist der cinzige derartige Fall, der bei den Pflanzen mit ursprünglich einzelligem Endosperm und sehr gestrecktem Embryonalschlauch bekannt geworden ist.

*) An frei gelegten Embryosäcken, etwas von der Aussenfläche des Embryosacks weg gebogen dargestcllt von Tulasne a. a. 0 . T. $10 \mathrm{~F}, 8 \mathrm{u}$, anderwärts. 


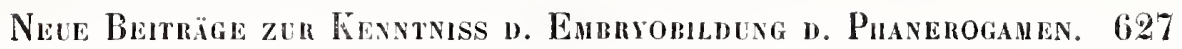

Die Querwand einzelner befruchteter Kiemblaschen bietet einen festen Punkt, dessen Dasein die Constatirung der Thatsache erlaubt, dass der Embryonalschlauch sich nicht nur durch Wachsthum an der Spitze, sondern auch durch Streckung älterer Theile verlangert. (Die Vergleichung der bei der nämlichen Vergrösserung gezcichneten Figuren 7 und 10 zeigt, dass die oberste Zelle des Embryotraigers nach ihrer Abscheidung von der nächstunteren cylindrischen Zelle noch beträchtlich in die Länge gewachsen ist.) Sehr bald nach Ankunft des Pollenschlauchs am oberen Ende des Sackes hat sich in der Erweiterung an der Beugungsstelle desselben die erste Zelle des Endosperms gebildet: von beträchtlicher Grösse, die Mittelgegend des Sackes völlig ausfüllend, einen grossen, kugeligen Kern einschliessend (F.4). Das Endosperm ist durch wiederholte $Z$ weilheilung etwa achtzellig geworden, wenn das untere Ende des Vorkeims bei ihm aulangt und zwischen seine Zelien eindringt (F. 8). Hier schwillt es sofort in die Breite an. Nach wiederholter Querwandbildung über dem stumpfen Ende geht aus der Terminalzelle das Embryokügelchen hervor (F.9). Erst jetzt wird die Zellvermehrung im Endosperm lebhafter. Dieses Gewebe, bisher nur eine dünne Hülle um das Embryokügelchen darstellend (F. 9), wächst rasch an Masse, besonders oberhalb des Embryo (F. 10, 11, 15), von welchem es indess gegen die Samenreife hin grossentheils verdrängt und aufgezehrt wird.

Die obere Ausweitung des Embryosacks nimmt nach der Befruchtung noch beträchtlich an Umfang zu, vorwiegend in der Richtung von der Raphe abwärts (F. 9, 14, 15). In dieser Anschwellung des Sackes treten freie Zellkerne auf, oft schon sehr früh; diese ersten dann von beträchtlicher Grösse (F. 4, 7). Auf späteren Zustainden werden nur kleinere Kerne gefunden (F. 8, 9). Die Bildung geschlossenen Gewebes in der oberen Erweiterung des Sackes wurde nie beobachtet.

Dic zahlreichen und genauen Untersuchungen befruchteter Eychen von Labiaten, welche wir Tulasne verdanken*), zeigen eine im Wesentlichen vollständige Ucbereinstimmung des Entwickelungsganges der

*) Ann. se. nat. IV. Série T. IV. p. 66 Ir. ; F. 7-10. - Dass Tulasne aueh bei diesen neueren Untersuehungen vom Dasein der Keimbläschen vor der Befruehtung sieh nieht zu überzeugen vermoeht, messe ieh aueh hier seiner Untersuehungsmethode bei: der aussehliesstiehen Anwendung der Zergliederung, der Unterlassung des Anfertigeus von Durehsehnitten. 
untersuchten Arten mit dem geschilderten des Lamium purpureum. Auffallende Abweichungen finden sich nur in der Form der Anhängsel der Embryosäcke (colossale einseitige Anschwellung der oberen Ausweitung an der der Raphe abgewandten Fläche bei Thymus Acynos L. und Dracocephalum peltatum, verbunden bei letzterem mit blinddarmăhnlichen Ausstülpungen des unteren zellenleeren Endes des Sackes; Doppelgabelung des seitlichen Auswuchses der oberen Erweiterung des Sackes bei Betonica officinalis; wihrend Staclyys sylvatica und Galeopsis Ladanum mit Lamium völlig übereinstimmen*). Um so auffallender ist es, dass die Entwickelung des befruchteten Embryosackes von Prostanthera violacea nicht eine der besonderen Eigenthümlichkeiten jener mitteleuropaischen Labiaten theilt.

Der Embryosack der Prostanthera violacea erscheint kurze Zeit nach der Befruchtung in seiner Gestalt nur wenig verändert, wohl aber beträchtlich vergrössert, in die Länge gestreckt, im oberen Theile etwas angeschwollen. Der Anhängsel, der einseitigen Ausstuilpungen der Membran entbehrt er durchaus. Seine Mitte ist von einem, aus wenigen grossen Zellen zusammengesetzten Endosperm ausgefüllt. Die Anordnung der Zellen desselben lässt auf seine Entstehung durch wiederholte Theilung der einzigen Urmutterzelle schliessen (F. 18). Bis gegen das untere Ende des Endosperms reicht der lange, cylindrische Embryonalschlauch, der oben, schräg abgestutzt, mit langgezogener Ansatzlläche an der Innenwand des Embryosacks haftet (F. 18 a). Die Membran des Embryosackscheitels hat das Pollenschlauchende umwachsen, so dass dieses auf eine nicht unerhebliche Strecke in eine taschenförmige Einstiilpung der Embryosackhaut eingeschlossen erscheint: ein Verbältniss, dem ähnlich, welches bei Narcissus ${ }^{*}$ ), Digitalis ${ }^{* * * *}$ ) und sehr ausgeprägt bei Campanula t) und bei Najas vorkommt. Das erweiterte obere Drittheil des Sackes ist zu dieser Zeit noch zellenleer. Später, nach der Anlegung des Embryokügelchens füllt es sich, wie es scheint durch freie

*) Ueber Stachys sylvatica vergleiche auch Deecke in Bol. Zeit. 1856, 121. Dcn Irrthum Deecke's, der Embryoträger und Pollenschlauchende im Zusammenhange darstellt, brauche ich nicht weiter zu erörtern.

**) Hofmeistcr Entstehung des Embryo. T. II. F. 39.

***) Tulasne Ann. sc. nat. III. Sér. XII. T. III. F. 8, 9.

†) Tulasne a. a. O. Tf. 3 ; XYII. Abschnitt dieser Abhandlung. 
Zellenbilduing, mit lockerem weitzelligem Gewebe, das durch die Grösse seiner Zellkerne vom Endosperm auffällig sich unterscheidet (F. 19). Dieses Gewebe vertrocknet gegen die Samenreife hin, ebenso wie das zellenleere untere Ende des Embryosackes.

Es tritt bei Lanium wie bei Prostanthera ein Verhältniss mit besonderer Deutlichkcit hervor, welches anch vielfach anderwärts sich zeigt, und vielleicht eine ganz allgemeine Verbreitung hat: die unbefruchteten Keimbläschen sind von sïchtlich grösserem Umfang (Breitendurchmesser) als das obere Ende des Vorkeims. Es bestehen nicht bloss Grössen-, sondern wesentliche Formunterschiede zwischen den unbefruchteten (unteren) Keimbläschen und der oberen Zelle des Vorkeims. Der letztere ist durchwegs von weit schlankerem Umriss; die Differenz des Durchmessers ihrer Ansatzfläche an der Embryosackhaut von dem grössten Querdurchmesser der Zelle ist geringer, die Entfernung der dicksten Stelle der Zelle von der Ansatzlläche ist grösser bei der obersten Zelle des Vorkeims (Embryoträgers), als bei unbefruchteten Keimbläschen - und dies nicht nur bei den genannten Labiaten, sondern auch bei Oenothera, Tropaeolum, Anemone, bei Grảsern, bei Funkia, und in vielen anderen Fällen. Der Versuch liegt nahe, diese Thatsache durch die Annahme zu erklaren, dass die zartere, meist gallertweiche, halbliussige Wand der unbefruchteten Keimblaschen durch den anschwellenden Inhalt ausgedehnt werde, der von dem Wasser aufnimmt, in welchem das Präparat liegt*). Diese Annahme ist aber unzulässig. Die Keimbläschen erscheinen nicht merklich kleiner, wenn die Präparate augenblicklich nach ihrer Anfertigung in Speichel, in Oel oder in concentrirter Lösung von kohlensaurem Ammoniak untersucht werden. Damit ist der Beweis für eine Verkleinerung des Keimbläschens, für ein Schrumpfen desselben während oder unmittelbar nach der Befruchtung gegeben. Diese Verkleinerung kann in keiner anderen Weise erfolgen, als durch Ausscheidung von Wasser. Es ist derselbe Vorgang, der die nothwendig mit Zusammenziehung des Inlialts verbundene endogene Vermehrung von Zellen ganz allgemein begleitet. Bei Pflanzen, deren

*) So Crüger in Bot. Zeit. 1851, :59. Tulasne hat in meinen früheren derarligen Beobachtungen einen Wahrscheinlichkeitsgrund gegen meine Darstellung von der Umwandlung eines der vor der Befruchtung iorhandenen Keimbläschen in die oberste Zelle des Vorkeims zu finden geglaubt. 
Keimbläschen schon vor Ankunft des Pollenschlauchs am Embryosacke starre Zellstoffwainde erhalten haben, wie z. B. Lathraea und Pedicularis, kann die elastische Haut sich nicht verkleinern, ivenn auch der bildungsfähige Zellinhalt Wasser ausscheidet. Das Wasser wird hier in der Zellhöhle verbleiben; der Unterschied der Gestalt unbefruchteter und befruchteter Keimbläschen findet nicht statt.

\section{XII.}

\section{Selagineen.}

\section{Hebenstreitia dentata Thunl.}

Taf. XXV. F. $1-6$.

Das schlanke hängende Eychen (F. 2) dieser Selaginee enthält innerhalb des einzigen, dicken Integuments, dessen innerste Zellschicht aus horizontal gestreckten Zellen besteht, einen cylindrischen, am oberen Ende plötzlich zugespitzlen Einbryosack (F.1), der vor der Befruchtung zahlreiche Amylumkörnchen den Wandbeleg aus Protoplasma eingebettet enthält. Die zwei kurzen Keimbläschen haften in der Scheitelwölbung des Sackes ungleich hoch an dessen Innenwand. Der primäre Kern des Sacks ist klein, scheibenförmig (F. 1). Gegenfüsslerzetlen der Keimbläschen sind bald in Ein-, bald in Dreizahl vorhanden; im unbefruchteten Embryosack gleich den Keimbläschen sehr kurz, fast kugelig (F. 1).

Der Pollenschlauch erreicht die Aussenfläche des Embryosackscheitels noch während der Frische der Corolle. Er haftet jetzt und fernerhin nur lose an der Haut des Sackes; bei der Freilegung des letzteren löset sich der Pollenschlauch von ihm ohne Ausnalıme unverletzt, bei Jeisem Ziehen. Erst später, zur Zeit da das Embryokügelchen angelegt wird, gelingt es, Embryosack und Pollenschlauchende im Zusammenhange frei zu legen (F. 6). Sofort nach seiner Ankunft beginnt eine starke Lảngsstreckung aller Theile des Embryosacks. Seine Mittelgegend schwillt dabei etwas an. Am oberen Ende dieser bauchigen Erweiterung 
entsteht eine Querwand, welche den Embryosack in zwei Tochterzellen theilt, in deren unterer sofort neue Theilung durch Querwände erfolgt, entweder hintereinander wiederholt (F. 2), oder mit Längswänden wechselnd (F. 4, 5). Das befruchtete, untere Keimbläschen streckt sich inzwischen zu beträchtlicher Länge, während das andere zeitig versch ıvindet (F. 2, 3), oder noch einige Zeit unverändert sich erhält (F. 4, 5). Eine Längsstreckung, bald sehr beträchllich (F. 2, 6), bald minder bedeutend (F. 3, 4, 5), triit auch an den Gegenfüsslerzellen der Keimbläschen hervor.

Wabrend fortdauernder Verlangerung des ganzen Embryosacks mehrt sich die Zahl der Zellen des, seine unteren zwei Drittel ausfüllenden Endosperms, vorwiegend in der Längsrichtung (F.6). In das Gewebe desselben dringt das nntere Ende des zum Embryonalschlauche ungewandelten Keimbläschens (F. 4, 6). Nachdem derselbe, die auf seinem Wege liegenden Endospermzellen zusammen drückend, bis auf ein Viertel der Länge der Endospermmasse in diese hinein gewachsen, entsteht über seinem zugerundeten Ende eine Querwand, welche den cylindrischen Raum des langen oberen Theils des Embryonalschlauchs von dem halbkugeligen unteren scheidet (F.6). Die Endzelle schwillt an, und wird durch eine Reihe von Zweitheilungen zum Embryokügelchen. Der zellenleere obere Theil des Embryosacks bleibt wăhrend dieser Vorgänge ohne alle Anlıängsel.

\section{XIII.}

\section{Globulariaceen.}

\section{Globularia vulgaris L. Taf. XXV. F. 7.}

In Form und Bau des Eychens und Embryosacks verhält sich Globularia mit Hebenstreitia völlig übereinstimmend. Auch die Entwickelung des Endosperms und des Embryo weicht nur in wenigen Punkten von jener ab. Es wird auch die oberste, die Keimbläschen einschliessende Zelle des Endosperms durch eine Längswand getheilt, an die ange- 
schniegt das zum Embryonalschlauche auswachsende befruchtete untere Keimbläschen zum Endosperm herab wächst. Das untere Ende des Embryosacks bleibt völlig zellenleer, auch die beiden untersten Zellenpare des Endosperms vermehren sich nicht weiler, strecken sich aber dafür ganz ungewöhnlich in die Länge (F. $7 x$ und $y$ ), namentlich das unterste.

\section{XIV.}

\section{Bignoniaceen.}

Catalpa syringaefolia Sims.

Taf. XXIII. F. 7 .

Das anatrope, nur schwach gekrummte Ey zeigt schon im unbefruchteten Germen breil gezogene Fornı, die indess, jetzt sowohl als später, nur auf Entwickelung des einzigen dicken Integuments vorwiegend parallel der Flache der Placenta beruht. Der vom Integument umschlossene Hohlraum ist langgezogen spindelförmig, schon früh lediglich vom Embryosacke allein ausgefüllt, welcher die übrigen Zellen des Eykerns völlig verdrängt hat.

Ausser ungewöhnlicher Längsstreckung zeigt der unbefruchtete Embryosack keine besonderen. Eigenthümlichkeiten. Die Ansatzflàchen der Keimbläschen sind breiter, als hei Globułarieen und Selagineen; im Uebrigen Alles den dort beschriebenen Verhältuissen ähnlich. Sehr bald nach Ankunft des Pollenschlauchendes an der Aussenfläche des Embryosackscheitels schwellen das obere und das untere Ende des Sackes, während rascher und starker Grössezunahme aller Theile des Eychens, etwas an. In der oberen Anschwellung treten einige freie Zellkerne und Zellen auf, welche später wieder verschwinclen, ohne geschlossenes Gewebe zu bilden. Die untere Anschwellung wird ron einer einzigen grossen Zelle eingenommen, welche durch wiederholte quere, später auch durch Längstheilungen zu einem, vorerst keulenförmigen, aus vier Längsreihen von Zellen zusimmengesctzten Endospermkörper 
sich umbildel. In diesen dringt das untere Ende des zu einem überaus langen Embryonalschlauche gestreckten, befruchteten (unteren) Keimbläschens bis zur Mitle ein. Dann schwillt sein Ende an; bald ohne Weiteres (F. \%, 76 links), bald nach vorgängiger ein-oder mehrmaliger Querscheidewandbildung dicht oberhalb der Spitze (F. $\% 6$ rechts). Die Anschwellung wird durch forlgesetzte Zellvermehrung zun Embryokigelchen.

\title{
XV. \\ Hydrophylleen.
}

\author{
Nemophila insignis Benth. \\ Taf. XXII. F, 16, 17.
}

Das anatrope Eychen von Nemophila sitzt mit tief eingeschniurter Verbindungsstelle am dicken freien Theile des Funiculus. Gleich denen der im Vorausgehenden und der Mehrzahl der im Folgenden besprochenen Formen entbehrt es der Gefässe. Es ist von einem einzigen, vergleichungsweise dünnen Integument bekleidet, dessen innerste Zellschicht aus quergestreckten kurz prismatischen Zellen besteht (F. 16). Der Embryosack füllt den Hohlraum innerhalb des Integuments vollstäudig aus. Er ist kurz und dick, ziemlich gleichweit. In seiner Scheim telwölbung haften zwei Keimbläschen; sein entgegengesetzles Ende wird von der einzigen Gegenfiisslerzelle derselben ausgefüllt; niclıt selten fehlt diese letztere. Der grosse kugelige Kern des Sackes liegt in dessen Mittelgegend der Wand an. Verästelte Protoplasmafäden strahlen von ihm aus (F. 16 b). Nach Ankunft des Pollenschlauchendes an der Aussenfläche der nicht unbeträchtlich verdickten Membran des Embryosackscheitels erscheint in der anschwellenden Mittelgegend des Sackes, diese völlig ausfüllend, eine grosse Zelle; die Anfangszelle des Endosperms. Dic erste der rasch cinander folgenden Theilungen derselben geschieht durch eine Längswand (F.17). Das eine Keimbläschen 
verschwindet früh; das andere entwickelt sich langsam zu einem mässig langen Embryonalschlauche, welcher in das heranwachsende Endosperm eindringt. Das zellenleere untere Ende des Embryosacks schwillt während dieses Vorgangs zu einer ziemlich umfangreichen Blase an.

\section{XVI.}

\section{Pyrolaceen.}

\section{Pyrola rotundifolia L.}

Taf. XXV.F. 17-20.

Das Ey von Pyrola stimmt in allen Stuicken genau uberein mit dem von Monotropa*). Es ist sehr klein, vollkommen durchsichtig, anatrop, von nur einem, aus zwei Schichten tafelförmiger Zellen bestehenden Integumente bekleidet, dessen Hohlraum schon lange vor der Befruchtung vom Embryosacke allein ausgefüllt wird, der frühe die uibrigen Zellen des Eykerns verdrängte (F. 17). Der Embryosack ist keulenförmig; er enthält im Mikropyle-Ende zwei, seltener drei der Innenwand ungleich hoch ansitzende, kurz birnförmige Keimbläschen; eine einzige, fast kugelige Gegenfüsslerzelle derselben, und in seiner Mittelgegend einen grossen, wandständigen Kern, von welchem Stränge körnigen Protoplasmas strahlig ausgehen. Nach Ankunft des Pollenschlauchs an der Aussenseite der Embryosackspitze theilt sich der Sack in seiner Mitte durch eine Querwand. Bisweilen zeigt sich noch eine zweite Querwand beinahe gleichzeitig dicht aber der Gegenfüsslerzelle der Keimbläschen, so dass diese von der unteren der beiden Zellen ausgesperrt wird, in welche der Embryosack sich theilte. - Beide neu gebildete Zellen theilen sich sofort wieder durch Querwände: die obere meist nur einmal, die untere öfter. Die der Mitte des Embryosackes năheren Tochterzellen der letzteren werden darauf auch durch Längswände

\footnotetext{
* Hofmeister Entstehung des Embryo. S. 34.
} 
Neue Beiträge zur Kenntniss D. Embryobildung D. Phanerogamen. 635

getheilt. Es entsteht ein ellipsoïdischer Zellkörper, der an einem oder beiden Enden in eine kurze Reihe linear geordneter Zellen ausgeht. Häufiger, als bei Monotropa, setzt sich bei Pyrola die Theilung durch Längswände bis in die untersten der wenigen Zellen dieses Endosperms fort (F. 20).

Das untere Keimbläschen beginnt erst dann zu einem Embryonalschlauche sich zu verlängern, wenn die Bildung des Endosperms schon ziemlich weit vorgerückt ist. Das obere, fehlschlagende Keimbläschen verschwindet früh. Der Embryonalschlauch wächst bis in die Mitte der ellipsoïdischen Endospermmasse; bildet darauf eine Querwand über seinem halbkugeligen Ende. Die so abgeschiedene Endzelie schwillt an, und wird durch eine Quertheilung, der nur eine oder zwei Längstheilungen folgen, zum vier- bis achtzelligen, kugeligen Embryo.

\section{XVII.}

\section{Vaccinieen.}

\section{Vaceinium uliginosum L. Taf. XXV. F. 14-16.}

Die anatropen Eychen der einheimischen Vaccinien sind seitlich abgeplattet. Die Hauptmasse des Eys nimmt die Raphe ein; der Embryosack ist eng, schlank keulenförmig; das ihn umhüllende einzige Integument ist aus nur venigen Zellenlagen gebildet, die indess, zahlreiche Stärkekügelchen enthaltend (namentlich soweit sie den Mikropylekanal und den oberen Theil des Embryosacks umgeben), trotz ihrer Dünne die Beschaffenheit des Embryosacks im unverletzten Ey nicht erkennen lassen. Es bedarf zur Untersuchung der Darstellung dünner Längsdurchschnitte, die aus den, weit grösseren, Eychen des Vaccinium uliginosum leichter sich herstellen lassen, als aus den sehr kleinen des Vacc. Myrtillus.

In der etwas erweiterten Scheitelgegend des Embryosackes haften die beiden Keimbläschen, verschieden hoch an der Innenseite der nicht 
unbeträchtlich verdickten Wand: zartwandige, mehr quer als langgeslreckte Zellen, einen dünnen Wandheleg von feinkörnigem Protoplasma enthallend, welchem der schwierig zu sehende Zellenkern cingebeltet liegt (F. 14 b). Der primäre Kern des Sackes liegt in dessen Mittelgegend. Ein dicker Strang von Proloplasma führt von ihm aufivärts zu den Keimbläschen und abwärts zum Grunde des Sackes. Zahlreiche Stärkemehlkörner sind diesem Strange, wie auch dem Wandbelege des Sacks aus Protoplasma eingelagert. Gegenfüsslerzellen der Keimbläschen fehlen entweder gänzlich, oder nur eine einzige fiillt das untere Ende des Sackes aus.

Der Pollenschlauch, dessen Waude sich zeitig stark verdicken, legt sich der Spitze des Embryosacks seillich an (F. 1ä). Darauf verlängert sich das untere der Keimbläschen zu einem Embryonalschlauche von mässiger Länge, während das obere in einen unregelmässig begränzten Ballen grobkörnigen Schleims sich verivandelt (F. 15). Das Endosperm entsteht aus wiederholter Zweitheilung einer einzigen, die unteren zwei Drittel des Embryosackes einnehmenden Zelle. Nachdem der Embryonalschlauch bis zu diesem Gewebe herabgewachsen, bildet sich dicht über seinem halbkugeligen Ende eine Querwand. Nach ein - bis dreimaliger' Wiederholung dieser Quertheilung in der, zwischen je zwei Theilungen etwas sich verlängernden Endzelle des Vorkeims entsteht durch allseitige Vermelırung des Endglieds der kurzen Zellreihe das Embryoliügelchen (F. 16).

Uebereinstimmend in seinem Baue mit dem von Vaccinium ist das unbefruchtete Ey von Leiophyllum buxifolium (T. XXV. F. 22), Ledum palustre, Calluna vulgaris. Die Eychen von Epacris grandiflora(T. XXV. F. 2I) schliessen in ihrer allgemeinen Gestaltung hier ebenfalls sich an, namentlich auch im Bau des sehr durchsichtigen Integuments. Die Beschaffenheit des Eykerns dagegen stellt einen Uebergang zu Drosera dar, indem auch bei Epacris der Embryosack nur in seiner Scheitelregion die ihn umhüllende Zellschicht des Eykerns vollständig verdrängt; weiter abwärts aber von ihr umhüllt bleibt. 


\section{XVIII.}

Droseraceen.

\section{Drosera rotundifolia $L$.}

Taf. XXV. F. 23 .

Das äussere Integument des sehr lang gestreckten, anatropen Eys von Drosera rotundifolia besteht aus nur wenigen Zellenlagen. Es umschliesst lockier das, dem lang eyförmigen Eykern dicht anliegende, aus zwei Zellenlagen gebildete innere Integument. Das Endostom wird vom Exostom weit überragt.

Die ganze Längsachse des Eykerns wird von dem gestreckt leierförmigen Embryosacke eingenommen. Die Seiten desselben sind von einer einfachen Zellschicht umhüllt; seine Scheitelgegend berührt unmittelbar die Innenwölbung des inneren Integuments, ähnlich wie bei Epacris. Vor der Befruchtung haften zwei fast halbkugelige Keimbläschen in der Scheitelwölbung des Sackes. Gegenfüsslerzellen derselben wurden nicht beobachtet.

In jungen Samen, Blüthen entnommen deren Corolle nur eben welkte, erscheint der Innenraum des Embryosackes in eine Längsreihe von wenigen, zivei his vier grossen Endospermzellen umgewandelt, die offenbar der wiederholten Zweitheilung des Embryosacks ihre Entstehung verdanken. Jede dieser Zellen enthält einen umfangreichen, abgeplatteten, an Umriss elliptischen Kern, von dem Protoplasmastränge ausstrahlen. Die oberste der Endospermzellen enthält das zum Vorkeim umgewandelte Keimbläschen. Es erscheint jetzt als eine zweigliedrige Längsreihe von Zellen, die mit breiter Ansatzlläche an der. Innenwand des Embryosacks haftet. Nicht weit von dieser Stelle ist das Ende des Pollenschlauchs der Aussenwand des Sackes angeschmiegt.

Bei der weiteren Entwickelung verdrängt das heranwachsende, in rascher Zellvermehrung begriffene Endosperm sehr bald die einfache Zellschicht des Perisperms, während der Vorkeim tiefer in das Gervebe des Endosperms dringl, und seine Endzclle zum Embryokügelchen sich entwickelt. 


\section{XIX.}

\section{Campanulaceen.}

Taf. XXVI.

Die Eychen der Campanulaceen bestehen aus einem schlanken Eykern, welchen ein einziges, mässig dickes Integument umkleidet. Die Zellen dieses letzteren fülıren nur wenige körnige Stoffe; die der innersten, dem Eykern angränzenden Schicht sind, wie bei den meisten Eychen mit nur einer Eyhülle, quer gestreckt, von prismatischer Form (F. 1). Die Eychen von Campanula, Adenophora, Prismatocarpus sind seitlich stark abgeplattet; die von Glossocomia und Codonopsis zeigen kreisförmigen Querschnitt. Der Embryosack wächst sč̀on frühe aus der ihn umbüllenden und bedeckenden einzigen Rindenschicht von Zellen des Eykerns hervor. Unmittelbar vor der Blüthezeit ist nur sein unteres Ende von dieser Zellenlage umhüllt; vier Fünftheile (oft noch mehr) seiner Länge ragen frei in den vom Integument umschlossenen Hohlraum hinein. - Der Embryosack ist spindelförmig, am oberen Ende seitlich zusammengedrückt, derbwandig, besonders im zusammengedrückten Theile. Die Keimbläschen, langgestreckt birnförmig, mit sehr zarter, in Wasser rasch sich aufblähender und zerfliessender Wand, sind der Wand des Embryosacks auffällig verschieden hoch angeheftet (F. 2, 3, 4, 9, 12); das zusammengedruickte Nikropyle-Ende desselben lassen sie häufig leer (F. 2, 4). Unter ihnen liegt der primäre Kern des Sackes, ein gestrecktes Ellipsoïd, in der Regel mit zwei Kernkörperchen (F. 2, 4, 9, 12).

Unmittelbar nach der, noch während der vollen Frische der Corolle erfolgenden Ankunft des Pollenschlauchendes am Embryosack beginnt ein sehr lebhaftes Wachsthum (vorwiegend Längenwachsthum) aller Theile des befruchteten Eychens. Das Pollenschlauchende drängt sich zunächst nur eine kleine Strecke zwischen die Aussenseite des Embryosacks und die Innenfläche des Integuments; meist bis zu der Stelle, an welcher das untere Keimbläschen an der Innenseite der Embryosackhaut haftet. Bei dem raschen Wachsthum des Embryosacks in die Dicke und Länge wir d das Pollenschlauchende bald in eine, vorerst seitliche (F. 5), taschenförmige Einstülpung der Embryosackhaut nach Innen einge- 
schlossen. Diese Einstülpung des Sackes erscheint mehr und mehr scheitelständig, je mehr sie sich verlängert; ein je grösseres Stück des Pollenschlauchendes von der aufwärts wachsenden Embryosackspitze umsclieidet wird. So erscheint sehr bald nach der Befruchtung das Pollenschlauchende eingeschlossen in einer mehr oder minder tiefen, genau ihnn anpassenden Einsenkung der Ėmbryosackhaut. Die Länge dieser Einstiilpung ist bei ein und derselben Pflanze, in Eychen sogar die dem nämlichen Fruclitknolen entnommen sind, sehr veränderlich : in manchen Fällen kaum mehr als den Querdurchmesser des Pollenschlauchs betragend (F. 14), in anderen diesen um das Fünfzehnfache übertreffend*). Ebenso schwankend ist das Verhältniss der Keimbläschen zu der vom Pollenschlauchende ausgefillten Einstülpung des Embryosacks. Der bäufigste Fall ist der, dass der liefste Punkt der Einslülpung mit der Anheftungsstelle des unteren, zum Befruchtelwerden bestimmten Keimbläschens zusammenfällt. Der Vorkeim haftet dann an dem unteren Ende der Einstülpung (F. 6, 11 b, 14, 15). Nicht selten ist indess das obere Ende des Vorkeims seitlich an der Einstülpung befestigt (F. 8, 10, 13). Bistveilen ragt die Einstilpung mit freiem Ende in den Raum des Embryosacks herein; der Vorkeim haftet seitwärts an einer ganz anderen Stelle der Innenwand des Sackes (F. 5, 7, 11).

Mit derselben Schnelligkeit, wie die Zunahme des Umfanges von Eychen und Embryosack, treten nach Ankunft des Pollenschlauchendes an der Aussenseite des Sackes, Verănderungen der Keimbläschen ein. Das obere derselben verliert seine scharfe Umgränzung, und verwandelt sich in einen Klumpen körnigen zähen Schleimes, der allmälig verfliissigt wird, bald früher, bald später (F. 5, 6, 7, 10, 14). Das untere Keim-

*) Tulasne, der zuerst dieses Verhältniss beobachlele (Ann. sc. nat. III Série. T. XII, p. 57; T, V. F. 2-10), fasst es auf als eine Einstülpung der Embryosackhaut durch das Pollenschlauchende. Ich glaube mit Unrecht; vergleichende Messungen zeigen bald, dass sich das Pollenschlauchende, vou der Ausseumüudung der Mikropyle an gemessen, nur wenig verlängert, während ein grösseres Stück seiner unteren Extremität dadurch frei wird, dass die Innenwand des Integuments sich stärker wölbl, und so ein beträchtlicher Theil der Wände des Mikropylekanals in die Bildung des den heranwachsenden Embryosack umschliessenden Hohlraums mit eingeht. Das Längenwachsthum des befruchteten Embryosacks ist dagegen sehr beträchtlich. - Schacht hat die Einsenkung des Embryosacks für einen Theil des Embryoträgers erklärl (in. Pringsheim, Jahrbücher I, 206 ; Tf. XV. F. $11-14)$; - ein Irrthum, welcher durch das Vorausgeschickte widerlegt wird. 
bläschen formt sich, durch rasches Spitzenwachsthum, zu einem Cylinder um, der in Kurzem bis gegen die Mitte des Embryosacks hin vordringt. Hier trifft er auf das inzwischen angelegte Endosperm. Die erste Zelle desselben füll die Mittelgegend des Sackes vollständig aus (F. 6, 8). Der Augenschein zeigt, dass sie ihre Entstehung der Bildung zweier Querscheidewände im Embryosacke verdankt, deren untere die zuerst gebildete sein mag. Durch rasch einander folgende Zweitheilungen dieser Multerzelle des Endosperms wird dasselbe binnen Kurzem zı einem vielzelligen Körper von beträchtlicher Lïnge; das Längenwachsthum des Embryosacks beschränkt, sich fortan fast ausschliesslich auf den vom Endosperm ausgefiullten Theil desselben. In das Gewebe des Endosperms dringt die Spitze des Embryonalschlauchs, in welcher jetzt, oft schon früher (F. 6, 7) eine Querscheidewand eutsteht, nachdem der grösste Theil des Protoplasma des Embryonalschlauchs in dessen Ende wanderte. Die obere Zelle des Vorkeims ersclıeint fortan farblos durchsichtig (F. $11 b, 13,15)$. Die zunächst halbkugelige Endzelle entwickelt sich wieder zum Cylinder (bisweilen bauchig anschwellend, F. 1 $1 b$ ) gliedert ibr Ende durch eine Querwand vom cylindrischen Raume ab, und entwickelt aus dieser Endzelle, nach nochmaliger, selbst wiederholter Quertheilung derselben (F. 13, 14) das Embryokiigelchen.

Die Zellen des Vorkeims untersclıeiden sich auffällig von den sehr durchsichtigen des Endosperms durch ihren, von überaus zahlreichen Körnchen tief getrübten Wandbeleg aus Protoplasma (F. 11, 1 1 b, 13, 14); mehr noch durch die leichte Zerfliesslichkeit ihrer Wandungen. Selbst die Wände der drei- bis vierzelligen Vorkeime von Campanula americana, Codenopsis viridiflora widerstehen nur kurze Zeit der Einwirkung des Wassers; dann bläht ihre Substanz sich auf und vertheilt sich in der umgebenden Fliissigkeit. Bei Campanula medium leisten die Zellhäute etwas besseren Widerstand. Bei Prismatocarpus Speculum dagegen, einer Art, welche vermöge der Grösse und des Baues ihrer Eychen sich besonders gut zur Untersuchung eignet, ist die Zerfliesslichkeit der Zellmembranen des Vorkeims so gross, dass es fast unmöglich ist, ein klares Bild des befruchteten Eychens sich zu verschaffen. 


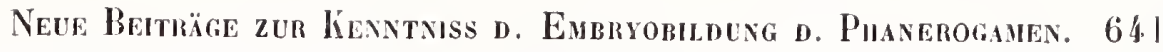

XX.

Loasaceen.

\section{Lo as a tricolor Lind.}

Taf. XXVIr. F. $2-6$.

Loasa tricolor stimınt im Baue ilires Eychens vollständig mit Pedicularis sylvatica iberein. Das Ey ist halb umgewendet, stark gekriimmt: das einzige Integument sehr dick. Der Embryosack hat zur Zeit der Befruchtung die übrigen. Zellen deș Eykerns vollständig verdrängt, und von seincm Scheitel aus, weit hincin in den langen, halbkreisförmig gekrimmten Mikropylekanal eine färlliche Fortsetzung getrieben. Der Sack ist nun von ungemeiner Lainge, im unteren Theile bauchig, im oberen gekrummten cylindrisch. Soweit das Integument der weiteren unteren Hälfte des Embryosacks angränzt, besteht eine innerste Zellschicht aus quergestreckten, prismatischen Zellen.

Der primäre Kern des Embryosacks liegt in dessen bauchigem unteren Theile. Die Keimbläschen, zwei bis drei, haften im Scheitel des Embryosacks; kurz vor der Befruchtung ist oft nur cines derselben vorhanden, die anderen zu formlosen Massen zusammen geschrumpft (F. 3): Gegenfüssler der Keimbläschen sind innerhalb einer Ausweitung des Grundes des Embryosaclis in Molırzahl anwesend. Da wo die untere Ausweitung des Sackes in dessen weiteren mittleren Theil einmindet, findet sich öfters eine grosse, diese Gregend des Embryosacks völlig ausfüllende Zelle (F. 3). An der Einmiindlungsstelle des cylindrischen oberen Theils des Sackes in dessen Mittelgegend zeigt sich noch vor der Befruchtung eine nur schwach hervortretende, gegen die Raphe gekehrte Ausstülpung der Membran (F. 3).

Nach Ankunft des Pollenschlauchendes an der Aussenseite der Embryosackspitze streckt sich das deren Innenwand am tiefsten angeheftete Keimbläschen (F. 4) zu einem Embryonalschlauche von sehr beträchtlicher Länge (F. 5). Während derselbe zu dem weiteren Theile des Embryosackes herabsteigt, entwickelt sich die kurze Ausstiilpung an der Miindungsstelle der engen Embryosackhälfte in die weitere zu 
einem umfangreichen blinddarmartigen Fortsatze, der tief in das Gewebe des Integuments nach der Anheftungsstelle des Eychens hin eindringt (F. 5). Ist die Spitze des Embryonalschlauchs an der Einmündung dieser Ausstülpung vorbei gewachsen, so trifft sie auf das, die bauchige untere Hälfte des Embryosacks ausfullende Endosperm: eine cylindrische Masse, zusammengesetzt von einer einfachen Längsreihe scheibenförmiger Zellen (F. 5), der Nachkommenschaft einer wiederholt quer getheilten einzigen Urmutterzelle. Während dieses Gewebe durch lebhafte Zellvermehrung nach allen Richtungen an Umfang und Zellenzahl rasch zunimmt, dringt die Spitze des Embryonalschlauchs in dasselbe ein, und bildet sich bald zum Embryokügelchen um (F. 6).

Der innere Bau des Eychens, und die Entwickelung des Embryo der Cajophora lateritia sind dem der Loasa tricolor ibereinstimmend.

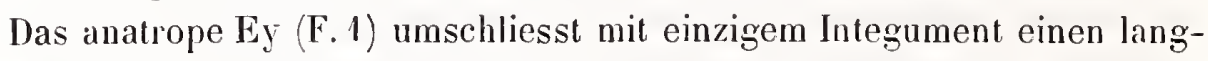
gestreckten, in der Mitte stark eingeschnürten Embryosack. Im Scheitel der oberen Erweiterung haften die zwei bis drei Keimbläschen, deren eines, nach der Befruchtung zu einem langen Embryonalschlauche umgebildet, in die untere, vom Endosperm erfullte Erweiterung des Sackes herabıächst, zwischen die Zellen des Endosperms eindringt und den Embryo entwickelt. Gleich den Eychen von Loasa und Bartonia enthält auch das von Cajophora trotz beträchtlichen Umfanges kein Gefässbündel; - auch in dieser Beziehung eine Uebereinstimmung mit den Eychen der Orobancheen, Scrophularineen, Plantagineen und Labiaten zeigend. 
Neue Beiträge zur Kenntniss d. Eubryobildung d. Puanerogamen. 643

\section{XXI.}

Bartonieen.

\section{B a to nia a urea Lindl.}

Taf. XXVII. F. 7-11.

Bereits in einer früheren Veröffentlichung ${ }^{*}$ ) habe ich die auffallenden Eigenthümlichkeiten der Entwickelung des Eychens von Bartonia aurea geschildert. Der Einbryosack, der frühzeitig die uibrigen Zellen des Eykerns verdrängte, entwickelt nach Bildung der Keimbläschen eine scheitelständige, umfängliche, einen Zellenkern enthaltende, weit hinauf in den bauchig sich erweiternden Mikropylekanal reichende Ausstülpung. Die neuerdings mehrfach mir gelungene Freilegung des unverletzten unbefruchteten Embryosacks hat gezeigt, dass an der Verbindungsstelle der Ausstülpung mit dem urspriinglichen Raume des Sackes eine Querscheidewand sich befindet, unterhalb derer die Keimbläschen, deren in der Regel nur zwei vorhanden**), der Seitenwand des Sackes anhaften. Es unterliegt keinem Zweifel, dass diese meist etwas schräge Scheidewand sehr früh, gleich nach dem ersten Hervorsprossen der Aussackung ${ }^{* * *}$ ) gebildet wird. Der Unterschied der Entwickelung des Embryosacks von Bartonia von der des gleichen Organs von Loasa und Cajophora, das auch ein sehr beträchtliches nachträgliches Längenwachsthum des Scheitels zeigt, bei dem aber die Keimblaschen in dem Scheitel der auswachsenden Fortsetzung mit empor gehoben werden, lảsst sich kurz so ausdrücken, dass bei Cajophora und Loasa das Längenwachsthum der Membran der Embryosackspitze ein intercalares ist, auftretend in einer dicht unter dem Scheitel und den Ansatzstellen der Keimbläschen gelegenen cylindrischen Zone; bei Bartonia dagegen ein rein apicales.

Bei Freilegung des Embryosacks von Bartonia aurea wird Protoplasma und Zellenkern der Keimbläschen durch den auf diese zarten

*) Hofmeister, Entstehung des Embryo. Leipzig 4849, S. $38 \mathrm{ff}$.

**) vergl. a. a. O. Tf. II. F. $37-40$.

***) a. a. 0 . Tf. II. F. 35 . 
Zellen unabsichtlich geübten Druck in der Regel ausgetrieben. Dic Membranen bleiben gleichwohl schr deutlich kenntlich (F. 7 - 9), aber sie nehmen einen merkliclı kleineren Raum ein, als bei den unverletzten Keimbläschen. Dieser Umstand verdient Beachtung als ein Bewcis für die Elasticität der Membranen der unbefruchteten Keimbläschen, und für den von ihrem Inhalt auf die Haut geübten Druck. -

Das Pollenschlauchende, noch während der Frische der Blumenkrone in Eymunde anlangend, drängt sich scitlich an der langen, scheitelständigen Ausstülpung des Embryosackes vorbei $($ F. 1)*); bis scine Spitze etwas unterhall der Scheidewand anlangt, welche den ursprünglichen unteren Theil des Sackes von jener Aussackung trennt. Hier haftet die Pollenschlauchspitze der Aussenwand des Sackes an; bald inniger, bald lockerer, und in der Regel, wie auch anderwärts, an einer anderen Stelle als auf der Aussenseite der Beruhrungsstelle der Embryosackhaut mit dem zu befruchtenden Keimbläschen (F. 10, 11). Das untere Keimblasschen verlängert sich darauf zum kurzen Embryonalschlauche, während das obere verschwindet, und durch wiederholte Zweitheilung des ganzen Raumes des Embryosaclis unterhalb der über den Keimblaschen ausgespannten Querwand das Endosperm angelegt wird. - In Betreff der weiteren Entwickelung des Embryo und Sameus verweisc ich auf meine mehrerwälnnte frühere Arbeit.

*) Früher hatte ich angegeben (a. a. O. S. 39) der Pollenschlatuch dringe in diese Ausstülpung ein. Dies war ein Irrthum, hervorgerufen durch unvollsländige Freilegung des Embryosackes. 


\title{
Erklärung der Abbildungen.
}

\author{
Tafel I.
}

Loranthus europaeus.

F. 1. Längsdurchschnitt der Anlage eines weiblichen Blüthenstandes, Mitte Juli des Jahres vor der Blüthe. In den Achseln der Deckblätter $b b$ stehen die Anlagen der Blüthen a $a$ von Form flacher, oberseits schwach vertiefter Warzen aus kleinzelligem, gleichartigem Gewebe. Vgr. 25.

- 2. Stück einer solchen Inflorescenz, einen Monat später, in perspectivischer Ansicht. $c$ die Calyculus genannte wulstförmige Wucherung des' Parenchyms des Blüthenbodens; $p$ Perigonialblätter. Vgr. 10.

- 2b. Ansicht von oben einer der Blüthen dieser Inflorescenz. Inmitten der zusanmen neigenden 6 Perigoniatblätter zeigen sich die 6 sterilen Staubfäden (S. 539) Vgr. 20.

- 3. Längsdurchschnitt einer solchen Blüthe; $c$ Calyculus, $p$ Perigonialblätter, $s$ sterile Stamina, $v$ fortwachsendes Ende der Blüthenachse. Vgr. 50.

- 4. Längsdurchschnitt einer weiblichen Blüthenknospe, Ende Aprils (1852). Zu den in den vorigen Abbildungen bemerktichen Organen sind noch die 3 Carpelte $(c a)$ hinzugekommen, deren eines (rechts) vom Schnitle in seiner Mittellinie getroffen ist. Diesem gegenüber geht der Schnill durch die bereits verwachsenen Seitenränder der beiden anderen Carpelle (bei $\left.c a^{\prime}\right)$. Unterhatb der Einsenkung, welche die Carpelle umstehen, ist der halbmondförmige Durchschnitt der meniskenförmigen Gewebsstelle mit lufterfültten Intercellularräumen sichtbar, welche die Chataza bezeichnet. Vgr. 30 .

- 5. Der Grund jener Einsenkung (das noch in Zeltenvermehrung und Wachsthum begriffene Ende der Blüthenachse), in 120facher Vgr.

- 6. Aehnliches Präparal, wie. F. 4, 9 Tage später, bei weiter vorgerüchter Verwachsung der Carpelle unter sich. Vgr. 40:

- 7. Längsdurchschnitt einer weiblichen Blüthenknospe, an 12 Mai. Zwischen den bereits beträchtlich verläıgerten: und an den Rändern verwachsenen Carpellen hat das Ende der Btüthenachse zu einem flach kegelförmigen Wärzchen sich erhoben. Vgr. 10.

- 8. Dieses Ende dér Blülhenachse in 80 facher $\mathrm{Vgr}$. 
F. 9. Lïngsdurchschnitt (welcher keinen der sterifen Staubfillen traf) einer solchen Knospe, am 20. Mai. Der Griffelkanal ist noch offen. Vgr. 20.

- 10. Ein Theil des Gewebes oberhalb der halbmondförmigen dunkeln Stelle ch (der Chalaza) der vorigen Figur, der Art präparirt, dass die unteren Enden der be reits lang gestreckten Embryosäcke frei gelegt wurden. Vgr. 80 .

- 11. Längsdurchschnittene weibliche Knospe am 28. Mai, dem Grilfelkanal entlang der Art auseinander gelegt, dass Lage und Grösse der zwei Embryosäcke $e$ deutlich wird. Vgr. 9.

- 12. Eine dem Aufbrechen nahe Knospe (vom nämlichen Tage) im Längsdurchsclınitt. Der Griffelkanal von den verfizten papillös geworlenen Zellen seiner Wandung bereits verschlóssen, doch noch kenntlich. Die Embryosäcke $(c)$, sehr gestreckt, liegen in einer spindelförmigen Masse durchscheinenderen Gewebes. Vgr. 18.

- 13. Das freigelegte obere Ende des Embryosacks, zwei Keimbläschen enthaltend, aus einer Knospe ähnlicher Entwickelung. Vgr. 160.

\section{Tafel II.}

\section{Loranthus europaeus.}

F. 1. Querdurchschnitt einer Anthere, Ende April. Vgr. 25.

- 16. Ein Fach der in voriger Figur dargestellten Anthere in Täfacher Vgr.

- 2. Perigoniallhlatt einer aufgeblühten weiblichen Blïthe von innen gesehen; $s$ der sterile Staubfaden. Vgr. 15.

- 3. Anthere, einer dem Oeffnen nahen männlichen Blüthe entnommen, Seitenansicht. Vgr. 15.

- 4. Eine solche, quer durchschnitten. Gleiche Vgr.

- う.ti. Perigonialblätter männlicher Blüthen, aufgesprungene Antheren tragend, von der Seite gesehen. Vgr. 15.

- 7. Reifes Pollenkorn. Vgr. 120.

- \&. Längsdurchschnill einer männlichen Blälhenknospe, Ende April. c Calyculus, $p$ Perigonialblätler, $s$ Stauhfäden, ca Carpelle, bereits zum fehlschlagenden Pistill verwachsen. Vgr. 30 .

- 9. Aehnliches Präparat, Anfang Mai. Gleiche Vgr.

- 10. Lingsdurchschnitt einer weiblichen Blüthe am 8. Juni, zur Zeit da die Perigonialblätter welken und abzufallen beginnen. Der Griffelkanal unkenntlich. e Embryosäcke. Vigr. 22.

- 11. Ein Embryosack aus einer eben geöffneten Blüthe (Anfang Juni) röllig frei gelegt. Im erweiterten oberen Ende ist ein Keimbläschen sichtbar. Rechts haftet diesem Embryosacke ein Bruclıstïck eines zweiten, kürzeren an. Vgr. 180.

12. Drei Embryosäcke aus einer anderen Blüthe gleicher Entwickelung; in grösseren Theile ihrer Länge frei gełegt, gegen den Grund hin durch das angränzende Zellgewebe zusammen gehalten. Vgr. 180. 
Tafel III,

\section{Loranthus emropaeus.}

F. 1. Aus einer oben geöffneten Blïithe, Längsdurehsehnitt der von durchseheinendem Gewebe erfüllten axilen Gegend des Germen (des mit den Innenflïelien der Carpelle verwaelısenen Eyes). $e$ ein von den Schnitten blosgelegter Embryosack; - ch Chalaza.

- 2. Unterer Theil des Embryosaeks aus einer Blüthe mit welkenden Perigonialblättern (am 13. Juni), beim Präpariren vom oberen Ende abgerissen. Aus der Rissstelle ragt ein Stück des bereits zweizelligen Vorkeims hervor; vielleieht aus seiner natürlichen Lage rüekwärts geschoben. Im unteren Ende des Embryosacks die einzige Mutterzelle des Endosperms. Vgr. 250.

- 3. Ein Stüek des Pollenschlauchs, nebst einigen der Wandzellen des obiiterirten Griffelkanals, frei präparirt. Vgr. 120.

- 4. Embryosack aus einem befruehteten Germen (bei Abfall der Perigonialblätter am 15 . Juni) frei gelegt. Dem unteren Ende nahe haften einige der benachbarten Zellen, zum Theil langgestreekte, zum Theil fast eubische, der Aussenflïebe des Saekes an. $k$ das zum langen Embryonalschlauche gestreckte befruehtete Keimbläschen; $e d p$ Endospermzellen. Vgr. 150.

- 5. Aehnliches Präparat. Dem Scheitel des Sackes haftet das Pollenschlauehende an. Vgr. 150 .

- 6. Embryosack aus einem befruchteten Germen, am 20. Juni frei gelegt. Am Gipfel des Sackes haftet das Pollenseblauehende. Die Endospermzellen quer getheilt. Vgr. 150. Perspeetivisehe Ansicht; die Umrisse des Vorkeims innerhalb des Endospermkörpers sind in punktirten Linien angedeutet.

- 7. Eín Stück einer längsdurchsehnitlenen weibliehen Blüthe, am 15. Juni. Die eine Lüngshälfte des Griffels, dessen Kanal von den zwei Parallelschnitten gestreift wurde, ist entfernt. Man sieht den Pollenschlauch $t$ im Zusammenhang mit dem, im Griffelkanale weit empor gedrungenen Scheitel des Embryosacks $e$. Der untere Theil des Germen ist gänzlich entfernt. Auf der Narbe liegen Pollenkörner $g$. Vgr. 30.

- 8. Seheitel eines Embryosacks, mit dem ihm anhaftenden, ein Stüek rüeklïufigen Pollenschlauehende $t$. Der Embryonalschlaueb $k$ häingt aus der Oeffnung des abgerissenen Sackes ein Stück lervor. Vgr. 200.

- 9. Der untere, erweiterte, mit Endosperm erfüllte Theil eines Embryosaekes nebst einem Stücke des ihn überragenden cylindriseben Theiles, am 2. Juli frei gelegt und von aussen gesehen. Die Umrisse des durehschimmernden, zum Vorkeim umgewandelten Embryonalschlauches sind in punktirten Linien angegeben. Vgr. 150.

- 10. Aehnliehes Präparat, am nämlichen Tage einem etwas weiter entwiekelten Germen entnommen, im Läıgssehnitt. Gleiche Vgr. 


\section{Tafel IV.}

\section{Loranthus europaeus.}

F. 1. Der wenigzellige, das untere Ende eines befruchteten Embryosackes ausfüllende Endospermkörper im Längsdurchschnitt. Er ist durchzogen von dem Vorkeime $k$, dessen untere, angeschwollene, durch das Endosperm bis auf die Haut des unteren Embryosackendes gedrungene Extremität in einer Protoplasmaansammlung zwei Zellenkerne zeigt. Am 3. Juli 1853 präparirt. Vgr. 150.

- 2. Aehnliches Präparat, am 12. desselben Monats dargestellt. Gleiche Vgr.

- 3. Aehnliches Präparat, einem etwas weiter vorgerückten Eychen am nämlichen Tage entnommen. Das angeschwollene untere Ende des Vorkeims ist bereit. mehrzellig. Vgr. 120.

- 4. Längsdurchschnitt durch das vom Endosperm erfüll'e erweiterte untere Ende eines Embryosacks, nebst dem umgebenden Gewebe des Germen, am 21. Juli. Die Vermehrung der Zellen des Endospermkörpers ist am oberen Eude desselben einseitig stärker, so dass der cylindrische, vom Embryoträger durchzogene obere Theil des Embryosacks, $f$, zur Seite geschoben erscheint. Der untere, dicke Theil des Vorkeims besteht aus vier Längsreihen von Zellen. ch isı die Gewebspartie, welche der Chalaza des Eychens entspricht. Vgr. 90.

- 4b. Der Vorkeim und die ihın angränzenden Zellen des Endosperms der vorigen Figur, 180 fach vergrössert.

- 5. Längsdurchschnitt eines jungen Samens, am 30. Juli, in 16 facher Vgr. Die vom Endosperıkörper $e d$ aufwärts verlaufende dunkle Linie $f$ ist der cylindrische Theil des Embryosacks, welcher auch hier (und in der folgenden Figur) zur Seite geschoben erscheint. Vgr. 20.

ăb. Der Vorkeim, nebst einigen Endospermzellen aus demselben Präparate, 60 fach vgr. Eine (die vorderste) der vier Längsreihen von Zellen des Vorkeims ist iı Anlegung des Embryokügelchens hegriffen.

- 6. Längsdurchschnitt einer jungen Frucht am 23. August. Vgr. 10.

- 6b. Eyweisskörper, Embryo und Chalaza $(c h)$ aus einem dem vorigen gleich entwickelten Germen gelöst, lïngsdurchschnilten und $40 \mathrm{mal} \mathrm{vgr}$.

- 7. Eyweisskörper im Längsdurchschnitt aus einer etwas weiter vorgerückten Frucht; - der Embryo ist bereits vom Endosperm wieder eingeschlossen. Seillich am Embryoträger ist eine der drei Längsreihen von Zellen des Vorkeims bemerklich, in deren Endzellen die Zellvermehrung nach den drei Richtungen des Raums nicht eintrat. Vgr. 60.

- 8. Aehnliches Präparat, am 1. Sptbr. ch Chalaza. Ygr. $1 \%$.

9. Embryo aus einer reifen Frucht (29. Sptbr.) im Längsdurchschnitt / Embryoträger: $r$ die im Radicularende eingeschlossene (endogene) Wurzel. Vgr. 10. 
Tafel V.

\section{Viscum album.}

F. 1. Ein weiblicher Blïthenstand, Anfang März (1830), im Längsdurchschnitte durch die Medianen des unter ihm stehenden Paares von Laubblättern, 3fach vergrössert. $/ l$ sind die Stiele dieser Laubblätter, $x$ die in ihren Achseln stehenden, zur Entfaltung während des bevorstehenden Sommers bestimmten Sprossen; $d$ die längsdurchschnittenen beiden Bracteen der terminalen Blüthe. (Die lateralen beiden anderen Blüthen der armblüthigen Traube sind vom Schnilte nicht getroffen.) Vgr. 3.

- E. Einer der in den Achseln der Laubblätter Anfang März stehenden Sprossen, die in der vorhergehenden Figur mit $x$ bezeichnet sind, im Längsdurchschnilt parallel zur Fläche seiner und der Laubblätter des Tragblatts (rechtwinklig zum Längsschnitt der in der voraufgehenden Figur die Sprossen $x$ (raf). aa die schuppenförnigen, rechts und links vom Sprosse slehenden Vorblätter desselben'; $b$ das eine Laubblatt, von der Fläche gesehen; $c$ die unteren Bracteen des zur Blüthe gelangenden Sprossendes, in deren Achseln die zwei seitenständigen Blüthen derTraube entstelıen werden. Mit $x$ ist die Stelle bezeichnet, an welcher (der Schnittfïche abgewandt) die Anlage des zur Entfaltung im ¿weitnächsten Jahre bestimmten Sprosses in der Achsel des Laubblatts $b$ sitzt. Vgr. 30 .

- 2b. Die Spitze der Endknospe dieses Prïparats, 200 fach vergr. Die Gränzen der dem genau axilen Schnitte von unten her zunächst angränzenden Zellen sind in zarteren Linien angegeben.

- 3. Längsdurchschnitt, gleichsinnig dem vorigen, durch den Theil oberhalb der Laubblätler eines in der Entfaltung begriffenen diesjährigen Sprosses, am 1. Nai (1850). yy die Anlagen der beiden axillaren Blüthen; $d$ eine der Bracteen der terminalen, deren Anlage, der Scheitel des Stengelendes, jetzt als schwach vertiefte Fläche erscheint (Beginn der Bildung der Perigonialblätter). $c c$ hat die Bedeutung wie in voriger Figur. Gleiche Vgr.

- 4. Längsdurchschnitt derselben Theile, rechtwiuklig zu den beiden vorhergehenden, am 9. Mai desselben Jahres. $x$ die Anlagen der zur Entfaltung in nächsten Jahre bestimmten Sprossen mit ihren von der Fläche gesehenen Vorblättern. Bedeutung der übrigen Buchstaben wie vorher. $\mathrm{Vgr} .15$.

- 5. Längsdurchschnitt rechtwinklig zu diesem, gleichsinnig dem in F. 2 und 3 dargestellien, derselben Theile am 17. Juni desselben Jahres. Bedeutung der Buchstaben wie bei F. 3. Die Mitle des Stengelendes (Anlage der terminalen Blüthe) jetzl wieder convex, die äusseren Perigonialzipfel schon angedeutet. Noch deutlicher treten sie an den durchschnittenen seitlichen Blüthen $y$ hervor. Vgr. 30 .

- br. Eine solche seitliche Blüthe, auf derselben Entwickelungsstufe, gleichsimnig zu dem vorhergehenden Schnitte längs durchschnitlen. Man sieht einen der äusseren Perigonialzipfel von der Innenfläche: die beiden inneren sind rom Schnitle getrofen. Vgr. 200. 
F. 6. Dieselben wie die F. 5 dargestellten Theile, im in gleicher Weise geführten Längsdurchschnitte am 24. Juni. Vgr. 20.

- 7. Dieselben, in zu diesem rechtwinkligem Durchschnitte am 2. Juli. Vgr. 10.

\section{Tafel VI.}

\section{Viscum album.}

F. 1. Dieselben Theile wie F. 3-7 der vorausgehenden Tafel, im Längsdurchschnitt paraliel den Flächen des Laubblätlerpaares dieses Sprosses, rechtwinklig zu den Schnilten F. 4, 7, gleichsinnig denen F. 3, 5, 6 der Tafel V, an 2. Juli. Die Endblïlhe ist vom Schnitte nur gestreift, so dass ihre vier Perigonialzipfel in perspectivischer Ansicht vorliegen. Vgr. 20.

- ?. Männliche Inflorescenz, zur nämlichen Zeit in gleicher Richtung längsdurchsclinitten. Vgr. 5 .

- 3. Weibliche Endblüthe, am 1'. Juli längsdurchschnitten. Innerhalb der beiden äusseren Perigonialzipfel sind zwei kleine Höcker sichtbar, die Carpelle. Der Schnitt ist rechtwinklig zum vorigen. Vgr. 36.

- 3b. Spilze eines der Perigonialzipfel der vorigen Figur. Vgr. 180.

- 4. Weibliche Endblüthe, am 3̈. August längsdurchschnitten. Vgr. 30.

- 5. Narhe und axiler Theil des Germen einer solchen, am 10. August (1849); durch und durch noch aus gleichartigem Gewebe bestehend. Vgr. 150.

- 6. Laterale weibliche Blüthe, am 28. Septbr., im Längsschnitt. Die Umrisse des axilen durchsichtigeren Gewebes, welches die Embryosäcke einschliesst, sind angedeutel. Vgr. 20.

- 7. Weibliche Inflorescenz im Längșdurchschnitt parallel den Flächen der Laubbłätter, Anfang October. Vgr. 8.

- 7b. Embryosack aus einer der seitlichen Blüthen dieses Präparats, frei gelegt. Er zeigt zwei völlig ausgebildete Keimbläschen. Ygr. 150.

- 8. Längsdurchschnill der axilen Gewebmasse eines Germen am 12. Fbr. (1849). Der Schnitt hat die beiden Embryosäcke gestreift, so dass ihre Umrisse deutlich wabrzunehmen sind. Nicht nur die Keimbläschen, sondern auch ihre Gegenfüsslerzellen sind vorhanden. Ygr. z̈0.

- 86 . Das verjüngle untere Ende eines solchen Embryosacks frei präparirt (des rechts gelegenen). Vgr. 200.

- 8c. Dasselbe mit Clılorcalciumlösung behandelt. Der Inhalt der Gegenfüisslerzelle hat sicls contrahirt.

9. Das obere Ende eines am 14 . März frei präparirten Embryosacks, mit drei derbwandigen Keimbläschen. Vgr. 200.

\section{Tafel VII.}

Viscum album.

1. 1. Ein an 12. April (1849) freipräparirter Embryosack mit zwei Keimbläschen in Mikropyle-Ende, der Gegenfïsslerzellen derselben entbelıend. Neben ilın 
sind die Umrisse des anderen Embryosacks desselben Germen angedeutet, in der Lage zu dem vollstïndig gezeichneten, wie sie vor der Freilegung des letztereı in dem nur durch Schnitte dargestelten, noch nicht mit der Nadel zergliederten Prïparate war. Vgr. 200.

F. 2. Embryosack (unbefruchteter) am 19. Hai (1849) frei präparirt. Er enthält drei dünnwandige Keimbläschen. Vgr. 300 .

- 3. Vor Kurzem befruchteter Embryosack, am 9. Mai (1852) frei präparirt. Das untere (befruchtete) der zwei Keimbläschen erscheint etwas verlängert; der Raum des Embryosacks durch zwei Querwände in drei Zellen getheilt. Vgr. 50.

- 3b. Der obere Theil des vorigen Pröparals in 200 facher Vgr.

- 4. Vor ganz Kurzem befruchteter Embryosack, ann 21. Mai (1856) frei präparirt (das untere Ende des Sackes ist bei der Präparation abgerissen). Der Raum des Embryosacks durch eine Querwand in zwei Zellen getheilt. Der Pollenschlauch triff mil einem kurzen seillichen Fortsatze auf die Aussenseite eines der Tüpfel des Embryosackscheitels, und verlïuft dann mil rechtwinkliger Bieguug weiter, um zugerundet zu enden. Unter jenem Tüpfel das, obere, unbefruchtet gebliebene Keimblischen, bereits etwas zusammengeschrumpft und von grumösem Aussehen. Dahinter und etwas tiefer das befruchtete, nit grossem Zellenkern und einer Anordunng des Protoplasma zu von diesem Kern ausstrahlenden Strïngen. Vgr. 200.

- 46 Die Scheitelgegend dieses Embryosacks nebs! den Keimbläschen und dem Pollenschlauchende, כ̋00 fach vergrössert.

- 4c. Dasselbe Präparat, un $120^{\circ}$ un seine Läıgsachse gedreht. Vgr. 200.

- 5. Das obere Ende eines zur nämlichen Zeit frei gelegten befruchteten Embryosacks mit bel'ruchtetem und zwei unbefruchteten Keimblïschen, welche letztere in die über die Aussenfläche des Enbryosacks vorragenden, die Tüpfel desselben verschliessenden Häutchen hinein reichen. Der Pollenschlauch ist abgetreunt. Vgr. 500.

- 6. Aehuliches Präparat, mit dem einzigen Tüpfel des Embryosacks anhaftendem Pollenschlauchende. Die oder das unbefruchtete Keimblisschen ist bereits verschwunden. Gleiclıe Vgr.

\section{Tafel VIII.}

\section{Viscum albums.}

F. 1-6. Obere Enden befruchteter Enbryosicke, rom 21. bis 25. Nai $\langle 1856 ;$ frei präparit, und 200 mal vergrössert, um die verschiedenartige Weise des Antretens des Pollenschlauchs zu zeigen. $t$ Pollenschlauchende; $k$ unbefruchtete, $k^{\prime}$ befruchtete Keimbläschen, $p$ Tüpfel der Embryosackhaut. F. 6 und $6 b$ sind die durch einen Längsschnitt getheilten beiden Hälften eines und desselben Embryosacks, vou innen gesehen.

- 7. Befruchteter Embryosack, am 27. Mai (1849) frei präpariri. Vor. 250.

- 8. Stiick des Pollenschlauchs, aus dem Narbengewcbe desselben Germens heraus präparirt. Vgr. 250. 
F. 9. Aehnliches Präparat, einen Tag später frei gelegt. Gleiche Vgr.

- 9b. Das von diesem Embryosack unverletzt abgelöste Pollenschlauchende.

- 10. Aéhnliches Präparat, am 9. Mai (1852) dargestellt. Vgr. 200.

- 11. Oberes Ende eines Embryosacks, in welchem das befruchtete Keimbläschen abnormer Weise sehr fern vom Scheitel des Sackes an der Wand desselben sitzt. Vgr. 200.

- 12. Befruchteter Embryosack, in welchem die Zellenvermebrung des oberen Endes in Richtung der Dicke schon weiter vorrückte, am 9. Nai 1852 frei gelegt. Vgr. 200.

- 13. Embryosack, am 16. Juni desselben Jahres frei präparirt. Vgr. 200.

- 14.15. Obere Enden längsdurchschnittener befruchteter Embryosäcke, am 3. Juli 1831. Vgr. 200. e Embryo.

Tafel IX.

\section{F. 1-6. Lepidoceras Kingii (nach Herbarienexemplaren).}

F. I Längsdurchschntt eines $1 \frac{1}{2}$ M.M. langen Germen, ron dem vermuthlich ganz vor Kurzem erst die Perigonialblätter abfielen, 30 fach vergrössert. Das lange, konische aufrechte Ey $g$ ist von lockerem weitzelligem Gewebe $v$ umgeben. Im Grunde des Eychens sind 3 Embryosäcke $e$ bemerklich.

- 2. Ein solches Germen quer durchschnitten. Gleiche Vgr.

- 3. Aehnliches Prïparat aus einem weiter entwickelten Fruchtknoten. Das Gewebe $v$ der vorigen Figur ist nicht mehr vorbanden; ein Hohılraum umgiebt das Ey. Die bleibende Fruchthnotenwand hat sich zu drei Gewebschichten differenzirt. Die innerste, $a$, ist eine einfache Lage von Zellen mit verdickten Wänden. Die mittlere, $b$, besteht aus langgestreckten engen Zellen mit sehr hygroskopischen Wandungen. Die äusserste, $c$, ist derbes Parenchym. Vgr. 30.

- 4. Der in seinem unteren Theile von Endosperm erfüllte Embryosack aus dem vorigen Präparate, frei gelegt, mit Embryoträger. und Embryo k. Vgr. 90.

- 5. Längsdurchschnitt eines ziemlich reifen Samens. $k$ Embryo; ed Endosperm (eine dïnne, nur aus zwei Zellenlagen bestehende Gewebschicht); übrige Buchstaben haben die Bedeutung wie bei F. 3. Die Aussenfläche der Frucht ist stark runzelig; im Leben vermutblich etwas fleischig. Vgr. 10.

- 6. Ein Theil des vorigen Präparats in 150 facher Vgr. $k$ die Epidermis des Embryo (an der Einfügungsstelle des Kotyledon links); Bedeutung übriger Buchstaben wie bei $F$.

\section{F. 7-10. Myzodendron quadriflorum (nach Herbarienexemplaren).}

- 7. Längsdurchschnilt einer weiblichen Blüthe, bald nach erfolgter Befruchtung. $s$ Griffel. $b r$ Bractee, $p l$ Samenträger; $g g$ zwei der drei Eychen. Vgr. 30.

- 8. Samenträger mit zwei Eỵchen (das dritte liegt nach hinten) aus einem Germen ähnlicher Entwickelung. Das Eychen $g$ (links) ist unbefruchtet; der Embryosack $e$ eingesclılossen. An dem Eychen $g^{\prime}$ ('rechts) hängt ein Pollenschlauch $t$; 
der befruchtete Embryosack $e$ ist hervorgetreten und zeigt die Umrisse einiger Endospermzellen. Vgr. 150.

F. 9. Lảngsdurchschnitt einer ziemlich reifen Frucht. k Embryo, $e$ Endosperm; Bedeutung der übrigen Buchstaben wie bei F. 7. Vgr. 1 oี.

- 10. Samenträger mit längsdurchschnittenem Samen aus einer Frucht gleicher Entwickelung frei gelegt. $g$ ein abortirtes Eychen. Gleiche Vgr.

\section{F. I1, 12. Myzodendron linariaefolium (nach Herbarienexemplaren).}

- 11. Junger Embryo, frei präparirt. cc Anlage der Kotyledonen, $p$ Endknospe, $x$ papillös werdende Zellen um das Wurzelendc her; $y$ diese Zellen umgebende Hautfalte. Vgr. 45.

- 12. Reifer Embryo, von einem Längsschnitte gestreift. $r$ Wurzelende, $x$ dasselbe umgebende Haare; $y$ diese Haare einhüllende Hautfalte, $c$ Kotyledonen; die durch deren Masse scheinende, die Endknospe $p$ einschliessende Höhlung ist in punktirten Linien angedeutet. Gleiche Vgr.

(Nach diesen Beobachtungen ist es ausser Zweifel, dass die Entwickelung des Samens von Myzodendron in der gleichen Weise erfolgt, w e die von Thesium.)

\section{Tafel X.}

\section{F. 1-5. Thesium alpinum.}

F. 1. Längsdurchschnitt eines unbefruchteten Eychens mit eingeschlossenem Embryosack $e$ und einem Theil des Samenträgers $p l$, Anfang Juni 1854. Vgr. 150, wie auch der folgenden drei Figuren.

- 2. Längsdurchschnitt eines eben befruchteten Eycheus, aus welchem der Embryosack $e$ hervorgetreten isı, die umhüllende Zellschicht durchbrechend. k zwei Keimbläschen, $t$ Pollenschlauch.

- 3. Etwas weiter vorgerückter Zustand. Der hervorgetretene Theil des Embryosacks vom übrigen durch eine Querwand gescheden und mit Endosperm erfüllt.

- 4. Noch weiter entwickeltes Eychen, ebenfalls im Längsschnitt. Die Embryoanlage bereits dreizellig und stark nach unten gekrümmt. Das zellenleere hiulere Ende des Embryosacks beginnt cinen Fortsatz abwärts in das Gewebe des Samenträgers zu treiben.

- 5. Längsdurchschnitt durch einen jungen Samen nebst Samenträger. $g$ ein unbefruchtet gebliebenes, vom Schnitte nur gestreiftes Eychen. Vgr. 100.

- 6. Thesium intermedium. Längsdurchschnitt eines befruchteten Eychens, dessen Entwickelung zwischen der der beiden vorigen Figuren in der Mitte steht. Vgr. 150.

\section{F. 7, 8. Aristolochia Clematitis.}

- 7. Längsdurchschnitt eines befruchteten Eychens, senkrecht auf desscu Fläche (Anf. August 1853), e Endosperm. Vgr. 30. 
F. 7b. Ein solches Eychen, im Längsdurchschnitt parallel der Fläche, die Lage des jungen Endosperms zu zeigen. 2fach vergrössert.

- 8. Längsdurchschnitt des oberen Theiles des frei gelegten Eykerns, etwas weiterer Entwickelung; von der Fläche (rechtwinklig zum Schnitte F. 7) gesehen. $m$ Kernwarze, $e$ Endosperm, $k$ befruchtetes Keimbläschen. Vgr. 90 .

\section{F. 9-12. Asarum canadense.}

- 9. Längsdurchschnitt eines unbefruchteten Eychens, Anfang Mai (1852). $x$ grosse Zellen, die von einer Lage kleiner Zellen umhüllt das Anhängsel der Raphe bilden. ie äusseres, $i$ in inneres Integument; $k$ Keimbläschen, $a$ Gegenfüsslerzellen derselben. Vgr. 40.

- 9b. Die Scheitelregion des Embryosacks nebst den Keimbläschen desselben Präparats, bei 120 facher Vgr. gezeichnet.

- 10. Ein Embryosack ähnlicher Entwickelung, mit zahlreicheren Gegenfüsslerzellen der Keimbläschen. Vgr. 80 .

- 11. Embryosack mit Kernwarze, welche rom Pollenschlauch $t$ noch nicht völlig durchbohrt ist. Der Raum des Embryosacks erscheint bereits durch eine Querwand in zwei kernhaltige Zellen getheilt. Gegenfüssler der Keimbläschen fehlen. Gleiche Vgr.

- 12. Aehnliches Präparat, etwas weiter vorgerückter Zustand. $t$ Pollenschlauch, $c$ Endosperm, $k$ Keimbläschen, $a$ Gegenfüssler derselben. Vgr. 150.

\section{F. 13-16. Asarum europaeum.}

- 13. Längsdurchschnitt eines hałbreifen Samens, Ende Mai 1853. $x$ Anhängsel der Raphe; $e$ Endosperm; $a$ die vertrocknenden, sehr gewaclssenen Gegenfüsslerzellen der Keimbläsclıen. Vgr. 10.

- 14. Embryo aus eincm solchen Samell, ncbst einigen der angränzenden Endospermzellen frei gelegt. Vgr. 130 .

- 15.16. Embryonen ziemlich reifer Samen, frei gelegt. Gleiche Vgr.

\section{F. 17-23. Cytinus Hypocistis Tommasini.}

- 17.18. Samenträger aus quer durchschnittenen jungen Ovarien, 10 fach vgr.

- 19. Zwei junge Eychen. Längsdurchschnittsansicht. Vgr. 120, wie auch der folgenden Figuren.

- 20. Ein solches. weiter entwickelt.

- 21. Längsdurchschnittsansicht des Kerns eines weiter entwichelten Eychens. in dessen Embryosack die Bildung der Kerne der Keimb]äschen erfolgte.

- 22-24. Derglcichen, von zur Befruchtung bereiten Eychen.

- 25. Pollenkorn; 25̃b ein solches, einen Pollenschlanclı treilentr. 
Tafel XI.

Cynomorium coccineum Mich.

F. 1. Weibliche Blüthe unnittelbar vor der Befruchtung, der untere Theil in Längsdurchschitt, der keines der Perigonialblätter traf und beiderseits an der Einfügung des Griffels vorbei ging, ihn unverletzt lassend. Die durch die Oberhaut des rechtswendig gedrehten Griffels, nach dessen Bleichung mit in wässeriger Salpetersäure gelöstem chlorsaurem Kali und nachherigem Auswaschen mit Ammoniak, durchscheinenden Gefässbündel sind in der Zeichnung durch punktirte Doppellinien ausgedrückt. Auf der Narbe einzelne Pollenkörner, welche Schläuche getrieben haben. $i$ Integument des Eys; $e$ Embryosack, $m$ Mikropyle. Vgr. 30.

- 2. Eine ähnliche Blüthe (letzte Verzweigung eines der Dichasien, ohne alle Perigonialblätter) in genau durch den Griffelkanal gelegtem Längsdurchschnitt. Gleiche Vgr.

- 3. Perspectivische Ansicht eines vor Kurzem befruchteten Embryosacks, völlig frei präparirt. Primordialschlänche der Endospermzellen contrahirt (Folge der Aufbewahrung in Alkohol). So auch bei den folgenden Figuren. $k$ Befruchtetes Keimbläschen. Die dem Objectträger parallelen Längsscheidewände der obersten Endospermzellen schneiden die nach oben gekehrte Aussenfläche des Embryosackes etwas unterhalb des Scheitels desselben. Vgr. 210.

- 4. Oberer Theil eines etwas weiter entwickelten, frei prïparirten Embryosacks, mit anhängendem Pollenschlauchende $(t)$. Vgr. 1300.

- 5. Ein Theil des Integuments, mit der Mikropyle $m$ im Längsschnitt, darunter einige Zellen vom Scheitel des Eykerns; unter diesen der von ihnen los präparirte obere Theil des befruchteten Embryosackes e, der mittelst des ihm anhaftenden Pollenschlauchendes $t$ an jenen Zellen der Kernwarze lose hängt. $k$ das befruchtete Keimbläschen, noch einzellig. Vgr. 120.

- 6. Längsdurchschnitt eines befruchtteten Germen. Zwei Perigonialblätter, ein völlig entwickeltes $(a)$ und ein rudimentäres $(b)$ sind vom Schnitte getroffen. Vgr. 30.

- 7. Oberer Theil eines frei präparirien Embryosacks, der während des Freilegens zerriss. Durch das mit dem Präpariren verbundene Zerren und Quetschen wurden die Endospermzellen aus dem Verband unter sich und mit der Embryosackhaut gelöst; auch aus dem Risse derselben zum Theil hervorgetrieben. Drei derselben sind sichtbar, zwischen ihnen die dreizellige Embryoanlage $k$. Vgr. 250 .

- 8. Oberer Theil eines frei präparirten Embryosacks mit vierzelliger Embryoanlage. Vgr. 1 \%0.

- 9. Oberer Theil des Eykerus nebst befruclttetem Embryosacke in Längsschnitt. Bedeuturg der Buclistaben wie vorher. Vgr. 120. 


\section{Tafel XII.}

\section{Langsdorffia hypogaea Mart.}

F. 1. Der Theil eines zarten Längsdurchschnitts einer weiblichen Inflorescenz, welcher einer axil vom Schnitı getroffenen weiblichen Blüthe entspricht. Im oberen, zellig gezeichneten, wachshaltigen Theil des Germen ist etwas Substanz der Nachbarblüthen mit gezeichnet. c Fruchtknotenhöhle. s Griffelkanal. Vgr. 30 .

- 2. Oberes Ende und Griffel einer solchen Blüthe, im Läıgsdurchschnitt. z Cuticula, $y$ verdickte, $x$ dünnwandige Prosenchymzelten. Vgr. 200.

- 3. Sehr zarter Längsschnitt aus einer solchen Blüthe, Gegend der Fruchtkıotenhöhle. Die Zellen derselben sind zum Theil mit der Präparirnadel entfernt, um die Anheftung des Eys deutlicher zu zeigen. $e$ Ey (= Embryosack); $f$ dessen Stielzelle. Vgr. 250 .

- 4. Der gleiche Theil des Längsdurchschnitts einer andern Blüthe, nach Behandlung mit kalter Salpetersäure in der chlorsaures Kali gelöst, und Ammoniak. Bedeutung der Buchstaben die gleiche. Gleiche Vgr.

- 5. Befruchteter Embryosack, halb frei präparirt. Gleiche Vgr.

- 6. Aelunliches Präprarat, gleiche Vgr. $t$ Pollenschlauch, $k$ befruchtetes Keimbläschen.

- 7. Der einer einzelnen Frucht entsprechende Theil eines Längsschnitts durch den reifen Fruchtstand. $p t$ Steinschale, edp Endosperm, e Embryo, $s p$ dessen Träger. Vgr. 50 .

- 8. Oberer Theil eines lïngsdurchschnittenen reifen Endospermkörpers (Sanıens). Der Trïger des Embryo biegt sich über der Stelle, wo die punklirte Linie ihn triff, nach abwärts und ist der dem Objectiv' abgekehrten Wand des Embryosacks angesetzt. Ygr. 200.

\section{Tafel XIII.}

\section{Sarcophyte sanguinea Sparrm.}

F. 1. Längsdurchschwitt einer weiblichen Blütlıe kurz nach der Bestäubung. s Griffelkanal, g Fruchtknotenhöhle, o Eychen. Igr. 50.

- 1b. Fruchthnotenhöhle und Eychen der vorigen Figur, in 350 facher Vgr. t Pollenschliuch, $k$ Keimbläschen.

- 2. Aehnliches Präparat aus einem anderen Germen in gleicher Vgr.

- ․ Fruchthnoten mit zweificherigem Germen im Längsdurchschnilt. Vgr. 35.

- 4. Reife Frucht im Längsdurchschnitt. edp Endospern, $c$ Embryo, $p$ Steinschale. Vgr. 10.

- 5. Aehnliches Präparat. Vgr. 20.

- 6. Sane im Längsdurchschnitt, parallel den breiten Flächen. Igr. 30.

- 7. Embryo nebst Stück seines Trägers und einigen Endospermzellen aus einem anderen längsdurchschnitlenen Samen. Der Embryo zeigt Andeutungen zweier Kotyledonen. Ygr. 150. 
F. 8. Längsdurchschnitt eines dreikantigen, schlanken Sanens. Vgr. 60.

- 9.10. Stïcken der Steiuschate nornirler Früchte im Längsschnitt. Vgr. 300.

- 11. Verholzter Scheinsame im Längsdurchschnitt. Vgr. 40.

\section{Tafel XIV.}

F. 1-3. Balanophora dioïca R. Br.

F. 1. Sehr junges Germen, von einem Längsschnilt getrotren. Vgr. 300.

- 2. Ein solches, von aussen gesehen. Die Anfangszelle des Eys scheint durch. Gleiche Vgr.

- 3. Spitze des Grilfels einer solchen, Durchschniltsansicht. Gleiche Vgr.

\section{F. 4, 5. Balanophora fungosa Forst.}

- 4. Junges Germen, von aussen geselıen. Gleiche Vgr. 200.

- 5. Monströses Germen, mit zwei Griffehn. Aus der nämlichen Inflorescenz wie F. 4. Vgr. 200.

\section{F. 6-8. Balanophora involucrata Hook. f.}

- 6.7. Längsdurchschnitte (erhalten in der S. 585 angegebenen Weise; so auch die folgenden). junger Fruchtknoten. o Eychen, st Griffelkanal. Vgr. 200.

- 8. Unterer Theil eines weiter entwickelten Germen. Der Schnitt, welcher die Fruchtknotenhöhle öffnete, liess den Griffel unverletzt. Dieser ist von aussen gesehen. $e$ Embryosack. Vgr. 20.

\section{F. 9-11. Balanophora polyandra Griff.}

- 9. Theil eines zarten Längsdurchschnitts eines weiblichen Blüthenstandes. Zwischen und an den durchschnittenen kolbenförmigen Sprossungen der Hauptachse stehen die, durch den Schnitt zum Theil geöffneten Blüthen. Vgr. 20.

- 10. Oberes Ende eines Griffels. Auf seinem Scheitel ein Pollenkorn, das in den Griffelkanal einen Schlauch getrieben hat (nach einem durch gelindes Erwärmen in der Schultze'schen Macerationsflüssigkeit und nachheriges Auswaschen mit Ammoniak durchsichtiger gemachten Präparate). Vgr. 160.

- 11. Längsdurchschnilt eines unbefruchteten Fruchtknotens. Die Anheftungsstelle des Eys ist nicht vom Schnitl getroffen. Das Präparat behandelt wie das vorhergehende. Vgr. 200.

\section{Tafel XV.}

\section{F. 1-3̈. Balanophora polyandra Griff.}

F. 1. Unbefruchtetes Germen im Längsdurchschnitt, der nicht die Anheftungsstelle des Eys traf. Vgr. 120.

- 2. Vor Kurzem befruchtetes solches, im Längsschnitt. Embryosack in zwei Endospermzellen getheilt. Gleiche Vgr. 
F. 3. Aehnliches Präparat. Der Schnitt ist durch die Anheftungsstelle des Eychens gegangen. Vgr. 160.

- 4. Längsdurchschnittener, in vier Ėndospermzelleı getheilter Embryosack mit anhaftenden mehreren Zellen des Eys und Pollenschlauchende t, frei gelegt. $k$ befruchteles Keimbläschen. Vgr. 300 .

- 5. Frei gelegter, von Endosperm ausgefüllter Embryosack, von aussen gesehen. Bedeulung der Buchstaben wie zuvor. (Das Präparat war in oben angegebener Weise durchsichtiger gemacht.) Gleiche Vgr.

\section{F. 6-11. Balanophora fungosa Forst.}

- 6. Vor Kurzem befruchtetes Germen im Längsdurchschnitt. $k$ Keimbläschen. Vgr. 120.

- 7. Der längsdurchschnittene von Endosperm erfüllte Embryosack eines solchen. frei gelegt. Gleiche Vgr.

- 8. Oberer Theil der Fruchtknotenhöhle eines längsdurchschnittenen ähnlichen Germen. Der Pollenschlauch $t$ ist ein weites Stück im Griffelkanale zu verfolgen. Vgr. 250 .

- 9. Minder entwickeltes Germen, im Längsdurchschnitt. Vgr. die gleiche.

- 10. Weiter vorgerücktes Germen, längsdurchschnitten. Vgr. 120.

- 11. Hälfte eines durch einen Längsschnitt, der den Griffel entfernte, getheilten Germen weiterer Entwickelung, von imnen gesehen. Der Vorkeim $k$ bereits zweizellig. $\mathrm{Vgr} .100$.

\section{F. 12, 13. Balanophora dioïca R. Br.}

- 12. Halbreifes Germen, durch einen Längsscbnilt geöffnet und von innen gesehen. $x$ einige noch erhaltene Zellen des Eys; $k$ Embryo-Anlage. Vgr. 200.

- 13. Reifes Germen in axilem Längsdurchschnitte. $k$ der am Embryoträger läıgende Embryo. Gleiche Vgr.

\section{Tafel XVI.}

\section{F. 1-3. Helosis mexicana Liebm.}

F. 1. Sehr junge weibliche Blüthe im Längsschnilt (das Präparat mil der Schultze'schen Nacerationsflüssigkeit und Ammoniak gebleicht). $c c$ die Carpelle; $p$ Perianthium; o das aufrechte Ey. Vgr. 200.

- 2. Weibliche Blüthe, zur Befruchtung bereit, und die Spreuschuppen zu ihrer Rechten und Linken im zarten Längsschnitt. Die eine Spreuschuppe $x$ ist perspectivisch gezeichnet, um die Felderung ihrer Cuticula zu zeigen. ch die Chalazagegend. Vgr. 100.

- 3. Embryosack aus einer ähnlichen weiblichen Blüthe, frei präparirl. Vgr. 300.

F. 4, 5. Helosis guyanensis Rich.

- 4. Reife Frucht im Läıgslurchschnitl. Vgr. 100. 
F. 5. Der obere Theil des Endosperms nebst dem Embryo einer eben solchen Frucht; im Längsdurchschnitt. Vgr. 350 .

\section{F. 6, 7, 8. Rhopalocnemis phalloïdes Jungh.}

- 6. Reife Frucht im Längsschnitt parallel den breiten Flächen. $p$ Pericarp, $e d p$ Endosperm, $k$ Embryo. Vgr. 45.

- 7. Reife Frucht im Längsschnitt senkrecht auf die breiten Flächen. Bedeutung der Buchstaben wie vorher. Vgr. 90.

- 8. Querdurchschnitt einer solchen Frucht. Gleiche Vgr.

- 9. Corynea crassa Hook. f. Freigelegter unbefruchteter Embryosack, dessen zerrissene Haut in Fetzen umherhäıgt, während der in Essig erhärtete Primordialschlauch die ursprüngliche Form des Embryosacks zeigt. $k$ die Keimbläschen. Vgr. 300 .

\section{Tafel XVII.}

\section{F. 1-6. Scybalium fungiforme Schott und Endl.}

F. 1. Weibliche Blüthe, unbefruchtet, in durch beide Griffel gelegtem Längsdurchschnitte. o Ey, ch Chalaza, $e$ Embryosäcke. Vgr. 70.

- 2. Eben solche, Längsdurchschnitt rechtwinklig zu vorigem. Gleiche Vgr.

- 3. Eben solche, Querdurchschnitt aus der Gegend der Embryosäcke. Vgr. 70.

- 4ab. Querdurchschnitte von Spreuschuppen; an $4 b$ aussen die Cuticula angedeutet. Vgr. 100.

- 5. Junge Frucht im Längsdurchschnitt, dessen Fübrung dem F. 1 abgebildeten übereinstimmend ist. Rechts im Innern ein befruchteter, endospermerfüllter Embryosack, links ein fehlschlagender. Vgr. 30 .

- 6. Längsdurchschnitt einer der Reife nahen Frucht. Vgr. 40.

- 6b. Oberer Theil des Endosperms nebst Embryo aus dem nämlichen Präparat. Vgr. 150.

\section{F. 7, 8. Phyllocoryne jamaïcensis Hook. .}

- 7. Längsdurchschnittenes Endosperm mit dreizelligem Vorkeim. Vgr. 200.

- 8. Junge Frucht im Längsdurchschnitt, gebleicht. Daneben eine lăngsdurchschnittene Spreuschuppe. Bedeutung der Buchstaben wie früher. Vgr. 100.

\section{Tafel XVIII.}

\section{Lathraea squamaria L.}

F. 1. Eykern und Embryosack eines unbefruchteten Eychens frei präparirt; aus einer dem Aufblühen nahen Knospe, deren Antheren noch geschlossen waren. Zelleninhalt des Sackes und der Keimbläschen sind wenig in ihrer Anordnung gestört. Die Ansatzflächen beider Keimbläschen haften an der nach oben gekehrten Seite des Embryosacks. Am 24. April 1834. Vgr. 280. 
F. 2. Embryosack aus einem ähnlichen Eychen. Der Inhalt des Embryosacks ist ausgetrieben. Die Ansatzflächen der Keimbläschen nehmen die ganze Scheitelregion des Sackes ein; jede der Ansatzstellen ist nur zur Hälfte, im Profil, zu sehen. Am 21. April 1854. Gleiche Vgr.

- 3. Aehuliches Präparat. Der Embryosack völlig unverletzt. Anheftung der Keimbläschen wie bei F. 2. Gleiche Vgr.

- 4. Oberer Theil des frei gelegten Embryosacks aus einem ähnlichen Eychen. Die Ansatzfläche des oberen Keimbläschen ist von vorn, die des unteren im Profil gesehen. Gleiche Vgr.

- 5. Aebnlichies Präparat. Am 17. April 183̈6. Gleiche Vgr.

- 6. Frei gelegter Embryosack aus einem Eychen, in dessen Mikropyle ein Pollenschlauch (offenbar erst vor Kurzem) eingetreten war. An der Stelle des primären Kerns sind jetzt'zwei Zellenkerne sichtbar; sie sind durch Wasser, welches während des Freipräparirens des Sackes durch einen zufällig entstandenen Riss in denselben drang, etwas zum Zusammenschrumpfen gebracht. Am 28. April 1853 . Vgr. 200.

- 7. Frei gelegter Embryosack, aus einem vor Kurzem befruchteten (1 1 Stunden nach künstlicher Bestäubung der Narbe aus dem Germen genommenen) Eychen. Dem Scheitel des Sackes haftet das Ende eines Pollenschlauchs an. Keimbläschen unverändert; der Embryosack durch eine Querwand getheilt. Am i 8. April 1853. Gleiche Vgr.

- 8. Oberer Theil des frei gelegten Embryosacks aus einem ähnlichen Eychen; am Scheitel des Sackes ein hakenförmiges Anhängsel seiner Wand. Daneben dẹr abgelösté, an der Spitze zweiarmige Pollenschlauch. Gleiche Vgr.

- 9. Frei gelegter ganzer Embryosack aus einem ähnlichen Eychen. Das befruchtete Keimbläschen etwas gestreckt; das unbefruchtete verschwunden. Im Mittelraume des Sackes zwei Querscheidewände. Ueber dem Scheitel des Sackes das unverletzt abgelöste Pollenschlauchende.' Am 16. April 1854. Gleiche Vgr.

- 10. Frei gelegter, eben befruchteter Embryosack, von welchem der Pollenschlauch abgetrennt. Anheftung der Keimbläschen wie bei F. 1. Die Primordialschläuche der beiden Zellen, in welche der Embryosack getheilt ist, sind contrahirt. Am 25. April 185 \%. Tgr. 280.

11. Weiter entwickelter Embryosack, mit anhaftendem, tief herabgedrungenem Pollenschlauche. In den zwei mittleren Endospermzellen ist bereits Lüngstheilung erfolgt; in der obersten noch nicht. Die Primordialschläuche sämmtlicher Endospermzellen sind zusammengezogen. Das befruchtete, untere Keimbläschen ist merklich gestreckt. Ende April 1854. Vgr. 200.

- 12. Aehnliches Präparat, mit unverändertem Inhalte der Endospermzellen, anch deren oberste, die Keimbläschen einschliesșende bereits durch eine Längswand getheill ist. Am 27. April 1835 . Gleiche Vgr.

- 13. Weiler vorgerückter Embryosack, frei gelegt; das Pollenschlauchende abgetrennt. Der Zelleninhalt ist nicht mit gezeichnet; ebenso bei mehreren der folgenden Figuren. Ende April 1853 . Gleiche Vgr.

- 14. Aehnliches Präparat, mit dem Sacke anhaftendem Pollenschlauchende. Am 13. April 18\%3. Gleiche Vgr. 
F. 15. Oberes Ende eines frei gelegten Embryosacks, mit ungewöhnlich angeschwollenem fehlschlagendem (oberem) Keimbläschen. Der Pollenschlauch ist abgelöst und entfernt. Am 11. April 1853. Gleiche Vgr.

- 16. Oberes Ende eines frei gelegten Embryosacks; dicht neben dessen Scheitel das abgetrennte Pollenschlauchende. Eine der obersten Endospermzellen beginnt die Entwickelung der seitlichen Ausstülpung. Am 20. April 1853. Gleiche Vgr.

- 17. Ganzer Embryosack frei gelegt, daneben der abgelöste Pollenschlauch. Die Entwickelungsstufe hält die Mitte zwischen denen der Fig. 13 und 14. Mitte April 1833. Gleiche Vgr.

- 18. Oberes Ende eines Embryosacks; darüber der abgetrennte Pollenschlauch. Die seitliche Ausstülpung der eimen oberen Endospermzelle ist zerrissen. Gleiche Vgr.

- 19. Ganzer Embryosack, frei gelegt, mit anhaftendem Pollenschlauchende, aus einem weiter entwickelten Eychen. Beide oberste Endospermzellen haben Ausstülpungen getrieben. Diese Ausstïlpungen, wie auch die umfangreiche der zellenleeren unteren Hälfle des Embryosacks, haben die Lage wie im unverletzten Eychen. Am 26. April 1853. Gleiche Vgr.

- 20. Oberer Theil eines frei gelegten befruchteten Embryosacks mit sehr geringer seitlicher Ausstülpung der obersten Endospermzelle. Ueber dem Scheitel des Sackes der abgelöste Pollenschlauch. Ende April 1853. Gleiche Vgr.

- 21. Frei gelegter Embryosack eines weiter entwickelten Eychens; Endosperm schon vielzellig. Die Entwickelung einer Ausstülpung aus einer der oberen Endospermzellen ist abnormer Weise völlig unterblieben. Neben dem Scheitel des Sackes, dessen Haut sehr stark verdickt, haftet das Pollenschlauchende. Anf. Mai 1852. Gleiche Vgr.

- 22. Frei gelegtes oberes Ende eines weiter entwickelten Embryosacks; dessen seitliche Ausstülpung in Fetzen zerrissen. Neben dem Embryosackscheitel das sehr unscheinbar gewordene Pollenschlauchende. Mitte Mai 1852. Gleiche Vgr.

- 23. Frei gelegtes oberes Ende eines Embryosacks mit anhaftendem Pollensclılauche;

- Entwichelung etwas weiter vorgerückt als die der Fig. 19. Gleiche Vgr.

- 24. Frei gelegte Embryosackspitze aus einem weiter vorgerückten Eychen, in welchem bereits das Embryokügelchen angelegt war. Die Einmündung der seitlichen Ausstülpung der einen obersten Endospermzelle in deren ursprünglichen Raum ist nach oben gewendet, die darmförmige Ausstülpung (in der Zeichnung ist ihr äusseres Ende weggelassen) ist zur Seite geschlagen. In Folge davon scheint es auf den ersten Blick, als rage das vom obersten Theile des Embryoträgers völlig ausgefüllte äusserste Ende des Embryosackes aus einer llautfalte desselben hervor. Am Scheitel des Sackes haftet ein Rest des Polleuschlauchendes. Nach einem Präparate Schacht's, dessen Ansicht mir verstattet wurde. Gleiche Vgr.

Tafel XIX.

\section{Lathraea squamaria.}

F. 1. Embryosack mit anhaftendem Pollenschlauch, frei präparirt, Entwickelung dem Abland. d. I. S. Ges. d. Wissenseh. VI. 
F. 19 vorhergehender Tafel abgebildeten gleich. Nur die Umrisse der Zellen sind gezeichnet. Vgr. 360 .

F. 2. Oberes Ende eines weiter vorgerückten, frei präparirten Embryosackes mit anhaftendem Pollenschlauch; perspectivische Ansicht. Vgr. 480.

- 3. Ganzer Embryosack, gleicher Entwickelung, durch einen Längsschnit halbirt und darauf frei gelegt, un den Verlauf des Embryoträgers innerhalb des Endosperms zu zeigen. Vgr. 170.

- 4. Ganzes Eychen ähnlicher Entwickelung, im Längsdurchschnitt. Vgr. 60.

- 5. Oberes Ende eines weiter entwickelten, halbirten und frei gelegten Embryosackes. Neben dem Embryoträger zwei unbefruchtet gebliebene, wenig gestreckte Keimbläschen. Vgr. 200.

- 6. Dieselben Theile eines Embryosackes gleicher Entwickelung mit anhaftendem Pollenschlauchende. Vgr. 200.

- 7. Embryokügelchen, mit Träger, aus etwas weiter entwickeltem Eychen, frei gelegt. Vgr. 250 .

- 8. Oberes Ende eines frei präparirten, unbefruchteten Embryosackes (einem Eychen aus einer noch geschlossenen Blüthenknospe entnommen). Der Inhalt des Sackes sowohl, als der Keimbläschen ist bei der Präparation ausgetrieben worden; nur die elastischen Zellmembranen sind erhalten. Nach einem, fünf Jahre in Chlorcalciumlösung aufbewahrten Präparate gezeichnet. Vgr. 600.

\section{Tafel XX.}

\section{Pedicularis sylvatica.}

F. 1. Eykern, am 19. Mai (1836) aus dem Integumente geschält, einer Knospe entnommen, deren Corolle nur erst einen leisen rothen Anflug zeigte. Die Zellen der peripherischen Zellenlage zeigen sehr deutlich eine Anordnung, welche aus wiederholter Quertheilung ursprünglich weniger einzelner Zellen hervorging. Durch diese einfache Zellschicht schimmert der Embryosack hindurch. Vgr. 120.

- 2. Eykern aus einer wenig weiter entwickelten Knospe. An seinem Scheitel ist die peripherische Zellschicht aufgebrochen und der obere Theil des Embryosacks aus ihr hervorgewachsen. Gleiche rgr.

- 3. Eychen aus einem 7 Stunden vorher bestäubten Pistill im Längsdurchschnitt. Ein Pollenschlauch $t$ ist bereits in den Eymund gelangt, aber noch nicht bis an den Embryosack. Der grosse Zellenkern des Embryosacks ist nocb vorhanden. Vgr. 20.

- 4-7. Obere Ihälften frei gelegter Embryosäcke von Eychen aus Knospen, deren Antheren noch geschlossen waren. In F. 6 drei, in den übrigen je 2 Keimbläschen. Vgr. von F. 4-15̆0, der übrigen 120.

- 8. Eykern nebst Embryosack aus einem Eychen aus einem, etwa 24 Stunden zuvor bestäubten Pistill, am 23. Mai 1835 völlig frei gelegt. $t$ Pollenschlauch, $k$ das unentwickelt bleibende obere, $k^{\prime}$ das befruchtete untere Keimbläschen, welches zum Embryonalschlauche sich zu verlängern beginnt. ed das bereits zweizellig gewordene Endosperm. Vgr. 150. 
F. 9-14. Frei gelegte obere Enden von Embryosäcken mit unbefruchtetem oberen und befruchtetem unteren Keimbläschen, aus 12 bis 24 Stunden zuvor geöffneten Blüthen in der Zeit vom 19.-30. Mai (1854 u. 5a) präparirt; Fig. 9, 11 u. 1'k mit unverletzt abgetrenntem, die übrigen mit anhaftendem Pollenschlauchende $t$. Vgr. 120.

- 15.16. Aehnliche Präparate aus etwas weiter in der Entwickelung vorgerückten Eychen. Das unbefruchtete Keimbläschen bereits verschwunden. Gleiche Vgr.

- 17. Aehnliches Präparat, das unbefruchtete Keimbläschen noch erhalten; das befruchtete bereits stärker verlängert. Vgr. 150.

\section{Tafel XXI.}

\section{F. 1-7. Pedicularis sylvatica.}

F. 1.2. Frei gelegte obere Enden befruchteter Embryosäcke mit anhaftendem Pollenschlauchende $t$, befruchtetem und unbefruchtetem Keimbläschen, aus Blüthen mit welkender Corolle. Vgr. 120.

- 3. Frei gelegter ganzer Embryosack aus einer Blume mit verwelkter Corolle. Der anhaftende Pollenschlauch $t$ ist stark gekrümmt, ein Stück rückläufig; das Endosperm 8zellig. Vier dieser Zellen sind in der Seitenansicht sichtbar. Gleiche Vgr.

- 4. Oberes Ende eines frei gelegten Embryosacks, gegen den Scheitel hin umgeknickt, eine Knickung die sich auch auf den noch kurzen Embryonalschlauch erstreckt. Gleiche Vgr.

- 5. Oberes Ende des Embryosacks aus einem Eychen gleicher Entwickelung. Neben dem Embryonalschlauche das noch unveränderte unbefruchtete Keimbläschen. Der Pollenschlauch $t$ ist unverletzt von der Aussenfläche des Sackes abgelöst. Gleiche Vgr.

- 6. Ganzes Eychen im Längsdurchschnitt, etwa 18 Tage zuvor befruchtet. $e$ der Embryosack mit seiner blinddarmförmigen, gegen die Raphe gerichteten Aussackung. ed Endosperm. Vgr. 35 .

- 7. Oberstes Stück des Embryosacks nebst dem ganzen Embryoträger und den Embryo aus einem Eychen ähnlicher Entwickelung, völlig frei gelegt. Vgr. 120.

\section{F. 8-4 0. Pedicularis comosa.}

- 8. Unbefruchteter Embryosack, einer noch geschlossenen Knospe entnommen, völlig frei gelegt. Er enthält zwei Keimbläschen. Vgr. 120.

- 9. Oberes Ende eines befruchteten Embryosacks mit aussen anhaftendem Pollenschlauche, unbefruchtetem und zum Embryonalschlauche gestrecktem befruchtetem Keimbläschen, frei gelegt. Das Präparat entspricht dem Fig. 5 von Pedicularis sylvatica abgebildeten. Vgr. 120.

- 10. Scheitelregion des Embryosacks mit Ansatzstelle des Embryonalschlauches aus einem weiter entwickelten Eychen. Gleiche Vgr.

- 11. Dieselben Theile aus einem jungen Samen, dessen Entwickelungsgrad denı- 
jenigen des Fig. 6 von Pedicularis sylvatica abgebildeten ungefähr gleich war. Gleiche Vgr.

F. 12. Oberer Theil des Embryosacks aus einem jungen Sanen der Euphrasia officinalis, frei gelegt. ed Endosperm. k Embryotrïger (dessen oberes Ende sehr aufgebläht erscheint). $t$ Pollenschlauch. Die seitliche Aussackung des Embryosacks, nach hinten gelegen, ist nicht mit gezeichnet. Vgr. 120.

\section{F. 13-16. Mazus rugosus.}

- 13. Unbefruchteter Embryosack mit zwei Keimbläschen, nahe dem unteren Ende des Sackes dessen Zellenkern, frei gelegt. Vgr. 120.

- 14. Vor Kurzem befruchteter Embryosack, mit achitzelligem Endosperm, frei gelegt. Der Pôllensclılauch ist bei der Präparation abgetrennt worden; so auch bei den als Fig. $1 \ddot{z}$ und 16 abgebildeten Präparaten. Gleiche Vgr.

- 15. Aehnliches Präparat aus einem weiter vorgerückten Eychen. Das untere Keimbläschen bereits zum Embryonalschlauche verlängert; eine der obersten vier Zellen des Endosperms beginnt eine seitliche Ausstülpung zu treiben.

- 16. Embryosack aus einem halbreifen Samen, frei gelegt. Jede der obersten vier Endospermzellen hat eine lange Aussackung getrieben. Die eine derselben ist unverletzt, die anderen drei sind abgerissen. Gleiche Vgr.

\section{Tafel XXII.}

\section{F. 1-3. Rhinanthus hirsutus.}

F. 1. Embryosack aus einem unbefruchteten Eychen. Der Sack ist durch einen der durch das Ey geführten beiden Längsschnitte in der Gegend seiner Mitte gestreift*), die Anordnung seines Inhalts aber wenig dadurch gestört. Vgr. 200.

- 2. Vor Kurzem befruchteter Embryosack, völlig frei präparirt. Der Pollenschlauch hat sich abgelöst. Der Inhalt der den oberen Theil des Sackes einnehmenden Endospermzellen und des befruchteten Keimbläschens $(k)$ ist bei der Präparation ausgetrieben worden; die untere Hälfte des Sackes dagegen zeigt noch ihren vollständigen Inhalt. Vgr. 150. (Ende Juni 1853.)

- 3. Gipfel eines weiter vorgerückten Embryosacks, frei präparirt. Links oben haftet das Pollenschlauchende $p$; nach rechts ist die grosse seitliche Ausweitung einer der oberen Endospermzellen sichtbar. Vgr. 300 .

\section{F. 4, 5. Rhinanthus minor.}

- 4. Unbefruchteter Embryosack, aus der Mittellamelle eines mit zwei Längsschnitten präparirten Eychens. Vgr. 200.

- 5. Vor Kurzem befruchteter Embryosack, völlig frei gelegt. Nelsen dem Scheitel haftet das Pollenschlauchende $p$. Unter diesem das bereits etwas gestreckte,

*) In diesem Sinne ist der Ausdruck, ,längsdurchschniltenc Eychen" hier überhaupt zu verstrhen. 
befruchtetc Kcimblåschen $k$. Das unbefruchtete ist verschwunten. Vgr. 200. (Anf. Juni 18\%4.)

\section{F. 6-11. Veronica Buxbaumii. (Mitte Mai 1854.)}

F. $6 a$. Embryosack aus eincm längsdurchschnittenen Eychen, einer Knospe entnommen, dic kaum einc Färbung der Corolle zeigtc. Vgr. 250.

- 6b. Embryosack aus einer weiter entwickeltcn Knospe. Gleiche Vgr.

- 7. Embryosack aus ciner dem Aufblühen ganz nahen Knospe. Gleiche Vgr.

- 8. Embryosack und benachbarte Theile des Integuments aus der Mittellamelle eines vor Kurzem befruchteten, durch zwei Lïngsschnitte präparirten Eychens. Vgr. die gleiche.

- 9. Aehnliches Präparat, glcicher Entwickelungszustand. Die mittlere Anschwellung des Embryosacks füllt die ihm entsprechende Erweiterung des vom Integument umschlossenen Hohlraumes nicht völlig aus. Mikropyle und Pollenschlauch sind nicht mitgezeichnet. Gleiche Vgr.

- 10. Endospermkörper und zwischen seine Zellen eingedrungener Vorkeim; Theile eines auf die nämliche Art aus einem weiter vorgeschrittenen Eychen dargestellten Präparats. Gleiche Vgr.

- 11. Embryosack aus einem weiter entwickelten jungen'Samen im Längsdurchschnitt. Vgr. 180.

- 12.13. Embryosäcke mit anhaftenden Pollenschlïuchen. $(p)$ von Veronica hederaefolia, Anfang Mai 1855 frei präparirt. F. 12 mit einzelligem Endosperm und noch kurzem befruchteten Keimbliischen $(k)$; F. 13 mit mehrzelligem Endosperm und zu eincm langen Embryonalschlauche entwickeltem befruchteten Keimbläschen. Vgr. 200.

\section{F. 14, 15. Veronica triphyllos. (Anfang Mai 1854.)}

- 14. Oberer Theil eines vor einiger Zeit befruchteten, frei pråparirten Embryosackes. Die Längsscheidewand der oberen Anschwellung, des Sackes ist parallel zur Augenachse. Der Embryonalschlauch $(k)$ ist dieser Wand angeschmiegt. Vgr. 180.

- 15. Obere Anschwellung eines anderen frei präparirten Embryosacks; - die Längsscheidewand derselben ist der Ebene des Objcctträgers parallel. Gleiche Vgr.

- 15b. Theil der obercn Anschwellung des Embryosackes eines weiter entwickelten jungen Samens im Längsdurchschnitt. Das Netz aus Zellhautstoffbalken hat sich, nach längerem Liegen des Präparats in Glycerin, an einer Stelle von der Embryosackhaut gelöst. Vgr. 350 .

- 15c. Stück eines ähnlichen Präparats aus eincm jungen Șamen nach wetcr vorgerückter Entwickelung. Vgr. 500 .

F. 16, 17. Nemophila insignis.

- 16. Unbefruchtetes Eychen im Längsdurchschnitt. Vgr. 30.

- 16b. Embryosack daraus, 100 fach vergrössert. 
F. 17. Frei präparirter Embryosack eines vor Kurzem befruchteten Eychens. Vgr. 120.

\section{Tafel XXIII.}

\section{F. 1-6. Melampyrum nemorosum.}

(Ende Juli 1855.)

F. 1. Unbefruchtetes Ey im Längsdurchschnitt. Vgr. 35 .

- 2. Embryosack daraus. Vgr. 125.

- 3. Innerste Zellschicht der Mikropyle (vom Pollenschlauch durchzogen) und daran haftendes oberes Ende eines vor Kurzem befruchteten Embryosacks, frei präparirt. Vgr. 250.

- 4. Aehnliches Präparat; Embryosack völlig unverletzt. Gleiche Vgr.

- 5. Längsdurchschnitt eines frei präparirten, im oberen Theile vom bereits umfangreichen Endosperm erfüllten Embryosacks aus einem weiter entwickelten jungen Samen. Vgr. 25.

- こ̌b. Der Scheitel dieses Embryosackes vom Endosperm abgelöst, in 120 facher Vgr. Im innern der scheitelständigen Ausstülpung des Sackes sind die Reste des Zellcylinders eingeschlossen, welcher die Wand des Mikropylekanals bildete. Darunter haftet der Embryoträger an der Innenwand des Sackes; - an sejnem unteren Ende hängt das aus dem Endosperm hervorgezogene Embryokügelchen.

- 6. Dasselbe Präparat, von seiner unteren Fläche gesehen. In der Mitte der Figur das Embryokügelchen. Vgr. 120.

- 7. Catalpa syringaefolia, Längsdurchschnitt eines vor nicht langer Zeit befruchteten Eychens (am 6. Septbr. 1854), in 50facher Vgr.

- 7b. Terminale Anschwellung des Embryonalschlauchs aus demselben Präparat. Daneben Ende des Vorkeims aus einem anderen, weiter vorgerückten Eychen. Vgr. 200.

- 8. Acanthus spinosus, Längsdurchschnitt eines eben befruchteten Eychens (Anfang Juli 1855). Vgr. 25.

- 9. Unterer Theil des Embryosacks aus einem Eychen etwas weiter vorgerückter Entwickelung, frei präparirt. $e$ Endosperm, $k$ unteres Ende des Embryonalschlauches. Vgr. 200.

\section{Tafel XXIV.}

\section{F. 1-12. Lamium purpureum.}

(Anfang Mai 1853.)

F. 1. Längsdurchschnitt eines unbefruchteten Eychens. Vgr. 30.

- 1b. Stück der längsdurchschnittenen Epidermis mit einem der ihr aufsitzenden Haare. Vgr. 120.

- 2. Embryosackspitze desselben Präparats. Vgr. 120.

- 3. Ganzer Embryosack aus einem längsdurchschnittenen Ey. Vgr. 150. 
F. 4. Vor Kurzem befruchteter Embryosack, aus einem rechtwinklig zur Medianebene längsdurchschnittenen Ey (das umgebogene untere Ende des Sackes ist durch den Schnitt entfernt). Vgr. 120.

- 5.6.7. Obere Enden der Embryosäcke aus ähnlichen Präparaten. Vgr. 150.

- 8.9. Embryosäcke im Lïngsdurchschnitt, weiter vorgerückte Zustände. Vgr. 120.

- 10. Noch weiter entwickelter Embryosack, frei präparirt und von der Vorderflïche gesehen. Vgr. 90.

- 11. Längsdurchschnitt des Endospermkörpers und Embryokügelchens aus einem jungen Samen ähnlicher Entwickelung. Vgr. 60.

\section{F. 12-15. Lamium maculatum.}

- 12.13. Unbefruchtete Embryosäcke aus längsdurchschnittenen Eychen. Vgr. 150.

- 14. Pollenschlauch, obere Anschwellung des Embryosacks und Stück des Embryonalschlauchs aus einem vor Kurzem befruchteten, längsdurchschnittenen Eychen. Gleiche Vgr.

- 15. Junger Same, längsdurchschnitten, in 15 facher Vgr. Die schattirte Stelle is Endosperm; in ihm das Embryokügelchen. Der Verlauf des Trägers desselben ist durch eine dunkle Linie bezeichnet. Die Hauptmasse des jungen Samens ist das herangewachsene Parenchym des lnteguments.

\section{F. 16-19. Prostanthera violacea.}

- 16. Längsdurchschnitt eines Fruchtknotenfachs und unbefruchteten Eychens. Vgr. 35 .

- 16b. Embryosack aus diesem Präparat. Vgr. 150.

- 17. Querdurchschnitt eines Fruchtknotens. 8 fach vgr.

- 18. Vor nicht Langem befruchteter Embryosack, frei präparirt, in Längsdurchschnittsansicht. Vgr. 150.

- 19. Obere zwei Dritttheile eines weiter vorgerückten, frei gelegten Embryosacks. Gleiche Vgr.

- 20. Ajuga reptans. Fruchtknotenfach und unbefruchtetes Eychen im Längsdurchschnitt. Vgr. 50 .

\section{Tafel XXV.}

\section{F. 1-6. Hebenstreitia dentata.}

(Anfang September 1854.)

F. 1. Embryosack und innerste Zellschicht des Integuments aus einem unbefruchteten (einer geschlossenen Knospe entnommenen) längsdurchschnittenen Eychen. Vgr. 1 \%.

- 2. Vor Kurzem befruchtetes Eychen im Längsdurchschnitt, gleiche Vgr.

- 3. Embryosack und Pollenschlauchende aus einem ähnlichen, minder weit entwickelten Präparate. Gleiche Vgr.

- 4.5. Befruchtete Embryosäcke, völlig frei präparirt. Gleiche Vgr. 
F. 6. Embryosack aus einem weiter vorgerückten Eychen, nebst anhaftendem Pollenschlauchende, frei präparirt. Vgr. die nämliche.

- 7. Globularia vulgaris. Embryosack aus einem nicht lange zuvor befruchteten Eychen, frei präparirt. Gleiche Vgr. (Am 1. Juni 1855.)

\section{F. 8-12. Plantago lanceolata. (Juli 1855 und 1858.)}

- 8. Unbefruchtetes Eychen und Theil der Placenta im Längsdurchschnitt. Vgr. 50.

- 8b. Der Embryosack aus diesem Präparat, in 200 facher Vgr.

- 9. Vor Kurzem befruchteter Embryosack, aus einem längsdurchschnittenen Eychen. Gleiche Vgr.

- 10. Aehnliches Präparat, aus einem in der Entwickelung weiter vorgerückten Eychen. Gleiche Vgr.

- 11. Embryosack, noch etwas weiter entwickelt, längsdurchschnitten und nebst anhaftendem Pollenschlauchende frei präparirt. Vgr. 100.

- 12. Junger Same im Längsdurchschnitl. e Endosperm, $k$ Embryokügelchen, a zellenleere Ausstülpungen des Embryosacks. Vgr. 30.

- 13. Weiter vorgerückter Same, nebst einem Theil der Placenta $(p l)$ im Längsdurchschnitt. Gleiche Vgr.

\section{F. 14-16. Vaccinium uliginosum.}

(Nitte Juni 1853.)

- 14. Unbefruchtetes Ey im Längsdurchschnitt. Vgr. 50.

- 14b. Gipfel des Embryosacks aus diesem Präparat. Vgr. 250.

- 15. Scheitel eines befruchteten Embryosacks, nebst anhaftendem Pollenschlauche, frei präparirt. $k$ oberes Ende des befruchteten, zum Embryonalschlauche gestreckten Keimbläschens; $l^{\prime}$ fehlgeschlagenes Keimbläschen; $p$ Pollenschlauch. Gleiche Vgr.

- 16. Embryokügelchen nebst Träger, frei präparirt. Vgr. 125.

$$
\begin{gathered}
\text { F. 17, 18, 19. Pyrola rotundifolia. } \\
\text { (Juni 1853.) }
\end{gathered}
$$

- 17. Unbefruchtetes Eychen, Längsdurchschnittsansicht. Vgr. 80.

- 18. Embryosack aus einem solchen, drei Keimbläschen enthaltend. Vgr. 120.

- 19. Embryosack nebst Pollenschlauchende aus einem vor Kurzem befruchteten Eychen. Gleiche Vgr.

- 20. Die nämlichen Theile aus einem weiter vorgerückten Eychen. Die Gränzen der anstossenden Zellen des Integuments sind angedeutet. Gleiche Vgr.

- 21. Epacris grandiflord. Längsdurchschnitt eines unbefruchteten Eychens. Vgr. 120. (Ende Nai 1854.)

- 22. Leiophyllum buxifolium. Längsdurchschnitt eines unbefruchteten Eychens. Vgr. 100. (Ende Mai 1834.)

- 23. Drosera rotundifolia. Inneres Integument und Eykern aus einem vor Kurzem befruchteten Eychen im Längsschnitt; im Endostom das Pollenschlauchende. Ygr. 150. (August 1855.) 


\section{Tafel XXVI.}

F. 1-5. Campanula americana.

(Anfang Juli 1854.)

F. 1. Unbefruchtetes Eychen im Längsdurchschnitte. Vgr. 30.

- 2.3. Eykern und Embryosack aus solchien. Vgr. 180.

- 4. Desgleichen. Vgr. 240.

\section{F. 6-8. Campanula Medium.}

(Anfang Juli 1854.)

- 5. Oberes Ende eines frei gelegten, vor Kurzem befruchteten Embryosacks. Der Pollenschlauch ist abgetrennt; die Einsenkung der Haut des Embryosackscheitels, welche er ausfüllte, ist leer. Keines der Keinbläschen haftet am unteren Ende dieser Einsenkung. Vgr. 180.

- 6. Aehnliches Prïparat, aus einem weiter entwickelten Eychen. Das Pollenschlauchende steckt in der, hier tieferen, Einsenkung des Embryosackscheitels, an deren unterem Ende das zum Embryonalschlauche gestreckte Keimbläschen haftet. Oberhalb der Ansatzstelle desselben sind die Reste des unbefrucbteten Keimbläschen sichtbar. Unter dem Ende des Embryonalschlauchs, welches bereits eine Querwand enthält, geht quer durch den Embryosack die Scheidewand, welche die Anfangszelle des Endosperms von der der Erweiterung des oberen Embryosackendes trennt. Vgr. 120.

- 7. Oberes Embryosackende, ähnlicher Entwickelung, frei präparirt. Der Embryonalschlauch ist der nach vorn gewendeten Fläche des Sackes angesetzt, in einiger Entfernung vom unteren Ende der vom Pollenschlauch ausgefüllten, tiefen Einstülpung des Embryosackscheitels. Vgr. 180.

- 8. Ganzer Embryosack, etwas minderer Entwickelung; frei gelegt. Das Pollenschlauchende hat sich bei der Präparation aus der Einstülpung des Einbryosackscheitels gelöst. Gleiche Vgr.

\section{F. 9-11. Glossocomia clematidea.}

(Anfang Juli 1854.)

- 9. Embryosack aus einem längsdurchschnittenen, unbefruchteten Eychen. Vgr. 200.

- 10. Oberes Ende eines frei präparirten, vor Kurzem befruchteten Embryosackes. Gleiche Vgr.

- 11. Dieselben Theile aus einem weiter entwickelten Eychen. Die vom Pollenschlauch ausgefüllte Einstülpung des Embryosacks ist sehr lang. Der Embryonalschlauch haftet, feru von deren unterem Ende, an der Seitenwand des Sackes. Gleiche Vgr.

- $11 b$. Aehuliches Präparat, weiter vorgerückter Zustand. Der Embryonalschlauch ist stark angeschwollen. Vgr. 120. 


\section{F. 12-15. Codonopsis viridiflora.}

(Anfang Juli 1854.)

F. 12. Embryosack aus einem längsdurchschnittenen unbefruchteten Eychen. Vgr. 180.

- 13-15. Obere Enden frei präparirter Embryosäcke. Bei F. 14 ist die den Pollenschlauch umscheidende Einstülpung des Embryosackscbeitels sehr kurz; bei F. 13 und 15 dagegen sehr lang. Vgr. 200.

\section{Tafel XXVII.}

F. 1. Gajophora lateritia. Unbefruchtetes Eychen im Längsdurcbschnitt. Vgr. 60 . (Anfang August 1854.)

\section{F. 2-6. Loasa tricolor. (Anfang August 1854.)}

- 2. Unbefruchtetes Ey im Längsdurcbscbnitt. Vgr. 20.

- 3. Embryosack daraus. Vgr. 100.

- 4. Scheitel eines eben befruchteten Embryosacks, nebst anhaftendem Pollenschlauchende frei präparirt. Gleiche Vgr.

- 5. Vor Kurzem befruchteter Embryosack, nebst dem Scheitel anbaftendem Pollenschlauchende, unverletzt frei präparirt. Gleicbe Vgr.

- 6. Oberes Ende des Endospermkörpers nebst Embryokügelchen und Stück des Embryoträgers, aus einem längsdurchschnittenen jungen Samen. Vgr. 150.

\section{F. 7-11. Bartonia aurea.}

(Mitte Juli 1854.)

- 7.8.9. Unbefruchtete Embryosäcke, unverletzt frei präparirt. Vgr. 150.

- 10. Vor Kurzem befruchteter Embryosack, frei präparirt. Das Stück des scheitelständigen Anhängsels desselben, an welchem der daneben herabsteigende Pollenschlaucb haftet, ist abgerissen und liegt links neben der Rissstelle. Gleiche $\operatorname{Vgr}$.

- 11. Oberer Theil eines etwas weiter vorgerückten, frei präparirten Embryosacks. Das scheitelständige Anhängsel desselben ist völlig unverletzt. Die Spitze des Pollenschlauchs $(p)$ haftet etwas unterbalb der Ansatzfläche des befruchteten Keimbläschens $(k)$ an der Aussenseite des Embryosacks. Bei der Präparation ist der Pollenschlauch von der Embryosackoberfläche hinweg gebogen worden, der er vorher dicht anlag. Gleicbe Vgr. 


\section{I d e $\mathrm{x}$.}

Acanthus spinosus 621 .

Adenophora 638 .

Aristolochia clematitis 567 .

Asarum canadense 568, 569 .

europaeum 568, 569.

Balanophora dioïca 585 .

$$
\begin{array}{r}
\text {, " junge Germina } 586,587 . \\
, \quad \text { lialbreife und reife Samen } 590 . \\
, \quad \text { fungosa; junge Germina } 586 . \\
\text { Befruchtung } 589 . \\
\text {, globosa } 592 . \\
\text { involucrata; unbefruchtete Germi- } \\
\text { na } 587 . \\
\text { polyandra; junge Germina } 586 . \\
\text { Germina kurz vor der } \\
\text { Befruchtung } \mathbf{5 8 7 .} \\
\text { Pollenschläuchc } 588 . \\
\text { Befruchtung } 589 .
\end{array}
$$

Balanophoreen, systematischc Stellung derselben 602 .

Bartonia aurea 643

Betonica officinalis 628 .

Cajophora lateritia 642 .

Campanula $628,638-640$.

Catalpa syringaefolia 632 .

Codonopsis viridiflora 638,640 .

Corynea crassa 597.

Cynomorium coccineum $572 \rightarrow 576$.

Cytinus Hypocistis $\mathbf{5 7 0 - 5 7 2 . ~}$

Digitalis 628 .

Dracocepbalum peltatum 628 .

Drosera rotundifolia 637 .

Einschliessung des Pollenschlauchendes in eine Einstülpung der Embryosackhaut 628,639 .

Endospermbildung durch Tbeilung einer einzigen Mutterzelle 535.

Typische Formen dieses Entwickelungsganges 536 .

Epacris grandiflora 636

Galeopsis Ladanum 628 .

Globularia vulgaris 631 .

Glossocomia clematidea 638 .

Gunnera 603. Anmrk.

Haloragis 603. Anmrk.

Hebenstreitia dentata 630 .

Helosis guyanensis 595 .

, mexicana 593.

Hippuris vulgaris 603. Anmrk.

Keimbläschen, unbefruchtete, mit fester Zellstoffhaut 605,611 .

, Raumverkleinerung derselben nach der Befrucbtung 629 .
Lamium purpureum und maculatum 624 .

Keimbläschen, Quertlıeilung befruchteter, vor ihrer Längsstreckung 626

Langsdorffia hypogaea $576-581$.

Lathraea squamaria.

Bau des Eykerns, Hervorbrechen des Embryosacks aus demselben 604.

Verdickung der Haut des Scheitels des Embryosacks 604 .

Die Keimbläschen 605 .

Der Pollenschlauch; Auftreffen desselben auf den Embryosack 606.

Anlegung des Endosperms 607.

Entwickelung des unteren Keimbläschens zum Embryonalschlauche 608 .

Bildung des Einbryokügelchens 609.

Ausstuilpungen des Embryosackes 609 .

Leiophyllum buxifolium 636 .

Leistenförmige Erhabenheiten derAussenfläche des Embryosackscheitels 582, 605.

Lepidoccras Kingii 552.

Loasa tricolor 641.

Loranthaceen, natürliche Verwandtschaft derselben 562.

Loranthus apliyllus $\mathbf{5 5 0}$

, bicolor 548,549

europaeus 539 .

Ânlegung des Calyculus, des Perigons und der Staubfäden 539 .

Anlegung der Carpelle, Verwacbsung derselben 540

Das Eycben 540, 544 .

Die Embryosäcke 541 .

Die Keimbläschen 542 .

Ankunft des Pollenschlauchendes am Embryosack 542 .

Strcckung des befrucbteten Keimbläscbens zum Embryonalschlauche 542.

Anlegung des Endosperms 542.

Durchbohrung des jungen Endosperms durch den Vorkeim 543.

Anlegung des Embryokügelchens 543.

Ueberwallung und Einschliessung des Embryokügelchens durch das Endosperm 544 .

Differenzirung der Fruchtknotenwand zu verschiedenartigen Gewebsschichten 545.

Viscinbildung 545.

Auftreten von Kotyledonen u. Wurzel 546 .

Messungen und Zellenzäblungen 546 .

Männliche Blüthen 541 . 
Loranthus globosus 548,549 .

$$
\text { ,, Scurrula 548, } 551 .
$$

Mazus rugosus 615 .

Melampyrum nemorosum 617.

Monotropa Iypopitys 591, 634 .

Myzodendron linariaefolium 653 .

Najas" 628 quadriflorum 652

Narcissus 628.

Nemophila insignis 633 .

Oelgehalt des Protoplasina sehr junger Zellen $579,608$.

Osyris nepalensis 565,566 .

Passowia odorata 551 .

Pedicularis sylvatica und comosa.

Bau des unbefruchteten Eychens 609.

Bau des Eykerns, IIervorbrechen des Embryosacks aus demselben 610

Die Keimbläschen 611 .

Der Pollenschlauch 612 .

Näcliste Folgen der Befruchtung 612.

Formånderung des unteren Kieimbläschens 613.

Verschwinden des oberen Kieimbl 613.

Auftreten des Endosperms 613 .

Ausstülpungen der Embryosackhaut 613 .

Bildung des Embryokügelchens 614 .

Phyllocoryne jamaïcensis 597.

Plantago lanceolata 622.

Prismatocarpus speculum 638, 640.

Prostanthera violacea 625,628 .

Pyrola rotundifolia 634 .

Rhinanthus minor und hirsutus 616 .

Rhopalocnemis phalloïdes 598 .

Richtung des Embryo in Beziehung zur Intensität der Entwickelung des Endosperms 565 .

Sarcoplyte sanguinea 581 .
Scybalium fungiforme 599 .

Stachys sylvatica 628 .

Thesium alpinum und intermedium 563 .

Umlenkung derEntwickelungsrichtung des Vorkeims und des Embryo 565.

Thymus Acinos 628 .

Vaccinium uliginosum 635 .

Veronica Buxbaumii, hederaefolia, triphyllos 619.

Viscum album.

Anlegung des zum Plühen bestimmten Sprosses 553

Anlegung des Calyculus und der Perigonialblätter 554 .

Anlegung der Antheren 555. • ,, der Carpelle, Verwachsung desselben 555

Anlegung des Eychens 555 .

Die Embryosäclie 556.

Die Keimbläschen 557 .

Tüpfel der Haut des Embryosackscheitels 557.

Differenzirung der Fruchtknotenwand in verschiedenartige Gewebsschichten 557.

Vordringen des Pollenschlauchs zum Embryosack 558 .

Theilung des Embryosacks in Tochterzellen (Anlegung des Endosperms) 559.

Zellvermehrung im befruchteten lieimbläschen 560

Decaisne's Untersuchungen 560 .

Meven's 561 .

Treviranus' ," 561 .

Zellstoffbalken in Erweiterungen von Embryosäcken bei Plantago lanceolata 624 .

,$\quad$ Pedicularis sylvatica 613 .

,. Veronica triphyllos 620 .

Berichtigung. S. 610-612 lies statt Taf. XJV. . . . Taf. XX.

, XV. ... " XXI. 


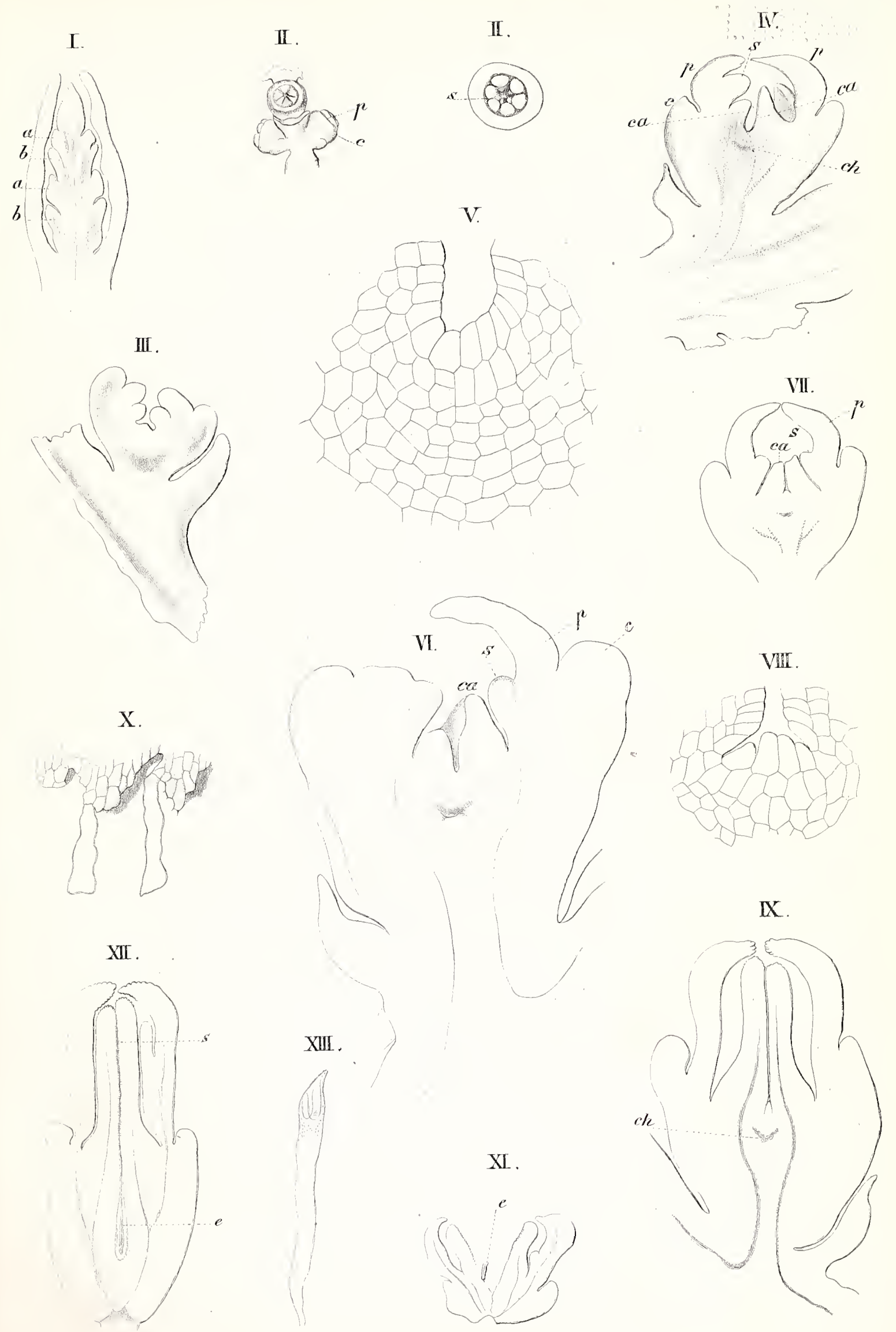

Loranthus europacus. 



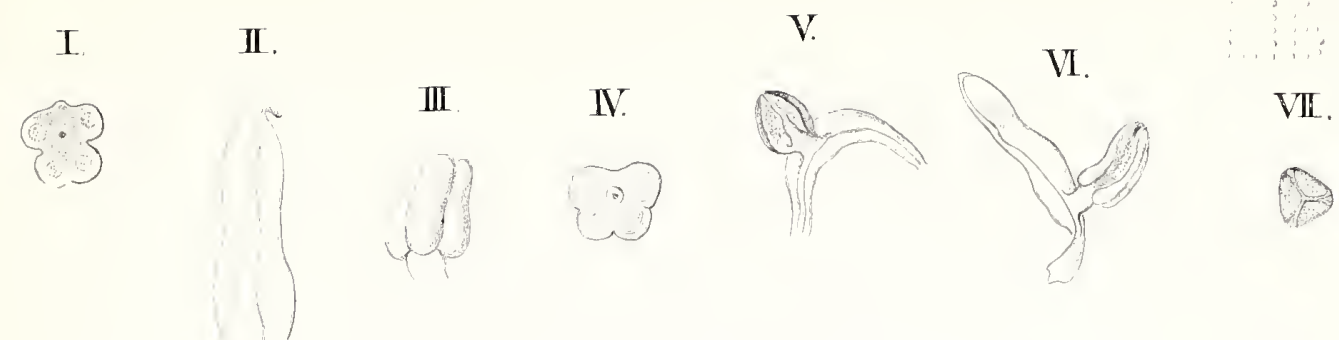

[?
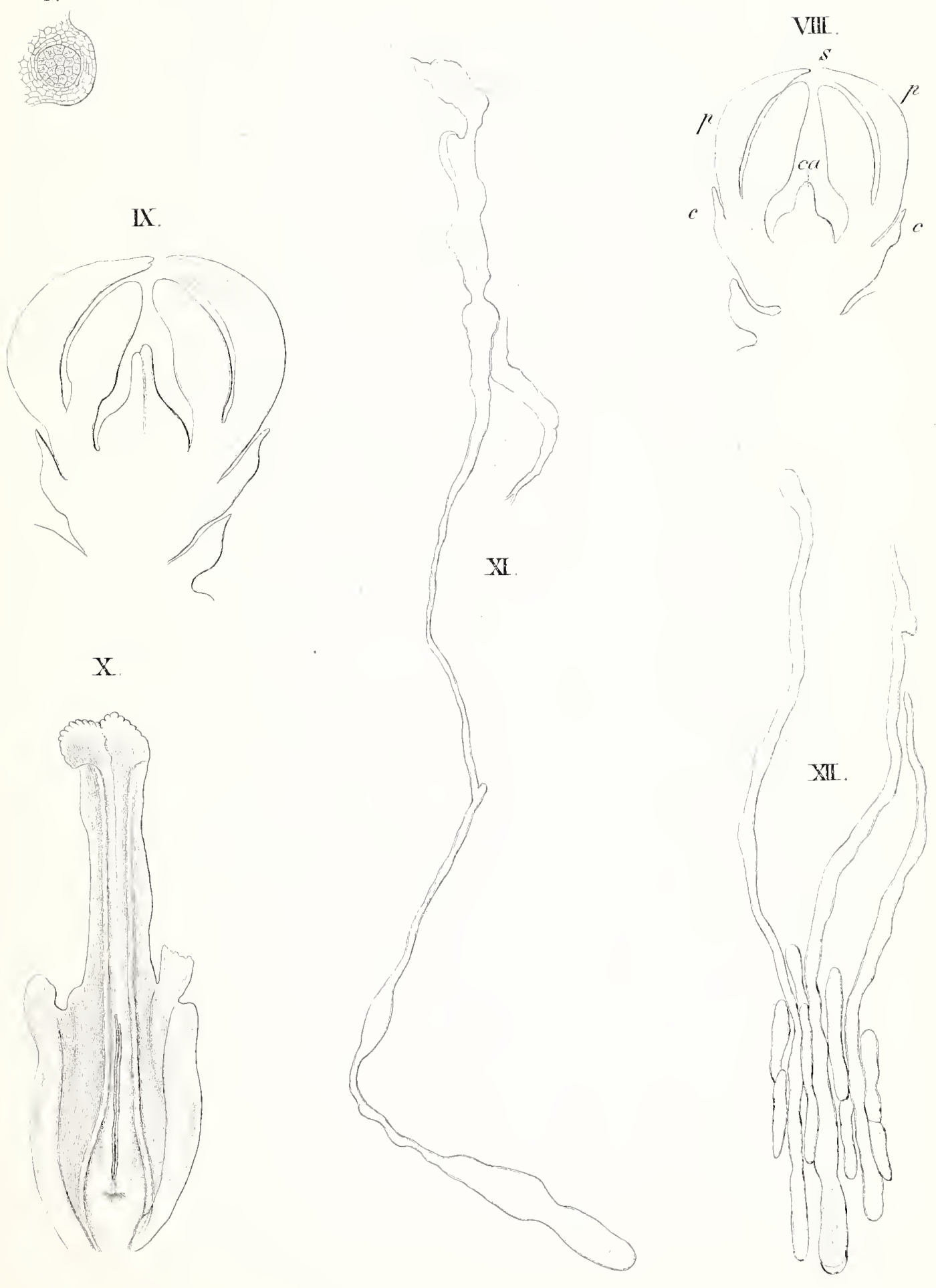

Loranthus emopaeus. 



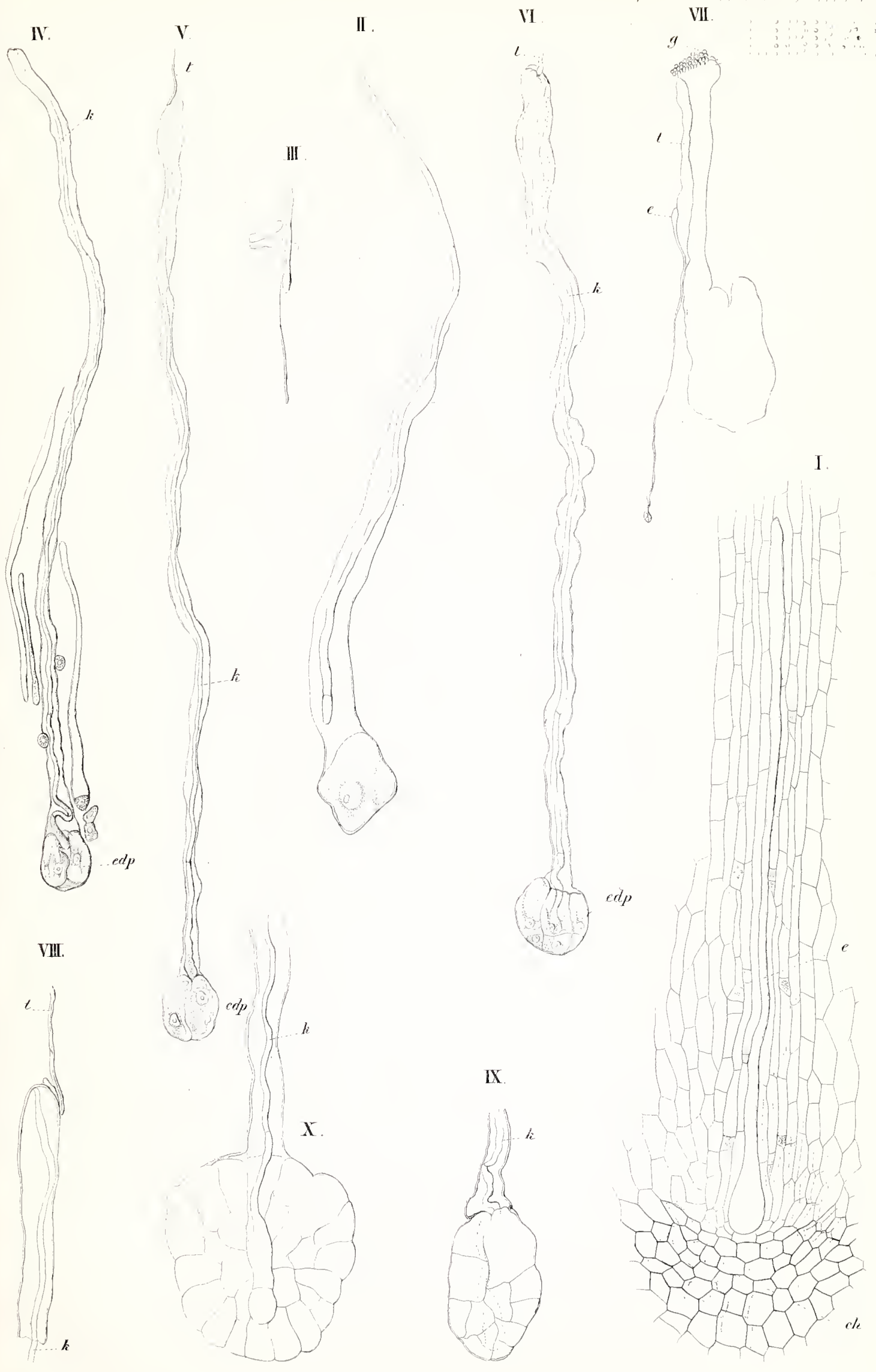



II.

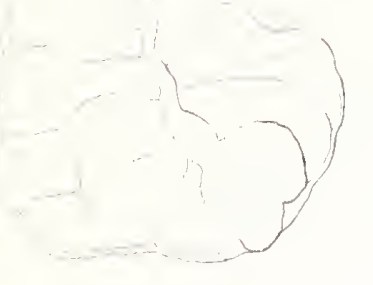

IV

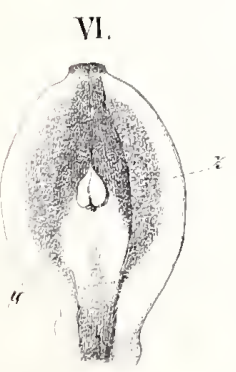

III.
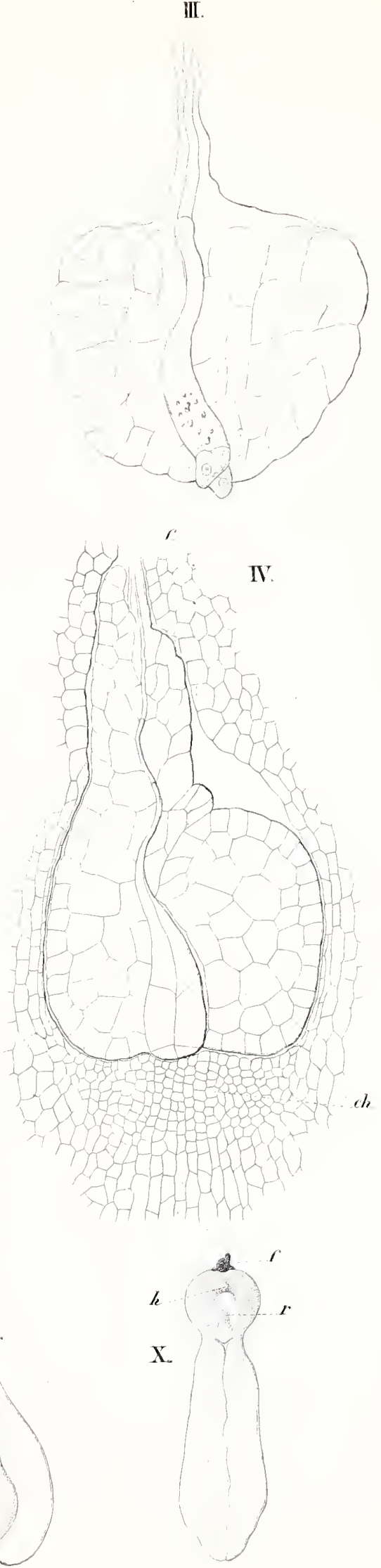
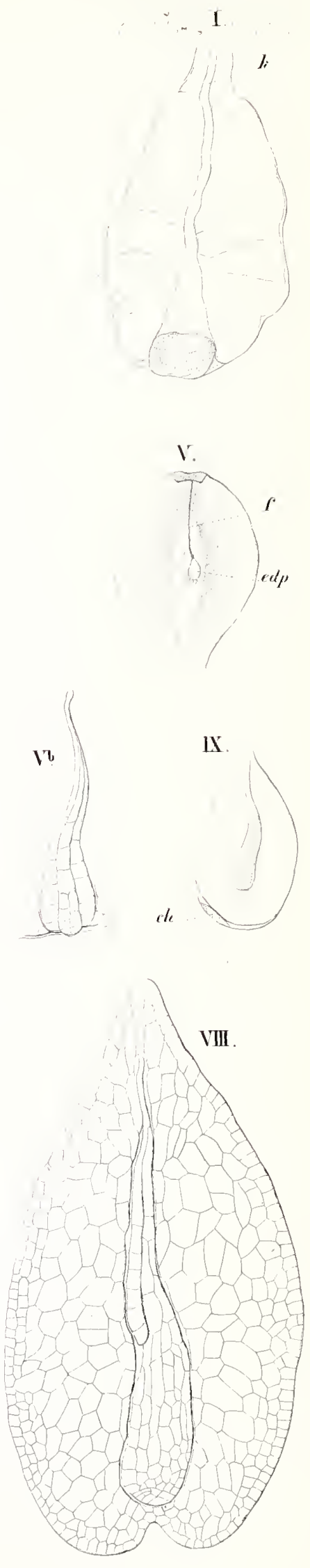

V

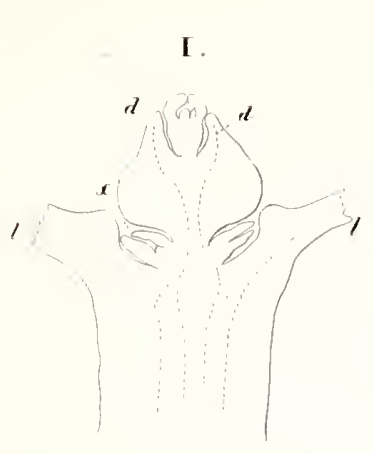

II.

II!

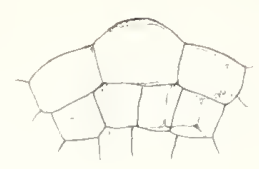

IV

III.
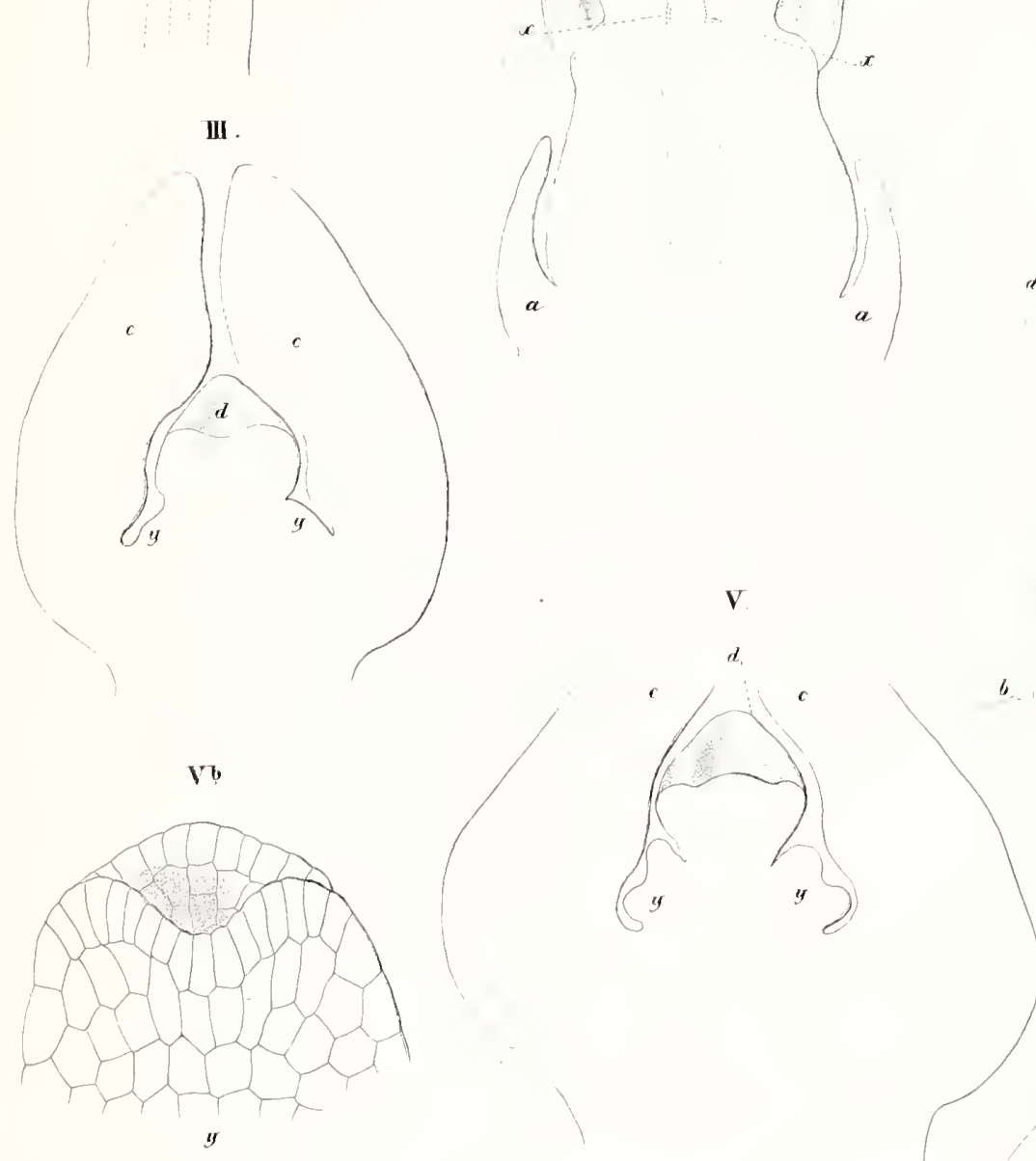

VII

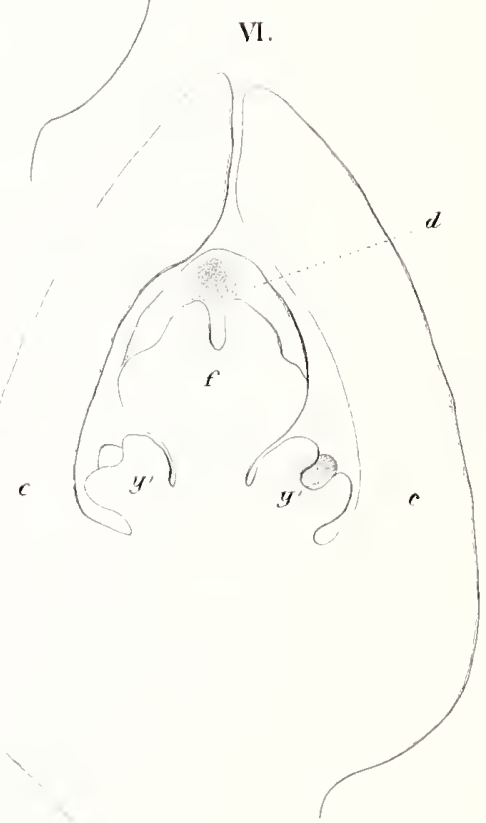

Whotmeister dol

Viscum album.

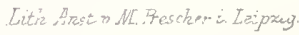



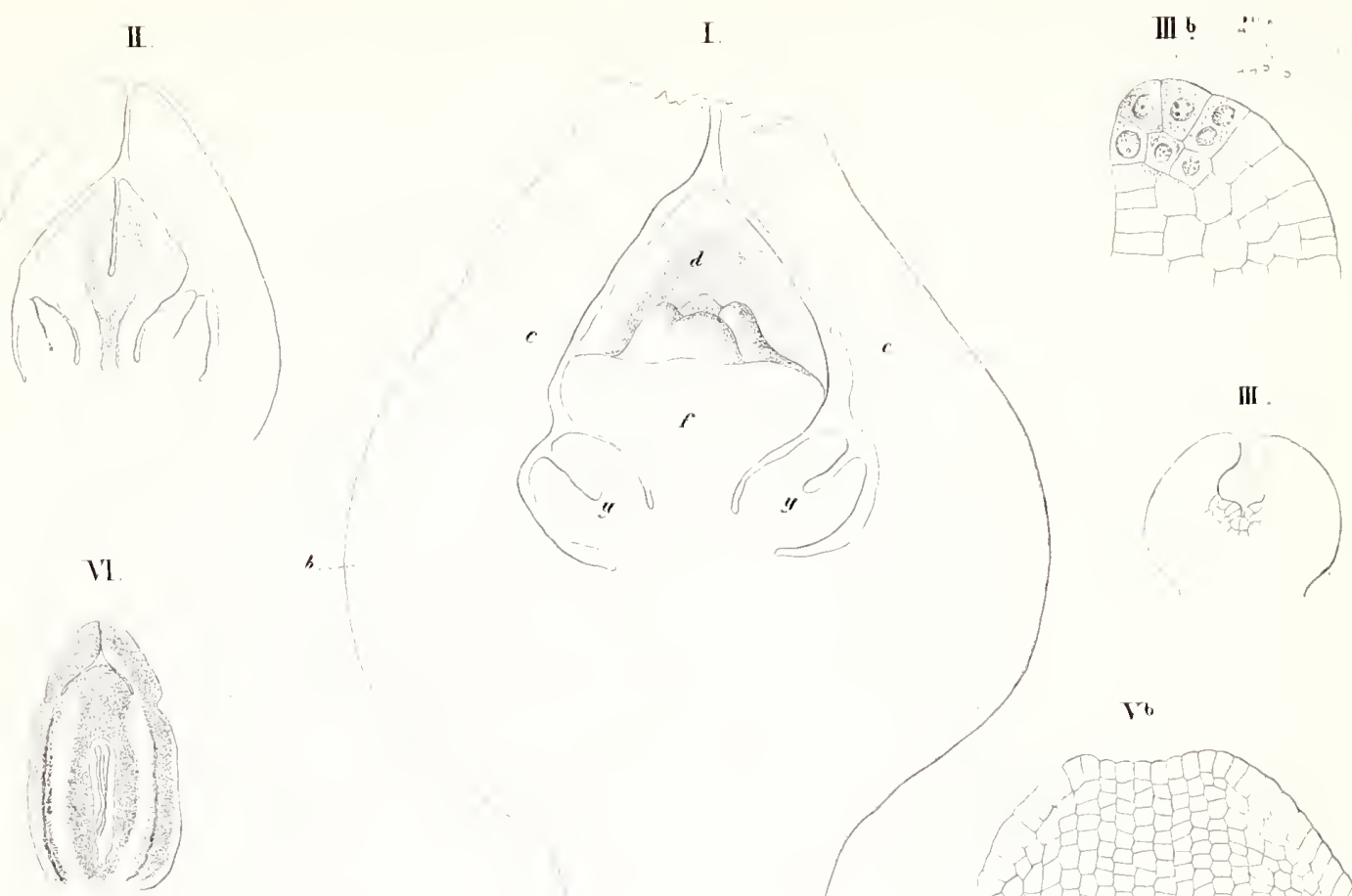

IV
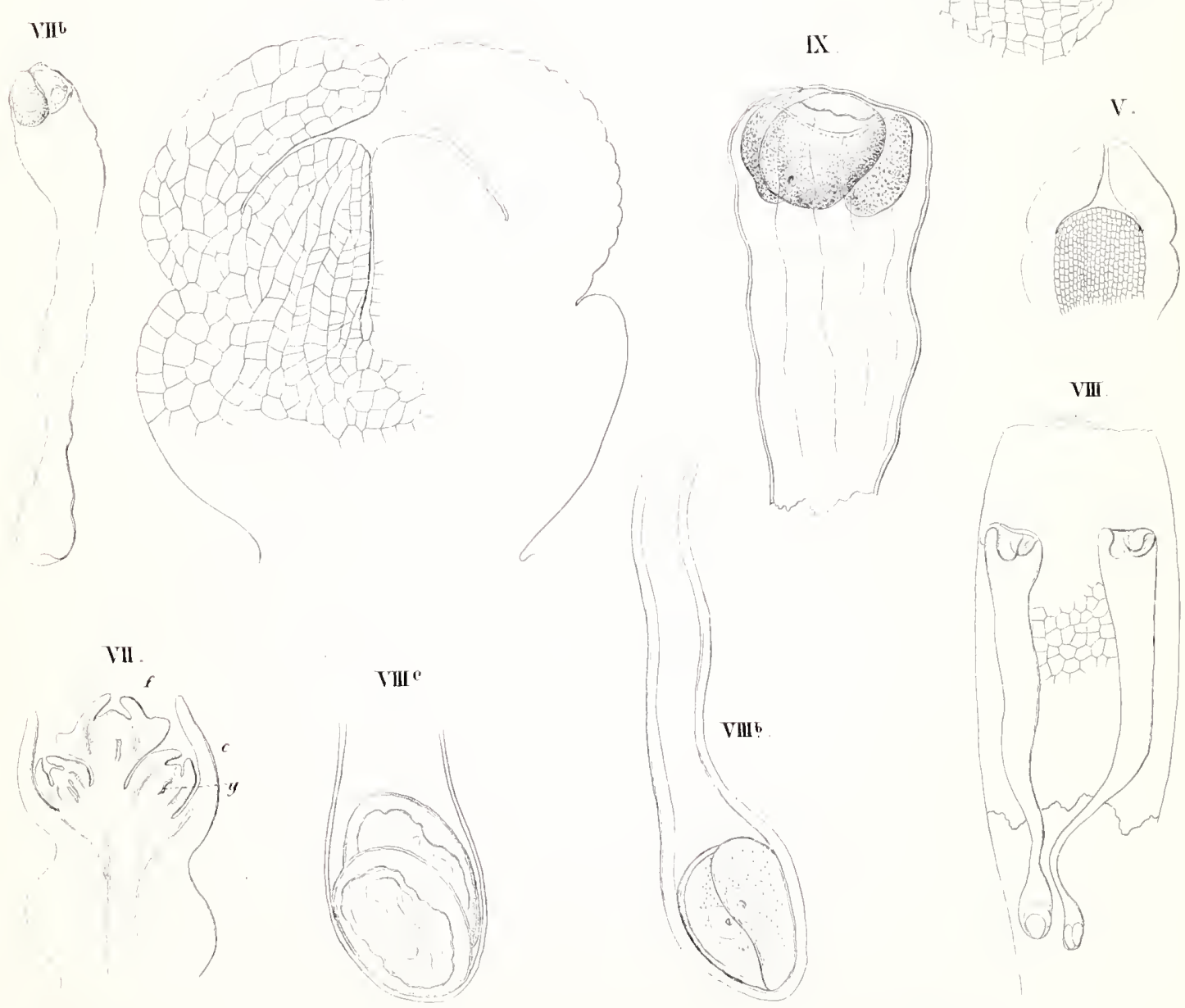

Viscrum album. 



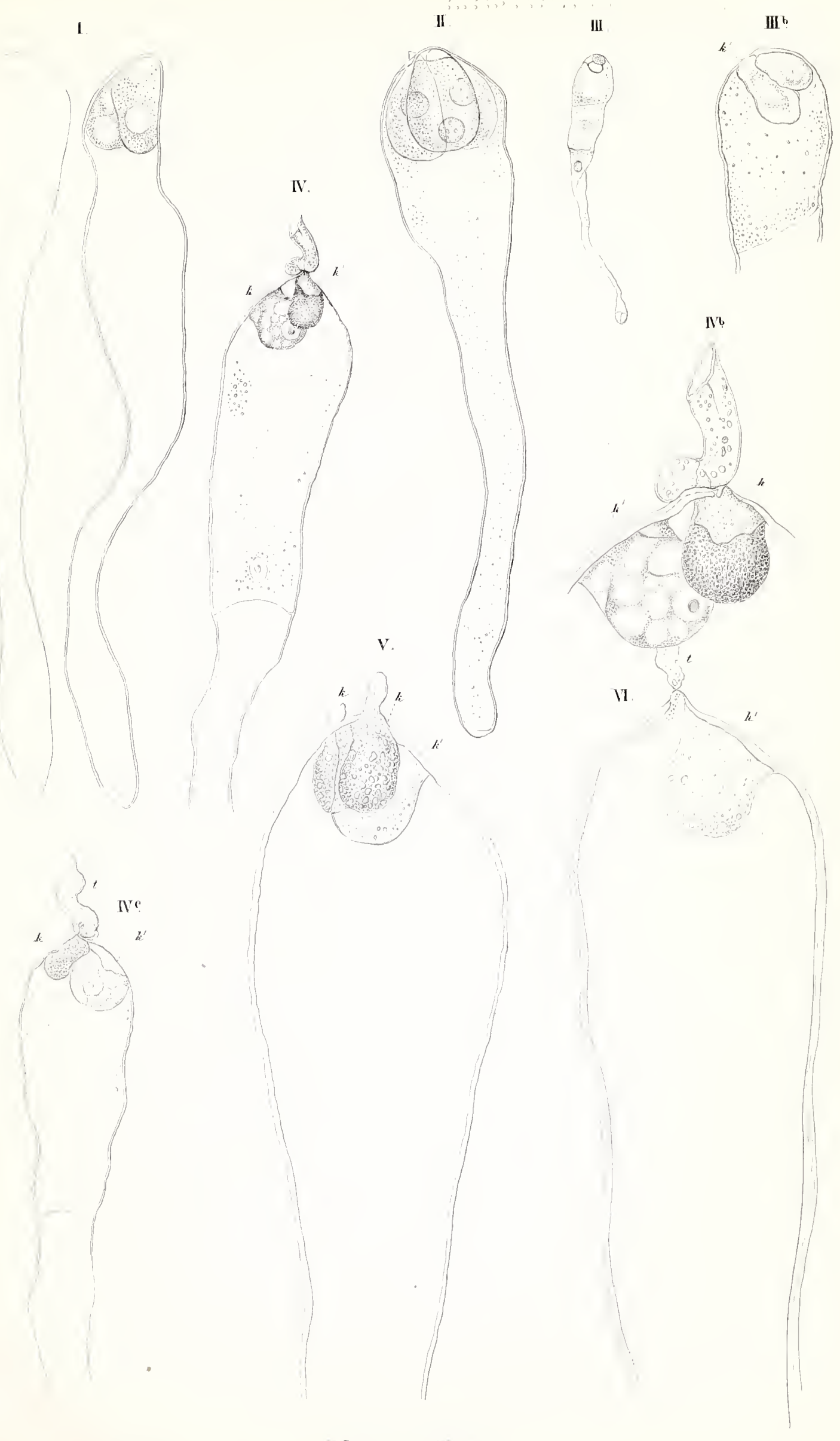

Viscum album. 



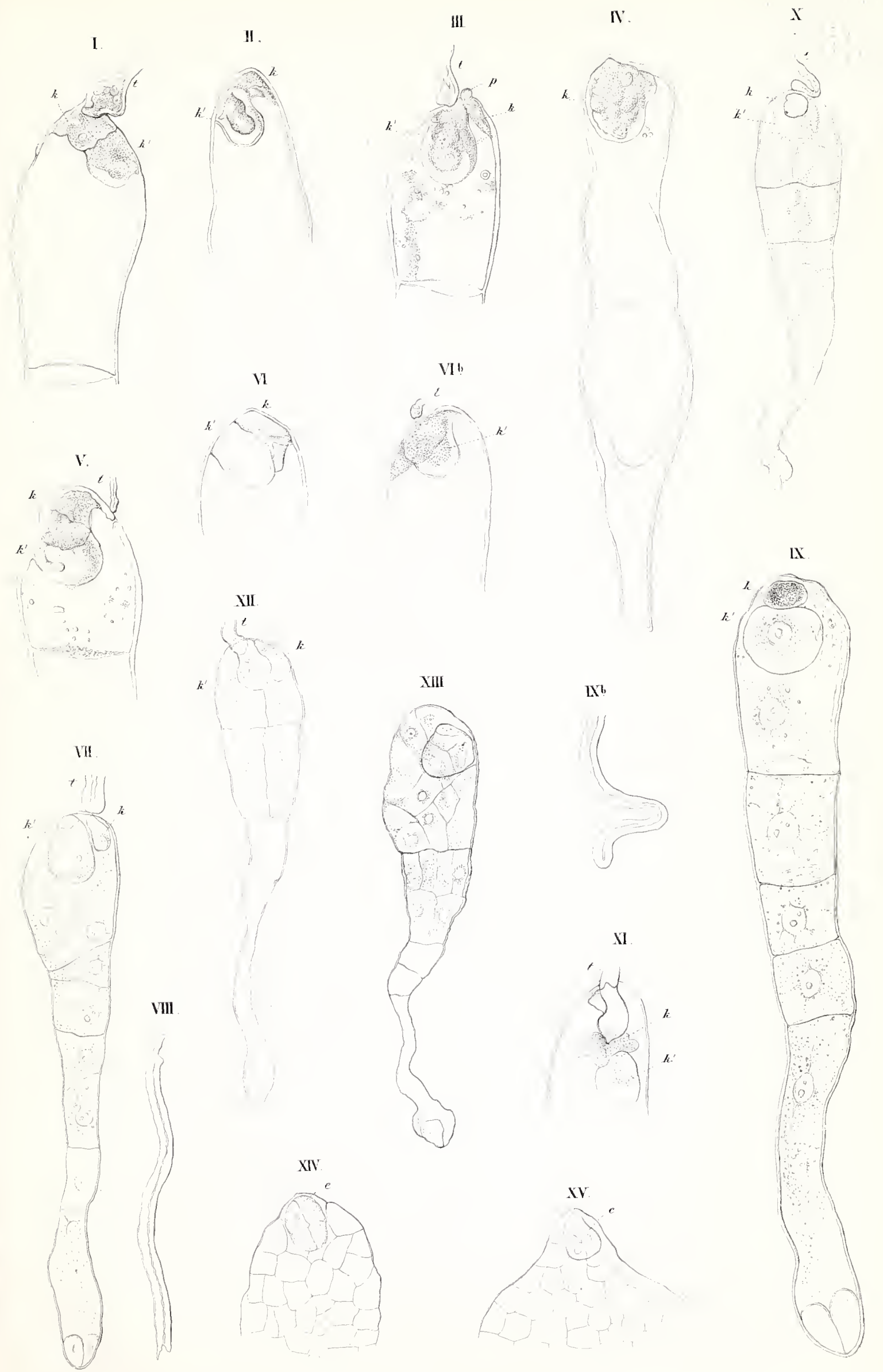

Viscum album. 

I.
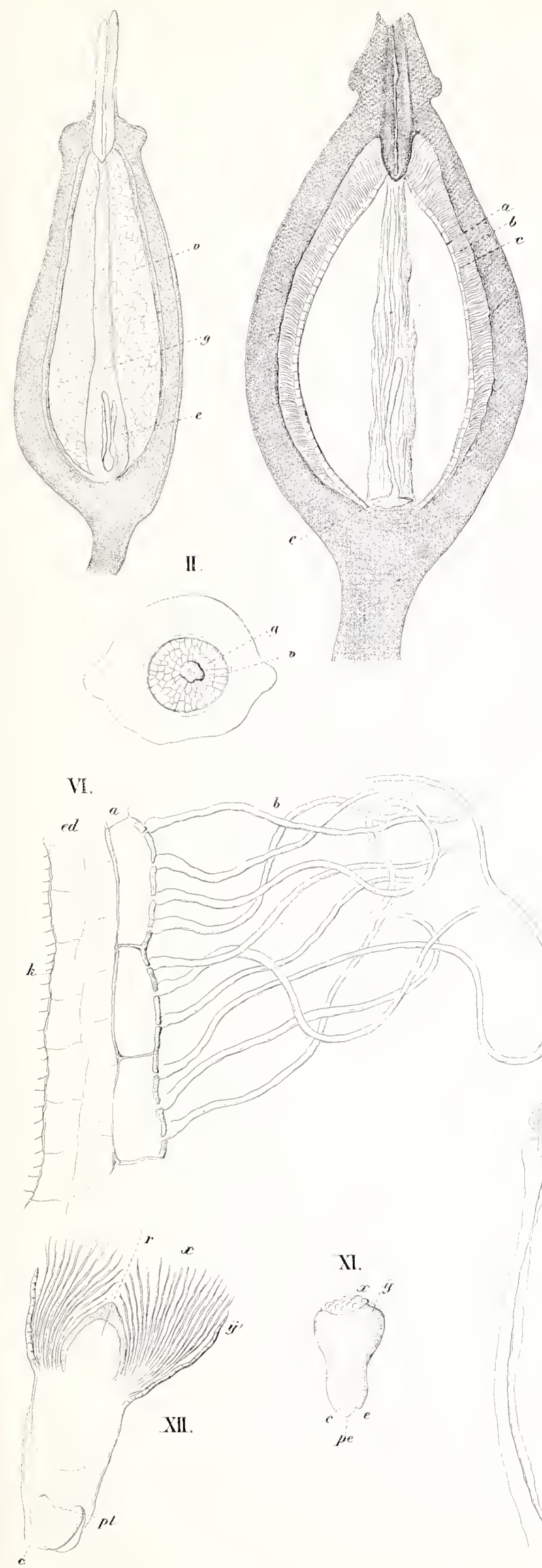

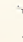

I.
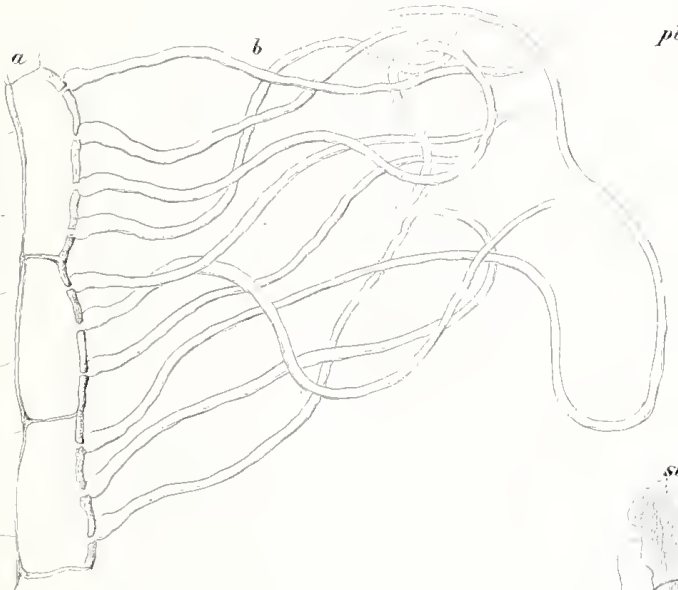

$p^{2}$

st VII .

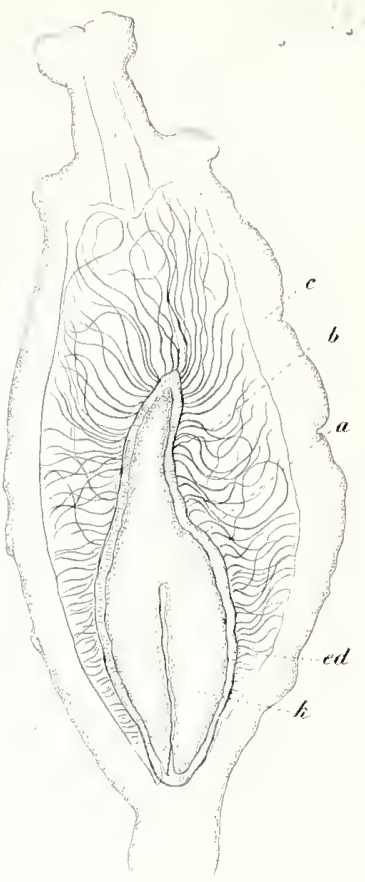

VIII

st $\quad$ X

N

V.
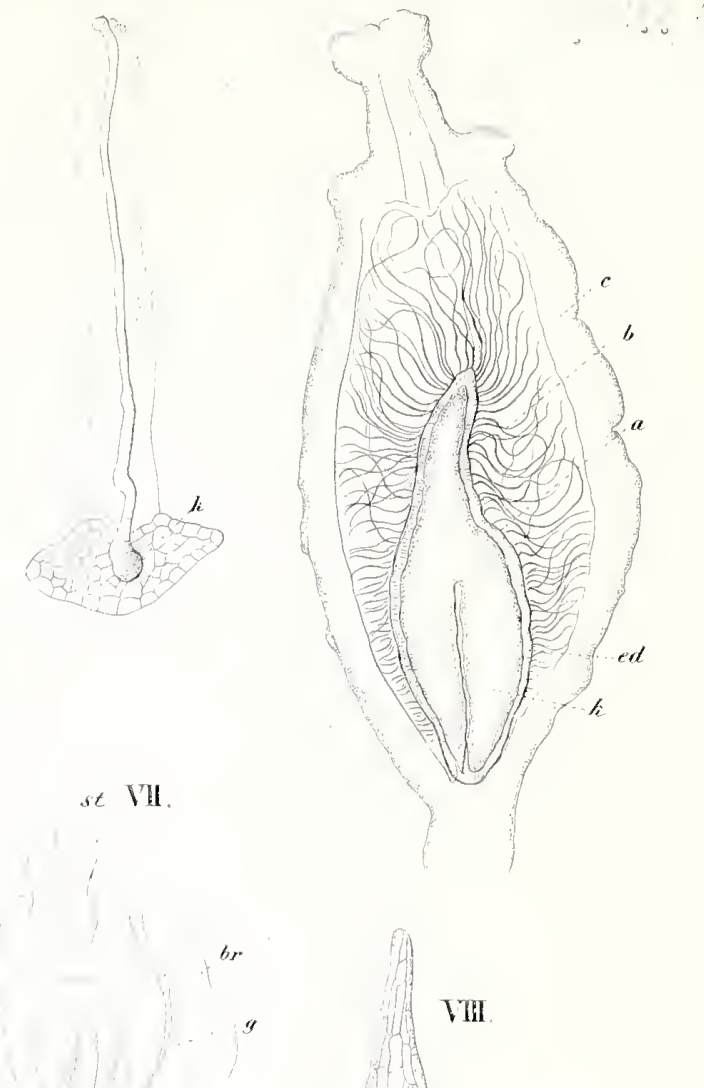

II.

1.
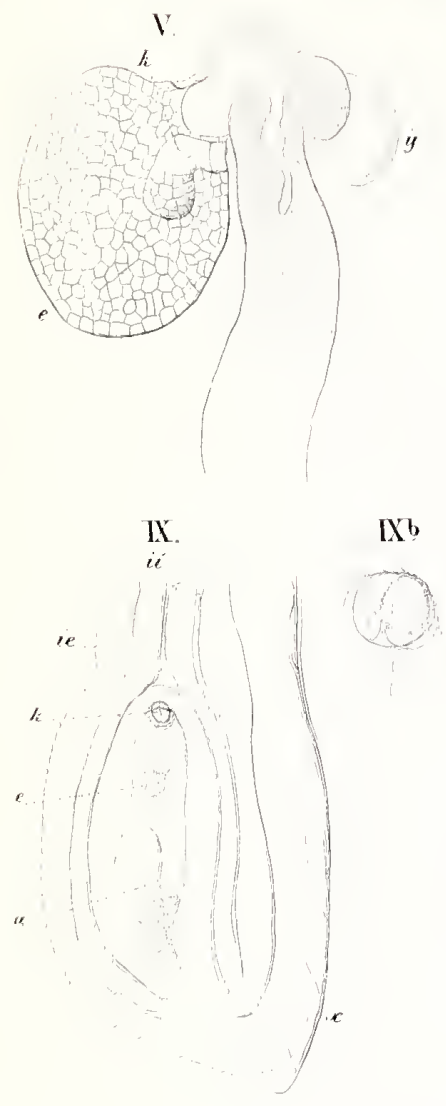

XYIII.

XVIL.

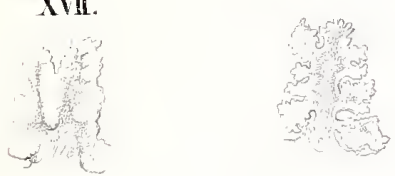

XXI.

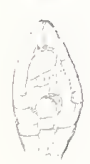

XIX

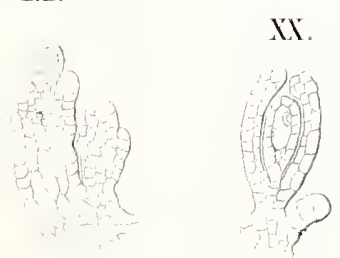

TII.

VI.

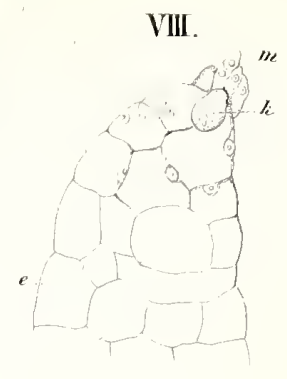

VII

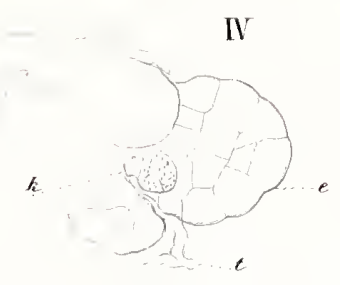

$\mathrm{XI}$

XIII

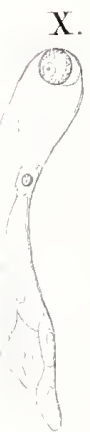

XIV

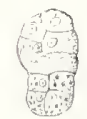

XIT

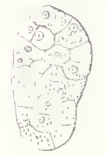

XXTV.
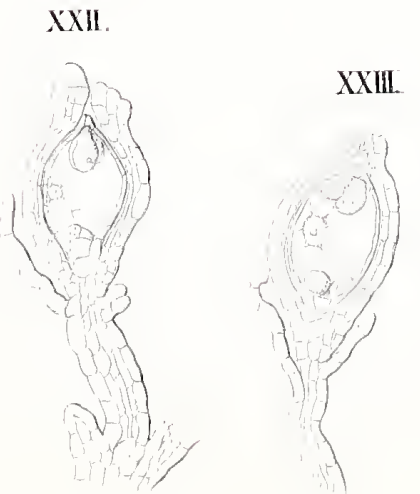

$\mathrm{XXY}$

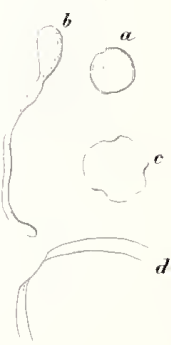

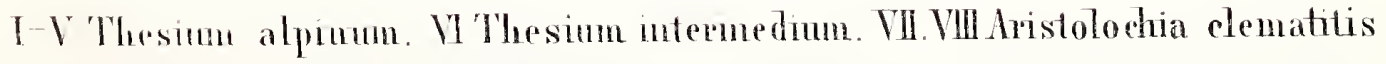
X-XII Asarum canadense. IX XIII-XVI Asarum europaenu. XVII-XXV Cytinus Hÿpo= cistis. 



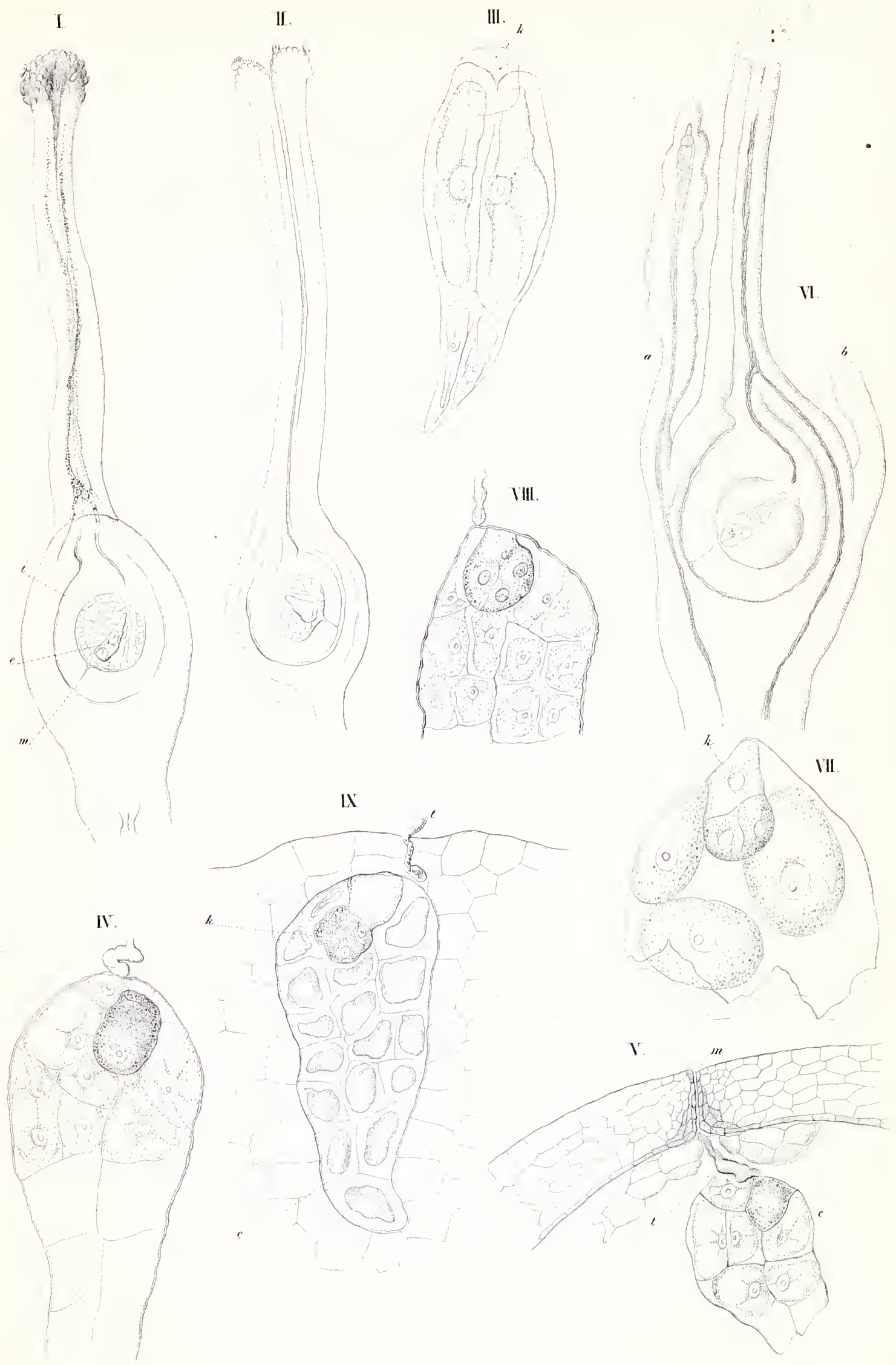

CYnomorium roceinsum. 



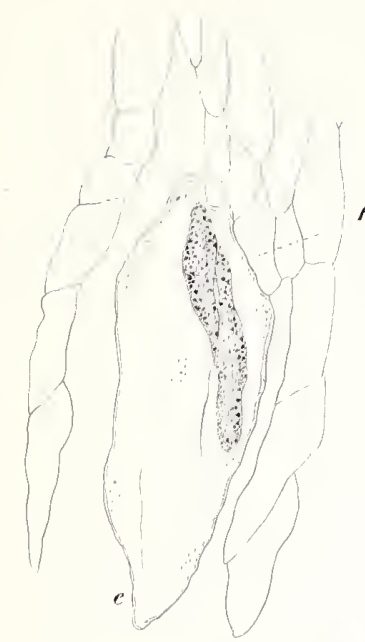

S
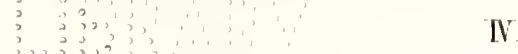

II.
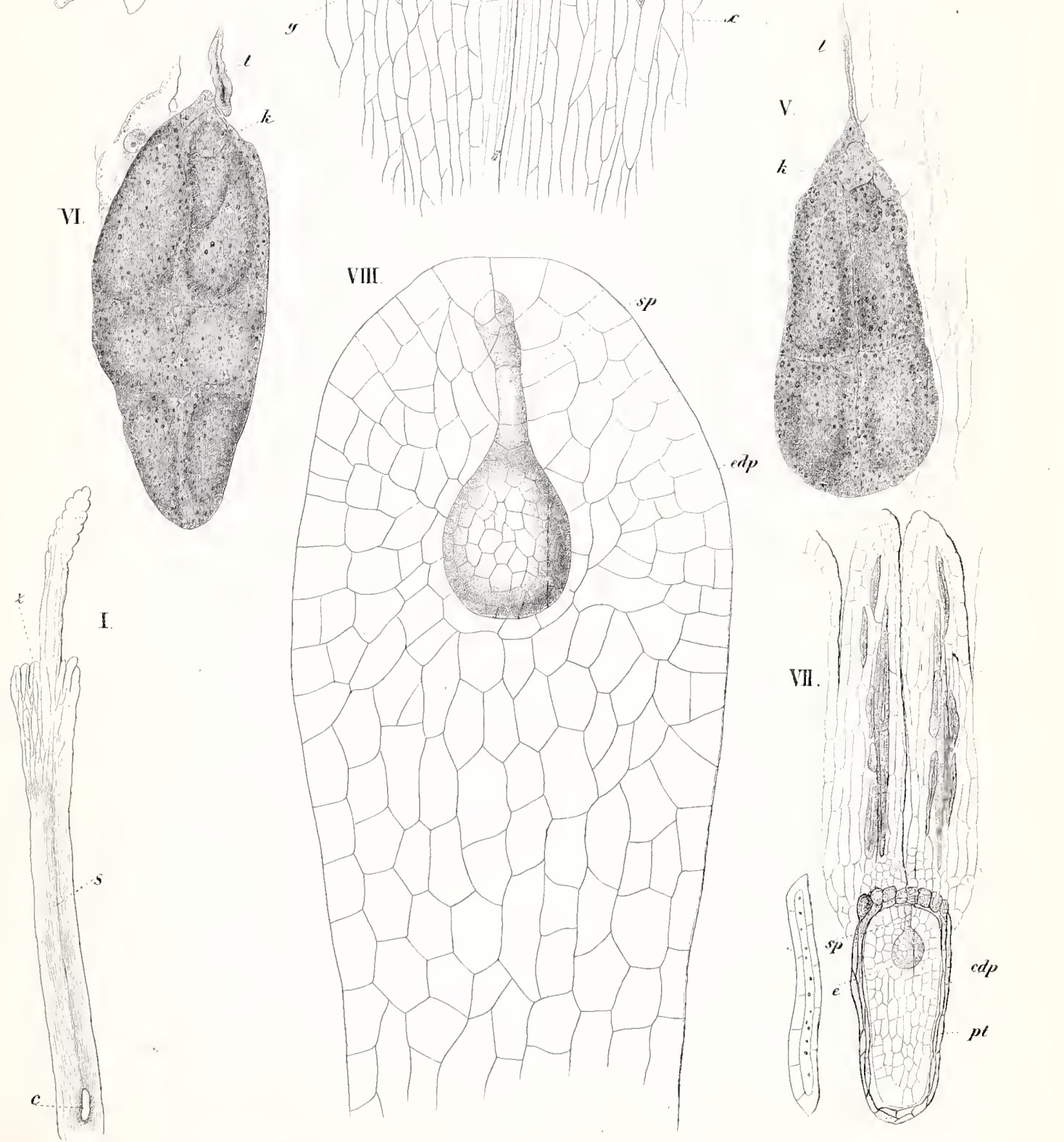

Langs sorffia hÿpogaca 

XIII.
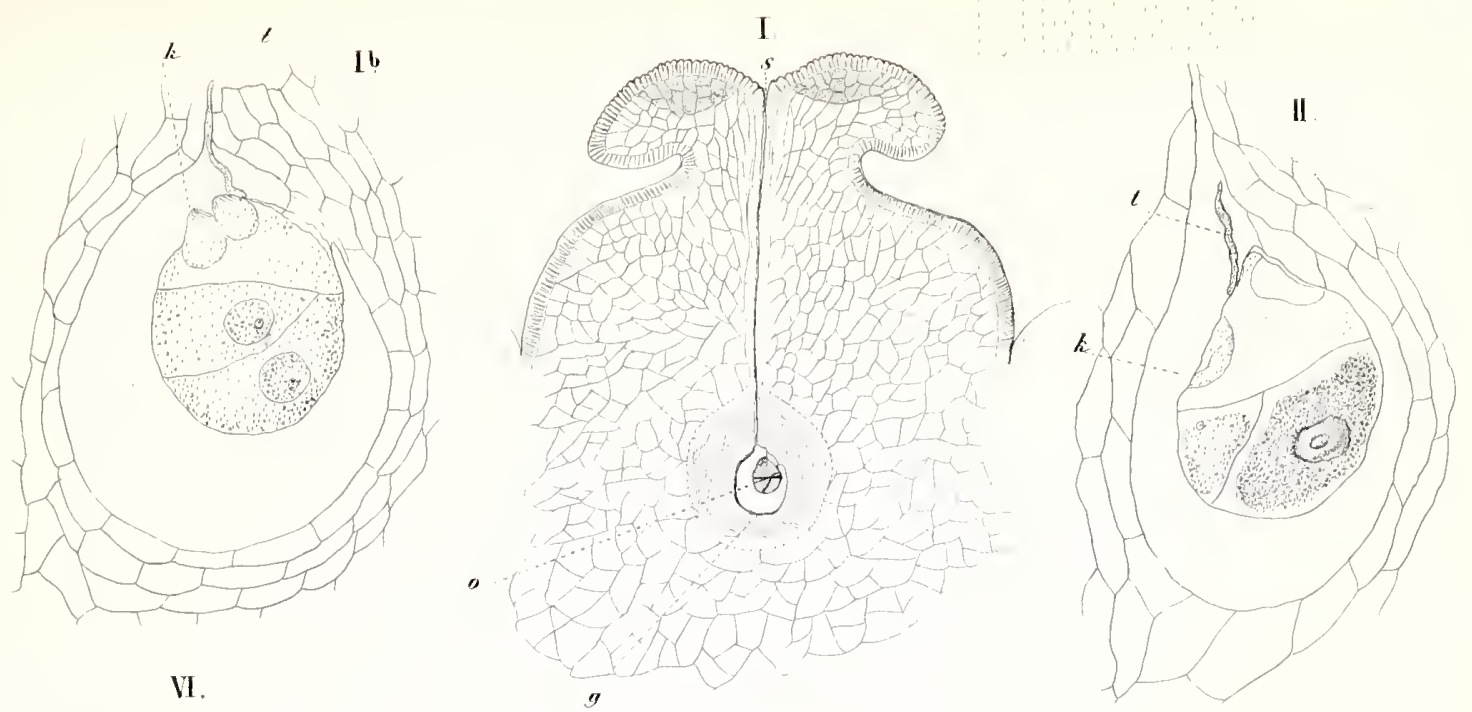

VI.
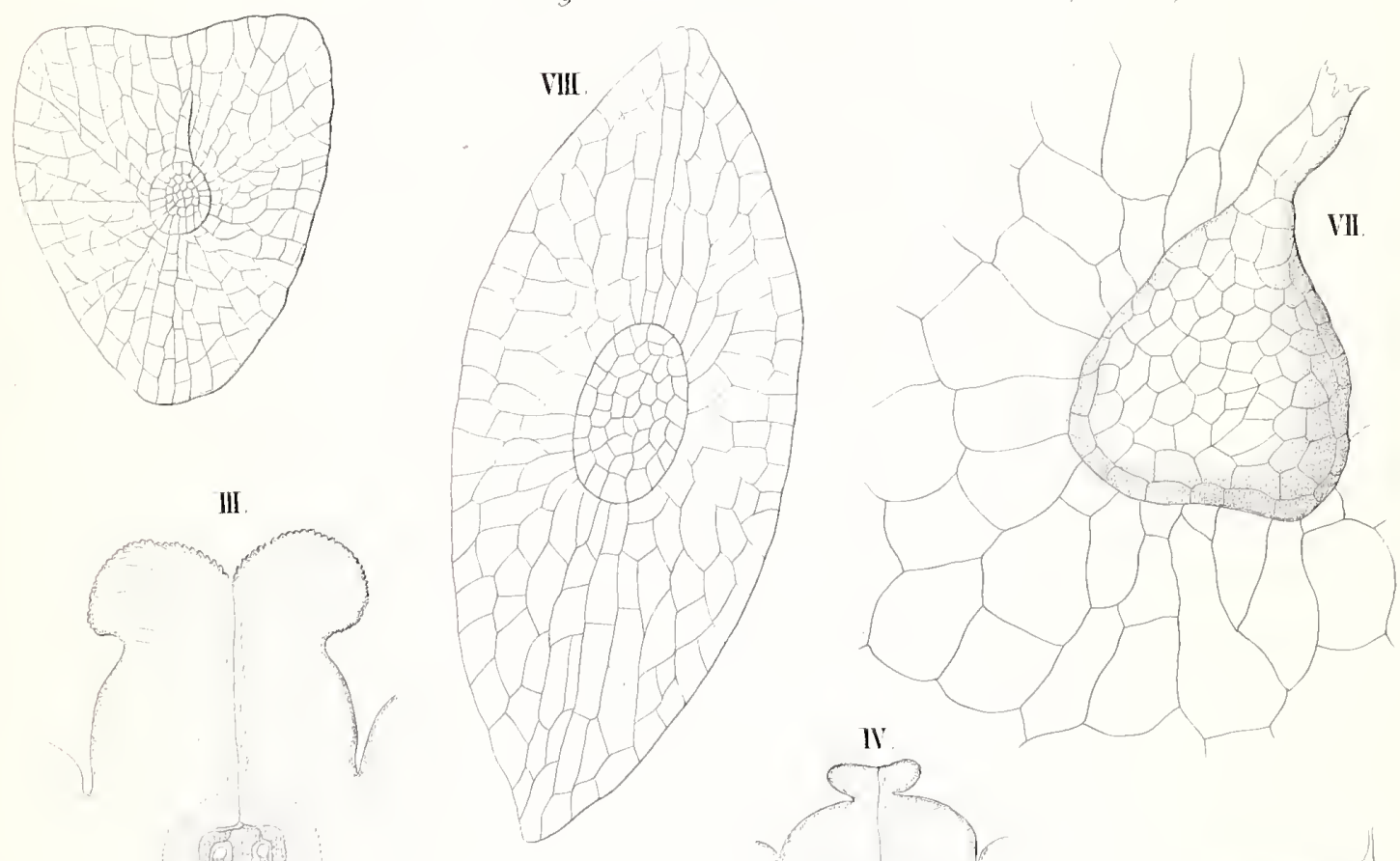


$$
\text { . }
$$


XII.

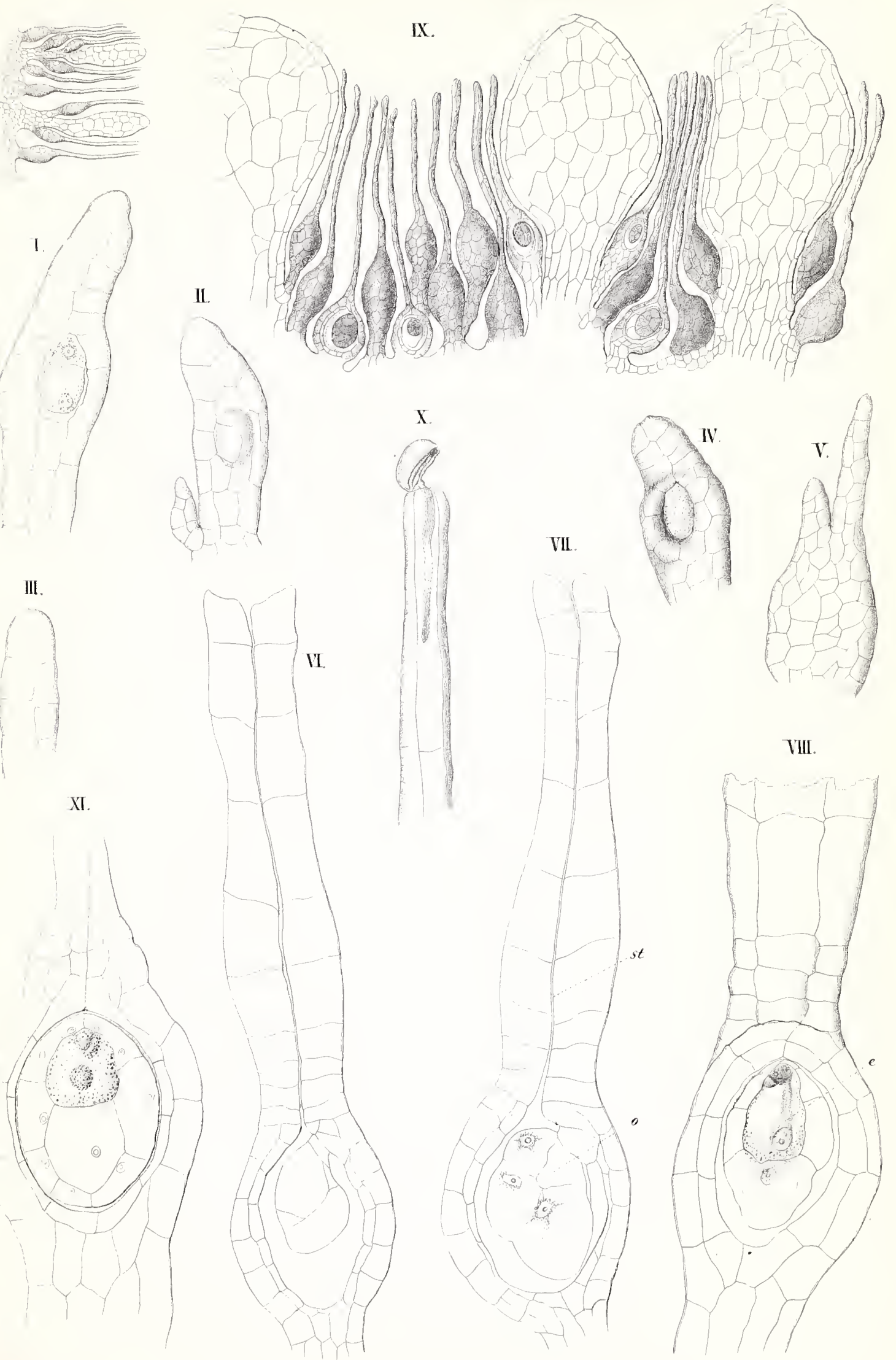

1-III Balanophora dioica. IV I XII B fungosa VI VII VIIIB Burolucrata IX-XIB polyandra. 



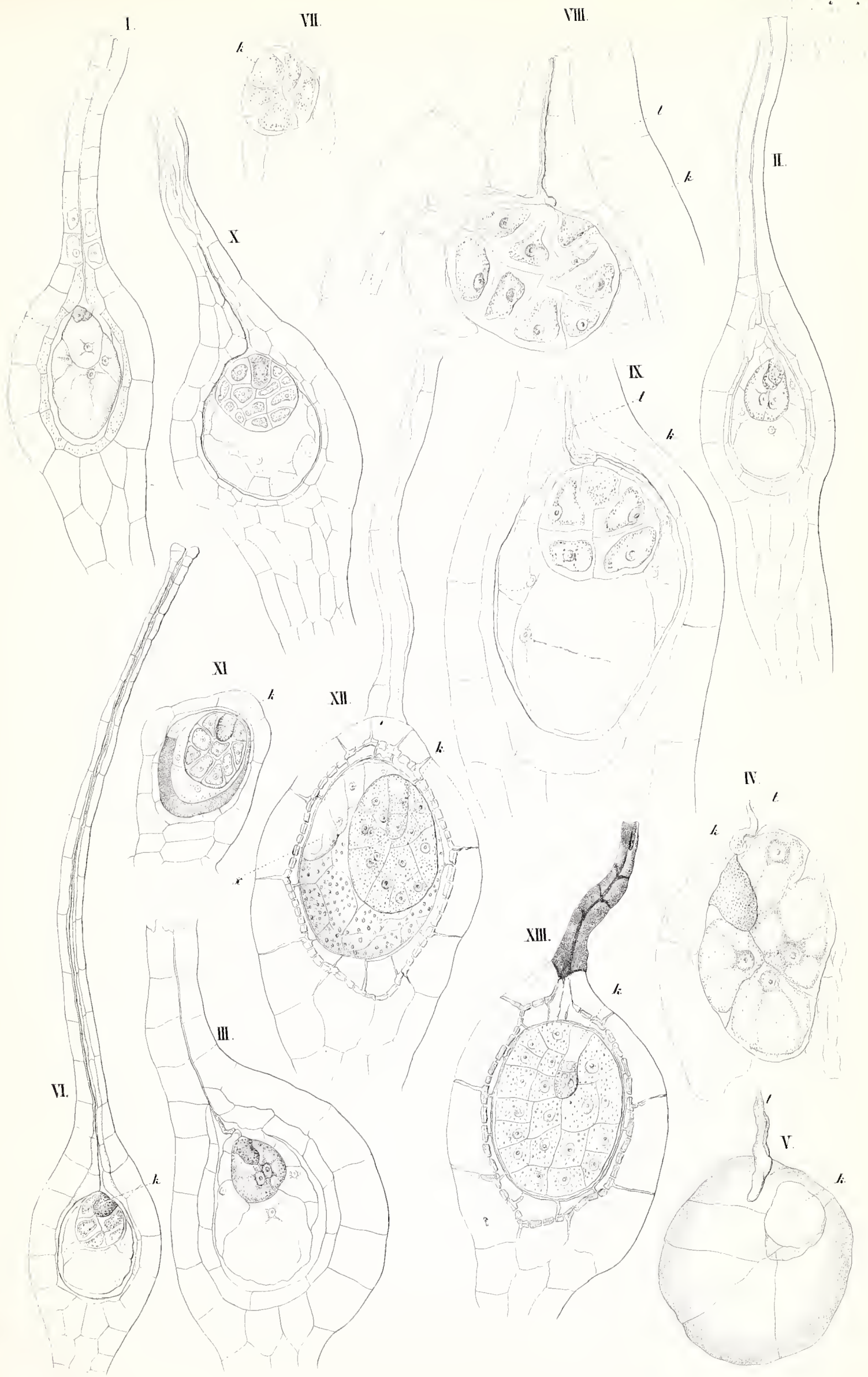

I-Y Ralanophora polyandra. VI-XI B. Rungosa. AlI XIII B dioica. 


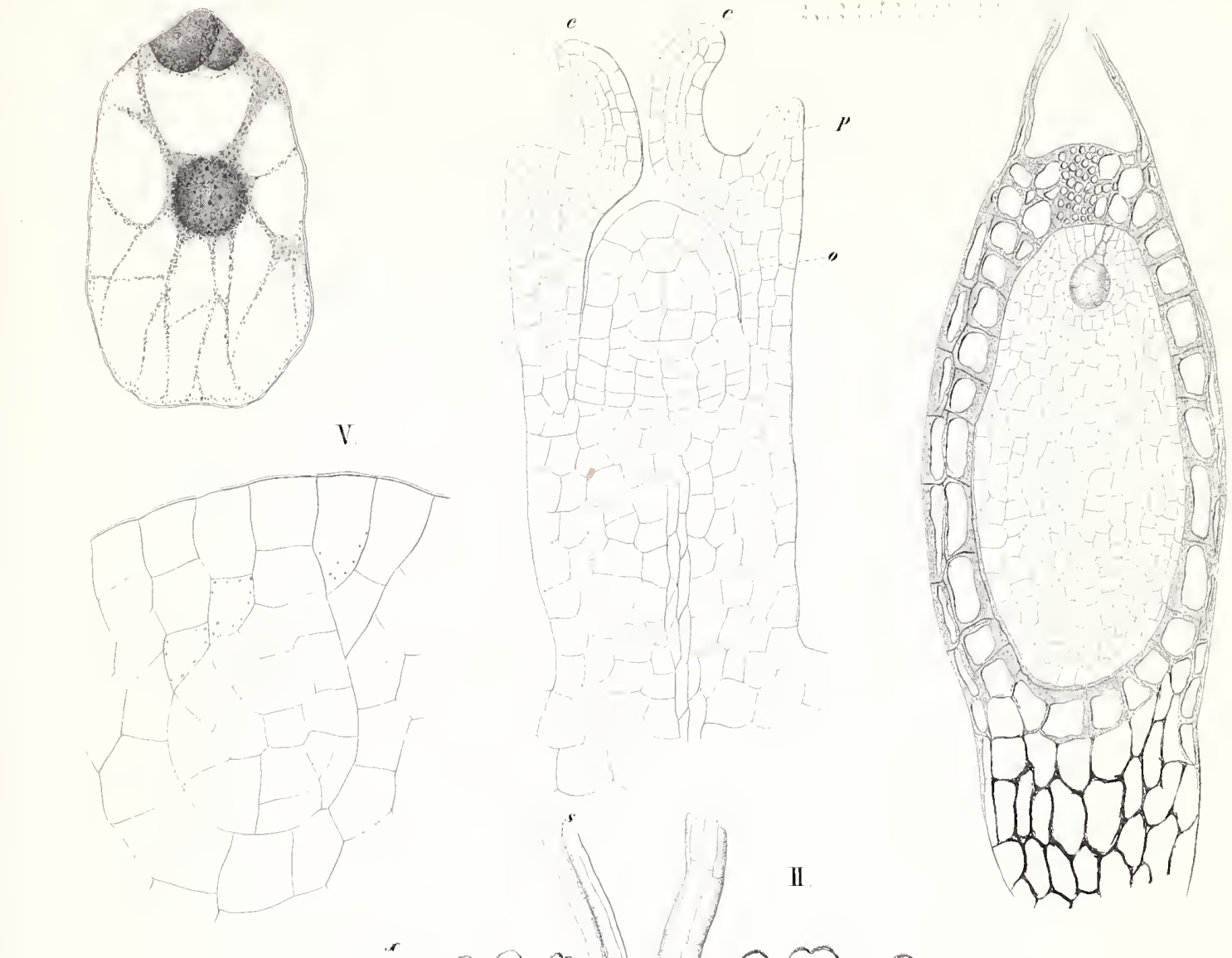

II

$m$
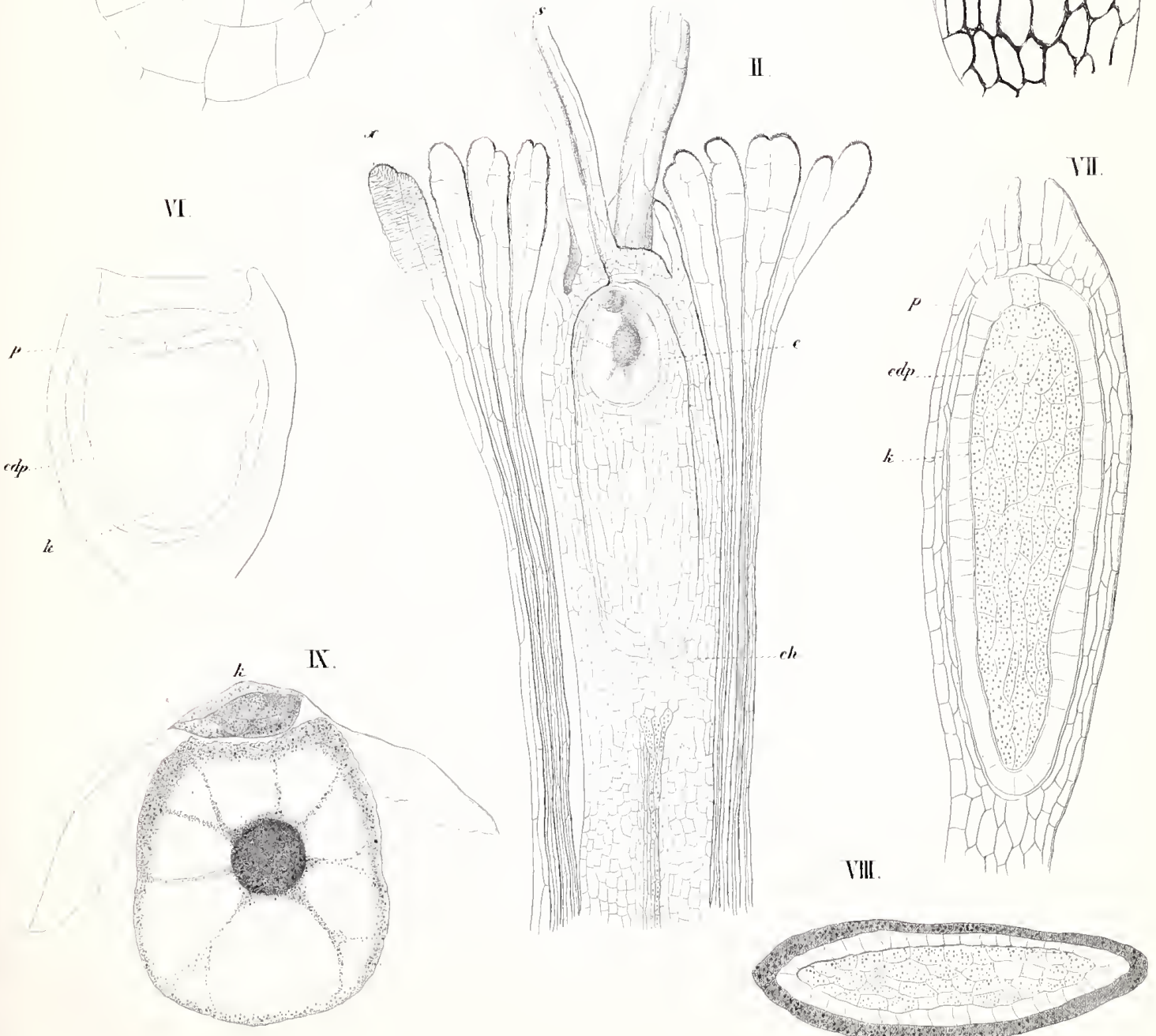

VIII.

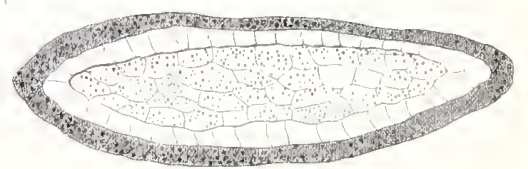

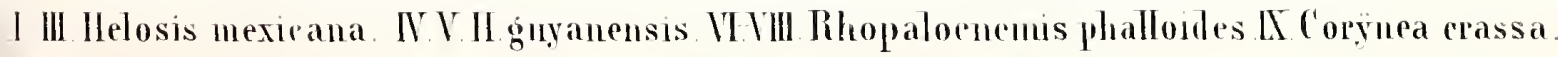



XVII.
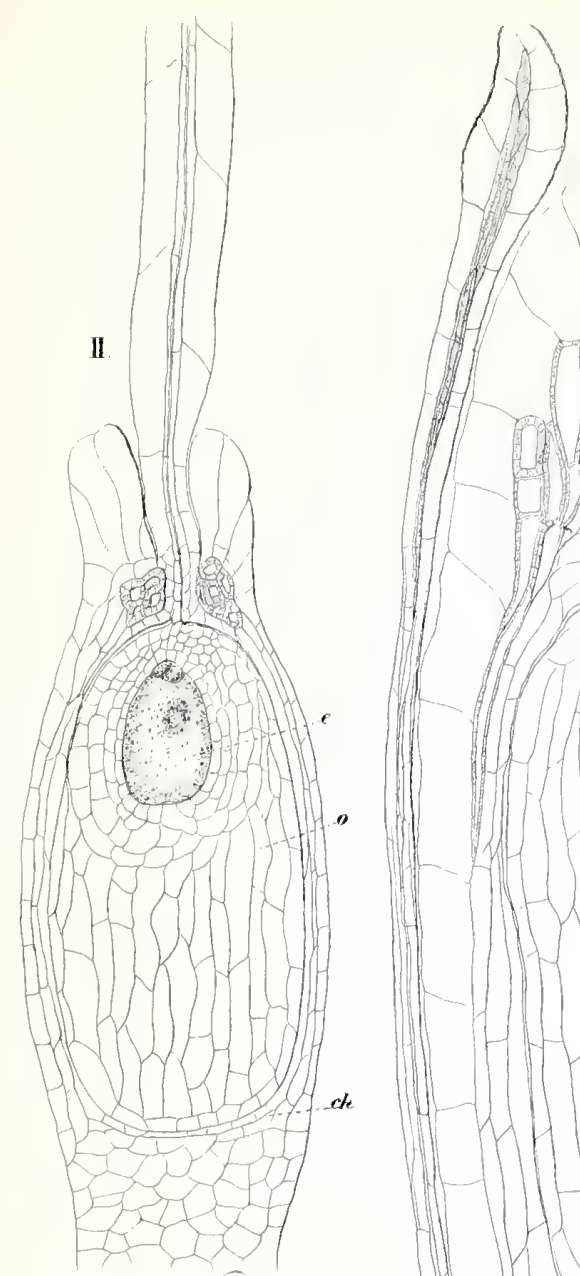

VIII.

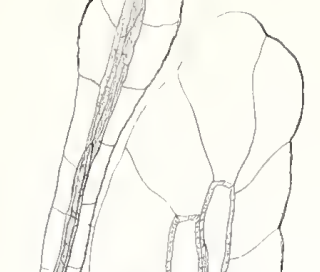

I
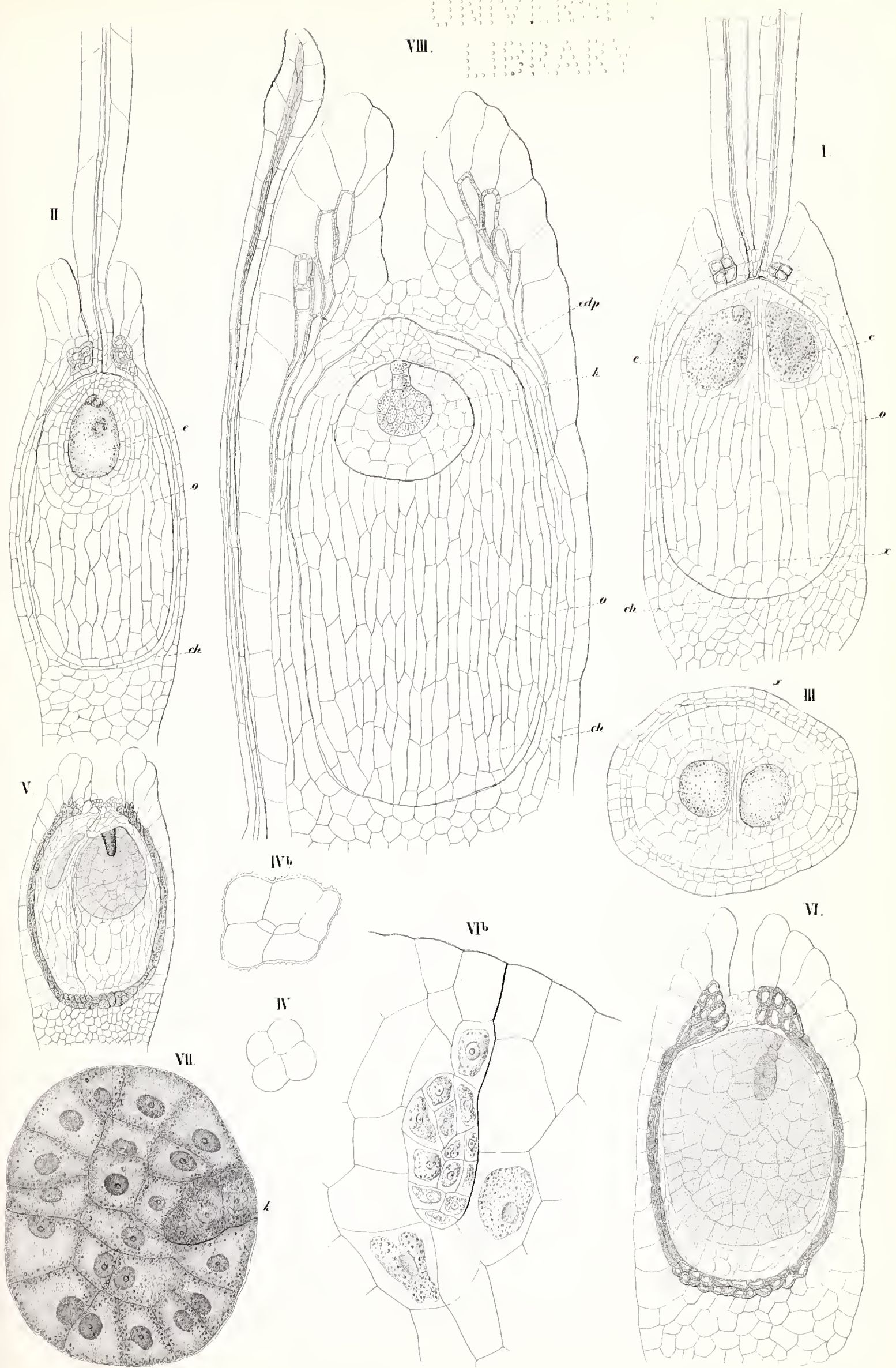

1-VI Scybalium fungiforme. VII. VIII Phÿlocorỹue jamaicensis.

WW Hofmeister in

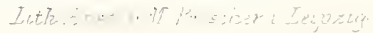





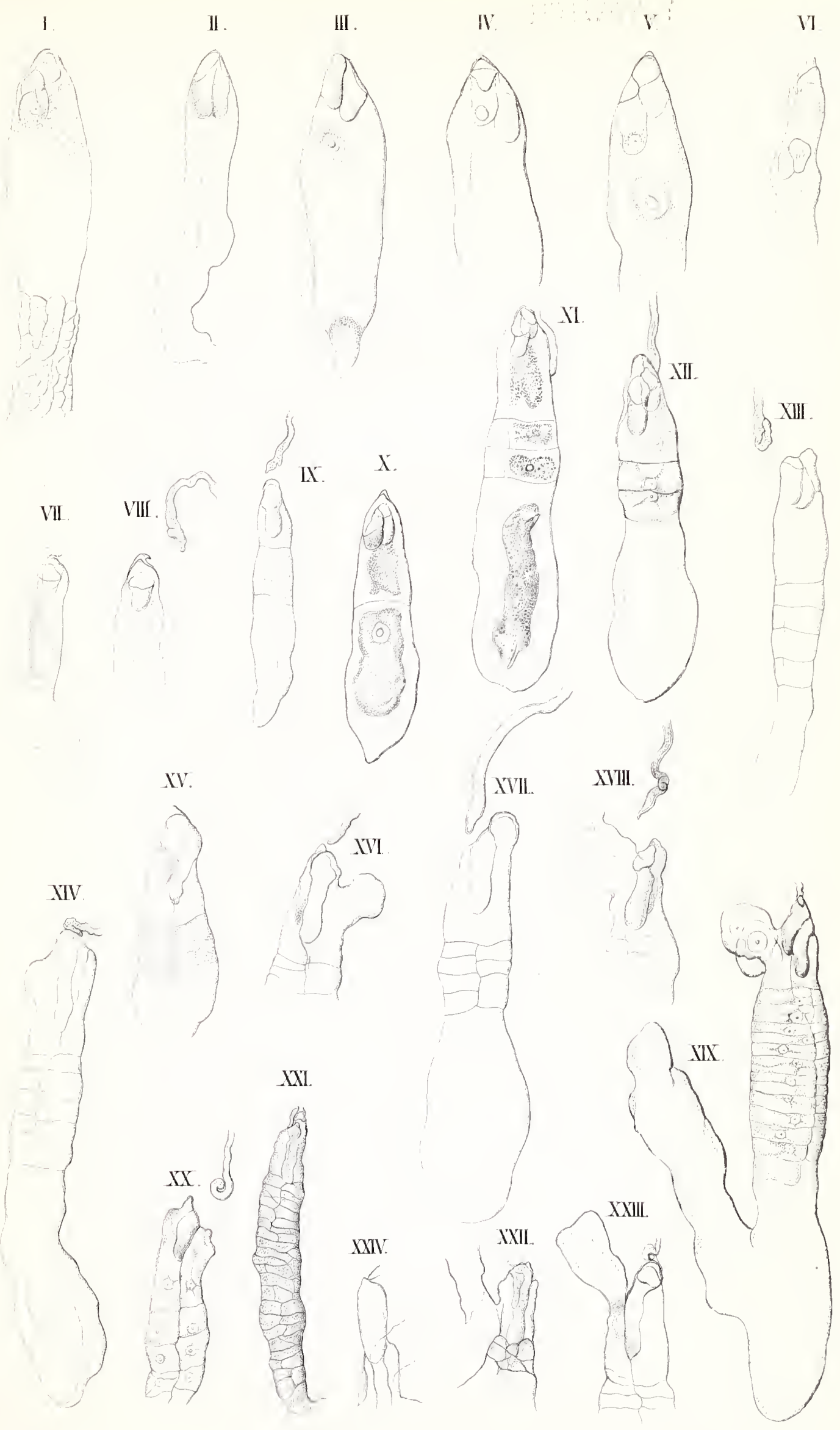

Lathraea squamaria. 

XIX. 


II
IV
I.
II.
YII

$\frac{1}{4}$
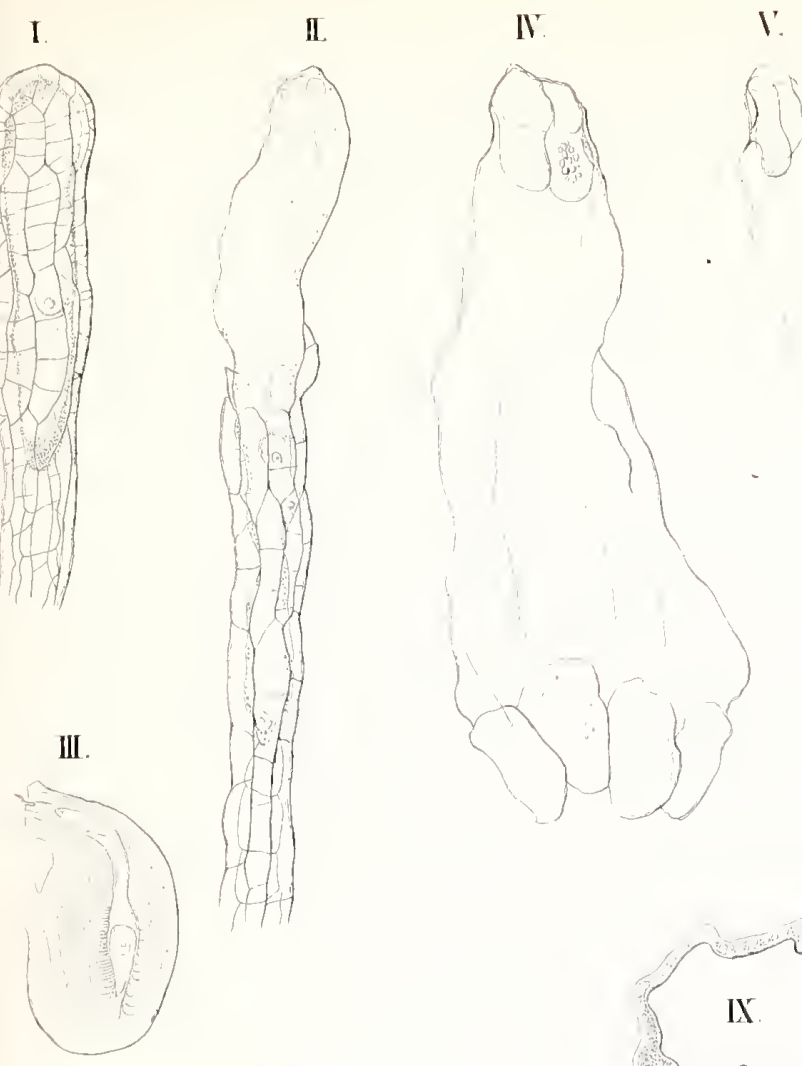

SU

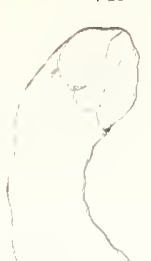

I'III.
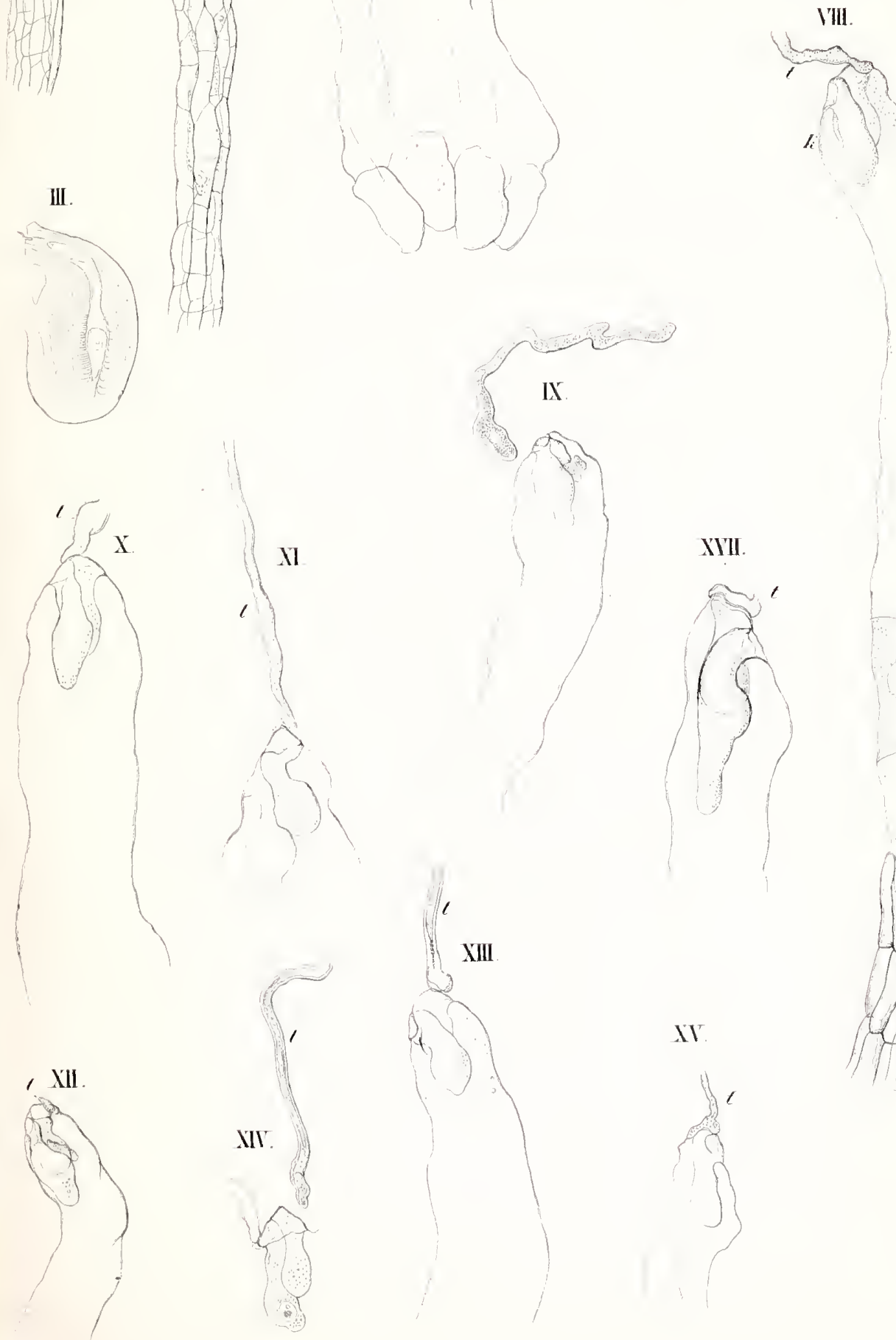

$\mathrm{NT}^{\mathrm{T}}$

, XII.
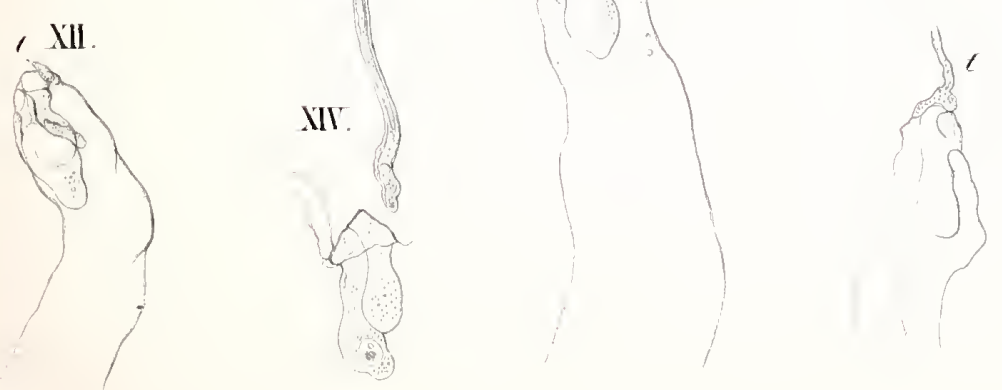

XII.

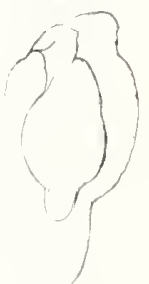

Pedicularis sylvatica. 



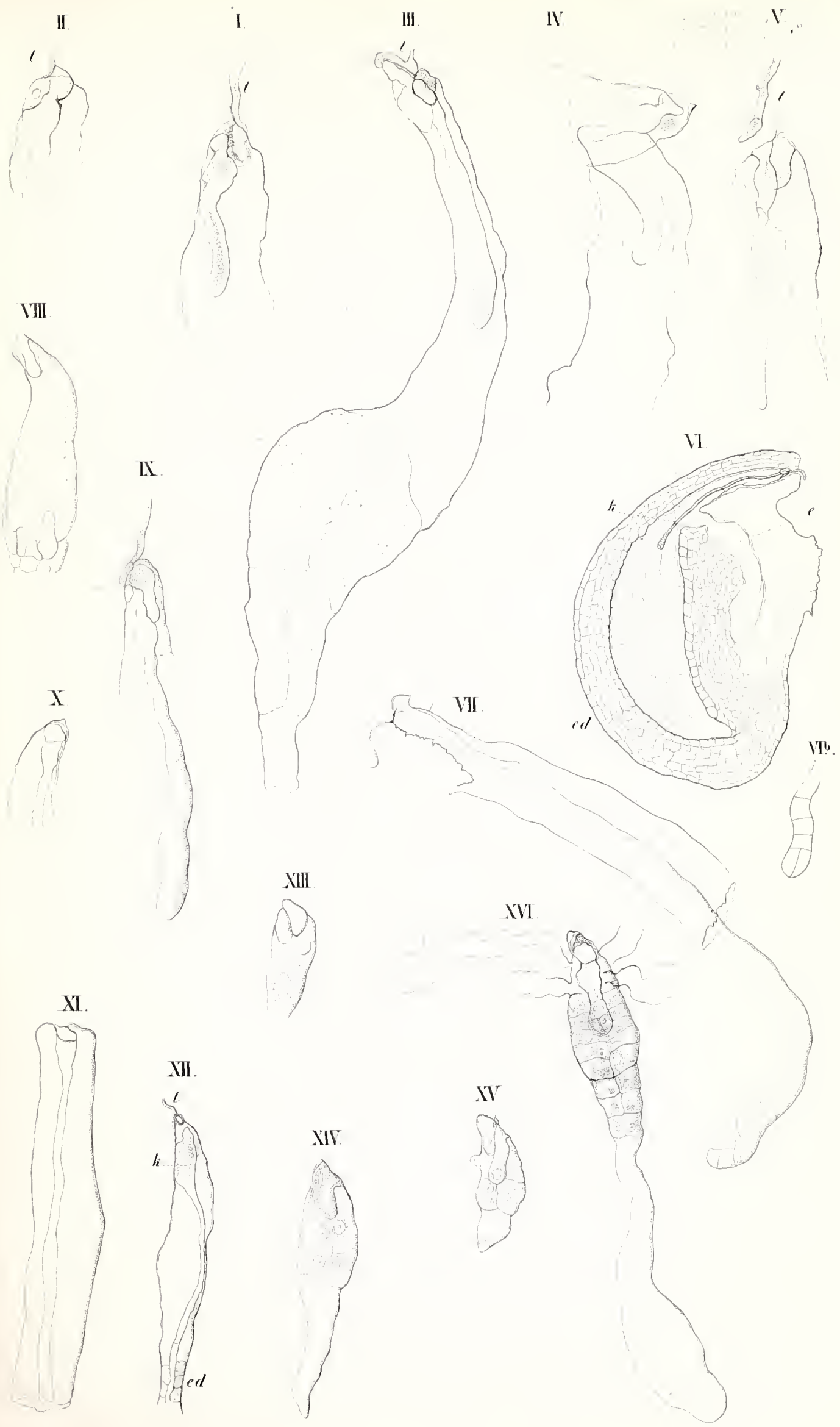

I-VII, Pedicularis sylvatiea. VIII-XI,Pedicularis comosa Xll, Luphrasia officinalis .XII-XVI, Mazus. 

1.
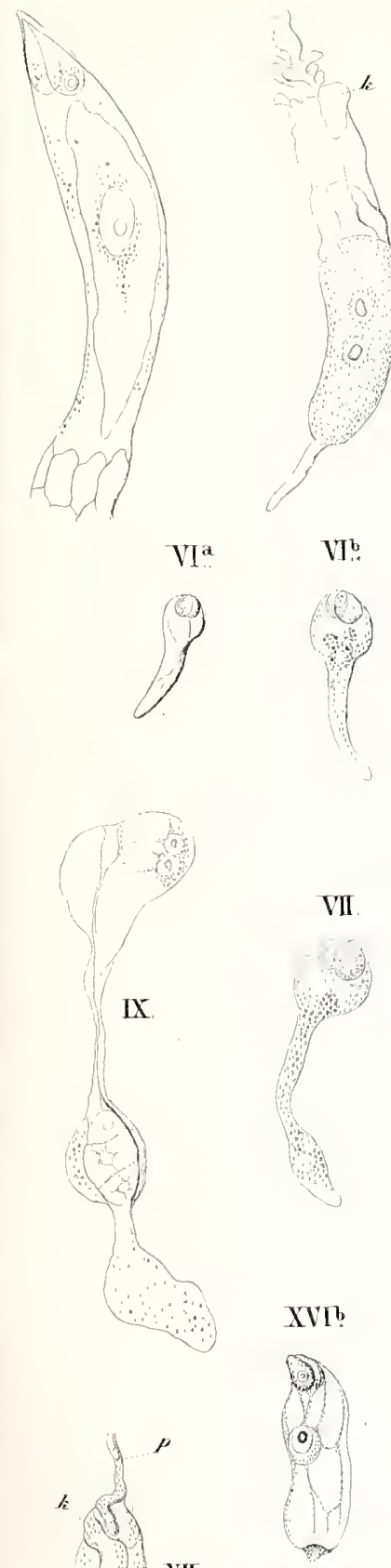

XII.

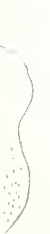

II.

V.

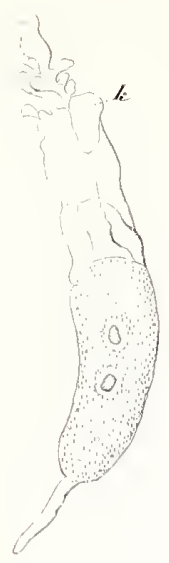

$\mathrm{VI}$.

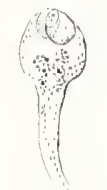

VII

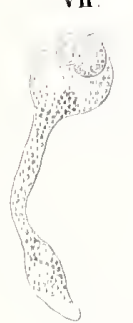

XVก!

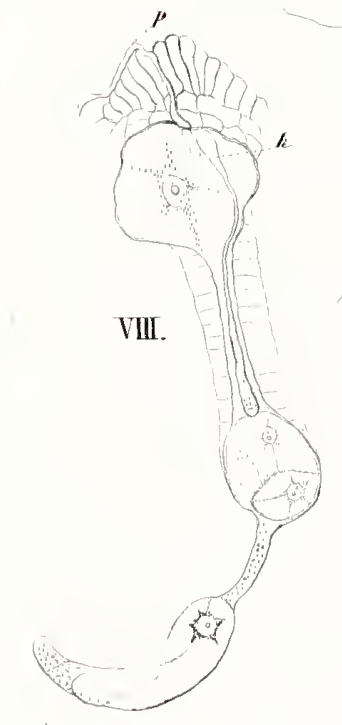

XI.

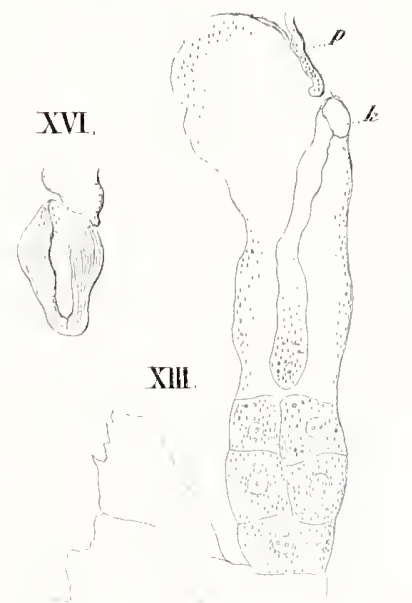

$\mathrm{XV}$ ?
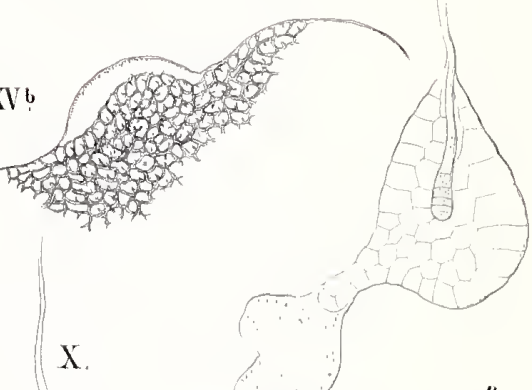

iV

食
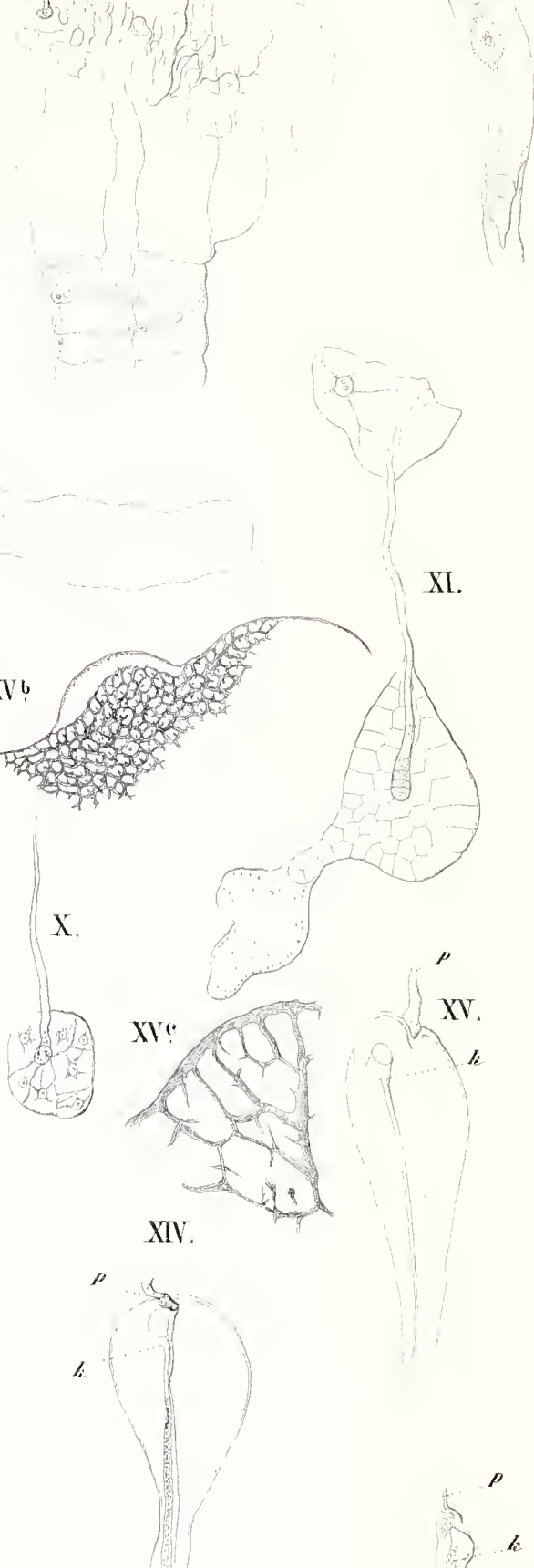

XVII.

I-III Rhinanthus hirsulus. IV-V Rhinanthus minor. VI-XI Veronica Buxbaumii. XII. XIII. Veronica hederaefolia. XIV.XV Veronica triphÿlos. XVI XVII Nemophila insignis. 

III.

II.

II.

VII.

VIII

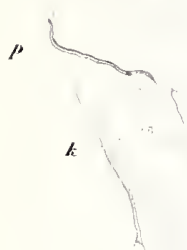

VII

IX

V.
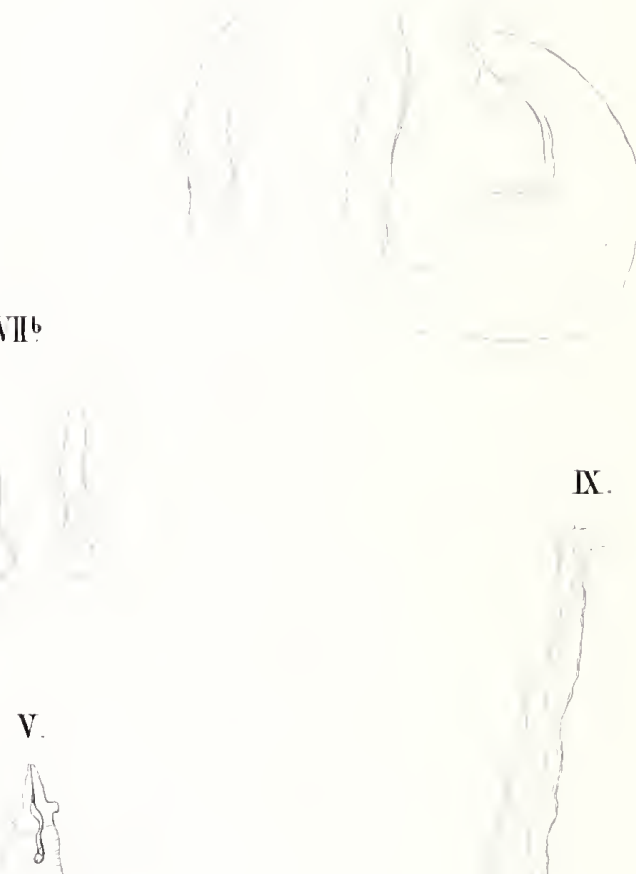

I-VI. Melampyrum nemorosum. V'll Catalpa syringacfolia VIIL IX Aeanthus spimosus. 
I.

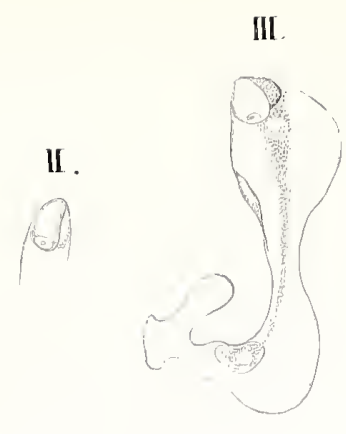

VIII.

VII.

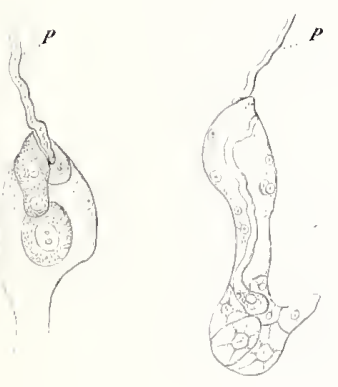

XII

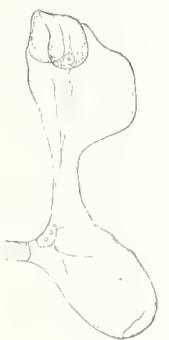

XVI!

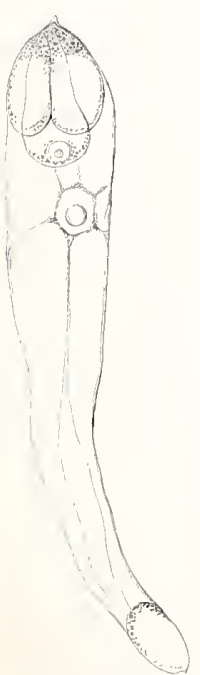

IX.

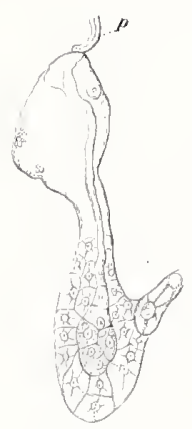

XVI

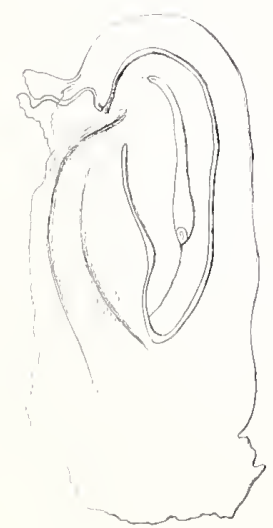

IV.

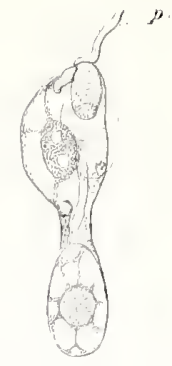

X.

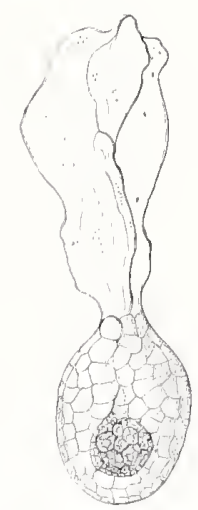

II

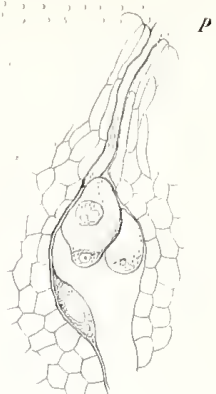

XIV.

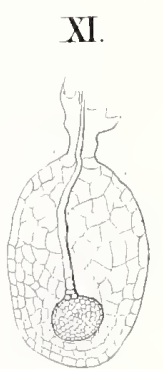

XVIII.

XV
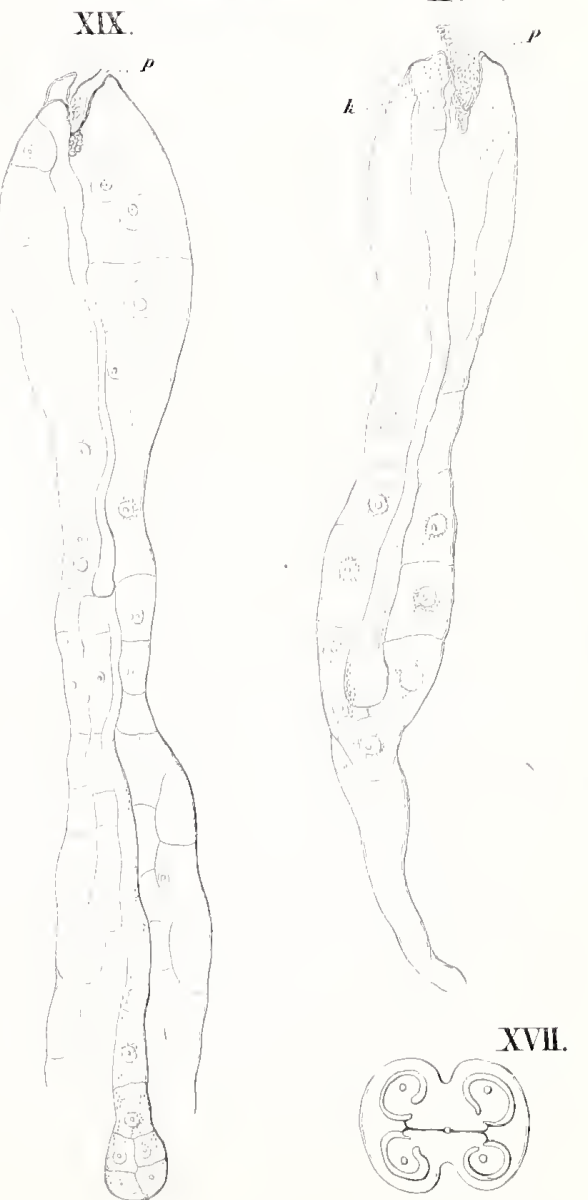

XX

I-XI Lamiun purpureum. XII-XV Lamium maculatum. XVI-XIX Prostanthera violacea. XX Ajuga reptans. 
प 


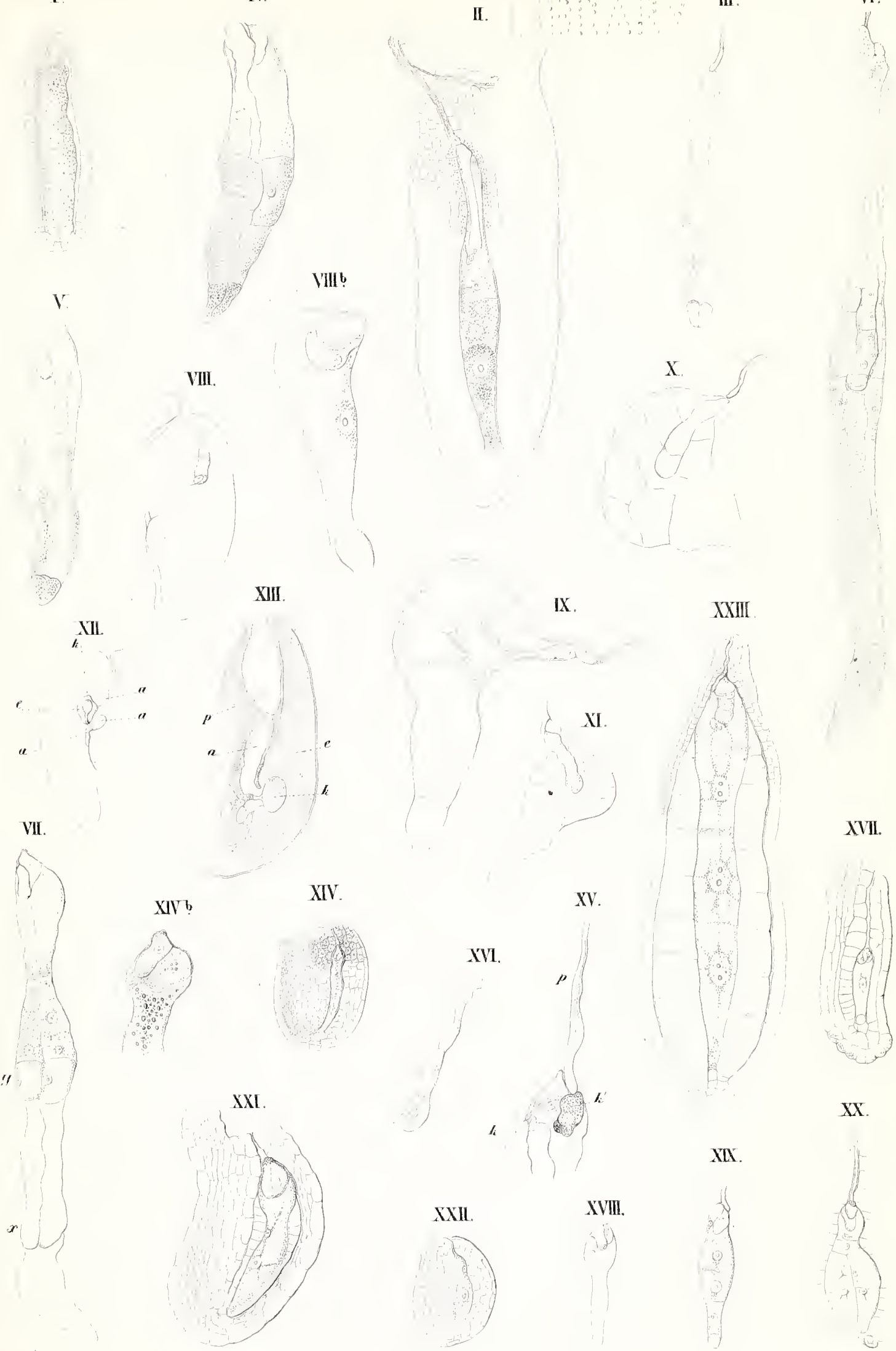

I-VI, Il cbenstrentia dentat. VII Globularia vulgaris VIII X7II Pantago lanceolata. XIV-XVI Vartinium uligiuosum. XVII-XX Pyrola rotundilolia XXI Epacris grandillora. XXII Leiophyllum buxifoliun. XXIII Drosera rotundifolia. 



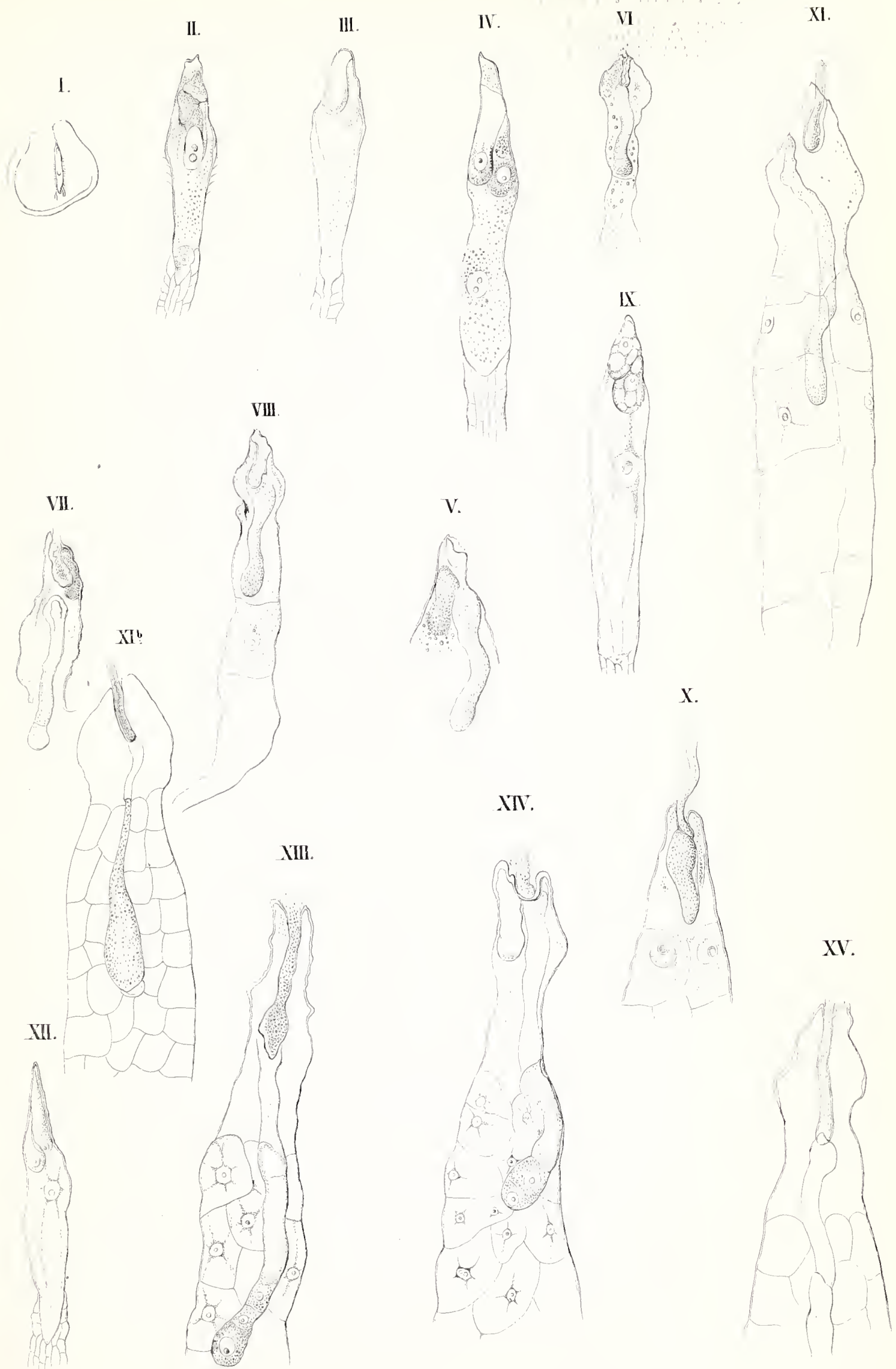

[-V. Campanula amerionat. V-VII Campanula medium. IX-XI Glossocomia. XII-XV Codonopsis viridiflora. 



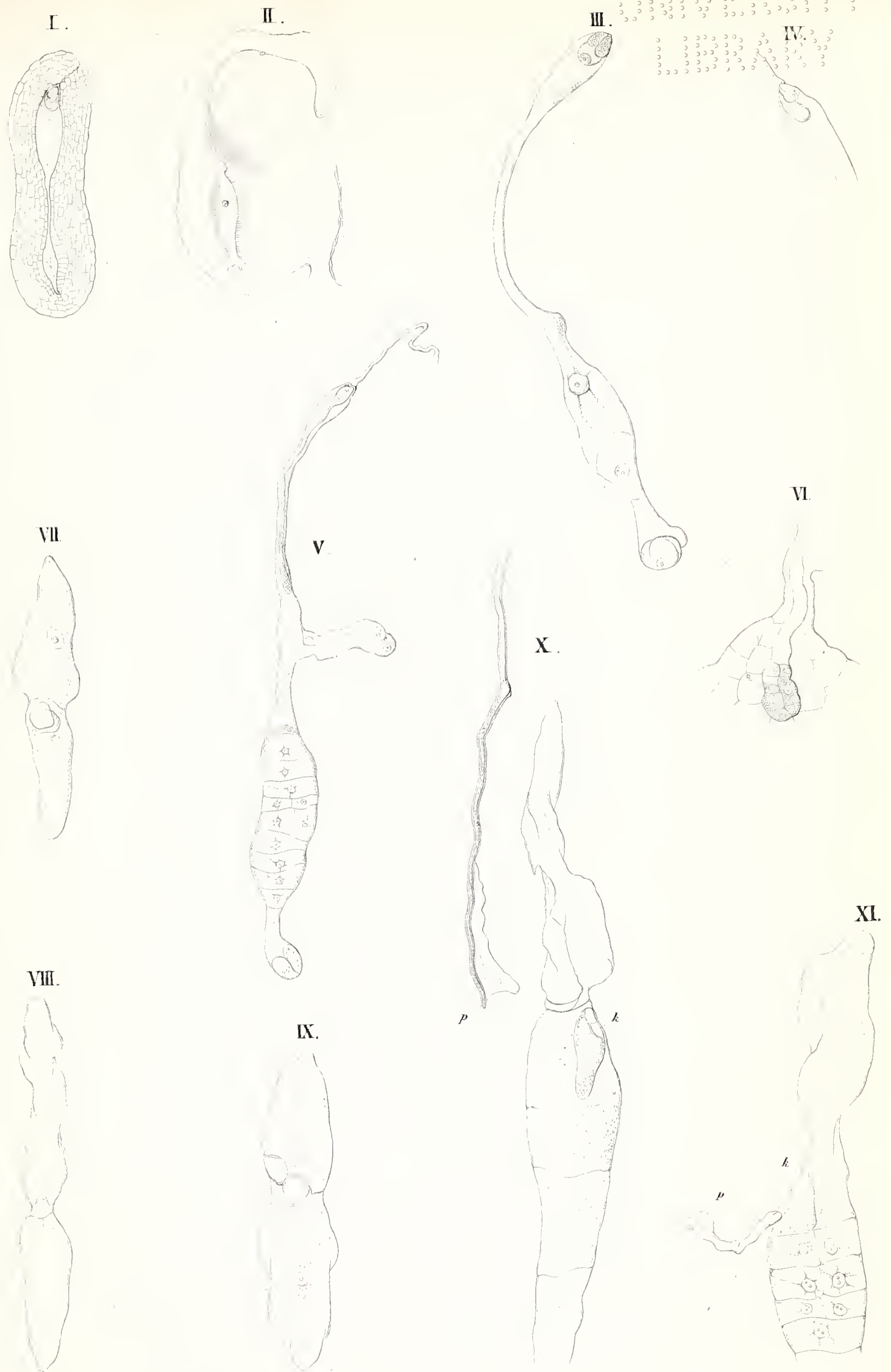

I. Cajophora laleritia. II-VI Loasa tricolor. VII-XI Baptonia aurea. 

P. A. HANSEN, Entwickelung des Products einer Potenz des Radius Vectors mit dem Sinus oder Cosinus eines Vielfachen der wahren Anomalic in Reihen, die nach deu Sinussen oder Cosinussen der Vielfachen der wahren, exeentrischen oder mittleren Anomalie fortsehreiten. 1853

l Thlr. Entwickelung der negativen und ungraden Potenzen der Quadratwurzel der Function $r^{2}+r^{\prime 2}-2 r r^{\prime}\left(\cos U \cos U^{\prime}+\sin U \sin U^{\prime} \cos J\right)$. 185. 4 . I Thlr.

o. SCHLÖMLCH, über die Bestimmung des Massen und der Trägheitsmomente symmetrischer Rotationskörper von ungleichförıniger Diehtigkeit. 1854 . Ueber einige allgemeine lieilienentwickelungen und deren Anwendung auf die elliptischen Functionen. 1854 .

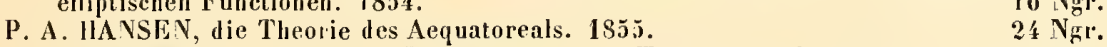

C. F. NAUMANV, über' die Rationalität der 'Tangenten-Verhältuisse tautozonaler Kirytallfächen. 1855 .

$10 \mathrm{Ngr}$.

A. F. MÖBIUS, Die Theorie der Freisverwandtschaft in rein geometriseher Darstellung. 1855.

$20 \mathrm{Ngr}$.

FÜNFTER BAND : Abhandlungen der mathemalis ch-physis che en Classe.

Dritter Band. Mit 15 Tafeln. hoch 4. 1857. br. l'reis 6 Tulr. 12 Ngr. Inhalt:

M. IV. DR0BISCH, Nachträge zur Theorie der musik. Tonverhältnisse. $18 j 5.12 \mathrm{Ngr}$.

P. A. HANSEN, Auseinandersetzung, einer zweckmässigen Methode zur Berechnung der absoluten Stïrungen der kleinen Planeten. $1856 . \quad$ I 'Thtr. $20 \mathrm{Ngr}$.

R. LOHLRAUSCH und W. WEBER, Elektrodynamische Maassbestimmungen insbesondere Zurückführung der Stromintensitäts-Mlessungen auf mechanisches Manss. 1856. $16 \mathrm{Ngr}$.

H. D'ARREST, Resultate aus Beobachtungen der Nebelfecken und Sternbiufen. Erste Reihe. 1856.

$24 \mathrm{Ngr}$.

W. G. HANKEL, Elektrisehe Untersuchungen. Erste Abhandlung: über die Messung der atıosphärisehen Elektricität nach absolutem Maasse. Mit 2 Tafeln. 18j6. 2 Thlr.

W. HOFMEISTER, Beiträge zur' Kenntniss der Gefässkryptogamen. No. 11. Mit 13 'Tafeln. 1857.

I Thıtr. $10 \mathrm{Ngr}$.

SECHSTER BAND : Abhandlungen der $\mathrm{m}$ a the $\mathrm{m}$ a $\mathrm{t}$ is $\mathrm{ch}$ - phy $\mathrm{s}$ is ch e n Classe.

Vierter Band. Mit 29 Tafeln. hoch 4. $1859 . \quad$ Preis 7 Tlulr. 15 Ngr. In hal't:

P. A. HANSEN, Auseinandersetzung einer zweckmässigen Methode zur Berechnung der absoluten Störungen der kleinen Plaueten. Zweite Abhandlung. 1857. 1 Thlr. $10 \mathrm{Ng}$.

IV. G. HANKEL, Elektrische Uutersuchungen. Zweite Abhandlung: über die thermoelektrischen Eigenschaften des Buracites. 1857

$24 \mathrm{Ngr}$.

W. G. HANKEL, Elektrische Untersuchungen. Dritte Abhandlung: über Elektricitäiserregung zwischen Metallen und erhitzten Salzen. I8j8. $16 \mathrm{Ngr}$.

P. A. HANSEN, Theorie der Sonnenfinsternisse und verwandten Erseheinungen. Mit 2 Tafeln. 1858 .

2 Thlr.

G. T. FECHNER, Über ein wichtiges psychophysisehes Grundgesetz und dessen Beziehung zur Schätzung der Sterngrössen. $18 \tilde{5} 8$.

$20 \mathrm{Ngr}$.

W. HOFMEISTER, Neue Beiträge zur Renntniss der Embryobildung der Phanerogamen. l. Dikotyledonen mit ursprünglich einzelligem, nur durch Zellentheilung wachsendem Endosperm. Mit 27 Tafeln. 1859.

2 Thlr. $20 \mathrm{Ngr}$.

\section{SITZUNGSBERICHTE.}

\section{KLEINERE ABHANDLUNGEN.}

BERICHTE übcr die Verhaudlungen der königlich sächsischen Gesellschaft der Wissenschaften zu Leipzig. Erster Band. Aus den Jahren 1846 und 1847. Mit Kupfern. gr. 8. 12 Hefte.

Zweiter Band. A us dem Jahre 1848. Mit Kiupfern. gr. 8. 6 Hefte.

Vom Jahre 1849 an sind die Berichte der beiden Classen getrennt erschienen.

Mathematisch - physische Classe. 1849 (3) 1850 (3) 1851 (2) 185: (*)

1853 (3) 1854 (3) $18.55(2) 185(j(2) 1857$ (3) 1858 (3).

Philologisch - historische Classe. 1849 (5) 1850 (4) 1851 (5) 1852 (4)

1853 (5) 1854 (6) 1855 (4) 1855 (4) 1857 (2) 1858 (2).

Jedes Heft der Berichte ist einzeln zu dem Preise von $10 \mathrm{Ngr}$, zu baben.

Aus den Berichten besonder's abgedruckt :

Das Edict Diocletians de pretiis rerum venalium. Herausgegeben von Th. Mommsen. Mit Nachträgen. 1852.

M. Valerius Probus de notis antiquis. Herausgegeben von Th. Mommsen. $1853.10 \mathrm{Ngr}$. W. ROSCHER, ein nationalökonomisches Hauptprineip der Forstwissensehaft. $1854.6 \mathrm{Ngr}$.

Lẹipzig, März 1859.

S. Hir'zel. 


\title{
SCHRIFTEN
}

DER

\section{FÜRSTLICH - JABLONOWSKISCHEN GESELLSCHAFT}

\author{
ZU LEIPZIG.
}

ABHANDLUNGEN bei Begrändung der Königl. Sächsischen Gesellschaft der Wissenschaften am Tage der zweihundertjährigen Geburtsfeier Leibnizens herausgegeben von der Fürstl. Jablonowskischen Gesellschaft. Mit dem Bildnisse von Leibniz in Medaillon und zahlreichen Holzschnitten und Fupfertafeln. 61 Bogen in hoch 4. 1846. broch.

Preis 5 Thlr.

In balt:

W. WACHSMUTH, Briefe von Leibniz an Christian Plilipp.

(Einzeln 16 Ngr.)

A. F. MöBIUS, Ueber eine neue Behandlungsweise der analytischen Sphärik. Mit eineı Tafel.

(Einzeln $16 \mathrm{Ngr}$.)

M. W. DROBISCH, Ueber die mathematische Beśtimnung der musikalisclıen Iotervalle.

A. SEEBECK, Ueber die Schwingungen der Saiten.

(Einzeln 12 $1 / 2 \mathrm{Ngr}$.)

C. F. NAUMANN, Ueber die Spiralen der Conchylien.

(Einzeln $10 \mathrm{Ngr}$.)

F. REICH, Elektrische Versuche.

(Einzeln $16 \mathrm{Ngr}$.)

W. WEBER, Elektrodynamische Maassbestimmungen. Mit Holzschnitten. (Einzeln 1 Thlr.)

E. H. WEBER, Zusätze zur Lehre vom Baue und den Verrichtungen der Geschlechtsorgane. Mit 9 Kup fertafeln.

(Einzeln 1 Thlr. $10 \mathrm{Ngr}$.)

C. G. LEHMANN, Beiträge zur Kenntniss des Verhaltens der Kohlensäureexhalation unter verschiedenen physiologischen und pathologischen Verbältnissen.

(Einzeln $10 \mathrm{Ngr}$.

PREISSCHRIFTEN gekrönt und herausgegeben von der Fürstlich Jablonow skis chen Gesells chaft.

1. H. GRASSMANN, Geometrische Analyse geknüpt an die von Leibniz erfundene geonıtrischc Characteristik. Mit einer erläuternden Abhandlung von A. F. Möbius. hoch 4. 1847 .

$20 \mathrm{Ngr}$.

2. H. B. GEINITZ, das Quadergebirge oder die Kieileformation in Sachsen, mit Berücksichtigung der glaukonitreichen Sclsichten. Mit 1 color. Tafel. hoch 4. $1850.16 \mathrm{Ngr}$.

3. J. ZECH, Astronomische Untersuchungen über die Mondfinsternisse des Almagest. hochli 4. 1851 .

$10 \mathrm{Ngr}$.

4. J. ZECH, Astronomische Untersuchungen über die wichtigeren Finsternisse, welche von den Schriftstellel'n des classischen Alterthums erwähnt werden. hoch 4. 1853. $20 \mathrm{Ngr}$.

5. H. B. GEINITZ, Darstellung der Flora des Hainichen-Ebersdorfer und des Flöhaer Kohlenbassius. Loch 4. Mit 14 Kupfertafeln in gr. Folio. 185 \}.

8 Thlr.

6. TH. HIRSCH, Danzigs Handels- und Gewerbsgeschichte unter der Herrschaft des deutscben Ordens, hoch 4. 1858.

2 Tulr. $20 \mathrm{Ngr}$.

CHR. AD. PESCHECK, die Böhmischen Exulanten in Sachsen. hoch 4. 1857.

Leip $\approx i g$.

1 Thlr. $10 \mathrm{Ngr}$.

S. Hirzel.

Ferner ist bei mir erschienen :

WIETERSHEIM, E. von, Gedächtnissrede auf Seine Majestät Friedrich August, König voı Sachsen, gehalten in der öffentlichen Sitzung der Königl. Sächs. Gesellschaft der Wissenschaften am 27. Oct. 1854. boch 4. broch. $10 \mathrm{Ngr}$. 


\section{NEUE BEITRÄGE}

ZUR

\section{KENNTNISS DER EMBRYOBILDUNG}

DER

\section{PHANEROGAMEN}

VON

\section{WILHELM HOFMEISTER.}

\section{II.}

MONOKO T YLEDONEN. 

Im Entwickelungsgange der Organe geschlechtlicher Fortpflanzung der Monokotyledonen herrscht eine grosse Uebereinstimmung im Allgemeinen. Abweichungen der Formen der wesentlichsten Theile des Generationsapparats, des Pollens und der Eychen, von denjenigen, welche der grossen Mehrzahl der Phanerogamen zukommend, als deren normale Typen bezeichnet werden können, sind um Vieles seltener, als unter den Dikotyledonen. Sie sind ungleich weniger oft, als dort, bestimmten Verwandtschaftsgruppen zugewiesen. Innerhalb der Formenkreise, welche man als Familien oder Ordnungen auffasst, ist meist die grosse Mehrzahl, in den an Abnormitäten reichen Gruppen mindestens eine Zahl von Ausnahmen in der erwähnten Beziehung dem bei Weitem grösseren Theile der Phanerogamen übereinstimmend beschaffen. Die Abweichungen von dem gewöhnlichen Baue, die unter den Monokotyledonen sich finden, lassen sich endlich ungleich leichter als blosse Hemmungs - oder Wucherungsbildungen erkennen, als die bei Dikotyledonen vorkommenden. Aus diesen Gründen ist eine zusammenhängende Darstellung der die Befruchtung begleitenden Erscheinungen, wie sie aus den vorliegenden Beobachtungen sich erschliessen lassen, leicht ausführbar im Vergleich mit der Darlegung derselben Verhältnisse bei Dikotyledonen, wo die grosse Mannichfaltigkeit der bekannten Thatsachen zu einer mehr ins Einzelne gehenden Behandlung des Stoffes, die zu vermuthenden nicht minder grossen Abweichungen des Entwickelungsganges bisher noch nicht untersuchter Formen zu ängstlicher Vorsicht in allgemeinen Sclılüssen nöthigen.

\section{Entwickelung des Pollens.}

Die weit uiberwiegende Mehrzahl in Bezug auf den Bildungsgang der Pollenzellen untersuchter Monokotyledonen zeigt bis in die untergeordneten Einzelnheiten den für die Phanerogamen überhaupt typischen 
Verlauf dieser Entwickelung. Es differenziren sich im Innern der Anthere vier dem Connecliv parallele Längsreihen von Zellen vom übrigen Gewebe dadurch, dass sie in der Vermehrung durch Theilung hinter den benachbarten zurück bleiben. Diese verhältnissmässig grossen, mit dickflüssigem Protoplasma sich anfüllenden Zellen sind die Urmutterzellen des Pollens*) (XX, 11 bei Crocus vernus). Die Zellen dieses Stranges mehren sich durch wiederholte Theilungen**) in allen Richtungen des Raumes. Haben sie die, dem pollenbildenden Gewebe zukommende Anzahl von Zellen erreicht, so hebt eine Verdickung der Zellenwände an, begleitet vom Beginn der Auflösung der äussersten Schicht der Haut jeder Zelle: die Zellen, Mutterzellen des Pollens, treten aus dem parenchymatischen Zusammenhange. Gleichzeilig erweitert sich jedes Antherenfach durch Dehnung der seine Wandungen bildenden Zellenmassen. In dem weiter gewordenen Raume schwellen die Pollenmutterzellen an, der Kugelform mehr oder weniger sich nähernd, nur selten sie erreichend (z. B. Tradescantia). Ihr primärer Kern ist noch vorhan-

*) Unter den Pflanzen, an welchen diese für die Entwickelungsgeschichte des Pollens hochwichtige Thatsache durch Nägeli entdeckt wurde, ist eine der charakteristischen Formen von Monokotyledonen: Lilium tigrinum (Nigeli, zur Entwickelungsgeschichte des Pollens, Zürich 1842, S. 9 ; Taf. I f. 2-4).

**) Der Zelltheilung geht, wie allerwärts in kernhaltigen Zellen, eine Verdoppelung des Zellkerns voraus. Dass vor dem Auftreten der zwei secundären Zellkerne auch bei der Vermehrung der Urmutterzellen der primäre aufgelöst wird, davon habe ich bei Lilium bulbiferum, Neottia ovata und bei Orchis Morio aufs Bestimmteste mich überzeugt. Man findet in Knospen einer und derselben Inflorescenz, in Knospen deren Stellung anzeigt, dass ibre Entwickelung die Mitte hält zwischen solchen, in denen der pollenbildende Zellstrang auf den Querschnitt nur sehr wenige, und solchen in denen er zahIreiche Zellen zeigt, sehr häufig Antlıeren, in deren pollenbildendem Zellstrange gar kein Kern zu finden ist, wohl aber im Centrum der Zelle eine klare Flüssigkeit, die auf Einwirkung von Wasser in ähnlicher Weise zu mehreren formlosen Klumpen gerinnt, wie ich dies für die zur Theilung sich anschickenden Pollenmutterzellen von Tradescantia virginica geschildert habe (Botan. Zeiluug 1848; s. 427). Die Zuslände, aus welchen Wimmel eine Theilung der Kerne bei der Vermelsung der Urmutterzellen wie der Mutterzellen des Pollens erschliesst, erklären sich seinen Abbildungen nach leicht als Coagulationen der Substanz der neugebildeten Zellkerne nach Wassereinwirkung. Zwei dicht an einander liegende neu entstandene secundäre Kerne werden bei Gerinnung der eyweissartigen Stoffe ilırer Substanz in der Regel zu feiner Masse zusammen zu fliessen scheinen. (Vergleiche u. A. meine Abbildungen in Vermehrung der Kerne begriffener Zellen von Staubfadenhaaren von Tradescantia virginica in meiner Entstehung des Embryo, Leipzig 1849 Taf. XIV f. 21. 28.) 
den; jetzt unter allen Umständen central. Mit anderen Worten: die frei gewordene Pollenmutterzelle enthält keine Vacuole mehr in dem sie erfüllenden Protoplasma, während in den Urmutterzellen des Pollens in einigen Fällen (Arum maculatum, Iris florentina) noch während der ersten Zelltheilungen das Protoplasma, den Zellkern einhüllend, die Innenwand der Zelle als dicke Schleimschichte überzieht; der Mittelraum der Zelle aber mit von dieser Schicht scharf abgegränzter wässeriger Flüssigkeit erfüllt ist. Die Wand der frei gewordenen Mutterzelle nimmt bei den meisten Arten rasch und beträchtlich an Dicke zu; - am stärksten bei solchen Mutterzellen, deren Form sehr weit von der Kugel abweicht, z. B. an denen der meisten Arten von Iris (XX, 13). Die Wandverdickung ist dann ungleichmässig; überall dahin gerichtet den Zellraum zur Kugelgestalt abzurunden. Sobald als die Zellwand eine gewisse Dicke erreicht hat, zeigt sie Schichtung; bald mehr bald minder deutlich. Oft ist die Zahl erkennbarer Schichten sehr beträchtlich. Die Schichten sind da, wo sie weit ausspringende Ecken der Zelle ausfüllen, nur kappenförmig, sie bekleiden nicht die ganze Innenfläche der Zelle als zusammenhängende Membranen, sondern sie keilen sich da aus wo sic an dünnere Stellen der Zellhaut reichen.

Die inneren Lamellen der verdickten Haut der Pollenmutterzellen quellen bei reichlicher Wasserzufulır stark auf; in weit höherem Maasse als die äusserste Schicht. Oft ist der Unterschied so beträchtlich, dass die Zellhaut berstet. Zwei Erscheinungen geben den Beweis, dass diese Sprengung der Zellhaut auf dem Anschwellen ihrer eigenen Substanz, nicht auf dem der Inhaltsflüssigkeit beruht. Wenn Mutterzellen vor der Theilung platzen, so wird, unmittelbar nach Entstehung des Risses in der Haut, ein Theil des Inhalts durch denselben ausgetrieben. Dann schliesst sich der Riss fest in Folge der Elasticität der Zellmembran. Aber nur auf kurze Zeit: indem ein weiteres Aufquellen der inneren Hautlamellen stattfindet, wird der Riss wieder geöflnet, und wiederum ein Theil des Inhalts hervorgetrieben.*) Der Vorgang kann sich noch zu mehreren Malen wiederholen. Ein noch schlagenderer Beweis ist das Hervortreten bercits von der Exine bekleideter Pollenzellen oder Tetraden aus den aufplatzenden Höhlen in Wasser gelegter älterer Mutterzellen. Hier findet man, in sehr vielen Fällen (Iris parisiensis, Neottia ovata z. B.), dass die

*) Bot. Zeit. 1848, 653 . 
entleerte Mutterzelle, oder das entleerte Fach derselben merklich grösser ist, als die ausgeschlüpfte Pollenzelle (V, 8.9). Das Quellen der Mutterzellmembran erfolgte hier unzweifelhaft nach allen drei Richtungen des Raumes hin, überwiegend jedoch in radialer Richtung. Dieses Vorwiegen allein führte zur Sprengung der Zellhaut. Die Pollenzelle, oder die Pollentetrade hatte keinen Antheil daran; wie nicht allein aus ihrem hinter dem der Höhlung der entleerten Haut zurück bleibenden Volumen, sondern auch daraus hervor geht, dass schon vor dem Bersten der Mutterzelle die quellende Membran sich sichtlich erweitert. Zwischen ihrer Innenfläche und der Aussenfläche der Pollenzellen bildet sich ein ziemlich breiter, wassererfüllter Raum.

Bald nach dem Freiwerden der Pollenmutterzelle wird ihre bevorstehende Theilung durch Auflösung des Zellkerns eingeleitet. Die Grösse desselben nimmt zu, die Schärfe seiner Umrisse nimmt ab; seine Kernkörperchen verschwinden. Endlich ist der kugelige Mittelraum der Zelle nur von klarer, das Licht aber stark brechender Flüssigkeit erfültt, die von der einer Vacuole schon dadurch sich unterscheidet, dass keine scharfe Abgränzung derselben von dem körnigen Protoplasma stattfindet, welches die peripherische Region des Zellraums einnimmt. Bei kurzer Einwirkung reinen Wassers gerinnt die klare Flüssigkeit der Zellenmitte zu mehreren Klumpen unbestimmter Gestalt. Diese Erscheinung, - leicht und sehr deutlich wahrzunchmen bei Tradescantia virginica, ${ }^{*}$ ) - ward allerwärts wiedergefunden wo eine geniigende Zahl der von der Zelle sehr rasch durchlaufenen Entwickelungsstufen untersucht wurde, so bei Iris pumila, Lilium bulbiferum, Hemerocallis flava, Neottia ovala (einiger Abietineen und Dikotyledonen zu geschweigen). Sie ist ein unwiderleglicher Beweis der vollständigen Auflösung des primären Zellenkerns vor der Bildung der secundären. Der unbestreitbare Nachweis dieser Thatsache ist von Wichtigkeit für die Feststellung des Begriffes des Elementarorganes der Pflanze. Wenn bei jeder Vermehrung durch Theilung kernhaltiger Zellen die Theilung des Kerns der Theilung der Zelle vorauf ginge, so würde eben dieser selbststandig erscheinenden Vermehrung der Zellkerne eine ungleich grössere Bedeutung zugeschrieben werden müssen, als der Auflösung des primıären Kernes und der Neubildung der secundären.

*) abgebildet von mir Botan. Zeit. 1848. Taf. IV f. 10-12. 
Die neu entstandenen zwei Zellkerne erscheinen bei ihrem ersten Auftreten sofort in ihrer späteren Grösse, als ellipsoïdische, in seltenen Fällen als beinahe kugelige Tropfen einer kaum merklich durch feine Körnchen getrübten Flüssigkeit, welche das Licht nur wenig stärker bricht, als die sie umgebende Inhaltsflüssigkeit der Zelle. Kernkörperchen treten in dem secundären Zellkerne in der Regel erst späterhin auf. Die Gränzen der neuen Zelikerne sind oft nur schwierig zu erkennen; namentlich bei Anwendung minder vollkommener Instrumente treten sie erst bei beginnender Gerinnung der Substanz nach Wassereinwirkung deutlich hervor. $\left.{ }^{*}\right)$ Die Lage der neuen Zellkerne ist in Mutterzellen von nicht genau kugeliger Form stets so, dass eine durch sie gelegte Linie die grösste Achse der Zelle darstellt. ${ }^{*}$ ) Wo die Zelle die Form eines Ellipsoïd hat, fallen die Mittelpunkte der secundären Kerne mit den Brennpunkten des Ellipsoïds zusammen. Der Bildung secundärer Kerne folgt bald eine weitere Veränderung des Inhalts der in Theilung begriffenen Pollenmutterzelle. Die gröberen Körnchen des die Zelle füllenden Protoplasma ordnen sich zu einer plattenförmigen Anhäufung, welche senkrecht auf der, durch die beiden secundären Kerne gelegten Achse der Zelle steht.*****) Bei der Kleinheit der in der Inhaltsfluissigkeit der Pollenmutterzellen von Monokotyledonen schwebenden festeren Theilchen erscheint die Körnerplatte in der Seitenansicht in der Regel nur als dunkle Linie, $\dagger$ ) so bei Hemerocallis Ilava, Iris florentina, - deutlich aus gröberen Körnern zusammengesetzt bei Najas major (I, \& a $)+t$ ).

Dem Auftreten der Körnerplatte folgt entweder sofort deren Spal-

*) Hofmeister in Bot. Zeit. 1848,671.

**) $\Lambda$ uf die aus diesem Verhältniss folgende Stellung der später auftretenden ersten Scheidewand der Pollenmutterzelle hat zuerst Pringsheim aufmerksam gemacht (Bau u. Bildung der P(lanzenzelle, 52). Es ist ein allgemein zutreffendes, soweit meine Beobachtungen reichen. Wimmel nimmt an, dass die secundären Kerne, die er als Theilungsproducte des primären betrachtet, nach ihrer Entstehung mehr und mehr nach den Polen der Zelle hin rücken. Unter meinen zahlreiehen Beobachtungen sind keine, welebe auf eine solche Wanderung der seeundären Kerne der Pollenmutlerzellen zu schliessen gestatten. Mir seheint, dass auch zu diesen Folgerungen Wimmels die Nichtbeachtung des die Gerinnung der Zelllüssigkeit und der Zellkernsubstanz begleitenden Erseheinungen beigetragen hat.

***) Hofmeister, Botan. Zeit. 1848,671 .

†) Zuerst gesehen von Unger, über merismatische Zellbildung, 184k, f. 12.

计) Die römische Ziffer bezeichnet die Tafel, die arabische die Figur. 
tung in zwei, und die Bildung einer planen Zellstoffhaut zwischen beiden, welche als Scheidewand den Raum der Zelle querdurchsetzt. Nach Wiederauflösung ihres Kerns, Bildung zweier neuer, Entstehung von Körnerplatten zwischen diesen theilt sich dann jede der secundären Zellen in zwei tertiäre. Oder aber die beiden secundären Zellkerne, sowie die sie trennende Körnerplatte, verschwinden wieder. An Statt jedes der ellipsö̈dischen secundären Kerne treten zwei kugelige tertiäre auf; unter ganz den gleichen Erscheinungen wie die secundären. Die tertiären Kerne sind entweder so gestellt, dass sie alle vier in eine, die grösste, Durchschnittsebene der Zelle fallen, oder so, dass die zwei Kerne der einen Zellhälfte in einer Ebene, die beiden der anderen Zellhälfte in einer auf dieser Ebene rechtwinkligen Ebene liegen; - oder endlich so, dass die durch jeden der vier Kerne und den Mittelpunkt der Zelle gelegten Ebenen ein System von vier, im Mittelpunkt der Zelle mit ihren Spitzen zusammentreffenden, Tetraëdern darstellen : die Kerne stehen den Ecken eines Tetraëders entsprechend, dessen Mittelpunkt mit dem der Zelle zusammenfällt. Ihr erstes Sichtbarwerden erfolgt an den Stellen, welche sie später annehmen; eine Ortsveränderung vor der Theilung der Pollenmutterzelle ist auch an den tertiären Kernen nicht beobachtet.

Bei einzelnen Arten steigt die Zahl der in der Pollenmutterzelle vor ihrer Theilung auftretenden Zellkerne auf mehr als vier, indem auch die tertiären Zellkerne, einzelne oder sämmlliche, wieder aufgelöst werden, und an ilırer Stelle neue sich bilden; so bei den Arten von Iris mit gebarteten Perigonialblättern; bei mehreren Orchideen. *) - Nach der Ausbildung der vier (oder mehr) Zellkerne ordnen sich die Körner des Protoplasina der Mutterzelle aufs Neue zu plattenförmigen Anhäufungen; zwischen je zwei Zellkernen zu einer, die senkrecht steht auf der kürzesten, je zwei Zellkerne verbindenden Linie. An derStelle der Körnerplatten findet man auf wenig weiter vorgerückten Entwickelungsstufen die Mutterzelle in Fächer theilende Scheidewände.

*) Lycaste aromatica und Deppei, Ornithidium coccineum, Leptotes bicolor, Epidendrum virgatum in der Candicula. (Reichenbach fil. de pollinis Orchidearum genesi, Lpzg. 1852, S. 36.) — In einigen dieser Fälle ist es noch zweifelhaft, ob nicht nachträgliche Theilungen einiger der vier Tochterzellen einer Pollenmutterzelle vorkommen. - Unter den Dikotyledonen ist Passiflora coerulea ein sicheres Beispiel des Auftretens von mehr als vier Zellkernen in der Pollenmutterzelle vor ihrer Theilung (Hofmeister, Botan. Zeitg. 1848, 655); unter den Gymnospermen Pinus Larix. 
Die Theilung der Mutterzelle in successiv zwei mal zwei Tochterzellen ist unter den Monokotyledonen entschieden der häufigere Fall, derjenige der simulianen Theilung in vier Tochterzellen der seltnere. Der erste ist z. B. typisch für alle darauf untersuchten Liliaceen, für Tradescantia, für viele Gräser. Als sichere Beispiele des zweiten können Najas major und Iris florentina, parisiensis u. A. bärtige genannt werden. Uebrigens ist bei keiner Art, weder von Mono- noch von Dikotyledonen, einer der beiden Entwickclungsgänge der ausschliesslich hırrschende. Man findet bei jeder Art, für die der erstere Regel ist, einzelne Ausnahmen: Pollenmutterzellen die nach der Weise des zweiten sich vermehren, *) und umgekehrt.

Die Scheidewände, welche die Pollenmutterzelle theilen, erscheinen bei allen von mir untersuchten Monokotyledonen beim ersten Sichtbarwerden schon als gleiclmässsig dünne, von der einen Innenfläche der Haut ohne Unterbrechung quer durch die Zelle zur anderen gespannte zarte Membranen. Das allmälige Wachsen der Scheidewand von der Innenfläche der Mutterzellmembran bis zu ihrem Mittelpunkt hin, wie es bei Dikotyledonen, namentlich bei Malvaceen**) unzweifelhaft festgestellt ist, vermochte ich bei keiner monokotyledonen Pllanze zu beobachten.

An den Mutterzellen des Pollens von Iris pumila, florentina, parisiensis u. A., die eben zur Theilung sich ansclicken, tritt dagegen eine Erscheinung hervor, welche deullich zeigt, dass hier die Bildung der Scheidewände in einer von der jener Dikotyledonen einigermaassen abweichenden Weise erfolgt. Lässt man die zur Untersuchung bestimınten Antheren, bevor man die in ihnen enthaltenen Pollenmutterzellen frei legt, etwas abwelken (etwa eine halbe Stunde lang), so erscheint der Inhalt der Mutterzellen, unmittelbar nachdem man sie in Wasser brachte,

*) So namentlich bei Tradescantia; Bot. Zeit. 1848, 430 .

**) Mohl, die Pflanzenzelle in Wagners IIandwörterb. d. Physiol. IV, 118. Nur dieser Beobachtung, in welcher der aus der zersprengten Mutterzelle ausgetretene vierlappige Primordialschlauch isolirt gesehen wurde, vermag ich Beweiskraft zuzuerkennen. Wenn man an eben getheilten Pollenmulterzellen, deren Inhalt zur Contraction gebracht wurde, die zarten Scheidewände nur bis an den zusammengezogenen Inhalt, innerhalb der wenig durchsichtigen Masse desselben aber nicht weiter verfolgen kann, so liegt darin kein Beweis, dass sie nicht bis zum Mittelpunkt der Zelle reicion. Vergl. Nägeli, Entwickelungsgesch, d. Pollcns, 16. 
schwach zusammen gezogen, von der Innenfläche der Zellhaut entfernt. Dieser contrahirte Inhalt zeigt in Mutterzellen, welche in Theilung begriffen sind, auf seiner Oberfläche seichte Furchen, deren Verlauf genau den künftigen Berührungskanten der Scheidewände mit der Innenfläche der Mutterzellhaut entspricht. Aber auch die besten Mikroskope lassen keine der Innenfläche der Mutterzellhaut aufgesetzten, in die Furchen des Zellinhalts hinein reichenden Leisten aus Membransubstanz erkennen $(\mathrm{XX}, 16)$. Es ist klar, dass hier die beginnende Abschnürung des Zellinhalts zu einer Anzahl secundärer Primordialzellen nicht von soforliger Bildung von festen Zellhåuten an den Aussenflächen der sich abschnürenden Inhaltspärtieen begleitet ist.

Wo die verdickte Haut der Mutterzelle Schichtung zeigt, da erscheinen die Scheidewände, welche die Mutterzelle in Fächer theilen, als unmiltelbare Fortsetzungen der innersten, die Innenfläche der Mutterzellhaut gleichmässig auskleidenden Schichten; - sie gehen ohne sichtbare Unterbrechung in diese über. Bei dem gegenwärtigen Stande der Lehre vom Baue der Zellhaut ist es kaum nöthig, anzumerken, dass dieser Umstand, und das ihm ähnliche Verhältniss der Scheidewände getheilter dickwandiger vegetativer Zellen mit geschichteter Wand zur innersten Lamelle dieser Iaut, ebensowenig die Einschachtelung geschlossener Zellhäute der Tochterzellen in die Membran der Mutterzelle entscheidend beweiset, als die Schichtung einer Zellmembran mit allen bekannten Nebenumständen (Tüpfelung u. s. w.) ein Beweis dafür ist, dass diese Schichten durch Anlagerung auf die Innenfläche einer primären, dünnen, äussersten Lamelle der Ilaut gebildet wurden. Sie können ebenso wahrscheinlich durch Differenzirung der durch Intussusception gewachsenen Haut in Lamellen verschicdener Dichtigkeit entstanden sein; und für viele Fälle hat diese Ansicht der Entstehungsweise einen höheren Grad von Wahrscheinlichkeit.*)

Eine so beträchtliche Verdickung der Häute der Specialmulterzellen, der in ihrer ganzen Dicke mikrochemisch gleichartig reagirenden Tochterzellwände der Pollenmuttcrzelle, wie sie bei vielen Dikotyledonen vorkommt (z. B. Malvaceen, Cucurbitaceen, Passillora), ist bei Monokotyledonen nirgends beobachtet. Gewöhnlich wird sehr bald in jeder Specialmutterzelle eine, deren Innenfläche dicht anliegende, dünne

*) Vergleiche Nägeli, Pflanzenphysiol. Untersuch. II, Zürich 1838, 277 ff. 
Haut sichtbar, deren Beschaffenheit von der der Wände der Specialmutterzellen abweicht. Sie haftet nur lose an der ihr nächsten Schicht der Specialmutterzellenmembran, obwohl sie dieser auf allen Punkten dicht anliegt. Ihre Elasticität übertrifft weit die jener. Wenn durch das Aufquellen der inneren Lamellen ihrer eigenen Haut eine oder mehrere Specialmutterzellen berstet, bleibt jene neu erschienene Haut ganz, und tritt aus dem Risse blasenförmig hervor. Unter Umständen wird sie als geschlossene Blase, den gesammten Inhalt der Zelle einschliessend, ausgetrieben (so bei Iris parisiensis, pumila; mit einer später zu erwähnenden Modificalion bei Neottia ovata). Diese neue Schicht der Zellhaut ist die Grundlage der künftigen bleibenden Membran der Pollenzelle. Die frühesten, der Beobachtung zugänglichen Zustände der ganz oder theilweise freigewordenen Membran zeigen in ihren mikrochemischen Reactionen keinen wesentlichen Unterschied von den geschichteten Häuten der Specialmutterzellen. Wie diese, färben sie sich bei Behandlung mit Jod und Schwefelsäure blau, meist aber reiner und intensiver (so bei CampeliaZanonia); anderwärts dunkler, aber mit einem Slich ins Grüne, während der Färbung der äusseren Schichten Roth beigemengt ist (Iris parisiensis, Neottia ovata). Gleich den äussersten Schichten wird auch die innerste Lamelle auf ihrer frühesten Entwickelungsstufe durch Einwirkung concentrirter Schwefelsäure vollständig zerstört, nur langsamer.

Diese gleicharlige Cellulosereaction der neuen Lamelle der Membran in ihrer ganzen Dicke dauert nur sehr kurze Zeit. Sie erscheint, auf nur wenig weiter vorgerückterer Stufe, aus zwei optisch und chemisch verschiedenartig sich verhaltenden Schichten zusammen gesetzt. Die innere reagirt gleich einer gewöhnlichen Zellstoflhaut, die äussere gleich der Cuticula. Jene ist die Grundlage der Intine, diese die der Exine des Pollenkerns.

Die Exine wächst in der Mehrzahl der Fälle rasch in die Dicke. Sie bedeckt sich mit den für die Polleıkörner der verschiedenen Arten je nach den specifischen Unterschieden charakterislischen Hervorragungen: Wärzchen, Stacheln, netzlinig verlaufenden Leisten u. s. w., noch wähırend des Bestehens der spröderen Häute der Mutter- und Specialmutterzellen. Die Ausbildung der Exine wird um so beträchtlicher, je dicker diese Häute sind. Dieses Verhältniss erweiset sich als überall zutreffend, nicht nur wenn man Arten mil sehr entwickelter Exine mit solchen vergleicht, deren Pollenkörner von nur dünner Exine bekleidet 
sind, z. B. Iris, Hemerocallis, Allium einerseits mit Tradescantia, Campelia, Crocus andererseits. Sondern es pflegt auch an ein und demselben Pollenkern die Exine an der, im Complex der von der Mutterzelle noch umschlossenen vier Pollenzellen nach aussen gekehrt gewesenen Fläche, welche von Zellstoffschichten von grösserer Mächtigkeit bedeckt ward, um Vieles stärker ausgebildet zu sein, als an denjenigen Flächen des Pollenkerns, welche den Schwesterzellen zugekehrt waren.

Die Häute der Mutter- und Specialmutterzellen werden in der grossen Mehrzahı der Fälle von aussen her aufgelöst, so dass, nach der Entblössung der freien Aussenwände eines Complexes junger Pollenzellen, und nach dem Heraustreten der Pollenzellen aus den jetzt nach aussen hin offenen Fächern der Mutterzelle, die Scheidewände, welche die Specialmutterzellen trennten, noch eine Zeit lang im Zusammenhange kenntlich sind (z. B. bei Iris squalens, parisiensis, Cephalanthera rubra). Eine Ausnahme von dieser Regel scheint Maranta zebrina durch das Zerfallen der intacten Specialmutterzelle, nach Anlegung der Exine zu machen. Man findet jede junge, freie, sphärische Pollenmutterzelle von einer der Exine dicht anliegenden, ablösbaren Zellstoffhaut umschlossen, welche füglich nichts anderes sein kann, als die noch unversehrte Specialmutterzelle.

Die Intine verändert sich nach ihrer Differenzirung von der Exine in den meisten Fällen bis zur Reife des Pollenkerns bei Monokotyledonen nur wenig. Nur sehr selten lässt sie eine Schichtung erkennen. ${ }^{*}$ ) Ihr Dickevachsthum ist meist ebenso gering, ***) als ihr Aufquellungsvermögen in Wasser. Der Pollen von Maranta zebrina macht auch in letzterer Beziehung eine Ausnahme. Wird das junge Pollenkorn ins Wasser gelegt, so quillt die dicke Intine rasch auf; zunächst das ganze Korn so weit ausdehnend, als die Elasticilat der Exine es erlaubt. In Folge dieser Zunahme des Volumen wird die Ilaut der Specialmutterzelle gesprengt und abgestreift, welclı — wie eben erwähnt - der Exine dicht anliegend das Pollenkorn umschliesst. Das weitere Aufquellen der Intine, welchem die Exine Widerstand leistet, versetzt den Inhalt der Pollen-

*) Zwei Schichten bei Tigridia Pavonia, Fritzsche in Mém. Acad. S. Petersbourg p. div. silv. III, $1837,711$.

**) Bei den Carices ist bekanutlich die Intine an mehreren Stellen stark verdickt; Fritzsche, ebend. 722. 
zelle unter so hohen Druck, dass schr bald Exine und Intine bersten, und der Inhalt aus dem Risse mit grosser Gewalt ausgetrieben wird. Das Aufquellen der Intine, nun ungehindert, dauert dann noch fort bis zur Ausfüllung des grössten Theils des Lumens der Pollenzelle (VI, 2ٌ̈ $-27)$.

So weit die Beobachtungen reichen, werden die Pollenzellen der Monokotyledonen verhältnissmässig früh frei; lange bevor sic ausgewachsen sind, zu einer Zeit, wo dic Exine noch wenig ausgebildet ist, wo feinkörniges Protoplasma den Zcllraum gleichmässig erfüllt, der Zellkern noch centrale Lage hat. Später erst, wälırend des Heranwachsens der frei im Antherenfache liegenden Pollenzellen, tritt im Protoplasma eine grosse oder mehrere kleine Vacuolen auf, bilden sich Amylumkörnchen.**)

*) Ieh habe in der vorstehenden Darlegung die Ansicht Nägeli’s festgehalten, weleher das Auftreten der bleibenden Haut der Pollenzelle als die Bildung einer einzigen, die (Special-) Mutterzelle ausfiillenden Toehterzelle auffasst. Die Anschauung der Entstehung der Pollenzellhaut als einer blossen Modifieation des Verdiekungsprocesses der Häute der Toehterzellen, welche Schacht neuerdings durchzuführen versuehte (Pringsheims Jahrbüeher II, 1859, 109 fr.) halte ieh für nicht berechtigt. Diese Anschauung setzt voraus, dass gesehiehtete Specialmutterzellhäute durch schichtenweise Anlagerung auf die Inncnfläche in die Dicke gewaehsen seien. Für diese Annahme fehlt jeder Beweis. Das Waehsthum der Mutter- und Specialmutterzellhäute kann eben so wahrseheinlich dureh Intussuseeption, die Schiclttenbildung durch nachträgliche Differcnzirung der Substanz in concentrisehe Lamellen erfolgen. - Dagegen unterlicgt es keinem Zweifel, dass die Haut der Pollenzelle durch Apposition eines neuen, von dem der Specialmutterzellhaut versehiedenen Stofles auf die Innenflïche dieser Haut entsteht (wie ich bereits früher ausgesproehen, Bot. Zeit. 1848, Ł31). Einen entseheidenden Beweis werde ieh weiterhin, bei Besprechung der Pollenentwiekelung des Phajus variabilis, beibringen. In der Art dieser Anlagerung aber waltet ein wesentlieher Untersehied von der Verdickungsweise vegetativer Zellen ob. Bei letzterer ist kein Fall bekannt, in welehem die "neugebildete Verdickungsschicht« nicht der nnächstäIteren Sehieht " fest anhaftete; kein Fall, in welehem eine soeben neuaufgetretene, innerste Lamelle einer und derselben Zellhaut nicht mit der von aussen ihr zunäelıst angränzenden gleiehartig reagirte. - Schacht nimmt an, dass das Diekerwerden der Pollenzellhaut lediglich dureh in eentripetaler Folge vor sich gehende sehielttenweise $\Lambda \mathrm{n}$ lagerung erfolge (a. a. 0.153 ) : eine völlig unhaltbare Ansicht. Der Nachweis auch centrifugalen Dickenwaehsthums ist für kaum irgendeine pflanzliche Nembran leichter zu führen, als für die der Pollenkörner, auf deren ursprünglieh stets glatter Oberfläelıe mehr und mehr an Grösse zunehmende Hervorragungen sich bilden. Wenn Schaelıt die nach aussen mündenden Kanäle der Exine von Mirabilis Jalapa (Sch. schreibt Ipomaea Jalapa; es ist aber unzweifelhaft Mirabilis gemeint) mit den Tüpfelkanälen 
Von diesem, dem typischen Entwickelungsgange der Pollenzellen finden sich unter den Monokotyledonen zweierlei Abweichungen; an sich geringfügig, in ihren Endergebnissen aber sehr auffällig. Die eine zeigen die unter Wasser blühenden Najadeen, von denen Najas major und Zostera untersucht sind.

Die Pollenmutterzellen von Najas major treten sehr frih aus dem parenchymatischen Zusammenhange, und erfüllen die geräumigen vier Fächer der grossen Anthere $(I, 1)$ als ein lockerer Brei aus fast kugeligen Zellen. Den Antherenfächern fehlt die Auskleidung aus weichwandigen, locker vereinigten, radial gestreckten Zellen, welche bei der grossen Mehrzahl der Phanerogamen sich findet. Bis zur simultanen Theilung der Mutterzelle in vier, meist in einer Ebene liegende dünnwandige Tochterzellen bietet der Entwickelungsgang nichts Eigenthümliches (I, 2-6). Die Tochterzellen bleiben aber nur kurze Zeit im Zusammenhange. Sehr bald, und ohne dass eine merkliche Verdickung ihrer Wände voraufgegangen wäre, erscheinen die Zellen von einander getrennt, lose im Antherenfach liegend (I, 7 a. b). Jede der vereinzelten Zellen ist jetzt von einer, unmessbar dünnen, Cuticula umgeben. - Die Trennung der kurz zuvor fest vereinigt gewesenen Zellen ist nicht füglich anders denkbar, als durch Verflüssigung der äussersten Schicht der Häute der Tochterzellen und der sie umschliessenden Mutterzellhaut, wenn auch diese Hautlamellen verschwindend dünn sein mögen. Dies zugegeben, wird ein wesentlicher Unterschied zwischen der Entwickelung des Pollens von Najas und der des Pollens der Mehrzahl der Dikotyledonen nicht aufgestellt werden können. Die Häute der Specialmutterzellen von Najas bleiben äusserst diunn und werden sehr frühe wieder aufgelöst : dies ist Alles. Die Pollenzellen sind nach ihrer Vereinzelung nicht ganz von der halben Grösse der reifen. Sie enthalten jetzt meistens zwei Zellenkerne,

dickwandiger Zellen vergleicht, und die Ausmündung jener nach aussen aus der Auflösung der ïussersten Lamellen der betreffenden Zellhaut erklärt, so vergisst er, dass die von Kanälen durchsetzte Schicht jener Exine erst nach dem Freiwerden der Pollenzelien entwickelt wird. - Der Ansicht, welche die Wände der Specialmutterzellen für durch Ausdehnung der Pollenzellen comprimirte Gallerte nimmt - vor einiger Zeit noch von Wimmel vertheidigt (Bot. Zeit. 1850, 269), und der Vermuthung Nïgeli's von der Entslehung der Pollenzelle durch freieZellbildung innerhalb der Specialnutterzelle (Ztschr. wiss. Bot. III u. IV [1846], 51), brauche ich, als wahrscheintich allseitig aufgegeben, hier nur geschichtlich zu erwähnen. 
wie dies auch anderwärts an jungen Pollenzellen öfters vorkommt*) (z. B. bei Cypripedium Calceolus, Narcissus poëticus), ohne dass eine Theilung der Pollenzellen erfolgt. Vielmehr verschwindet der eine Zellkern bald wieder; das der Reife nahe Pollenkorn besitzt nur noch einen $(I, 9.10)$. Erst in der einkernig gewordenen Pollenzelle bilden sich die spindelförmigen, theils geraden, theils schwach gebogenen Amylumkörnchen aus, welche dem Pollen von Najas ein so eigenthümliches Ausselıen geben (I, 9-12). Der reife Pollen besitzt eine zwar sehr dünne, aber deutliche Exine, welche an schlauchtreibenden Pollenkörnern besonders scharf hervortritt (I, 11). Die Pollenzellen entwickeln selır oft schon in den Fächern der aufgesprungenen Anthere lange Schläuche.

Die Anthere von Zostera marina**) und nana tritt als ein wenig erhabener, halbellipsoïdischer Zellhöcker auf der Oberseite der flachen, blattförmigen Achse des Blüthenstandes auf. Das Vorder- und Hinterende des zelligen Wärzchens entwickeln sich zu den beiden, je zweifächerigen Antherenhälften, dieses stets früher als jenes; die Mittelgegend wird zum Connectiv, welches, excessiv in die Breite wachsend, die beiden, Spindelform annehmenden Hälften des Staubkölbchens weit von einander entfernt. In jeder Hälfte des Staubkolbens unterscheiden sich schon früh zwei Längsreihen höherer als breiter und langer Zellen, deren je eine in die Achse einer der durch eine seichte Furche getrennten Hälften (Fächer) der Staubkolbenhälfte verläuft, von den benachbarten Zellen durch Grösse und reichen Gehalt an Proloplasma: die Urmutterzellen des Pollens. Sie theilen sich oft wiederholt durch Quer- und Längswände, welche sammt und sonders auf einer durch die Längsachsen beider Antherenfächer gelegten, der Vorderlläche der Aclıse der Inflorescenz parallelen Ebene senkrecht stehen. Das pollenbildende Gewebe, der Inhalt jedes Antherenfachs bleibt somit fortwährend eine einfache Schicht von Zellen, deren Form immer gestreckter prismatisch wird, je mehr das Antherenfach durch Wachsthum seiner Wande sich erweitert und je weiter die Theilungen in der aus Vermehrung der

*) S. a. Wimmel, Bot. Zeit. $1830,290$.

**) Die Entwickelung der Zostera ist von Grönland (Botan. Zeit. 1851, 185) und von mir insbesondere die des Pollens und der Eychen (dieselbe Zeitschrift 1852, 121 ff.) erörtert worden. Ich wiederhole hier kurz die Ergebnisse jener meiner Untersuchung mit einigen Zusäızen. - 
Pollen-Urmutterzellen hervorgegangenen Zellenmasse vorschreitet. Dabei bleiben diese Zellen fortwährend in innigem Zusammenhange; lassen sich ohne Verletzung nur schwer von einander trennen, und zeigen auch in der relativen Dicke ihrer Wände keine Unterschiede, welche es möglich machten irgendwelche Complexe von Zellen mit Sicherheit als die Nachkommenschaft einer Mutterzelle zu betrachten. Das Gewebe hat durchaus das Ansehen einer in stetiger Zweitheilung aller ihrer Zellen begriffenen Zellenmasse. Eine Andeutung der Entstehung von je vier Zellen letzter Generation in einer Mutterzelle kann nur darin gefunden werden, dass je vier der Zellen besonders fest an einander zu haften pflegen, wenn deren Länge die Höhe etwa um das Dreifache übertrifft. Doch findet in dieser Beziehung nichts weniger statt, als eine ausnahmslose Regelmässigkeit. Complexe von drei, von fünf und mehr Zellen bleiben nicht selten vereinigt, wenn der Inhalt einer aus einem Antherenfache durch zwei parallele Längsschnitte herausgenommenen Lamelle mit den Präparirnadeln aus einander gezupft wird.

Wenn die Länge jeder Zelle auf etwa das Achtfache der Höhe gestiegen ist, vereinzeln die Zellen sich leicht. Fortan findet aber keine weitere Zellvermehrung in ihnen statt; die Pollenzellen sind bereits gebildet: jetzt meist von Keulen-, seltner Spindelform, von körnigem Protoplasma erfüllt, in dessen Mitte eine Vacuole aufzutreten beginnt; des Zellierns entbehrend, von einer dünnen Cuticula umhüllt, welche von dem Zeitpunkte an als die äusserste Lamelle der Haut jeder Pollenzẻlle sich zeigt, wo die leichtere Trennbarkeit der einzelnen Zellen anhebt. Die L.̈̈sung der Pollenzellen von einander scheint eben auch hier auf ler Verllüssigung der verschwindend dünnen Specialmutterzellhaut nach dem Auftreten der Cuticula der Pollenzelle zu beruhen.

Die Länge dẹ Pollenzellen nimmt im stetig sich erweiternden Antherenfach fortan noch sehr bedeutend zu. Die Ausdehnung der Wände jedes Antherenfaches, auf welcher die Erweiterung des Raumes beruht, erfolgt in der Hinterwand in der Richtung abivärts, in der Vorderwand in der Richtung aufwärts. Die Pollenzellen, deren grösster Längsdurchmesser in den früheren Entwickelungszuständen auf der Fläche der platten Achse der Inflorescenz senkrecht stand, erhalten in Folge der einander entgegengesetzten Wachsthumsrichtungen der beiden Antherenfachwände, welchen ilıre Enden anhaften, mehr und mehr eine zur Vorderflache der Bliuthenstandachse geneigte Richtung; in der reifen Anthere liegen sie 
dieser Fläche fast parallel. - Jetzt, beim Aufspringen der Anthere, übertrifft der Längsdurchmesser jeder der langcylindrischen Pollenzellen den Querdurchmesser um das Sechzig - bis Achtzigfache. Die Culicula ist noch dünner worden, als sie beim ersten Auftreten war, aber leicht und deutlich nachweisbar. - In Wasser - süssem oder brackigem untersucht, zeigt jede Pollenzelle eine lebhafte Strömung des Wandbelegs aus körnigem Protoplasma: der Strom, ein aus in sehr langgezogenen Schleifen anastomosirenden breiten Faden zusammengesetztes Band, geht der Achse der Pollenzelle parallel die eine Hälfte ihrer Innenwand entlang, und biegt im Ende der Zelle um, um an der gegenüberliegenden Hälfte der Wand in entgegengesetzter Richtung zu verlaufen.

Eine zweite Reihe von Abweichungen im Bildungsgange des Pollens von dem gewöhnlichen Typus bietet die grosse Mehrzahl der Orchideen. Wie bei den Najadeen lassen sich auch hier diese Abweichungen auf eine ungewöhnliche Entwickelungszeit der Pollenhaut zurückführen. Während aber bei den Najadeen das Ungewöhnnliche in der, unverzüglich nach Bildung der dünnhäutigen Specialmutterzellen eintretende Ausscheidung der von dünner Cuticula bekleideten Pollenzellhaut beruht, besteht es bei der Mehrzahl der Orchideen entweder in der Entwickelung einer von vollständiger oder die Zelle nur theilweis umgebender Cuticula umbüllten, oder der Exine ganz entbehrenden Pollenzellhaul, welche noch vor Theilung der Mutterzelle gleichsam als innerste oder zweitinnerste Lamelle der Haut derselben auftritt. Neben der gewöhnlichen Entwickelungsweise des Pollens, wie sie z. B. bei Cypripedium*) unter den Orchideen sich findet, kommen in dieser Familie dreierlei Abweichungen von ihr vor. ${ }^{*}$ )

Bei den Orchideen mit pulverigem, aus Tetraden bestehendem Pollen, unter den gemeineren Einheimischen namentlich bei Neottia ovata und Nidus aris, den Arten von Epipactis, bleiben die Multerzellen des Pollens im parenchymatischen Verbande noch lange nachdem die Wände

*) Reichenbach fil., de pollinis orchidearum genesi. Lpzg. 1852. Taf. II. f. 117 -134 .

**) Die Bildung des Pollens der Orchideen ist von Reichenbach fil. in der eben angeführten Schrift ausführlich abgehandelt worden. Meine Beobachtungen stimmen mit den seinigen vollständig überein, einige untergeordnete Punkte abgerechnet. Iclı gehe auf den Gegenstand hier nochmals ein, hauptsächlich um einige Angaben über das erste Auftreten der Exine beizubringen. 
sich stark verdickten, der primäre Kern sich auflöste, zwei secundäre, nach deren Wiederverfluissigung vier tertiäre Kerne gebildet wurden; bis endlich auf der Innentvand der Mutterzelle vorspringende Leisten sich entwickeln, deren Lauf der künftigen Stellung der Scheidewände entspricht (V, Aufquellen der inneren Schichten in Wasser barst, so wurde der Inhalt als formloser Brei hervorgetrieben. Von nun an, etwa gleichzeitig mit der beginnenden Vereinzelung der Mutterzellen, ändert sich dieses Verhadıniss. Wenn die geschichtete Zellhaut platzt, tritt aus ihr die innerste Lamelle in Form einer ellipsoüdischen zartwandigen Zelle hervor, welche den gesammten Zellinhalt einschliesst. Der Zellraum ist jetzt noch nicht durch Scheidewände getheilt $(V, 8)$. Die Membran der ausgetretenen Zelle widersteht der Einwirkung von Schwefelsäure um Vieles länger, als die entleerten geschichteten Lamellen der Mutterzellhaut. Mit Jod und Schwefelsäure behandelt, nimmt sie blaugrüne Farbe an. - Wenig späler erscheint die Membran aus zwei Lamellen zusammengesetzt, deren aussere, sehr dünne als ächte Cuticula, die innere als reiner Zellstoff reagirt. Ungefähr gleichzeitig zeigen sich auf der Innenfläche vorspringende Leisten, in ihrem Verlaufe genau dem der Leisten der aufgequollenen entleerten Schichten der Mutterzellhaut entsprechend $(\mathrm{V}, 8, b)$. Unmittelbar darauf, an Pollentetraden, die sich im nämlichen Antherenfach mit den eben beschriebenen untermengt finden, theilen durchgehende Scheidewände, Fortsetzungen jener Leisten, den Raum der Zelle in vier Fächer: die vier aus der einen Mutterzelle hervorgegangenen Pollenzellen, welche durch die allen vier gemeinsame Cuticula dauernd zusammengehalten, zu einer Tetrade vereinigt sind. - Auch die junge Tetrade wird aus den aufquellenden ausseren Schichten der Mutterzellhaut ausgetrieben, wenn sie in Wasser gebracht wird; selbst dann noch, wenn die von vorspringenden Leisten gefelderte Cuticula eine beträchtliche Entwickelung erreicht hat $(\boldsymbol{V}, 9)$. Der Innenraum der entleerten Schichten ist unter allen Umständen von beträchtlich grösserem Umfange, als die ausgetriebene Tetrade (V, 8. 9). Die des Aufquellens fähigen Schichten der Mutterzellhaut werden endlich aufgelöst; die fertigen Tetraden heften sich an einander und stellen beim Aufspringen des Antherenfaches die lose verbundenen Pollenmassen dar.*)

*) Die Entwickelung einiger der bei Phanerogamen rorkommenden Pollentetraden 
Die Pollenentwickelung von Cephalanthera rubra und pallens, welche in Uebrigen von der den Phanerogamen gewöhnlichen nicht abweicht, nähert sich der von Neottia insofern, als auch bei Cephalanthera die Mutterzellen bis nach ihrer Theilung durch Scheidewände aus der verdickten Wand gleichartigem Stoffe, selbst bis nach der Theilung in je vier Specialmutterzellen in parenchymatischem Verband bleiben (VI, 8). Interessant ist bei Cephalanthera rubra*) das Verhalten der jungen bleibenden Wand der Pollenzelle gegen Reagentien. $\mathrm{Zu}$ der Zeit, da die Pollenmutterzellen sich leicht von einander trennen, wird auf der jungen Haut der Pollenzelle die Anlage der künftigen Zeichnung der Exine bereits sichtbar. 'Behandelt man Mutterzellen dieser Entwickelungsstufe mit Chlorzinkjodlösung von einer bestimmten Concentration, so färben sich die äusseren Schichten der Wande des Complexes von Mutter- und Tochterzellen weinroth (VI, 10,a); die diinne innerste Schicht der Wand jeder Specialmutterzelle (VI, 10,b) färbt sich blau; die junge Pollenzellhaut bleibt farblos, zieht sich aber, gleich dem Zelleninhalte, zusammen; nur minder stark als dieser (VI, 10,c).

Die Ophrydeen, und auch die grosse Mehrzahl der Ceriorchideen, unterscheiden sich in Bezug auf die Pollenentwickelung dadurch von Neottia, dass nur ein geringer Theil von Pollentetraden - diejenigen, welche die Aussenflächen der Massulae (bei Ceriorchideen die Aussenfläche der Pollenmassen) zusammen setzen - eine Exine erhalten, und zwar eine unvollständige, die nur die Aussen - und einen Theil der Seitenflächen der Tetraden bekleidet.***)

Jede Massula ist die aus der wiederholten Theilung einer einzigen Urmutterzelle des Pollens hervorgegangene Gruppe von Zellen, Dies geht sowohl aus der Untersuchung frühester Zustande hervor, $\left.{ }^{* * *}\right)$ als auch aus der der Hemmungsbildungen, wie sie sich bei den Orchisarten im Grunde jedes Antherenfaches, an der Anfangsstelle der Caudi-

(z. B. Pyrola rolundifolia und Periploca graeca) stimmt mit der von Neottia und Epipactis völlig überein.

*) Das Material zu dieser Untersuchung, wie zu mancher anderen, verdanke ich der Güte meines Freundes Prof. Irmisch, der von Sondershausen mir frische Pflanzen sandte.

**) Zuerst beobachtet von Fritzsche; Mém. Acad. St. Petersbourg p. divers savants (1837), 699 .

***) Reichenbach fil. a. a. O. Taf. I f. 1. 2 (Orchis Morio) f. 21 (Physurus pictus). 
cula zu finden pflegen (III, 8, $b$ ). Die den ganzen Zellcomplex einer Massula umschliessende Haut, ein Einschachtelungssystem der Membranen der Urmutterzelle und der einander folgenden Generationen von Tochterzellen, erscheint von Anfang an merklich dicker, als die das Innere in Fächer theilenden Scheidewände(III, 8, $b .8, c$ ). Wenn durch wiederholte Theilung der Zellen, insbesondere der äussersten, die Wand des Antherenfachs berührenden; die Vollzahl der der Massula zukommenden Zellen erreicht ist, tritt noch eine weitere Verdickung der Aussenwände der Oberfliche-Zellen ein. Die verdickten Wandungen bestehen durch und durch aus Cellulose; mit Jod und Schwefelsäure behandelt färben sie sich unter Aufquellen hellblau (III, 9). Bald darauf wird der primäre, centrale Zellkern jeder Pollenmutterzelle aufgelöst; an seiner Stelle erschemen zwei secundäre, nach deren Wiederverschwinden vier tertiäre gebildet werden. Mit diesen Vorgängen gleichzeitig wird eine, nur soweit sie die innerste Lamelle der verdickten Zellwände der Aussenflächen jeder Massula anliegt, aus zwei Schichten bestehende, Membran sichtbar, welche allseitig die Zelle auskleidet. Die äussere Schicht dieser Membran zeigt die Beschaffenheit einer Cuticula; die sehr dünne innerste Lamelle derselben die Eigenschaften einer Cellulose-Membran (VI, 1). Die Cuticula setzt sich auf seitliche, zwischen je zwei Pollenmutterzellen der Oberfläche der Massula, ein Stuick weit fort (VI, 2), so dass das zur deutlichen Cuticula umgebildete Zellhautstück die Form einer Kappe hat, welche die nach aussen gewendete Extremität der zur Theilung sich vorbereitenden Pollenmulterzelle bedeckt. Von den Stellen an, an welchen die Bekleidung der neuen Membran durch die kappenförmige Exine aufhört, ist jene von der sehr dünnen ursprünglichen Haut der Mutterzelle kaum zu unterscheiden. Gleich darauf erfolgt die Theilung, begleitet von der Verllüssigung der die Cuticula bedeckenden Schichten der Mutterzellhäute (III, 13). In Folge dieser Auflösung der Mlutterzellhaut werden die Massulae frei von einander und von der äusseren Wand des Antherenfaches, fortan nur noch mit ihren Innenenden an der Längsscheidewand der Antherenhälfte haftend (IV, ๖). Werden dünne Durchschnitte einer Massula mit Jod und concentrirter Schwefelsäure behandelt, so quellen alle Zellstoffivandungen auf, blaue Färbung annehmend, während die Cuticula-Kappen der Zellen der Aussenfläcbe ihre Form nicht ändern und sich gelb färben (IV, 10). Nach längerer Maceration einer durchschnittenen Massula in Schwefelsăure bleiben nur 
die leicht an einander haftenden Cuticula-Kappen der Tetraden der Oberfläche übrig; alle Zellstoffwandungen werden zerstört (IV, 15). Mässiger Druck auf das Deckglas genügt, die Tetraden einer Massula von einander zu trennen. An so vereinzelten Tetraden überzeugt man sich bei Behandlung mit Jod und Schwefelsäure, dass die Tetraden nicht völlig nackt sind. Eine äusserst dünne, nur bei vorsichtiger Behandlung des Objects, und nur mit sehr guten Instrumenten wahrnehmbare Schicht einer bräunlichen, der Schwefelsäure länger widerstehenden Substanz umschliesst die aufquellende, sich bläuende Cellulosehaut; bald mehr bald minder deutlich sichtbar (V, 11. 12). Dieser Umstand, verbunden mit der leichten Trennbarkeit der Tetraden, berechtigt zu der Annahme, dass die Pollenentwickelung auch der Ophrydeen durch Bildung einer die Mutterzelle völlig ausfüllenden Tochterzelle erfolge, deren Wand die bleibende Membran der Pollentetrade darstellt: ein Verhailtniss, das hier, wie bei Najas und Zostera, nur wegen der verschwindenden Dünne des grössten Theiles der Multerzellmembranen minder deullich hervortritt. Dass dem so sei, dafür spricht aufs Entschiedenste der Entwickelungsgang des Pollens von Phajus Wallichii.

Diese Entwickelung hält die Mitte zwischen der von Neottia und der von Orchis. Die Wände der ursprünglich sehr dünnhäutigen Mutterzellen (VI, 3) werden beträchtlich verdickt, noch bevor der primäre Kern jeder Zelle verschwindet. Die Verdickung überwiegt bedeutend an den nach aussen gekchrten Wänden der die Oberfläche jeder Pollenmasse zusammensetzenden Zellen; von da nach innen nimınt sie rasch und beträchtlich ab. Zu der Zeit, da in jeder Multerzelle dic vier tertiaren, für die Pollenzelle bestimmten Kerne eben gebildet sind, erschcint die äusscre Wand jeder Mutterzelle der Aussenfläche der Pollinarien aus drei Lamellen zusammen gesetzt: einer sehr dünnen äussersten, je zwei benachbarten Zcllen gemeinsamen; einer dickeren mittleren, und einer noch etwas breiteren innersten (VI, 4). Jede dieser Schichten ist völlig durchsichtig; die äusserste ist am stärksten, die innerste an schwächston lichtbrcchend. Bci etwas längerer Einwirkung von Wasser zicht sich öfters der körnige Zelleninhalt, scharf begränzt, von der innersten Lamelle der Haut eine kurze Strecke zuruick $(V I, 4, b)$. An Zellen, welche durch den Schnitt geölfnet wurden, erkennt man, dass die innerste Schicht nur von sehr geringer Festigkeit, gallertartig weich ist (VI, $4, d)$, und dass ihre Substanz, bci längerem 
Liegen in Wasser, in diesem siclı vertheilt. Wird ein frisches solches Präparat mit Chlorzinkjodlösung behandelt, so färben sich die beiden ausseren Lamellen der Zellhäute blassblau, die innere blassgelb, indem sie zu. gleich ein körniges Aussehen annimmt (VI, 4, c); der von der Innenfläche der Wand mit scharfer Begränzung sich zurück ziehende Zelleninhalt wird dunkel braungelb. - In den mächst älteren, nur sehr wenig weiter entwickelten Knospen der nämlichen Inflorescenzen findet sich, an Statt jener breiten, auf Jodzusatz ein körniges Aussehen annehmenden innersten Schicht der Haut, eine viel schmälere, aus zwei verschiedenen Lagen bestelıende (VI, 5), die innerste Lage glatt, mit Jod und Schwefelsäure sich bläuend; die äussere körnig, der Schwefelsäure widerstehend, mit Jod eine gelbe Färbung annehmend: die letztere die Exine, die erstere die Intine der noch nicht in vier Zellen getheilten Pollentetrade. Mittelstufen zwischen diesen beiden Zuständen vermochte ich bei oft wiederholter Untersuchung reichlichen Materials durchaus keine aufzufinden, so dass ich die Ueberzeugung gewonnen habe, jene weiche, dicke innerste Schicht verwandle sich plötzlich, unter beträchtlicher Abnahme ihres Volumen, in eine feste, gleich bèi der Erhärtung aus zivei chemisch verschicdenen Lamellen bestehende Membran. An den Seiten- und inneren Flächen der äusseren Mutterzellen ist die halbfeste Schicht weit minder mächtigg entwickelt. Noch schwächer ist sie $e s$ in den Zellen des Inneren jeder Pollenmasse. Damit stimmt überein, dass die Exine an der nach aussen gewendeten Extremität jeder oberflächlichen Tetradenanlage um Vicles schärfer markirt auftritt, als im übrigen Tlıcile. Dort ist sie zu einer Zeit bereits deutlich sichtbar, wo hier die Aussenfläche der küftigen Tetrade noch glatt erscheint (VI,6); ferner dass die Exine der inneren Tetraden jedes Pollinarium überhaupt nur eine sehr geringe Ausbildung erhält.

Dic Theilung jeder Mutterzelle in vier Pollenzellen erfolgt erst einige Zeit nach dem Auftreten der Exine (VI, 6); etwa vier bis sechs Knospen abwärts am Bluithenstande. Noch später löset sich der parenchymatische Zusammenhang der Pollenmutterzellen unter einander. Nach der Vereinzelung in Wasser gebracht, stossen sie die eingeschlossenen Tetraden durch densellen Mechanismus aus, wie Neottia ovata. Nach dem Freiwerden der Mutterzellen ron einander werden die Zellläute derselben, bis auf die Exine der Tetrade herab, rasch aufgelöst. 
Bei einigen, vielleicht bei zahlıeichen Ceriorchideen findet eine Modification der den Ophrydeen zukommenden Entwickelungsweise des Pollens statt, welche darin bestelı, dass jede släkere Verdickung der Mutterzellhäute und jede deutliche Cuticularbildung an den Pollentetraden unterbleibt. Der ganze Inhalt eines Pollenfachs bleibt bis zur Reife in parenchymatischem Zusammenhange, der nur durch starke Quetschung der Pollenmasse gelöst werden kann. Dann vereinzeln sich die Tetraden, sảmmtlich, auch die der Aussenfläche nur von einer so undeutlich entwickelten Culicula umschlossen, wie die des Inneren der Massulae von Orchis. Solche Verhälınisse finden sich bei Lycaste aromatica, Corallorhiza innata. Die Fälle schwacher Entwickelung der Exinekappen der oberflächlichen Pollentetraden mehrerer Maxillaren stellen Uebergänge von dieser Entwickelungsweise des Pollens zu der unmittelbar vorher geschilderten dar.

Einige Bemerkungen über den Entwickelungsgang einiger der, bei vielen Orchideen vorkommenden, zur Uebertragung des Pollens auf die Narbe behülflichen Organe, der Caudiculae und Retinaculae, mögen hier Platz finden.

Wir verdanken J. D. Hooker eine eingehende Untersuchung der Heranbildung des hintersten Segmentes des Griffels - des sogenannten Rostellum - von Neollia ovata zu dem, Zwei Viseintropfen, sogenannte Drüsen, tragenden plattenförmigen Organ, dessen Viscinmassen die aus der aufspringenden Anthere hervortretenden Pollenmassen sich anzuheften pflegen.*) J. D. Hooker schildert das Rostellum als zusammengesetzt aus einer Anzahl in einer Fläche liegender langprismatischer Fächer, deren Inhalt auf früheren Zuständen eine zellige Structur zeige. Der Inhalt tritt zur Zeil der Pollenreife aus den Fachern aus, und bildet die Drisen. Diese Darstellung bedarf einiger Ergảnzungen.

In der halb entwickelten Blüthenknospe der Neottia ovata, deren Pollenmutterzellen noch ungetheilt sind, erscheint das Rostellum als eine Platte aus Zellgewebe von der lialben Länge der Anthere, kurz spatelförmigem Umriss, an Vorderrande in eine wenig vortretende Spitze auslaufend $(V, 1.3 .4)$. Seine der Anthere zugekehrte Seite (morphologisch Unterseite, thatsiachlich Oberseite) wird fast vollständig eingenommen von einer Gruppe in einer Ebene liegender langgestreckter Zel-

*) Philos. Transact. 1854, 959; übersetzt in Ann. sc. nat. IV S. III, 84. 
len, 16 bis 20 an der Zahl, die etwa zwanzigmal so lang als breit und hoch sind. Diese Zellen enthalten jede einen, verhältnissmåssig nicht grossen Zellkern; ihr übriger Innenraum ist erfüllt von dicht gedrängten, bläschenähnlichen Kügelchen einer gegen die stärksten Säuren und Alkalien sehr indifferent sich verhaltenden Substanz. In ihrem Aussehen ähneln diese Kügelchen sehr denen des Milchsaftes der Siphonia elastica. Die zahlreichen übrigen Zellen des Rostellum, an dessen Grunde in sechs Schichten geordnet, die nach dem Vorderrande zu an Zahl allmälig abnelımen, zeigen in Form und Inhalt nichts Besonderes (V, 2). - Bis zur Blüthezeit erleidet das Rostellum nur dic eine Veränderung, dass jene grossen Zellen seiner Oberseite an ihren Vorderenden nach vorn gerichtete papillöse Ausstiilpungen treiben, welche schliesslich bis an den Vorderrand des Rostellum reichen, und mit einer in langgezogenen Massen gefelderten Cuticula sich bedecken ( $V, 4)$. Zur Blüthezeit bersten die stark turgescirenden Zellen dicht hinter den von dieser Cuticula überzogenen Stellen rechts und links von der Spitze des Rostellum; ein grosser Theil des Inhalts tritt aus und fliesst jederseits zu einem Tropfen aus zäher, fadenziehender Substanz zusammen, der häufig, aber nicht immer, der Inhalt eines Antherenfachs sich anheftet $(\mathrm{V}, 11)$. - Mit Neottia ovata im Bau des Rostellum völlig übereinstimmend verhält sich ihre Gattungsgenossin Neottia nidus avis, während der vor der Anthere stehende Narbenabschnitt der nahe verwandten Epipactis rubiginosa sich ganz anders beschaffen zeigt: aus gleichartigem Zellgewebe zusammengesetzt, am Vorderrande etwas umgeschlagen, die Oberseite papillös. Nur die Oberhautzellen des umgeschlagenen Randtheiles enthalten viscinähnliche Substanz, aber in viel kleineren Klümpchen, als Neottia, - die zur Oeffnungszeit der Anthere austritt (V, 15.16). Aehnlich bei Cephelanthera rubra und pallens (VI, 11. 12).

Die Bildung der Caudicula und Retinacula der Ophrydeen erfolgt in wesentlich verschiedener Weise: durch Verflüssigıng der Wände von Zellengruppen, in deren Innerem cin viscinähnlicher Stoff sich angehäuft hatte, und durch Zusammentreten dieser Substanz zu Massen, welche nach den IIohlräumen im Zellgewebe sich formen, die sie ausfüllen. Fülıt man bei Orchis Morio, zur Zeit da die Pollenzellen eben gebildet sind, einen Längsschnitl durch den unteren Theil einer Antherenhälfte, so findet man vom Grunde der Antherenficher bis in das stumpfe, von einem der Seitenflügel des Rostellum umschlossene Ende der Antheren- 
hälfte einen Strang verbältnissmässig grosser, dickivandiger Zellen verlaufen, die leicht aus dem parenchymatischen Zusammenhange sich lösen und von kleinen Tropfen jener viscinähnlichen Substanz erfült sind (III, $16 a, b .17)$. - Zivei Gruppen ähnlicher Zellen finden sich im Innern des Rostellum, jederseits eine genau unter der Endigung jeder Antherenhälfte. Bei weiter rückender Ausbildung der Knospe werden die Zellen beider Gruppen immer reicher an Viscin, ilire parenchymatische Verbindung wird immer lockerer durch allmälige Auflösung der Wände von aussen nach innen; endlich verschwinden die Wände ganz; das Viscin des Inhalts fliesst zusammen und verändert sich, bis zum Aufbliuhen der Knospe, in eine immer noch weiche Substanz von einer Elasticitäl, wie sie in lebenden Planzen bei gleich geringer Härte nirgends anders vorkommen dürfte.

\section{Entwickelung der Eychen.}

Der Typus der Eychen der Monokotyledonen, der Phanerogamen überhaupt, tritt auf besonders übersichtliche Weise in den einfach gebauten, aus verhältnissmåssig wenigen Zellen zusammengesetzten Eychen der Orchideen hervor.*) Im jugendlichen Fruchtknoten treten die Placenten auf als von den Innenwänden schwwach vorspringende Längsleisten, welclıe in den Verlängerungen der verwachsenden Seitenränder der, Anfangs schuppenförmigen, drei Carpellarblätter liegen: die eine unter der Mittellinie des Labellum (III, 6. 7), die beiden anderen um $120^{\circ}$ von ihr entfernt. Jede Placenta nimmt zunächst die Form der Hälfte eines abgeplatteten Cylinders an, bald darauf wird sie, durch ihren Seitenrändern entlang vorwiegend lebhafte Zellvermelırung zu einem schildförmigen, mit einer relativ kleinen Stelle der convexen Rückenfläche der Innenwand der Fruchtknotenhöhle ansitzenden platten Zellenkörper mit convexer Vorderfläche (III, 21). Zu beiden Sciten der medianen Längsfurche dieser Vorderfläclıe beginnt an, jederseits in eine

*) Schon vor längerer Zeit (Entstehung des Embryo S. 1 ff.) habe ich die Entwickelungsgeschichte der Orchideen-Eychen gegeben. Die Wichtigkeit des Gegenstandes veranlasste mich zur Wiederholung der einschlagenden Untersuchungen. Das Ergebniss derselben stimmt in alten Punkten mit den der früheren überein. Ich lege es hier aufs Neue dar, in bündigerer Form und von Abbildungen begleitet, welche anschaulicher $7 \mathbf{u}$ liefern durch optische Hülfsmittel besonderer Güte (Amici'sche Objective und Oculare) mir verstattet ist. 
Längsreihe geordneten, in den beiden Reihen mit einander alternirenden Stellen dicjenige Vermehrung von Zellen der Oberfläche der Placenta, welche die Bildung der Eychen zum Endergebniss hat.

Die in Folge dieser Zellvermehrung über die Fläche der Placenta halbkugelig sich erhebenden Gewebsmassen treten zunächst in deren Mittelgegend hervor; von hier aus schreitet ihre Bildung nach dem oberen wie dem unteren Ende der Placenta hin fort (III, 21). Von oben gesehen zeigt jede Erhebung deutlich eine Scheitelzelle, umgeben von einem Kranze von $5-6$, selten bis 8 Zellen (III, 20. 21). In der an zarten Längsdurchschnitten gewonnenen Scitenansicht stellt jede Erhebung in der Art sich dar, wie der Durchschnitt des Vegetationspunktes einer vegetativen Achse: die Scheitelzelle tritt meistens sehr deutlich hervor; die ihr benachbarten Zellen zeigen eine Anordnung, welche auf ihre Abstammung von, durch in der Scheitclzelle nach verschiedenen Richtungen geneigt entstandene, Scheidewände gebildeten Tochterzellen schliessen lässt (III, 19).

Diese Erhebungen sind die Anlagen, jede einer der Gruppen von Eychen, welche in zwei Längsreihen auf der Placenta der Orchideen stehen. Eine grössere Zahl von Eychen sprosst ziemlich gleichzeitig aus der Oberfläche jeder Erhebung hervor. Das gipfelständige ist auf den frühesten Zuständen vor dèn übrigen in der Entwickelung etwas voraus: es ist zweifelsohne das zuerst hervortretende, dem die anderen folgen. In welcher Ordnung ist schwer zu ermitteln: das wirre Bild, welches die Ansicht von oben der betreffenden Zustände bietet, ist nicht mit Sicherheit zu deuten. Doch glaube ich kaum zu irren, wenn ich die Stellung der Eychen jeder Gruppe für eine schraubenlinige halte.

Dagegen unterliegt die Ermittelung der Regeln, nach welchen die Zellen der sich entwickelnden Eychen sich vermchren, keiner besonderen Schvierigkeit.*) Auf zur Fläche der Placenten senkrechten Durchschnitten sowohl (III, 23), als bei Betrachtung von Abschnitten derselben von aussen erkennt man, dass bestimmte Zellen der Oberfläche der Hervorragungen - nach jeder Richtung je die zweite - an Grösse beträchllich zunehmen. In der grösser gewordenen Zelle, deren freie Aussenfläche nach aussen sich wölbt, tritt eine Querwand auf, welche

*) Hier schliessen die gegenwärtigen Millheilungen an die vorerwähnten früheren sich an. 
die Seitenwandungen der Zelle schneidet. In der äusseren der beiden Tochterzellen findet eine Reihenfolge von Theilungen durch von der Längsachse des werdenden Eychens hinweg geneigte Scheidewände stalt, welche die freie gewölbte Aussenwand der Zelle, und die von der inneren Schwesterzelle sie trennende Querwand schneiden. Die so entstandenen Tochterzellen, von veränderlicher Zahl, meist fünf, sind so geordnet, dass eine als Scheitelzelle des Organs erscheinende von den ubrigen, die einen Guirtel darstellen, eingefasst wird (IV, 2). Jede der letzteren theilt sich nochmals durch eine der von der Scheitelzelle sie trennenden Wand parallele Scheidewand (III, 22); oft auch eine, zwei oder mehrere derselben durch gleichfalls auf der freien Aussenfläche des jungen Eychens rechtwinklige Längswände. Gleichzeitig erfolgt eine Längsdehnung der eingeschlossenen Schwesterzelle der Mutterzelle aller dieser; die Zellschicht, welche aus der Vermehrung der äusseren der beiden Anfangszellen des Eychens entstand, nimmt die Form des Mantels eines Paraboloïds an, dessen Innenraum von der sich streckenden inneren Zelle ausgefültt wird. In dieser treten jetzt zwei neue Zellkerne an Statt des verschwundenen primären auf (III, 23); wenig später erscheint eine diese Kerne trennende Scheidewand. Das Eychen besteht jetzt aus einer axilen, von zwei Zellen gebildeten Längsreihe, die von einer einfachen, aus superponirten Gürteln von meist je 6 Zellen, mit einer einzigen, vier - bis sechsseitigen Scheitelzełle endigend, zusammengeselzten Zellschicht umrindet wird.

In der Scheitelzelle, und in der zunächst unter ihr gelegenen obersten der Zellen des axilen Stranges wiederholen sich die nämlichen Theilungen stetig bis zur Vollendung der Lãngenentwickelung des Eychens (III, 1-10). Nach etwa sieben derartigen Wiederholungen, an den terminalen Eychen einer Gruppe wohl auch früher, beginnt der Endtheil des jungen Organs sich seitlich zu krümmen. Die Krümmung erfolgt zunächst nur durch einseitige Dehnung der Zellwände der convex werdenden Seite; eine Theilung der Zellen derselben durch Querwandungen findet nur ausnahmsweise statt (IV, 11). Gleichzeitig mit der Krümmung hebt die Entwickelung der Integumente an. Die Zellen des von der Spitze zu viert- oder fünft-rückwärts gelegenen Gürtels der Rindenschicht wölben ilhre freie Wand nach aussen, so dass eine den Grund des Endtheils umfassende vorspringende Leiste aus diesen zusammenhängenden Auftreibungen von Zellwänden entsteht. Die gedehnten Zellen theilen sich, 
rasch wiederholt, durch zur Längsachse der Auftreibung quere, oder auch durch wechselnd gegen den Endtheil des Eychens hin und von ihm hinweg geneigte Winde; Theilungen die im Ringe fort und fort in die Lảnge wachsender Endzellen der so entstehenden röhrenförmigen, den Endtheil des Eychens umscheidenden Sprossung sich bis zum Aufhören des Längenwachsthums wiederholen. - Der unter jenem Gürtel peripherischer Zellen des Eyclıens gelegene nächste Gürtel folgt ihm in der gleichen Entwickelungsweise. So bildet sich die zweite, äussere, jener ersten dicht angeschmiegte Hülle des Eychens. Die Stelle stärkster Krümmung des Eys fällt mit der Insertion des äusseren Integuments, der Eintritl jener Krümmung mit dem Hervorsprossen dieses zusammen. In den Zellen des peripherischen, das äussere Integument entwickelnden Zellgürtels, welche den Innenwinkel der Krümmung einnehmen, unterbleibt die zur Entstehung der äusseren Eyhülle führende Tochterzellbildung. Das äussere Integument, der Anlage nach an der dem umgewendeten Endtheile des Eys entgegengesetzt gerichteten, zum Funiculus werdenden unteren Theile desselben offen, wie eines der Carpelle einer Nymphaea gegen das Ende der Blüthenachse hin es ist, wächst gleich beim Hervorsprossen mit seinen Seitenrändern an den Funiculus an. Die Zahl der Zellen des Funiculus im Querdurchmesser ist nach Vollendung der Entwickelung der Integumente nicht gesteigert, abgesehen von der weitcrhin zu erwähnonden Längstheilung seines axilen Zellstranges (III, 11.16)*). Der Theil des Eychens, welchen die heran-

*) Diese Entwickelungsweise des äusseren Integunents anatroper (und hemitroper) Eychen ist die ganz allgemeine. Die Nichtberechtigung der früher allseitig geltenden Voraussetzung, dass das äussere Integument, im ganzen Umfange des Eyes sich entwickelnd, an seiner dem Funiculus zugekehrten Seite mit diesem verwachse, ist zuerst von Pringsheim für Mercurialis und einige Pflanzen ähnlichen Eybaues dargethan worden (Bot. Zeit. 1851, 115). Mir ist kein Fall bekannt worden, welcher gegen die Allgemeingültigkeit der von Pringsheim für Mercurialis aufgestellten Sätze spräche. Einen Beweis gegen dieselben finde ich ebenso wenig in dem Umstande, dass von nahe verwandten Pflanzen mit ähnlich gebauten, aber verschieden gekrümmten Eychen diejenige mit nicht oder wenig gekrümmtem Eye das einzige oder äussere Integument im sullzen Umfange des Eyes entwickelt zeigt, die andere die Ausbildung dieses Integuments an der Berührungsstelle des Funiculus mit dem inneren Integumente oder dem Eykern unterlässt, - als in der bekannten Erscheinung, dass an abnorm atrop entwickelten Eychen von Pflanzen mit normal anatropen oder hemitropen Eyern das äussere Integument im ganzen Umfange jener abnormen Eyer entwickelt ist (z. B. Berberis, Morus, Mesembryanthemum). Die Vermehrung der Zellen des zum :iusseren oder ein- 
wachsenden Integumente, in ihre Höhlung ihn einschliessend, als E y kern von den übrigen Theilen des Eychens sondern, enthält nur die eine oberste Zelle des axilen Stranges. Diese Zelle begann schon vor dem Hervorsprossen der Integumente auf Kosten der sie umhüllenden zu wachsen. Während der Ausbildung der Integumente setzt sie dieses Wachstlıum fort. Nachdem die Mündung des inneren Integuments bis auf den engen Kanal des Endostoms sich schloss, ist die jene axile Zelle (den werdenden Embryosack) umhüllende Zellschicht bis auf geringe Reste der den Scheitel des Eykerns einnehmenden Zellen völlig verdrängt (IV, 11). Auch diese abgeplattet zusammengedrückten Reste der Scheitelzellen entschwinden bald darauf der Beobachtung. Die Haut des Embryosacks liegt der aus den bleibenden freien Aussenwänden der Rindenzellen des Eykerns zusammengesetzten IIüllhaut desselben auf allen Punkten dicht an (IV, 12-14).

Die Entwickelung aller darauf untersuchten Eychen von Monokotyledonen entspricht in den Hauptzügen der der Orchis Morio. Allen ist gemeinsam, dass die Anlage des Eyes ein aus peripherischen Zellschichten und einem axilen Zellstrange aufgebauter Zellkörper ist; dass eine der Zellen des axilen Stranges, Nachbarzellen zusammendrückend, auflockernd und verdrängend, zum Embryosacke heranwächst. Die Verschiedenheiten des Entwickelungsganges anderer Formen von dem der Orchideen beschränken sich auf abweichende Krümmungen; auf Verminderung oder Vermehrung der Zahl und Aenderung der Einfügung der Integumente; auf das Auftreten einer in bestimmten Richtungen erfolgenden Zellvermehrung im äusseren Integumente, oder in gewissen Gruppen der peripherischen Zellen der Anlage des Eychens, oder der axilen und der peripherischen Zellen der Anlage des Funiculus; auf die Entfernung der zum Embryosack heranwachsenden Zelle des Eykerns von dessen Scheitel, endlich auf die minder vollständige Verdrängung der peripherischen Zellen des Eykerns durch den Embryosack.

Dreierlei Krümmungen der Eychen sind überhaupt beobachtet: solche des freien Theiles des Funiculus, solche der Region, in welcher die Eyhüllen eingefügt sind, endlich solche des Eykerns selbst. Die ersteren, mannichfaltiger Art, in mehrsaamigen Fruchtknoten an ver-

zigen Integument sich entwickelnden Gürtels von Oberhautzellen unterbleibt eben nur in der tiefsten Stelle der Krïmmung des jungen Eyes; sie findet aber allseitig statt, wenn die Krümmung unterbleibt. 
schiedenen Eychen oft verschiedenartig, durch besondere Benennungen zu bezeichnen, erscheint überflüssig: die Angabe der Richtung, die ungefähre Bezeichnung des Grades der Beugung wird in allen Fällen ausreichen. Das völlige Unterbleiben derselben ist, wie überhaupt, auch unter den Monokotyledonen nicht häufig. Als Beispiele seien, ausser den Orchideen, die Gattungen Arum, Pistia, Calla, Carex, die einsaamigen Arten von Pontediria genannt. Beugung des Funiculus um nahezu $90^{\circ}$ nach einwärts ist der grossen Mehrzahl der Monokotyledonen mit parietalen, in der Längsachse des Fruchtknotens sich berührenden Placenten und zahlreichen horizontalen, an jedem der rückwärts geschlagenen Seitenränder in zwei Längsreihen stehenden Eychen eigen: den Liliaceen im weitesten Sinne, mit Einschluss der Irideen und Amaryllideen. Die Beugung ist meist eine sehr scharfe, auf eine kurze Stelle des Funiculus beschränkte, knieförmig. Eine ähnliche Beugung seitwärts zeigt der sehr kurze, dem Grunde des Fruchtknotens eingefügte, freie Funiculus von Najas major (I, 14), eine halb so grosse abwärts der Funiculus des ursprünglich schräg gestellten, später senkrecht abwärts gerichteten Eychens von Symplocarpus foetida (VIII, 4); eine von 45 bis $90^{\circ}$ steigende, von den oberen Eychen jeder Placenta zu den unteren hin zunehmende der lange Funiculus von Merendera caucasica (XV, 2. 3); eine noch grössere, bis zu $180^{\circ}$ gehende der von Bulbocodium vernum (XVIII, 11. 14. 15). Bei wenigsaamigen Liliaceen mit gestrecktem Eychen (z. B. bei Veltheimia, Gagea), ferner bei den Arten von Pothos findet eine Torsion des Funiculus um beiläufig $45^{0}$ statt.

Krümmungen der Längsachse des Eychens in der Einfügungsebene des äusseren oder einzigen Integuments sind es ausschliesslich, auf denen die Ablenkung des Laufes von dem geradlinigen der ganz oder halb umgewendeten Eychen beruht. Wenn diese Beugung $180^{\circ}$ beträgt und das Längenwachsthum der Integumente nicht oder nur wenig über die Krümmungsstelle des freien Theiles des Funiculus hinausgeht, so wird das Eychen anatrop, hemianatrop aber, wenn die Integumente, oder doch das äussere, über jene Stelle des Funiculus hinauswachsen : so bei Colchicum autumnale (XVII, 1), Pothos. Die anatropen Eychen bilden auch unter denen der Monokotyledonen die Mehrzahl: sie finden sich u. A. bei Triglochin, Rhodea, Calla, Carex, Veltheimia, Gagea, Funkia, Gloriosa, Bonapartea, Puschkinia, Scilla, Merendera, Bulbocodium, Iris, Crocus, Ixia; mit einer leichten Modification, insofern die Längsachse 
des Eychens in der Einfuigungsgegend der Integumente ausser der vollständigen Umwendung auch noch eine Beugung nach aussen zeigt, bei Hippeastrum aulicum (XIII, 1). Eine Andeutung dieses Verhältnisses kommt auch bei Leucojum vernum (XIII, 13. 25) und noch einigen anderen Amaryllideen vor.

In geringerem Maasse gebogen ist die Längsachse des Eychens in der Einfüguugsstelle des äusseren Integuments bei Tradescantia, um etwa $30^{\circ}$ (XXIV, 17); bei Triteleia uniflora um etwa $90^{\circ}(\mathrm{XX}, 1)$, bei Lemna um $30^{\circ}$, bei Asphodelus etwa $45^{\circ}$, bei Philodendron Imbe um $90^{\circ}$ in einer der gleich starken Beugung des Funiculus genau entgegengesetzten Richtung, so dass die Längsachse des Eykerns derjenigen des unteren Theiles des Funiculus parallel ist (VIII, 3). - Bei geringer Längsentwickelung des Funiculus hält es schwer, derartige Krümnungsformen von Beugungen des Funiculus scharf zu sondern; wie denn z. B. Zostera und Symplocarpus fast mit ebenso gutem Rechte als dorthin hieher gezogen werden könnten.

In allen den bisher erwähnten Fällen nahm der Eykern selbst an den Krümmungen des Eychens keinen Theil. Seine Längsachse ist eine gerade Linie. Krümmungen auch des Eykerns aber kommen unter den Monokotyledonen relativ häufiger vor, als unter den Dikolyledonen. Der Eykern aller Gräser, der Mehrzahl der Fluvialen, - beide grosse Abtheilungen mit Eychen, deren Chalaza-Gegend unmittelbar der Fruchtknotenwand ansitzt, ohne dass ein als Funiculus unterscheidbarer Theil des Eysprosses unterhalb der Ursprungsstelle der Integumente vorhanden ist-zeigt Beugungen: bei den Triticeen (Secale, Elymus, Triticum, Hor'deum XI, 13) und bei Ruppia, Zannichellia, Potamogeton (II, 2.3.8) eine Sförmige, im Chalaza-Ende des hängenden Eychens nach der Fruchtknotenwand unter der Anheftungsstelle des Eychens hinwärts, mit der Spitze des Eykerns in entgegengesetzter Richtung gebogen. Diese Krümmung wird bei Zannichellia, Potamogeton, und ganz besonders bei Ruppia erst nach erfolgter Befruchtung vollständig (II, 1-6). Bei den Paniceen (Sorghum, Zea, Coix) ist die Krümmung einfach, Cförmig, mil der Concavität des $180^{\circ}$ betragenden Bogens der Anheftungsfläche zugewendet; ebenso bei Allium. In den ersteren Fällen überwiegt die Längsentwickelung der concav werdenden Seite des Eychens die der entgegengesetzten so bedeutend, dass diese gegen jene fast verschwindet; in letzterem ist das Missverlabltniss minder grell. Den Eychen der Paniceen gleichartig, 
aber minder stark gekrümmt sind die von Crinum; der Bogen beträgt nur $90^{\circ}$ bei Crinum variabile, etwa $120^{\circ}$ bei Cr. capense (XIV, 1-3. 9. 11). Eine Cförmige Krümmung nach dem Funiculus hin zeigt der Kern der der Anlage nach anatropen Eychen von Alisma Plantago (II, 20), von Czackia Liliastrum (XIX, 2), von Canna, hier mit übermässiger Entwickelung der Chalaza-Region ; ) eine ebensolche, erst nach der Befruchtung vor sich gehende Beugung der Kern des anatropen Eychens von Najas major $(\mathbf{I}, 17, a)$.

Einen so einfachen Bau beider Integumente des Eychens aus nur einer bis zweien Zellschichten, wie die Orchideen, besitzt keine andere der genauer untersuchten Monokotyledonen. Das innere Integument, in der Regel minder entwickelt als das äussere, besteht überall anderwärts aus mindestens zwei, in der Umgegend des Endostoms meist aus drei bis vier Zellschichten. Dass auch am Endostom die Zahl der Zellschichten nicht über zwvei beträgt; dass die Verengung des vom inneren Integumente umschlossenen Raumes über der Kernwarze zum Mikropylekanal nur durch quere Streckung der inneren Zellschicht des Integuments bewirkt wird, ist ein nicht häufiger Fall; beobachtet bei Hippeastrum aulicum (XIII, 7), Hymenocallis ovata (XXV, 2), Triglochin maritimum (I, 2\%).

Eine stäkere Entwickelung des inneren Integuments ist nur bei dem, aus drei bis vier Zellschichten bestehenden einiger Arten von Allium, z. B. A. odorans mir vorgekommen.

Das äussere Integument ist bei den Monokotyledonen allerwărts massiger, als das innere; oft sehr auffällig durch beträchtliche Dicke von ihm unterschieden. So u. v. A. bei Arum, Lilium, Hippeastrum (bei letzterem und anderen Liliaceen auch durch reichlichen Chlorophyllgehalt von dem inneren ausgezeichnet). Bei Hippeastrum aulicum ist das äussere Integument in der der Raphe abgewendeten Seite weit überwiegend entwickelt, so dass diese seine Wucherung fast ausschliesslich die eigenthümliche Form des Eys hervorbringt (XIII, 1. 2). Am mindesten unterscheidet sich das äüssere Integument vom inneren bei den Gramincen, einigen Aroïdeen (Pothos pentaphylla, Philodendron).

Dass die Mündung des äusseren Integumentes an der Bildung des Mikropylekanals sich betheiligt; dass das Endostom gleich dem Exostom 
bis auf einen engen Kanal sich schliesst, kommt unter den Monoliotyledonen nur selten vor. Pistia Stratiotes (VII, 18. 19. 22), Pothos pentaphylla (IX, 3) sind die einzigen mir bekannt gewordenen derartigen Fälle. Wenn anderwärts das Längenwachsthum des ausseren Integuments dasjenige des inneren übersteigt, so bleibt doch das Exostom weit offen: so bei Orchis (IV, 15-17), Najas major (1, 17, a), Ruppia maritima (II, 3), Philodendron Imbe (VIII, 1), Arum ternatum (VII, 5), Caladium bicolor (VIII, 8), Calla palustris (VIII, 13), Secale cereale (XI, 1), Merendera caucasica (XV, 2. 7), Uvularia grandillora (VII, 9), Crzackia Liliastrum (XX, 2), Allium odorans (XX, 8), Hymenocallis ovata (XXV,1). Bei den meisten Monokotyledonen aber ragt zur Blüthezeit das Endostom frei aus dem Exostom hervor: so bei der grossen Mehrzahl der Liliaceen und Gräser, den Carices, bei Arum maculatum, orientale, divaricatum (VII, 1. 8), bei Zostera. Das Zurüickbleiben der Längsentwickelung des äusseren Integuments hinter der des inneren ist in mehreren Fällen sehr bedeutend: so bei Symplocarpus foetida, wo die äussere Eyhülle nur als ein niedriger, den Grund der inneren umgebender Ringwulst erscheint (VIII, 4-6; der Saum des innern Integuments ist in vier dreieckige, zusammen neigende Lappen getheilt [f. 6], eine bei keiner anderen Pflanze bis jetzt beobachtete Beschaffenheit des Eymundes). In ähnlicher Weise unentwickelt ist das äussere Integument bei Epipactis, $\left.{ }^{*}\right)$ ferner bei Zea und Sorghum: der an der convexen Seile stärkeren Entwickelung des gebogenen Eyes widersprechend reicht das äussere Integunent nur an der concaven Seite des Eys bis an den Saum des inneren; an der convexen Seite bedeckt es kaum die Hälfte des inneren. ${ }^{*}$ ) Dasselbe Verhältniss findet sich bei Triticum vulgare wieder, bis aufs Aeusserste gesteigert, insofern hier das äussere Integument nur an der concaven Seite des Eychens als kurze Schuppe entwickelt ist, auf der convexen Seite desselben aber völlig fehlt (XI, 13).

Abweichungen von der Zweizahl der Eyhüllen sind unter den Monokotyledonen höchst selten. Ein drittes, äusserstes Integument, schon

*) Meyen Pflanzenphysiol. III. Taf. XV f. 23 ; Schacht, Entw. Gesch. d. Pflanzenembryon Taf. Y f. 19-21.

**) Schleiden N. A. A. C. L. Taf. XIX,I f. 19. 20 ; Ilofmeister, Entst. d. Embryo Taf. XI f. 1. 24.

Abhandl. d. h. S. Ges. d. Wiss. VIl. 
vor der Befruchtung beträchtlich entwickelt, aber erst während des Reifens des Saamens diesen vollständig überziehend (einen Arillus) besitzen die Eychen des Asphodelus luteus*) und creticus; ${ }^{* *}$ ) einen langsamer sich entwickelnden, zur Blüthezeit nur eine niedrige Krause bildenden Arillus Aloë subtuberculata.*****) - I $^{\text {s }}$ von nur einem Integument bekleidet betrachte ich die Eychen der Arten der Gattung Crinum. Der Embryosack von Crinum capense und $\mathrm{Cr}$. asiaticum ist von einer aus 3 -4. Zellenlagen bestehenden Gewebsschicht umhüllt, durch welche am Scheitelpunkte des gekrümmten Eyes ein enger Kanal auf das obere, die Keimbläschen einschliessende Ende des Embryosackes zufuhrt (XIV, 3.4). Ich halte diesen engen Gang für den Mikropyle-Kanal, die den Embryosack umhiillende Gervebschicht für das einzige Integument des Eychens. + )

Das äussere Integument ist in der Regel der Chalaza-Region dicht unter dem inneren eingefügt. Die einzige unter den Monokotyledonen mir bekannt gewordene Abweichung bietel Allium, wo bei Allium odorans z. B. eine nach der Anlegung der Integumente, während der Beugung des Eykerns eintretende intercalare Vermehrung der in der Horizontalebene der Einfügung des inneren Integuments gelegenen Zellen die Vereinigungsstelle des Grundes dieses Integuments mit dem Eykern weit über die Ursprungsstelle des äusseren Integuments empor hebt (XIX, 7.8).

Die Einfachheit des Baues von Eykern und Chalaza aus so wenigen Zellen, wie bei Orchis, erhält sich bei keiner der untersuchten anderen

*) Hofmeister Entst. d. Embryo Taf. VI f. 6. 7; Brongniart Ann. sc. nat. IV S. 2 , Taf. I f. $6-8$.

**) Payer Organogénie Taf. 136 f. $19 ; 19^{\mathrm{b}}$.

***) Brongniart a. a. 0. Taf. I f. 12. 13.

†) Prillieux nimmt das Ey von Crinum für einen nackten, jeder Hülle entbehrenden Eykern (Ann. sc. nat. IY S. IX, 101.) Die frühesten Zustände, welche allein entscheidenden Aufschluss über den Bau dieser Eychen geben können, haben mir nicht zu Gebote gestanden. Eine Amaryllidee, die ich 18 ä 6 untersucht, deren Bestimmung ich damals versäumte und welche später zu Grunde ging (vermuthlich Brunswigia minor) hat anatrope Eychen, bej denen kein Zweifel über das Vorhandensein eines einzigen, sehr dicken, grïn gefärbten Integuments, dessen Höhlung vom Embryosack völlig ausgefüllt wird, obwalten kann. - Aehnlich Amaryllis Belladonna, uur dass hier das einzige Integument dicht unter dem Scheitel des Eykerns entspringt (nach mündlicher Nittheilung Prof. A Braun's); - ein Verhältniss, welches vielleicht als Uebergang zu dem bei Criuum obwaltenden zu betrachten ist. 
monokotyledonen Pflanzen auf die Dauer. Aber überall, wo die frühesten Zustände untersucht wurden, erwies sich der junge Eykern zusammengesetzt aus einer axilen, kürzeren oder längeren Längsreihe von Zellen und einer (in einigen Fällen aus zweien, augenscheinlich aber durch Theilung der Zellen einer einfachen Zellschicht entstandenen) peripherischen Lage von Zellen. So bei Zostera marina; $\left.{ }^{*}\right)$ Canna Sellowii, Arum maculatum (VII, 11. 12); Pistia Stratiotes (VII, 18,b); Allium odorans (XIX, 7) Funkia coerulea, Crocus vernus (XXI, 12); Iris pumila (XXI, 2.3); Paris quadrifolia (XXV, 9). In der weiteren Entwickelung wird der Bau des Eykerns zusammengesetzter, zunächst durch die Theilung der peripherischen Zellen desselben, dann auch derer des axilen Stranges mit Ausnahme der einen, welche zum Embryosack sich zu entwickeln bestimmt ist, durch Längs- und Querwände. Der axile Zellstrang wird in zwei bis vier parallele Längsreihen von Zellen umgewandelt, indem die in seinen Zellen auftretenden Längswände der Achse des Eykerns parallel, die Querwảnde zu ihr rechtwinklig sind. Die Theilungswănde der peripherischen Zellen sind um so stärker gegen die Achse des Eykerns geneigt, je weiter abwărts vom Scheitel und je weiter nach aussen die betreffenden Zellen sich befinden.

Die Theilungen der peripherischen Zellen wiederholen sich öfters; am lebhaftesten ist meistens die Zellvermehrung in einer, nahe über der Chalaza gelegenen Zone des Eykerns: von da gegen das MikropyleEnde hin nimmt ihre Intensitat rasch, gegen die Chalaza hin langsamer ab. Der Eykern erhält so eine ausgeprägte Ey - oder Keulenform: so in der grossen Mehrzahl der Fälle. Cylinder- oder Kegelform desselben ist selten; bei Zostera, Arum (VII, 4. 6). Bei diesen schlanken Formen von Eykernen ist die Zellenvermehrung absolut am geringsten. Die Zahl der den axilen Strang umschliessenden peripherischen Schichten steigt nicht über zwei bei Zostera, Alisma Plantago (II, 26), Arum (VII, 6), Pistia (VII, 18), Pothos longifolia (IX, \%.8), Bulbocodium vernum. Sie wächst im dicksten Theile des Eykerns auf vier bis sechs bei der Mehrzahl der Lilienartigen Gewächse (in weitesten Sinne), so bei Iris, Crocus (XXI, 4--6, 12-15), Triteleia uniflora (XX, 1), Gagea (XX, 2), Lilium, Tulipa, Fritillaria, Hippeastrum u. v. A. Am höchsten steigt sie bei den Gräsern.

*) Bol. Zeit. 1852 , Taf. IIl, f. 19. 
Die von allen diesen Theilungen ausgenommene Zelle des axilen Stranges, welche bestimmt ist zum Embryosacke heran zu wachsen, ist in allen beobachteten Fällen die oberste dieses Stranges. Ihre Lage wird aber häufig durch Vermehrungen der Zellen der sie umrindenden Schicht beträchtlich verschobeı. Grosse Verschiedenheiten walten in dieser Beziehung selbst zwischen nahe verwandten Formen ob. Der Embryosack bleibt, wie bei den Orchideen, wenigstens vorerst unmittelbar unter der den Scheitel des Eykerns bildenden einfaclien Schicht von Zellen seiner Aussenflache gelegen, bei Zostera, Pistia Stratiotes (VII, 18,b), Arum maculatum (VII, 12), Allium oḍorans (XIX, 7). Er wird von zwei Zellschichten bedeckt bei Iris pumila (XXI, 3.4), Veltheimia (XVIII, 1), Canna, Funkia, und woh! der Mehrzahl der Liliaceen; von dreien bei Crocus (XXI, 12), Hyacinthus, ${ }^{*}$ ) Najas major (I, 14. 19), Symplocarpus

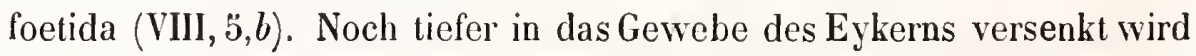
er bei Ruppia maritima (II, 1, b), bei Potamogeton, Zannichellia, Calla palustris (VIII, 15), Triglochin maritimum (I, 26), bei den Gräsern, den Caricineen.

Diese Zellvermelırung in dem den Embryosack umhülleıden Gewebe hält eine Zeit lang Schritt mit dem Wachsthum desselben. Aber nicht auf die Dauer. In sehr vielen Fállen greift der Embryosack durch sein Ausdehnungsstreben schon geraume Zeit vor der Befruchtung zerstörend ein in das ihn einschliessende Parenchym des Eykerns; und auch bei denjenigen Monokotyledonen, wo bis zur Befruchtung eine solche theilweise oder vollständige Zerstörung des Zellgewebes des Eykerns nicht nachweislich ist, erfolgt sie während der Ausbildung des Embryo.

Die Massenzunahme des den Embryosack umhüllenden Gewebes giebt diesem den bis zur Befruchtung zu seiner Entwickelung nöthigen Raum vollständıg bei Gräsern und Riedgräsern. Hier wird keine Erscheinung beobachtet, welche auf das Verdrängtwerden dem Embryosacke benachbarter Zellen hindeutete. Dasselbe gilt von Najas, Ruppia, Potanıgeton, und von Paris quadrifolia. Im jungen Ey der letzteren ist der Embryosack seillich und oben nur von einer einfachen Zellschicht umhüllt (XVII, 9.10); diese Schicht wird während der Blüthezeit eine doppelte, endlich eine dreifache (XVII, 11-13). Dagegen verdrảngt der

*) Hofmeister Entst. d. Embryo Taf. IV f. 1; VII, 1; XIV, 12. 
Embryosack anderer Monokotyledonen, aufwärts, oder seitlich, oder in beiden Richtungen zugleich stärker sich entwickelnd, die ihn umhüllenden, aus der Vermehrung der ursprünglich einfachen Rindenschicht des Eykerns hervorgegangenen Zellen meist schon sehr früh. - Das untere Ende des Embryosacks bleibt allerwärts an diesen Wachsthumserscheinungen unbetheiligt. Wo Veränderungen seiner Lage zu anderen Theilen des Eyes vorkommen, 'sind sie passive; hervorgerufen durch die, gleichzeitig mit dem raschen Wachsthum des oberen Theiles des Embryosackes eintretende lebhafte Zellvermehrung nach allen drei Richtungen des Raumes hin, welche im unteren Theile des Eykerns der meisten Irideen (Iris, Gladiolus), vieler Liliaceen und Verwandten statt findet. Diese Zellvermehrung verwandelt die untere Hälfte des Eykerns zu einem Gewebe aus verhältnissmässig kleinen nahezu würfeligen Zellen, mit protoplasmareichem, in durchfallendem Lichte gelblich erscheinendem Inhalte. - Das Gewebe des Eykerns, welches das untere Ende des Embryosacks zunächst ungiebt, ist, wie bei vielen Dikotyledonen, auch bei den meisten Monokotyledonen durch bei durchscheinendem Lichte dunklere Färbung auffällig gekennzeichnet: eine Färbung, welche durch die Anwesenheit sehr zahlreicher, äusserst kleiner, mikroskopisch kaum unterscheidbarer, lufterfüllter Intercellularräume bedingt wird.

Die gewöhnlichste Form des Wachsthums des Embryosackes ist die, dass derselbe in die Länge und in seinem oberen Theile auch in die Breite sich dehnend, bis an die Innenseite der oberflächlichen Zellschicht des Eykerns vordringt. Der Scheitel des Sackes ist dann nur von einer einfachen Zellschicht bedeclit. Dieses Verhältniss darf als das typische bezeichnet werden für die Tulipeen, Asphodeleen, Bromeliaceen, Amaryllideen, Narcissineen, Irideen, Pontedenaceen, Commelyneen, Zingiberaceen. So ist z. B. im jungen, noch nicht völlig von den Integumenten uberzogenen Eykern von Iris pumila der Embryosack, der noch früher die Terminalzelle der axilen Reihe darstellte (XXI, 2) von zwei Zellschichten bedeckt und umgeben (XXI, 3. 4), deren innere sein oberer Theil schon wieder verdrängt hat, wenn der Rand des inneren Integuments zum Endostom sich zusammen schliesst (XXI, 5). Aehnliche Beobachtungen liegen vor an Veltheimia (XVIII, 1.3), Canna,*) Funkia.**) Der

*) Hofmeister Entst. d. Embryo Taf. IV f. 1-4.

**) Hofmeister ebend. Taf. VII f. 1-4. 
Embryosack erhält in der Regel keulenförmige Gestalt. Nur in vereinzelten Fällen überwiegt sein Längenwachsthum so beträchtlich das in die Dicke, dass er Cylinderform erhält; und in diesen Fällen ist auch seine ganze Scitenflảche von nur einer einfachen Zellschicht bekleidet. Ein Beispicl ist Leucojum vernum (XIII, 13-15); annähernd ahnlich verhält sich der obere Theil des Embryosacks von Veltheimia viridiflora (XVIII, 3-9), insofern er wenigstens einscitig auch seillich die inneren Zellschichten des Eykerns völlig verdrängt. Dieselbe Pflanze zeigt eine, unter den Monokotyledonen bisher nirgend weiter beobachtete, Wucherung des Embryosackes. Dieser treibt, dicht neben seinem ChalazaEnde, einen tief in das Gewebe des Eykerns, parallel der Achse desselben eindringenden, blinddarmartigen Fortsatz, der bis zur Zeit der Befruchtung etwa zur Hälfte der Länge des Eykerns herabwächst (X VIII, 3, $3, b)$. - Anderwärts steigert sich jenes Wachsthum des Embryosackes bis zur völligen Verdräıgung der ihn deckenden Zellschicht: so bei Hemerocallis (XXI, 1); ferner bei Crocus, Gladiolus und verwandten Formen, wie Montrichardia, Tritonia, Ixia u. A. Der Embryosack, bis dahin in derselben Weise wie bei Iris, Lilium u. v. A. im Gewebe des Eykerns eingeschlossen (XXI, 2-16), durchbricht die ihn umhüllende Zellenlage zunächst auf dem Scheitelpunlit der Kernıarze (XXI, 26, 26, b). Weiterhin werden auch die seitlich der Durchbruchstelle angränzonden Zellen durch den Druck des Embryosackes mehr und mehr abgeplattet (XXI, 22). Auf gelungenen Durchschnitten erkennt man deutlich, dass dic Aussenwände dieser Zellschicht an der vom hervorwachsenden Embryosack durchbohrten Stelle zerrissen und zurück gekrümint sind. Der Vorgang ist ahnlich dem Hervorbrechen des Embryosackes aus dem Gewebe des Eykerns vicler Gamopetalen.*) - Endlich verschwinden die comprimirten Zellen völlig der Beobachtung, die Embryosackhaut liegt der Innenfläche des inneren Integuments unmittelbar und dicht an (XXI, 21). Die Scheitelgegend des Embryosacks ist schliesslich dem Mikropylekanal fest eingepresst, weit in denselben linaufreichend (XXI, 27. 28, XXII, 1); bei Ixia (XXIV, 10. 11), und nach Schachts Angaben zu schliessen bei Watsonia, selbst aus der Aussenmündung der Mikropyle noch hervorragend.

Die zweite, ziemlich verbreitete Wachsthumsform des Embryo-

*) Diese Abhandlungen, VI, 611 . 
sackes ist die Beschränkung der Ausdehnung seiner Haut auf die Seitenflächen. Diese verdrängen das ihnen angränzende Gewebe, wachsen dabei auch beträchtlich in die Länge. Das Parenchym der Kernwarze aber bleibt erhalten. Häufig vermehrt sich die Zahl dieser Zellen noch während der Verflüssigung der verschwindenden. Solche Embryosäcke haben meist eine sehr gestreckte, in vielen Fällen rein cylindrische Form, oder die eines schlanken, gestutzten Kegels. Die VerIrängung der seitlich dem Sacke angränzenden Zellen bleibt unvollständig, so dass eine Doppelschicht von Zellen seitlich den Sack umschliesst, während die Kernwarze ein massiges Gewvebe bleibı bei Triglochin maritimum (I, 26), Symplocarpus foetida (VIII, $5, b$ ), Rhodea japonica (VIII, 9). Die letztere Pflanze ist ausgezeichnet durch geringes Längenwachsthum der Seitenflächen des auch nach der Befruchtung noch breiteren als hohen Embryosackes. - Die seilliche Verdrängung ist nur am unterenTheile desSackes vollständig; eine haubenförmige,convex-concave Zellgewebsmasse deckt dessen Scheitel bei Calla palustris (VIII, 13-16), Caladium bicolor (VIII, 8). Ganz vollständig dagegen wird sie, so dass nur über der nahezu oder völlig planen Scheitellläche des Embryosackes das Gewebe der Kernwarze erhalten bleibı, bei der MehrzahI der Aroïdeen: Lemna minor (II, 22), Pistia Stratiotes (VII, 20. 21), Arum maculatum (einer der Fälle, in welchen nachweislich eine bedeutende Vermehrung der Zellen der Kernwarze während des Verschwindens der seitlich dem Embryosack angränzenden Zellen des Eykerns vor sich geht [VII, 11. 12.13]), Arum orientale, divaricatum und ternatum (VII, 3.6-10), Philodendron Imbe (VIII, 3), Pothos pentaphylla und longifolia (VII, 3.6-9). Ferner bei den Melanthaceen Merendera caucasica(XVII, 4-10), Bulbocodium vernum (XVII, 16.17), Colchicum autumnale(XVII, 1-10), Uvularia grandiflora (XVI,11-13); - endlich auch bei Allium: A. odorans (XIX, 8.9). - Fïr Allium gilt, in Bezug auf die Vermehrung der Zellen der Kernwarze, das von Arum maculatum Gesagte (man vergleiche XIX, 7 mil 8). Während der Verdrängung der Nachbarzellen des Embryosackes durch diesen erscheinen die Zellmembranen des Sackes und der im Verschwinden begriffenen Zellen gelockert, von gallertartiger Weichheit mit Ausnahme der ihre volle Festigkeit behaltenden, die Oberfläche des Eykerns bildenden freien Aussenwände. In dem Zeitpunkte, zu welchem der Inhalt der Nachbarzellen unkenntlich geworden ist, füllt eine durchsichtige, ziemlich dünnflüssige, auf Zusatz 
von Jodtinctur gelb und feinkörnig werdende Substanz den Raum zivischen jenen zu einer einfachen Membran verwandelten Aussenwänden, und der Umgränzung des Embryosackes: beobachtet bei Zostera marina, ${ }^{*}$ ) Polhos longifolia (IX, 7.8), Merendera caucasica (XVI, 5.6). Weiterhin legt sich die Haut des Embryosacks fest an die Aussenmembran des Eykerns, und verwächst erhärtend mit dieser, so dass auf etıvas späteren Zuständen die mehr oder minder vollständige Trennung der Kernivarze von der Scheitelfläche des Embryosackes möglich ist (IX, 11. 13. 17 ; X, 4; XVI, 5).

Der Verdrängung des seitlich den Embryosack umbüllenden Gewebes des Eykernes folgl bei Zostera schliesslich auch die des Parenchyms der Kernwarze, so dass hier die Haut des oberen Theiles des Embryosackes, ähnlich wie bei Crocus, der Innenfläclıe des inneren Integuments auf allen Punkten unmittelhar anliegt. Der Hergang ist bei Zostera aber insofern ein anderer, als hier der Embryosack nicht aus der oberflächlichen Zellschicht des Eykerns hervorwuchs; seine Mlembran hat vielmehr einen doppelten Ursprung: die äussere Schichı besteht aus den erhaltenen freien Aussenwänden der im Uebrigen aufgelösten Epidermiszellen des Eykerns; nur die innere Schicht, die häufig noch unmittelbar vor, bisweilen selbst noch nach der Befruclstung mit der äusseren nur in der Scheitelgegend des Sackes verschmolzen erscheint, ist die eigene Membran desselben. Die sehr oft zu beobachtende Trennung beider Schichten auf weite Strecken hat zweifelsohne ihren Grund in dem beschleunigten Längenwachsthum der Mittelgegend der Inneren. - Es steht mit diesem Ursprung der äusseren Schicht in ursächlichem Zusammenhange, dass bei Betrachtung derselben von der Fläche die Gränzen der einst sie zusammensetzenden Epidermiszellen deutlich erkannt werden können.

Bildung von Tochterzellen (der Keimbläschen und ihren Gegenfüsslerinnen) im unbefruchteten Embryosacke.

Gleich allen Zellen von Gefässpflanzen besitzt der Embryosack einen primären, schon vor der Entstehung der Zelle gebildeten Kern, auf den jüngeren Entwickelungsstufen von im Verhältniss zum Zellraume sehr

*) Botan. Zeit. 18:2, Taf. III f. 21-25. 
beträchtlicher Grösse. Weit später als in anderen Zellen des Eychens tritt im Embryosacke die Sonderung des den Kern einschliessenden feinkörnigen Protoplasma, innerlıalb dessen der Kern bei durchfaltendem Lichte als liellere Kugel erscheint, in Wandheleg und Vacuolen hervor. Die Anhäufung dickflüssigen Protoplasmas ist im jungen Embryosack sichtlich um Vieles beträchtlicher, als in seinen Nachbarzellen. Jene Sonderung wird in allen den beobachteten Fällen erst während der letzten, bedeutenden Grössenzunahme des Embryosackes deutlich: so bei Zostera, Orchis (III, 11), Arum (VII, 5-7), Allium (XIX, 7. 8), Iris (XXI, 5), Crocus (XXI, 12-1 3), Paris (XXV, 8-10). Soweit die Beobachtung reicht, tritt nur eine einzige Vacuole auf, die bei ihrem Sichtbarwerden etwa ein Drittel bis die Hälfte des Zellraumes einnehmend, während des ferneren Wachsthums des Sackes schneller und relativ bedeutender als dieser an Grösse zunimmt: der Wandbeleg aus Protoplasma, wird immer dünner. Am mächtigsten bleibt er in der nächsten Umgebung des von ihm umhüllten und der Wand angedrückten, mehr und mehr Linsenform annehmenden Zellkerns, und im oberen und unteren Ende des Sackes. Von diesen stärkeren Anhäufungen von Protoplasma aus verlaufen bandförmige dickere Plasmalagen über den Wandbeleg hin. In vielen, vielleicht allen Fällen ist zunächst nur ein einziger, aber breiter und dicker solcher Streifen vorhanden, welcher von dem, im oder nahe dem Aequator des Sackes der Wand anliegenden Zellkern und dessen beiden Enden hin sich erstreckt: Najas (I, 13), Arum (VII, 5. 7), Merendera (XV, 6), Bulbocodium (XVII, 16), Allimm (XIX, 8,b), Crocus (XXI, 15), Paris (XXV, 9). Auf spaiteren Entwıckelungsstufen erscheint dieser Protoplasmastreifen in mehrere, anastomosirende Aeste gespalten, die bei gewissen Arten, bei Aroüdeen z. B., fortwährend der Wand anliegen, in Formen mit stark erweiterten Embryosäcken aber von dem Wandbelege getrennt, in oder nahe der Längsachse des Embryosackes verlaufen: so u. A. bei Hyppeastrum aulicum (XIII, 3), Leucojum vernum (XIII, 17), Crocus vernus (XXI, 21), Veltheimia viridiflora (XVIII, 3. 5, b). Strömungserscheinungen werden an diesen Protoplasmabändern oder Strängen nur selten und vereinzelt beobachtet. Das nach der Präparation der Objecte rasch eindringende Wasser scheint diese Lebenserscheinungen schnell aufzuheben. Die deutlichsten, am längsten dauernden Bewegungen an den Protoplasmabändern hingleitender Körner sah ich bei Merendera caucasica und bei Arum maculatum. 
Die Lage des primären Kernes ist im grösser gewachsenen Embryosacke auch bei der nämlichen Art keine bestimmı̣te. Aın häufigsten in der Aequatorialgegend des Sackes gelegen, ist er doch auch nicht selten einer der Extremitäten desselben, bald der oberen, bald der unteren, selır genăhert. So bei Orchis, Arum, Pothos, Crinum, Merendera, Crocus, Paris u. A.

Bald nach der Zeit, zu welcher die Hauptmasse des Protoplasma des Embryosackes zu vom Kerne ausstrahlenden Fäden sich zu ordnen begann, tritt die Billung von Tochterzellen im Embryosacke ein. In der Ansammlung von Protoplasma, welclıe in der Scheitelwölbung des Embryosackes sich sammelt, bei vielen Arten auch in einer eben solchen Anhäufung im entgegengesezten Ende, wird eine Anzahl, zwei bis drei, sehr selten mehrere, freier Zellkerne sichtbar; bei ihrem ersten Erscheinen abgeplattet kugelige, bläschenförmige Massen, deren Substanz in durchfallendem Lichte durchscheinender ist als das sie unschliessende Protoplasma; - fester Inhaltskörper (der Kernkörperchen) zunächst entbehrend. Ich beobachtete diese jüngsten Zustände der Kerne der Keimbläschen (ausser bei mehreren Dikotyledonen) bei Zostera marina, Orchis Morio (IV, 11, $a^{*}$ ), Canna Sellowii, ${ }^{*}$ ) Iris pumila (XXI, 7. 8), Paris quadrifolia (XXV, 9), Funkia coerulea, Fritillaria imperialis, ${ }^{*}$ ) Tulipa Gesneriana. Auf wenig weiter vorgerükten Entwickelungsstufen erscheint jeder solcher Kern von einer sphärisclıen, zunächst undeutlich (IV, I I, b Orchis Morio), bald aber schärfer begränzten Ansammlung dichteren Protoplasmas umgeben, deren äusserste Schicht, eine dünne Lage eines glasartigy durchsichtigen, von eingemengten Körnchen völlig freien Stolfes, das Ansehen einer Membran erlıält; der Wassereinwirkung aber nicht widersteht, sich aufbläht, endlich zerfliesst. Die Widerstandsfähigkeit dieser Aussenschicht gegen den Einfluss von Wasser nimmt mit vorrückendem Alter rasch zu. Die groben Körnchen der von ihr umschlossenen Protoplasmamasse verschivinden; im Innern dieser Masse tritt eine Vacuole auf, welche schnell an Umfang zunehmend das immer homogener werdende Protoplasma als einen diinnen, nur an der Stelle, wo der Zellenkern ihm eingebettet ist, mächtigeren Wandbeleg erscheinen lässt. Die Lagerung des Zellenkernes ist ziemlich ausnahmslos sehr

*) Entst. d. Embryo Taf. I f. $31^{* *}$ ) Ebend. Taf. IV f. 3. ${ }^{* * *}$ ) Ebend. Taf. VII f. 3, Taf. VIII f. 4 . 
nahe dem zugerundeten unteren, in den Raum des Embryosacks herein ragenden Ende der inzwischen gestreckten, birnförmig gewordenen Zellen. Das obere, verjüngte Ende haftet, je nach den Arten verschieden, bald fester, bald loser, an der Innenfläche der Scheitehwölbung des Embryosackes. Diese Stufe der Entwickelung erreiclıen die Ke imbläschen aller Monokotyledonen, wie der angiospermen Dikotyledonen iberhaupt, noch vor dem Zeilpunkte der Befruchtung. In einigen Fällen geht aber die Ausbildıng noch einen Schrill weiter, insofern die Hautschicht der Keimbläschen alle Eigenschaften einer festen Zellstoffhaut erhält. Unter den Monokotyledonen findet sich diese Erscheinung vorzugsweise bei den Formen, deren Keimbläschen schon im Spätherbste angelegt, im Zustande weit vorgeriickter Ausbildung überwintern : Leucojum vernum, Crocus vernus; bei verschiedenen Individuen derselben Art indess in sehr verschiedenem Grade. Bei Crocus vernus beginnt die Bildung der Keimbläschen in dem noch ringsum, auch am Scheitel, vom Gewebe des Kerns eingeschlossenen Embryosacke Anfang Novembers vor der Blüthe. Sie ist Ende Decembers vollendet, lange bevor die Scheitelgegend des Embryosackes aus der Kernwarze hervorbricht. Die Keimbläschen erscheinen jetzl als völlig ausgebildete Zellen, in der Regel mit fester, meist zarter, bisweilen aber auch recht dicker Haut (XXI, 16-27), von welcher der Inhalt durch ihn zusammenziehende Reagentien abgelöst werden kann (XXI, 17-19. 23. 24). Bei Verletzung und Entleerung der Keimbläschen wirft deren Zellhaut nicht selten deutliche Falten (XXI, 16, 16,b). Zur Blüthezeit, unmittelbar vor der Befruchtung, ist die Membran der Keimbläschen von Crocus in der Regel wieder erweicht, gegen in den angeschnittenen Embryosack eindringendes Wasser minder widerstandsfihig, bisweilen völlig in demselben zerfliessend. Doch sind die Fälle nicht selten, in welchen sie auch noch zu dieser Zeit als elastische, von dem contrahirten Inhalt scharf unterschiedene Haut nachgewiesen werden kann (XXI, 27).*)

*) Es wird kaum der Bemerkung bedürfen, dass es bei Freilegung der Spitze des unbefruchteten Embryosackes einer grossen Zartheit der Manipulation bedarf, um die immerhin dünne Haut der Keimbläschen nicht zu zerreissen und zu zerstören; die grosse Dünne der Haut macht zu ihrer Erkennung die besten optischen Hülfsmittel nothwendig. Die negativen Resultate, zu welchen Schacht bei seinen Untersuchungen über die Existenz der schon früher (Pringsheims Jahrbb. I, 162) von mir angegebenen 
Schon die Unstetigkeit des Grades der Festigkeit der Keimbläschenmembranen von Crocus ist ein Beweis gegen die Ansicht, welche der Abwesenheit oder dem Dasein einer elastischen Haut der zu befruchtenden Zelle eine entscheidende Rolle beim Befruchtungsalit einräumen will.

Die Kembläschen mit derber, elastischer Haut haften fest an der Innenflàche der Sclteitelwölbung des Embryosackes: so namentlich die von Crocus. Anders die, deren Membran dem Wasser minder widersteht. Bei solchen ereignet es sich sehr häufig, dass das Keimbläschen, durch Einsaugen wälırend der Präparation in den Embryosack eingedrungenen Wassers sich vergrössernd und der Kugelform sich nähernd, ihre Ansatzflächen an die Innenwand des Embryosackes in die Kugelform hineinziehen, dadlurch von der Haut des Sackes sich lösen und frei in dessen Innenraum hineintreten, wo sie dann völlige Kugelform annehmen. Beobachtet unter Monokotyledonen bei Zostera marina, Coïx Lacryma (XII, 12,b.c), Arum ternatum, divaricatum, Calla palustris, Canna Sellowii, *) Hippeastrum aulicum, Hyacinthus orientalis, $\left.{ }^{* *}\right)$ Asphodelus Iuteus, ****) Funkia coerulea, $\dagger$ ) Allium odorans (XIX, 8, b.c.d), Paris quadrifolia, Scheuchzeria palustris, Iris pumila tt) u. A.

Wie meine neueren Untersuchungen die Zweizahl der Keimbläschen als deu unter den Phanerogamen überhaupt häufigeren Fall herausgestellt haben, so ist sie es auch bei den Monokotyledonen. Unter den Najadeen, Gräsern, Cyperaceen, Arö̈deen, Melanthaceen wird sie nur selten überschritten. Die Dreizahl der Keimbläschen kommt etwas häufiger vor bei Orchideen (doch waltet auch bei Orchis Morio z. B. die Zweizahl entschieden vor; man vergleiche Taf. VI); bei Liliaceen und Amaryllideen. Die Eychen ein und desselben Fruchtknotens oder Bliithenstandes verhalten sich hierin verschieden; immer aber ist die Mehrzahl mit nur zwei Keimbläschen versehen. Mehr als drei Keimbläschen sind bis jetzt unter den Monokotyledonen von mir nur bei polyenibryonen Arten beobachtet: bei Funkia coerulea und Hymenocallis caribaea. Und auch von der Letzteren gilt, was ich früher von der ersteren erwähnte: $+t+$ )

elastischen Haut der Keimbläschen von Crocus gelangte (Flora 1858, 565) mögen aus dem eben Erwähnten sic’ı erklären.

*) Entst. d. Embryo Taf. IV f. 5, 6. **) Ebend. Taf. VI f. 2. ***) Ebend. Taf. VI f. $8-10$.

t) Ebend. Taf. vil f. 6. th) Ebend. Taf. X f. 5. 5, 6. 詁) Entst. d. Embryo S. 16. 
in der Mehrzahl unbefruchteter Eychen werden nur zwei bis drei Keimbläschen gefunden. **)

Soweit meine Beobachtungen reichen, nimmt stets nur eines der Keimbläschen den Scheitelpunkt der obern Wölbung des Embryosackes ein. Das zweite, oder das zweite und dritte sind zwar dicht neben diesem, aber doch etwas tiefer mit illren oberen Enden der Innenwand des Sackes angeschmiegt. Das oberste, den Scheitelpunkt des Embryosackes berührende Keimbläschen entwickelt sich niemals (polyembryone Formen ausgenommen) nach der Befruchtung zu einem Embryo. ***)

Die vor dem Hervorbrechen des Embryosackscheitels angelegten Keimbläschen von Crocus nehmen an dem Spitzenwachsthum der Embryosackhaul, an deren Eindringen in den Mikropylekanal (S..666) insoweit Theil, als ihre Ansatzllache an der Innenwand des Sackes mit der Innenöffnung des Mikropylekanals correspondirt. Gewöhnlich ist es demnach nur das oberste, oder wenn drei Keimbläschen vorhanden, die beiden obersten Keimbläschen, deren obere, von der Embryosackhaut überzogene Enden in den Mikropylekanal eine Strecke weit hineinwachsen. Sie modelliren sich dabei nach dessen zusammengedrückter Form, von vorn und hinten her siclı abplattend (XXI, 21.25.27, XXII, 15a.b). Selten nimmt auch das unterste, zur Hervorbringung eines Embryo bestimmte Keimbläschen an diesem WachstlımeT heil (XXI,24, XXII, 28). Die Haut der Scheitelgegend des Embryosackes, welche die in den Mikropylekanal hineinragenden oberen Enden der Keimbläschen bekleidet, ist auf den frühesten Entwickelungsstufen dieses Wachsthums sehr deutlich als Fortsetzung des derben mitlleren Theiles der Membran des Sackes kenntlich (XXI, 17-20. 22. 23); späterhin, bei mit zunehmender Flächenausdehnung abnehmender Dicke der Haut des Embryosackes sowohl als der iı den Mikropylekanal hinein sich streckenden Keimbläschen wird das Verhältniss minder klar. - Bei dem Längenwachsthum des Embryosackscheitels und der innen ihm anhaftenden Keimbläschen findet die Ausdehnung der Membran, ubereinstimmend mit allen anderwärts

*) Tulasne beobachtete bis zu fünf Keimbläschen bei polyembryonischen dem Nothos cordon fragrans (Ann. sc. nat. IV S. IV, 991).

**) Dieser, schon vor Jahren von mir ausgesprochene Satz (Flora 1855, 259) hat auch seither durch die späteren Untersuchungen meiner selbst sowohl, als auch durch die Radkkofers nur Bestätigung erhatten (Radlkofer Befruchtung der Phanerog., Lpz. 1856,17 ff.). 
bekannten Erscheinungen, nur an den Stellen statt, welchen von innen lıer Zelleninhalt angränzt; nicht aber da, wo eine zur Embryosackhaut rechtwinklige oder spitzwinklige Zcllwand an die Innenfläche jener stösst. Die Zunahme der Fläche der Embryosackmembran unterbleibt an den Ber:ührungskanten derselben mit den Seitenwandungen des Keimbläschen. Wo die oberen Enden zweier Keimbläschen gleichzeitig dem Wachsthum des Embryosackscheitels in den Mikropylekanal hinein folgen, da fültt jedes Keimbläschen eine besondere Ausstiilpung der dünnen Embryosackhaut (XXI, 24. 26, 6).

Es kann keinem Zweifel unterliegen, dass in ähnlicher Weise wie bei Crocus die Entwickelung des Embryosackscheitels und der oberen Keimbläschen nicht allein von Gladiolus, Tritonia und Verwandten, sondern auch die von Watsonia und Ixia erfolgt. Bei diesen letzteren Gattungen ist jenes Längenwachsthum (wie Schacht zuerst für Watsonia gezeigt hat*) so sehr gesteigert, dass die oberen Enden der Keimbläschen eine Strecke weit aus der Mikropyle hervorragen (XXIV, 10. 11).

Es trägt sich oft zu, dass noch vor der Ankunft des Pollenschlauchendes am Embryosacke die Keimbläschen bis auf Eines wieder aufgelöst werden. Das sich erhaltende ist stets das unterste, neben und über dem die verschrumpften Reste der zu Grunde gegangenen als grumöse, meist der Kugelform genäherte Massen, selten formlos wolkig sich finden. Diese Erscheinung ist bei vielen Arten häufig, doch nie ausnahmslose Regel. Beobachtet wurde sie bei Zostera marina (nur selten), Ruppia maritima (II, 2, b), Arum divaricatum, maculatum (VII, 9, 13), Calla palustris (VIII, 14), Secale cereale (XI, 3), Hordeum vulgare (XII,1), Sorghum halepense (nur ganz ausnahmsweiseXII, 8), Canna Sellowii, ${ }^{*}$ ) Hyacinthus orientalis, $\left.{ }^{* * *}\right)$ Asphodelus luteus, $\left.t\right)$ Funkia coerulea, $\left.t_{t}\right)$ Uvularia grandiflora (XVI, 11-13), Allium odorans (XIX, 8), Gagea lutea (XX, 2), Iris sibirica. $t_{\dagger}+$ ) Anderwärts erhalten sich das oder

*) Pringsheims Jahrbücher I, 193. Schacht nimmt an, der Scheitel des Embryosacks sei durchbohrt, und die Keimblïschen ragten aus der Oeffnung hervor. Selbst bei Ixia, geschweige denn bei Gladiolus und Crocus, finde ich keine Erscheinungen, die auf ein solches Verhältniss hindeutelen. Die Unmöglichkeit des allgemeinen Vorkommens desselben geht aus der oben (S. 672) erwähnten Ablösbarkeit vieler Keimbläschen von der Innenfläche des Embryosackes schlagend hervor.

**) Entst. d. Embryo Taf. IV f. 6. ${ }^{* * *}$ ) Ebend. VI, 2.

†) Ebend. VI, 10. †) Ebend. VII, 6. 9. 计) Ebend. X, 25. 
die oberen Keimbläschen ausnahmslos bis zu der Befruchtung: so bei Crocus vernus (XXI, 16-28), Leucojum vernum (XIII, 14. 13 ), Merendera caucasica (XV, 4-9), Bulbocodium vernum (XVII, 46. 17), Veltheimia viridillora (XVIII, 2-4), Puschlinia scillö̈des (XX, 10.11). Aber auch in diesen Fällen pflegt der Inhalt des zum Fehlschlagen bestimmten, oberen Keimblaschens eine abweichende Beschaffenheit anzunehmen. Die Sonderung in protoplasmatischen Wandbeleg und grosse contrale Vacuole wird aufgehoben; der Zcllenkern verschwindet; zahlreiche, unregclmässig gestaltete Körnchen sind durch den ganzen Imnenraum der Zelle, oder doch des erwciterten, zugerundeten unteren Endes vertheilt (z. B. XIII, 14-19; XV, 5. 8; XVII, 2; XX, 11; XXI, 27; XXII, 1 ff.; XXIII, 1 fl.)

Die mit ungewöhnlichem Längenwachsthum begabten jungfräulichen Keimbläschen mehrerer Monokotyledonen erhalten in dem der Befruchtung kurz vorhergehenden Zcitraume eine eigenthümliche Beschaffenheit des Inhalts ihres oberen Theiles. Am Extremsten ausgebildet die von Watsonia: das Innere des cylindrischen, durch den Mikropylekanal sich erstreckenden und aus diescm hervorragenden Theiles ist, wie Schacht darlegte, $\left.{ }^{*}\right)$ »mit fascrig-körnigem Inhalt erfiillt, in welchem eine ganz bestimmte Anordnung vom Umkreis abwärts zur Mittc verlaufender Stränge unverkennbar ist. Dieser Inhalt zieht sich bei Bchandlung mit Chlorcalcium nicht, wie das Protoplasma im Allgemeinen, unregelmaissig zusammen; er behält vielmchr seine faserige Structur; auch wird die Anordnung der scheinbaren Fäden dadurch nicht verändert, wobei nur selten eine dicselben umgebende Membran deutlich sich abhebt. Jod und Schwefelsäure färben die dunkeln körnigen Streifen braungclb, die helleren Friden zwischen ihnen hcllbla u." - Sehr ähnliche Verhältnisse zeigt der aus der Mikropyle hervorragende Theil der Keimbläschen von Ixia rosea. Glashılle Fäden, welche durch Quetschung sich breit driicken lassen, strahlen anastomosirend von der Längsachse der KeimblasschenFortsätze aufivarts und auswärts nach der ziemlich dicken Zellhaut. Mit Jod und Schwefelsäure färben sich diese Fäden blassblau, das ihre Zwischenräume erfüllende Protoplasna braungelb. Bei Zusatz von Chlorcalcium - oder Glycerinlösung zieht sich der ganze Inhalt der Hervorragungen, die Fäden eingeschlossen, von der innerseits glatten Zellhaut 
einseilig oder allseitig zurück (XXIV, 11). - Anderwärts finde ich kaum mehr als Andeutungen einer ähnlichen Anordnung des Inhalts. Bei Puschkinia scilloïdes (XX, 10), Leucojum vernum (XIII, 18) zeigt der Inhalt des oberen Endes des eben befruchteten Keimbläschens einen längsstreiligen Bau, aber nur nach Contraclion des Zelleninhaltes; nie während der unveränderten Anordnung desselben. Ebenso verhält sich Gladiolus communis. Bei Crocus vernus ist nur setten, und nur in abortirenden Keimbläschen eine Spur davon wahrzunehmen. Die Aehnlichkeit dieses Vorkommens in seiner grössten Ausbildung, bei Watsonia und Ixia, mit den von Schacht in den Ausstiilpungen des Embryosackes von Pedicularis aufgefundenen Netzwerk von Zellstoffbalken liegt offen zu Tage.**) Wie dort, sind es auch bei den Monokolyledonen unwesentliche, weiterer Entwickelung nicht fähige Theile der Zelle, in welchen die Bildung auftritt. ${ }^{*}$ )

Die Gegenfusslerzellen der Keimbläschen, in der nämlichen Weise wie diese durch Zellbildung um Kerne entstanden, welche frei in der Anhäufung von Protoplasma des Chalaza-Endes des Embryosackes auftraten, werden - wenn überhaupt - früher ausgebildet, als die Keimbläschen. Sie sind bereits völlig ent wickelte Zellen zu einer Zeit, wo die Keimbläschen nur als schlecht begränzte Ballen ron Protoplasma erscheinen, wo selbst um die Kerne derselben noch liein Proloplasma sich geballt hat; so bei Zostera marina; Crocus vernus, Iris pumila. Häufig sind sie zur Zeit der Befruchtung von einer messbar dicken sehr festen Zellstoffhaut umschlossen, während die Membran der Keimbläschen um Vieles zarter und weicher ist: so bei Crocus vernus; in minderem Grade bei Leucojum vernum, Crinum capense und anderwärts. Ihre Anzahl, selbst ihr Dasein sind unstät; Abweichungen finden sich nicht nur bei nahe verwandten Arlen, sondern auch bei Individuen einer und derselben Art. Die Einzahl kann als Regel bezeichnet werden für Najas major (I, 13. 14. 16.

*) Beiträge zur Anatomie etc. Berlin 1854, 259. Aehnliche Bildungen, zum Theil verschieden, habe ich auch bei Veronica und bei Plantago nachgewiesen (diese Abhandlungen VI, 620,623 ).

**) Indem Schacht die mit Jod sich bläulich färbenden Fäden im oberen Theile der gestreckten Keimbläschen von Watsonia mit dem Gebilde zusammenstellt, welches er bei Gladiolus, Crocus und anderwärts mit dem Namen der Befruchtungsfiden, späterhin mit dem des Fadenapparats belegte, vermengl er zwei wesentlich rerschiedene Dinge, wie das Nachfolgende darthun wird. 
18. 19), Hippeastrum aulicum $(\mathrm{X}, 3)$, Bonapartea juncea $(\mathrm{XX}, 8)$; die Dreizahl für Lencojum vernum (XII, 14. 15), Allium odorans (XX, 8.9.), Gloriosa superba (XX, 5), Crocus vernus (XXI, 15.21), Ixia rosea (XXIV, 10), Narcissus poëticus und Jonquilla (XXV, 14). Drei, bisweilen aber auch nur zwei Gegenfüsslerzellen der Keimbläschen zeigen ferner Crinum variabile und capense (XIV, 1. 3.11), Tradescantia virginica (XXIV, 18), Symplocarpus foetida (VIII, 5), Pothos longifolia (IX, 6-8), Puja chilensis (XXV, 22), Uvularia grandiflora (XVI, 12.13), Bulbocodium vernum (XVII, 16.17). Ihre Zahl ist höher, sechs bis zwölf, bei den Triticeen : Secale cereale (XI, 2.3), Elymus arenarius (XI, 17), Hordeum vulgare (XII, 1). Die Gegenfüsslerzellen, meist zu zweien oder dreien vorhanden, werden in einzelnen Fällen völlig vermisst bei Merendera caucasica (XV, 4-8), Zostera marina, Paris quadrifolia (XXV, 10. 11), Arum orientale, maculatum, divaricalum, ternatum (VII, 6-9.13. 14), Carex arenaria, panicea (XII, 13.15.16). Sie fehlen in der Regel, sind nur ausnahmsweise vorhanden bei den Orchideen: z. B. Orchis Morio (IV, 11-14). Bei nachgenannten wurden sie in keinem der zahlreichen untersuchten Embryosäcke bemerkt: Ruppia maritima (II, 1-3), Potamogeton crispus (II, 18), Alisma Plantago (II, 20. 21), Zea Mays, Sorghum halepense (XII, 7-10), Coix Lacryma (XII, 12), Veltheimia viridiflora (XVIII, 3), Hymenocallis caribaea (XXV, 1), Scheuchzeria palustris (XXV, 18.19). - - In der grossen Mehrzahl der Fálle sind sie dem ChalazaEnde des Embryosackes fest angezwängt. Nur in einzelnen Eychen des Narcissus Jonquilla sah ich sie seitwarts von dieser Extremität des Sackes der Wand des flachen unteren Theiles desselben anhaften (XXV, 14).

Bei einigen Monokotyledonen findet sich, kurze Zeil nach Ausbildung der Keimbläschen, an der Lagerstätle des primären Kerns des Embryosackes ein ziemlich grosses, oft den Mittelraum des Sackes völlig ausfüllendes, bläschenförmiges Gebilde, mit mehr oder minder fester Haut; bald mit wasserhellem Inhalt, bald einen Körper einschliessend, welcher völlig das Aussehen des primären Kernes des Sackes hat, bald mehrere Zellkerne enthaltend. Man wird die Ersclieinung kaum anders deuten können, denn als die Bildung einer freien Zelle um den primären Kern. Beobachtel ist sie beiAsphodelus luteus, unbestindig, ${ }^{*}$ ) Funkia coerulea, ${ }^{*}{ }^{*}$ )

*) Entst. d. Embryo Taf. VI f. 11. **) Ebend. Taf. VII f. 8-10. 
Fritillaria imperialis, ${ }^{*}$ ) Tulipa Gesneriana, Gagea lutea, $\left.{ }^{*}\right)$ Iris pumila, ${ }^{*}{ }^{*}$ ) Scheuchzeria palustris (XXV, 17. 19). Insofern bei mehreren der Genannten, namentlich bei Fritillaria und Tulipa, die Umgränzung des blasenförmigen Gebilıles schon geraume Zeit vor der Befruchtung undeutlich, seine Membran weich und zerfliesslich wird, schliesst sich an dieses Vorkommen die unter den Monokotyledonen häufige, an Dikotyledonen noch nirgends mit Sicherheit beobachtete Erscheinung der Auflösung des primären Kerns noch vor der Befruchtung an, der das Auftreten kleinerer, secundärer Kerne zu folgen phlegt: Zostera marina, Pothos longifolia (IX, 7, 9), Sorghum halepense (XII, 8), Allium odorans (XIX, 8,6), Gagea lutea $(\mathrm{XX}, 2)$, Gloriosa superba (XX, 5), Tradescantia virginica (XXIV, 18), Asphodelus luteus, $\dagger$ ) Hemerocallis flava, $+\dagger$ ) Zea Mays. $t+t$ )

Das Vorhandensein anderer bestimmt geformter Inhaltsgebilde des unhefiuchteten Embryosackes von Monokotyledonen ist selten; es beschränkt sich auf das Auftreten von Amylum. Beobachtet bei Merendera caucasica, wo dem Protoplasma des, auch die Keimbläschen überziehenden, Wandbeleges und der vom Kern ausgehenden Plasmastränge anfangs wenige grössere, später sehr zahlreiche, fast unmessbar kleine Amylumkörnchen in grosser Zahl eingelagert sind, welche diesen Theilen, im auffallenden Lichte betrachtet, das Aussehen geben als wären sie aus Silber ciselirt (XV, 5-8); ferner bei Pothos longifolia (IX, 7.8), Iris pumila (nur auf den früheren Zuständen des Embryosackes ist Amylum vorhanden, später verschwunden XX, 6.8). Die den Genannten nahe verwandten Bulbucodium vernum, Pothos pentaphylla, Crocus vernus zeigen auf keiner Entwickelungsstufe des Embryosackes Amylum in dessen Innern. Dagegen ist das Vorkommen von Amylum in den Nachbarzellen des jungen Embryosackes sehr häufig, fast Regel: so z. B. bei Crocus vernus (XXI, 13). In den Zellen der Kernwarze erhält es siclı bis nach der Befruchtung bei Nerendera caucasica, doch mit abnehmenler Zahl der Körnchen, bis nach der Befruchtung (XVI, 8-19). Ebenso bei Colchicum autumnale (XVIII, I-8), während es bei Pothos longifolia auch hier schon vor der Befruchtung verschwindet (IX, 9), bei Bulbocodium vernum noclı fiüher vermisst ivird (XVII, 16. 17).

*) Enist. d. Embryo Taf. VIII f. 4-9. **) Ehend. IX, 4. 5. ***) Ehend. X, 3.

t) Ebend. VI, 10. ti) Ebend. VI, 16. ttt) Ebend. XI, 4. 6. 
Die Membran des Embryosackscheitels erlıält bei mehreren Monokotyledonen nach Ausbildung der Keimbläschen eine eigenthümliche Beschaffenheit: sie erscheint durch nach aussen vorspringende, schwach wellige Leisten verdickt. Diese Leisten sind Längsleisten bei Sorghum halepense (XII, 7.9.10), Crocus vernus (XXI, 24.26.27; XXI u.XXIII), Gladiolus communis (XXIV, 9), Tritonia crocata (XXIV, 12); - Querleisten bei Ixia rosea (XXIV, 11). Bei letzterer Pllanze erscheinen die kurzen Leisten selır deutlich als örtliche Verdickungen der äussersten, fein gekörnelten Schicht der Hant; bei den anderen Genannten ist dieses Verhältniss minder hervortretend, bei Crocus vernus in einzelnen Fällen indess ebenfalls sehr kenntlich, namentlich in denjenigen, wo das Mikropyle-Fnde des Embryosackes besonders steil keilförmig zugeschärft ist, und in Folge dieses Umstandes die aussere Schicht der Haut auf der Schneide die innere eine Strecke weit uberragt (XXIII, 15), oder wo es gelang, die äusserste, gestreifte und gekörnelte Schicht in grösseren, unzerrissenen Fetzen von der darunterliegenden abzulösen (XXI, 27). Die untere Schicht erscheint dann an ihrer Aussenfläche völlig glatt. Die Anordnung der Längsstreifen ist stets eine gegen den höchsten Punkt des Embryosackscheitels convergirende. Hat dieser, wie bei Crocus und Gladiolus nicht selten, zwei gipfelständige Hervorragungen, deren jede vom oberen Theile eines Keimbläschens ausgefüllt wird, so trägt jede dieser Hervorragungen ein System von Streifen (XXI, 24. 26, b, XXIV, 10. 28. 32). Wo dagegen das Mikropyle-Ende des Embryosackes in eine einzige Spitze ausgeht, da ist keine Beziehung in der Anordnung der Längsstreifen zu den, innen der Embryosackhaut anhaftenden Keimbläschen zu erkennen. Die Streifen verlaufen, ununterbrochen, über die Ansatzflächen beider Keimbläschen bei Sorghum halepense (XII, 7.9.10); sie reichen sehr häufig, fast in der Regel, nicht bis zur Ansatzfläche des unteren, zum Befruchtetwerden bestimmten herab bei Crocus vernus(Melı'zahl der Abbildungen der Tafeln XXI, XXII u. XXIII), Gladiolus communiṣ (XXIV, 9), Tritonia crocata (XXIV, 12). Ihre Entwvickelung ist in verschiedenen Eychen derselben Art, oft desselben Fruchtknotens, eine sehr verschiedene. (Man vergleiche z. B. XXI, 8.17; XXIV, 3 mit XXII, 28. 32; XXIII, 24). Gegen Reagentien und gegen polarisirtes Licht verhält sich die streifenförmige Leisten tragende Membran wie eine Cuticula. In Chlorzinkjodlösung färbt sie sich entschieden braungelb, während bei Crocus vernus häufig, nicht immer, die unter ihr liegende Mem- 
branschicht eine bläuliclı-rolhe Farbe aunimmt. Stärker noch tritt dieser Unterschied bei Bebandlung mit Jod und Schwefelsäure hervor, welch letztere auch bei bedentender Concentration die gestreifte Schicht kaum angreift. Nach Einschaltung einer Gypsplatte in den Polarisationsapparat erscheint der optische Querschnitt der gestreiften Schicht der Embryosackhaut (ebenso wie der des Pollenschlauches) in der complementären Färbung von den, in der Lage ihnen entsprechenden übrigen Theilen der Membranen des Embryosackes und der Keimbläschen. Eine schlagende Achnlichkeit mit der Cuticula der Narbenpapillen zeigt die streifige Schicht ferner in ihrem, weiterhin zu besprechenden, Verhalten zum Pollenschlauche. Sie ist also als Cuticula des Embryosackes zu betrachten, als schwache Andeutung des Gebildes, welches bei Coniferen als körnige, äussere Schicht der Membran den Embryosack vollständig überkleidet, und bei den, dem Embryosack morphologisch gleichwerthigen Sporen der höheren Kryptogamen in stärkster Entwickelung auftritt.*)

Vielen Plianerogamen, auch vielen Mlonokotyledonen, fehlt jede Andeutung derartiger Bildung. Der Gipfel des freigelegten Embryosackes von Zostera marina, Veltheimia viridiflora, Puschkinia scilloüles (XIX, 2. 3. 6.10.11; XX, 10.11) erscheint auch bei Anwendung der besten Mikroskope als völlig homogene Membran. Bei Orchideen ist keine Spur jener Organisation wahrzunehmen, während doch unsere optischen Hülfsmittel clie Erkennung anderer fernerer Einzelnheiten der Embryosackspitze gestatten (IV, 12-14).

Diese Cuticula des Embryosackscheitels von Gladiolus, Crocus, Zea u. A. ist es, welche Schacht als einen integrirenden Theil der aus einer Scheitelöflnung des Embryosackes hervorragenden Keimbläschen auffasst, und mit dem Namen des Fadenapparates belegt.**) Dass der "Fadenapparal“ den Keimblasschen angehöre, widerlegt sich sofort durch die Ablöslichkeit der unbefruchteten von der Innenwand des Embryo-

*) Aus einem bisweilen eintretenden Lagenverhältniss dieser Schicht zum Pollenschlauchende glauble ich früher die Vermuthung folgern zu müssen, dass sie von den Zellen der Innentläche des inneren Integuments secernint werde (Pringsheim Jahrb. I, 162). Ich übersah dabei, dass schon damals die analoge Bildung am Embryosacke von Sorghum mir bekannt war (a.a. 0. 15 k ), der im Parenchym des Eykerns eingeschlossen ist.

**) Bol. Zeit. 1858, 21; Pringsheim Jahıb. 1, 196 ff.; Flora 1858, 563. Eine trïhere Ausicht Schachıs, welche in einigen Punkten von seiner letzlen abwich (Monatsb. berliner Akad. 1856, Mai) übergehe ich, als von hrem Urheber modifizirt. 
sackes (oben S.672). Von einer Oeffnung des Embryosack-Gipfels ist in der Natur nirgends, und auch in Schachts eigenen Abbildungen kaum irgendwo etwas zu sehen. Die Behauptung, dass die Keimbläschen aus dem Embryosack hervorragten, entbehrt der Grundlage. Dass der obere Theil der Keimbläschen nicht aus Fäden besteht, wie Schacht behauptet, sondern dass nur die Aussenseite der für die oberen Enden der Keimbläschen und Embryosackspitze auscheincud gemeinsamen Membran-Leisten in Forın von Längsstreifen trägt, kann keinen Augenblick zweifelhaft sein, wenn die Beobachtung den Inhalt und die Membran streng sondert. Dass dies vou Schacht nicht geschah, erwähnte ich bereits (S. 676). Er begreift unter seinen "Fadenapparat" a u $\mathrm{ch}$ die fadenförmigen Stränge im In n er n der Keimbläschen von Gladiolus, Watsonia; wesentlich von der Cuticula verschicdene Dinge, die bei Ixia, und wie mir scheint auch bei Watsonia, zugleich mit einer, der von Grocus und Gladliolus analogen, wenn auch etwas anders gebildeten Cuticula vorkommen.

Schachts Ansicht von der Bedeutung seines "Fadenapparats "für den Befruchtungsakt richtet sich selbst. Scliacht hat dafur, dass dieser nApparat" bei der Befruchlung iberhaupt irgendwelche Rolle spiele, nichts anzuführen, als scin häuliges Vorkommen. Die schlagendsten Thatsachen, zum Theil eigene Beobachtungen Schachts sprechen aber gegen seine Hypothese. Der befruchtende Pollenschlauch braucht nicht mit den Ansátzfächen der Keimbläschen in Berührung zu kommen, um dic Entwickeluug des Embryo anzuregen. Die Beriihrungsstelle des Pollenschlauchendes fallt sogar in der Regel ni ch 1 mit der Ansatzflache eines der Keimbläschen zusammen. Das ist eine durch meine, Tulasne's und Radlkofer's übereinstimmenden zahlreichen Beobachtungen ausser allem Zweifel gestellte Thatsache. Dagegen darf behauptet werden, dass dic Berührung des Pollenschlauches mil dem Fadenapparate Schachts, also mit dem von ejner Cuticularschicht bekleideten Ende des Embryosackes sowohl, als mit dem Theile desselben, welcher durch den von fadenförmigen Strängen durchzogenen Theil der Keimbläschen von Watsonia ausgefüllt wird, nich $\mathbf{t}$ geniigt um die Befruchtung zu bewirken. Warum hälı bei Watsonia der befruchtende Pollenschlauch in seinem Wachsthum nicht inne, wenn er das obere Ende des Embryosackes und der Keimbläschen erreicht hat? Warum drängt cr sich durch den langen Mikropylekanal bis zu der Stelle herab, wo der Embryosack plötzlich sich 
erweitert?*) Ebenso bei Crocus, Gladiolus ohne Ausnahme. Der „Fadenapparat" fehlt eudlich so gut wie in der Regel bei Crocus der Stelle des Embryosackes, an welcher innen das zu befruchtende keimbläschen schon vor der Befruchtung haftet. Schacht bestreitet das; $\left.{ }^{* *}\right)$ die Taf.XX, f. 21.25-27 abgebildeten Präparate(die Herstellung ähnlicher hat keine besondere Schwierigkeiten) mögen zu seiner Widerlegung genügen. Um das auch von Schacht erkannte, ganz sicher stehende Faktum zı erklären, dass nach der Ankunft des Pollenschlauches am Embryosacke eines der Keimbläschen, und zwar das zum Embryo sich entwickelnde, tiefer an der Innenwand des Embryosackes hafte, als das oder die anderen, bedarf Jener der, leitender Thatsachen völlig baren Hypothese, dass eines der Keimbläschen nach der Befruchtung tiefer herabtrete, vom Fadenapparat sich trennend, der kaum noch kenntlich sei. Kaum noch kenntlich! Weder in der Natur, noch an Schachts eigenen Abbildungen ist der "Fadenapparata des »herabgetretenen « Keimblïschens irgend wo zu bemerken.

\section{Eintreffen des Pollenschlauchendes am Embryosacke; sein Verhalten daselbst.}

So beträchtliche, zwischen wenigen Stunden und mehreren Monaten schwankende Unterschiede der Zeit, in welcher die Pollenschläuche den Weg von der Narbe bis zu den Mikropylen der Eychen zurücklegen, wie sie unter den Dikotyledonen sich finden, kommen unter den Monokotyledonen nicht vor. Bei Gräsern und Riedgräsern werden Pollenschläuche schon 5-7 Stunden nach künstlicher Bestäubung der jungfräulichen Narben im Eymund gefunden; bei Zostera marina nach 10 Stunden. ${ }^{* * *}$ ) Bei der Mehrzahl der Monokotyledonen, namentlich bei Liliaceen und Arö̈deen, ist das Wachsthum der Pollenschläuche träger. Die von Crocus vernus brauchen unter den giinsligsten Umständen, bei warmer feuchter Luft und hellem Sonnenschein wăhrend der Tagesstunden, 24 Stunden zum Herabsteigen bis in die Mikropylen; bei trockenerer kiuhlerer Luft 48 bis 72 Stunden. Aehnlich ist das Verhältniss bei Iris pumila, bei Arten von Lilium, bei Leucojum vernum, Colchicum autumnale, Merendera caucasica (Minimum der nöthigen Zeit bei meinen

*) Schacht in Pringsheims Jahrb. I, Taf. XI, f. 4-7.

**) Flora 1858,567 .

***) Bot. Zeit. 1852, 138 . Anmerk. 
Beobachtungen 16 Stunden, Maximum 7 Tage), Puschkinia scillö̈des u. v. A. - Bei Arum maculatum brauchen die Pollenschläuche zur Erreichung ihres Zieles mindestens 5 Tage; bei Pothos longifolia eine noch längere Zeit; die längste - mindestens 10 Tage von der Uebertragung des Pollens auf die Narbe an — bei den Orchideen. ${ }^{*}$ )

Die Entwickelung von Schläuclıen aus den Pollenkörnern beginnt auch bei denjenigen Monokotyledonen, deren Pollenschläuche nur langsam weiter wachsen, selı bald nach Bestäubung der Narben: bei Crocus vernus schon nach 3-4, bei Arum maculatum nach 5-7 Stunden. Bei Najas major, survie bei Exemplaren von Orchis Morio die in sehr feuchter Luft (unter Glasglocken) vegetirten, sah ich öfter's den Pollen schon in der, eben geölfneten, Anthere massenhaft Schläuche treiben. Diese Schläuche fanden bei Orchis Morio den Weg bis in die Ovarien: sie traten aus den Antherenspalten vielfach verschlungen und gekrummt als ein dichter Filz hervor, folgten aber beim Weiterwachsen, wenn auch unter mannigfachen wellenförmigen Beugungen beiderseits der Vorderflache der Anthere, am Rostellum vorbeigehend, bis sie die feuchte Narbenfläche erreichten.

Dieser Fall zeigt noch deutlicher, als das Verhalten der fortwachsenden Pollenschlauchenden in weiten Fruchtknoten ( - in denen von Orchideen z. B.) das Bestreben derselben, sich derOberfläche des Pflanzentheiles anzuschmiegen, mit welchem sie in Berührung kommen. Der nächste Grund der Erscheinung ist vermuthlich derselbe allgemeine Vorgang, vermittelst dessen das Winden von Ranken und Schlingpflanzen, das feste Anschmiegen mancher Kletterpflanzen (Ficus stipulata, Hedera Helix) an ihre Stützen erfolgt: die Verminderung des Flächenwachsthums der in Dehnung begriffenen pflanzlichen Zellhaut an den Stellen, in welchen ein fremder Körper sie berührt. - Die Bahn der Pollenschläuche ist nur da eine gradlinige, wo sie zahlreich in engem Raume zusammengedrängt, durch gegenseitigen Druck die Richtung ihres Wachsthums regeln. Wo die Schlauche grössere Freiheit der Bewegung finden, da zeigt ihr Verlauf im Einzelnen keine erkennbare Regel: sie sind wellenlinig, kniebogig, nicht selten rückwärts abgelenkt, verschlungen, und besonders häufig zu zweien, seltener zu mehreren, um einander gewunden, wie die Stränge einer Schnur. So auf den Placenten von Fagea, von

*) R. Brown in Transact. Linn. Soc. XVI, $705 \mathrm{ff}$. 
Orchideen, in der schleimerfullten Fruchthnotenhöhle von Pothos longifolia, und - wie ich weiterhin zeigen werde — innerhalb der erweiterten Höhle, welche die Integumente der Eychen von Colchicum und Bulbocodium unschliessen. Nur im Grossen und Ganzen folgt der Verlauf der Schläuche im Fruchtknoten der Orchideen und Liliaceen den durch papillöse Beschaffenheit der oberflächlichen Zellen gekennzeichneten secernirenden Flächen. Dass die Enden der Schläuche, an der Oberfläche der Eychen hinkriechend, endlich einzeln, wenn auch oft spät, bis in die Mikropyle gelangen, hat bei der Zahl der Pollenschläuche, welche in allen bekannten Fällen die der Eychen weit überwiegt, nach dem Vorausgeschickten nichts Wunderbares; um so weniger als in den Fállen, wo die Richtung der Mikropyle den Eintritt der Pollenschläuche nicht besonders begünstigt, dieser Eintritt auffallend spät zu erfolgen pflegt. So namentlich bei den atropen Eychen von Arum, deren Vorderenden in den lufterfüllten Hohlraum des Fruchtknotens hinein reichen.

Verästelungen der Pollenschläuche im Staubwege scheinen bei Mo: nokotyledonen noch seltener vorzukommen, als bei Dikotyledonen. Nur bei Gagea sylvatica habe ich deren bemerkt. Dagegen verzweigt sich der Pollenschlauch nicht selten beim Eintritt in die Mikropyle. Bei Crocus vernus ist es fast Regel, dass der Pollenschlauch im Mikropylekanal eine seitliche Abzweigung bildet, die bisweilen ein nicht unbeträchtliches Längenwachstlum erreicht (XXII, 2.4.9.11.14.18.21.25-28; XXIII, 2-4, 7.12.18). Achnliches kommt vor bei Leucojum vernum (XIII, 22), Crinum capense $(\mathrm{XIV}, 8)$. Einmal sah ich bei Crocus vernus den Pollenschlauch, von der Eintrittsstelle ins Exostom an, in zwei ziemlich gleichlange Gabeläste ausgewachsen (XXII, 31), die beide in den engen Mikropylekanal hinabstiegen. - Mannigfaltigere Verzweigungen, Seitenäste von verschiedenartigster Gestalt und Länge, entwickelt der Pollenschlauch von Hippeastrum aulicum im weiten Kanale des Endostoms (XIII, 4-7). Nicht selten treffen zwei solcher Fortsätze mit den Spitzen auf einander (XIII, כ). Zuverlässig ist es nur eine Weiterentwickelung solcher Zustände, wenn der Pollenschlauch im Mikropylekanale eine geschlossene Masche bildet, ähnlich wie Fäden des Hypothallus mancher Flechten (XIII, 7): die Spitze eines langen Seitenastes mag auf den Hauptstamm des Pollenschlauches getroffen haben; die Vembranen beider mögen an der Berührungsstelle verflussigt worden, und so die Verbindung der Lu- 
mina hergestellt worden sein. Besonder's lıăufig ist vielfache Verästelung des äussersten Endes des Pollenschlauches (XIII, 6). Bei Funkia coerulea kommt sie in ganz ähnlicher Weise vor (XXII, 6). Noch bunter verästelt sind die Verzweigungen, welche bei Pothos longifolia die Pollenschläuche, vor und bei dem Eintritt in die Mikropyle, in den die Fruchtknotenböhle erfüllenden gallertähnlichın Schleim entsenden (X, 1. 2). Mit ihren geschıvollenen Enden ähneln sie Pilzfäden.

Der Inhalt des schlauchtreibenden Pollenkerns wandert im sich verlängernden Schlauche herab, in dessen unterem Ende sich anläufend, wăhrend die am weitesten rückwärts gelegenen Theile nur wässerige Flüssigkeit enthalten. Sie sterben endlich von hinten her $a b$, bei llonokotyledonen, wie es scheint, sehr allgemein, bevor noch die Pollenschlauchspitze in die Mikropyle eintritt. Jene Wanderung ist besonders augenfällig bei Najas major, wo das Pollenschlauchende, auch nach seinem Zusammentreffen mil dem Embryosacke, mit den im Pollenkorn enthalten gewesenen spindelförmigen Anylumkörnern vollgestopft erscheint (I, 11. 14. 15). Aber auch anderwärts macht die Anhaufung fester Inhaltsgebilde in unteren Ende des Pollenschlauches sich bemerklich : bei Orchis Morio (IV, 15-19), Canna Sellowii (VI, 23-26), Pothos longifolia (IX, 12-17, X, 3. 5), Crinum capense (XIV, : -8 ), Merendera caucasica $(\mathrm{XV}, 16.19 .21, \mathrm{XV}, 3.0)$, Colchicum autumnale (XVIII, 1. 2. 4-7), Crocus vernus (XXIV, 24. 29. XXIII, 1. 4). Die Inhaltskörper sehr verlängerter Pollenschläuche sind häufig, sämmtlich oder zum Theil von gestreckter, spindelförmiger Gestalt, ibereinstimmend mit der Form des Chlorophylls langgestreckter Zellen, z. B. denen sehr verlängerter Auszweigungen von Moosvorkeimen. So bei Pothos longifolia (X, 3, b), Crinum capense (XIV, 5), Merendera caucasica (XY, 14. 18, XVI, 4), Crocus vernus (XXII, 10, XXIII, 1.15). Bewegungen tionnten an diesen Inhaltskörpern, den rundlichen ebenso wenig als den gestreckten, nirgends beobachtet werden; selbst nicht noleculare.

Die Beobachtung ergiebt ausnahmslos, dass in allen Fällen, in denen Folgen der Befruclıtung - Weiterentwickelung eines der Keimbläschen, beginnende Endospermbildung - im Embryosacke sichtbar werden, das Ende eines Pollenschlauches mindestens bis zur Aussenflàche des Sackes vorgedrungen ist. Die Berïhrung des Pollenschlauchendes mit der Aussenwand des Embryosackes erscheint demnach als nothwendige Bedingung der Befruchtung. Bei den Pflanzen mit allseitig vom 
Parenchym des Eykerns umschlossenem Embryosacke bahnt sich der Schlauch seinen Weg zum Scheitel des Sackes durch das Gewebe der Kernivarze, dessen Zellen auseinander drängend. Der Verlauf des Schlauches innerhalb dieses Parenchyms ist meist ziemlich geradlinig; auch da wo er mehrere Zellschichten zu durchbohren hat, z. B. bei Najas major (I, 14-17.19), Calla palustris (VIII, 15.16). Auch bei einigen der Monokotyledonen, bei denen vom Eykern nur das Gewebe der Kernwarze sich erhalten hat, durchbohrt der Pollenschlauch dieses Gewebe: so bei Arum maculatum und orientale (VII, 13.15.17); bisweilen auch bei Pothos longifolia (IX, 12. 15, X, 3). Häufiger geschieht es jedoch bei letzterer Pflanze, und noch regelmässiger bei Merendera caucasica, Colchicum autumnale, Allium odorans, Hymenocallis caribaea, dass das Ende eines oder mehrerer Pollenschläuche zwischen dem inneren Integument und der Kernwarze hinabwächst, bis es die Aussenfläche des Embryosackes beruhrt (IX, 10-13.14.16, X, 5-8, XVI, 12 -21, XVI, 2-7, XVII, 1-4.6-9, XIX,1.7, XXV, 5). Das Herabwachsen des Pollenschlauchendes wird bei Pothos und den Colchicaceen dadurch sehr erleichtert, dass nach dem Eintritte des Schlauches in den Nikropylekanal sofort eine beträchtliche Dehnung der Eyhïllen nach allen Richtungen eintritt, welcher Eykern und Embryosack nicht sofort folgen. Es bildet sich zwischen diesen und der Innenfläche des inneren Integuments eine oft ziemlich gerảumige Höhlung, in welche man bisweilen das Pollenschlauchende frei herein hängen sieht (XV, 12, XVII, 1. 2). Später füllt der Eimbryosack durch plötzlich eintretende Ausdehnung den Hohılraum wieder völlig aus, und drängt das Pollenschlauchende dicht an das innere Integument an. - Diese Formen zeigen das stärkste, nach dem Zusammentreffen des Pollenschlauches mit dem Embryosacke noch fortdauernde Längenwachsthum des Schlauches. Bei Pothos longifolia biegt der Pollenschlauch öfters knieförmig um, und wächst zwvischen Kernwarze und innerm Integument eine Strecke weit gegen die Innenöffnung der Mikropyle hin (IX, 14; X, 3.5). Oder er treibt Seitenäste, deren Wuchs verschiedenartige Richtungen einschlägt $(X, 7.9)$. Oder er wächst eine Strecke weit auf der Aussenfläche des Embryosackes hin $(X, 6)$. Das letztere Verhälniss kommt auch bei Merendera caucasica häufig vor (XV, 16. 20. 21; XVI, 3); in einem Falle soweit gesteigert, dass der Pollenschlauch bis gegen das Chalaza-Ende des Embryosackes an dessen Aussenfläche herab gewachsen war, hier um- 
bog, unter seinem äteren Theile sich durehdrängte, und zweimal in links geswundener Schraubenlinie denselben umschlingend, rückwärts nach dem Mikropyle-Ende des Sackes hin kroch, nahe welchem er mil einer stark abgeplatteten Erweiterung endete (XVI, 1. 1, b).

Eine zweite Form des nach dem Auftreflen des Pollenschlauchs auf den Embryosack noch fortdaueruden Längenwachsthums des ersteren ist die Einstiulpung des Sackes durch das Ende des Pollenschlauches: beobachtet bei Canna*) (VI, 19_23), Najas major (I, 14-18), Narcissus poëticus**) und Jonquilla (XXV, 15), Tillandsia sp.****). Der Vorgang ist bei den beobachteten Monokotyledonen stets mit beträchtlicher Erweichung der Membran des Embryosackscheitels verbunden, die dann vom Pollenschlauch bis zu unkenntlicher Dünne gedehnt wird. Er ist nur für Canna und Tillandsia Regel; bei den anderen Genannten häufigen Ausnahmen unterworfen (man vergleiche I, 14.17.18.19 mit I, 15.16). Bei Canna steigert sich die Einstüpung endlich bis zu unzweifelhafter Durchbrechung der Membran des Sackes namentlich in der laăufigen, Individuen verschiedener Arten zukommenden Erscheinung geschlängelten, selbst Schleifen und Knoten bildenden, Längenwachsthums des Pollenschlauches innerhalb des Embryosackes (VI, 20. 2I). Die Falle besonderer Steigerung derartigen Pollenschlauchwachsthums (wie f. 20. 21) scheinen abnorme: die Keimblaschen der Embryosäcke, aus denen solche Schlauchenden hervorgezogen wurden, liessen kein Zeichen der Weiterentwickelung erkennen. $\rightarrow$ )

Bei dem Zusammentreffen des Pollenschlauchendes mit der Scheitelgegend solcher Embryosäcke, welche auf der Aussenfläche des Mikropyle-Endes vorspringende Längsleisten aus einer, vom Zellhautştoffe verschieden reagirender Substanz in hohem Grade ausgehildet zeigen, geschieht es sehr häufig, dass der Pollenschlanch sich zwisclıen die ächte Zellstoffhaut des Embryosackes, und die jene Leisten tragende

*) Zuerst durch Schleiden: N. A. A. C. L. XIX, I Taf. III, f. 30.31.

**) Hofmeister Entst. d. Embryo Taf. IX f. 39 . 40 .

***) Crüger, Bot. Zeit. 1856, 8. 15; Tof. XV f. 3 fl.

†) Die Krümmungen des Pollenschlauchendes im Embryosacke von Canna sind zuerst von de Bary beobachtet worden, der die Erscheinung irriger Weise für den Beginn der Bildung durch Abschnürung vom Schlauche sich trennender Tochterzellen hielt, deren eine zum Embryo sich entwickele (Verhandl. d. Vers. deutsch. Naturf. zu Tübingen, 18537 . 
äusserste Schicht der Membran desselben einschiebt, diese von jener auf kürzere oder längere Strecke ablösentl. So namentlich bei Crocus vernus (XXII, ๖̋. 16. 27 ; XXIII, 6. 8, b). Die Aehnlichkeit dieses Verhaltens des Pollenschlauchendes zur leistentragenden Schicht mit denen des Pollenschlauches zur Culicula der Narbenpapillen ist nicht zu verkennen.*) Bei gewvaltsamer Lostrennung des Schlauchendes rom Sacke geschieht es sehr häufig, dass ein Theil der Cuticula am Pollenschlauchende hängen bleibt (XXII, 18. 25. 26. 30; XXIII, 8, a. 15. 17) - ein weiterer Beweis für die klebrige Beschaffenheit der in Rede stehenden Schichl, wie für die geringe Innigkeit ihrer Verbindung mit der Zellstoffschicht der Embryosackhaut, wetcher sie aufgelagert ist. An den abgetrennten Cuticulafetzen ist oft die zwischen den Längsleisten verlaufende. feinkörnige Haut deutlich zu erkennen. In vielen Fällen aber machen die Enden der Leisten unter dem Mikroskop den Eindruck isolirter Fasern (XXII, 25.26) - eine Erscheinung, fur welche die nämlichen Erwägungen gelten, welche in Bezug auf die faserige Structur unter dem DissectionsMikroskop zerfaserter Zellhautlamellen Platz greifen.**)

In anderen Fällen dagegen lässt sich das Pollenschlauchende auch bei Crocus vernus vom Embryosacke ohne alle Verletzung des einen oder des anderen Theiles ablösen (XXII, 7. 8. 24); - die geringe Entwickelung der Keimbläschen ergiebt, dass diese Embryosäcke vor ganz kurzer Zeit erst vom Pollenschlauche erreicht worden waren. Das gleiche Verhältniss, leichte Abtrennbarkeit des Schlauchendes vom Sacke kurz nach dem Zusammentreffen beider; festes Haften derselben an einander nach längerer Berührung, findet sich, wie bei vielen Dikotyle-

*) Ich habe früher geglaubt (Pringsheim's Jahrbücher I, 162), aus dem Vorkommen von Theilen der aus welligen Leisten und kleinen Klumpen zusammengesetzten Masse auf der dem Embryosack abgewendeten Seile des Pollenschlauchendes ron Crocus den Schluss ziehen zu müssen, dass die Entwickelung dieser Nasse nach Ankunft des Poltenschlauches am Embryosacke noch fortdauere, und deshalb diese Masse für ein Secret der nächstbenachbarlen Gewebe - hier der Innenfläche des inneren Integuments - erklären zu sollen. Weitere Untersuchungen des Gegenstandes haben mir gelehrt, dass die häufig beobachtete, völlige Trennung des auf der Aussenscite des Pollenschlauches zu findenden Theiles jener Masse von dem übrigen, auf dem Embryosacke gelagerten Theile desselben nur eine Folge der bei der künstlichen Freilegung des Embryosackscheitels nur selten zu vermeidenden Zerreissung der dem klebrigen, auch der Innenfläche des inneren Integuments etwas anhaftenden Schicht ist.

**) v. Mohl, Botan. Zeit. 1853, 761. 
donen*) auch bei mehreren Monokotyledonen wieder: bei Pothos longifolia (IX, 10.11), Triticum vulgare, Hordeum vulgare, Crinum capense (XIV, 7), Merendera caucasica (XV, 11. 12.14 einerseits; XV, 13. 45, XVI, $1-6$ andererseits). Bei Puschlinia scilloüdes, Veltheimia viridiflora, Hyacinthus orientalis erwies sich die Verbindung beider Theile auch auf späteren Zuständen in allen beobachteten Fállen als eine nur lose.

Die Membran des Pollenschlauches erscheint auch bei Monokotyledonen lıaufig beträchtlich verdickt, soweit er innerhalb des Eyes verläuft. Die Verdickung ist am stärksten am Pollenschlauchende; nach rückwärts nimmt sie allmälig ab. Am deutlichsten zeigt sich dieses Verhăltniss bei den grossen Liliaceen (im weitesten Sinne) : bei Crinum capense (XVI, 5. 6. 8), Hippeastrum aulicum (XIII, 4-8), Crocus vernus. Bei Letzterem wird in der verdickten Wandstelle oft deutlich Schichtenbildung erkannt (XXII, 1. 2. 5, XXIII, 3.5). Nicht selten findet sich bei Crocus in dem äussersten Ende des Schlauches, rings umschlossen von der stảrksten Verdickung der Wand, ein eng unschriebener dünnläutiger Raurn, ein ächter Tüpfel. Die ihn verschliessende Membran erscheint als unmittelbare Fortsetzung der äussersten Lamelle der verdickten Wand (XXII, 18,b. 31, XXIII, 3, c. 8, b. 18, b. c). Wirkliclıe Oeffnungen im Pollenschlauchende sind mir bei Monokotyledonen ebensowenig irgendwo vorgekommen, als bei Dikotyledonen. - Im Allgemeinen sind es nur die älteren Zustände von Pollenschläuchen, welche starke Wandverdickung zeigen. Je weniger an den der Untersuchung unterworfenen Präparaten die Keimbläschen verändert erscheinen, desto gleichartiger dünn und von den der oberen Theile des Pollenschlauches kaum verschieden pflegt auch die des Pollenschlauchendes zu sein (XXII, 2-7. 14). - Die Wandverdickung tritt häufig so rasch nach dem Eintreffen des Schlauches am Embryosacke auf (las XXII, 1 abgebildete Präparat z. B. ist aus einem Pistill genommen, welches nur 24. Stunden vor der Untersuchung, noch jungfräulich, künstlich bestäubt worden war), dass jenes Dickerwerden der Wand nicht anders aufgefasst werden kann, denn als ein Aufquellen derselben. ${ }^{*}$ ) Auch nach dem Aufquellen ist die Membran des Schlauches noch fest; sie lässt sich durch Quetschung nicht breit drücken:

*) Diese Abhandlungen, VI, 607.612.

**) Vergl. meinen Aufsatz in Pringsheim's Jahrb. I, 179. - Auch von Schacht ist die Sache so angesehen worden (Pringslıeim's Jahrbücher 1, 201). 
Den Eintritt mehr als eines Pollenschlauches in die Mikropyle eines und desselben Eychens beobachtete ich nur bei wenigen Monokotyledonen: bei Pothos longifolia (IX, 12; X, 3.6. T), Puschkinia scilloïdes (XX, 1I), Hyacinthus orientalis.

\section{Nächste Veränderungen der Eychen nach Ankunft des Pollenschlauches.}

Das Verschwinden des primären Kernes des Embryosackes ist auch bei den Monokotyledonen die nächste sichtbar werdende Folge des Eintreffens des Pollenschlauchendes am Embryosacke. Sehr zahlreiche Beobachtungen haben keinen einzigen Fall dargeboten, in welchem ein Embryosack, dessen Scheitelgegend vom Pollenschlauclie erreicht war, jenen Kern noch enthalten hätte. Nur insofern erweiset sich bei Monokotyledonen das Fehlen des Embryosackkernes als zweifelhaftes Zeichen erfolgter Befruchlung, als bei manchen von ihnen dieser Kern häufig noch vor Eintreffen des Pollenschlauches am Embryosacke unsichtbar wird (S. 678).

Eine unter den Monokotyledonen ebenso verbreitete als deutlichst ausgeprägte Erscheinung ist die rasche Grössenzunahme des Fruchtknotens und der Eychen von dem Zeitpunkte an, zu welchem die Pollenschläuche in die Höhle des Fruchtknotens eintreten. Dieses Wachshhun beginnt in vielen Fällen schon vor der Ankunft von Pollenschlauchenden in den Mikropylen von Eychen: so bei Gagea, Puschkinia und zahlreichen anderen Liliaceen; am entschiedensten aber bei Orchideen. Bekanntlich ist der Fruchtknoten der Ophrydeen zur Bliithezeit schlank, dünn, fast cylindrisch. Die Eychen sind zu dieser Zeit nur bis zur Anlegung der Integumente als niedrige Ringwülste entwickelt. Erst gleichzeitig mit dem Welken der Perigonialblätter beginnt der Fruchtknoten, unter Ausgleichungen seiner Drehung, zu schwellen; und beginnen die Eychen sich weiter auszubilden. Aber diese Vorgänge treten nicht an alleı Bliithen ein. Oft schlägt die Melırzahl der Fruchtlinoten eines Bliithenstandes fehl; bisweilen die Gesammtheit. Sehr zahlreiche Untersuchungen haben mir gezeigt, dass alle anschwellenden Fruchtknoten die durch R. Brown ${ }^{*}$ ) bekannten Pollenschlauchbiindel enthielten, dass dagegen in uicht anschwellenden Fruchtknoten nie Pollenschläuche zu 
finden waren. Ich hege keinen Zweifel, dass die Weiterentwickelung der Fruchtknoten und Eychen hier von dem Eintritt der Pollenschläuche in die Fruchtknotenhöhle bedingt ist.

Diese Dehnung der einzelnen Theile der Eychen ist bisweilen ungleich : ein Fall der auf sehr fruher Entwickelungsstufe, namentlich bei den Formen vorkommt, deren Embryosack allein oder fast allein den von den Integumenten unıschlossenen Hohlraum ausfüllt: - bei Orchideen, Arö̈deen, Colchicaceen. Die Integumente nehmen früher an Grösse zu als der Embryosack, so dass die Höhlung innerhalb der Eyhïllen schneller an Weite zunimmt, als der Embryosack an Umfang. Dieser füllt jene Höhlung vorerst nicht mehr vollständig aus. In den freien Raum über und neben ihm kann der Pollenschlauch eine Strecke weit herabwachsen, und tief seitlich dem Embryosack sich anlegen. Beobachtet bei Orchis Morio, Pothos Iongifolia (IX, 10), Merendera caucasica (XV, 12), Colchicum autumnale (XVII, 1. 2). Nach einiger Zeit holt das Wachsthum des Embryosackes jenes der Integumente wieder vollständig ein. Er füllt dann die von diesen umschlossene Höhlung wieder prall aus, das Pollenschlauchente fest an die Innenwand des inneren Integuments drängend. Bei Orchis Morio beobachtete ich öfters, dass das Pollenschlauchende durch diesen Druck gesprengt, sein körniger Inhalt auf der Aussenfläche des Embryosackes verstreut war (IV, 16); - ein schlagender Beweis gegen das Bestehen einer offenen Verbindung zivischen den Innenräumen des Pollenschlauchendes und des Embryosackes. - Anderwärts tritt erst später, nach Anlegung des Embryokügelchens, in den Integumenten ein Ueberwiegen des Flächenwachsthums iiber das des Embryosacks ein: so bei Gagea lutea, *) Crocus u. m. A. Bei Ixia rosea beobachtete ich das gleiche Verhältniss selbst an noch unbefruchteten Eychen (XXIV, 10).

Bei den Formen, deren Embryosack allseitig vom Gewebe des Eykerns umschlossen ist, erweitert sich der Embryosack nach Ankunft des Pollenschlauches auf Kosten des umgebenden Gewebes, dieses mehr oder weniges vollständig verdrängend, und so den schon vor der Befruchtung begonnenen Prozess (S. 665) fortsetzend. In der grossen Mehrzahl der Fälle erfolgt die Verdrängung der seitlich den Embryosack umschliessenden Zellenlagen früher, als diejenige der seinen Scheitel

*) Hofmeister Entst. d. Embryo 24; Tal. IX f. 20. 
deckenden, so dass bald nach der Befruchtung die Seitenflächen des Embryosacks der Innenwand des inneren Integuments unmittelbar anliegen, während das vom Pollenschlauch durchbohrte Parenchym der Kernwarze vorerst noch erhalten bleibt: Alisma Plantago (II, 21), Symplocarpus foetida (VII, 7), Leucojum vernum (XIII, 16. 17. 21. 24. 27), Gagea lutea $(\mathrm{XX}, 3,4)$, Iris pumila, Narcissus poëticus und Jonquilla alles Pflanzen, denen nahe Verwandte schon vor der Befruchtung eine ähnliche Verdrängung der seitlich den Embryosack umgebenden Gewebe zeigen (S. 667). Bei Gräsern, Cyperaceen (wie Carex, XII, 17), bei Najas (I, 14-20), Ruppia (II, 3-6), Zannichellia, Potamogeton, auch bei einigen Liliaceen, wie Veltheimia (XVII, 9, 12) geschieht diese Verdrängung gleichmässiger. Bei allen Monokotyledonen schreitet sie endlich bis zu völliger Vernichtung des Gewebes des Eykerns vor, mit einziger Ausnahme von endospermlosen Formen: Cannaceen, Scisameen und Musaceen, bei denen Perisperm die Stelle des Endosperms vertritt. Ein Fall gleichzeitigen Vorhandenseins von Endosperm und Perisperm in reifen Saamen, wie ihn unter den Dikotyledonen die Piperaceen, Nymphaeaceen und Malvaceen*) bieten, ist unter den Monokotyledonen noch nicht bekannt geworden.

In einigen Fallen greift der Embryosack auch von Monokotyledonen, nach Verdrängung der ihn umhüllenden Zellen des Eykerns, noch in andere Theile des Eychens, in das Gewebe des innern Integuments oder der Chalaza, zerstörend ein, wie dies unter den Dikotyledonen bei Labiaten, Personaten u. A. sehr allgemein vorkommt. - So wird bei Allium odorans schon sehr früh, fast gleichzeitig mit der Befruchtung, die Mittelgegend des inneren Integuments einseitig, in der concaven Halfte des Eys, vom Embryosack verdrängt (XIX, 9). Ebenso erfolgt die Ver drängung und Sprengung der den endospermerfüllten Embryosack umhiillenden Zellschichten von Crinum capense, welche ich als einziges Integument auffasse (S. 662), früher an einer nicht fest bestimmten Stelle des Eychens, als an den übrigen. Bei den Ophrydeen ist die Verdrängung des innern Integuments eine allseitig gleichmässige.

*) Hofmeister in Pringsheim's Jahrbiicher I, 92. 


\section{Beginn der Entwickelung eines der Keimblïschen zum Embryo.}

In der weitïberwiegenden Melırzahl der Fälle ist es nur eines der Keimbläschen jedes Embryosackes, welches nach Ankunft des Pollenschlauches am Sacke die Weiterentwickelung zum Embryo anhebt. Bei allen darauf untersuchten Formen von Mono- wie von Dikotyledonen geschieht diese Veränderung mit demjenigen der Keimbläschen, dessen geradlinige Entfernung vom Chalaza-Ende des Embryosackes die geringste ist.*) In Embryosäcken mit spitzer Wölbung des Scheitels erscheint das weiter sich entwickelnde Keimbläschen sehr deutlich als das, dem Mikropyle-Ende des Sackes fernere. So auch bei Monokotyledonen ganz in der Regel: Najas major (I, 15. 16.18. 19), Zannichellia palustris (II, 10.11), Orchis Morio (IV, 15. 16), Arum orientale und maculatum (VII, 2. 13.16), Pistia Stratiotes (VII, 22), Calla palustris (VIII, 45), Pothos longifolia (IX, 10.13.15), Secale cereale (XI, 5), Triticum vulgare (XI, 14), Elymus arenarius (XI, 18), Hordeum vulgare (XII, 2), Sorghum halepense (XII, 9. 10), Hippeastrum aulicum (XIII, 4. 7. 8), Leucojum vernum (XIII, 18-21.24.25), Crinum capense (XIV, 5.6.8), Veltheimia viridiflora (XVIII, 4-11), Hemerocallis lutea (XIX, 1), Czackia Liliastrum (XIX, 3), Allium odorans (XIX, 9. 10), Gagea lutea (XX, 4), Puschkinia scilloïdes (XX, 10.11), Crocus vernus (XXII und XXIII, sämmtliche Figuren), Gladiolus communis (XXIV, 9), Tritonia crocala (XXIV, 12), Paris quadrifolia (XXV, 13). Nur bei Formen mit völlig abgeplattetem Embryosackscheitel kommt die Entwickelung des genau dem Sclıeitelpunkte des Sackes anhaftenden Keimbläschens zum Embryo vor, und auch hier nur, wenn eine Verschiebung des oberen Embryosackendes, ein einseitig stärkeres Längenwachsthum der Seitenfläche des Embryosackes das im Centrum der Scheitelfläche haftende Keimbläschen dem Chalaza-Ende des Sackes relativ genähert, das excentrische Keimbläschen von diesem entfernt hat: Colchicum autumnale (XVII, 3. 4), Merendera caucasica (XVI, 7). Das umgekehrte Verhaltniss, die Entwickelung des excentrischen Keimblïschens zum Embryo, muss auch für diese Formen als Regel bezeichnet werden: Colchicum autumnale

*) Vergl. Hofmeister in Flora 4855, 259; Radikofer, Befruchtung d. Phanerog. Lpzg. $1856,17$. 
(XVII, 6-8), Merendera caucasica (XV, 15.16; XVI, 1. 2. 3. 4. 7). Auch bei den polyembryonischen Formen, deren sämmtiche Keimbläschen zu Embryonen sich zu entwickeln pflegen, eilt das am tiefsten der Scheitelwölbung des Sackes anhaftende den iibrigen in der Entwickelung beträchtlich voraus: Funkia coerulea (XX, 7), Hymenocallis ovata (XXV, 3). Diese relativ grössere Entwickelungs - und Lebensfähigkeit des untersten der Keimbläschen findet sich schon im unbefruchteten Embryosacke durch das luaulige zeitige Absterben der übrigen ausgesprochen (S. 674). Der Grund der Erscheinung ist muthmaasslich derselbe, welcher die Entwickelung des Embryo genau in der Längsachse des Embryo, die rasche Verlängerung der Träger vieler Embryonen, und, in polyembryonen Embryosäcken von Monokotyledonen wie von Coniferen die Beguinstigung des Wachshums des am tiefsten gegen die Chalaza herab gedrungenen Embryo bedingen mag: der Umstand, dass die Zuleitung der Nahrungsflüssigkeit für den Embryo nur von der Chalaza her erfolgt.

Der beginnenden Weiterentwickelung des unteren Keimbläschens zum Embryo geht bei den Monokolyledonen weit allgemeiner ein Festerwerden seiner Zellhaut voraus, als bei den Dikotyledonen.*) Aber diese Erhärtung der Häute beschränkt sich nicht auf das zur Weiterentfaltung bestimmte Keimbläschen: sie erstreckt sich auch auf das oder die oberen, welche baldigem Fehlschlagen und Absterben verfallen sind, dafern diese oberen Keimbläschen zur Zeit des Festerwerdens der Membran Jes unteren nur iberhaupt noch lebensfähig sind. So bei den meisten Liliaceen, Amaryllideen und Irideen: besonders regelmässig bei Crocus (XXII, XXIII). Die Erlıärtung der Haut auch der oberen Keimbläsclıen dieser Formen, das in dieser Beziehung schwankende Verhalten vieler anderen, wie Leucojum vernum, Crinum capense, Hippeastrum aulicum, Sorgh um halepense, Najas major u. s. w., deren abortirende Keimbläschen bald feste Membranen erhalten, bald nicht, - sprechen ebensosehr für die Unwesentliclıeit des Vorhandenseins einer festen Zellstoffhaut am Keimbläschen nach, und des Fehlens derselben vor der Befruchtung, als der Umstand, dass die Keimbläschen mancher Formen schon v or der

*) Unter welchen Lupinus, Prismatocarpus und Mirabilis z. B. noch am vielzelligen Vorkeim zerfliesslich weiche Zellwandungen besitzen : vergl. Hofmeister in Pringslieim's Jahrb. I, 181. 
Befruchtung des Eychens eine, wenn auch dünne doch feste Zellhaut zeigen (S. 671).

Uin so deutlicher unterscheidet sich, bald nach Ankunft des Pollenschlauches am Embryosacke, der Inhalt des in Weiterentwickelung begriffenen Keimbläschens von dem der fehlschlagenden. Während nunmehr (wenn es nicht schon früher geschah; S. 675) in diesen die scharfe Sonderung des Inhalts in einen Wandbeleg aus Protoplasma und einen grossen centralen Raum mit wässeriger Flüssigkeit bald aufgehoben wird, und der ganze Innenraum der Zelle mit einer von zahlreichen, feinen Körnchen ziemlich gleichmässig getrübten Flüssigkeit erfüllt ist (XXII, 1-4.6.10.11. 14.15, li; XXIII, 1; ferner IV, 15. 16, XVI, 1; XVII, 3. 4. 7 u. a. Abb.), prägt sich diese Sonderung in jenem, dem weiter sich entwickelnden, durch Zunahme der Masse und Dichtigkeit des Protoplasma um Vieles schärfer aus; besonders dadurch, dass an der Ansammlung von Protoplasma, welche das freie untere Ende des Keimbläschens ausfüllt, zahlreiche feste, körnige Gebilde aus mit Jod sich bräunendem Stoffe von auffallender Grösse auftreten (XXII, 1.6. 10.14.15; XXIlI, 1). Noch bevor dies geschieht, pflegt in sämmtlichen Keimbläschen, den fehlschlagenden wie dem weiter fortschreitenden, der primäre Zellenkern zu verschwinden (IX, 10; XIII, 16.17; XIV, 5; XV, 9.11.13-16.17-21; XVI, 2. 3.4, XVII, 4. 6-10; XVIII, 4; XXII, 2. 3. 4. 11), während gleichzeitig mit jenen Körnchen, und in derselben Anhäufung von Protoplasma, welcher sie eingebettet sind, ein durch starke Lichtbrechungsvermögen seiner Substanz vor dem verblassten primären sehr ausgezeichneter neuer Kern, aber nur in dem, zu weiterer Entwickelung bestimmten unteren Keimbläschen sichtbar wird.*)

*) Bei Formen, deren Embryoentwickelung eine rapide ist, könnte an dem Unterschiede des secundären Kernes von dem primären gezweifell werden, da es nur selten gelingt, Zwischenzustände der Keimbläschen aufzufinden, in denen diese des Zellenkernes entbehrten. Ausser der Analogie mit langsamer sich entwickelnden Formen, unter denen namentlich Colchicum autumnale vom Herbst an bis Anfang Mai des nächsten Jahres niemals einen Zellenkern im befruchteten Keimbläschen zeigt, ist noch der Umstand eine Stütze meiner Auffassung, dass in einzelnen Fällen die Bildung des secundären Kernes noch während der Existenz des primären erfolgt. So bisweilen bei Gagea lutea (Entst. d. Embryo Taf. IX f. 9, 10) und bei anderen Formen mit blasig anschwellender oberster, tragender Zelle des Vorkeims wie Zannichellia, Najas. Ferner dass Grösse und Aussehen des primären und des secundären Kernes dieser Formen auch dann sehr verschieden sind, wo der primäre vor Sichtbarwerden des secundären verschwindet; dieser ist viel kleiner, und minder abgeplattet als jener. 
Diesem Zustande folgt bald die erste Theilung des befruchteten Keimbläschens durch eine Scheidewand: bei den Monokotyledonen in allen Fällen eine quere, dem unteren freien Ende des Keimbläschens näher, als dem oberen angewachsenen gerückte. Der secundäre, neue Kern des Keimbläschiens kann vor der Bildung der Scheidewand in zweierlei Weise sich verhalten. Entweder so, dass an seiner Stelle zwei tertiäre Kerne erscheinen, zwischen denen beiden der Inhalt des Keimbläschens zu zwei getrennten Hälften sich abschnürt, in deren Berührungsflächen dann die neue Zellhaut als anscheinend homogene Platte auftritt. Oder aber so, dass ein kleinerer, aber an plastischen Stoffen reicherer Theil des Inhalles, um den im unteren Ende des Keimbläschens gelegenen secundären Kern angesammelt, von dem übrigen Inhalte durch quere Abscheidung sich sondert, worauf, wie im vorigen Falle, in der Berülırungsebene der beiden Primordialzellen die neue Zellstoffhaut erscheint. Die oberste, die Trägerzelle des nun zıveizelligen Vorkeims ist dann kernlos, nur die untere, kleinere kernhaltig. Beide Fälle kommen bei gewissen Arten neben einander, selbst in Eychen des nämlichen Fruchtknotens vor. Der erstere ist fast ausschliessliche Regel bei Formen mit relativ kleiner Trägerzelle, wie z. B. Pothos longifolia, Secale cereale, Orchis Morio, Leucojum vernum (IV, 18. 19, IX, 12-17, XI, 4-6, XIII, 21-24); der Letztere ist der häufigere bei Formen mit grosser Trägerzelle, wie Najadeen, Potamogetoneen, Gagea, Erythronium, Fritillaria. Bei Crocus, Veltheimia, Puschkinia, anderen Gräsern finde ich, bei je den nämlichen Arten und Individuen, den ersten Fall zwar den häufigeren, aber auch den zweiten sehr oft.

Der Vorgang der Sonderung des Inhattes einer in Zweitheilung begriffenen Zelle in zwei wohlbegränzte, einander berührende Massen (Primordialzellen), welche noch vor dem Auftreten einer sie trennenden festen Scheidewand durch Anwendung wasserentziehender Reagentien als getrennte, geschlossene Schläuche zur Anschauung gebracht werden können, lässt kaum irgendwo leichter und sicherer sich constatiren, als in den befruchteten, zur ersten Theilung sich anschickenden, Keimbläschen einiger Liliaceen und Amaryllideen : vorzugsweise solcher, deren Entwickelung zeitig im Jahre, bei niederer Temperatur und langsam vor sich gcht. Wird ein Präparat, welches ein befruchtetes, bereits gestrecktes und zwei Zellenkerne enthaltendes Keimbläschen von Leucojum vernum, oder Veltheimia viridiflora, oder Puschkinia scilloïdes klar über- 
blicken lässt, mit einer indifferenten Lösung (verdünnter von Glycerin, oder kohlensaurem Ammoniak) behandelt, so ziehı häufig der Inhalt in Form zweier getrennter, geschlossener Schläuche von der Zellhaut sich zurück, ohne dass zwischen beiden Schläuchen selbst mit den besten Instrumenten auch nur die Spur einer sie trennenden Scheidewand zu erkennen wäre (XIII, 21 Leucojum; XVIII, 5̋ Veltheimia).

Die Zeit, welche zwischen der Ankunft des Pollenschlauchs am Embryosacke, und der ersten Zellentheilung des befruchteten Keimbläschens verfliesst, ist auch bei den verschiedenen Formen von Monokotyledonen von schr ungleicher Dauer. Von sehr kurzer bei den Gräsern. Nur selten findet man bei Untersuchung von Eychen, bis zu deren Embryosack der Pollenschlauch vorgedrungen, das untere Kcimbläschen noch nicht quergetheilt. Etwas langsamer ist die Entwickelung bei Najadeen und Potamogetoneen: bei Zostera marina schätze ich jene Frist auf etwa 12, bei Najas major auf 24. Stunden. Bei Orchis Morio kann sic kaum niedriger veranschlagt werden, als auf 48 Stunden, selbst bei hoher Temperatur und heiterem Wetter. Noch länger ist sie bei der Mehrzahl der Liliaceen, Amaryllideen, Irideen und Aroïleen. Sie beträgt bei Crocus vernus unter günstigsten Verhältnissen 19 bis $96 \mathrm{St}$., bei Leucojum vernum $5-7$ Tage; bei Veltheimia viriditlora 3-4. Tage, bei Arum maculatum 8-10 T., bei Merendera caucasica 12-20 Tage. Ihr Maxiınum erreicht sie bei Colchicum autumnale (durch die zwischen das Eintreffen des Pollenschlauches und die Weiterentwickelung des befruchteten Keimblaschens fallende Winterruhe) mit 8 Monaten, Mitte Septembers bis Mitte Mais.

Der ersten Zeltheilung des befruchteten Keimbläschens geht häufig eine Grössenzunahme desselben voraus. Doch ist dies bei den Monokotyledonen eine minder allgemeine, auch bei einzelnen Formen eine minder beständige Erscheinung, als bei den Dikotyledonen. Ein häufiger Fall ist eine Vergrösserung des Keimbläschens nach, allen Richtungen; ein Anschwellen desselben ohne wesentliche Veränderung der Form. Die zweite, untere Zclle des Vorkeims nimmt dann nur einen kleinen Theil der gewölbten Endlliache der zur umfangreichen Blase gewordenen Trägerzclle ein. So ist es Regel für die meisten Najadeen, Potamogetoneen und Juncagincen, z. B. Ruppia maritima (II, 3. 4), Zannichellia 
palustris (II, 10-I3), Zostera marina, ${ }^{*}$ ) Alisma Plantago (II, 21), Triglochin maritimum (I, 26. 27). Ferner bei einigen Tulipeen: Gagea lıtea (XX, 3.4), Erythronium dens canis (XIX, 5. 6); bei Arum maculatum und orientale (VII, 2. 3. 15. 16). Bei Najas major, Scheuchzeria palustris zeigt sich diese Erscheinung in verschiedenen Eychen in sehr ungleichem Maasse, bisweilen kaum merklich (I, 15-20; XXV, 20. 21), ebenso bei Fritillaria imperialis. ${ }^{*}$ ) - Anderwärts stellt sich die Grössezunahme des befruchteten Keimbläschens als eine Streckung dar, welche vermittelt wird durch Längenwachsthum der Membran des freien Endtheils des Keimbläschens: so sehr deutlich bei den Orchideen, deren vor der Befruchtung birnförmige Keimbläschen nach derselben, schnell wachsend, die Eyform des Embryosackes annehmen, den sie vor ihrer ersten Zelltheilung nahezu, nicht selten sogar schon vollständig ausfüllen (z. B. Orchis Morio, V, 16. 17). Ferner u. v. A. bei Polhos longifolia (hier in sehr ungleichem Maasse, IX, 10-16), bei Gräsern (XI, 4-7. 18. 19, XII, 2-4. 8-10), bei Hippeastrum aulicum (XIII, 7. 8. 10), Leucojum vernum (XII, 21.23. 24), Veltheimia viridiflora (auch hier in sehr ungleichem Grade; XVIII, 5. 10. 11 einerseits, XVIII, 9 andrerseits), Czackia Liliastrum (XIX, 3), Puschkinia scillö̈des (XX, 10. 11), Crocus vernus (bei diesem nur in sehr beschränktem Maasse, XXII, 1-20). Die Jetztere Pflanze stellt einen Uebergang zu der Reihe jener Formen dar, deren befruchtete Keimblasschen vor der ersten Zelltheilung in Form und Grösse sich nicht merklich verändern : wie Crinum capense (XIV, 6-8), Herendera caucasica (XVI, 1-9), Colchicum autumnale (XVII, 1-10), Allium odorans (XVIII, 1-10), Pontederia cordata (XXIV, 13. 16), Tradescantia virginica (XXIY, 18. 20), Narcissus Jonquilla (XXV, 15), Paris quadrifolia (XXV, 10--I3).

Von dem Zeitpunkte der Erhärtung der Zellhaut der Keimbläschen an haften diese fester an der Innenwand des Embryosackes, als vorher. Doch ist die Innigkeit dieser Verbindung bei verschiedenen Formen sehr ungleich. Bei Crocus, Leucojum, bei Hyacinthus, Puschkinia und anderen Liliaceen hängt das befruchtete Keimbłäschen noch im einzelligen Zustande vermittelst seiner Ansatzfliche, trotz des oft geringen Umfanges derselben, dem Embryosacke so fest an, dass die Trennung beider

*) Hofmeister in Bot. Zeit. 1852 Taf. III f. 26--29.

**) Entst. d. Embryo Taf. VIII f. 11-13.15. 
durch Zichen mit der Präparirnadel kaum je gelingt. Die Membranen reissen eher, als dass sie von einander sich lösen. ${ }^{*}$ ) Bei Gräsern, noch mehr bei Potamogetoneen und Najadeen, ist die Verbindung viel loser. Bei Secale und Triticum genuigt zu ihrer Aufhebung häufig schon eine leichte Berühırung des Keimbläschens mit der Nadel. BeiZostera marina bcolbachtete ich, dass die blasenförmige Trägerzelle des bereits mehrzelligen Embryokïgelchens von der Anheftungsstelle am Embryosack sich schon dadurch ablösete, dass sie, während des Liegens des Präparats in Wasser des Objectträgers, durch Flüssigkeitsaufnahme ihre Form der sphärischen annäherte. ***)

\section{Entwickelung des Vorlieims.}

Es ist eine allgemeine Erscheinung, ${ }^{*} *$ **) dass das Keimbläschen der Phanerogamen nicht vollständig selbst an der Bildung des Zellenkörper's des Embryo theilnimmt, sondern dass die Endzelle einer terminalen Sprossung des Keimbliischens es ist, wolche durch längere oder kürzere Zeit fortgesetzte Theilungen die Zellenmasse bildet, deren Zellräume bei herannahender Saamenreife mit zur Ernährung dienlichen Stoffen sich fuilten, und die so im reifen Saamen den Embryo darstellt. Das ursprüngliche Keimbläschen, und scine endständige Sprossung, so weit sic nicht in die Embryobildung eingeht, belegte ich mit dem Namen des Vorkeims; es ist derselbe Theil, der nach der Entwickelung des Embryokiigelchens den Embryoträger darstellt.

Die Formverhältnisse desselben sind bei den Dikotyledonen sehr mannichfaltig, und für bestimmte Verwandtschaftskreise scharf kennzeichnend. Unter den Monokotyledonen ist weder die Verschiedenheit der äusseren Bildung des Vorkeins so gross, noch waltet bei verschiedenen Individuen derselben Art die nämliche, fast ausnahmslose Regelmässigkeit in Bau und Form ob, wie dort. - Die gemeinste Form des Vorkeims ist auch bei den Monokotyledonen die eines Zellfadens, entstanden durch je in der Endzelle sich wiederholende Quertheilungen des

*) Vergleiche auch Tulasne in Ann. sc. nat. IV. Ser. IV, 98, 105, der diesem Umstande ein viel zu grosses Gewicht beilegt, indem er aus ihm auf die Entstehnngsweise des Keimbläschens zurück schliesst.

**) Bot. Zeit. 1852,140 .

***) Wie ich bereits vor 10 Jahren dies ausgesprochen: Entst. d. Embryo, 59. 
sprossenden Keimbläschens. So bei den meisten Najadeen, Potamogetoneen, Alismaceen, Aroïdeen, Irideen, Amaryllideen, Liliaceen, Orchideen, bei Canna, Carex u. s. w. Die Länge dieses Zellfadens ist fast durchgehends gering; sie beträgt nicht über fünf Zellen, deren Längsdie Querdurchmesser um höchstens etwa das Dreifache übertreffen. Eine grössere Zellenzahl, bis zu zehnen, fand ich nur bei Alisma Plantago (II, 21) und bei Gagea lutea (XX, 4). Einen nur zweizelligen Vorkeim, dessen zweite Zelle schon zum Embryo wird, also einen einzelligen Embryoträger fand ich unter den Monokotyledonen nur bei einigen Formen mit blasenförmig anschwellender Trägerzelle: bei Zostera marina und minor, ${ }^{*}$ ) bei Ruppia maritima (II, 3, b. 5.6), und bei Arum orientale und maculatum (VI, 2. 4. 15). Als Ausuahme kommt das gleiche Verhältniss hier und da bei Formen mit fädlichem, aber kurzem Vorkeim vor: so bei Crocus vernus (XXIII, 23, b), bei verschiedenen Arten von Orchis (hier auf späteren Entwickelungsstufen durch das Auftreten einer Zellenvermehrung in der obersten Zelle des Vorkeims, einer wiederholten Quertheilung desselben, zum Theile verdeckt.**) Wic die Zellenzahl, so ist auch die Länge der fädlichen Vorkeime bei der nämlichen Art veränderlich. Nur schwach und undeutlich tritt das, bei Dikotyledonen scharf ausgeprägte Verhältniss hervor, dass in langgestreckten Embryosäcken der Vorkeim eine beträchtlichere Länge erreicht, als in kurzen und weiten. - Sehr häufig erscheint die Regelmässigkeit des Baues der fidlichen Vorkeime von Nonokotyledonen durch das Auftreten von Schräg - oder Längswänden in einzelnen der Gliederzellen gestört: ein ganz gewöhnlicher Vorgang in den Zellen, welche der Mutterzelle des Embryokügelchens zunächst angränzen, abcr auch in weiter rüickivärts gelegenen Gliederzellen, bisweilen selbst in der Trägerzelle, beobachtet bei verschiedenen Arten von Canna, bei Symplocarpus foetida (VIII, 7), Pothos longifolia (X, 9), Scheuchzeria palustris (XXV, 20), Gagea lutea, $\left.{ }^{*}{ }^{*}\right)$ Iris pumila, $t$ ) Hippeastrum aulicum, Habranthus chi-

*) Bot. Zeit. 1852, Taf. III f. 26-35.

**) Vergl. Amici in Flora 1847, Taf. IIl f. 8. 9; Bot. Zeit. 1847. 385; v. Mohl, Bot. Zeit. 1847, 471; Hofmeister, Entst. d. Embryo Taf. II f. 8-16. Ein ähnlicher Vorgang findet bei mehreren Arten von Asclepias statt, Hofmeister in Pringsheim's Jahirb. I, 124 .

****) Entst. d. Embryo Taf. IX f. 21. 22.

†) Ebend. Taf. X f. 15. 
lensis (XIII, 12), Crinum capense (XIV, 9, b), Crocus vernus (XXIII, 21. 22). Diese Formen des Vorkeims bilden den Uebergang zu der massigen, aus einem keulenförmigen Zellenkörper bestehenden, der durch Theilungen schon der Zellen des nur wenigzelligen Vorkeims nach verschiedenen Richtungen gebildet wird. Diese Form des Vorkeims kommt sehr allgemein den Gräsern zu: Secale, Triticum, Hordeum (XI, 4-10. 14. 15; XII, 2-5), Zea, Sorghum. ${ }^{*}$ ) Vereinzelt tritt sie auch in anderen Verwandtschaftskreisen auf: Pistia Stratiotes (VII, 23), Erythronium dens canis (XIX, 5.6), Fritillaria imperialis, Funkia coerulea, ${ }^{*}$ ) Tradescantia virginica (XXIV, 20).

\section{Endospermbildung.}

Bei der grossen Mehrzahl der Monokotyledonen erfolgt rasch nach der Befruchtung eine reichliche Entwickelung von Endospermzellen; allerwärts durch gleichzeitige Bildung zahlreicher Tochterzellen um frei in Protoplasma des den Embryosack auskleidenden Wandbeleges auftretende Zellenkerne, bei welcher Zellbildung - wie bei der in nämlicher Weise vor sich gegangenen der Keimbläschen und ilırer Gegenfüsslerzellen - nur ein Theil des plastischen Inhalts der Mutterzelle verbraucht wird. - Die Zellenkerne der Endospermzellen sind bei ihrem ersten Sichtbarwerden bläschenförmige Gebilde, in deren Innerem keine festen Bildungen sich erkennen lassen.*****) Die Grösse dieser Bläschen übertrifft in allen untersuclıten Fällen die der späteren Kernkörperchen der betreffenden Zellenkerne (IX, 10 Pothos longifolia, zum Theil; XIII, 24 Leucojum vernum; XXIV, 12 Tritonia crocala). Fortgeselzte Untersuchungen haben auch in mir die Ansicht befestigt, dass die "freie Zellbildung", wie überhaupt, $\uparrow$ ) so auch im Embryosack der Phanerogamen, stets im protoplasmatischen Wandüberzuge der Mutterzelle ihren Ausgangspunkt habe; dass die Fälle, in welchen sehr junge Zellenkerne in der Fluissigkeit des Mittelraums des Sackes frei schwimmend gefunden wurden, auf Störungen der ursprünglichen Anordnung des Zelleninhalts durch den Schnitt oder die Zergliederung zurück ge-

*) Entst. d. Embryo Taf. XI f. 10-13. 30-33.

**) Ebend. Taf. VII f. 26-34, Taf. VIII, f. 17-20.

***) Vergleiche Entst. d. Embryo, XI, 11.

†) Vergleiche Pringsheim, Bau u. Entw. d. Pflanzenzelle, Berl. 1854, 64, Anmerk. 
führt werden müssen. - Der Wandbeleg des Embryosackes aus Protoplasma ist in vielen Fällen, namentlich bei Irideen und Liliaceen, nach Innen hin überhaupt nicht scharf begränzt; das Protoplasma selbst sehr dünnllüssig, bei Weitem nicht von der Zähigkeit und Consistenz, wie z. B. bei Ranunculaceen. Damit mag es im Zusammenhange stehen, dass von mir bei Monokotyledonen noch nicht die, bei mehreren Ranunculaceen, Papaveraceen u. a.m. Dikotyledonen beobachteteErscheinung der Bildung von Kernen für Endospermzellen in der Protoplasmaschicht gesehen wurde, welche die Aussenseite des befruchteten Keimbläschens bekleidet.

Bei den meisten Formen von Monokotyledonen, welche ein bleibendes Endosperm erhalten, ist der Beginn der Entwickelung desselben im ganzen Umfange des Embryosackes gleichmässig vertheilt. Die Zellenkerne der künftigen Endospermzellen sind in ziemlich gleichen Entfernungen im Wandbelege vertheilt (IX, 10.11; XII, 2. 9; XIII, 23; XVI, 6; XXIV, 12); die Bildung einer Zelle um jeden derselben erfolgt nahezu gleichzeilig, indem um jeden Zellenkern und eine ihn einhüllende Protoplasma-Masse eine - zunächst zarte, zerfliessliche - Zellhaut sichtbar wird. Waren die Zwischenräume zwischen den einzelnen Zellkernen gering, so wird durch Ausdehnung jener Zellhäute (wobei das Protoplasma mit dem von ihm eingeschlossenen Zellenkern deren Innenfläche überzieht, während im Centrum der Zelle ein mit wässeriger Fliissigkeit gefuillter Raum auftritt,) der Embryosack mit einer Schicht seitlich einander berührender Zellen ausgekleidet, welche der Innenfläche der Embryosackhaut angesclimiegt sind. Ein leichter Druck löset sie vorerst noch von derselben, bis die Membranen der Endospermzellen erhärten, dann erst haften sie jener fest an. Dieses Verhältniss ist ganz das nämliche, wie das der Keimbläschen zur Embryosackmembran. Auf der inneren, mit der Fluissigkeit des Mittelraumes des Embryosacks in Berührung stehenden Fläche ist die Schicht der Endospermzellen mit einer Lage von Protoplasma überzogen, in welcher der nämliche Vorgang sich bis zum Verbrauche des plastischen Inhaltes des Embryosackes, in der Regel auch bis zur vollständigen Ausfüllung desselben durch ein geschlossenes Gewebe wiederholt. Während der Anlagerung neuer Zellschichten auf die Innenfläche der bereits vorhandenen findet auch in diesen eine, oft sehr lebhafte Zellvermehrung statt; vorwiegend Theilung durch zu den Radien des Embryosackes rechtwinklige Scheidewände. Vorzugsweise auf dieser Form der Zellvermehrung, und im 
minderen Grade auf radialer Streckung der peripherischen Zellen des Endosperms, beruht die meist sehr deutlich strahlige Anordnung der Zellen der äusseren Schichten desselben. So ist der Hergang namentlich bei den Gräsern mit geräumigem Embryosacke: den Paniceen, wie z.B. Sorghum, Zea, Panicum; ferner bei vielen Liliaceen, Amaryllideen und Irideen, u. A. bei Crinum capense (XIV, 9), Colchicum autumnale, Merendera caucasica (XVI, 9), Allium odorans und victoriale, Hemerocallis llava, Czackia Liliastrum, bei Hyacinthus, Scilla, Puschkinia, bei Iris pumila, Crocus vernus (XXIII, 23). Ist der Embryosack eng, so berühren sich schon die Zellen der ersten, der Wand selbst angelagerten Zellen des Endosperms bei ihrem zeitigen Wachsthum in der Längsachse des Sackes. Der Embryosack erseheint dann schon sehr frühe von geschlossenem Gewebe ausgefüllt. Dies ist namentlich der Fall bei den Triticeen: Secale, Triticum, Hordeum, Elymus (XI, 5. 1 घ̆. 19; XII, 3); ferner bei Pothos longifolia (IX, 10-17, X, 4.).

Die Anfüllung des Embryosackes mit Endospermzellen geht in etwas anderer Weise bei denjenigen Formen von Monokotyledonen vor sich, in deren Embryosäcken die Zellkerne der ersten Endospermzellen in weiteren Entfernungen von einander dem protoplasmatisehen Wandbelege eingelagert auftreten, und deren junge Endospermzellen bei ihrer ersten Ausdehnung völlige Kugelgestalt erlangen, bevor sie seitlich einander berühren. Durch Annahme der Kugelform lösen sich die jungen Endospermzellen völlig vom Wandbelege, und treten frei schwimmend in den Mittelraum des Embryosackes. Indem nun einestheils die gleiche Zellvermelarung im Wandbelege des Embryosacks sich wiederholt, anderntheils ${ }^{2}$ in den jungen Endospermzellen die Bildung freiel Tochterzellen oder auch Zelltheilung stattindet, fuillt sich der Embryosack binnen Kurzem mit einem Breie loser, zartwandiger Zellen, die endlich zum Gewebe sich zusammen schliessen, und deren Häute nun erst erbärten. 'So u. A. bei Leucojum vernum (XIII, 23), Gagea lutea, ${ }^{*}$ ) Scheuchzeria palustris (XXIV, 20). Auch bei diesem letzteren Verhalten der jungen Endospermzellen kann die vollständige Ausfüllung eines engen, schlanken Embryosackes sehr frühe erfolgen, indem die Endospermzellen, in den Mittelraum des Embryosackes gelangt, bei rascher Grössenzunahme jede für sich einen Querabschnitt des Sackes ganz und gar

*) Entst. d. Embryo, S, 24. 
einnimmt, so dass der ganze Sack sehr bald nach der Befruchtung durch eine Längsreihe scheibenförmiger Endospermzellen ausgefüllt ist. So bei Pistia Stratiotes (VII, 22. 23); mit einer kleinen Modification, insofern nur der obere Theil des Embryosacks mit Endosperm sich füllt, der untere leer bleibt, ist das Gleiche für alle untersuchte Arten von Arum Regel (VII, 1. 2. 16. 17).

Die Füllung nur eines Theiles des Embryosackes mit Endosperm, das Leerbleiben des anderen Theiles, scheint unter den Aroïdeen ziemlich verbreitet zu sein. Bei Pothos longifolia sieht man häufig, aber nicht mit ausnalımloser Regelmässigkeit, den eben befruchteten Embryosack durch eine Querwand in zwvei Zellen getheilt, deren obere die grössere ist. Nur in dieser oberen findet dann die Bildung von Endosperm statt (IX, 10. 11). Die endospermleere untere Zelle ist häufig noch am halbreifen Saamen als Anhängsel des Endospermkörpers kenntlich $(\mathrm{X}, 12, x)$. In anderen befruchteten Eychen derselben Pflanze findet man den Embryosack durchweges von Endosperm ausgefïllt ( $X, 4.10)$. Bei Arum maculatum, orientale, ternatum hingegen ivird regelmässig der schlank kegelförmige Embryosack, gleich nach Beginn der nur in seinen oberen zwei Dritttheilen eintretenden Endospermbildung, durch Anschwellen der untersten der jungen Endospermzellen etwas unter der Mittelgegend verstopft (VII, 16. 17). Unterhalb dieser Stelle findet keine Endospermbildung statt; das während des Reifens des Saamen beträchtlich wachsende untere Ende des Sackes stellt zu allen Zeiten einen von Flüssigkeit erfüllten Hohlraum dar. Den Boden dieser Höhlung nehmen die, zu ungewöhnlicher Grösse heranwachsenden, Gegnerfüsslerzellen der Keimbläschen ein (VII, 4). Bei Calla palustris fütlt sich nach der Befruchtung zunächst nur der engere untere Theil des Embryosackes mit Endosperm; das kolbige obere Ende bleibt vorerst zellenleer (VII, 15. 16). - Bei Voltheimia viridiflora füllt sich nur die obere Hälfte des Embryosackes mit Endosperm; die untere bleibt leer (XVIII, 12). Obschon auch in der sie auskleidenden ProtoplasmaschichtZellenkerne auftreten (XVIII, 8), verschwinden diese doch späterhin wieder, ohne dass Endospermzellen um sie sich bilden. Auf dem Grunde des endospermleeren unteren Endes des Embryosackes findet sich im halbreifen Saamen häufig eine grosse Druse von Krystallen eines Kalksalzes (XVIII, 12). Kleinere Krystalle und Krystalldrusen desselben Salzes treten in den periphe- 
rischen Zellen des unteren Theiles des Endosperms auf*) (XVIII, 12, $12, b)$.

Das Wachsthum, die Ausdehnung und Vermelırung der Zellen des Endosperms endigt nicht mit der Ausfüllung des Embryosackes, sei es des ganzen oder eines Theiles desselben. Doch ist bei vielen Liliaceen und Verwandten, deren Eychen bald nach der Befruchtung ziemlich die volle Grösse der reifen Saamen erlangen, dieses spätere Wachsthum nicht beträchtliclı. Das Endosperm von Colchicum autumnale, Gagea lutea, Iris pumila, Crocus vernus u. A. nimmt nur um etwa ein Fünftheil seines Längs - und Querdurchmessers an Grösse noch zu, nachdem es den Embryosack ausfüllte. Die allgemeine Form des reifenden Saamens verändert sich währenddessen nicht. Das Wachsthum beruht hier in der Regel nur auf Dehnung der Endospermzellen; Theilungen von solchen kommen nur ausnahmsweise vor. Anders bei den Liliaceen, von deren Eykern nach der Füllung des Embryosackes noch ein beträchtlicherer Theil des Gewebes vorhanden ist; dieses Perisperm wird vom heranwachsenden Endosperm völlig verdrängt. So bei Czackia Liliastrum bei vorwiegendem Dickenwachsthum des Endosperms, bei Veltheimia viridiflora bei gleich starkem Längen - und Dickenwaclıstlıum desselben. Ebenso bei Caricineen. Die sehr beträchtliche Vergrösserung des Endosperms wird vermitlelt durch stelig sich wiederholende Dehnung und Theilung, durch radiale und tangentale Wände, der peripherischen Zellen desselben. - Bei den Arö̈deen lıält das Endosperm, in derselben Weise nach allen Richtungen sich ausdehnend, in seiner Grössezunahme Schritt mit dem nach vollständiger oder theilweiser Ausfüllung des Embryosackes nocheintretenden, sehr beträchtlichen Wachsthum des jungen Saamens; da bei noch stärker in die Dicke, als in die Länge wachsend (VII, 16.17.4; 22-24; X, 10.11.12). Auf ebensolchen Vorgängen in Zellen der Aussenfläche des Endosperms berubt das bedeutende Wachsthum desselben bei den Gräsern. Hier aber ist das Wachsthum nicht allseitig von gleicher Intensität, sondern am Chalaza-Ende und zugleich an der, dem Anheftungspunkte des Eychens zugewendeten Längskante

*) Dass Endospermzellen Krystalle anorganischer Verbindungen führen, ist ein selten vorkommender Fall. Aus eigener Anschauung kenne ich keinen Zweiten. Schleiden erwähnt das Vorkommen nadelförmiger Krystalle in gewissen Zellen des Endo-sperms von Pothos rubricaulis (N. A. A. C. L. N. C. XIX, II, 87). 
am stärksten, von da allseitig abnehmend, am Mikropyle-Ende und an der jener gegenïberliegenden Kante Null. Das Endosperm wïchst vorzugsweise in von der Rückenfläche des Carpells und von der Mikropyle abgekehrter Richtung.

Das stärkste überhaupt bekannte derartige Wachsthum eines Endosperms besitzen Crinum capense und einige andere Amaryllideen mit "knollenförmigen“, gefässbündelförmigen Saamen. ${ }^{*}$ ) Die Vermehrung der peripherischen Endospermzellen beginnt zu einer Zeit, in welcher der Mittelpunkt des Embryosacks noch durch einen von wässeriger Flüssigkeit erfüllten Hohlraum eingenommen wird; die mehreren Lagen von Endospermzellen aber, welche den Embryosack auskleiden und den Embryo einhüllen, bereits ein fest geschlossenes Gewebe darstellen. Gleichzeitig mit dem Beginn der Vermehrung der peripherischen Zellen tritt in, zwischen den Zellen der mittleren Lagen sich bildenden Intercellularräumen Luft auf (XIV, 10). Diese Luftausscheidung in Intercellularräumen riickt sowohl gegen das mit Zellen sich füllende Centrum, als auch gegen die Peripherie des rasch an Umfang zunehmenden Endosperms vor, in dem Maasse, als die neu gebildeten, bei ihrer Entstehung ziemlich würfeligen Zellen radial sich strecken. Das Wachsthum des Endosperms, welches in circa 50 Tagen von 2 M.H. Durchmesser bis auf 18 M.M. Durchmesser zunimmt, sprengt nach einiger Zeit die Eyhülle, endlich auch die Kapselwand. Noch bevor das Integument röllig zerstört wird, tritt in den peripherischen Zellen des Endosperms Chlorophyll auf; in geringer Menge zwar, aber hinreichend der Aussenfläche

*) Vergl. R. Brown, Transact. Linn. Soc. XII, 149 ; Verm. Schr. II, 756 ; Prilliaux Ann. sc. nat. IV Sér. IX, 97, 102, der bereits die richtige Darstellung des Hergangs giebt. Ich selbst habe fr üher (Pringsheims Jahrb. I, 160) die Masse des reifen Saamens des Crinum capense (Amaryllis longifolia) für eine Umbildung des einzigen Integuments (vgl. S. 662 dieser Abhandlung) gehalten. Unzureichendes Material war die Ursache dieses Irrthums. In den Kapseln des C. capense fịden sich in der Regel neben wenigen zur Entwickelung kommenden Saamen eine Anzabl fehlschlagender. Diese enthalten im mit wässeriger Flüssigkeit erfüllten Embryosacke einen, oft ziemlich weit entwickelten Embryo (XIV, 10), aber keine Spur von Endosperm. Junge, vor Kurzem befruchtete Saamen normaler Ausbildung halten bei meiner damaligen Untersuchung mir nicht zu Gebote gestanden. Ich glaubte diese Hemmungsbildungen für stehengebliebene Entwickelungszustände nehmen zu dürfen, und erschloss aus ihnen irriger Weise, dass die Endospermbildung überhaupt gering oder Null sei. Bestärkt wurde ich darin durch die anderwärts beispiellose Beschaffenheit des reifen Endosperms: seine Luftlücken und seinen Chlorophyllgehalt. 
des Endosperms eine blassgruine Farbe zu geben. Bei weiterer Entwickelung des Saamens erstreckt sich die Chlorophyllbildung ziemlich tief ins Endosperm hinein, etwa bis in die zehnte Lage von Zellen, von der Peripherie nach Innen gezählt.

Bei allen endospermbildenden Monokotyledonen schliesst sich das Endosperm zu geschlossenem Gewebe um den jungen Embryo zusammen, bevor dessen Wachsthum und Ausbildung beendet ist. Sein ferneres Wachsthum hat unter Verdrängung eines Theiles des Endosperms zu erfolgen. Bei deı Gramineen verschwindet während der Entwickelung des Embryo das auf früheren Zustanden die Embryoanlage allseitig einschliessende Endosperm (XI, 5.9.11.15.18, XII, 3) um das Wurzelende desselben her und an der dem Anheftungspunkte des Eychens abgewendeten Seite vollständig. Bei den eyweisslosen Aroïdeen wird das Endosperm, bei Symplocarpus im jungen Saamen reichlich vorhanden (VIII, 7), gegen die Zeit der Reife hin vom Embryo vollstăndig aufgezehrt. *)

Bei der Mehrzahl der eyweisslosen Monokotyledonen, den Najadeen, Potamogetoneen, Alismaceen, Orchideen, Cannaceen u. s. w. unterbleibt dagegen die Bildung eines geschlossenen Gewebes von Endospermzellen ganz und gar. Bei Zostera, Ruppia, Zannichellia, Triglochin treten nur in seltenen Fällen freie Zellkerne im Wandbeleg des Embryosackes auf; die Bildung von Zellen um diese Kerne sah ich hier nie. Noch seltener ist das Erscheinen von neuen Zellkernen im befruchteten Embryosacke von Orchideen: doch habe ich hier in einem Falle eine wohl ausgebildete, kernhaltige freie Zelle gesehen.**) Im befruchteten Embryosack von Scheuchzeria palustris pflegt die Endospermzellenbildung reichlicher zu sein (XXV, 20), doch ohne dass die Zellen zu einem Gewebe zusammen traten. Bei zahlreichen Untersuchungen verschiedener Arten von Canna endlich ist mir nie auch nur einc Andeutung von Endospermzellenbildung vorgekommen.

\section{Entwickelung des Embryo aus dem Vorkeime.}

Die Zellenvermehrung, vermittelst deren aus der Endzelle des Vorkeims das Embryokügelchen entsteht, unterscheidet sich nur bei Orchi-

*) Reife Saamen habe ich nicht untersuchen können.

***) Entst. d. Embryo Taf. II f. 5. 
deen, bei Ruppia und Zostera, ausser diesen aber kaum bei einer einzigen monokotyledonen Pflanze in so scharfer Weise von der des Vorkeimes, wie bei der Mehrzahl der Dikotyledonen. Auch bei Monokotyledonen mit im Allgemeinen fädlichem Vorkeime tritt eine Zellvermehrung nach zweien, oder nach allen dreien Richtungen des Raumes venigstens in der einen Gliederzelle des Vorkeims ein, welche der als Mutterzelle des Embryokiigelchens sich erweisenden Endzelle des Vorkeims zunächst angränzt. So bei Najas major (I, 20), Triglochin maritimum (I, 26). Der Zellvermehrungsform des Vorderendes des massigen Vorkeims noch weit gleichartiger ist die des Embryokuggelchens der Gräser, an deren Embryonen die Gräinze zwischen dem Embryo im engeren Sinne und dem zum Träger gewordenen Vorkeime erst dann hervortritt, wenn dieser abzusterben, jener seine Zellen mit assimilirten Stoffen zu füllen beginnt.

Die Schnelligkeit der Ausbildung des Embryo steht in geradem Verhältniss zur Dauer der Zeit, nach deren Verlauf das befruchtete Keimbläschen in zwei Zellen sich theilt (S. 697). Das Wachsthum und die Ausbildung des Embryo ist eine sehr rasche bei den Gräsern, Najadeen, Potamogetoneen; eine sehr langsame bei der Mehrzalıl der Orchideen, Liliaceen und Amaryllideen. Der Embryo von Leucojum vernum z. B. ist Mitte Mai höchstens fünfzellig (Zellen des Trägers mit gerechnet), oft noch einzellig. Merendera caucasica, Colchicum autumnale, Crocus vernus brauchen vom Beginn der Bildung des Embryokügelchens bis zur Anlegung des Kotyledon mindestens zwei Monate; Secale cereale, Triticum vulgare und andere Cerealien kaum vierzehn Tage. Von der ersten Theilung der Endzelle des Vorkeims durch eine Längswand, bis zur Bildung der sämmtlichen (60 bis 80 ) Zellen des kugelförmigen Embryo von Orchis Morio verstreichen mindestens 4. Wochen; bei Zannichellia palustris liegt zwischen den beiden entsprechenden Entwickelungsstufen kaum mehr als ein Viertheil dieses Zeitraumes.

Die Unterbrechung der Weiterentwickelung der durch geschlechtliche Zeugung gebildeten neuen Pflanzen, welche mit dem Reifen des Saamens eintritt, erfolgt bei keiner monokotyledonen Pflanze auf so niedriger Entwickelungsstufe, wie bei einigen Dikotyledonen (bei Monotropa und Pyrola z. B.). Bei Monotropa ist der reife Embryo zweizellig, bei Pyrola secunda 8-16zellig; die Zellenzahl der Embryonen von Orchideen, der mindest ausgebildeten, ist eben erwähnt. 
Es ist eine, auch unter den Dikotyledonen weit verbreitete Erscheinung, dass während des Hervorsprossens der ersten Bläter, der beiden Kotyledonen aus der Achse des Embryo, als welche das Embryokügelchen sich darstellt, die Weiterentwickelung des Achsenendes oberhalb der Kotyledonen völlig stillsteht. Die Terminalknospe ist punktförmig, eine kaum oder gar nicht hervortretende Zellengruppe, welche die tiefste Stelle zwischen den Kotyledonen einnimmt. So bei Labiaten, Scrophularineen, Asclepiadeen, Syngenesisten u. v. A. Aehnlich bei der Mehrzahl der Monokolyledonen. Da bei diesen, namentlich bei den Liliaceen und nächstverwandten, der Kolyledon gleich von Anfang an sehr dick und massig angelegt wird, und rasch in die Dicke wächst, während das Längenwachsthum der embryonalen Achse sich verlangsamt oder stillsteht, so nimmt jener sofort den mathematischen Scheilelpunkt des Embryo ein, das morphologische Ende der Achse weit zur Seite schiebend. *) Nur das Dickenwachsthum derselben begleitet die Entwickelung des Kotyledon. Dies die Ursache, durch welche die Terminalknospe des Embryo meist zu einer nur schwachen Hervorragung im Grunde der basilaren Spalte des Kotyledon umgebildet wird. In einigen Fällen plattet sie sich vollsländig ab, die convexe Wölbung gänzlich einbüssend. **) So ist der Vorgang indess nicht ausnahmslos. Die Dicke des Kotyledon ist bisweilen im Vergleich zur Masse des Embryo wenig beträchtlich; die Entwickelung des Endes dieses während des Auftreten jenes nicht gehemmt. Der Kotyledon, in allen beobachteten Fällen als stängelumfassendes Blatl, als Ringwulst um die Stängelspitze auftretend, wird bei Pistia Stratioles als dünner, häutiger Saum sichtbar, in dessen Mitte das Ende des Embryo als sehr stumpfer Kegel emporragt (VII, 25). Aehnlich bei Pothos Iongifolia. Auch bei der Entwickelung des ersten Blattes des Embryo der Orchideen, die erst nach der Trennung der Saamen von der Mutterpflanze, während der Keimung erfolgt, walten ähnliche Verhältnisse ob $\left.{ }^{* * * *}\right)$ (VI, 15. 16); nicht minder bei den Formen, deren lyypokotyle Achse eine geraume Zeit vor dem Hervorsprossen des ersten Blattes eintretende, einseitige Wucherung zeigt: vielen Najadeen und den Gräsern.

*) Vergl. Jussieu, A. de, in Ann. sc. nat. II. Ser. II, 349 ; Schleiden Grundz. II. Aufl. 374 .

**) So z. B. bei Fritillaria imperialis am reifenden Embryo (Entst. d. Embryo, 21).

****) Vergl. Irmisch, Beitr. z. Biol. d. Orchid. Lpzg. 1883, 6. 23. 26. 61 . 
Diese einseitige Förderung der Entwickelung der embryonalen Achse, stets an ter, der Anheftungsstelle des Eychens zugewendeten Seite des Embryo eintretend, stellt sich zur Lage der morphologischen Spitze des Embryo in das nämliche Verlältniss, wie der Kotyledon der Liliaceen. Der einseitige Auswuchs der Achse des Embryo, rasch in die Dicke sich entrvickelnd, rückı dessen Endlinospe zur Seite. Das Bild, welches gelungene Durchschnitte der Embryonen von Gräsern geben, lässt lieinen Zweifel daruiber, dass das Hervorsprossen dieser Wucherung, des Scutellum, auf der Vermehrung einer Gruppe von Zellen nahe unterhalb des Embryoscheitels beruht (XI, 9. 16).*) Während der Anlegung dieses Auswuchses hält die Entwickelung der Endlinospe des Embryo inne. Erst nachdem die Wucherung der embryonalen Achse Plattenoder Schildform erreicht hạt, wö̈lbt die Endknospe sich aufs Neue zur Halbkugel oder zum Kegel, und nun erscheint an ilı das erste Blatt als hiiutige, rings umfassende Scheide, mit der Ruickenfliche der Wucherung der liypokotylen Achse zugekehrt (XI, 12, $a, b)$.

*) Schon $\Lambda$. de Jussieu hat gezeigt (a. a. 0. 334, 359), dass die Formen der Embryonen der Najadeen, von Potamogeton an durch Ruppia, Posidonia, Zostera zu don Triticeen, endlich zu den Oryzeen, eine ununterbrochene Reihe allmäliger Steigerungen eines und desselben Verhältnisses darstellen. Die von mir früher gegen diese Anschauung aus der Entwickelungsgeschichte des Embryo von Zostera geschöpften Zweifel (Bot. Zeit. 1852, 141 ff.) erachte ich nach Erlangung genaucrer Kenntniss des Entwickclungsganges der Embryonen von Gräsern nicht mehr für begründet. - Wenn A. de Jussieu den Embryo der Cyperaceen dem der Gräser gleich stellt, so kann ich ihm nicht beipflichten. Das zweitc Blatt dieser Embryonen ist dem unzweifelhaften Kotyledon derselben gegenständig, niclıt superponirt (XII, 20-23). Ich habe auch jetzt noch das Scutellum der Grïser and die analogen Bildungen von Zostera u. s. w. als Auswuchs der $\Lambda$ chse, nicht als Blatt aufgefasst. Der aus der Stellung des nächsten Blattes hergenommene Grund dafür hat durch die Auffindung der 1/1 Stellung der ersten Blätter an den Seiteusprossen von Colchicun, Calla palustris, Tofieldia u. a. Monokotyledonen; Irnisch, Zwiebelgew. Bal. 1850, 122 (A. Braun Verh. Bot. Ver. Brandenb. I. 1859,90) zwar an Gewicht verloren. Aber die Analogie nit Ruppia, die durch diese Pllanze vermittelte Achnlichkeit mit Potamogeton, und die von der der Blälter so weit abweichende Form und Beschaffenheit des Scutellum der Triticeen sind Thatsachen, welche auch der Bildung des Scutellum von Oryza gegenüber (XII, 2 4) die Jussieu'sche Deulung noch immer als die wahrscheinlichere erscheinen lassen. 
Monstrïse Enhwieliohng ron Forthfianzungszellen imerhalb des Eychens.

Wesentliche Abweichungen von der normalen Fortbildung des Pollenschlauches am und im Embryosacke, nnd der Keimblaschen sind bis jetzl nur bei einer einzigen Pflanze vorgekommen: bei Crocus vermus, und zwar an kïnstlich getriebenen, bereits Ende Februars im Zimmer blïlıenden Exemplaren. Unter vielen Eychen normaler Entwickelung fanden sich, in den nämlichen Fruchtknoten mit ihnen, die Mlissbildungen in geringer Anzahl. Sie waren zweierlei Art: theils Wucherungen der Pollenschlauchenden, theils solche der Keimblaschen. - Die Pollenschlauchwucherungen schliessen sich in den einfacheren Fällen ziemilich nahe an die bei Canna öfters vorkommenden an. In einem Falle war der Pollenschlauch ausserhalb des Embryosackes verblieben, hatte sich aber nach dem Auftreffen auf den Sack noch beträchtlich in die Liinge entwickelt, sich rückivä̀ts und seitwärts gekrümmt und mehrfach sich verschlungen. Das untere, allein noch vorhandene Keimblasschen war hier in regelmässiger Weise quer getheilt $(\mathrm{XXIV}, 4)$. In einem anderen Eycluen, in dessen Endostom zwei Pollenschlauche eingetreten waren, latte der eine den Embryosack durchbrochen; sein Ende hatte sich melırfach gekrümmt. An diesem Ende hafteten die Keimbläschen, inhaltsarm, versclirumpft, weiterer Entwickelung offenbar unfähig (XXV, $\vec{b}, a$ und $b$ ). In einem dritten Eychen war der Dolienschlauch gleichfalls ins Innere des Embryosacks gedrungen und in dessen Scheitclwölbung zu einer dickhäutigen, kngelförmigen Auftreibung, ungefahr vom Volumen eines Keimbläschens angeschwollen, von welcher aus ein kurzer, blinddarmähnlicher Fortsatz frei in den Innenraum des Sackes ragte. Die Keimbläschen waren völlig verschwunden. Der extremste Fall ist als cine Steigerung dos eben erwähnten zu betrachten. Der Pollenschlauch war, nach einigen Krümmungen an der Aussenseite des Embryosacks, in dessen Scheitelgegend eingedrungen; hier war er zu einer birnfömigen Blase, ebenfalls vom Umfange eines Keimbläschens, erweitert, und von dieser Erweiterung entsprangen zwei lange, cylindrische Fortsátze; der eine, liüzere, mit spitzem Ende; die Endigung des anderen mehrfach gebogenen war durch einen der zwei, das Ey öfnenden parallelen Läingsschnitte getroffen und entfernt worden (XXIV, 8). 
712 Wilielm Hofmeister, Nece Beiträge z. Kínntwiss d. Embryobild. etc.

Die beobachteten monströsen Entwickelungen der Keimbläschen bestehen in der Erweiterung eines derselben zu einem Sacke von elwa einem Zehntel des Volumens des Embryosacks. In dem einen Falle hatte dieser Sack eine gestreckte Form, und war mehrfach gebogen(XXIV, 7); im anderen war er verkehrt birnförmig, und enthielt im freien unteren Ende drei lileine, rosetlenartig geordnele Zellen (XXIV, 6). 


\section{Erklär'ung der Abbildungen.}

\section{Tafel I.}

\section{Figur 1-25. Najas major. (Milte August 18ว4.)}

Fig. 1. Längsdurchschnitt cincr männlichen Blüthe, 20fach vergr. a Anthere, $\alpha$ deren Fächer; $b b$ Bracteen, ff Blätter, $s s$ Laubsprossen, $v$ Scheidenblatt.

Fig. 2. Zwei Pollcnmutterzellen aus einer jungen Anthere, 150 fach vergrössert.

Fig. 3. Pollenmutterzelle weiterer Entwickelung nach der Auflösung des primären Kernes, $3^{\text {a }}$ unmittelhar nachdem sie in das Wasser des Objectträgers ge-

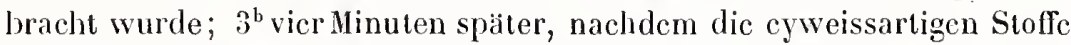
der Flüssigkcit, welche das früher vom primären Kernc eingenonmenc Centrum der Zclle erfüllt, zu cinigen Klumpen geronnen sind. Gleiche Vgr.

Fig. 4. Pollenmutterzelle weiterer Entwickelung, nach Bildung eines Kcrnes für jede der vier Pollenzellen.

Fig. 5, 6. Zwei Pollenmutterzellen, einem und demselben Anthercnfach entnommen. F. 5 kurz vor der Bildung der, zwischen je zweien der secundären Zellenkerne verlaufenden Scheidcwände, nach Auftreten der, jenen Scheidewänden cntsprcchend verlaufenden Körnerplatten. Fig. 6 glcich nach Bildung der Schcidewände. Gleiche Vgr.

Fig. 7. Tetrade von Pollenzellen, bcim Bcginne der Vereinzclung derselben. Gleiche Vgr.

Fig. $7^{\mathrm{b}}$. Eine dicser Pollenzcllen vereinzelt, nach Bchandlung mil Jod und Schwefelsäure 300 fach vergrössert. Die schwach aufgequollene Zellhaut ist in ihrer ganzen Dicke grünlich blau gefärbt. Die Zelle cnthält bereits zwei Kerne.

Fig. 8. Drei junge Pollenzellen, kurz nach der natürlichen Vereinzelung einer Tetrade, 200fach vergr. In einer der Zcllen nur ein, in Auflösung begriffener, in jeder der anderen zwei Zellenkerne.

Fig. 9. Junge Pollenzelle weitercr Entwickelung. Es ist nur ein Zellenkern in ihrem Inneren wahrzunehmen. Eine grosse Zahl zur Zeit noch kugeliger Amylumkerne ist in schleimigem Belege der Innenwand der Zelle aufgetreten. Gleiche Vgr. 
rig. 10. Jïinzelne Pollenzelle, kurze Zeit vor der Reife. Die Amylumkörner, stablörnig geworden, sind in einen Wandbeleg und eine, den Acquator der Zelle sehneidende Querplatte geordnct. Gleide Vgr.

Fig. 11. Schlauchtrcilsende Pollenzelle, aus den Fache einer aufgesprungenen Anthere genommen. Der Kern ist verschwunden; die Amylumkörner sind grösstentheils in den Pollenschlauch gewandert.

Fig. 12. Eines der Amylumkörner, 1500 fach vergr.

Fig. 13. Längsdurchschnitt des Kernes eines unbefruchteten Eychens, 1:j0fach vergr. Keimbläschen und deren Gegenfüssler füllen den keuligen Eıbryosack fast vollstiandig aus.

Fig. 1'. Längsdurchschnitt einer weiblichen Blüthe, sehr hald naeh Ankunft des Pollensehlauchendes am Scheitel des Embryosacks. Vgr. 15. Das von zwoi Integumenten überzogene Eychen ist zur Zeit halbgewendet, der Kern aber gerade. Das leitende Zellgewehe lıängt als ein Büsehel aus grossen heulenförmigen Zellen in die Fruehtknotenböhle.

Fig. 14". Das Eychen aus dem nämliehen Präparate, 80 fach vergr.

Fig. 14 Der Scheitel des Eykerns und Embryosacks aus dem nämliehen Prijparate, 950 fach vergr., das tiefe Eindringen (Einstülpen?) des angeschwollenen, von herahgewanderten Amylumkörnern vollgestopften Pollenschlauchendes in den Embryosack deutlicher zu zeigen.

Fig. 15, 19. Lmbryosäeke und Kernwarzen aus Längssehnitten vor Kurzem befruchteter Eychen, in lö0lacher Yergr. In beiden Fällen ist das Pollenschlauehende nur wenig tief in den Embryosaek gedrungen; das unlefruchtet gebliebene obere Keimbläschen noch vorhanden. In Fig. 16 Andeutung von Endospermbildung.

Fig. 17. Befruchtetes Eychen im Längsdurchschnitt. Zur halben Wendung des Eyos ist eine halbe, $90^{\circ}$ hetragende, Krümmung seines Kerns gekonmen. a a sind Stïcke der dünnen Fruchtknotenwand. Vgr. 20.

Pig. 17'. Der Embryosackseheitel nebst dem Pollensehlaueh. Aus dem nämlichen Präparate, 150 fach vergr.

Fig. 18. Aelnnliehes Präparat, die Zeichnung umfasst den ganzen Embryosack. Torkeim bereits eine dreigliedrige Zellreihe; fehlschlagendes Keimbläs-chen noch vorhanden. Zwei (transitorisebe) Endospermzellen haben sich gebildet und erscheinen links der Wand des Embryosackes angeschniegt.

Fig. 19. Eykern eines befruchteten Eycs ähnlieher Entwickelung im Längsdurchschnilt. Das in den Embryosack eingedrungene, angeschwollene Pollensehlauchende erseheint etwas verschrumpft. Vgr. 120.

Fig. :0. Theil eines Liingsdurchschnittcs aus einem weiter vorgeriickten jungen Samen, in 200lacher Vgr. Unterhalb der zwei Zellschiehten der Kern-warze haltet die geschwollene Trägerzelle des jungen Embryo an der Innenwand des Embryosackes, neben ihı das fehlgeschlagene Keimbläschen. Einige freie Zellonkerne, Andeutungen transitoriselier Endospermbilang, sind in der Nähe dem Wandbeleg des Lmbryosaekes eingebettet.

Fig. 21. Längsdurehschnitt eines jungen Embryo, 100 fach vergr. 
Fig. 22. Junger Embryo, weiter vorgerückt, Vgr. 50 .

Fig. 23. Embryo an welchem die Bildung des Kotyledon beginnt, in 30facher Vergr.

Fig. 24. Embryo dessen Kotyledon die Endknospe zu umscheiden beginnt. Gleiche Vgr.

Fig. 25. Der Reife nahes Embryo in Längsdurchschnitte. Ygr. 20.

Fig. 25̆. Plunnula nebst deren Scheide aus demselben Präparat, 100 fach verger.

\section{Wigua 28, 29. Strauiotes aloïdes *).}

Fig. 28. Reifer Enbryo im Längsturchschnit, Vgr. I

Fig. 29. Ilunnula desselben, nahe ihrer Basis quer durchschnitten. Vgr. 30.

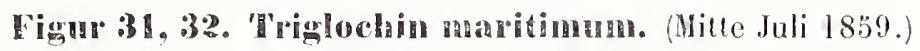

Fig. 31. Spitze des Eykerns und Embryosackes eines vor nicht langer Zeit befruchteten Eychens. In der Kernwarze ist der Lauf des Pollenschlauchs noch kenntlich. Am unteren Ende des langen Vorkeims, noben dessen Trägerzelle das fehlgeschlagene kieimbläschen noch intact an der Innenwand des Embryosackes haftet, beginnt die Bildung des Embryokügelchens. Von Endospermbildung ist keine Spur vorhanden. Vgr. 150.

Fig. 32. Endostom, Kernwarze und oberer Theil des Embryosackes aus rinem halbreifen Samen im Längsschnith. Der Pollenschlauch ist noch immer wohl erhalten; sein Lauf innerhalb der Kernwarze alier durch den Schnitt nicht blosgelegt. Am unteren Ende des Embryoträgers ist nur der Anfang des Wurzelendes des bereits sehr grossen Embryo gezeichnet. Von Endosperınbildung auch hier keine Andeutung. Gleiche Vor.

\section{Tafel II.}

\section{Fign̈r - Ruppia maritima.}

Fig. 1. Fruchtknoten im Längsschnitt, jung. Vgr. 50 .

Fig. 1'. Das Eychen daraus. Vgr. 200.

Fig. 2. Eychen, kurz vor dem Befruchtetwerden, iı! Läingsdurchschnitt. Vgr. 80.

Fig. $2^{b}$. Der Embryosack daraus. Vgr. 230.

Fig. 3. Befruclitetes Eychen im Laingsdurchschnitt. Vgr. 80.

Fig. 3. Die Scheitelgegend desselben, mit Weglassung des äusseren Integuments in 300 facher Vgr. Das ungleichmässige Wachsthum des Eys hat bereits die Embryoanlage von der Hikropyle eine Strecke weit entfernt. Der Pollenschlauch kriecht diese Strecke entlang zwischen Embryosackhaut und Gewebe des Eykerns hin.

Fig. 4. Ein Fruchtknoten weiter vorgerückter Entwickelung im Längsdurchschnitt. Die Wegriickung der Embryoanlage vom Exostom ist sehr gesteigert. Auch das Endostom fällt mi diesem nicht ınehr zusammen. Vgr. 30 .

\footnotetext{
*) Die Mittheihng reifer Samen verdanke ich Prof. Mettenius.
} 
Fig. 5. Die Embryo-Anlage daraus. Vgr. 300.

Fig. 6. Junge Frucht im Längsdurchschnitt. Vgr. 30.

Fig. $\mathbf{6}^{\text {b }}$. Die Embryoanlage daraus. Vgr. 200.

Fig. 7. llalbreifer Embryo, längsdurchschnitien. Vgr. 30.

\section{Figur 8-16. Zannichellia palustris.}

Fig. 8. Fruchtknoten zur Blïthezeit in Längslurchschnitt. Aul der Narbe einige schlauchtreibende Pollenkörner. Vgr. 100.

Fig. 9. Der Embryosack aus einem längsdurch schnittenen Eychen ähnlicher Entwickelung. Vgr. 250.

Fig. 10. Scheitelwölbung des Embryosacks, Kernwarze, vom Pollenschlanch durchzogen, eines befruchteten Eychens. Ueber der stark geschwollenen Trägerzelle des Vorkeims das unbefruchtet gebliebene zweite Keimbläschen. Vgr. 200.

Fig. 11. Scheitelwölbung eines frei gelegten Embryosackes mit einem fehlgeschlagenen, und einem zum Träger und Embryokügelchen entwickelten Keimhläschen. Gleiche Vgr.

Fig. 12. Oberer Theil eincs weiter entwickelten, frei priparirten Embryosackes; an der Wand desselben einige freic Zellkerne. Gleiche Vgr.

Fig. 13. Junger Embryo, an welchem der Koṭledon vor Kurzem angelegt wurde. Vgr. 150.

Fig. 14. Junger Embryo weiterer Entwickelung, längsdurchschnitten. Vgr. 30.

Fig. 15. Späterer Zustand eines solchen. Vgr. 13.

Fig. 16. Keimptlänzchen. Vgr. 5.

\section{Fignr 17-19. Potamogreton crispus.}

Fig. 17 Unbefruchtetcs Germen im Längsdurchschnitt. Vgr. 30.

Fig. 18. Der Embryosack aus dem längsdurchschnittenen Eychen eines solchen. Vgr. 250 .

Fig. 19. Mikropyle, oberes Ende des Eykcrns und Embryosackes unmittelbar nach Ankunft des Pollenschlauches im Längsdurchschnitt. Gleiche Vgr.

Fig. 20. Alisma Plantago. Unbefruchtetes Eychen im Längsdurchschnitt. Vgr. 150 .

Fig. 21. Eykern und in der Kernwarze haftender Pollenschlauch, aus einem längsdurchschnittenen Eychen derselben Pflanze. Gleiche Vgr.

\section{Fignu 22-28. Lemun minor.}

Fig. 22. Unbefruchtetes Eychen im Längsdurchschnitt. Vgr. I:30.

Fig. 23. Reifer Samen, längsdurchschnitten. Unter dem angeschwollenen Endostom, dessen Zellen einzcln gezeichnet sind, die sclıräg rückwärts gerichtcte Plunnula des Embryo. Die zellig schattirte Masse, deren Achse dieser einnimmt, ist das Endosperm. Vgr. 50 .

Fig. ":3b. Die Plunnula (das abgeplattetc zweite Stängelglied) desselben Prijparats in 300 facher Vgr. Man bemerkt am Grunde derselbon die Anlage des dritten Internodium, in dic Substanz des zweiten in ähnlicher Wreise eingesenht, wie die des ersten es in den Kotyledon ist. 
Fig. 24. Beginn der Keimung. Das Hinterende des Embryo ist aus dem Samen hervorgetreten; das zweite Internodium der Pflanze, die Plunnula, ist beträchtlich gewachsen; in seinem Grunde ist die Anlage des 3. Internodium bemerklich. Das Endostom (die Embryotega) ist abgestossen. Vgr. 50 .

Fig. 25. Etwas weiter vorgerückter Zustand, ebenfalls im Längsdurchschnitt. Seitlich an der Keimpllanze haftet die Embryotega. Unter derselben hemerkt man im lnnern des Gewebcs die Anlage der ersten Wurzel. Gleiche Vgr.

Fig. 25 $5^{b}$. Diese Wurzel in 400 facher Vgr. Man sieht, dass ihre Wurzelhaube, von dem deckenden Gewebe völlig gesondert, von der anderer Nebenwurzeln nicht abweicht.

Fig. 26. Keimender Saame ähnlicher Entwickelung wie der vorige; die ihn zerlegenden Schnitte sind rechtwinklig zu denen geführt, welche das Präparat Fig. 28 herstellten. Das zweite Stängelglied ist bereits platt; die Anlage des dritten an der einen Seite seines Grundes hat an Grösse gegen die Fig. 24 zugenommen. Gleiche Vgr.

Fig. 27. Weiter entwickelter Zustand, nach Hervorbrechen der ersten Nebenwurzel, völliger Ausbreitung des zweiten Internodium und Heranwachsen des dritten; im Längsdurchschnitt senkrecht auf die Flächen der Stöngelglieder. Gleiche Vgr.

Fig. 28. Eine Keimpllanze gleicher Entwickelung, bei 20facher Vgr. von vorn gesehen.

Fig. 28 $8^{\text {b }}$. Bas zweite Internodium derselben mit anhaftender Wurzel, isolirt.

Fig. 28c . Der Kotyledon und das erste Stängelglied ebendaraus.

Fig. 28d. Das dritte Stängelglied ehendaraus, an seinem Grunde jederseits die Anlage eines neuen.

\section{Tafel III.}

\section{Figur 1-24. Orehis Morio.}

Fig. 1. Querdurchschnitt der Säule dicht üler der Narbe, Mitte Februars vor der Blithe, $a$ Grund des Rostellum, $l$ Lippe, e e Basis der seitlichen Anhängsel der Säule (der Staninodien). Vgr. 30.

Fig. 2. Querschnitt aus der nämlichen Säule, höher, dicht unter den Enden der Antherenfächer geführt und von unten gesehen, so dass die Enden der Antherenfacher, die künftigen Caudiculae $(c c)$ durch eine dünne Schicht des Gewebes des Rostellum (a) durchschimmern. Gleiche Vgr.

Fig. 3. Querdurchschnitt dersellıen Säule, durch die Enden der Antherenfächer gelegt. Vgr. 90 .

Fig. 4. Qucrdurchschnitt der ganzen Knospe, aus welcher jene Säulenquerschnitte entnommen waren, nahe dem oberen Ende des tief eingefalteten Mittellappens des Rostellum $(a)$ gelegt. Vgr. 2ä.

Fig. 5. Querschnitt aus derselben Knospc, durch die Nitte der Antherenfächer gehend. Gleiche Vgr. 
Fig. 6. Säule aus einer Ende Februar geöfneten Knospe, von rorn gesehen. Die Lage der hinteren Placenta im Germen ist dureh punktite Linien $(p)$ angedeutet: $l$ Stumpf der weggesehnittenen Lippe; $b b^{l}$ die beiden hinteren Absehnitte der Narbe; a der vordere derselben (das Rostellum): $d$ dessen tief eingefalteter vorderer Zipfel. Ygr. 20

Fig. 7. Durch eincn axilen Längsschnitt geölfnete solche Knospe, deren Perigonialblätter weggeschnitten sind, $m$ Comnectiv der Anthere; Bedeutung der übrigen Buchstaben wie zuvor. I'gr. 27.

Fig. 8. Längsdurehschnilt eines Faehes aus einer Anthere ähnlicher Entwickelung, ma Massulae, di das in einem Winkel von etwa $30^{\circ}$ aul seiner Fliaehe durchschnittene Dissepiment. Vgr. 30.

Fig. $8^{b}$. Ein Stück dieses Präparats aus ler Nitte des Antherenfachs in 200facher Vgr. Ber Inhalt der Zellen (Pollenmutterzellen) der cinen Massula ist vollständig gezeichnet, in der anderen nur die Lage der Zcllkerne angedeutet. Rechts von den beiden Massulis die langsdurehsehnittene, aus diei Zellenlagen bestehende Wand des Antherenfachs.

Fig. $8^{c}$. Die Gegend um den Grund des rechten Antherenfachs aus dem nämliehen Präparate, 200 fach verğössert. Die unterhalb der rudimentäen untersten Nassulae gelegene Gruppe von Parenchymzellen, aus denen ein Strang späler zur Caudicula sich umbildet, ist jetzt ihren Nachbarzellen noch gleichartig (wie ateh aus Fig. 3 zu ersehen).

Fig. 9. Die Ecken zweier Massulae aus einer, an 20. März querdurchschniltenen Anthere, naeh Behandlung mil Jod und Schwefelsiure 200fach verg̣issert. Die aufyequollenen Gränzen jeder Massula (die verdichten Meubranen der Uimutterzellen des Poltens) erscheinen jetzl noch durch und durch in blassbłauer Firbung. Noeh ist keine Schicht dieser llitute zu Cutienla umgewandelt. Die Pollenmutterzellen sind noch nicht in Tetraden getheilt.

Fig. 10. Stück der Aussengränze einer Massula, am 4. April dargestellt, nach Behandlung mit Jod und Sehwefelsäure 500fach vergrössert. Die Gränzen der zu Tetraden von Pollenzellen umgewandelten Mutterzellen sind innerhall, der zu blassblauer Gallerte aufgequollenen Membranen der Tetraden deutlich kenntlich. Eine kappenfömige Schicht der nach aussen gekehrten Wand jeder der Tetraden der Oberfliche der Massula verhält sich jetzt als Cutieula. Sie ist nicht aufgequollen und blassbraun gefailit.

Fig. 11. Tetrade der Oberflielse, Fig. 12. Tetrade des Inneren einer Massula aus einem ähnlichen Präparate, durch gelinden Druck aufs Deckglas vereinzelt, in gleicher Vgr.

Fig. 13. Kante eines frischen Durchsehnitts einer Massula, am 10. April. Die Cuticula ist um vieles stärker entwickelt. Vgr. 300 .

Fig. 14. Hembranen einer durch Quetschung vereinzelten und ihres Inhalts entleerten Tetrade gleicher Entwickelung. Tgr. 500 .

Fig. 15. Die an einander haftenden Cutieula-Kappen aus einer durchsehnittenen Massula gleicher Entwickelung, nach Wegsehaffung der Zellstoffschichten (ler Häute durch vorsichtiges Wasehen in Schwefelsäure, bei gleicher Vgr, von Innen gesehen. 
Fig. 16. Durclıscbnitt einer Anthere gleicher Entwickelung, längs durch das eine Fach gelegt, die jetzt rom umgcbenden Parenehym gesonderte Caudieula zu zeigen: a Seitentheil des Rostellum, darin durch einen Schatten die Gewebstelle angedeutet, welche zum Retinaculum sich umbildel. Vgr.10.

Fig. $16^{\text {b }}$. Der Theil dieses Präparats, welcher die längsdurchschnittene Caudicula enthält, in 150 facher Vgr.

Fig. 17. Eine der, in Wasser leieht sich vereinzelnden, diekhäuligen Zellen aus einer Caudicula gleicher Entwickelung, 500fach vergrössert. In Innern zahlreiche Tropfen das Lieht stark brechender, zäher, halbflüssiger Substanz.

Fig. 18. Einige Zellen aus einem diünnen Schnitte des zum Retinaculum sich umbildenden Gewebes aus einer Knospe gleicher Entwickelung. In jeder Zelle ein grösserer Klumpen und zahlreiche kleine Troplen jenel viscinartigen Substanz.

Fig. 19. Oberes Stück des zarten Längsdurchschnitts aus einer Placenta, am 26. März (1859) aus einer Knospe dargestellt. Vgr. 300.

Fig. 20. Das obere Ende einer Placenta ähnlicher Entwiekelung, bei gleicher Vgr. von vorn gesehen.

Fig. 21. Ganze Placenta, am 3. April (1853) von vorn gesehen. Vgr. 75.

Fig. 22. Stück des Querschnitts der, in der Entwickelung am Weitesten vorgerickten Hitte einer Placenta, am 6. April 1859, mit der Anlage zweier Eychen. In der centralen Zelle beider zwei, noch durch keine Ouerwand geschiedene Zellkerne: Anfang der Bildung des axilen Zellstranges des Eychens. Vgr. 200 .

Fig. 23. Stuck des Querschnitts des oberen Endes einer jungen Placenta, zur nämlichen Zeit. Daran die durch Grösse ausgezeichnete Anfangszelle eines Eychens. Vgr. 1 गे0.

Fig. 24. Längsdurchschnittsansicht eines noch in der Entwickelung begriffenen jungen Eychens, Mitte April (1853). Vgr. 100.

\section{Tafel IV.}

\section{Figur 1-19. Orchis Morio.}

Fig. 1. Junges Eychen, Seitenansicht. Durch die Zellen der peripherischen Schicht schimmern die zwei Zellen des axilen Stranges hindurch. Vgr. 500 , wie auch die der folgenden Figuren.

Fig. 2. Seheitelansicht eines noch jüngeren Eychens. â die vierseitige Scheitelzelle.

Fig. 3. Scheitelansicht eines Eychens von der Entwickelung des Fig. I dargestellten etwas schräg genommen.

Fig. 4. Scheitelansicht eines weiter entwickelten Eychens, an welchem eine der der Scheitelzelle a benachbarten Zellen bereits durch eine Liangswand getheilt ist.

Fig. 5-10. Schematische Zeichnungen zur Erlizuterung der Zellenfolge hei Anlegung der Eychen. Die Gränzen der Zellen der Aussenfläche sind durch ganze, die Zellengränzen im Inneren durch punktirte Linien angedeutet. 
Fig. 5. Halbsehematisehe Ansieht von oben der ersten Anlage eines Eyehens ( $w$ ie sie auf Fig. 20 u. 21 der Taf. $Y$ sichtbar sind). Die ältere, nach links gewendete der beiden Zellen der peripherisehen Sehicht bereits zweimal durch Längswände getheilt; die Seheitelzelle also von vier Zellen umgeben. Von der mittelsten der drei so entstandenen Zellen ist, durch das Auftreten einer, der Tangente des Seheitelpunkts der Aussenfläehe parallelen Wand die erste Zelle des axilen Stranges abgesehieden.

Fig. 6. Die Seheitelansicht eines weiter vorgeriekten Zustandes; insofern von derNatur abweichend schematisirt, als mehrere einander folgende Theilungen der Scheitelzelle durch wechselnd nach zwei Richtungen geneigte Wände gezeielınet sind, denen nicht sofort (wie in der Wirkliehkeit stets) Theilungen durch auf den Aussenflächen senkreehte Wände folgten.

Fig. 7. Seheitelansicht eines Zustandes, der als Uebergang von der ersten Jugend zum mittleren Alterszustand zu betrachten ist. In der Seheitelzelle, die hisher nur dureh wechsehnd naeh zwei entgegengesetzten Riehtungen geneigte Wände sich theilte, ist eine geneigte Seheidewand aufgetreten, die ron der letztentstandenen um $90^{\circ}$ divergirt.

Fig. 8. Seheitelansieht zu der Zeit, da die Vermehrung der Scheitelzelle dem Erlöschen nahe ist, die fernere Zell vermehrung des Eyehens nur eine interealare, - wiederholte Quertheilung der Zellen des künftigen Funieulus - sein wird. Seheitelzelle vier-, oberste axile Zelle achtseitig.

Fig. 9. Seitenansicht eines sehr jungen Eyehens, senkreeht auf die in der Scheitelzelle entstehenden Theilungswände.

Fig. 10. Ebensolche Ansicht eines weiter vorgerủekten Eyehens.

Fig. 11. Lingsdurchschnittsansieht eines Eykerns, in dessen Embryosacke die Zellkerne der Keimbläschen sich eben gebildet haben.

Fig. 11 ${ }^{\text {b }}$. Lingsdurchsehnittsansieht (durch Einstellung des Mikroskops auf die Medianebene des durehsiehtigen Eychens gewonnen, ebenso die folgenden) eines Eychens, in dessen Embryosaek die Keimbläschen, eben angelegt, als undeutlieh begränzte, die früher schon vorhanden gewesenen Zellkerne umlaüllende Massen körnigen Sehleimes er'seheinen. Der primäre Zellkern des Embryosaekes, sehr deutlieh wahrzunehmen, liegt dieht über den bereits seharf ungränzten Gegenfüsslerzellen der Keimbläsehen. Vgr. 400; ebenso der folgenden Figuren.

Fig. 12. Lingsdurchschnittsansieht eines zur Befruehtung bereiten Ejehens mit langgedehnten Keimbläsehen.

Fig. 13, 14. Inneres Integument und Embryosack ähnlicher Ex̣ehen; der Embryosack und sein lnhalt sind perspectiviseh dargestellt, um die Umgränzung der Anheftungsstellen der Keimbliischen an die Innenfläehe des Embryosaeks zu zeigen.

Fig. 15. Längsdurchschniltsansieht (mit perspectirischer Darstellung des Embryosackes und seiner Umgebung) eines Eychens, in welehes ganz kurz zuror ein Pollenschlauch eintrat. Die Spitze dessetben ist bereits zwisehen Eubryosackhaut und lnnenfläche des innern Integumentes breit gedrückt. Die Keimbläsehen noeh unverändert. 
Fig. 16. Aehnlicher Zustand; das abgeplattete Ende des Pollenschlauches ist geborsten; ein Theil seines körnigen Inhaltes auf der Aussenfläche des Enbryosackes ausgestreut.

Fig. 17. Weiter (um etwa 4.8 Stunden) vorgeriickter Zustand. Das eine (obere) Keimbläschen ist verschwunden. Das andere, herangewachsen, fuullt den Embryosack fast vollständig aus.

Fig. 18, 19. Inneres Integument und Embryosack befruchteter Eychen mit bereits zweizelligem, den Embryosack fast ausfüllendem Vorkcine.

\section{Tafel V.}

Figur 1-11. Neottia ovata. (Anfang Mai 1859.)

Fig. 1. Sehr junge Knospe, in deren Anthere die Pollennassen vom umgebenden Gewebe kaum merklich differenzirt sind, im Längsdurchschnitt bei 30facher Vergr.

Fig. 2. Rostellum aus einer wenig weiter vorgerickten Knospe, im zarten Längsdurchschnitt bei 120 facher Vergr. Die colossalen langgestreckten Zellen der Oberseite des Rostellum enthalten, ausser einem in der Zeichnung angedeuteten Zellkerne, schr zahlrciche, die Zclle dicht erfüllende, scharf begränzte kugelige Tropfen zäher Substanz, deren eine Anzahl gezeichnet ist.

Fig. 3. Rostellum aus eincr Knospe, deren Pollentetraden eben ausgebildet sind, von der unteren, Fig. 4 von der oberen Fläche gesehen, bei 40 facher Vergr. Die langen Zellen der oberen, coneaven Fläche ragen mit ihren vorderen Enden über diese Flächc etwas hervor, und sind hier mit einer, in langgezogenen Maschen netzigen, Cuticula bekleidet.

Fig. 5. Pollenmutterzellen; Thcile eines zarten Längsdurchschniltes der Kante einer Pollenmasse aus einer Knospe von der $\Lambda$ usbildung derjenigen, aus Welcher das Fig. 2 dargestellte Rostellum genonmen ist. Die primären Zellkerne sind bereits verflüssigt; dic eyweissartigen Stoffe der, ihre Stellen einnehmenden, Flüssigkeit sind zu Klümpchen geronnen. Vgr. 200.

Fig. 6. Theil eines ähnlichen Schnitles aus ciner etwas weiter vorgeriuckten Anthere. In jeder Pollenmutterzelle sind bereits zwei secundäre Zellkerne gebildet. Glciche Vgr.

Fig. 7. Theil eines ähnlichen Schnittes aus einer entwichelteren Anthere. In jeder Mutterzelle vier tertiäre Zellenkerne. Den Innenwänden der stark verdickten Zellhäute sind vorspringende Leisten aufgesetzt, deren Lauf den Gränzen der künftigen Scheidewände der Tetrade entspricht. Platzen jetzt die Mutterzellen durch Wassereinsaugung, so fliesst ihr Inhalt noch formlos aus. Der parenchymatische Zusammenhalt der Mutterzelle unter sich ist noch ein sehr fester. Gleiche Vgr.

Fig. $7^{\text {b }}$. Durch Präparation vereinzelte Mutterzelle; sie ist geplatzt und hat die junge Tetrade $\left(7^{c}\right)$ austreten lassen. Diese erscheint als zartwandige einfache Zelle. Vgr. 500 . 
Fig. $7^{4}$. Eine in gleicher Weise befreite andere Tetrade mit verdünnter Lösung von kohlensaurem Ammoniak behandelt. Die Vembran hat siclı vom Inhalt etwas abgehoben. Dieser zeigt vier kreuzweis gestellte seichte Furchen der Oberfläche, welchen Furchen noch keine auf der lnnenfläche der MemIran vorspringende Leisten entsprechen. Gleiche Vgr.

Fig. 8. Mutterzelle weiterer Entwickelung, durch vorsichtiges Zupfen mit der Nadel aus einem Durchschnitt des Inhalts eines Antherenfachs vereinzelt. Nach kurzem Liegen in Wasser ist (wie in den beiden vorigen Fällen) die Zellhaut, deren Schichten sänmtlich, an stärksten die innersten aufquellen, in Folge des Aufquellens dieser letzteren geborsten; aus dem — in der Zeichnung nicht ausgedrückten, weil nach oben gekehrt gewesenen - Riss wurde der Inhalt der Zelle ausgetrieben: eine die Hölılung der gequollenen Zellhaut bei Weitem nicht ausfüllende zarte Blase, deren dinne Ilaut schon jetzt der Einwirkung ziemlich concentrirter Schwefelsäure widersteht. Der Innenfläche dieser Ilaut sind dünne, nach innen kurz vorspringende Leisten aufgesetzt, deren Lauf mit den dicken Leisten der Innenfläche der dicken, aufgeplatzten äusseren Haut übereinstimnt, und rlem der Scheidewände entspricht, welche bınnen Kurzen die Tetrade in vier Fïcher theilen werden. Vgr. 500.

Fig. 9. Aehnliches Präparat aus einer weiter vorgerückten Knospe. Die Tetrade ist vollständig in vier Fächer getheilt; ihre Exine schon sehr ausgelsildet. Solche Mutterzellen vereinzeln sich sofort, wenn der Inhalt eines Antherenfaches in Wasser gebracht wird. Gleiche Vgr.

Fig. 10. Siule aus einer Knospe solcher Entwickelung. Seitenansicht. Igr. 10.

Fig. 11. Säule aus einer geöffneten Blïthe, nach Aufspringen der Anthere und der viscinhaltigen Zellen des Rostellum, leren Inhalt als Tropfen austrat, im Längsdurchschnitt. Gleiche Vgr.

\section{Tafel VI.}

Fig. 1. Orchis fusca. Theil des Querdurchschnitts einer Massula des Pollens, zur Zeit da an den noch nicht in vier Zellen getheilten Anlagen der Tetraden die Exine auftritt. Vgr. 350 .

Fig. 2. Aehnlicher Durchischnitt; etwas späterer Zustand, nach Resorption der Mutterzellıäute. Gleiche Vgr.

Fig. 3-7. Phajus Wallichii. Fig. 3 Theil des Querdurchschnitts einer jungen Anthere, die zwei Zeltenlagen der Antherenwand und einige der noch dünnhäutigen Pollenmutterzellen zeigend. Vgr. 400.

Fig. 4. Theil des Randes einer querdurchschnittenen Pollenmasse, unmiltelbar vor dem Auftreten der Exine. Die Zelle $a$ ist so gezeichnet, wie sie an frischen Präparat erschien; b nach kurzer Einwirkung von Wasser, $c$ nach Behandlung mit Chlorzinkjodlösung, $d$ ist eine aufgeschnillene Zelle; an ihr hat, wie an $c$, die innerste Schicht der Wand eine kürnige Beschaffenheit angenommen. Gleich!e Tq̣r. 
Fig. 5. Eine Pollenmutterzelle vom Rande der Pollenmasse ciner quer durchschnittenen, nur wenig älteren Anthere; die Exine ist angelogt. Gleiche $\mathrm{Vgr}$.

Fig. (j. Wenig weiter entwickelter Zustand. Die Tetrade ist in die vier Pollonzellen getheilt. Gleiche $\mathrm{Vgr}$.

Fig. 7. Exine einer Tetrade, nach Behandlung mit concentrirter Schwefelsäure allein übrig geblieben. Gleiche Vgr.

Fig. 8-12. Cephalanthera rubra. - Fig. 8 Rand des Querdurchschnitts einer Pollenmasse, unmittelbar nach Anlegung der Specialmutterzellen. Gleiche Vgr.

Fig. 9. Ein Complex aus einer Hutter- und vier Specialmutterzellen, kurz nach Anlegung der Vorsprüinge der Exine. Gleiche Vgr.

Fig. 10. Ein ebensolches Object, aus dem namlichen Antherenfach, mil Chlorzinkjodlösung behande!t. Die Häute der Pollenzellen sind contrahirı. Gleiche Vgr.

Fig. 11. Gynostemium von vorn, Fig. 12 von der Seite, die geringe Lntwickelung der viscinhaltigen Zellen der Narbe $(a)$ zeigend. Vgr. 25.

Fig. 13, 14. Keimpflanzen von Gymnadenia conopsea im Längsdurchschnilt. Vgr. 40.

Fig. 15. Embryo von Solnalia macrantha, in Begiun der Keimung, frei präparirt. Die kurze Zellenreihe am Hinterende des Embryo ist ohne Zweifel ähnlicher Entstehung, wie das haarfömige Anhängsel am dinterende des Embryo von Orchis. Der Kotyledon (der kleinzellige Theil des nach unten gewendeten Vorderendes) ist noch nicht völlig stängelumfassend. Es war von schön griuner läbe. Vgr. 120.

Fig. 16. Längsdurchschnilt, senkrecht auf die Fläche des Kotyledon, des Vorderendes eines etwas weiter entwickelten Keimpflänchens derselben Orchidee, a Endknospe, b Kotyledon, c Scheidentheil desselben. Gleiche Vgr.

Fig. 17. Weiter entwickelte Keimpflanze derselhen Sobralia, im Längsdurcìschnitt parallel der Flichen des Kotyledon und des ilm opponirten zweiten Blattes. Letzteres sieht man in seiner ganzen Ausdehnung von vorn; ersterem ist die Spreite durch den Schnitt entfernt, und nur die Durchschnitte des Scheidentheils $b$ sind sichtbar. An flinterende der hypokotylen Achse $a$, die einige Wurzelhaare, aber noch keine Wurzel entwickelt hat, haftet die zersprengte Testa.

Fig. 18. Thalia dealbata Embryosack eines längshurchschnittenen unbefruchteten Eychens. Vgr. 150.

Fig. 19-23. Cama Sellowii ; 19, 22 und 93 Kernwarze und Scheitelwälbung des Embryosacks mit eingedrungenem Pollenschlauchende; 20 dieselluen Theile, ausserhall, deren auch das Endostom milgezeichnet ist; 21 ein aus dem Embryosacke hervorgezogenes, zusammen gekuäueltes Pollenschlauchende. Vgr. 150.

Fig. 24. Maranta zebrina. 24 Mutterzelle des Pollens, in 4. Specialmulterzellen getheilt; 20̈ Pollenzelle, welche die vereinzelte Specialmutterzelle gesprengt und völlig abgestreift hat; 26 Pollenzelle, aus der Specialmut- 
terzelle zur Hälfte hervorgetreten; 27 Pollenzelle, welche durch Aufquellen der Intine geplatzt ist. Vgr. 250.

\section{Tafel VII.}

\section{Figur 1-4. Arum orientale.}

Fig. 1. Vor Kurzem befruchtetes Ey im Längsdurchschnitt. Vgr. 20 .

Fig. 2. Oberer von Endosperm gefüllter Theil des Embryosackes aus demselben frei präparirt. Vgr. 150 .

Fig. 3. Oberes Ende des Embryosackes und Kernwarze aus einem etwas weiter entwickelten Eychen. Gleiche Vgr.

Fig. 4. Längsdurchschnitt cines halbreifen Saamens. e Endosperm, welches den Embryo umschliesst, und mit dem erweiterten, zellenleeren unteren Raume des Embryosackes $h$ mit einer Schicht zur Gränze diesesRaumes senkrecht gestreckter Zellen angränzt. Auf dem Grunde des Raumes $h$ die drei, zu gewaltiger Grösse herangewachsenen Gegenfüsslerzellen der Keimbläschen $g$. Vgr. 36.

\section{Figur 5-7. Armu ternatum.}

Fig. 5. Unbefruchtetes Eychen im Längsschnitt. Vgr. 10.

Fig. 6. Inneres Integument und Eykern eines solchen. Vgr. 200.

Fig. 7. Eykern eines etwas schlankeren solchen Eychens. Gleiche Vgr.

\section{Figur 8-10. Arum divaricatum.}

Fig. 8. Unbefruchtetes Eychen im Längsschmitt. Vgr. 60.

Fig. 9. Embryosack und Kernwarze eines solchen. Vgr. 200.

Fig. 10. Oberer Theil des Embryosacks und Kernwarze eines ebensolchen. Gleiche Vgr.

\section{Figur 11-1\%. Arum maculatun.}

Fig. 11. Sehr junges Eychen, an welchen das äussere Integument noch nicht angelegt, im Längsschnitt. Vgr. 100.

Fig. 12. Kern desselben, 300 fach vgr.

Fig. 13, 14. Längsdurchschnittsansichten von Embryosäcken mebst Kernwarzen, kurz vor der Befruchtung. Vgr. 300 .

Fig. 15. Oheres Ende eines befruchteten Embryosackes nelsst der vom Pollenschlauch durchbohrten Kernwarze. Gleiche Vgr.

Fig. 16. Vor Kurzem bcfruchteter Embryosack, in welchem die Endospermbildung begonnen hat, nebst der Kernwarze und dem dieser seitlich anhaftenden Pollenschlauche frei präparirt. Vgr. 200.

Fig. 17. Achnliches Prüparat in 100 facher Vgr.

\section{Fignr 18-2\%. Pistia Stratiotes (texensis kl.)}

Fig. 18. Junges Eychen im Längsschnitt. Vgr. 75.

Fig. 18 $8^{\text {b }}$ Eykern desselben in 300 facher Vgr.

Fig. 19. Eychen, kurz vor der Befruchtung im Längsdurchschnitt. Vgr. 30. 
Fig. 20. Der Kern eines solchen in 150 facher Vgr.

Fig. 21. Oberer Theil des Embryosackes und kappenförmige Kernwarze eines eben solchen. Gleiche Vgr.

Fig. 22. Vor Kurzem befruchtetes Eychen im Längsdurchschnitt. Der Verlauf der Gefässbündel im äusscren Integument ist durch punktirte Linien angedeutet. Gleiche Vgr.

Fig. 23. Oberer Theil des Eykerns und des inneren Integuments eines etwas weiter entwickelten Eychens im Längssehnitt. Die Guticula des Integuments hat sich ron den Epidermiszellen abgehoben. Gleiche Vgr.

Fig. 24. Halbreifer Saame im Längsdurchschnitt. Das Gewebe, welches das Exostom umgränzt, beginnt zu Embryotega zu verhärten. Unter der Aussenfläche dcs äusseren Integuments hahen einzelne, in regelmässigen Abständen vertheilte Zellen an Grösse zugenommen, Kugelgestalt erhalten, und Krystalldrusen im Innern gebildet. Vgr. 50.

Fig. 2う. Sehr junger Embryo, im Beginn der Bildung des Kiotyledon, längsdurchschnitten. Vgr. 100.

Fig. 26. Längsdurchschnitt eines weiter entwickelten Embryo. Vgr. 30.

Fig. 27. Ein wenig weiter ausgebildeter Embryo, von vorn gesehen. Vgr. 50.

\section{Tafel Vill. .}

Fig. 1-3. Philodendron Imbe, Fig. 1. Fruchtknoten im Querdurchschnilt. Vgr. 10.

Fig. 2. Derselbe im Längsdurchschnilt. Vgr. 20 .

Fig. 3. Unbefruchtetes Eychen im Längsdurehschnitt. Vgr. 300.

Fig. 4-7. Symplocarpus foetida. Fig. 4. Blüthe kurz vor dem Stäuben der Antheren längsdurehschnitten. Vgr. 15.

Fig. 5. Unbefruchtetes Eychen im Längsdurchschnitt. Vgr. 36.

Fig. 5 ${ }^{\mathrm{b}}$. Der Eykern desselben in 200faeher Vgr.

Fig. 6. Unbefruchtetes Eyehen, Ansicht von aussen. Vgr. 36.

Fig. 7. Oberes Ende eines einige Zeit zuvor befruchtcten Embryosackes, aus der IIöhle des innern Integuments herausgenommen. Es ist nur noeh ein kleiner Rest vom Gewebe des Eykerns übrig (dic dunkel gchattenen Zellen oben links, neben der Ansatzstelle des Vorkeims). Vgr. 200.

Fig. 8. Caladium bicolor. Unbefruchtetes Eychen im Längsdurchschnitt. Vgr. 150.

Fig. 9, 11. Rhodea japonica. Fig. 9. vor Kurzem befruchtetes Ey in Längsdurehschnitt, Vgr. 30; - Fig. 11. Längsdurchschnitt des Endostoms, des oberen Theiles des Endosperms und des Embryo eines reifen Saamens. Vgr. 30.

Fig. 12-16. Calla palustris. Fig. 12. Jungfräulieher Fruchtknoten irn Längsdurchschnitt. Zwischen den Eychen erhebt sich eine Fortsetzung der Blüthenaehse. Vgr. 7 .

Fig. 13. Unbefruchtetes Ey im Längsdurchschnitt. Vgr. 100.

Fig. 14. Der Eykern eines solchen. Vgr. 200.

Fig. 15. Embryosiake und (bis auf die Kernwarze verdrängte) Gykerne befruehteter Eychen in Längsdurchschnitt. Vgr. 150. 


\section{Tafel IX.}

\section{Nigur 1-3. Pothos pentaphylla.}

Fig. 1. Knospe, kurz vor dem Aufblühen, im Querdurchschnitt. Zu iusserst die vier, in zwei zweigliedrigen Kreisen stehenden Perigonialblätter; darauf lie vier, mit ihnen alternirenden, extrorsen Antheren. In Nittelpunhte der zweificherige Fruchtknoten, nahe der oberen Wöbung seiner llöhle quer durchschnitten. Seiner flachen Längsscheidewand, zu der die Vorderfichen der Antheren in Winkeln von $40^{0}$ stehen, sitzen die zwei liangenden Eychen an; eines jederseits; — das eine mit der Wikropyle nach rechts, das andere nach links gekehrt. Ueber den Eychen eine Anzahl der von der Scheidewand ausstrahlenden, langen Papillen. Vgr. $2 \%$.

Fig. 2. Fine solche Knospe im Längsdurchschnitt rechtwinklig zur Scheidewand des Fruchtknotens. $p$ Perigonialblätter, von denen zwei seitwärts von den Medianen vom Schnitı getroffen sind, während von den beiden anderen (inneren) die durchschnittenen, klappig übergreifenden Endtheile in die Ebene des Schnittes fallen. Anth die Antheren, der Schnitt geht zwischen zweien der seitlichen Fächer derselben durch, so dass ron del Anthere links eines der mittleren, von der rechis eines der seitlichen der vier Fächer sichtbar ist. g Germen; der den dichen Scheitel desselben durchziehende Griffelkanal ist vom Schnitte getroffen. Unter dessen Einmündung in die Fruchtknotenhöhle erscheint als stumple Endigung der Lingsscheidewand des Germen die Stelle, an welcher die zwei, je in eins der Fruchtknotenfächer führenden letzten Endigungen des Styluskanals in dessen längeren Haupttheil einminden. Der obere Theil dieser Scheidewand ist mit langen Papillen besetzt. Unter diesen haften die hängenden, halbungewendeten Eychen an dem Dissepiment. Die Richtung der Eychen, das eine mit der abwärts gekehrten Mikropyle nach vor'n, das andere nach hinten gewendel, ist in der Zeichnung ausgedrückt. Gleiche Vgr.

Fig. 3. Eychen aus einer solchen Knospe im Längsdurchschnitt. Vgr. 300.

\section{Figur 4-17. Pothos longifolia.}

Fig. 4. Fruchtknoten, kurze Zeit nach der Bestäubung, im Längsdurchschnitt parallel der Scheidewand. Der Schnitı hat das eine Fach geöffnet und gestattet den Einblick auf die Fläche des Dissepiments, in welchem, dicht oberhalb der mit strahlig georkneten Papillen besetaten Stelle, ein kleines ovales Loch, die Innenöfnung eines der zwei Endarme des Styluskinals sichtbar ist. Der weitere Verlauf des Styluskanals aufwärts ist durch punktirte Linien angedeutet. An einer mit jenen langen Papillen besetzten warzenfömigen Hervorragung der Scheidewand haftet das schief nach unten gerichtete hall, ungewendete Eychen. Die punktirte Linie von der Ansatzstelle desselben senkreeht abwärts deutet den Lauf des axilen Gefissbindels der Scheidewand an. Vgr. 20. 
Fig. 5a . Querdurchschnitt eines solchen Fruchtknotens, dicht über der Stelle, an welcher der'Styluskanal in die zwei, jc in eincs der Fruchtknotenficher führenden Endarme sich thcilt. Glciche Vgr.

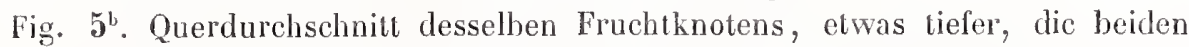
Eychen und ihre von Papillen umstandenen Anheftungsstellen, von oben gesehen, zeigend. Gleiche Vgr.

Fig. 6. Unbefruchtetes Eychen aus einer dem Aufblühen nahen Knospe, im Lingsdurchschnitt. Vgr. 40 .

Fig. 7,8. Die Eykerne solcher Eychcn, mit ihrer den mittleren und unteren Theil nur losc umgebenden Hüllhaut, frei präparirt, in Längsdurchschnillsansichten, in 250facher Vgr. (Anf. Februar 1855 u. 1856.)

Fig. 9. Embryosack und Kernwarze aus einem zur Befruchtung bereiten Eychen frei präparirt, in Längsdurchschnittsansicht. Vgr.150. (Mitte März 1850.)

Fig. 10. Dieselben Theile aus einem vor Kurzem befruchteten Eychen, frei gelegt. Der Embryosack durch eine Querwand getheilt; in seiner oberen Tochterzelle eine Anzahl der Innenwand anliegender, zur Hervorbringung von Endospermzellen bestimmter Zellenkerne. Das befruchtete Keimblåschen gestreckt, durch eine Querwand zweizellig geworden. IIinter ihm das unbefruchtete unveränderte Keimbläschen. Ueber der Kernwarze der obere Theil des abgetrenntcn, von zwei Längsschnitten gestreiften innern Integuments in Umrissen gezeichnet. Im Eudostom sleckt das Pollenschlauchende, dessen etwas angeschwollene Spitze vom Embryosack ohne Verletzung abgelöst worden ist. Vgr. 250. (Mitte März 1855.)

Fig. 11. Der obere Theil des Embryosacks, die Kernwarze und zwei ihr anhaftende Pollenschlauchenden aus einem Eychen gleicher Entwickelung frei präparirt. Obere Zelle des Embryosacks und befruchtetes Kcimbläschen verhalten sich wie bei Fig. 10; - das unbefruchtete Keimbläschen ist verschwunden. Die Kernwarze ist, durch einerseits an den Pollenschlauchenden, andererseits am unteren Ende des Embryosacks ausgeübten Zug quer durchrissen. Einige ihrer Zellen sind an der Scheitelfläche des Embryosacks hängen geblieben. Die ührigen werden von den Extremitäten der beiden Pollenschläuche umklanmert. Vgr. 250. (Mitte März 1856.)

Fig. 12. Aehnliches Präparat, die Pollenschlauchenden $(p)$ noch stärker gekrümmt als bei dem Vorigen; die Spitze des einen (linken) sehr breit gezogen. Vgr. 150.

Fig. 13. Aehnliches Präparat aus einem etwas weiter entwickeltcn Eychen. Die oberc Zelle des Embryosacks (von der nur der oberc Theil gezeichnet) bereits von grosszelligem Endosperm ausgefüllt. Der Pollenschlauch in zwei Endarme verzwcigt, deren einer rcchts an der Aussenfläche der längsdurchrissenen Kernwarze endet, während der andere an der Aussenfläche des links nchen der Kernwarze eine Auftrcibung zeigenden Eimbryosacks haftet. Vgr. 100. 
Fig. 14. Aehnliches Präparat; Kernwarze unverletzt. Zwei Pollenschläuche haften an ihr; der eine endet auf ihrem Scheitel nit kurzer Unbiegung nach vorn. Der andere ist neben der Kernwarze herab bis zur Aussenfläche des Embryosacks gewachsen, und lenkt lier mit knieförmiger Biegung um, sein Endc schräg aufwärts richtend. Torkeim dreizellig: unbefruchtetes Keimbläschen verschwunden. Ygr. 130. (Anfang April 1853.)

Fig. 15. Achnliches Präparat; - der Pollenschlauch ist bis in die Mitte des Gewebes der Kernwarze eingedrungen, und haftet hier mit stumpfem Ende an der Aussenseite der Scheitelltäche des Embryosackes. Die Zellen der Kernwarze sind zum grösseren Theile hinweg präparirt. Vgr. 1 渵.

Fig. 16. Oberer 'Theil cines Embryosacks nebst unvertetzter Kernwarze und nelien dieser herab gewachsenem Pollenschlauche, freigelegt. Vorkeim dreizellig, mit ungewöhnlich kleiner Ansatzfläche an der Innenwand des Embryosacks haftend; - neben ihm das unverändert erlaltene, fehlschlagende Keimbläschen. Vgr. 150.

Fig. 17. Oberes Ende eines Embryosacks, von dem der grösste Theil der liernwarze und der ihr anhaftende Pollenschlauch hinweg priparirt sind. Vgr. 5̆. (Ende März 1855.)

\section{Tafel X.}

\section{Figur 1-13. Pothos longifolia.}

Fig. 1. Stück eines verzweigten Pollenschlauchs, aus dem Schleime genommen; welcher die Fruchtknotenhöhle erfüllt. Vgr. 150 .

Fig. 2. Endostom mit in dasselbe eingetretenem Pollenschlauche, welcher vor der Eintrittsstclle mehrere wiederholt rerzweigte Seitenåste getrichen hat. Vgr. 120.

Fig. 3. Oberes Ende eincs befruchteten Embryosacks mit dreizelligem Vorkeim. Darüber die abpräparirte Kernwarze, mit drei Pollenschläuchen; von denen zwei an der Oberfläche jener herabgewachsen sind, der dritte sie durchbohrt und einc knieförmige Umbiegung seines unteren Endes ausgeführt hat. $\mathrm{Vgr} .130$.

Fig. $3^{\text {b }}$. Das Ende dieses letzteren Pollenschlauches in 600facher Vgr.

Fig. 4. Ganzer Embryosack mit Kernwarze und dieser anhaftenden Pollenschliuchen, frei präparirt. Vgr. 30 .

Fig. 5. Aehnliches Präparat wie Fig. 3. Am Embryosackscheitel sind nicht allein einige Zellen der Kernwarze, sondern auch das letzte Ende a der dünnen seitlichen Sprossung des an der abpräparirten Kernwarze links haftenden Pollenschlauches hangengeblicben.

Fig. $5^{b}$. Jenes Pollenschlauchende mit dem obcren Stücke der seitlichen Sprossung, 4 50fach vergr.

Fig. 6. Aehnliches Präpară. Von den zwei Gabelästen des an der Kernwarze haftenden einen Pollenschlauchs liuft der eine quer über die Vorderfläche 
des Embryosacks weg; sein Ende trifft mil dem des andern $\Lambda$ stes zusammen. Vgr. 150.

Fig. 7. Aehnliches Präparat, drei Pollensehläuche an der Kernwarze. Gleiche Vgr.

Fig. 8. Aehnliches Prïparat, weiter vorgerückter Zustand. Der Pollenschlauch endigt ziemlieh fern vom Embryosack. Wahrscheinlich ist eine zarte Abzweigung desselben unbemerklich geworden. Gleiche Vgr.

Fig. 9. Oberes Ende des Embryosaeks, mit dem im Endosperm eingeschlossenen jungen Embryo; darüber die Kernwarze mit anhaftendem verästclten Pollenschlauche im Längsdurchschnitt. Das Verhälıniss des Pollenschlauches zum Embryosacke ist ähnlich wie bei Fig. 8. Vgr. 120.

Fig. 10. Junger Saame im Längsdurchschnitt. Vgr. 30.'

Fig. 11. Ein halbreifer Saame, rechtwinklig zu einer dureh den Funiculus und die Längsachse gelegten Ebene längsdurchschnitten. Man sieht den Embryo von der Seite. Gleiehe Vgr.

Fig. 12. Ein ebensolcher Saame, im Längsdurehschnitt dureh den Funiculus. Die Vorderfläche des Embryo ist sichtbar. Gleiche Vgr.

Fig. 13. Embryo aus einem fast reifen Saamen, im Längsdurchschnitt. Die dunkeln Flecken an der Peripherie bezcichnen Raphidenbündel führende Zcllen. Gleiche Vgre.

\section{Tafel XI.}

\section{Figur 1-12. Secale cereale.}

Fig. 1. Jungfräuliches Germen im Längsdurchsehnitt. Vgr. 80.

Fig. 2. Embryosïcke aus längsdurchschnitlenen unbefruchteten Eyehen. Vgr. 200.

Fig. 3. Frei präparirtes oberes Ende eines vor Kurzem befruchteten Embryosackes mit anhaftendem Pollenschlauchende, einem felılgeschlagenen und einem dreizellig gewordenen befruchteten Keimbläschen. Rechts am Embryosackseheitcl жwei nicht abgetrennte Zellen der Kernwarze. Vğr. 400 .

Fig. 5. Aehnliehes Präparat; der Innenraum des Embryosacks ist bereits von geschlossenem Endospcrm gefüllt. Vgr. 200.

Fig. 6. Aehnliches Präparat, vor Beginn der Endospermbildung hergestellt. Gleiche Vgr.

Fig. 7. Vom Pollenschlauch durchbohrte Kernwarze und oberes Ende des Embryosacks aus einem kurz zuvor befruchteten Eychen im Längsdurchschnitt. Gleiche Vgr.

Fig. 8. Junger Einbryo im Längsdurchsehnitt. Vgr. 300.

Fig. 9. Oberes Ende eines mit Endosperm gefüllten Embryosacks, einen Embryo ähnlicher Entwickelung einschliessend, im Längsdurchschnitt. Vgr. 200 .

Fig. 10. Etwas weiter entwiekelter Embryo, frei präparirt. Vgr. 300. 
Fig. 11. Oberes Ende eines Embryosackes nach weiler vorgeschritlener Entwickelung; der Embryo ist durch den Schnitt blos gelegt, aber nicht verletzt. Vgr. 150 .

Fig. 12. Embryo nach beinahe vollständiger Ausbildung des Scutellum, und Anlegung des Kotyledon a von der Seite, Fig. 12 $2^{\text {b }}$ von vorn gesehen.

\section{Figur 13-16. Triticum vulgare.}

Fig. 13. Jungfräuliches Germen im Längsdurchschnitt. Vgr. 60 .

lig. 14. Kernwarze, vom Pollenschlauch durchbohrt, und oberes Ende eines kurz zuvor befruchteten Embryosackes, im Längsdurchsclınitt. Vgr.400.

Fig. 15. Obcres Ende cines frei präparirten Embryosacks weiterer Entwickelung. Gleiche Vgr.

Fig. 16. Noch weiter entwickelter Embryo im Längsdurchschnitı. Vgr. 300.

\section{Figur 1:-19. Elynus arenarius.}

Fig. 17. Embryosack aus einem unbefruchteten längsdurchschnittenen Eychen. $\mathrm{Vgr} .200$.

Fig. 18, 19. Obere Enden frei präparirter befruchteter Embryosäcke. Gleiche Vgr.

\section{Tafel XII.}

\section{Figur - - Hordeum vulgare. (Juli 1833.)}

Fig. 1. Embryosack aus einem längsdurchschnittenen unbefruchteten Eychen. Vgr. 200.

Fig. 2. Kernwarze, vom Pollenschlauch durchbohrt, und oberes Ende des En:bryosackes eines vor Kurzem befruchteten, längsdurchschnittenen Eychens. Gleiche Vqr.

Fig. 3. Frei präparirtes olseres Ende eines mit Endosperm gefüllten Embryosacks. Gleiche Vgr.

Fig. 4, 5. Längsdurchschnittsansichten frei präiparirter Embryoanlagen. Gleiche $\mathrm{Vgr}$.

Wig. 6. Embryo, nach Anlegung des Scutellum und vor der des Kotyledon frei präparirt, von der Seite;

Fig. $\mathbf{6}^{b}$. von vorn geschen. Gleiche Vgr.

Wig. (ir. Oberes Ende eines längsdurchschnittenen jungen Saamens, im Längsdurchschnitl. Das ïussere Integunent ist nicht mitgezeichnet. Vgr. 30 .

\section{Figur z-10. Sorghum halepense.}

liig. 7. Embryosack aus einem unbefruchteten Ejchen frei präparirt. Vgr. o000.

Fig. 8. Achnliches Präparat, in welchem das cine Keimblaschen algestorben ist. Vgr'. จ00.

Fig. 9. Oberer Theil eines frei präparirten befruchteten Embryosacks, zur Zeit des Beginns der Endospermbildung. Der Pollenschlauch ist abgetrennt Vgr. 300 . 
Fig. 10. Frei präparirter befruchteter Embryosaek mit anhaftendem Pollenschlauchende und zweizellig gewordenem befruehteten keimbläsehen. Gleiche Vgr.

Fig. 11. Coix Lacryma. Embryosack aus einem lägsdurchschnittenen unbefruchteten Eychen. Vgr. 100.

liig. 12. Oberes Ende dieses Embryosacks mit den Keimbläschen. Vgr. 400.

[Fig. 12". Das grössere dieser Keimbläschen, durch Wassereinsaugung von der Embryosackhaut gelöst und kugelig geworden. Gleiche Vgr.

liig. 13. Carex panicea. Embryosaek aus einem längsdurchschnittenen unbefruchteten Eychen. Vgr. 120.

Fig. 14. Mikropyle-Ende eines befruchteten Embryosacks mit in Endosperm eingeschlossenem Embryo, frei präparirt. Gleiche Vgr.

Figna" 10-19. Carex arenaria. (Juni 1852.)

Fig. 15. Jungfräuliches Germen im Längsdurchschnitt. Vgr. 30.

Fig. 16. Der Embryosack aus einem unbefruchteten, längsdurehschnittenen Eychen. Vgr. 100.

Fig. 17. Halbreife Frucht im Längsdurchschnitt. Vgr. 25.

Fig. 18. Längsdurchschnitt der Saamenschale, Fig. 19 Längsdurehschnitt der Fruchtknotenwand desselben Entwickelungszustandes. Die freic Fläche beider Schalen ist der in der Zeichnung links gewendete Rand.

Fig. 20. Carex trinervis. Reifer Embryo im Längsdurchschnitt. Vgr. 30.

Fig. 21. Plunnula und benachbarte Gewebe desselben Präparats, 200 fach vgr.

Fis. 22. Carex Grayi. Reifer Embryo im Längsdurchschnitt.

Vig. 23. Plunnula und angränzende Gewebe desselben Priparats. 200fach vgr.

\section{Tafel XIII.}

\section{Figur -10. Mippeastrum aulicum. (Februar 1859.)}

Fig. 1. Unbefruchtetes Eychen im Längsdurchschnitt. Vgr. 50.

Fig. 2. Ein ebensolches, etwas unterhalb des Embryosackes quer durchschnitten. Vgr. 30.

Fig. 3. Embryosack und Kernwarze aus einem solchen. Vgr. 200.

Fig. 4. Oberes Ende des Embryosackes und Kernwarze bald nach Ankunft des Pollenschlauches. Vgr' 300.

Fig. 5. Dieselben Theile; die Haut des Embryosackes ist beim Schnitte dem Messer ausgewichen und unverletzt geblieben, so dass die Ansatzfläche des bereits beträchtlich gewachsenen befruchteten Keimbläschens von vorn sichthar ist. $\mathrm{Vgr}$. 400 .

Fig. 6. Stark verästeltes Pollenschlauchende, frei präparirt. Vgr. 300.

Fig. 7. Oberes Ende des Embryosackes, Kernwarze und Endostom eines vor Kurzem befruchteten Eychens im Längsdurchschnitt. Der Pollenschlauch zeigt vollständige Schleifenbildung (vgl. S. 684). Vgr. 300.

Fig. 8. Obere Wölbung des Embryosaeks und Kernwarze eines weiter entwickelten Eychens im Längsdurehsehnitt; Vorkeime fünfzellig. Der Verlauf 
des Pollenschlauchendes hinter der dem Objectiv abgewendetcn Fläche des Embryosackes ist in der Zeichnung angedeutet.

Fig. 9. Inneres Integument und Kern eines befruchteten Eychens im Längsdurchschnitt. Der Embryosack hat einen grossen Theil des Eykerns verdrängt. Vgr. ら0.

Fig. 10. Der Embryo und einige Zellen der Kernwarze aus diesem Eychen, 300 fach vergrössert.

Fig. 11. Stück des frei präparirten Embryosackes von Habranthus chilensis mit anhaftendem Vorkeim, 300 fach vergrössert.

Fig. 12. Aehnliches Präparat aus einem halbreifen Saamen derselben Pflanze. Das Embryokügelchen ist bereits vielzellig.

Figur 13-21. Leucojum vernmm. (Anfang April 185\% u. 1859.)

Fig. 13. Unbefruchtetes Eychen im Längsschnitt. Vgr. 20.

Fig. 14. Oberer Theil des Kernes desselben. Vgr. 150.

Fig. 15. Ebensolches Präparat aus einem Eychen, an desscn Embryosack der Pollcnschlauch soeben anlangte Vgr. 200.

Fig. 16. Der Embryosack aus einem wenig weiter entwickelten Eychen, unverletzt frei gelegt. Ueber ihm die vom Pollenschlauch durchbohrte, abpräparirte Kernwarze. Gleiche Vgr.

Fig. 17. Oberer Theil eines frei prijparirten Embryosackes ähnlicher Entwickelung, in welchem das unbefruchtetc Keimbläschen bereits verschwunden. Darüber dic Kernwarzc mit dem Pollenschlauche. Gleiche Vgr.

Fig. 18-20. Obere Enden frei präparirter befruchteter Embryosäcke, jecler zwei Keimbläschen enthaltend. An dem Fig. 20 haftet das Pollenschlauchende. $\mathrm{Vgr} .750$.

Fig. 21, 23, 24. Obere Enden von befruchtcten Embryosäcken nebst den von Pollenschläuchen durchbohrten Kernwarzen, im Längsdurchschnitt. Die Endospcrmbildung hat begonnen Vgr. 150.

Fig. 25. Ein Eychen derselben Entwickelungsstufe im Längsdurchschnitt. $\mathrm{Vgr} .20$.

Fig. 95'. Eine der, leicht aus dem Zusammenhange tretenden, mit Amylumkörnern gefüllten Zellen des untern Theiles des Kerns eines solchen Eychens. $\mathrm{Vgr}$. 150 .

Fig. 26. Zwcizellige, Fig. 27 neunzclliger Vorkeim, im Lüngsdurchschnitt, aus der Reife nahen Saamen (am 7. Mai 1855) genommen.

\section{Tafel XIV.}

\section{Figur 1, 2. Crinum variabile.}

Fig. 1. Ein Fruchtknotcnfach, querdurchschnitten; ein Ejchen im Längsdurchschnitt, das andere von aussen zeigend. Vgr. 40.

Fig. 2. Embryosark und Vorderende eines längsdurchschnittenen Eychens; a die Keimbläschen, b dcren Gegenfüsslerzellen. Vgr. 160 . 


\section{Figur 3-11. Crinuun capense.}

Fig. 3. Unbefruehtetes Eychen im Längsdurchschnitt. Vgr. 130.

Fig. 4. Ey- und Mikropylc-Ende des Embryosackes eines solcben. Vgr. 400.

Fig. 5. Dieselben Theile, unmittelbar nach Ankunft des Pollenschlauchs. Gleiche Vgr.

Fig. 6. Diesclben Theile; etwas späterer Zustand, nach der ersten Quertheilung des befruchteten Keimbläschens. Gleiche Vgr.

Fig. 7. Oberes Endc eines befruchteten Embryosackes mit der Innenfläche anhaftendem, befruehtetcn, quergetheilten Keimbläschen, frei präprarirt. Die Embryosackhaut ist neben der Anhcltungsstelle des Keimbläschens durchrissen. Gleiche Vgr.

Fig. 8. Oberes Ende des Embryosackes und Eymund, vom gabelïstigen Pollenschlauch durchzogen, nach Umbildung des befruchteten Keimblischens zu einer kurzen Zellenrcihe. Vgr. 200.

Fig. 9. Befruchtetes Eychen, nach Beginn der Endospermbildung, längsdurchschnitten. Vgr. 23.

Fig. 9 ${ }^{b}$. Eymund (in welchem der Pollenschlauch), Endospermerfülltes MikropyleEnde des Embryosacks und Vorkeim desselben Präparats, 200fach vgr.

Fig. 10. Schnitt durch das Endosperm und das Integument eines ctwas weitcr entwickelten jungen Saamens. Gleiche Vgr.

Fig. 11. Befruchtetes, aber dann fehlschlagendes Eychen im Längsdurchschnitt. Es enthält eine ziemlich weit cntwickelte Embryo-Anlage; aber keine Spur von Endospermbildung ist sichtbar. Vgr. 30 .

\section{Tafel XV.}

Merendera caucasica. (Anfang April 1955 u. 1859.)

Fig. 1. Einer der drei Griffel im Querdurchschnitt, 180 faeh vgr. Unten (an der nach aussen gewendet gewesenen Kante) das Gefässbündel, darüber die Höhlung des spaltenförmigen Griffelkanals.

Fig. 2. Unbefruchtetes Eychen mit stumpfwinklig angeheftetem Funiculus im Längsdurchschnitt. Vgr. 50 .

Fig. 3. Eben solches Eychen mit rechtwinklig angeheftetem, auf der Oberseite papillösem freiem Theile des Funiculus. Vgr. 30.

Fig. 4. Embryosaek nebst Kernwarze aus einem solchen Eychen, frei präparirt. Vgr. 230.

Fig. 5. Aehnliches Präparat, jüngerer Zustand. Die Zellen der Kernwarze enthalten in den Wandbeleg aus Protoplasma eingebettete grossc Amylumkörner. Kleinere Amylumkörner sind in sehr grosser Anzahl der die Wände des Embryosacks und auch die Aussenflächc der Kcimbläschen überziehenden Protoplasmaschicht eingemengt. Im auffallenden Licht erscheint diese Schicht glänzend weiss, wie aus Silber ciselirt ; an glänzendsten da, wo die kleincn Amylumkörner am dichtesten angehäuft sind: in der Umgebung des primären Kerns des Embryosackes und der Keim- 
bläschen. Die weiche Wand des Enbryosacks liegt noch nicht der Hüllhaut des Eykerns an; ähnlich wie auf jüngeren Zuständen von Zostera und von Aroïdeen. Vgr. 500.

Fig. 6. Aehnliches Präparat, an welchem man einen Theil der unteren Fläche der Kernwarze erblickt. Vgr. 2:50.

Fig. 7. Unbefruchtetes Eychen, einer eben sich öffnenden Blüthe entnommen, im Längsdurchschnitt. Vgr. 2300.

Fig. 8, 9. Frei präparirte Embryosïcke nebst Kernwarze aus solchen Eychen. Der F. 8 ist intact; der F. 9 zerrissen, sein Inhalt mit Ausnabme der Keimbläschen ausgetrieben. Der Amylumgehalt des Protoplasma des Embryosacks ist jetzt merklich geringer: Vgr. 500 .

Kig. 10. Kernwarze eines solchen Eychens, von oben gesehen. Vgr. 300.

Fig. 11. Kernwarze und oberer, die Keimbläschen einschliessender Theil des Embryosacks eines Eychens, in dessen Mikropyle kur'z zuvor ein Pollenschlauch trat (10 Stunden nach künstlicher Bestäubung bei kủhlem Wetter). Daneben das von der $\Lambda$ ussenfläche des Embryosackes unverletzt abgelöste Pollenschlauchende. Tgr. 400.

Fig. 12. Aehnliches Präparat, bei welchem das Pollenschlauchende in dem längsdurchschnittenen Endostom steckt. Vgr. 300.

Fig. 13. Aehnliches Präparat, bei welchem die Spitze des Pollenschlauchendes bei der Abtrennung von der Embryosackhaut barst und einen Theil ihres Inhalts austreten liess. Die Kernwarze liegt schief, etwas nach unten gewendet. Man sieht einen Theil ihrer unteren Fläche. Vgr. 400.

Fig. 14. Freigelegte Kernwarze mit oberem Theile des Embryosacks; daneben das abgetrennte Pollenschlauchende mit unverletzter Spitze und zahlreichen stabförmigen Inhaltskörpern. Ein vor der Freilegung des Präparats durch das Ey gefuhrter Längsschnitt ist ziemlich genau durch die Mittellinie der Kernwarze gegangen, die man im Lïngsdurchschnitt sieht. Nur ein Keimblischen ist zu sehen; das Andere wurde vermuthlich durch jenen Schnitt entfernt. Vgr. 500.

Fig. 15-21. Frei gelegte Embryosäcke nebst Kernwarze und der Embryosackhaut anhaftendem Pollenschlauchende, in perspectivischer Ansicht bei 250facher Vergrösserung.

lig. 15. Pollenschlauchende kurz abgerissen, einfach kolbig; im befruchteten, grösseren Keimbläschen der Zellkern noch vorhanden.

Fig. 16. Pollenschlauclıende auf eine längere Strecke der Embryosackhaut anliegend; Spitze desselben verbreitert und alggeflacht.

Fìg. 17. Pollenschlauchende wie bei F. 1. Die zwei Keimbläschen von völlig gleicher Grösse und Beschaffenheit.

Fig. 18. Embryosack völlig unverletzt, in seinem Grunde die drei Gegenfüsslerzellen der Keimbläschen. Das Pollenschlauchende verhält sich dem in F. 2 abgebildeten ähnlich. Die wenigen festen Inhaltskörper desselben sind von auffälig langgezogener Form. Die fehlschlagenden Keimbläschen sind bereits spurlos verschwunden.

Fig. 19. Das eine Keimblaschen ebenfalls nicht mehr vorhanden. Der Polienschlauch, an seiner Spitze in zwei sehr kurze Gabeläste getheilt, um- 
fasst mit denselben naeh Art einer Zange eine Längsfalte der Embryosaekhaut.

Fig. 20. Der Embryosaek ist an seiner Vorderfläehe dureh einen der zwei Längssehnitte verletzt und geöffinet, welehe vor seiner Freilegung durch das Eychen geführt wurden. Kernwarze und Pollensehlauehende sind von diesem Sehnitte nieht getroffen. Die Spitze des letzteren ist auf eine beträehtliehe Streeke, soweit sie der Embryosaekhaut anliegt, verbreiter' und abgeflaeht.

Fig. 21. Pollenschlauehende dreiarmig. Der oberste, kürzere dieser Zweige endet stumpf an der Aussenfläche der Kernwar'ze. Der mittlere ist, insoweit er der Embryosackhaut anliegt, verbreitert und abgeplattet. Der dritte trifl mit abgerundetem Ende auf eine tiefere Stelle der Wand des Embryosaekes.

\section{Tafel XVI.}

\section{Tigur 1-10. Merendera caucasica.}

Fig. 1. Frei präparirter Embryosaek, Anf. April 1859. Der Pollenschlaueh ist zwisehen der Innenfläehe des Integuments und der Aussenseite des Embryosaekes sehr weit, dem Grunde des letzteren bis auf ein Viertheil von dessen Länge nahe, herabgewachsen. Hier hat er, der Membran des Saekes fortan angesehmiegt, eine Wendung nach aufwïrts, dann eine seilwärts, hierauf wieder eine naeh abwärts gemacht; endlich sich wieder nach oben gewendet, indem er um seinen älteren Theil in links gerichteter Sehraubenlinie sieh sehlang. Sehliesslieh jst er, immer an der Embryosaekhaut anhaftend, noeh weiter naeh oben, bis nahe an die Kernwarze gewachsen, wo sein Ende zu einer flaeh ahgeplatteten Erweiterung von dreiseitigem Umriss wurde.

Fig. $1^{b}$. Dasselbe Präparat, um beiläufig $60^{\circ}$ um seine Längsaehse gedreht. Besehaffenheit und Anheftung der Keimbläschen treten in dieser Lage deutlieher hervor.

Fig. 2. Embryosaekhaut an der Vorderfläehe dureh den Sehnitt verletzt; Pollensehlauehende sehr varieös, einfaeh zugerundet und leieht abgeplattet endigend.

Fig. 3-5. Präparate, ähnlieh den auf der vorhergehenden Tafel dargestellten. In F.3 liegt das umgebogene, wenig abgeplattete Ende des Pollcnsehlauehes auf eine ziemlich lange Strecke der Embryosaekhaut an. In F. 5, wo die Embryosaekhaut an der Vorderflïehe durch den einen Längsschnitt geöffnet ist, haftet der Pollenschlaueh nur mit der äussersten Spitze an der Membran des Saekes. Das eine Keimbläschen erscheint hier, abnormer Weise, nicht blos der Seheitelfläehe, sondern auch einer der Seitenflächen des Embryosackes angeschmiegt. Der Inhalt des andern Keimbläschens wurde bei der Präparation zufällig ausgetrieben ; es ist nur dessen faltige Zellstoflhaut noeh vorhanden. 1)ie Kernwarze ist 
bei der Präparation, ebenfalls zufällig, vom Embryosacke halb abgetrennt worden.

Fig. 4. Der Pollenschlauch endet mit zugerundeter, abgeflachter Spitze. Die Lage der Kernwarze, die etwas nach unten gebogen ist, gestattet schräg auf deren untere Fläche zu sehen.

Eig. 6. Die nämlichen Theile aus einem weiter vorgerückten Eychen (Mitte Mai 4853) frei präparirt. Befrucbtetes Keimbläschen zweizellig; unbefruchtetes verschwunden. Die Endospermbildung hat begonnen. Zahlreiche freie Zellkerne liegen an der Innenwand des Embryosacks. Vgr. 190.

Fig. 7. Achnliches Präparat, bei wclchem die Trägerzelle des zweizelligen Vorkeims um Vieles schlanker ist. Das Pollenschlauchende $(p)$ ist schon ziemlich unkenntlich. Gleiche Vgr.

Fig. 8. Weiter entwickelter junger Saame, Ende Mai desselben Jahres, im Längsdurchschnitt. Der Embryosack ist noch nicht vom Endosperm erfullt; nur eine einfache Schicht in Bildung begriffener Zellen desselben bekleidet die Innenwand. Vgr. 15.

Fig. 9. Längsdurchschnitt eines jungen Saamens im ersten Drittel des Juni, bei gleicher Vergrösserung. Das Endosperm erfüllt den nicht grösser gewordenen Embryosack bis auf eine enge centrale Höhlung.

Fig. 10. Der junge Embryo nebst Träger aus dem nänlichen Präparat, 100 mal vgr.

\section{Figur 9-11. Uvularia grandiflora.}

Fig. 11. Eychen im Längsdurchschnitt. Vgr. 80 .

Fig. 12. Frei präparirte Embryosäcke nebst Kernwarze aus unbefruchtet gebliebenen Blüthen, deren Perigonialblätter zu welken begannen. F. $10 a, b$ Vgr. 250. F. 11. Vgr. 120. F. 10 $0^{\mathrm{b}}$ ist Seitenansicht der F. 10, in Umrisszeichnung.

\section{Tafel XVII.}

\section{Figur 1-10. Colchicun antumnale.}

Fig. 1. Eychen, unmittelbar nach Ankunft des Pollenschlauches an der Kernwarze, Mitte September (18a2), längsdurchschnitten. Vgr. 150.

Fig. 2. Aebnliches Präparat, bei dem vom inneren Integument nur die Umrisse angegeben, äusseres Integument und Raphe nicht mitgezeichnet sind. Gleiche Vgr.

Fig. 3, 4. Gipfel frei präparirter, befruchteter Embryosäcke nebst Pollenschläuchen und Kernwarzen, Mitte März. Das zum Fehlschlagen bestimmte Keimbläschen ist in die Breite gezogen. Gleiche Ygr.

Fig. 5. Unbefruchtet gebliebener Embryosack, Mitte März frei präparirt. Gleiche $\mathrm{Vgr}$.

Fig. 6, 7. Achnliche Präiparate wie die F. 3, 4 abgebildeten, ebenfalls Mitte März hergestellt. Die Kernwarze ist dem Embryosackscheitel schräg aufgesetzt; das excentrjsche keimblischen ist in beiden Fällen dasjenige, welches sich zum Embryo entwickeln wird. Vgr. 200. 
Fig. 8,9. Aehnliehe Prijparate, gleichzcitig mit den vorigen gewonnen. Die Lage der schrigg am Embryosack sitzenden Kernwarze ist so, dass man auf deren untere Fläehe sieht. In beiden Fällen ist nur noch ein Keimbläsehen vorhanden. F. 8 200fach, F. 9 400fach vgr’.

Fig. 10. Aehnliches Präparat, am 9. Mai hergestellt. Das allein noch vorliandene befruchtete Keimbläschen ist noch immer einzellig. Vgr. 150.

\section{Figur 11-17. Bulbocodium vernun.}

Fig. 11. Fruchtknoten im Querschnitt. Vgr. 15.

Fig. 12. Querdurchschnitt der Basis, Fig. 13 Querdurchschnitt des oberen Theils des Griflels. Gleiche Vgr.

Fig. 14. Eychen von aussen gesehen. Vgr. 30.

Fig. 15. Ein solehes im Längsdurchschnitt. Vgr. 60.

Fig. 16, 17. Kerne unbefruchteler Eychen im Längsdurchschnitt. Vgr. 180.

\section{Tafel XVIII.}

Veltheinia viridiflor'a. (Februar 1859.)

Fig. 1. Eyehen im Längsschnill, einer Knospe entnommen, die in etwa 14 Tagen aufgeblüht sein würde. Der Lmbryosaek ist einfach keulenförmig. Vgr. 100 .

Fig. 2. Frei präiparirtes oberes Ende eines zur Befruchtung bereiten Embryosacks, zwei von festen Zellhäuten umhüllte Keimbläschen einschliessend. Vgl' 2500 .

Fig. 3. Unbefruchtetes Eychen aus einer eben sich öflnenden Blüthe im Längsdurchsehnitt. Der Embryosack hat neben seinem Grunde abwärts eine umfangreiche Ausstiilpung entwiekelt, auf deren Grunde scin primłirer Kern liegt. Von der diesen umgebenden Protoplasma-Anhäufung führt ein Strang in der Längsaehse der Ausstiilpung aufwärts zu den Keimbläschen hin. Vgr. 25.

Fig. $3^{\text {b }}$. Der Embryosack aus eben diesem Präparale, in grössten Theile seines Unfanges frei gelegt und פ.50 fach vgr.

Fig. 4. Obcres Ende des Embryosacks und vom Pollensehlauch durchbohrte Kernwarze eines vor Kurzem befruchteten Eys in Längsschnitt. Der Inhalt der Keimbläschen hat sich in Folgc der Einwirkung reinen Wassers von den elastischen Zcllhiuten zurück gezogen. Gleiche Vgr.

Fig. 5. Achnliehes Präparat, etwas weiter vorgeruekter Zustand. Das befruch tete Keimblïsehen ist bereits länger' gestreckı; sein contrahirter Inhalt erschcint in zwei Hälften (Primordialschläuche) gesondert, welche noch durch keine feste Zellwand getrennt sind. Gleiche Vgr.

Fig. 6. Frei gelegte Scheitelregion eines befruchteten Embryosacks. Der Inhalt beider Kcimbläschen ist bei der Präparation ausgetrieben worden. Auf der Spitze des Embryosaeks einige unregelmässig verdickte Stellen der Nenbran: die einzige hier vorkommende Andeutung der anderwärts 
(Paniceen, Gladioleen) entwickelteren Cuticularbildung (Schacht's Fadenapparat). Vgr. 300.

Fig. 7. Längsdurchschnitt von dem Embryosackscheitel und der vom PollenschIauch durchbohrten Kernwarze eincs vor Kurzen befruchteten Eychens. Der Inhalt der Keimbläschen noch in seiner natürlichen Lage. Vgr. 250 .

Fig. 8. Befruchtetes Ey im Längsdurchschnitt bei 2:5facher Vgr. Dic Aussackung des Embryosacks ist bis zum Grunde des Eykerns herab gewachsen; in ihr zcigen sich die Anf:̈̈nge der Endospermbildung.

Fig. 9. Obere IIälfte des Kernes eines befruchteten Eychens im Längsdurchschnit, 250fach vergr. In der Umgebung des zweizelligen Vorkcims einige dickwandige, zum Theil in Vermehrung begriffene Endospermzellen. Das fehlgeschlagene Keimbläschen ist bereits in cinen formlosen Klumpen körnigen Schleims verwandelt.

Fig. 10. Scheitelregion eines befruchtcten Embryosacks frei präparirt. Vorkeim zweizcllig; neben ihm das fehlschlagende Keimbläschen, wohl erhalten. An der Wand des Embryosacks zahlreiche freie, zur Bildung von Endospermzellen bestimmte Kerne.

Fig. 11. Aehnliches Präparat mit dreizelligem Vorkeime und verschrumpftem abortirendem Keimbläschen. Vgr. 300.

Fig. 12. Halbreifer Same im Längsdurchschnitt, bei 20facher Vergr. Nur der obere Theil des Embryosackes ist vom Gewebe des Endosperms ausgefüllt, wclches den ellipsoïdischen jungen Embryo $(e)$ einschlicsst. Die grössere, nach unten sehr erweiterte untere Hälfte des Embryosackes ist zcllenlcer. Auf ilhrem Grunde liegt eine Druse von grosscn Krystallen eines (in Salzsäure sich ohne Aufbrausen lösenden) Kalksalzes $(\alpha)$. Drusen aus kleineren Krystallen desselben Salzes finden sich in den Zcllen der Aussenfläche der Mittelgegend des Endosperms (hci $a$ ).

Fig. 12b. Einige der krystallfühırenden Endospermzcllen, 120 fach vergr.

\section{Tafel XIX.}

Fig. 1. Hemerocallis lutea. Inneres lntegument und dessen Innenflächc auf allen Punkten anliegender Embryosack eines vor Kurzem befruchteten, im Beginn der Endospermbildung begriffenen Eychens. Vgr. 300.

Fig. 2. Czackia Liliastrum. Vor einiger Zeit befıuchtetes Ey im Längsdurchschnitt. Vgr. 25.

Fig. 3. Vom Pollenschlauch durchzogene Kernwarze und oberes Ende des Embryosacks desselben Präparats. Im Embryosack das unbefruchtete Keimblïschen und der mehrzellige Vorkeim. Vgr. 300.

Fig. 4. Erythronium dens canis. Unbcfruchtetes Ey im Längsdurchschnitt. Vgr. 15.

Fig. 5, 6. Obere Enden befruchteter Embryosäcke derselben Pflanze, mit den anhaftenden Pollenschläuchen frci präparirt. Vorkeime vielzellig. Vggr. 300 . 
Fig. 7. Allium odorans. Junges Eychen im Längsdurchschnitt. Vgr. 250.

Fig. 8. Eychen derselben Pllanze, aus einer geöfineten Blume, noch unbefruchtet. Vgr. 50 .

Fig. 8b. Der Embryosack desselben Präparats, 200fach vgr.

Fig. 9. Inneres Integument, Eykern und Embryosack eines vor Kurzem befruchteten Eychens. Gleiche Vgr.

Fig. 10. Kernwarze und Embryosackscheitel mit anhaftendem Pollenschlauch, unbefruchtet gebliebenen Keimbläschen und Embryo-Anlage, frei präparirt. Gleiche Vgr.

Fig. 11. Allium victoriale. Befruchtetes Eychen, nach vollständiger Verłrängung des innern Intcguments (mit Ausnahme des Endostoms) im Längsdurchschnitt. Vgr. 20.

\section{Tafel XX.}

Fig. 1. Triteleia uniflora. Unbefruchtetes Eychen im Längsdurchschnitt. (Februar 183̈9.) Vgr. 180.

Fig. 1 ${ }^{b}$. Fruchtknoten derselben Pflanze im Querdurchschnitt. Vgr. 25.

Fig. 2. Gagea lutea. Kern eines unbefruchteten, zur Befruchtung bereiten Eyehens im Längsdurchschnitt. Nur cin Keimbläschen ist noch vorhanden. Vgr. 300 .

Fig. 3. Der obere Theil des Eykerns eines vor nicht langer Zcit befruchteten Eychens derselben Pflanze (Ende April 1859), frei präparirt. Der seh. herangewachsene Embryosack hat die Zellen der ihn umgebenden Zellschicht verdrängt, die Kernwarze ausgenommen. Durch die Zellen dieser hindurch sieht man das Pollenschlauchende und die Anheftung der Trägerzelle des erst zweizelligen Vorkeins. Gleiche Vgr'.

Fig. 4. Aehnliches Präparat eines weiter vorgerückten Zustandes mit sechszelligem Vorkeim. In der Endzelle, welche zu einer neuen Quertheilung sich anschickt, zwei noch durch keine Querwand getrennte Zellkerne. Gleiche Vgr.

Fig. 5. Gloriosa superba. Unbefruchtet gebliebcnes Eychen aus einer Blüthe, deren Prigon hereits verwelkt war. Der Embryosack hat die Zellen des Eykerns völliğ verdrängt, bis aul die wenigen Zellen der Kernwarze, an dercn unterer Fläche dic Keimbläschen haften; - ganz wie bei Colchicum, Merendera und Bubbocodium. In Mittelpunkte des Embryosacks schweht eine grosse kugelige Luft)lase - das sichere Vorzeichen baldigen Absterbens unbefruchtet gebliebener Eychen. Vgr. 50.

Fig. 6. Funkia coeruloa. (August 1833.) Theil eines, durch die Scheitelgegend des Eykerns eines vor Kurzem bef'uchteten Eyes geführten Längsschnitts. In der Scheitehwölbung des Embryosackes haften zwei Keimbläschen, deren Inhalt bei der Präparation ausgetrieben wurde. Dancben der abpräparirte, an der Spitze mehrlach verästelte Pollenschlauch. Vgr. 300 . 
Fig. 7. Funkia coerulea Zarter Längsschnitt des oberen Theiles des Kerns eines vor Kurzem befruchteten Eychens. In der Scheitelwöllsung des Embryosackes drei Keimbläschen, von denen eines bereits lang gestreckt ist, in der Entwickelung dem andern vorauseilend. Zwischen den Zellen der Kernwarze das einfach zugerundete Ende des Pollenschlauchs. Gleiche Vgr.

Fig. 8. Bonapartea juncea. Embryosack und Kernwarze eines unbefruchteten Eychens im Längsschnitt. Vgr. 120.

Figur 9-12. Puschkinia scilloïdes. (Anfang April 1859.)

Fig. 9. Unbefruchtetes Ey im Längsdurchschnitt. Vgr. 25.

Fig. 10. Scheitelregion des Embryosackes eines vor Kurzem befruchteten Eychens. In der Wölbung des Sackes haften ein unbefruchtet gebliebenes, und ein zum bereits zweizelligen Vorkeim entwickeltes befruchtetes Keimbläschen; der Inhalt beider ist zusammengezogen. - Ueber dem Embryosacke die alpräparirte Kernwarze, zwischen deren Zellen das dünnwandige, einfach zugerundete Pollenschlauchende steckt. Vgr.300.

Fig. 11. Frei prajparirte Scheitelregion des Embryosackes aus einem Eychen ähnlicher Entwickelung. Links oben haftet an der Aussenseite der Embryosackhaut eine der Zellen der Kernwarze. Oben in der Mitte, etwas rechts über den Anheftungsstellen des befruchteten und unbefruchteten Keimbläschens, hängen aussen an der Membran des Embryosackes die Enden zweier kurz abgerissener Pollenschläuche. Im Innern des Enıbryosackes rechts eine zartwandige Endospermzelle. Vgr. 400.

Fig. 12. Junger Embryo, nebst einem Fetzen der Embryosackhaut, an welchem die oberste Zelle seines Trägers haftet. Vgr. 200.

\section{Tafel XXI.}

\section{Fignr 1-9. Iris pumila.}

Fig. 1. Ansicht eines ganz jungen Eychens von Aussen, Anfang Novembers vor der Blüthe. Die Zellengrånzen des optischen Längsdurchschnitts des Eychens sind durch punktirte Linien angedeutet. Vgr. כ000.

Fig. 2. Längsdurchschnitt eines jungen Eychens nebst einem Stück der Placenta, Nitte Februars. Vgr. 350 .

Fig. 3. Längsdurchschnitt cines weiter vorgerückten Zustands, Anfang April. Gleiche Vgr.:

Fig. 4. Längsdurchschnitt des Eykerns.

Fig. 5. Längsdurchschnitt des Eykerns und innern Integuments, beide Mitte April, etwa 14. Tage vor der Blüthe. Gleiche Vgr.

Fig. 6. Eykern aus einer Blüthenknospe, deren Perigonialblätter die erste Spur der Färlıung zeigen, im Längsdurchschnitt. Vgr. 200.

Fig. 7. Embryosack des längsdurchschnittenen Eychens aus einer etwas weiter entwickelten Knospe, in wolchem die Kerne ler Keimbläschen eben aufgetreten sind. Vgr. 400.

Fig. 8, 9. Aehnliche Präparate weiter vorgerủckter Zustảnde. Gleiche Vgrr. 


\section{Figur 10-28. Crocus vernus.}

Fig. 10. Knospe zu einer Blüthe des künftigen Jahres, Ende Mai im Längsdurchschnitt. Vgr. 15. Die Blüthenaclise erscheint als stumpfes Wärzchen ; noch keines der Blattorganc der Bluthe ist angelegl.

Fig. 11. Ebcnsolche Knospe, im Längsdurchschnitt, Anfang Juli. a Antheren, $p$ Pcrigonialblätter, $h$ Hochblätter, $l$ Laubblätter, $s$ Niederblätter. Vgr. 73.

Fig. 12. Eykern aus einer zur Entfaltung im nächsten Frühling bestimmten Knospe, Mitte September. Vgr. 200.

Fig. 13. Ein ebensolches Präparat, Anfang October. Gleiche Vgr.

Fig. 14. Eychen im Längsdurchschnitt, am 20. Novbr. Vgr. 80.

Fig. 15. Eykern im Längsdurchschnitt, Ende Dccember (1854). Vgr. 250.

Fig. 16. Aehnliches Präparat, am 20. October (1838). Gleiche Vgr.

Fig. 16 ${ }^{\text {b }}$. Scheitel des Embryosacks mit zwei Keimbläschen aus einem anderen, gleichzeitig dargestellten ähnlichen Präparate. (Beide Präparate zeigen Falten der bereits festen Haut der Keimbläschen.) Vgr. 400.

Fig. 17-20. Die oberen Enden frei präparirter Embryosäckc, Ende Januar (185\%). In allen Fällen hat sich der Inhalt der Keimbläschen von der bereits erhärteten Membran derselben zurück gezogen. Vgr. 180.

Fig. 21. Embryosack aus einem, am 26. März (1854) längsdurchschnittcnen Eychen. Vgr. 180.

Fig. 22. Eykern und aus dessen Scheitcl hervorragender Embryosack, am 2. Januar (1855) frei präparirt. Vgr. 150.

Fig. 23. Ein Präparat ähnlicher Art wic die F. 17-20 abgcbildeten, mit diesen gleichzeitig erhalten, und gleich stark vcrgrössert.

Fig. 24. Oberes Ende eincs Embryosackes, am 3. März (1855) frei präparirt. Beide Keimbläschen sind nach oben hin in den Mikropylckanal zu (von der Embryosackhaut und deren Cuticula bckleideten) Fortsätzen ausgewachsen. Vgr. 400 .

Fig. 25. Ein äbnliches Präparat wie F. 21, mit diesem gleichzeitig (am 26. März $1854)$ dargestellt. Vgr. 150.

Fig. 26. Oberes Ende eincs am 26. März (1854) frei präparirten Eykerns. Die Embryosackhaut hat die peripherische Zellschicht des Eykerns nur am Scheitel durchbrochen, und ragt nur insoweit aus derselben hervor, als ihre Scheitelwölbung von den beiden oberen Keimbläschen ausgefüllt wird. Vgr. 40 .

Fig. 26 ${ }^{\text {b }}$. Längsdurehschnitt der Scheitelregion desselben Eykerns, 150 fach vgr.

Fig. 27. Das obere Ende eines frei präparirten Embryosackes, am 4 . April 4859.

Ein Theil der Cuticula des Embryosackscheitels ist bei der Präparation zufällig abgerissen. Vgr. 600.

Fig. 28. Ein ähnliches Präparat, am 26. April 1834 dargestellt. Die Cuticula des Embryosacks ist nur sehr schwach entwickelt. Vgr. 150.

$k$ bedeutet bei allen mit Buchstaben bezeichneten Figuren die zum Fehlschlagen bestimmten, $k^{\prime}$ die zum Befruchtetwerden bestimmten Keimbläschen. 


\section{Tafel XXII.}

\section{Crocus vernus L.}

Obere Enden von eben befruchteten Embryosäcken, frei gelegt.

Fig. 1. Mit anhaftendem Pollenschlauch, der auf dem sterilen oberen Keimbläschen liegt, und in den Embryosack und jenes eine Rinne eingedruickt hat. Anordnung des Zelleninhalts beim Freilegen nicht gestört; primärer Kern des unteren Keimbläschens noch erhalten. Am 9. März 1854, im Zimmer getriebene Pflanze. Vgr. 150.

Fig. 2. Pollenschlauch keulig; Keimbläschen beim Freilegen gedrückt; ihr Inhalt zum formlosen Klumpen geballt. Am 10. April 1854. Gleiche Vgr.

Fig. 3. Kern des befruchteten Keimbläschens noch vorhanden, Pollenschlauchende stark verjüngt. Anf. April 1855. Gleiche Vgr.

Fig. 4. Pollenschlauchende kurz zweigabelig, der eine Arm bis zur Ansatzfläche des befruchteten Keimbläschens reichend. Anf. April 1855. Vgr. 200.

Fig. 5. Inhalt der Keimbläschen ausgctrieben. Das Präparat liegt so, dass das befruchtete Keimbläschen hinter und unter dem unbefruchteten sich befindet. Der Pollenschlauch hat sich zwischen Embryosackhaut und Cuticula gedrängt, und trägt einen Fetzen der letzteren an seiner, dem Sacke abgekehrten Seite. Ende Februar 1836. Gleiche Vgr.

Fig. 6. Primärer Kern des befruchteten Keimbläschens noch vorhanden. Die apicale Verlängerung des unbefruchteten Keimbläschens ist von ungewöhnlicher Länge. Vgr. 150.

Fig. 7. Pollenschlauch von der Embryosackhaut gelöst. Die Embryosackhaut ist an der Ansatzfläche des unbefruchteten Keimbläschens eingerissen; der Inhalt bcider Keimbläschen hat sich bei der Präparation contrahirt. Der Kern des befruchteten Keimbläschens ist, seiner Grösse und seinen nicht scharfen Umrissen nach zu schliessen, der primäre. Anfang April 1854. Vgr. 150.

Fig. 8. Pollenschlauchende von der Embryosackhaut gelöst. Der Scheitelpunkt des Embryosackes ist etwas nach unten gewendet, so dass seine apicale Ausstülpung nicht sichtbar ist. Anf. April 1854. Vgr. 150.

Fig. 9. Inhalt der drei Kcimbläschen bei der Präparation grösstentheils ausgetrieben. Pollenschlauch ungewöhnnlich dick. Anfang April 1854. Vgr. 150.

Fig. 10. Der Pollenschlauch, der einen kurzen Seitenast getrieben hat, trägt auf seiner dem Embryosack abgewendeten Seite einen Fetzen der Cuticula derselben. Im befruchteten untcren Keimbläschen ist der secundäre Kern desselben, in der Bildung begriffen, in undeutlichen Umrissen wahrzunehmen; nach oben zu ist eine Spur des noch nicht völlig verschwundenen primåren Kerns wahrzunehmen. Anf. April 1854. Vgr. 200.

Fig. 11. Befruchtetes Keimbläschen kernlos. Vgr. 150. 
Fig. 12. Das befruchtete Keimbläschen, mit ausgebildetem secundären Kern, und durch die Präparation etwas gestörter Anordnung des Inhalts, liegt über und vor dem unbefruchteten, oberen. Anf. März 1856. Vgr. 150.

Fig. 13. Der Inhalt des befruchteten Keimbläschens wurde bei der Präparation zum Theil ausgetrieben, seine Membran faltig. Das Stück der Embryosackhaut unterhalb der Ansatzstelle desselben ist zufällig nach oben gebogen. Anfang April 1856. Vgr. 150.

Fig. 14. Primärer Kern des befruchteten Keimbläschens noch vorhanden. Anf. April 1855. Vgr. 150.

Fig. 15. Beide Keimbläschen (im befruchteten ein muthmaasslich secundärer Kern) nebst dem sie bedeckenden Stücke Embryosackhaut vom Pollenschlauchende abgelöst. Die Embryosackhaut ist dicht rings um die Ansatzstellen der Keimbläschen abgerissen; das untere Keimbläschen liegt auf dem oberen, unbefruchteten Ende. Februar 1855. Vgr. 150.

Fig. 15 ${ }^{\mathrm{b}}$. Dasselbe Präparat, um $90^{\circ}$ um seine Längsachse gedreht.

Fig. 16. Der Inhalt der drei Keimbläschen durch Einwirkung von Chlorcalciumlösung zu formlosen Ballen contrahirt. Die Ansatzstelle des mittleren Keimbläschens ist durch das obere verdeckt. Die Cuticula des Embryosackscheitels ist zum Theil von dessen Membran gelöst. Anfang März 1855. Vgr. 200.

Fig. 17. Der Pollenschlauch ist vom Embryosackscheitel getrennt; hat aber dabei einen Fetzen der Cuticula desselben mit fortgenommen. Das Pollenschlauchende zeigt einen Tüpfel, in dessen Oeffnung man hineinsieht. Der Inhalt beider Keimbläschen ist durch die Präparation ausgetrieben; die Membran des befruchteten, unteren, hat Falten bekommen. Ende Februar 1856. Vgr. 200.

Fig. 18. Der zweiarmige Pollenschlauch hatte in den, vom oberen Keimbläschen aus gefüllten Embryosackscheitel eine tiefe Rinne eingedrückt. Es ist aus dieser Rinne gelöst; dabei ist an seinem kürzeren Arme ein Fetzen der Cutieula des Embryosackes hängen geblieben. Ende Februar 1856. Vgr. 200.

Fig. 18 ${ }^{\mathrm{b}}$. Dasselbe Präparat, um $60^{\circ} \mathrm{um}$ seine Längsachse gedreht. Man bemerkt eine bedeutende Krümmung des befruchteten Keimbläschens, und im Ende des längeren Arms des Pcllenschlasuchs einen engen Tüpfel.

Fig. 19, 20. Stücke der Embryosackhaut, an denen nur das befruchtete Keimbläschen haftet; das unbefruchtete ist durch einen zwischen beiden Keimbläschen durchgehenden Schnitt entfernt. Anf. April 1853. Vgr. 200.

Fig. 21. Pollenschlauch kurz zweiarmig; Inhalt der drei Keimbläschen bei der Präparation ausgetrieben; Membran des untersten sehr faltig geworden. Ende Febr. 1854. Vgr. 200.

Fig. 22. Ansatzfläche des befruchteten, kernhaltigen Keimbläschens ungewöhnlich eng umschrieben; Pollenschlauch sehr dickwandig. Anf.März 1854. Vgr. 200.

Fig. 23. Pollenschlauchende unverletzt vom Embryosackscheitel gelöst. Das 
befruchtete Keimbläschen befindet sich hinter und unter dem unbefruchteten. Anf. April 1855. Vgr. 150.

Fig. 24. Pollenschlauchende unverletzt vom Embryosacke gelöst, dessen Haut zwischen beiden Keimbläschen gerissen ist. Diese liegen demnach vereinzclt; links neben dem Pollenschlauch das obere, rechts das untere, befruchtete. Anfang April 1854. Vgr. 150.

Fig. 25, 26. Vom Embryosack gelöste Pollenschlauchenden, an denen Fetzen der Cuticula desselben hängen. Anf. April 1833. Vgr. 150.

Fig. 27. Inhalt beider Keimbläschen ausgetrieben. Dcr sehr dümnwandigc Pollensclılauch ist links iiber seiner Spitze geborsten, und hat einen Thcil seines lnlıalts austreten lassen. Anf. März 183̋. Vgr. 200.

Fig. 28. Der varicöse Pollenschlauch ist sehr tief, bis zur Ansatzfläche des unteren Keimbläschens, am Embryosack herab gewachsen. Der lnhalt des unteren lieimbläschens ist ausgetrieben, seine Membran faltig. Anf. März 1855. Vgr. 200.

Fig. 29. Pollenschlauch sehr dick, Cuticula des Embryosacks nicht merklich entwickelt, der Inhalt des Keimbläschens durch Glycerin contrahirt. Anf. April 1856. Vgr. 150.

Fig. 30. Der Pollenschlauch vom sehr dickwandigen Scheitel des Embryosacks abgetrennt. Ein Stuick der Cuticula ist an ihm hängen geblieben. Anf. März 1830. Vgr. 200.

Fig. 31. Pollenschlauch, der beim Eintritt in das Endostom sich gabelte, aus dem Endostom hervorgezogen. März 1835. Vgr. 200.

Fig. 32. Inhalt der Keimbläschen durch Einwirkung von Glycerinlösung contrahirt. Der Pollenschlauch ist links über seiner Spitzc geborsten, und hat einen Theil seines Inhalts austreten lassen. Anf. April 1856. Vgr. 200.

Fig. 32b. Dasselbe Präparat, von unten gesehen, dic Lage der Keimbläschen im Grundrisse zeigend. Vgr. 80.

\section{Tafel XXIII.}

\section{Crocus vernus.}

Fig. 1. Frei präparirtes oberes Ende eines vor Kurzem befruchtcten Embryosacks, mit anhaftendem Pollenschlauche. Im unteren Ende des befruchteten (unteren) Kcimbläschens ist bereits der ncue Kern, in seiner Umgebung eine Anhäufung grösserer Körnchen entstanden. Am 5. März 1856 (in Zimmer getriebenes Exemplar). Vgr. 200.

Fig. 2. Aehnliches Präparat. $p$ Pollenschlauch, $k$ fehlschlagendes, $k$ ' befruchtetes Keimbläschen. Ebenso ist die Bedeutung der Buchstaben bei den folgenden Figuren. Am 10. April 183̈1. Gleiche Vgr.

Fig. 3. Endostom und Embryosackende eines befruchteten Eychens, im Längsdurchschnitt, am 8. April 1852. Vgr. 130.

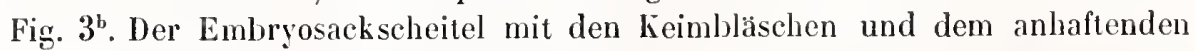
Pollenschlauchende aus dem nämlichen Präparate, frci gelegt und ein wenig nach links um die Längsachse gedreht. Vgr. 200. 
Fig. 3c. Dasselbe Präparat, um $90^{\circ}$ gedreht. Vgr. 150.

Fig. 4. Aehnliches Präparat, mit kurz zweiarmigem Pollenschlauche. Vgr. 150.

Fig. 5. Aehnliches Präparat, mit sehr schwach entwickelter Cuticula des Embryosackes, am 14. Febr. 1855. Vgr. 150.

Fig. 6. Aehnliches Präparat, mit ungewöhnlich tief herab gewachsenem Pollenschlauche, dem an der Spitze auf der Aussenseite ein durch ihn von der Embryosackhaut abgelöster Fetzen der Cuticula derselben anhaftet. Am 17. Febr. 1856. Vgr. 200 .

Fig. 7. Aehnliches Präparat. Nur ein sehr kurzes Stück des Pollenschlauches ist erhalten. Am 1. März 18̈̈6. Vgr. 1500.

Fig. 8. Aehnliches Priparat, bei welchem das Pollenschlauchende während der Präparation vom Embryosacke sich trennte, einen Fetzen der Cuticula desselben abreissend. Die Membran des fehlschlagenden (oberen) Keimbläschens ist eingerissen. Vgr. 300 .

Fig. $8^{\text {b }}$. Aelinliches Präparat; auf der Aussenseite des Pollenschlauchendes ein Fetzen von Cuticularsubstanz, wie bei F. 6. Die lläute beider Keimbläschen haben bei der Präparation Faltung erlitten. Die Substanz dieser Häute ist granulirt. Am 17. April 185\%. Vgr. 600.

Fig. 9. Aehnliches Präparat; das befruchtete Keimbläschen ist dreizellig. Am 26. April 1850. Vgr. 150.

Fig. 10-14. Aebnliche Präparate; die befruchteten Keimbläschen zweizellig. Vgr: 150.

Fig. 15. A ehnliches Präparat, bei welchem der Pollenschlauch, unter Mitnahme eines Cuticulafetzens, vom Embryosacke abgerissen ist. Vgr. 150.

Fig. 16, 17. Aehnliche Präparate; der Pollenschlauch bereits dünnbäutig geworden und zusammengesunken. Gleiche Vgr.

Fig. 18. Aehnliches Präparat. Die Embryosackhaut ist an der Anbeftungsstelle des oberen Keimbläschens etwas eingerissen. Das befruchtete Keimbläschen ist vierzellig. Vgr. 150.

Fig. 18 . Durchschnittsansicht der Pollenschlauchspitze des vorigen Präparats. Vgr. 800 .

Fig. 19. Aehnliches Präparat mit zweiarmigem Pollenschlauche, dessen beide kurze Gabeläste in der durch die Sehachse gelegten Ebene liegen. Befluchtetes Keimbläschen vierzellig. Vgr. 100.

Fiğ. 20. Obere Hälfte eines frei präparirten Embryosackes, von dem die Scheitelwölbung (und mit ihr das unbefruchtete Keimbläschen) durch Ziehen am Pollenschlauche abgerissen sind. Am 18. April 185.5. Vgr. 100.

Fig. 21. Sechszelliger Vorkeim, frei präparirt. Am 23. April 1853. Vgr. 150.

Fig. 22. Mikropyle-Ende eines frei präparirten Embryosackes mit fünfzelligem Vorkeim. Dem Embryosackscheitel ist eine älnnliche Zerreissung widerfahren, wie dem F. 20 abgebildeten. Im Mai 1853. Vgr. 150.

Fig. 23. Junger Saame in Längsdurchschnitt. Die Zellen des innern Integuments sind bedeutend quer gestreckt; der Embryosack ist grossentheils mit Endosperm gefúllt. Am 17. Mai 1855. Vgr. 15.

Fig. 23b . Die Embryoanlage daraus in 120facher Vgr. 
Fig. '24. Oberes Ende eines frei präparirten Embryosackes ähnlicher Entwickelung. e e Endospernizellen. Vgr. 120.

In den F. 1, 3a , 9, 12, 20-22 ist der Zelleninhalt in seiner natürlichen Anordnung dargestellt; in den übrigen so, wie er nach kürzerem oder längerem Liegen in Glycerin zusammen gezogen erscheint.

\section{Tafel XXIV.}

\section{Figur 1-8. Crocus vernus.}

Fig. 1. Reifer Saame, am 9. Septbr. 185ั, im Längsdurchschnitt (der die Raphe nicht getroffen hat). Der Embryo, durch den Schnitt blos gelegt, ist von vorn zu sehen. $\mathrm{Vgr}$. 15 .

Fig. 2. Der Embryo eines reifen Saamens, im durch die Spalte des Kotyledon geführten Längsschnitte. Vgr. ว0.

Fig. 3. Träger und Wurzelende eines reifen Embryo im Längsdurchschnitte. Rechts neben dem Träger ist das Gewebe des Endosperms mit gezeichnet; über seinem oberen Ende sind die Umrisse des Endostoms angegeben. Vgr. 120 .

Fig. 4, 丂, 8. Monströse Entwickelungen von Pollenschlauchenden. (S.741.) Vgr.200.

Fig. 6, 7. Monströse Entwickelungen von Keimbläschen; F. 6. Durchschnitl des Endostoms bei 120 facher Vgr.; F. 7. Durchschnitt des innern Integuments und Eykerns, 50fache Vgr.

Fig. 9. Gladiolus communis. Frei präparirtes oberes Ende eines befruchteten Embryosackes mit zwei Keimbläschen und anhaftendem Pollenschlauche. Vgr. 300.

Fig. 10. Ixia rosea. Unbefruchtetes Ey im Längsdurchschnitt. Vgr. 30.

Fig. 11. Endostom eines solchen Eychens mit den herausragenden, von den Keimbläschen ausgefüllten Ausstülpungen des Embryosackes. Vgr.600.

Fig. 12. Tritonia crocata. Obere Hälfte eines frei präparirten befruchteten Embryosackes. Vgr. 150.

Fig. 13. Montbretia lineata. Längsdurchschnitt eines vor Kurzem befruchteten Eychens, die bedeutende Querstreckung der äusseren der zwei Zellschichten des inneren Integuments zeigend. Vgr. 30.

Fig. 14. Pontederia cordata. Jungfräuliches Germen imLïngsdurchschnitt. Vgr.30.

Fig. 15. Oberer Theil des Eykerns mit dem Enbryosacke derselben Pflanze im Längsdurchschnitt. Vgr. 100.

Fig. 16. Vom Pollenschlauch durchzogene Kernwarze und Embryoanlage derselben Pflanze im Längsdurchschnitt. Vgr. 300.

Fig. 17. Tradescantia virginica. Eychen, in dessen Mikropyle ein Pollenschlauch eingetreten, im Längsdurchschnitt. Vgr. 15.

Fig. 18. Embryosack, Kernwarze und Pollenschlauch desselben Eychens, 200fach vergrössert.

Fig. 19. Junger Saame im Längsdurchschnitt. Vgr. 15.

Fig. 20. Das obere Ende des frei präparirten Enbryosackes mit der Embryoanlage, aus demselben Eychen. Vgr. 200. 


\section{Tafel XXV.}

\section{Figur 1-5. IIymenocallis ovata.}

Fig. 1. Unbefruchtetes Eychen im Längsdurchschnitt. Vgr. 15.

Fig. 2. Oberer Theil des Eykerns und Endostom eines solchen Eychens; in der Scheitelwölbung des Embryosackes drei Keimbläschen. Vgr. 300.

Fig. 3. Oberes Ende eines befruchteten Embryosacks, der von der auf eine wenig unfangreiche Zellgruppe geschwundenen Kernwarze bedeckt ist, frei präparirt. Der Pollenschlauch hat sich während der Präparation vom Embryosacke getrennt. Gleiche Vgr.

Fig. 4. Aehnliches Präparat, vier Keimbläschen enthaltend. Gleiche Vgr.

Fig. 5. Aehnliches Präparat, mit anhaftendem Pollenschlauchende, nur ein Keimbläschen ist vorhanden. Gleiche Vgr.

\section{Figur 6-13. Paris quadrifolia.}

Fig. 6. Längsdurchschnitt eines jungfräulichen Fruchtknotens. Vgr. 20.

Fig. 7. Querdurchschnitt eines aus 6 Carpellen bestehenden solchen. Vgr. 10.

Fig. 8. Unbefruchtetes Eychen im Längsdurchschnitt. Vgr. 50.

Fig. 9. Eykern, iın Beginn der Bildung der Keimbläschen im Längsdurchschnitt. Vgr. 400 .

Fig. 10,11. IVeiter vorgerückte Zustände von Kernen unbefruchteter Eychen, im Längsdurchschnitt. Vgr. 150.

Fig. 12, 13. Kernwarze und Scheitelwölbung des Embryosackes längsdurchschnittener, vor Kurzem befruchteter Eychen; bei F. 13 ist das PolIenschlauchende vom Schnitt blos gelegt; bei F. 19 durch ihn entfernt. Vgr. 300 .

Fig. 14. Narcissus Jonquilla. Unbefruchtetes Eychen im Längsdurchschnitt. Die Lage der Gegenfüsslerzellen des Keimbläschens ist eine ungewöhnliche. Vgr. 40.

Fig. 15. Kernwarze, vom Pollenschlauche durchzogen, und Scheitelgegend des Embryosackes eines längsdurchschnittenen befruchteten Eychens derselben Pflanze. Vgr. 300 .

\section{Figur 16-21: Scheuchzeria palustris.}

Fig. 16. Unbefruchtetes Eychen, längsdurchschnitten. Vgr. 15.

Fig. 17. Eykern eines solchen. Vgr. 90.

Fig. 18, 19. Embryosäcke solcher Eychen. Vgr. 200.

Fig. 20. Embryosack und vom Pollenschlauch durchzogene Kernwarze eines vor Kurzem befruchteten Eychens. Gleiche Vgr.

Fig. 21. Embryoanlage aus einem Eychen ähnlicher Entwickelung. Gleiche Vgr.

Fig. 22. Puya chilensis. Längsdurchschnittsansicht eines unbefruchteten Eychens. 


\section{$\operatorname{Index}$.}

Alisma Plantag0. Krümmung des Eykerns 660. Bau des Eykerns 663.

Fehlen der Gegenfüsslerzellen der Keimbläschen 677 .

Zeitige Verdrängung der den befruchteten Embryosack seitlich umbüllenden Zellschicht durch diesen 692 .

Zunahme des Umfanges des befruchteten Keimbläschens 698 .

Zellenzahl des Vorkeims 700 .

Alismaceen. Form des Vorkeims 700.

Allium odorans. Weite Oeffuung des Exostoms 661 .

Bau des jungen Eykerns 663 .

Lage der zum Embryosack sich entwickelnden Zelle des Eykerns 664.

Vollständige Verdrängung der, den unbefruchteten Embryosack seitlich umgebenden Zellschichten; Vermehrung der Zellen der Kernwarze während dieses Vorganges 667 .

Sonderung des Embryosackinhalts in Vacuole und Wandbeleg 669 .

Ablösbarkeit der Keimbläschen von der Embryosackhaut 672.

GelegentlichesVersch winden der unbefruchteten Keimbläschen bis auf eines 674 .

Gegenfüsslerzelleu der Keimbläschen 677 .

Verschwinden des primären Kerns des Embryosackes noch vor der Befruchtung 678 .

Vorbeiwachsen des Pollenschlauchs an der liernwarze 686.

Verdrängung des inneren Integuments durch den befruchteten Embryosack 692 .

Beharren deз des unteren Keimbläschens zum Embry o 693.

Entwickelang befruchteten Keimbläschens auf der Grösse des unbefruchtcten bis zur ersten Theilung 698 .

Allium victoriale. Verdrängung des inneren Integuments durch den Embryosack 739.
Aloë subtuberculata. Dreizahl der Integumente 661 .

Amaryllideen. Beugung des freien Theiles des Funiculus 652 .

Verdrängung den oberen Theil des unbefruchteten Embryosackes umbüllender Zellschichten 665 .

Dreizahl der Keimbläschen 672.

Erhärten der Membran auch der fehlschlagenden Kíimbläschen 694.

Form des Vorkeims 700.

Langsamkeit der Entwickelung des Embryo 708 .

Amaryllis Belladonna. Einziges Integument des Eychens 664.

Arö̈deen. Verdrängung des den Embryosack seitlich umhüllenden Gewebes 669 .

Zweizahl der Keimbläschen 672.

Form des Vorkeims 700 .

Wachsthum des Endosperms 705 .

Arum. Unterbleiben der Beugung des freien Theiles des Funiculus 653 .

Massenhaftigkeit des äussern Integuments 660 .

Hervorragen des Endostoms aus dem Exostom 661 .

Bau des Eykerns 663 .

Zeit, deren der Pollenschlauch bedarf, um von der Narbe bis in den Eymund zu gelangen 683 .

Endospermbildung 704 .

Arum divaricatum. Vollständige Verdrängung der, den unbefruchteten Embryosack seitlich umhüllenden Zellschichten 667 .

Ablösbarkeit der Keimbläschen von der Embryosackhaut 672 .

Geleyentliches Versch winden der un befruchteten Keimbläschen bis auf eines 674 .

Gegenfüsslerzellen der Keimbläschen 677.

Arum maculatum. Anordnung des Zelleninhalts junger Pollenmutterzellen 633 . 
Bau des jungen Eykerns 663.

Lage der zum Embryosack sich entwickelnden Zelle des Eykerns 664.

Vollständige Verdrängung der, den unbefruchtelen Embryosack seitlich umbüllenden Zellschichten; Vermehrung der Zellen der Kernwarze während dieses Vorganges 667 .

Sonderung des Embryosackinhalts in Vacuole und Wandbeleg 669.

Gelegentliches Verschwinden der unbefruchteten Keimbläschen bis auf eines 674 .

Gegenfüsslerzellen der Keimbläschen 677.

Durchbohrung der Kernwarze durch den Pollenschlauch 686 .

Entwickelung des unteren Keimbläschens zum Embryo 693.

Dauer der Zeit zwischen Ankunft des Pollenschlauchs am Embryosacke, und erster Theilung des befruchteten Keimbläschens 692.

Zunahme des Umfanges des befruchteten Keimbläschens 698 .

Kürze des Vorkeims 700 .

Arum orientale. Vollständige Verdrängung der, den unbefruchteten Embryosack seitlich umbüllenden Zellschichten 667 .

Durchbohrung der Kernwarze durch den Pollenschlauch 686.

Entwickelung des unteren Keimbläschens zum Embryo 693 .

Zunahme des Umfanges des befruchteten Keimbläschens 698 .

Kürze des Vorkeims 700.

Arum ternatum. Weite Oeffnung des Exostoms 661.

Vollständige Verdrängung der, den unbefruchleten Embryosack seitlich umhüllenden Zellschichten 667 .

Ablösbarkeit der Keimbläschen von der Embryosackhaut 672 .

Gegenfüsslerzellen der Keimblaschen 677 .

Asphodeleen. Verdränģung den oberen Theil des unbefruchteten Embryosackes umh üllender Zellschichten 66 .

Asphodelas luteus. Krïmmung der Längsachse der Chalazaregion 659 .

Dreizahl der Integumente 662.

Ablösbarkeit der Keimbläschen von der Embryosackhaut 672.

Gelegentliches Verschwinden der befruchteten Keimbläschen bis auf eines 674 .

Bildung einer freien Zelle um den primären Kern des Embryosackes 677.
Verschwinden des primären Kerns des Embryosackes noch vor der Befruchtung 678 .

Bonapartea juncea. Anatropie der Eyclien 659.

Einzahl der Gegenfüsslerzellen der Keimbläschen 677 .

Bromeliaceen. Verdrängung den oberen Theil des unbefruchteten Embryosackes umhüllender Zellschichten 665 .

Brunsvigia minor (?) Einziges Integument des Eychens 661.

Bulbocodium vernum. Beugung des freien 'Theiles des Funiculus 652.

Anatropie der Eychen 658.

Bau des Eykerns 663.

Vom Kern des Embryosackes ausgehende Protoplasmastränge 669 .

Gegenfüsslerzellen der Keimbläschen 677 .

Bau des Griffels und Fruchtknotens 737 .

Caladium bicolor. Weite Oeffnung des Exostoms 661 .

Vollständige Verdrängung der seitlich den unbefruchteten Embryosack umhüllenden Zellschichten durch den unteren Theil desselben 667 .

Calla palustris. Unterbleiben der Beugung des freien Theiles des Funiculus 652 .

Anatropie der Eychen 659.

Weite Oeffnung des Exostoms 661 .

Lage der zum Embryosack sich entwickelnden Zelle des Eykerns 664.

Vollständige Verdrängung der den unbefruchteten Embryosack umbüllendenZellschichten durch den unteren Theil desselben 667 .

Ablösbarkeit der Keimbläschen von der Embryosackhaut 672 .

Gelegentliches Verschwinden der unbefruchteten Keimbläschen bis auf eınes 674 .

Durchbohrung der Kernwarze durch den Pollenschlatich 686 .

Entwickelung des unteren Keimbläschens zum Embryo 693.

Endospermbildung 704 .

Bau des Fruchtknotens 725 .

Canna. Krümmung des Eykerns 660 .

Jüngste Zustände des Eykerns 663 .

Lage der zum Embryosack sich entwickelıden Zelle des Eykerns 664.

Verdrängung der den jungen Embryosack deckenden Zellschichten bis auf eine 665 .

Zellkerne der Keimbläschen, frei im Embryosack entstehend 670 .

Ablösbarkeit der Keimbläschen von der Embryosackhaut 672 . 
Gelegentlicbes Verscbwinden der unbefruchtelen Keimbläschen bis auf eines 674 .

Wanderung des Pollenscblaucbinhalts in dic fortwachsende Spitze 685 .

Eindringen des Pollenschlaucbendes in den Embryosack 687.

Wucherungen des Pollenscblauchendes im Embryosacke 687.

Form des Vorkeims 700 .

Unterbleiben der Endospermbildung 707.

Carex. Unterbleiben der Beugung des freien Theiles des Funiculus 652 .

Anatropie der Eychen 659.

Hervorragen des Endostoms aus dem Exostom 661 .

Lage der zum Embryosack sich entwickelnden Zelle des Eykerns 664.

Gegenfüsslerzellen der Keimbläscben 677 .

Schnelligkeit des Vordringens des Pollenschlauchs von der Narbe bis in den Eymund 682 .

Form des Vorkeims 700.

Wachsthum des Endosperms 705.

Bau des reifen Embryo 709.

Gephalanthera rubra. Allmäliges Fortscbreiten der Auflösung der Pollenmutterzellenwände von Aussen nach Innen 640 .

Contraction der jungen Pollenhaut bei Bebandlung mit Chlorzinkjod 647 .

Viscingebalt von Zellen des vorderen $\mathrm{Ab}-$ schnitls der Narbe 652 .

Colchicum autumnale. Vollständige Verdrängung der, den unhefruchteten Embryosack seitlich umbüllenden Zellschichten 667 .

Schnelligkeil des Herabwachsens des Pollenschlauchs von der Narbe bis in den Eymund 682.

Wanderung des Pollenschlauchinbalts in die forlwachsende Spitze 685 .

Vorbeiwachsen des Pollenschlauchs an der Kernwarze 686.

Rasche Debnung der Integumente nach Ankunft des Pollenschlaucbes im Eymunde 691.

Ort der Anheftung des zum Embryo sich entwickelnden Keimbläschens 693 .

Fehlen des Zellkerns in dem befruchleten Keimbläschen vom Herbst bis zum Mai 695.

Dauer der Zeit zwischen Ankunft des Pollenschlauchs am Embryosacke, und erster Quertbeilung des befruchteten Keimbläschens 697 .

Bebarren des befrucbteten Keimbläscbens auf der Grösse des unbefruchteten bis zur ersten Tbeilung 698.

Wachsthum des Endosperms 705.

Langsamkeit der Entwickelung des Embryo 708 .

Coix Lacryma. C-förmige Krümmung des Eykerus 659 .

Ablösbarkeit der Keimhläschen von der Embryosackhaut 672 .

Fehlen der Gegenfuisslerzellen der Keimbläschen 677 .

Grinum capense. Krümmung des Eykerns 660 .

Einziges Integument des Eychens 662.

Gegenfüsslerzellen der Keimbläschen 676, 677.

Verästelung des Pnllenschlauchs innerhalb der Mikropyle 684 .

Wanderung des Pollenschlauchinhalts in die forlwachsende Spitze 685 .

Inhaltskörper des Pollenschlauchendes 685 .

Verdickung der Wand des Pollenschlauchendes 689.

Verdrängung des Integuments durch den befruchtelen Embryosack 692.

Entwickelung des unteren Keimbläscbens zum Embryo 693.

Gelegentliches Unterbleiben der Bildung fester Zellhäute um dıe aborlirenden Keimbläschen 694 .

Beharren des befruchteten Keimbläscbens auf der Grösse des unbefrucbteten bis zur ersten Theilung 698 .

Vorkeim 701.

Endospermbildung 703 .

Verdrängung der Testa durch das Endosperm 706 .

Crinum variabile. Krümmung des Eykerns 660 .

Gegenfüsslerzellen der Keimbläschen 677.

Crocus vernus. Anatropie der Eycheu 658.

Bau des jungen Eykerns 663.

Zahl der Zellschichten des entwickelten Eykerns 663 .

Lage der zum Embryosack sich entwickelnden Zelle des Eykerns 664.

Vollständige Verdrängung der den Embryosack deckenden Zellschichten 666 .

Spitzenwachsthum der Scheilelgegend des Embryosackes 666 .

Sonderung des Embryosackinbalts in $\mathrm{Va}$ cuole und Wandbeleg 669 .

Feste Zellhaut der unhefruchteten Keimbläscben 671 .

Theilnahme der Anheftungsstellen der in 
der Scheitelwölbung des Embryosackes haftenden Keimbläschen am Spitzenwachsthum des Embryosackscheitels 673 .

Veränderungen des Inhalts des zum Fehlschlagen bestimmten Keimbläschens noch vor der Befruchtung 675 .

Auordnung eines Theiles des Inhalts der oberen Hälfte der Keimbläschen zu faserähnlichen Bildungen 676 .

Gegenfüsslerzellen der Keimbläschen 676 , 677.

Leistenförmige Verdickungen der Aussenseite der Haut des Embryosackscheitels 679.

Schnelligkeit des Herabwachsens des Pollenschlauchs bis in den Eymund 682.

Verästelungen des Pollenschlauchs in der Mikropyle 684.

Wanderung des Pollenschlauchinhalts in die fortwachsende Spitze 685 .

Inhaltskörper des Pollenschlauchendes 685.

Verhalten des Pollenschlauchendes zur Cuticula des Embryosackscheitels 688 .

Ablösbarkeit des Pollenschlauchendes vom Embryosacke 689 .

Verdickung, Schichtung und Tüpfelbildung der Wand des Pollenschlauchendes 689.

Wachsthum der Integumente, welches das des Eykerns überwiegt 691 .

Entivickclung des unteren Keimbläschens zum Embryo 693.

Erhärten der Membran auch der fehlschlagenden Keimbläschen 694 .

Gelegentliche Kernlosigkcit der Trägerzelle des Vurkeims 696 .

Dauer der Zeit zwischen Ankunft des Pollenschlauchs am Embryosacke, und erster Theilung des befruchteten Keimbläschens 697 .

Geringe Streckung des befruchtcten Keimbläschens 698 .

Haften des befruchteten Keimbläschens an der Innenwand des Embryosackes 698.

Vorkeim 700, 701 .

Endospermbildung 703.

Wachsthum des Endosperms 705.

Langsamkeit der Entwickelung des Embryo 708.

MonströseEntwickelung von Pollenschlauchenden und Keimbläschen 710 .

Gyperaceen. Zweizahl der Keimbläschen 672.

Verdrängung des Perisperms durch den Embryosack 692.
Gzackia Liliastrum. Weite Oeffnung des Exostoms 664 .

Entwickelung des unteren Keimbläschens zum Embryo 693.

Streckung des befruchteten Keimbläschens 695.

Endospermbildung 703 .

Wachsthum des Endosperms 705.

Elymus arenarius. $S$-förmige Krümmung des Eykerns 659.

Gegenfüsslerzellen der Keimbläschen 677 .

Entwickelung des unteren Keimbläschens zum Embryo 693.

Endospermbildung 703.

Epipactis. Entwickelung des Pollens 645.

Viscingebalt von Zellen des vorderen $\mathbf{A b}$ schnitts der Narbe 652.

Zurückbleiben des Längenwachsthums des äusseren Integuments hinter dem des Inneren 661 .

Erythronium dens canis. Hiiufige Kernlosigkeit der Trägerzelle des Vorkcims 696.

Zunahme des Umfanges des befruchteten Keimbläschens 698 .

Vorkeim 701 .

Fritillaria. Zahl der Zellschichten des Eykerns 663 .

Zellkerne der Keimbläschen, frei im Wandbeleg des Embryosackes 670 .

Bildung einer freien Zelle um den primären Kern des Embryosackes 677.

Kernlosigkeit der Trägerzelle des Vorkeims 696.

Unbeständigkeit des Maasses der Grössezunahme des befruchteten Keimbläschens 698.

Vorkeim 704 .

Funkia coerulea. Anatropie der Eychen 659 .

Bau des jungen Eykerns 663.

Lage der zum Embryosack sich entwickclnden Zelle des Eykerns 664.

Verdrängung der den Embryosack deckenden Zellschichten bis auf eine 665 .

Zellkerne der Keimbläschen, frei im Wandbeleg des Embryosackes 670 .

Ablösbarkeit der Keimbläschen von der Embryosackhaut 672 .

Höhere, als Dreizahl der Keimbläschen 672.

GelegentlichesVerschwinden der unbefruchteten Keimbläschen bis auf eines 674 .

Bildung einer freien Zelle um den primären Kern des Embryosackes 677.

Verästelung des Pollenschlauches innerhalb der Mikropyle 685. 
Frühzeitige Entwickelung des untersten Keimbläschens zum Embryo 698.

Vorkeim 704.

Gagea lutea. Beugung und Torsion des freien Theiles des Funiculus 652.

Anatropie der Eychen 658.

Zahl der Zellschichten des Eykerns 663.

Gelegentliches Verschwinden der unbefruchteten Keimbläschen bis auf eines 674.

Bildung einer freien Zelle um den primären Kern des Embryosackes 678.

Verschwinden des primären Kerns des Embryosackes noch vor der Bcfruchtung 678 .

Grössczunahme des Eychcns bei Ankunft des Pollenschlaucbs in der Mikropyle 690.

Wachsthum der Integumente, welches das des Eykerns überwiegt 691.

Zeitige Verdrängung der den befruchteten Embryosack seitlich umhüllenden Zellschicbt durch dicsen 692 .

Entwickelung des unteren Keimbläscbens zum Embryo 693.

Gelegentliche Bildung des secundären Kerns des befruchteten Keimblaschens noch während des Vorhandenseins des primären 695 .

Kernlosigkeit der Trägerzclle des Vorkeims 696.

Zunahme des Umfangs des befruchteten Keimblảschens 698 .

Vorkeim 700 .

Endospermbildung 703 .

Wachsthum des Endosperms 705.

Gladiolus communis. IIebung des untercn Endes des Embryosacks durch Massenzunahme des, dassellsc umschliessenden Gewebes 665 .

Vollständige Verdrängung der den Embryosack deckenden Zellschichten 666 .

Theilnalsme der Anheftungsstelen der in der Scheitelwölbuıg des Embryosackes Laftenden Keimbläschen an dem Spitzenwachsthum derselben 674 .

Leistenformige Verdickungen der Aussenseite der IIaut des Embryosackscheitels 679 .

Entwickelung des unteren Keimblïschens zum Embryo 693.

Gloriosa superba. Anatropie der Eyclien 630 . Gegenfüsslcrzellen der Keimbläschen 677.

Versclıwinden des primären Kerns des Embryosackes noch vor der Befruchtung 678.
Gramineen. Hcrvorragen des Endostoms aus dem Exostom 661 .

Zahl der Zellschichten des Eykerns 663 .

Lage der zum Embryosack sich entwickelnden Zelle des Eykerns 664.

Zweizahl der Keimbläschen 672 .

Schnelligkeit des Herabwachsens des Pollenschlauches von der Narbe bis in den Eymund 682.

Verdrangung des Perisperms durch den Embryosack 692.

Häufige Keınlosigkeit der Trägerzelle des Vorkeims 696.

Kürze der Zeit zwischen der Ankunft des Po!lenscblauches an Embryosacke, und der ersten Thellung des befruchtelen Keimbläschens 697 .

Streckung des bcfruchteten Keimbläschens 698.

Wachsthum des Endosperms 705.

Verdrängung des Endosperms durch das Wurzelende des Embryo 707.

Schnelligkeit der Ausbildung des Embryo 708.

Entwickelung des Scutellum 709.

Gymnadenia conopsea. Keimung 723.

Habranthus chilensis. Vorkeim 700.

Hemerocallis flava. Auflösung des primären Kerns der Pollcnmutterzellen 634.

Körnerplatten zwischen den secundären und tertiären Kernen der Pollenmutterzclle 635 .

Vollständige Verdrängung der den unbefruchtcten Embryosack deckenden Zellschichten 666.

Entwickelung des unteren Keimbläschens zum Embryo 693.

Endospermbildung 703.

Hippeastrum aulicum. Krümmung der Längsacbse der Chalazaregion 659 .

Einfachheit des Baues des Endostoms 660 .

Masscnhaftigkeit des äüsseren Integuments 660.

Zahl der Zellschichten des Eykerus 663.

Vom Kern des Embryosackes ausgehende Protoplasmastränge 669 .

Ablösbarkeit der lícimbläschen von der Embryosackhaut 672 .

Einzahl der Gegenfüsslerzellen der Keimbläschen 677 .

Veristelung des Pollenschlaucbes innerhalb der Mikropyle 684.

Verdickung der Wand des Pollenschlauchcndes $6 \$ 9$. 
Entwickelung des unteren Keimbläschens zum Embryo 693.

Gelegentliehes Unterbleiben der Bildung fester Zellhiute um die abortirenden Keimbläsehen 694 .

Strcekung des befruehteten Keimbläseh.698. Vorkeim 700 .

Hordeum vulgare. $S$-förmige Krümmung des Eykerns 659.

Gegenfüsslerzellen der Keimbläsehen 677 .

Ablösbarkeit des Pollensehlauehendes vom Embryosaeke 689.

Entwickelung des unteren Keimbläschens zum Embryo 693.

Vorkeim 701 .

Endospermbildung 703.

Ejacinthus orientalis. Lage der zum Embryosaek sieh entwiekelnden Zelle des Eykerns 664 .

Ablösbarkeit der Keimbläschen von der Embryosaekhaut 672 .

GelegentliehesVersehwinden der unbefruchteten Keimbläsehen bis auf eines 674 .

Ablösbarkeit des Pollensehlauchendes vom Embryosaeke 689.

Haften des befruehteten Keimbläschens an der Innenwand des Embryosackes 698.

Endospermbildung 703.

Hymenocallis ovata. Einfachbeit des Baues des Endostoms 660.

Weite Oeffnung des Endostoms 661 .

Hôhere, als Dreizahl der Keimbläsehen 672.

Feblen der Gegenfüsslerzellen der Keimbläschen 677 .

Vorbeiwaehsen des Pollensehlauchs an der Kernwarze; Auftreffen seines Endes auf die Seitenfläche des Embryosaeks 686 .

Frühzeitige Entwiekelung des untersten Keimbläsehens zu eiuem Embryo 694.

Irideen. Hebung des unteren Endes des unbefruehteten Embryosackes durch Massenzunahme des dasselbe eilsehliessendeu Gewebes; - Verdrängung den oberen Theil des unbefruehteten Embryosackes umhüllender Zellschiehten 665 .

Erhärten der Membranen aueh der lehlseblagenden Keimbläsehen 694.

Form des Vorkeims 700.

Iris. Unregelmässige Form der Pollcnmutterzellen 633.

Anatropie der Eyehen 658.

Hebung des unteren Endes des Embryosacks durch Massenzunahme des dasselbe umscbliessenden Gewebes 665 .
Iris. Arten mit gebarteten Perigonialblättern; - Fünf- und Mehrzahl in derselben Mutterzelle entsteheıder Pollenkörner 636.

Simultane Theilung der Mutterzelle in mehr als zwei Toehterzellen 637.

Aussehliipfen der Pollenzellen aus berstenden Speeialmutterzellen 639 .

Allmäliges Fortsehreiten der Auflösung der Mutterzellwände von Aussen naeh Innen 640 .

Iris florentina. Anordnung des Zelleninbalts junger Pollenmutterzellen 633.

Körnerplatten zwischen den secundären und tertiären Kernen der Pollenmutterzelle 635 .

Iris parisiensis. Aufquellen der inneren Sehiehten der Haut der Pollenmutterzellen 634 .

Iris pumila. Auflösung des primären Kerns der Pollenmutterzellen 634 .

Bau des jungen Eykerns 663 .

Zahl der Zellsehiehten des entwickelten Eykerns 663.

Lagc der zum Embryosaek sieh entwick clnden Zelle des Eykcrns 664.

Verdrängung der den jungen Embryosack deekénden Zellschiehten bis auf eine 665 .

Sonderung des Embryosackinhalts in $\mathrm{Va}$ cuole und Wandbeleg 669.

Zellkerne der Keimbläsehen, frei in Wandbelege des Embryosacks entstehend 670 .

Ablösbarkeit der Keimbläsehen von der Embryosaekhaut 672 .

Gegcnfüsslerzellen der Keimbläschen 676 .

Bildung einer freien Zelle um den primären Kern des Embryosackes 678 .

Amylumgehalt des unbefruchteten Embryosackes 678 .

Sehnelligkeit des Herabwachsens des Pollensehlauchs von der Narbe bis in den Eymund 680.

Zeitige Verdrängung der den befruchte en Embryosaek seitlieh umhüllenden Zellsehieht dureh diesen 692.

Vorkeim 700.

Endospermbildung 703.

Wachsthum des Endosperms 705.

Ixia rosea. Anatropie der Eyeben 658 .

Vollständige Verdrängung der den Embryosack deckenden Zellschiehten 666.

Spitzenwaehsthum der Scheitelgegend des Embryos ackes 666 . 
Theilnabme der in der Scheitelwölbung des Embryosackes haftenden Ansatzflächen von Keimbläschen am Spitzenwachstbum des Embryosackscheitels 674.

Bildung fester Längsfasern in dem ausgewacbsenen Theile der Keimbläschen 675.

Gegenfüsslerzellen der Keimbläschen 677 .

Leistenförmige Verdickungen der Aussenseite der Haul des Embryosackscheitels 679.

Wachsthum der Integumente, welcbes das des Eykerns überwiegt 691.

Lemna minor. Vollständige Verdrängung der, den unbefruchteten Embryosack seitlich umbüllenden Zellscbichten 667 .

Keimung 716.

Leucojum vernum. Krümmung der Längsachse der Chalazaregion 659.

Bau des Eykeros 663 .

Cylinderform des zur Befruchtung bereiten Embryosackes 666 .

Vom Kern des Embryosackes ausgehende Protoplasmastränge 669 .

Feste Zellbaut der Keimbläschen 671.

Veränderungen des Inhalts des zum Fehlschlagen bestimmten Keimbläschens noch vor der Befruchtung 675 .

Anordnung cines Theiles des Inbalts der oberen Hälfte der Keimbläschen zu faserähnlichen Bildungen 676 .

Schnelligkeit des Herabwachsens des PolIcnschlauchs von der Narbe bis in den Eymund 682 .

Verästelung des Pollenscblauchs innerhalb der Mikropyle 684.

Zeitige Verdrängung der, den befruchteten Embryosack seitlich umbüllenden Zellschicht durch diesen 692.

Entwickelung des unteren Ko:mbläscbens zum Embryo 693 .

Gelegentliches Unterbleiben der Bildung fester Zellhäute um die abortirenden Keimbláschen 694.

Kernbaltigkeit der Trägerzelle des Vorkeims 696 .

Sonderung des Inhalts in Quertheilung begriffener befruchteter Keimbläschen in zwei Hälften vor Bildung der Querwand 696.

Dauer der Zeit zwischen Ankunft des Poltcnschlaucbes am Emhryosacke, und erster Tbeilung des befruchteten Keimbläschens 697 .
Streckung des befruchteten Keimbläschens 698.

Haften des befruchteten Keimbläschens an der Innenwand des Embryosackes 698.

Auftreten der Kerne der Endospermzellen 701.

Endospermbildung 703 .

Langsamkeit der Entwickelung des Embryo 708 .

Liliaceen. Bcugung des freien Theiles des Funiculus 652 .

Massenhaftigkeit des äusseren Integuments 660 .

Hervorragen des Endostoms aus dem Exostom 661 .

Bau des Eykerns 663.

Dreizahl der Keimbläschen 672.

Grössenzunahme des Eychens bei Ankunft des Pollenschlauchs in der Mikropyle 690.

Erhärten der Memhran auch der fehlschlagenden Keimbläschen 694.

Form des Vorkeims 700.

Langsamkeit der Entwickelung des Embryo 708 .

Stillstand der Entwickelung des embryonalen Achsenendes beim Hcrvorsprossen des Kotyledon 709.

Lilium. Schnelligkeit des Herabwachsens des Pollenschlauchs von der Narbe bis in den Eymund 682.

Maranta zebrina. Aufquellen der Intine 640 .

Melanthaceen. Zweizahl der Keimbläschen 672.

Merendera caucasica. Beugung des freien Theilcs des Funiculus 652.

Anatropie der Eychen 658.

Weite Oeffnung des Endostoms 661 .

Vollständige Verdrängung der, den unbefruchteten Embryosack seitlich umbüllenden Zellschichten 667.

Anschmiegung der Embryosackhaut an die Hüllbaut des Eykerns 668.

Vom Kern des Embryosackes ausgehende Protoplasmastränge 669 .

Veränderungen des Inhalts des zum Fehlschlagen bestimmten Keimbläschens noch vor der Befruchtung 675 .

Gegenfüsslerzellen der Kcimbläsclien 677.

Amylumgebalt des unbefrucbteten Embryosackes 678 .

Schnelligkeit des Herabwachsens des Pollenschlauchs von der Narbe bis in den Eymund 682. 
Wanderung des Pollenschlauchinhalts in die fortwachsende Spitze 685 .

Inhaltskörper des Pollenschlauchendes 685 .

Vorbeiwachsen des Pollenschlauchs an der Kernwarze; Verhatten seines Endes an der Seitenfläche des Embryosacks 686 .

Ablösbarkeit des Pollenschlauchendes vom Embryosacke 689 .

Rasche Dehnung der Integumente nach Ankunft des Pollenschlauchs am Eymunde 692.

Ort der Anheftung des zum Embryo sich entwickclnden Keimbläschens 693 .

Dauer der Zeit zwischen Ankunft des Pollenschlauches am Embryosacke, und erster Theilung des befruchteten Keimbläschens 697.

Beharren des befruchteten Keimbläschens auf der Grösse des unbefruchteten bis zur ersten Theilung 698.

Langsamkeit der Entwickelung des Embryo 708.

Bau des Griffels und Fruchtknotens 733.

Najadeen. Zweizahi der Keimbläschen 672 .

Kernlosigkeit der Trägerzelle des Vorkeims 696.

Form des Vorkeims 700.

Schnelligkeit der Ausbildung des Embryo 708.

Najas major. Körnerplatten zwischen den tertiären Kernen der Pollenmutterzelle 635.

Simultane Theilung der Pollenmutterzelle in mehr als zwei Tochterzellen 637.

Bau der Anthere. Pollenbildung 642.

Beugung des freien Theiles des Funiculus 652.

Krummung des Eykerns 660 .

Weite Oeffnung des Exostoms 661 .

Lage der zum Embryosack sich entwickelnden Zelle des Eykerns 664.

Vom Kern des Embryosackes ausgehende Protoplasmastränge 669 .

Einzahl der Gegenfüsslerzellen der Keimbläschen 676 .

Entwickelung von Pollenschlauchen in den Antherenfachern 683.

Wanderung des Pollenschlauchinhalts in die fortwachsende Spitze 685 .

Durchbohrung der Kernwarze durch den Pollenschlauch 686 .

Tiefe Einstïlpung des Embryosacks durch den Pollenschlauch 687 .
Verdrängung des Perisperms durch den Embryosack 692 .

Entwickelung des unteren Keimbläschens zum Embryo 693.

Auftreten des secundären Kerns des befruchteten Keimblasschens vor Verschwinden des primären 695 .

Dauer der Zeit zwischen der Ankunft des Pollenschlaucbs am Embryosacke, und der ersten Quertheilung des befruchteten Keimbläschens 697 .

Unstetigkeit des Maasses der Zunahme des Umfanges des befruchteten Keimbläschens 698 .

Entwickelung des Embryo aus dem Vorkeime 708 .

Beschalfenheit der hypokotylen Achse 709 .

Narissineen. Verdrängung den oberen Theil des unbefruchteten Embryosackes umhüllender Zellschichten 665 .

Narcissus Jonquilla. Gegenfüsslerzellen der Keimbläschen; exceptionelle Lage derselben 677.

Einstulpung des Embryosacks durch den Pollenschlauch 687.

Zeilige Verdrängung der, den befruchteten Embryosack seitlich umbüllenden Zellschicht durch diesen 692.

Beharren des befruchteten Keimbläschens auf der Grösse des unbefruchteten bis zur ersten Theilung 698 .

Narcissus poëticus. Gcgenfüssterzellen der Keimbläschen 677.

Einstülpung des Embryosacks durch den Pollenschlauch 687.

Zeitige Verdrängung der den befruchteten Embryosack seitlich umhüllenden Zellschicht durch diesen 692 .

Neottia Nidus avis. Bau des Rostellum 648 .

Neottia ovata. Auflösung des primären Kerns der Pollenmutterzellen 634.

Entwickelung des Pollens 645.

Bau des Rostellum 651.

\section{Orchideen.}

Langsame Entwickelung des Embryo 708.

Verhältniss des ersten Blattes der Keimpflanze zum Achsenende 709.

Orchis. Entwickelung des Pollens 647.

Entwickelung der Caudiculae und Retinaculae 6 วั2.

Entwickelung der Eychen 653.

Unterbleiben der Beugung des freien Theiles des Funiculus 658.

Weite Oeffnung des Exostoms 661. 
Lage der zum Embryosack sich entwickelnden Zelle des Eykerns 664.

Sonderung des Embryosackinhalts in Vacuole und Wandbeleg 669 .

Freie Zellkerne der Kieimbläschen 670.

Zwei-bis Dreizahl der Keimbläschen 672.

Gegenfüsslerzellen der Keimbläschen 677 .

Fehlen der Cuticula des Embryosackscheitels 680 .

Zeit, deren der Pollenschlauch bedarf, um von der Narbe bis in den Eymund zu gelangen 683.

Entwickelung von Pollenschläuchen in den Antherenfächern 683 .

Wanderung des Pollenschlauchinhalts in die fortwachsende Spitze 685 .

Abbängigkeit der vollständigen Ausbildung von Fruchtknoten und Eychen vor Ankunft von Pollenschläuchen in der Fruchtknotenhöhle 690 .

Rasche Dehnung der Integumente nach Ankunft des Pollenschlauchs im Eymunde 691.

Geschlossenheit des Pollenschlauchendes bei der Befruchtung 692 .

Entwickelung des unteren Keimbläschens zum Embryo 693.

Kcrnhaltigkeit der Trägerzelle des Vorkeims 696.

Dauer der Zeit zwischen Ankunft des Pollenschlauchs am Embryosacke, und erster Quertheilung des befruchteten Keimbläschens 697.

Streckung des befruchteten Keimbläschens 698.

Vorkeim 700 .

Langsamkeit der Entwickelung des Embryo 708.

Oryza sativa. Verhältniss des Scutellum zum Kotyledon 709 .

Panicum. Endospermbildung 703.

Paris quadrifolia. Bau des jungen Eykerns 663 .

Zellvermehrung des den Embryosack umgebenden Gewebes 665.

Sonderung des Embryosackinhalts in Vacuole und Wandbeleg 669 .

Zellkerne der Keimbläschen, frei im Embryosack entstehend 670 .

Ablösharkeit der Keimbläschen von der Embryosackhaut 672 .

Gegenfüsslerzellen der Keimbläschen 677 .

Entivickelung des unteren Keimbläschens zum Embryo 693.
Beharren des befruchteten Kieimbläschens auf der Grösse des unbefruchteten his zur ersten Theilung 698 .

Phajus Wallichii. Entwickelung des Pollens 649.

Philodendron Imbe. Lŕrümmung der Lảngsachse der Chalazagegend 659 .

Geringe Dicke des äusseren Integuments 660 .

Weite Oeffnung des Exostoms 661 .

Vollständige Verdrängung der, den unbefruchteten Embryosack seitlich umhüllenden Zellschichten 667.

Bau des Fruchtinolens 725 .

Pistia Stratiotes. Schliessung des Exostoms zu einem engen hanale 661.

Bau des jungen Eykerns 663 .

Bau des entwickelten Eykerns 663 .

Lage der zum Embryosack sich entwickelnden Zelle des Eykerns 664.

Vollständige Verdrängung der, den unbefruchteten Embryosack seillich umhüllenden Zellschichten 667.

Entwickelung des unteren Keimblaschens zum Embryo 693.

Vorkeim 701 .

Endospermbildung 705 .

Anlegung des kiotyledon 709 .

Pontederia cordata. Unterbleiben der Beugung des freien Theiles des Funiculus 652 .

Beharren des befruchteten Keimbläschens auf der Grösse des unbefruchteten bis zur ersten Theilung 698 .

Potamogeton crispus. S-förmige Krümmung des Eykerns 659 .

Lage der zum Embryosack sich entwickelnden Zelle des Eykerıs 664.

- Verdrängung des Perisperms durch den befruchteten Embryosack 692.

Kernlosigkeit der Trägerzelle des Vorkeims 696.

Potamogetoneen. Form des Vorkeims 700.

Schnelligkeit der Aushildung des Embryo 708 .

Pothos longifolia. Bau des Eykerns 663 .

Vollständige Verdrängung der, den unhefruchteten Embryosack seitlich umhülIenden Zellschichten 667.

Anschmiegung der Embryosackhaut an die Ilüllhaut des Eykerns 668 .

Gegenfüsslerzellen der Keimbläschen 677 . Verschwinden des primären Kierns des Embryosackes noch vor der Befruchtung 678 . 
Amylumgehalt des unbefruchteten Embryosackes 678 .

Zeit, deren der Pollensehlaueh bedarf, um von der Narbe bis in den Eymund zu gelangen 683 .

Verästelung des Pollenschlauchs in der Frachtknotenhöhle 685 .

Inhaltskörper des Polleuschlauchendes 685.

Gelegentliche Durchbohrung der ǩernwàrze durch Pollenschläuche; regelmässiges Vorbeiwachsen der Schläuche an der Keruwarze $6 \$ 6$.

Ablösbarkeit des Pollenschlauchendes rom Embryosacke 689.

Eintritt mehrerer Pollenschläuche in dieselbe Mikropyle 690 .

Rasche Dehnung der Integumente naeh Ankunft des Pollenschlauches im Eymunde 691.

Entwickelung des unteren Keimblaschens zum Embryo 693.

Kernhaltigkeit der Trägerzelle des Vorkeims 696.

Streckung des befruehteten Keimbläschens 698.

Vorkeim 700 .

Auftreten der lierne der Endospermzellen 704.

Endospermbildung 703, 704 .

Anlegung des Kotyledon 709 .

Bau des Fruchtknotens 726 .

Pothos pentaphylla. Geringe Dicke des äusseren Integuments 660 .

Schliessung des Exostoins zu einem engen Kanale 661.

Vollstänłige Verdrängung der, den unbeIruehteten Embryosack seitlich umhüllenden Zellschichten 667 .

Puja chilensis. Gegenfüsslerzellen der Keimbläschen 677 .

Puschkinia scilloïdes. Anatropie der Eyehen 658 .

Veränderungen des Inhalts des zum Fehlsehlagen bestimmten Keimbläschens noch vor der Befruehtung 675 .

Anordnung eines Theiles des Inhalts der oberen Hälfte der Keimbläschen zu faserähnlichen Bildungen 676 .

Fehlen der Cuticula des Embryosackscheitels 680 .

Schnelligkeit des Herabwacbsens des Pollenschlauehs von der Narbe bis in den Eymund 683 .

A.bhanfl. d. hi, S, Ges, l. Wiss. Vll.
Ablösbarkeit des Pollensehlanchendes vom Embryosacke 689.

Eintritt mehrerer Pollenschlauche in dieselbe Miliropyle 690 .

Grössenzunabme der Eychen nach Ankunft des Pollenschlauches in der Mikropyle 690 .

Entwiekelung des unteren Keimbläschens zum Embryo 693.

Iäufige Kernlosigkeit der Trägerzelle des Vorkeims 696 .

Sonderung des Inhalts in Quertheilung begriffener befruchteter Keimbläschen in zwei llälften vor Auftreten der Scheidewand 696 .

Streckung des befruchteten Keimbläschens 698 .

Haften des befruchteten Keimbläschens an der Innenfläche des Embryosackes 698

Endospermbildung 703.

Rhodea japonica. Anatropie der Eychen 658 .

Verdrängung den unbefruchteten Embryosack seitlich umhillender Zellschichten 667.

Ruppia maritima. $S$-förmige Krummung des Eykerns 6059 .

Weile Oefrnung des Exostoms 661 .

Lage der zum Embryosaek sich entwiekelnden Zelle des Eykerns 664.

Gelegentliehes Verschwinden der befruchteten Keimbläsehen bis auf eines 674 .

Fehlen der Gegentüsslerzellen der Keimbläschen 677 .

Verdrängung des Perisperms durch den Embryosack 692.

Zunalime des Umfangs des befruchteten Keimbläschens 697 .

Kiuze des Vorkeims 700.

Entwickelung des Embryo aus der zweiten Zelle des Vorkeims 708.

Wucherung der hypokotylen Achse 709.

Scheuchzeria palustris. Ablösbarkeit der Kieimblàschen von der Embryosackhaut 672.

Fehlen der Gegenfüsslerzellen der Keimbläselsen 677 .

Bildung einer freien Zelle um den primären Keru đes Embryosackes 678.

Unstetigkeit des Maasses der Zunahme an Umfang des befrucbtelen Keimbläsehens 688.

Vorkeim 700 .

Endospermbildung 703, 707.

Scilla bifolia. Anatropie der Eychen 658 . 
Endospermbildung 703.

Secale cereale. $S$-förmige Krümmung dcs Eykerns 659.

Weite Oeffnung des Exostoms 661 .

Gelegentliches Verschwinden der unbefruchteten Keimbläschen bis auf eines 674.

Gegenfüsslerzellen der Keimbläschen 677.

Entwickelung des unteren Kieimbläschens zum Embryo 693.

Kernhaltigkeit der Trägerzelle des Vorkeims 696.

Ablösbarkeit des befruchteten Keimbläschens von der Innenfläche des Embryosackes 699 .

Vorkeim 704.

Endospermbildung 703 .

Schnelligkeit der Entwickelung des Embryo 70 s.

Sobralia macrantha. Keimung 723 .

Sorghum vulgare. $C$-förmige Krümmung des Eykerns 659 .

Geringe Entwickelung des äusseren Integuments 661 .

Ausnahmsweises Verschwinden der unbefruchteten Keimbläschen bis auf eines 674.

Fehlen der Gegenfüsslerzellen der Keimbläschen 677 .

Verschwinden des primären Kerns des Embryosackes noch vor der Befruchtung 678.

Leistenförmige Verdickungen der Embryosackhaut in der Scheitelgegend 679 .

Entwickelung des unteren Keimbläschens zum Embrỹo 693.

Vorkeim 701.

Endospermbildung 703.

Stratiotes aloïdes. Bau des reifen Embryo 715.

Symplocarpus foetida. Beugung des freien Theiles des Funiculus 652 .

Lagenverhältniss dieser Krümmungsstelle zum Eykern 659.

Weites Zurückbleiben des Längenwachsthums des äusseren Integuments hinter dem Innern 661.

Theilung des Endostoms in dreieckige Lappen 661 .

Lage der zum Embryosack sich entwickelnden Zelle des Eykerns 664.

Verdrängung den unbefruchteten Embryosack seitlich umhüllender Zellschichten 667.
Gegenfüsslerzellen der Keimbläschen 677 .

Zeitige Verdrängung der den befruchteten Embryosack seitlich umhüllenden Zellschicht durch diesen 692.

Vorkeim 700 .

Verdrängung des Endosperms durch den Eimbryo 707.

Thalia dealbata. Embryosack 723 .

Tradescantia virginica. A uflösung des primären Kerns der Pollenmutterzelten 634.

Krümmung der Längsachse der Chalazaregion 659 .

Gegenfüsslerzellen der Keimbläschen 677.

Verschwinden des primären Kerns des Embryosackes noch vor der Befruchtung 678.

Beharren des befruchteten Keimbläschens auf der Grösse des unbefruchteten bis zur ersten Theilung 698 .

Vorkeim 707 .

Triglochin maritimum. Anatropie der Eychen 658 .

Einfachheit des Baues des Endostoms 660 .

Lage der zum Embryosack sich entwickelnden Zelle des Eykerns 664.

Verdrängung den unbefruchteten Embryosack seitlich umhüllender Zellschichten 667.

Zunabme des Umfanges des befruchteten Keimbiäschens 698 .

Unterbleiben der Endospermbildung 707.

Entwickelung des Embryo aus dem Vorkeim 708 .

Triteleia uniflora. Krümmung der Längsachse der Chalazaregion 659.

Zah! der Zellschichten des entwickelten Eykerns 663.

Triticum vulgare. $S$-förmige Krümmung des Eykerns 659.

Verschwindend geringe Entwickelung des äusseren Integuments 661 .

Gegenfüsslerzellen der Keimbläschen 677 .

Ablösbarkeit des Pollenschlauchendes vom Embryosacke 689.

Entwickelung des unteren Kieimbläscbens zum Embryo 693.

Ablösbarkeit des befruchteten Keimbläschens von der Innenfläche des Embryosackes 699 .

Vorkeim 701.

Endospermbildung 703.

Schnelligkeit der Entwickelung des Embryo 708 . 
Tritonia crocata. Vollständige Verdrängung der den Embryosack deckenden Zellschichten 666 .

Theilnahme der Ansatzflächen in der Scheitelwölbung des Embryosackes haftender Keimbläschen am Spitzenwachsthum des Embryosackscheitels 674.

Leistenförmige Verdickungen der Aussenseite der Haut des Embryosackscheitels 679.

Entwickelung des unteren Keimbläschens zum Embryo 693.

Auftreten der Kerne der Endospermzellen 701.

Tulipa Gesneriana. Bau des Eykerns 663.

Zelleukerne der Kieimbläschen, frei im Waudbelege des Embryosackes 670.

Bildung einer freien Zelle um den primären Kern des Embryosackes 678.

Tulipeen. Verdrängung den oberen Theil des unbefruchteten Embryosackes unhuillender Zellschichten 665.

Uvularia grandiflora. Weite Oeffnung des Exostoms 661 .

Vollstindige Verdrängung der den unbefruchteten Embryosack seitlich umbüllenden Zellschichten 667.

Gelegentliches Verschwinden der unbefruchteten Keimbläschen bis auf eines 674.

Gegenfuisslerzellen der Keimbläschen 677.

Veltheimia viridiflora. Beugung und Torsion des freien Theiles des Funiculus 652.

Anatropie der Eychen 658.

Lage der zum Embryosack sich entwickelnden Zelle des Eykerns 664.

Verdrängung der den jungen Embryosack deckenden Zellschichten bis auf eine 665 .

Cylinderform des zur Befruchtung bereiten Embryosackes; Entwickelung einer Ausstuilpung dessclben im unteren Theile 666.

Vom Kern des Embryosackes ausgehende Protoplasmastränge 669.

Fehlen der Gegenfusslerzellen der Keimblaschen 677 .

Fehlen der Cuticula des Embryosackscheitels 680 .

Ablösbarkeit des Pollenschlauchendes rom Embryosacke $6 \$ 9$.

Verdrängung des Perisperms durch den belruchteten Embryosack 692.

Entwickelung des unteren Keimblaschens zum Embryo 693.
Gelegentliche Kernlosigkeit der 'Trägerzelle des Vorkeims 696.

Sonderung des Inbalts in Quertheilung begriffener befruchteter Keimbläschen in zwei IJälften vor Auftreten der Scheidewand 696 .

Dauer der Zeit zwischen Ankunft des Pollenschlauchs am Embryosacke, und erster Theilung des befruchteten Keimbläschens 697.

Streckung des befruchteten Keimbläschens 698.

Endospermbildung 704.

Wachsthum des Endosperms 705.

Zannichellia palustris. $S$-förmige kïümmung des Eykerns 659.

Lage der zum Embryosack sich entwickelnden Zelle des Eylierns 664 .

Verdrängung des Perisperms durch den befruchteten Embryosack 692.

Entwickelung des unteren Keimbläschens zum Embryo 693.

Auftreten des secundären Kerns des befruchteten Keimbläschens von Verschwinden des primären 695.

Zunalume des Umfangs des befruchteten Keimbläschens 698 .

Unterbleiben der Endospermbildung 707.

Schnelligkeit der Entwickelung des Embryo 708.

Aulegung des liotyledon 716 .

Zea Mays. $C$-förmige Krümmung des Eykerns 659.

Geringe Entwickelung des ausseren Integuments 661 .

Fehlen der Gegen füsslerzellen der Keimbläschen 677.

Verschwinden des primären lierns des Embryosackes noch vor der Befruchtung 678 .

Vorkeim 701.

Endospermbildung 703 .

Zostera marina. Entwickelung des Pollens 643.

Beugung des Funiculus; Lagenverhältniss der Beugungsstelle zur Chalaza 659.

Hervorragen des Endostoms aus dem Exostom 664 .

Jüngste Zustände des Eykerns 663 .

Bau desEykerns nach vollerAusbildung 663 .

Lage der zum Embryosack sich entwickelnden Zelle des Eykerns 664.

Vollständige Verdrängung der den unbefruchteten Embryosack umhüllenden und deckendenGewcbschicht; Anschmiegung 
der Embryosackhaut an die Hüllbaut des Eykerns 668 .

Sonderung des Embryosackinhalts in Vacuole und Wandbeleg 669.

Zellkerne der Keimbläscben, frei entstehend 670 .

Ablösbarkeit der Keimbläschen von der Embryosackhaut 672 .

Gelegentliches Verschwinden der unbefruchteten Keimbläschen bis auf eines 674.

Gegenfüsslerzellen der keimbläschen 677 .

Verschwinden des primären Kerns des Embryosackes noch vor der Befruchtung 678 .

Fehlen der Cuticula des Embryosackscheitels 680 .
Schnelligkeit des Herabsteigens des Pollenschlauchs von der Narbe in den Eymund 682 .

Dauer der Zeit zwischen der Ankunft des Pollenschlauches am Embryosacke, und der ersten Theilung des befruchteten Keimbläschens 697 .

Zunahme des Umfangs des befruchteten Keimbläschens 698 .

Ablösbarkeit des befruchteten Keimhläschens von der Innentläche des Embryosackes 699 .

Kürze des Vorkeims 700.

Unterbleiben der Endospermbildung 707.

Entwickelung des Embryo aus dem Vollime 708 .

Wucherung der bypokotylen Achse 709.

Eriata.

S. $661, Z .9$ v. oben für Crzackia lies Czackia.

S. $666, Z .17$ v. oben für Montrichardia lies Montbretia.

S. 669, Z. 8 v. unten für Hyppeastrum lies Hippeastrum.

S. 672, Z. 2 v. unten ) fur Hymenocallis cariboea

S. $677, Z$. 15 v. unten J Jies Hymenocallis ovata.

S. $692, \mathrm{Z} .14 \mathrm{v}$. oben fur Scisameen lies Scitamineen. 
1.

1.

2

$4 !$

i.

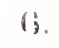

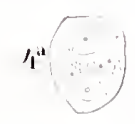

1 3 :

$i$

14

3.

11.

10.

III.

$2 \%$

1.3.

21.

18.

$14^{0}$

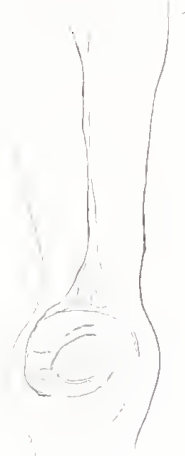

27.

19.

26.
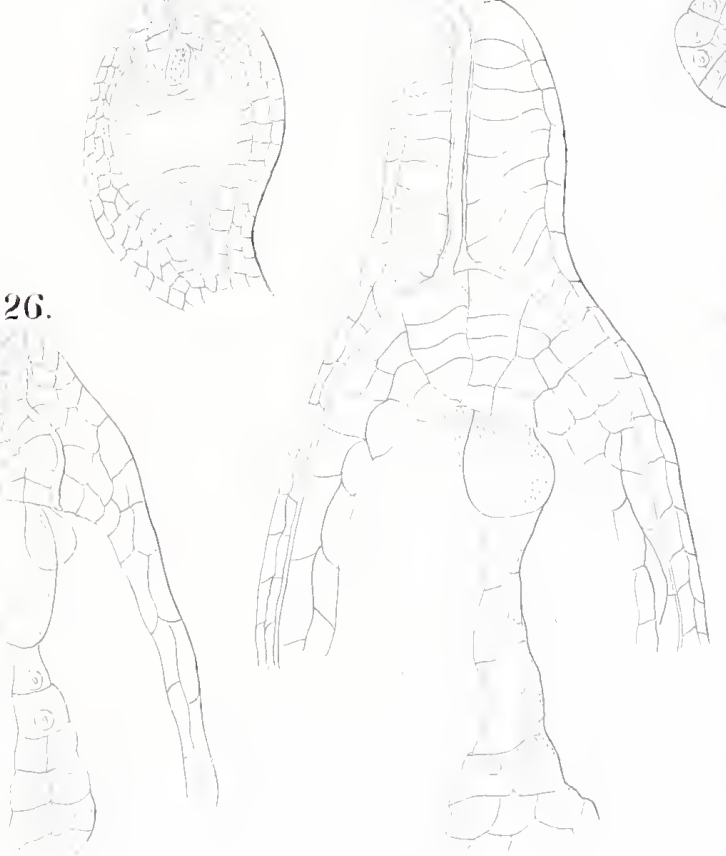

1.5

2.5.

28.

$2.5^{b}$

29.

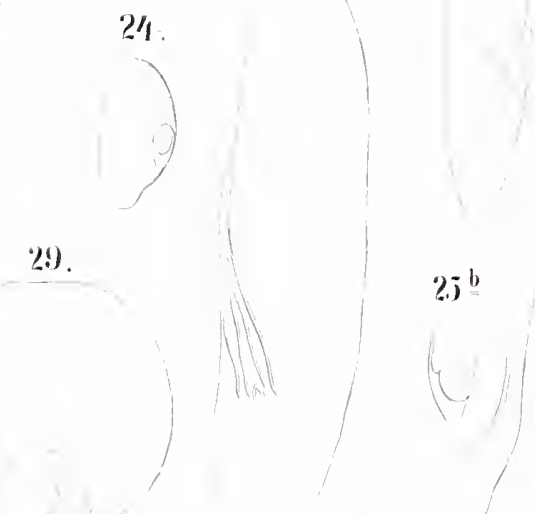

12.5 Najas major 2(3-27'Trighlorhin maritimum 2829) Stratioles aloides 

1.

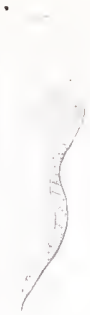

I

$\left(i^{2}=\right.$

(i.

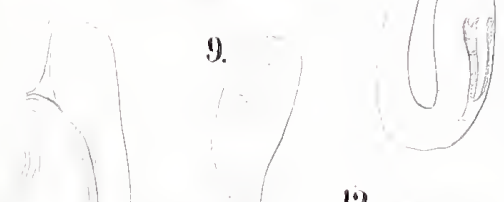

1.5.
?"

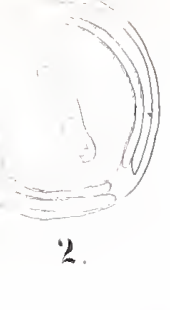

5.
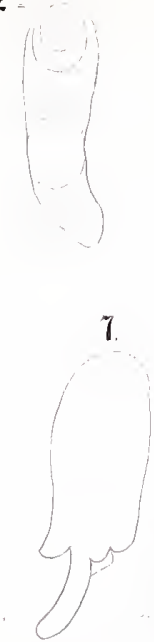

10.

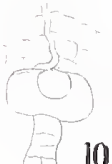

14.

11.

16.

Q<smiles>[Se]=[Se]</smiles>

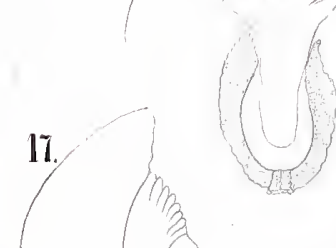

25.
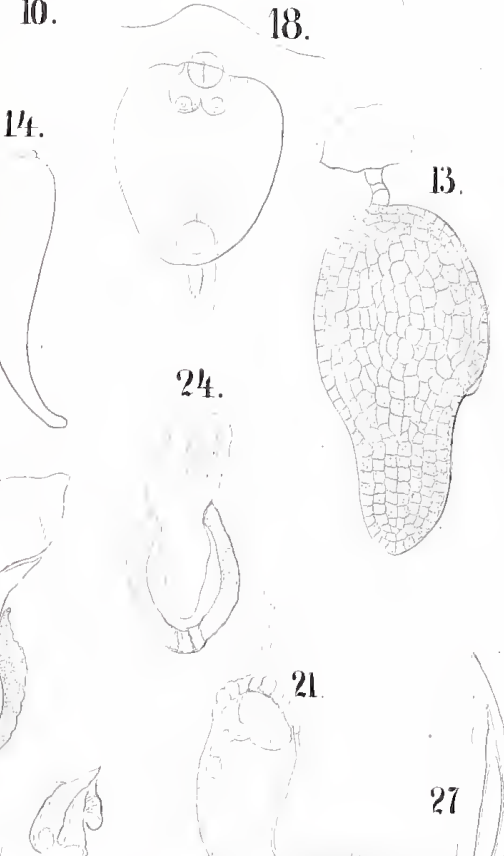

19.

4.

II.

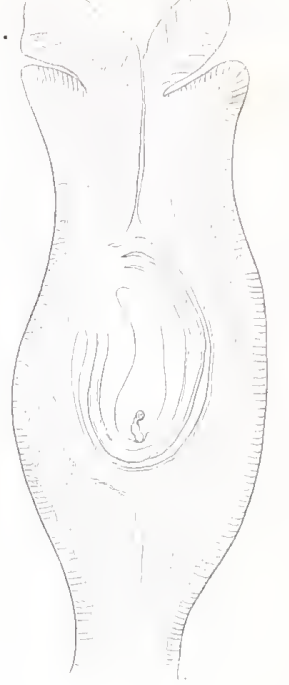

22.

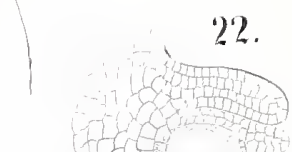

20.

23.

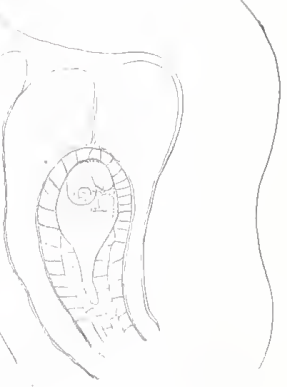

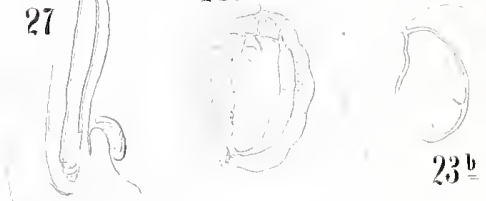

285

$28 \stackrel{2}{=}$

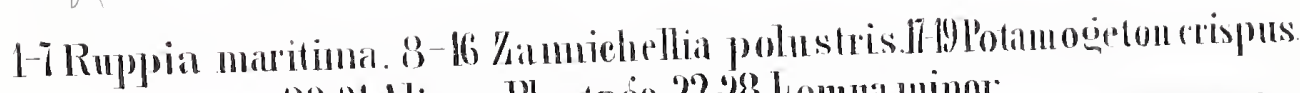
2021 Nisma Plantago. 2? 28 liemua minor: 


$$
\text { . }
$$


1.

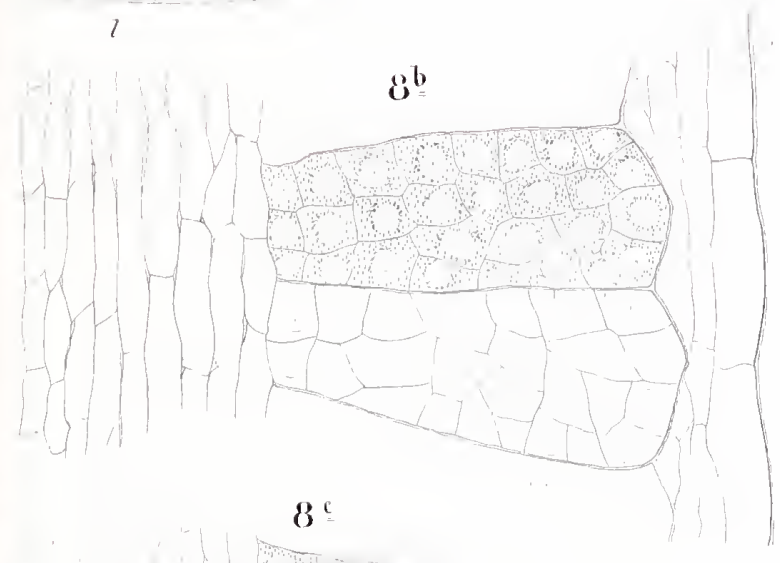

9

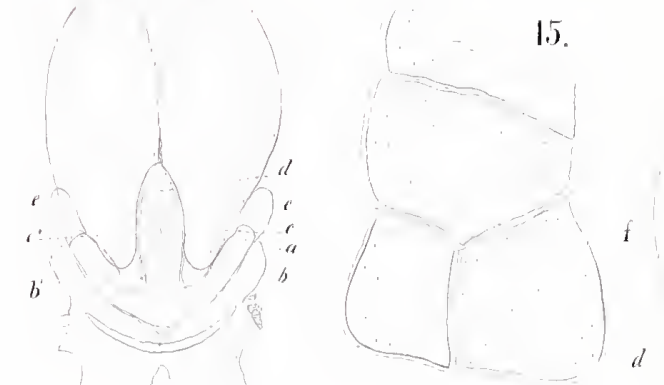

8. "Im

12.

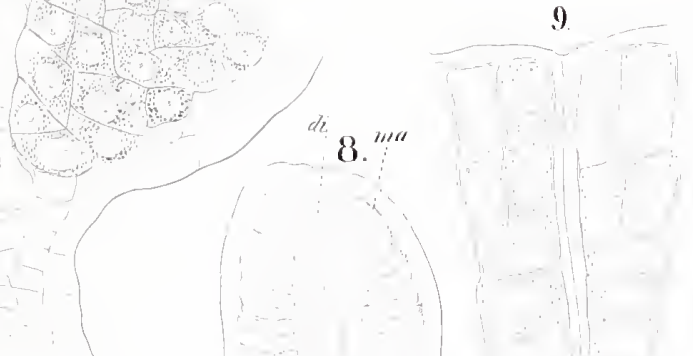

II

19.
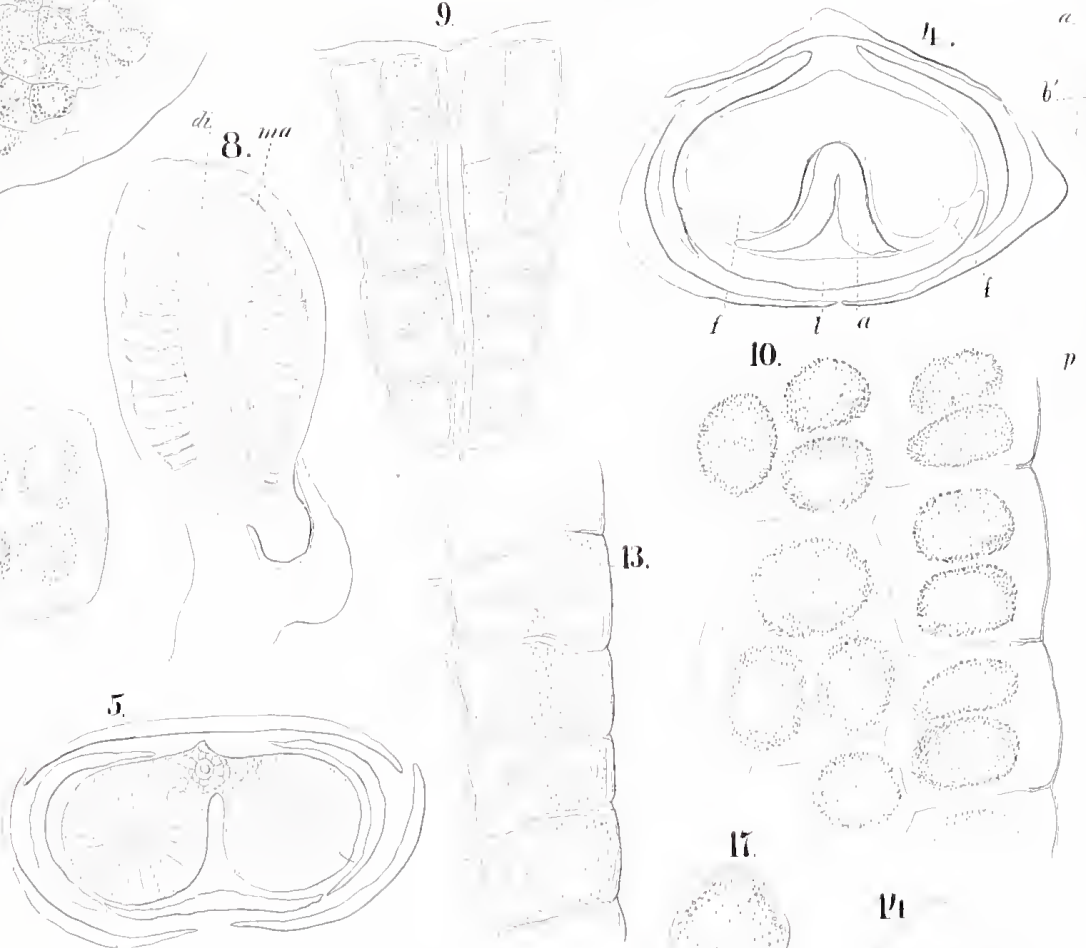

II

22.

20.

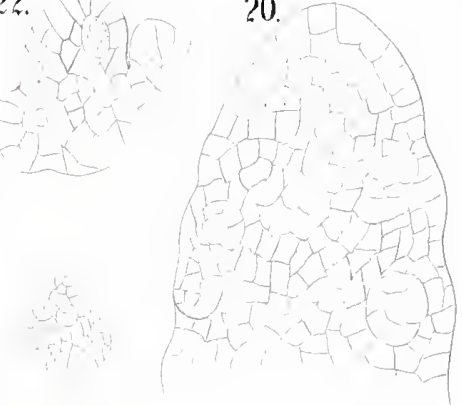

21.

18

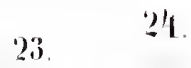

16.

$16^{\mathrm{b}}$

$1 / 1$

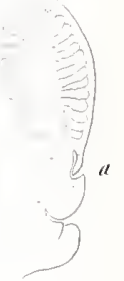

17

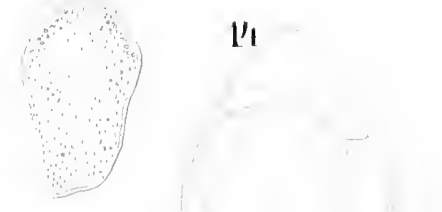

Orchis Morio 
3.

1.

11.

10

i.

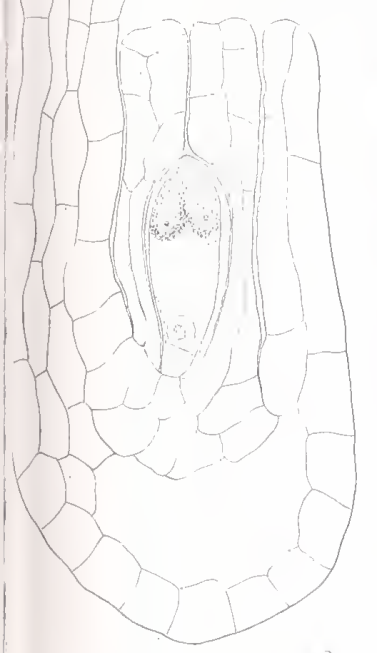

15

18.
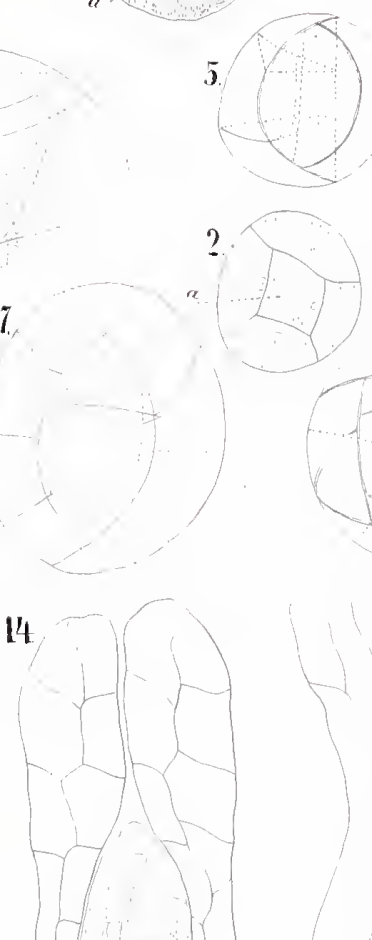

8.
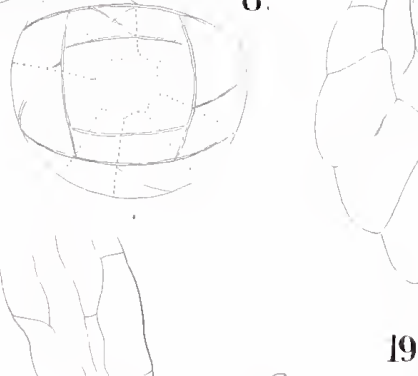

16.
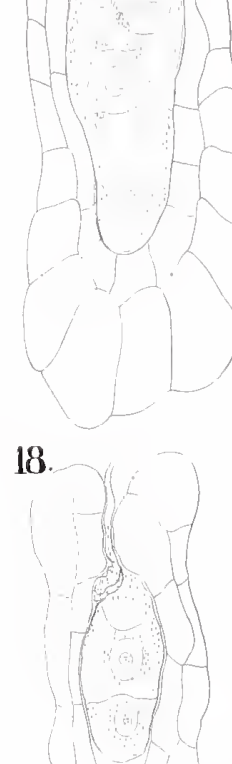

13.

IV.

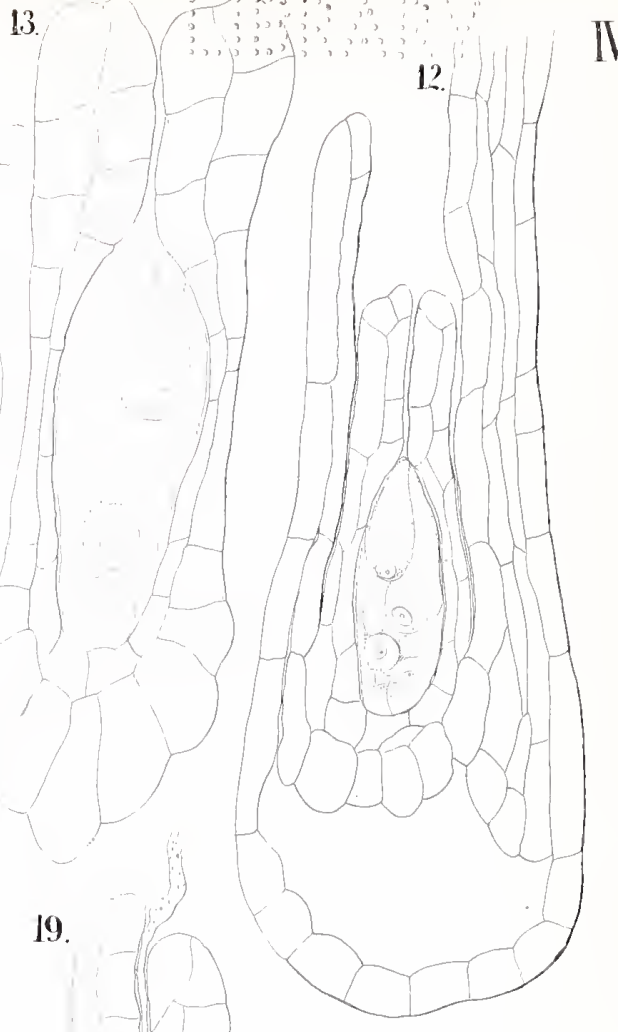

17.

11 :

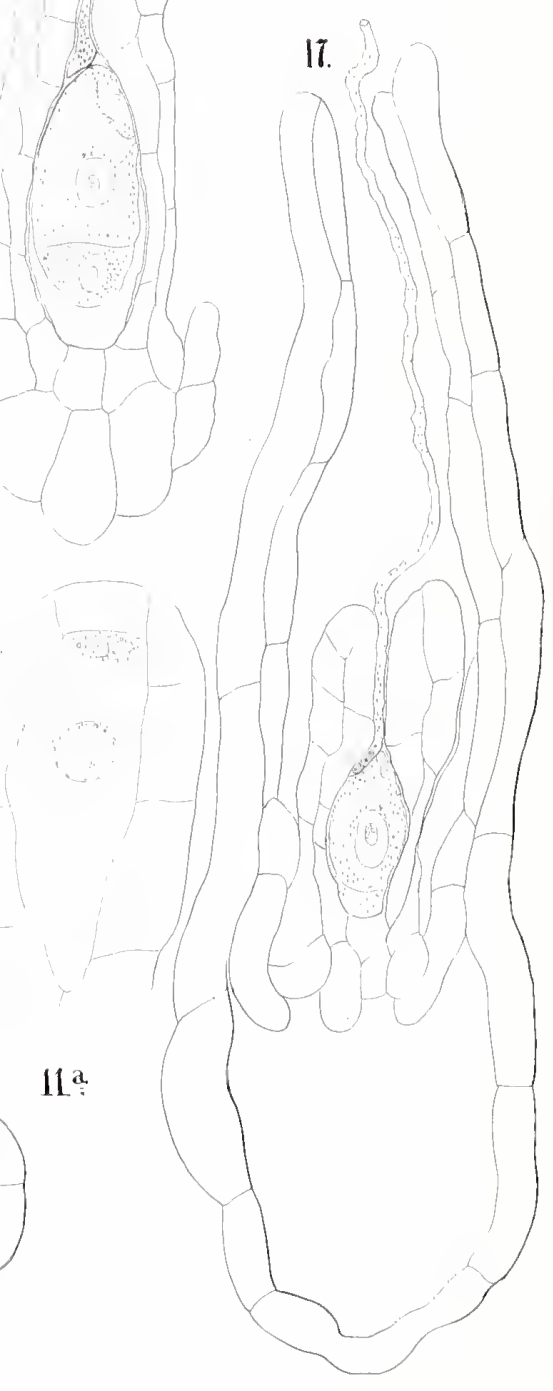




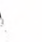



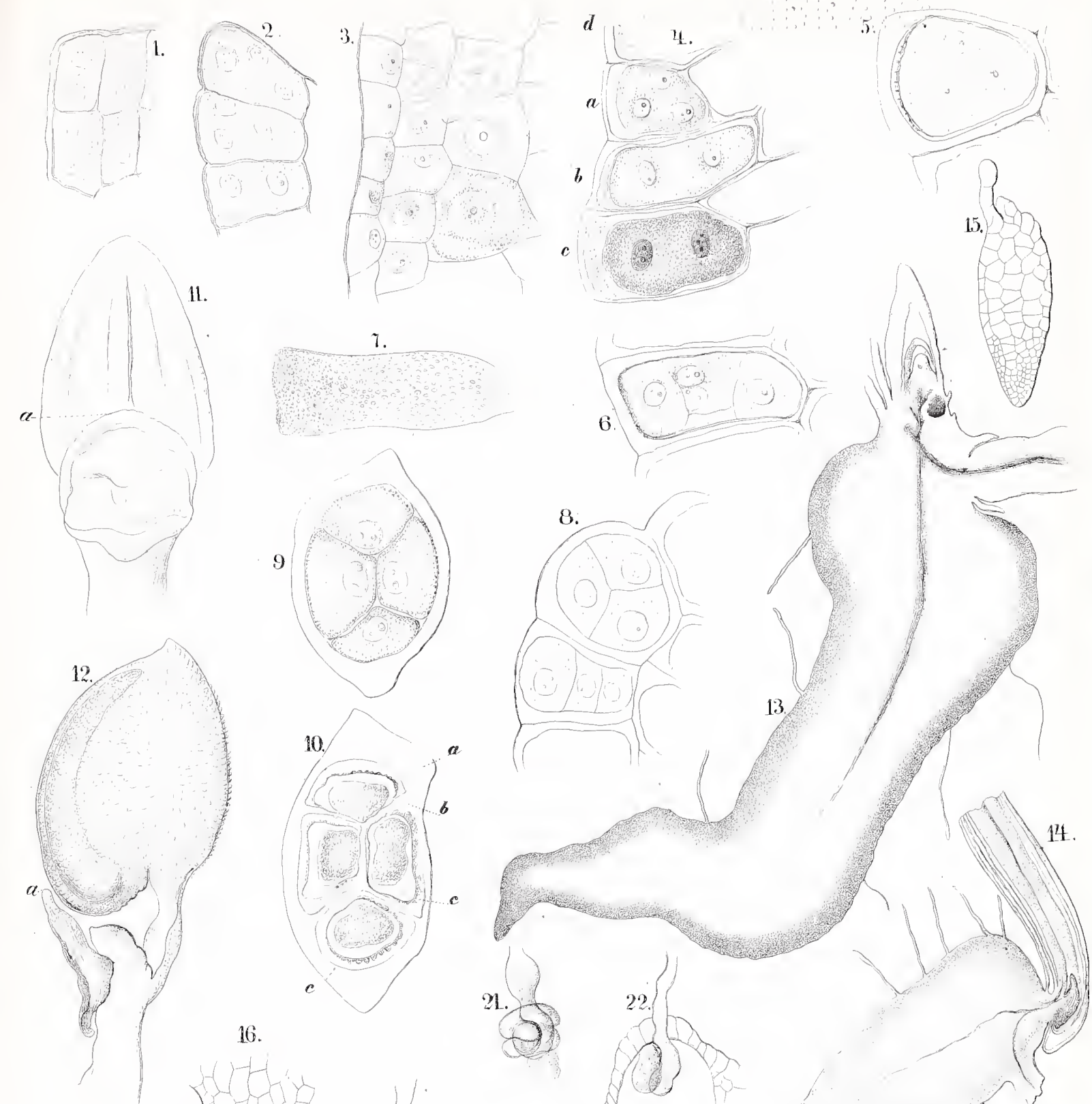

9
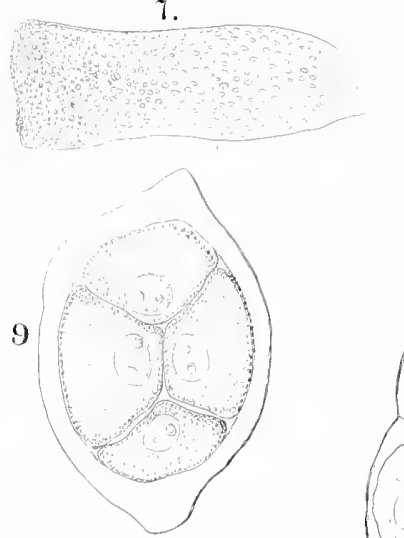

16.
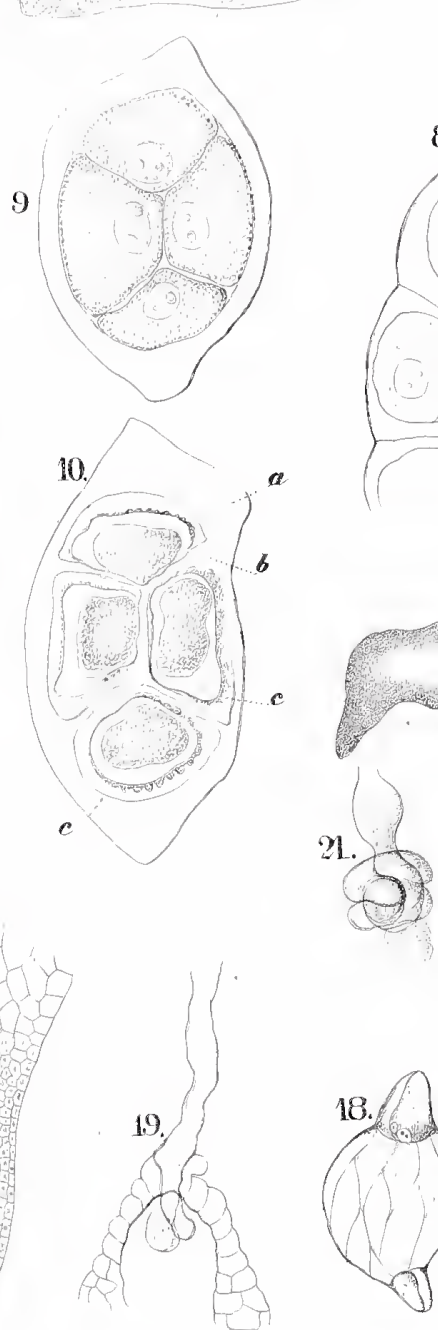

8.
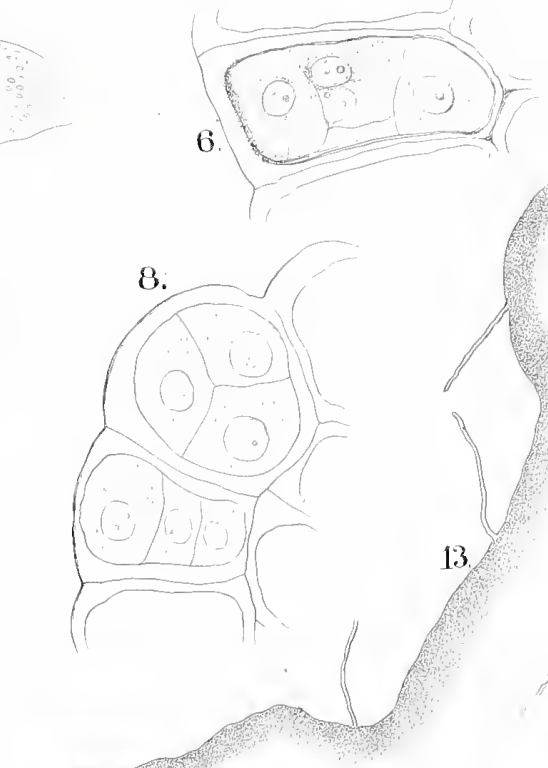

13.
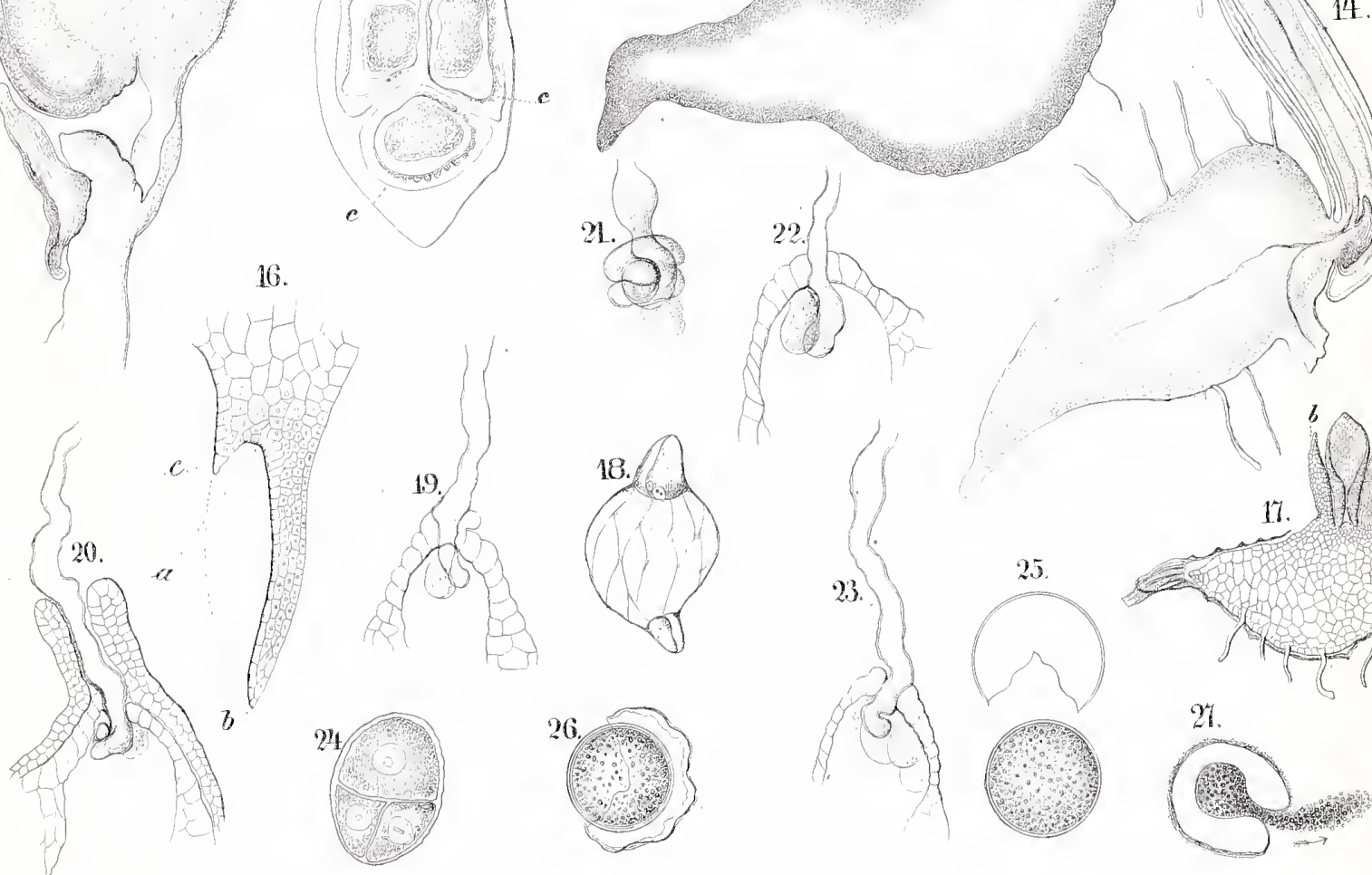

14.

1-2 0rchis fusca. 3-7 Phajus Wallichii. 842 Cephalanthera rubra. 13-14 Gymnadena conopsea 15. 1t Sobratia macrantha. 18Thalia dealbata. 19-23 Canna Sellowii. 
1.

1.

9

3

8

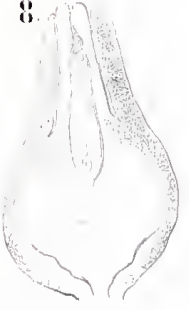

1ii.

19.
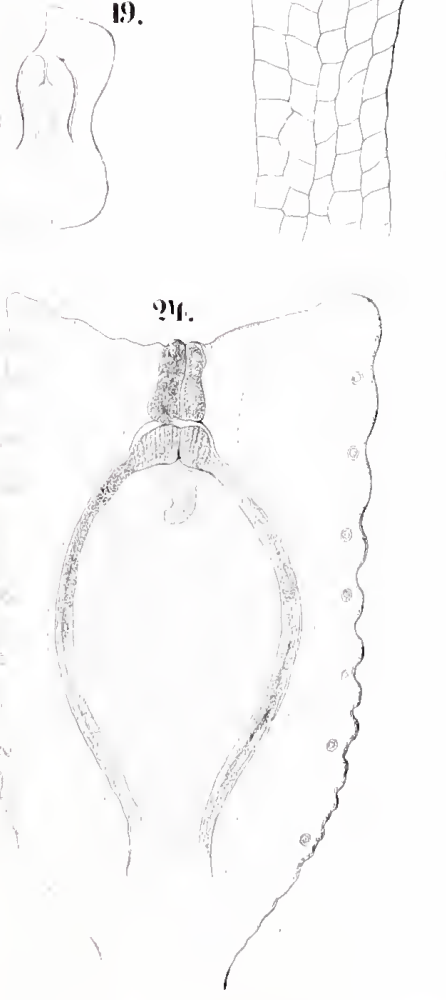

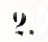

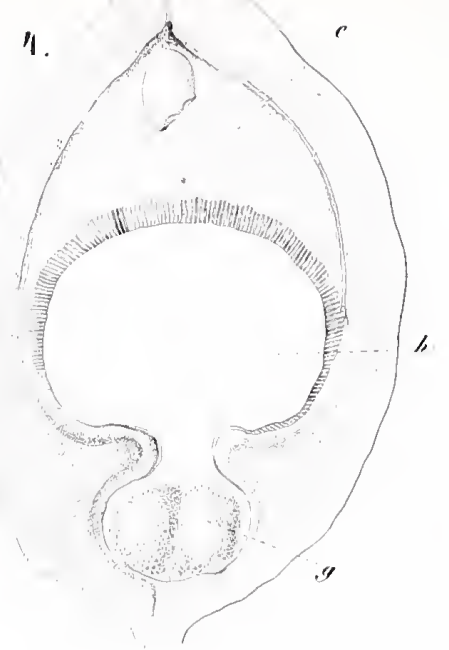

10.

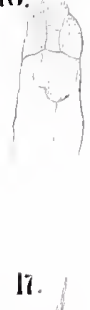

90

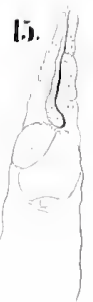

16.
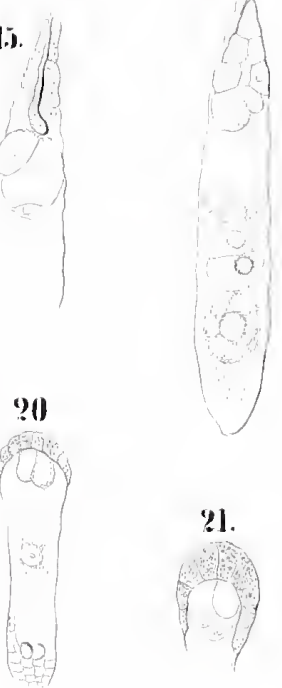

?

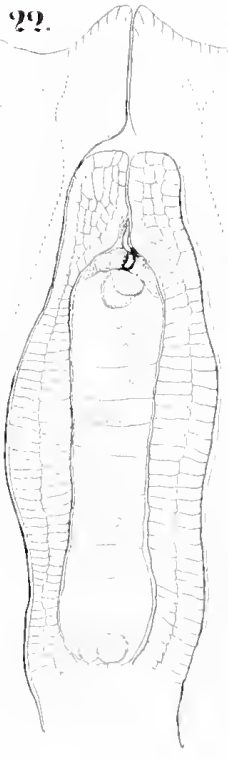

j.

h

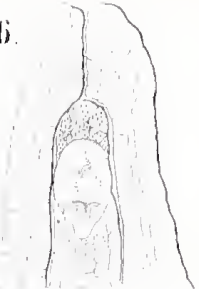

1.

iI.

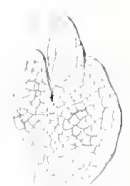

19.

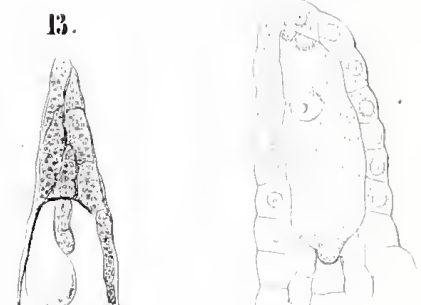

9.5.

26.

I'i.

2

$9 i$.

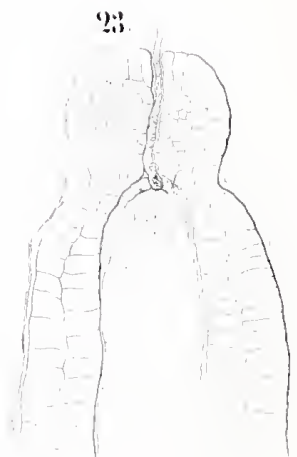

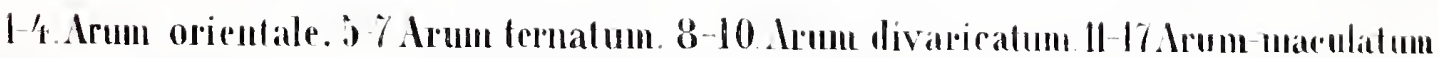
18-27 Prstia Siratiotes/torensis) 



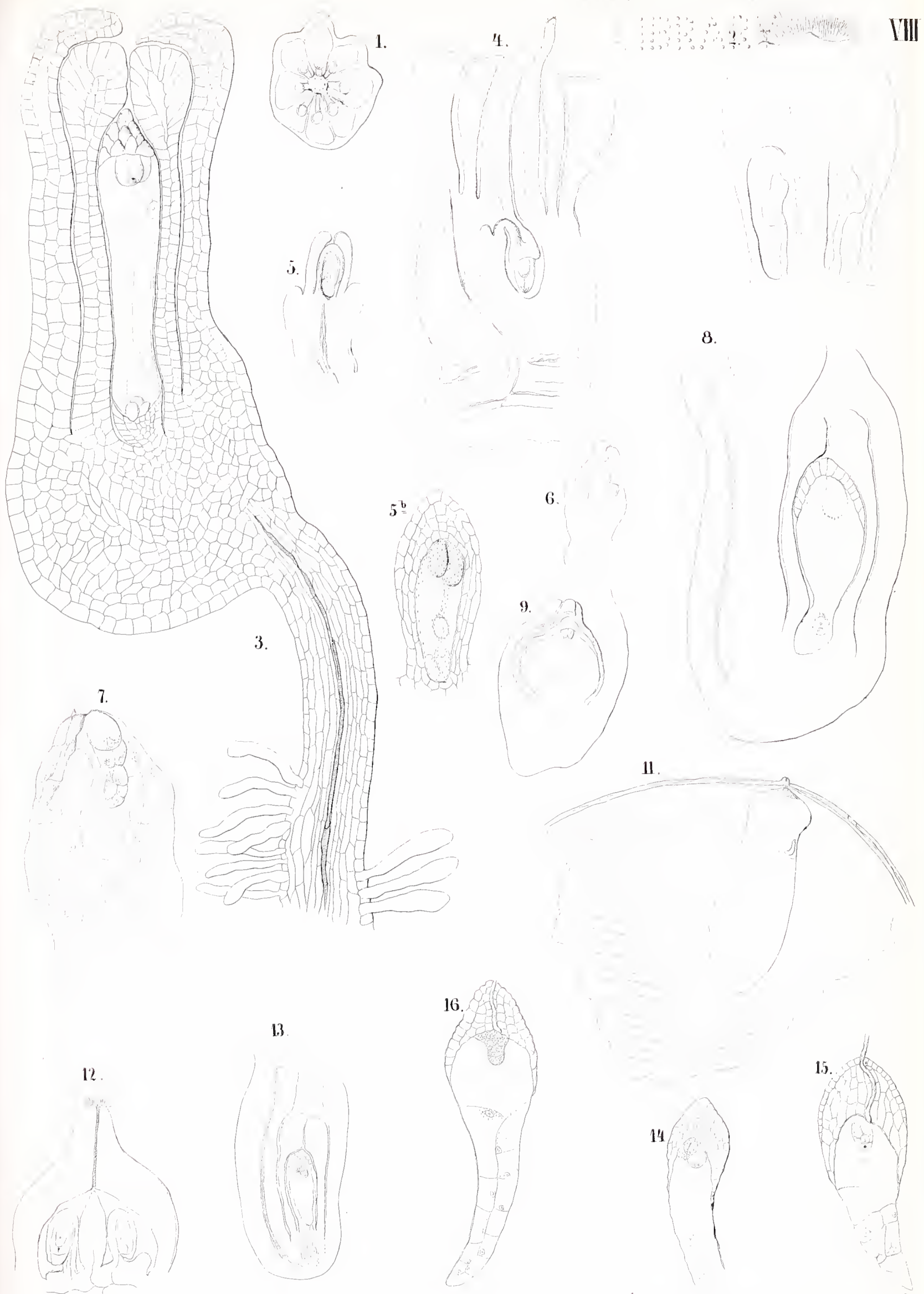

1-3 Philodendron Imbe 4 -7 Symplocarpus foctida 8 Caladium bieolor 9-1l Rhodea japonica 12. 16 Calla palustris. 



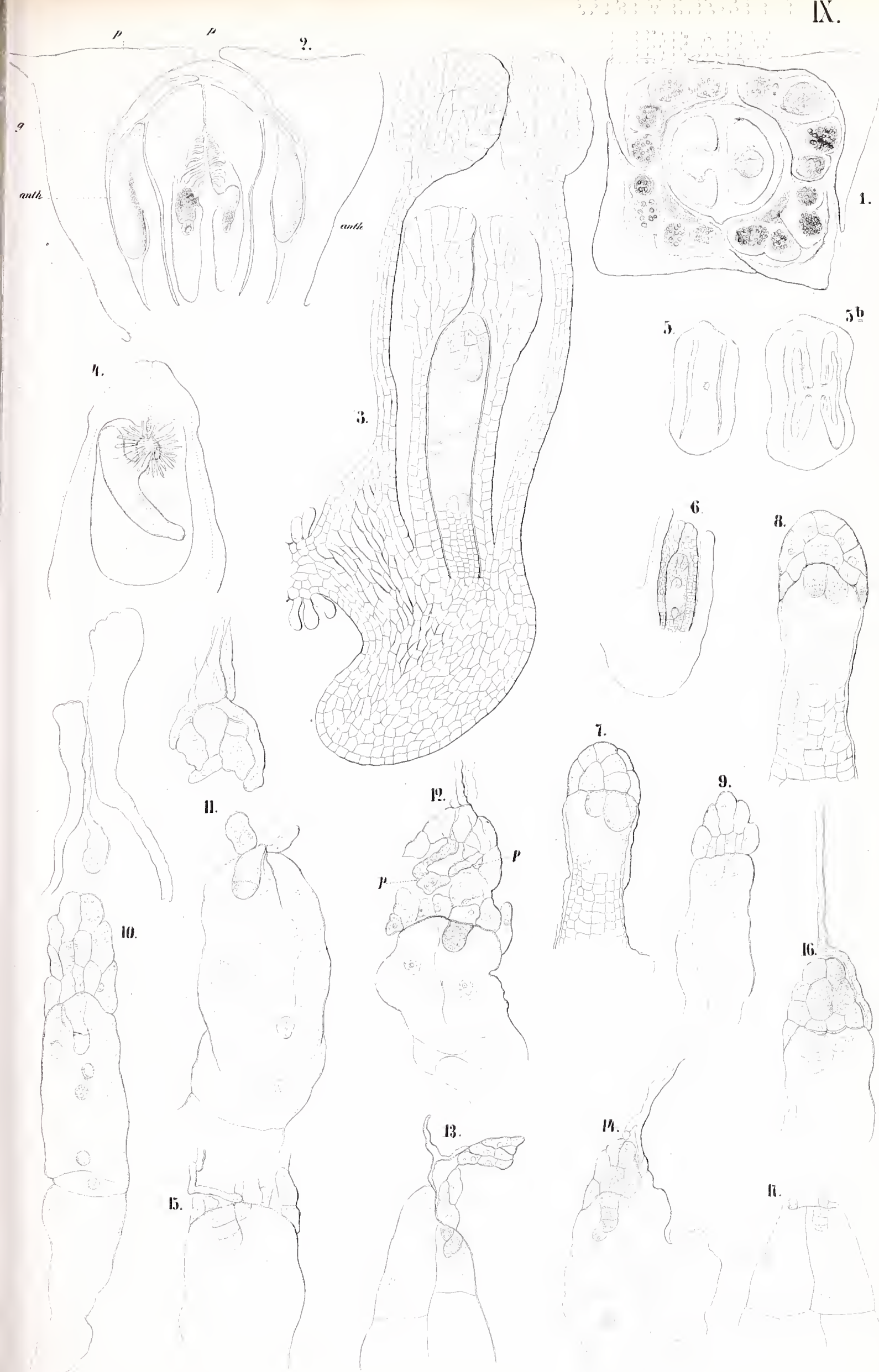



1.

$3 \stackrel{b}{=}$

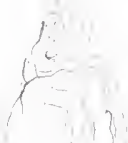

5.
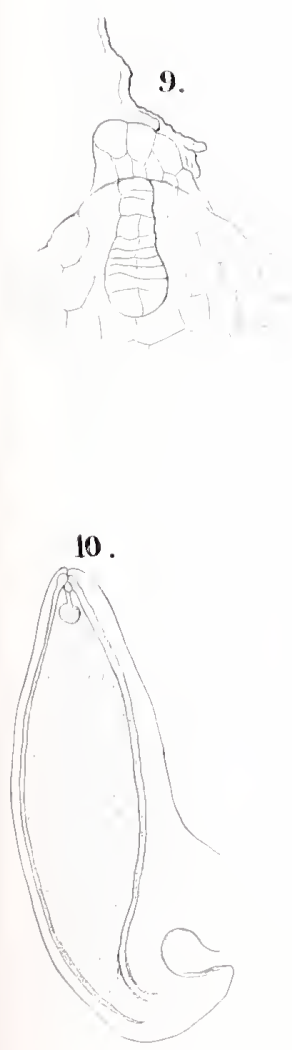

3.

2.

1.

8.

7.

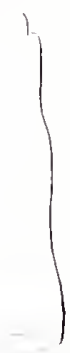

13

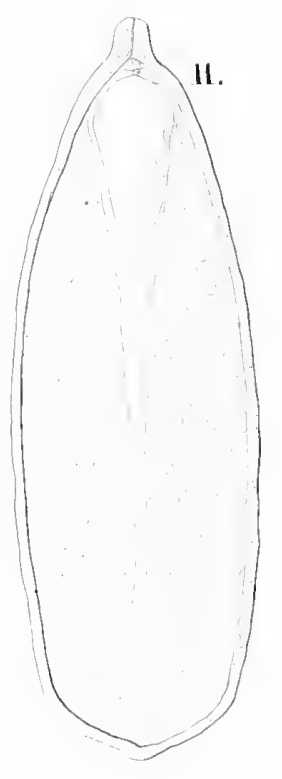

12.

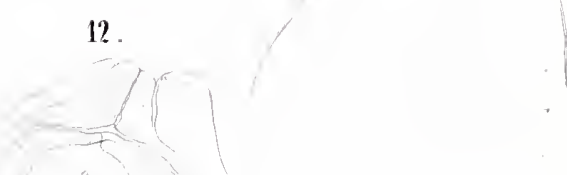





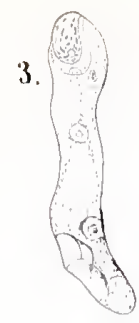

8.

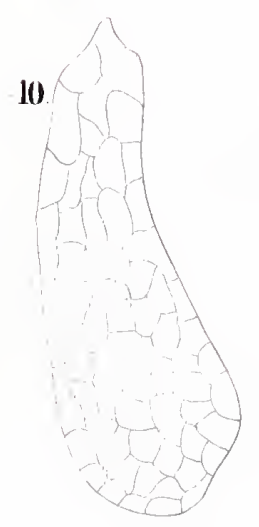

1.
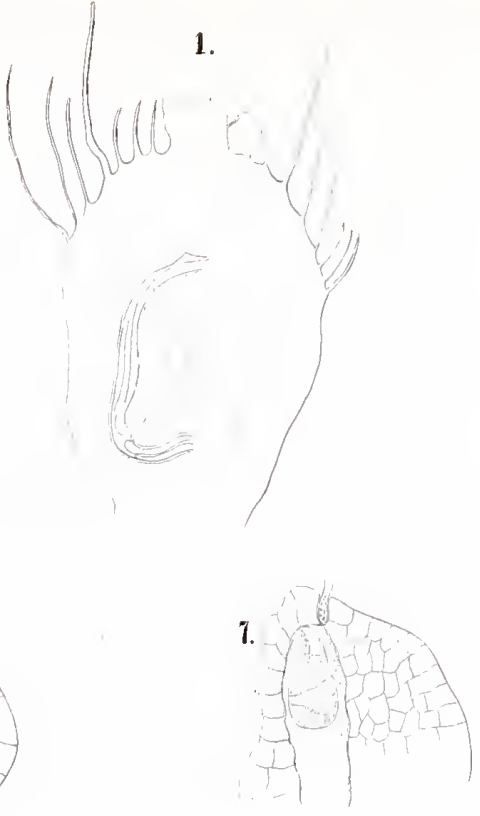

$12^{6}$

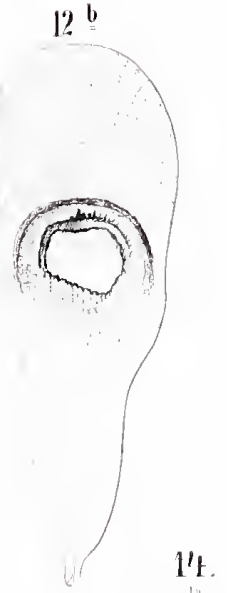

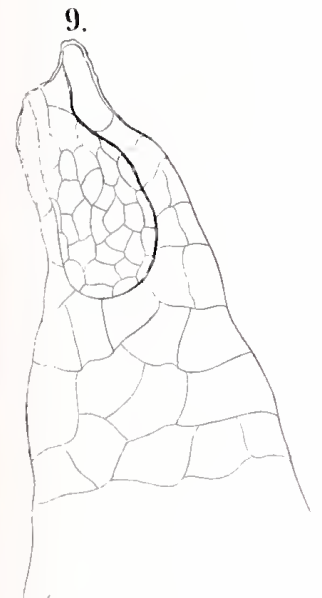

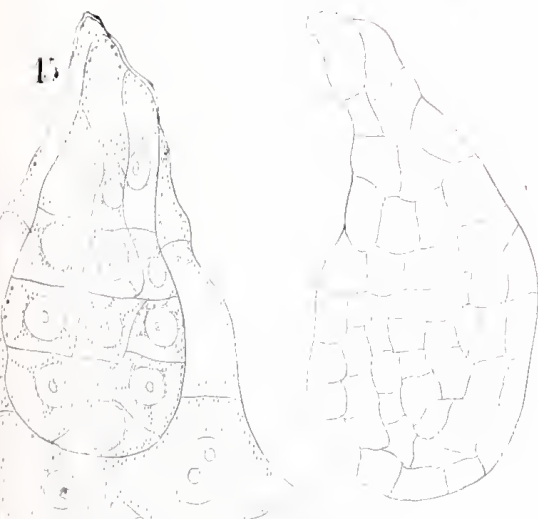

16.
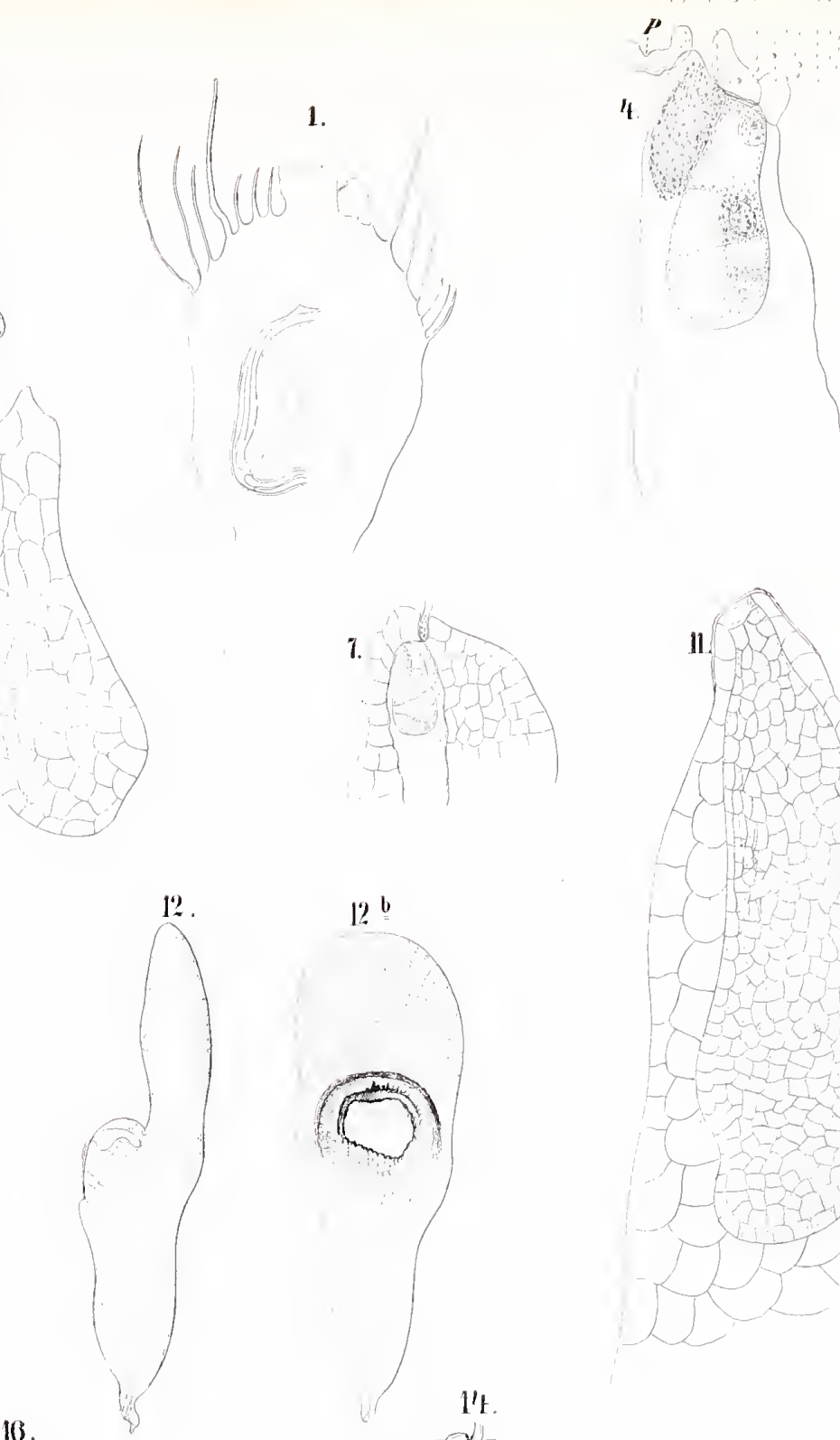

(i)
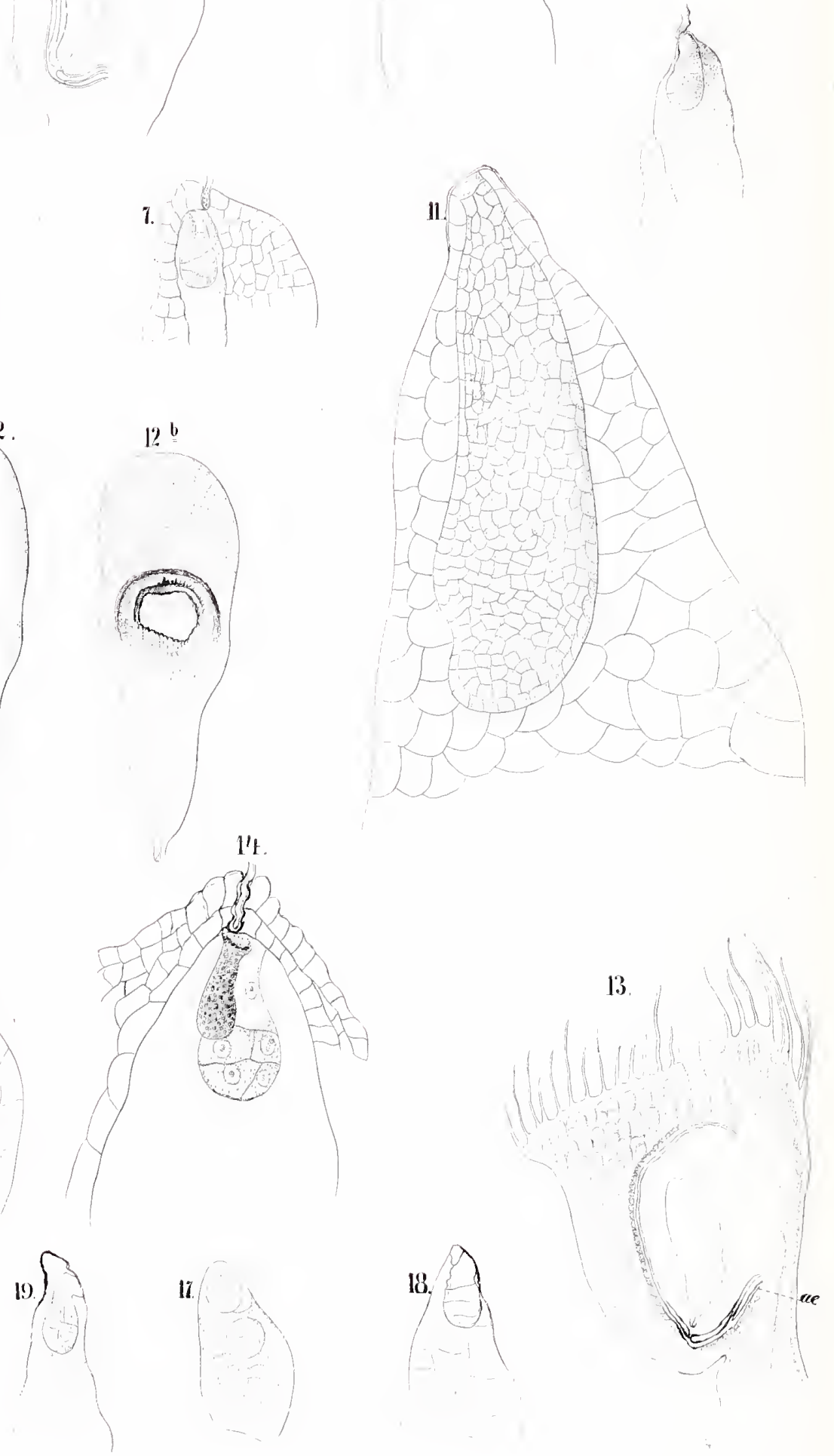

13

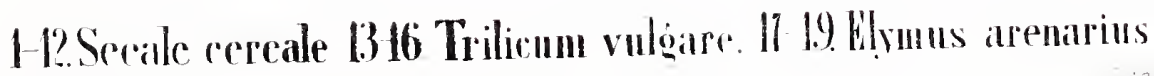



XII.

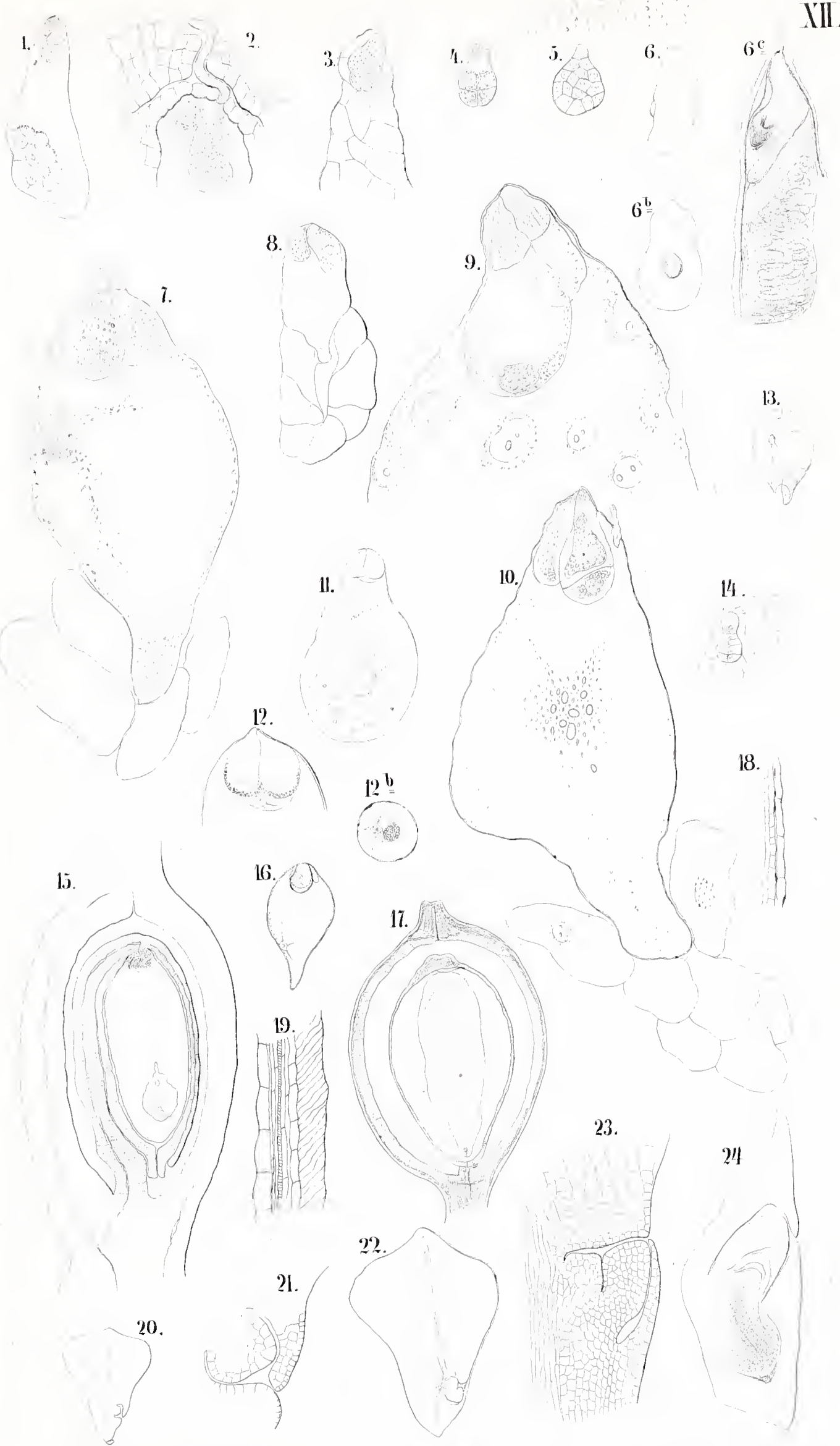

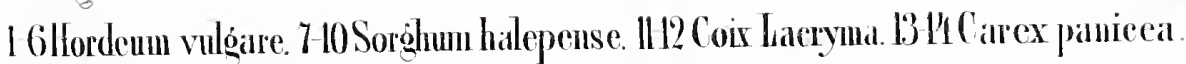




$$
\text { - }
$$


(i.

i

$+1.5$

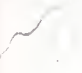

I'

1.

lis.

10.

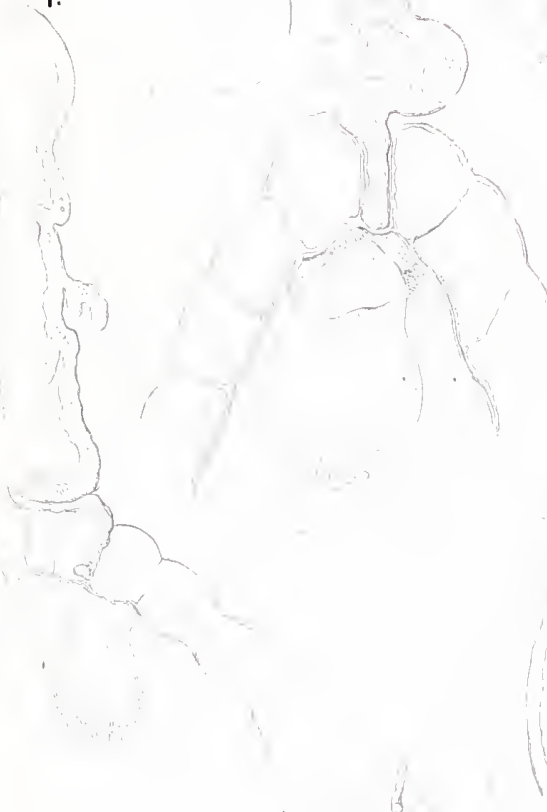

$\| ;$

1.5

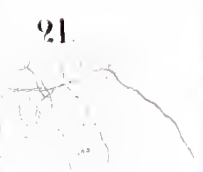

9

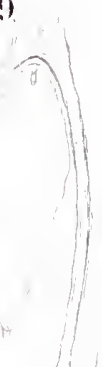

111.
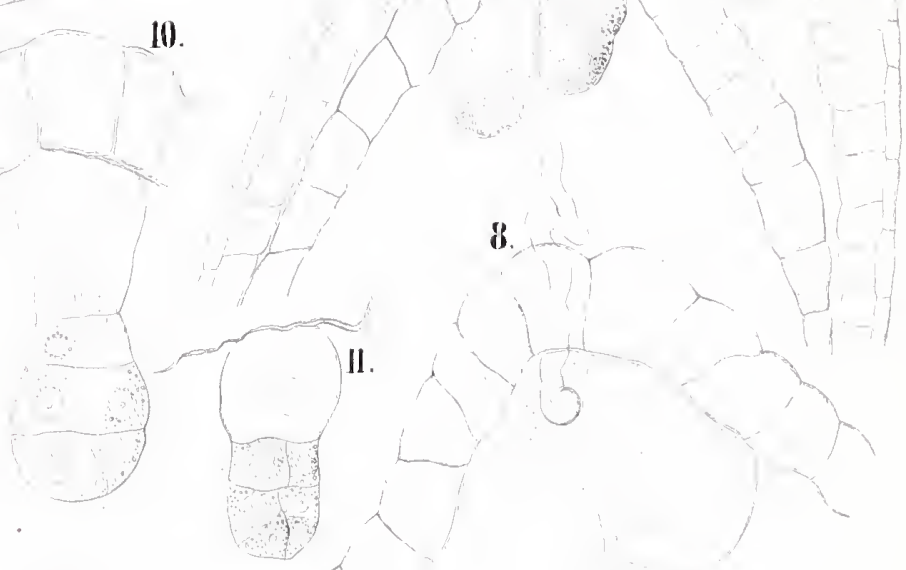

$$
8 .
$$

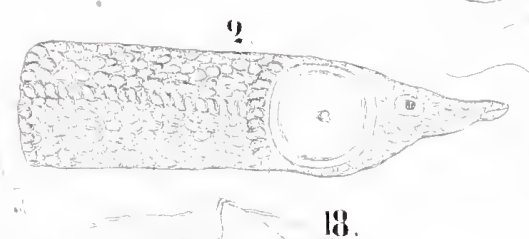

1 ?

$93^{12}$

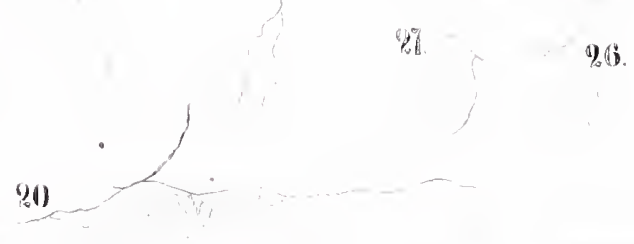

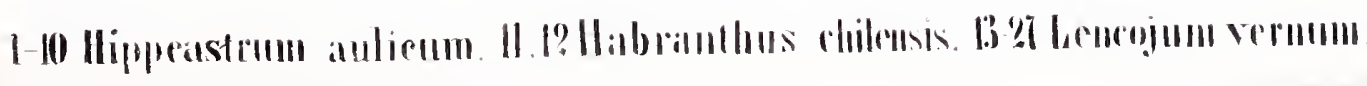




$$
\text { - }
$$


3.

I.

XII
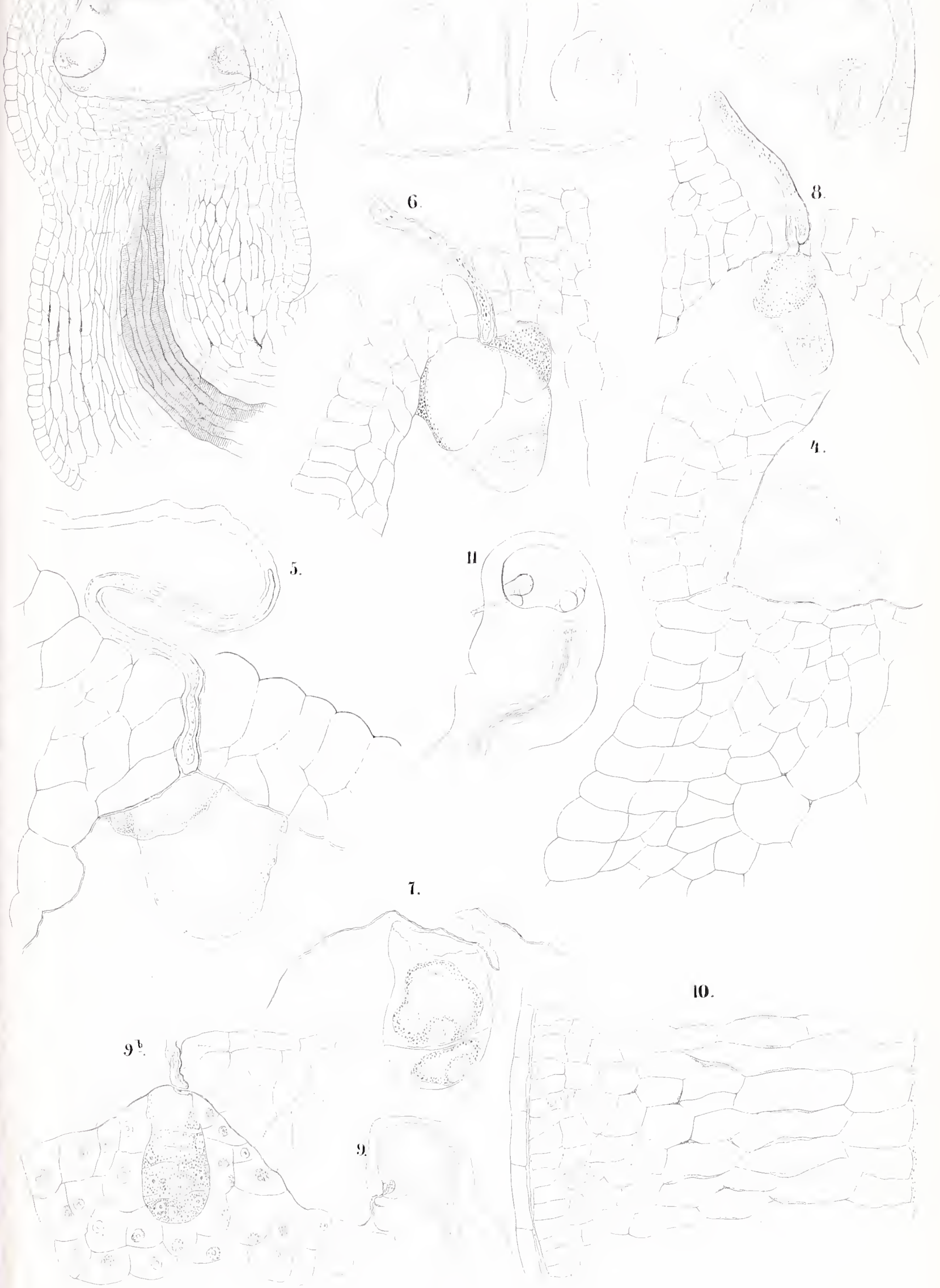

12 Crinum varriabile 3 11 Crimum capense. 




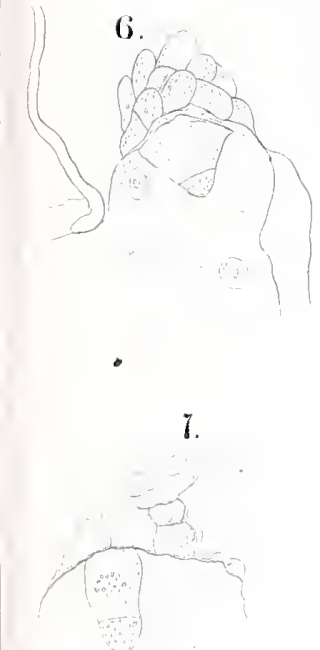

II.
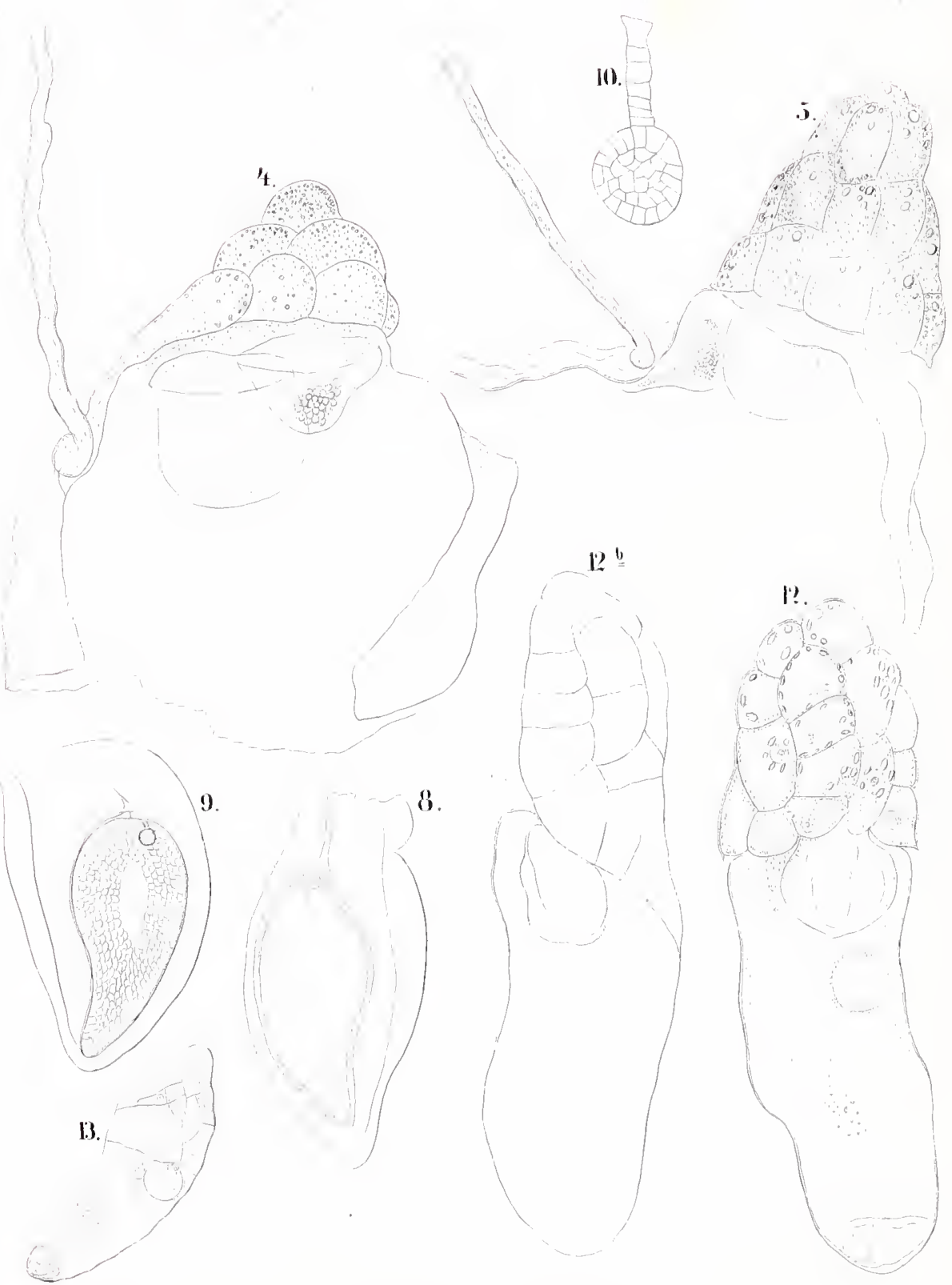

1-10 Mercudera cancasica. II to Lvularia grandiflora.

8.

(9.

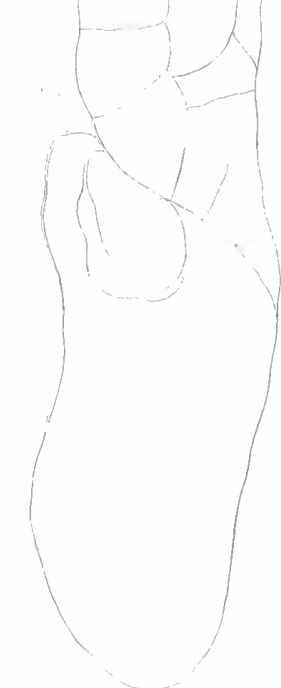




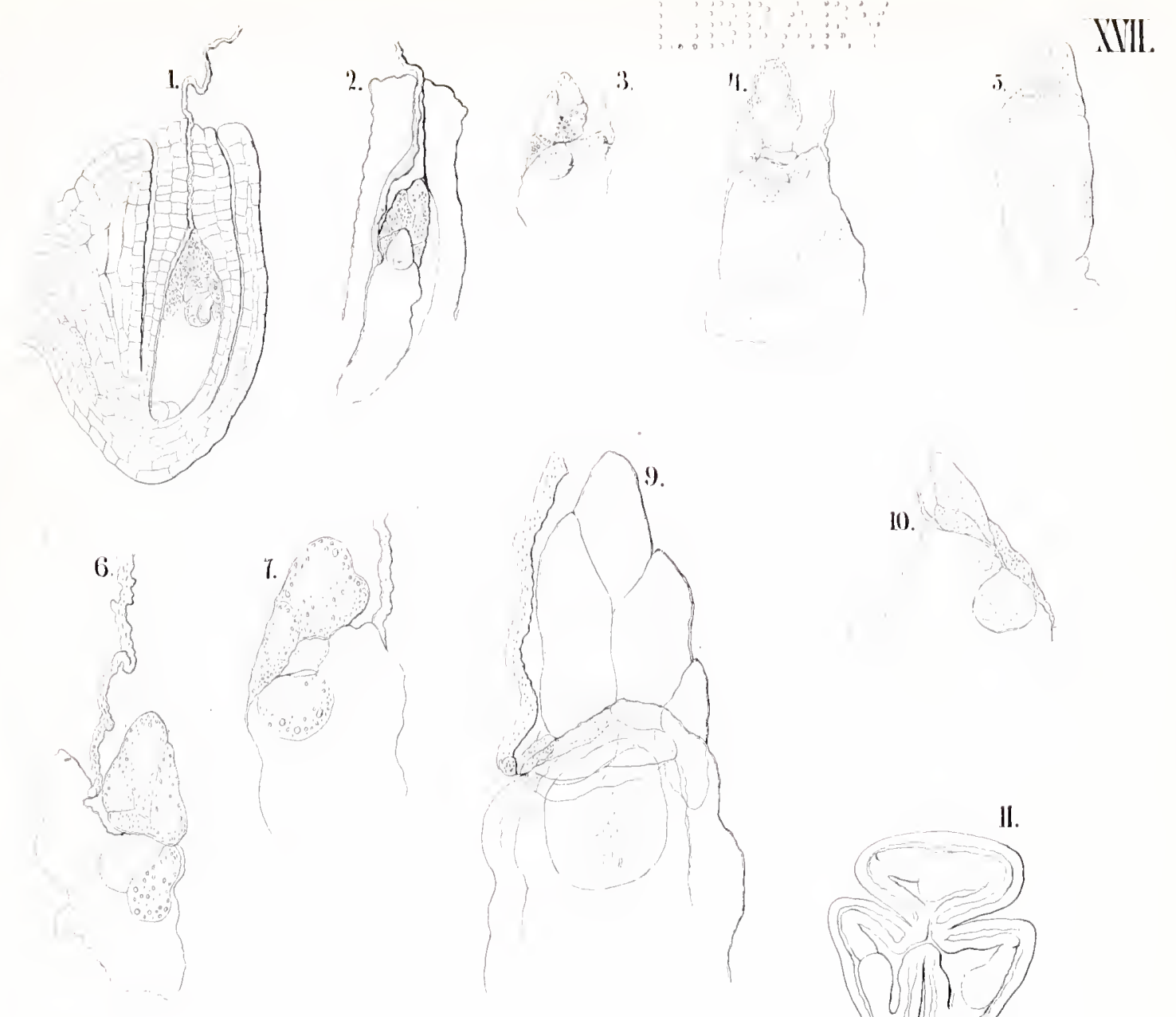

10.
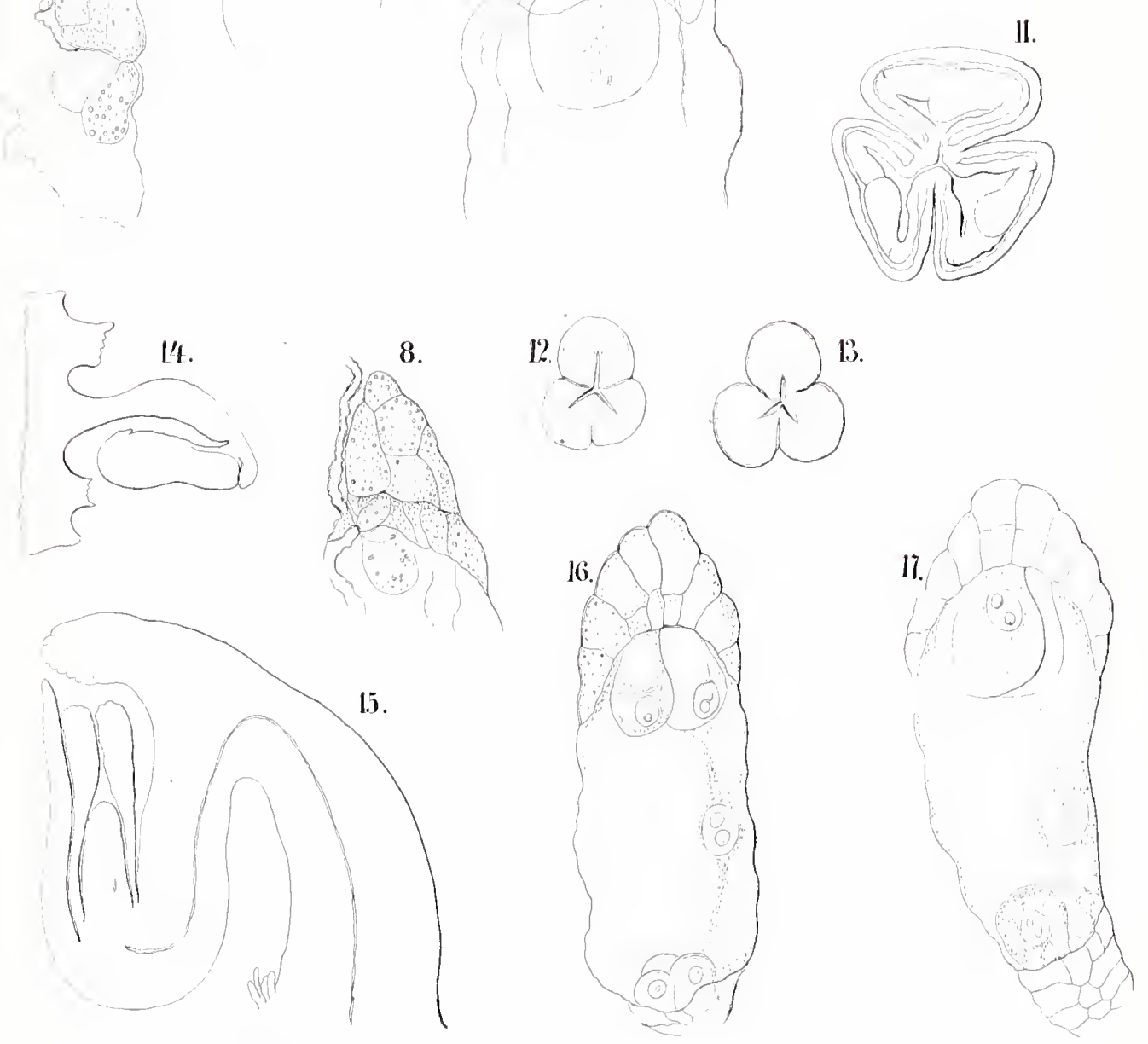

H0Colchicum autumnale. 1t-17 Bulbocodium vernum. 

IIIII.

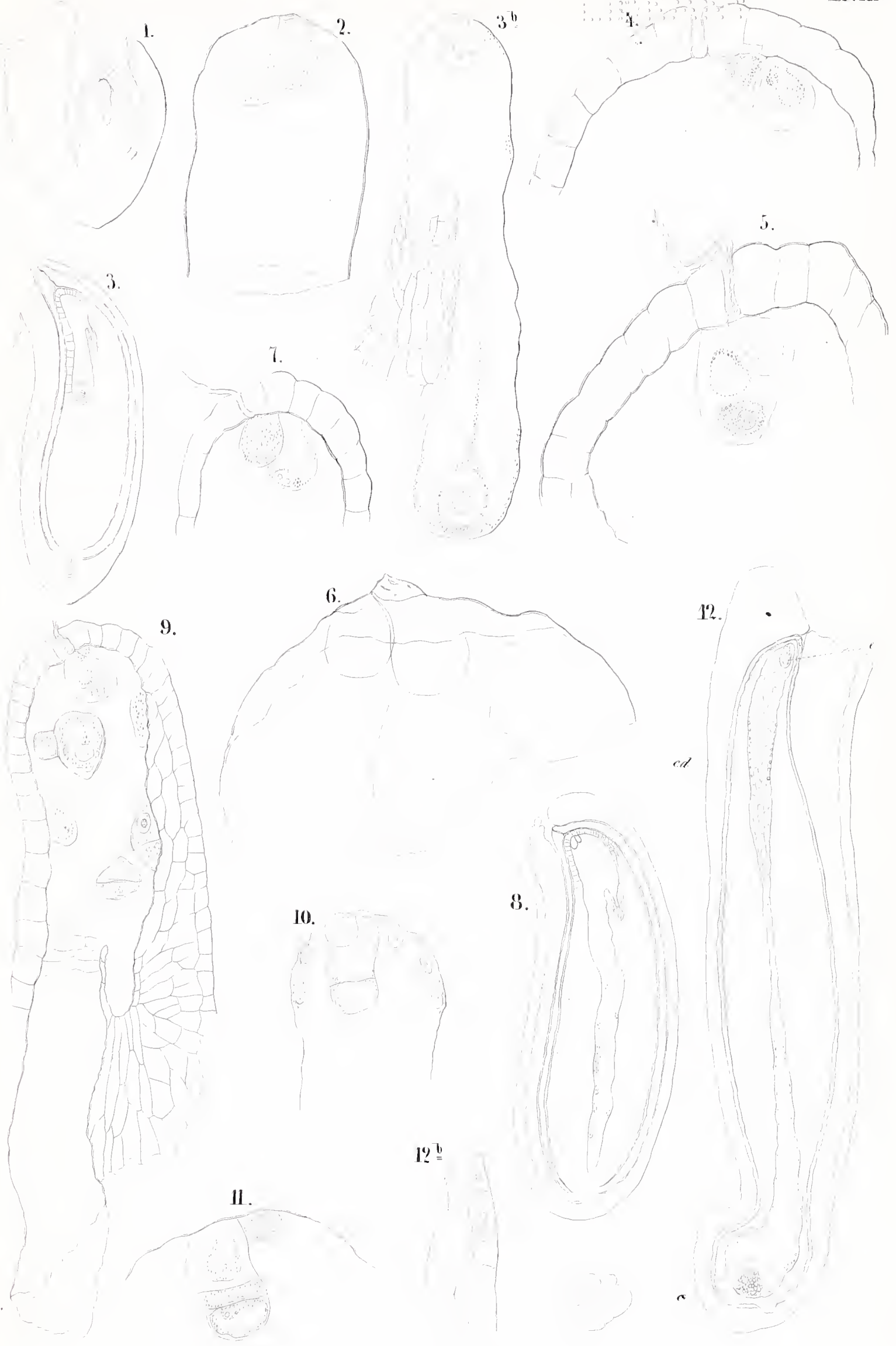

Veltheimia viridilloras. 



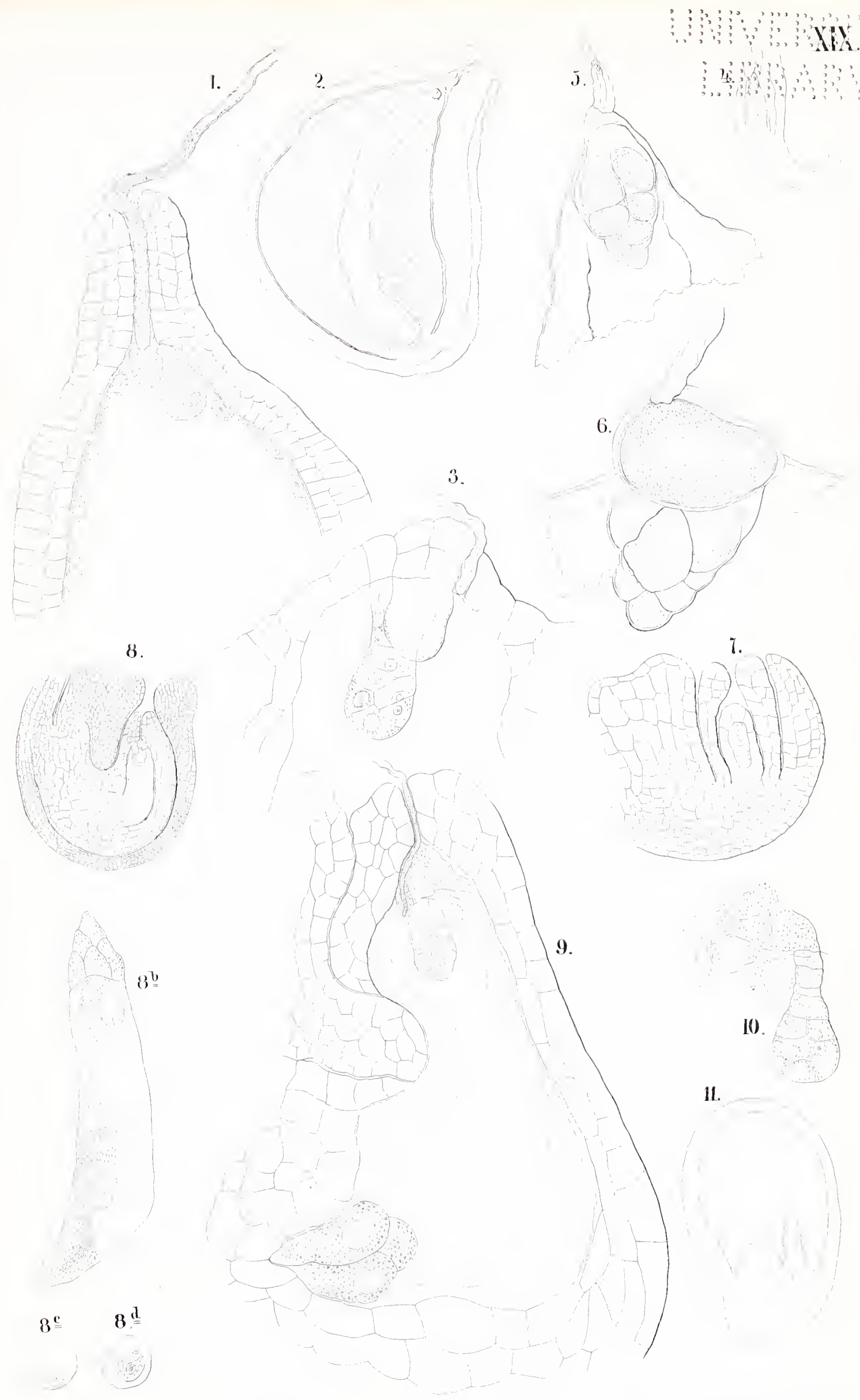

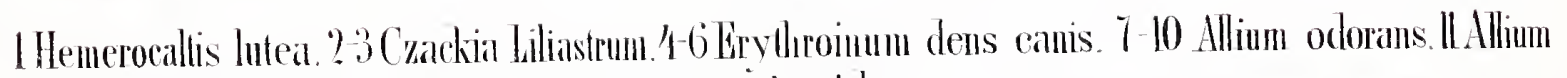
victoriale. 



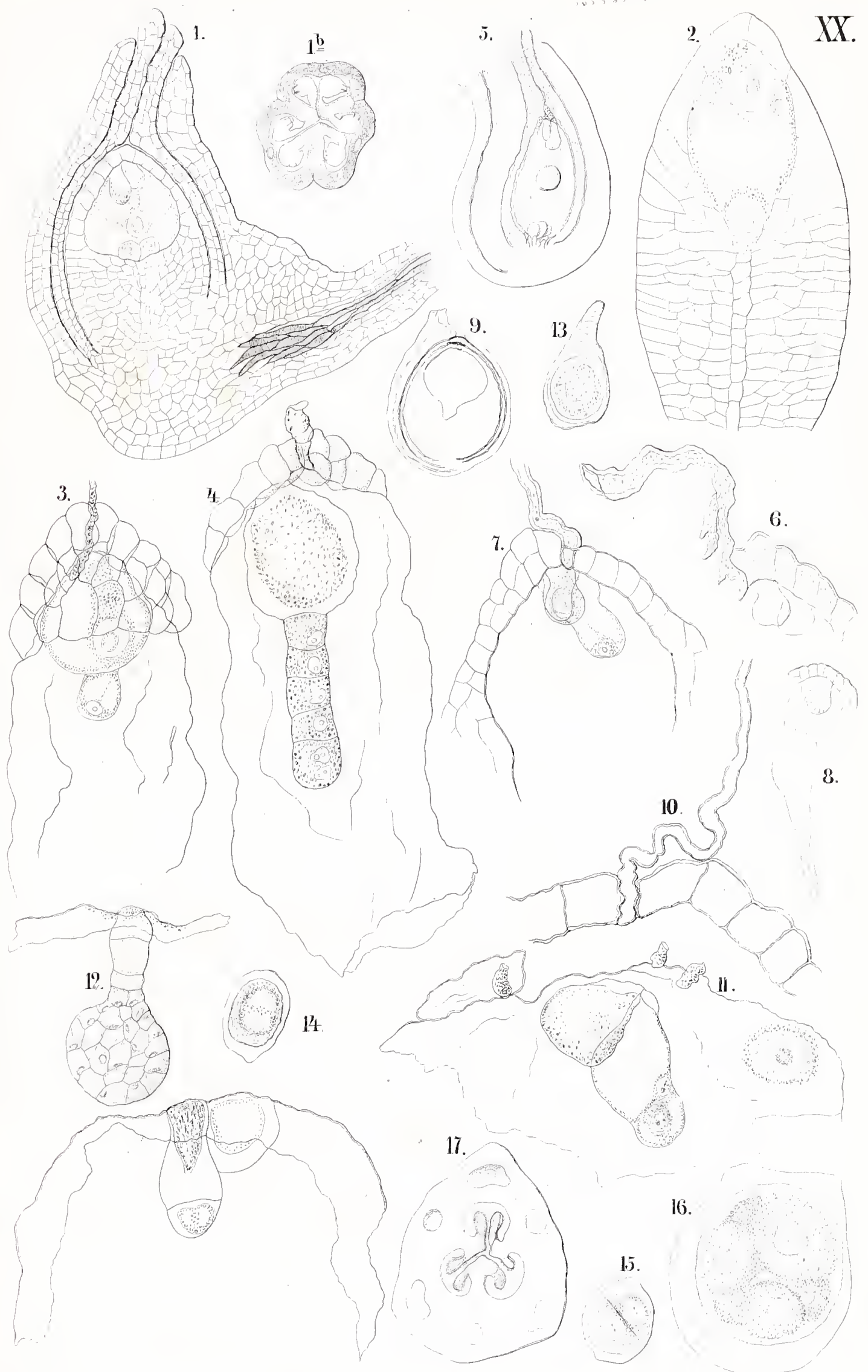

I'Tritcleia uniflora. 2-4 Gagea lutea. 5 Gloriosa superba. 6-7 Funkia coerulea. 8 Bonapartea juncea. 912 Puschinia scilloides. 1311 Iris punita. 



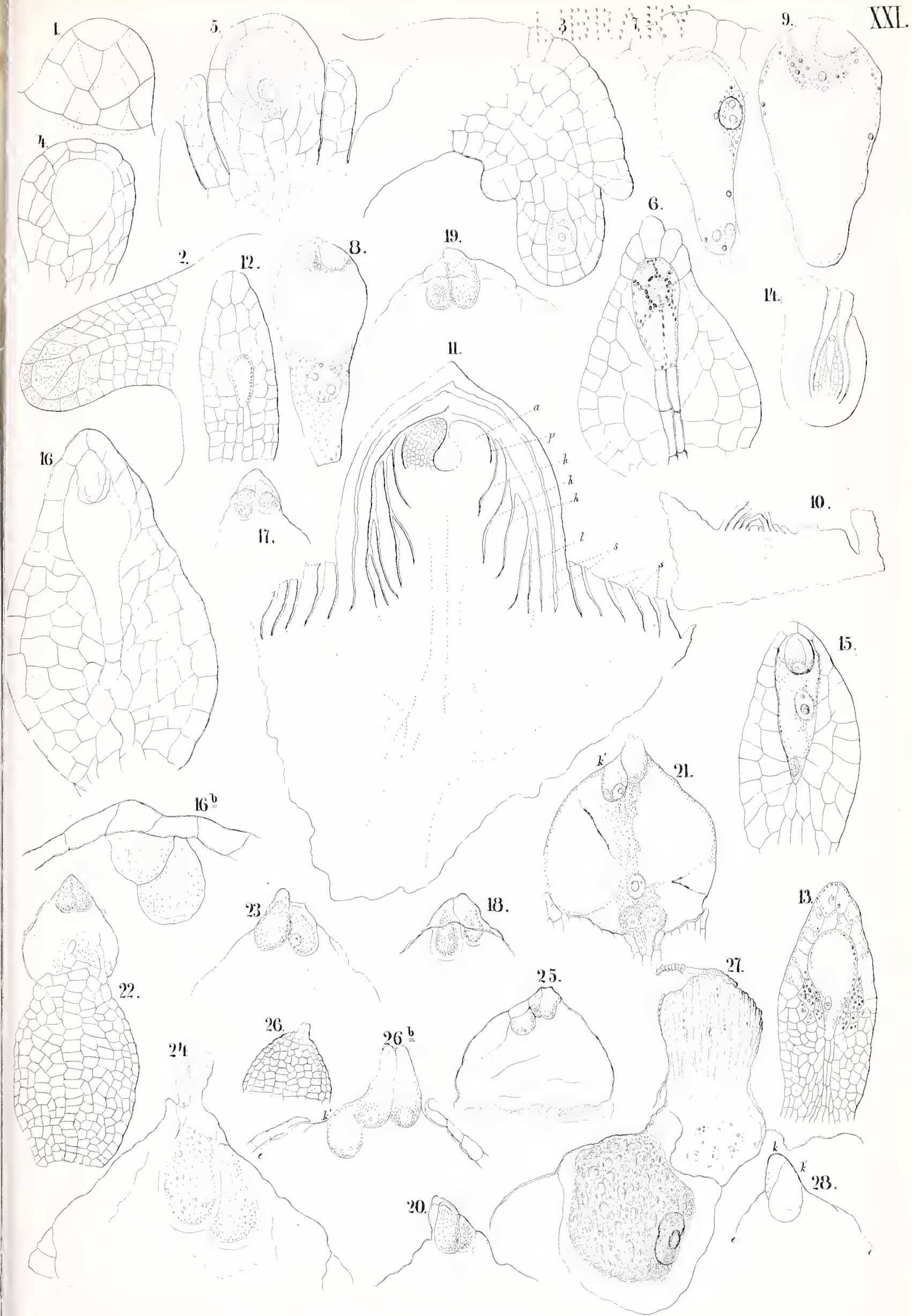

1-9 Iris pumila. 1028 Crocus vermus. 



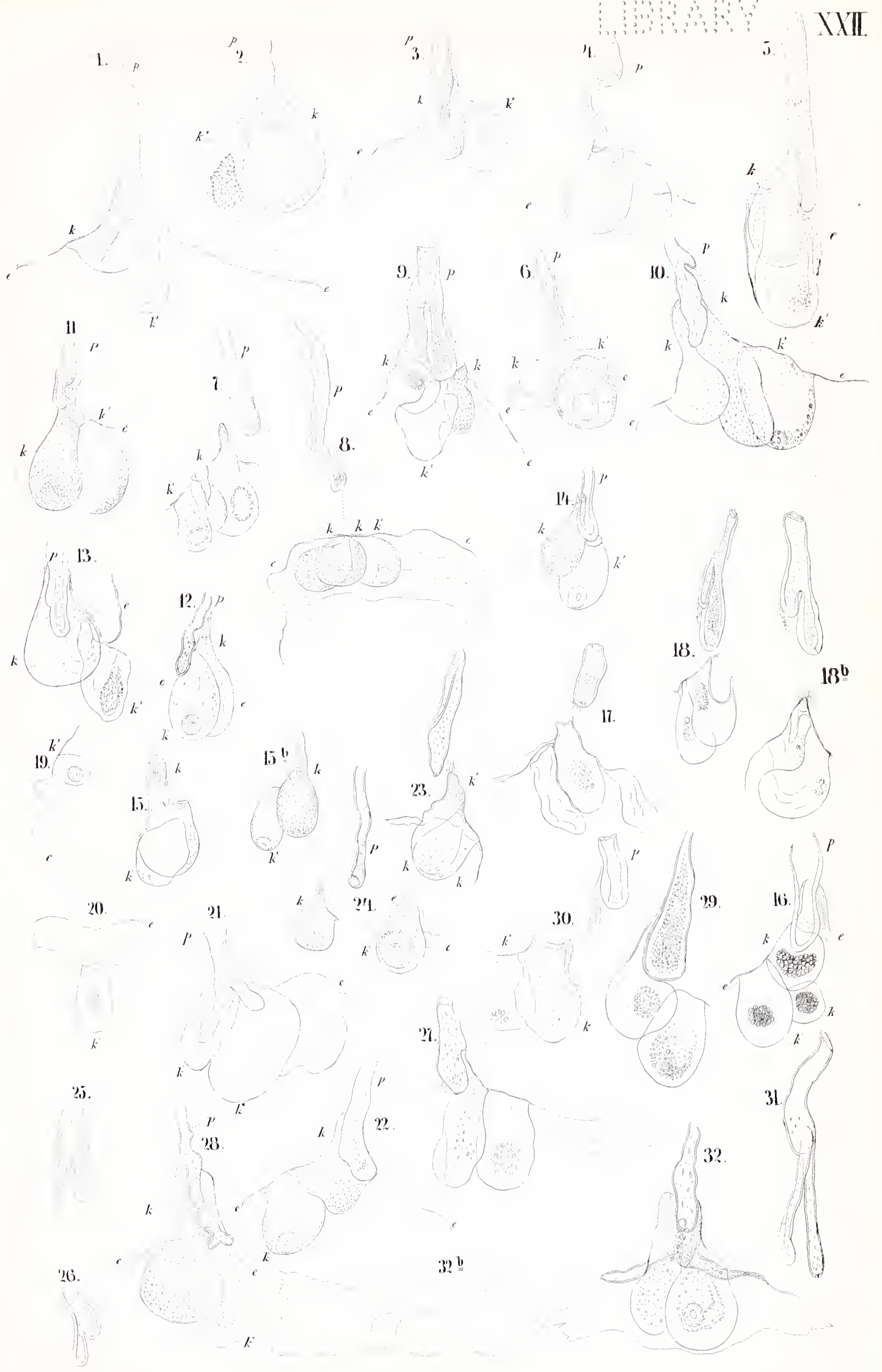





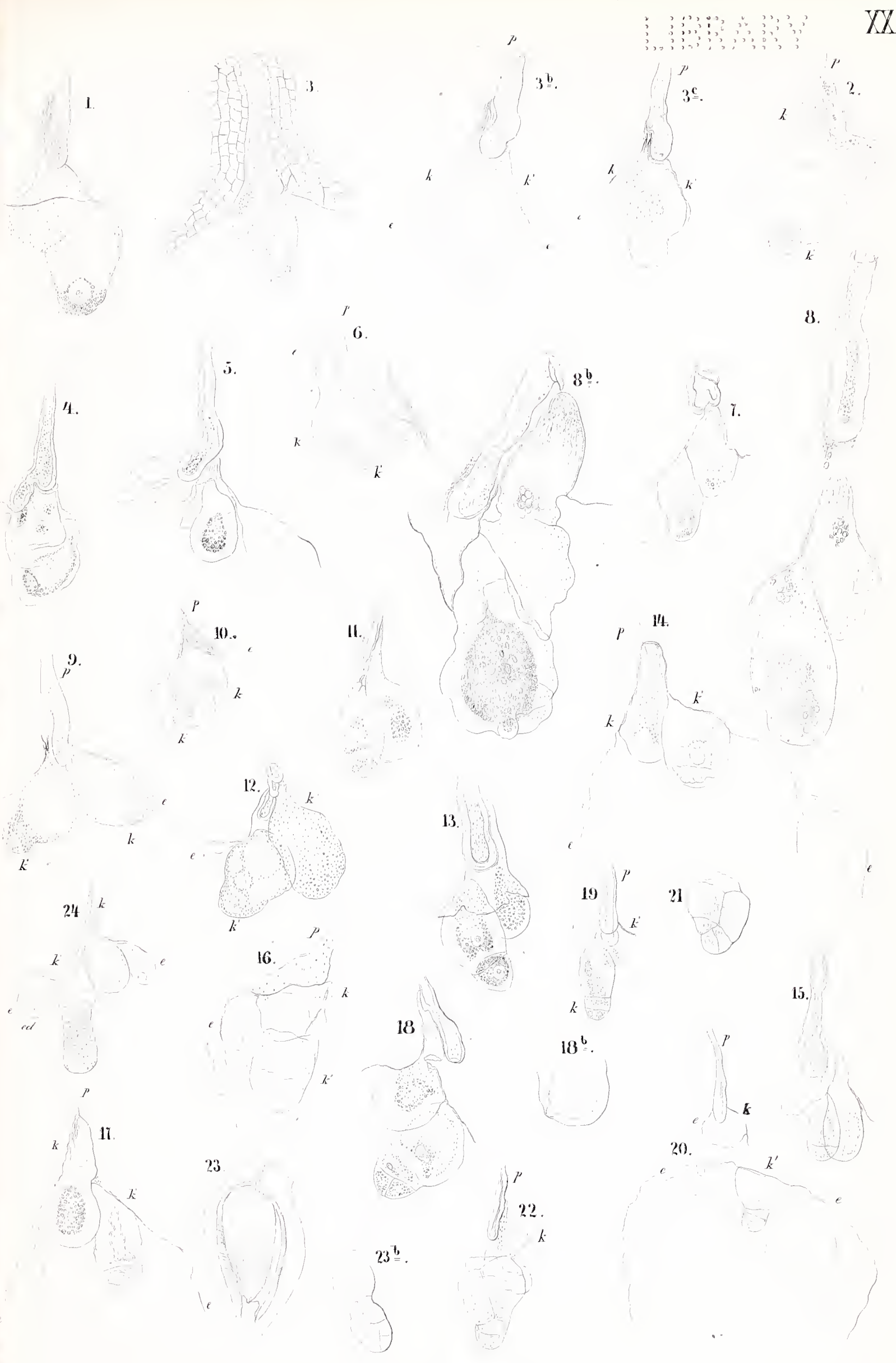

Th. Hormeister ael.

Crocus vernus. 



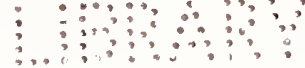

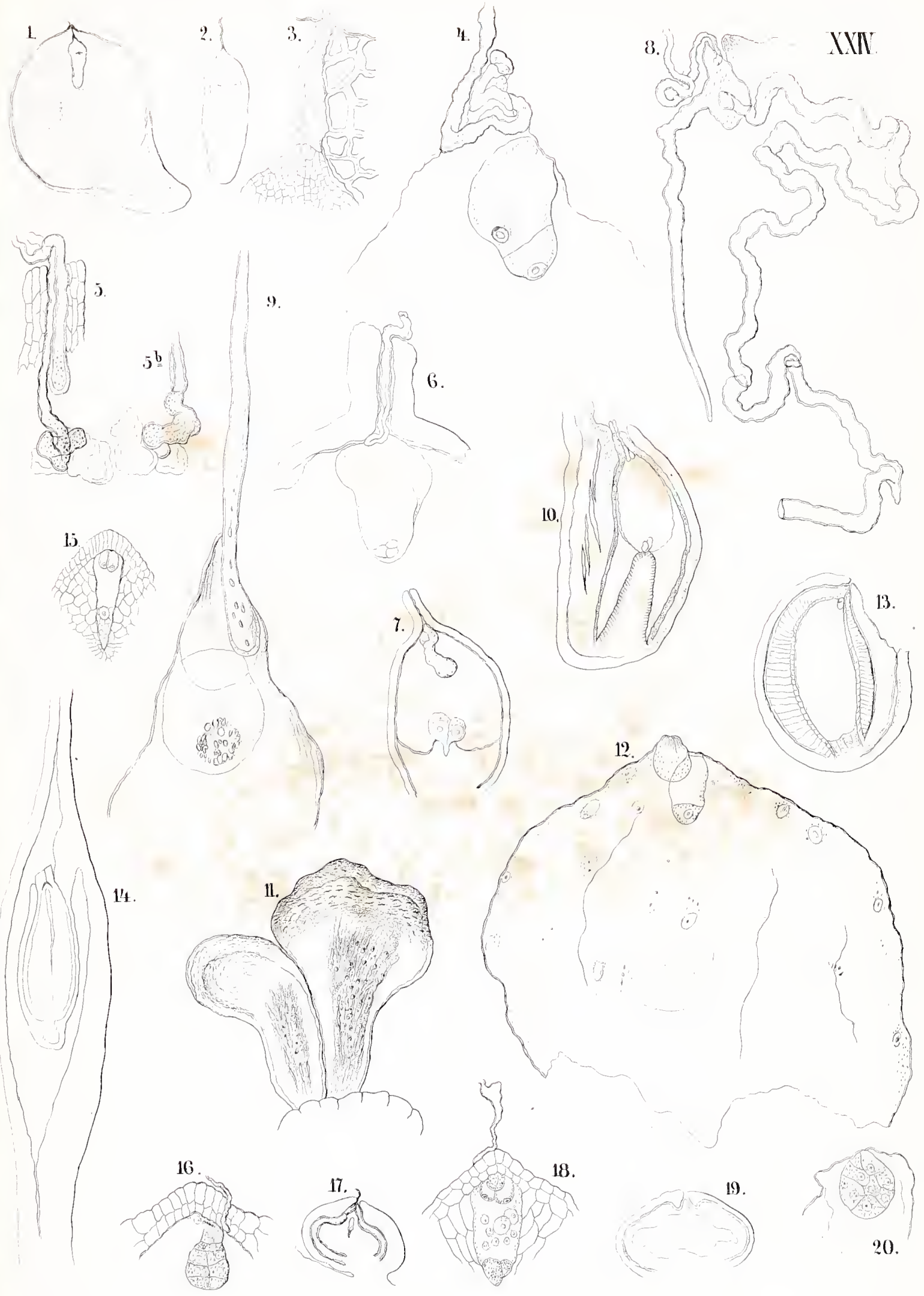

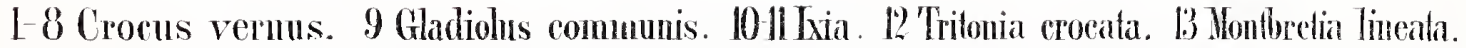
14-16 Pontederia cordata. 1'-20 Tradeseantia virginica. 



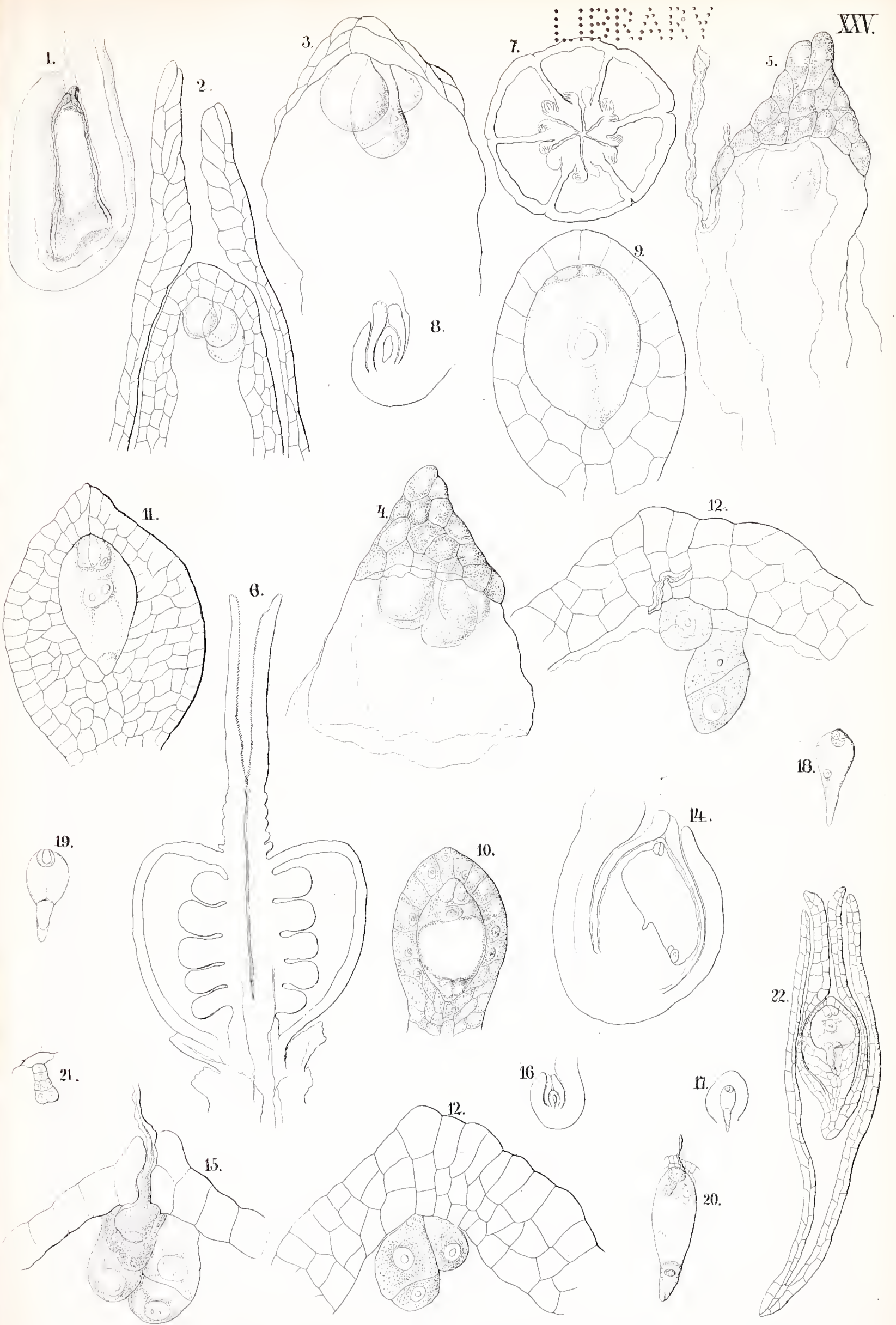

1-5 Hymenocallis ovatia. 6-13 Paris quadrilolia. 14-15 Narcissus Joncfuilla. 



it.

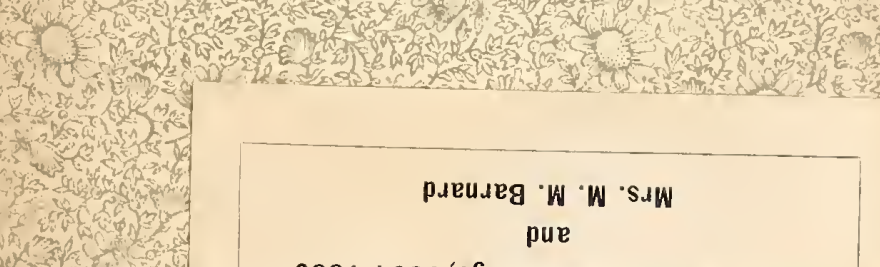

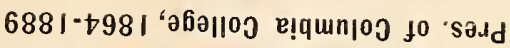
:0.77. p.puleg 'd $\forall j$

J) 189

zsonbag วप? mody

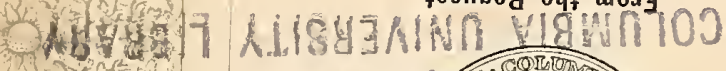

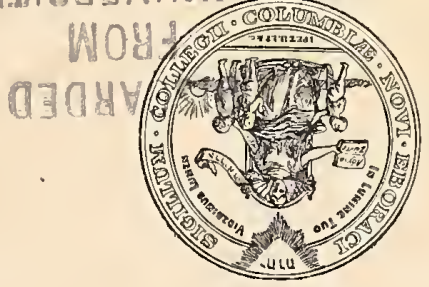

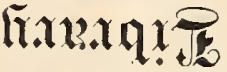

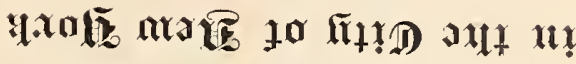

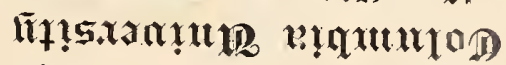

$\theta$

$129 \mathrm{H}$

ti189 [I

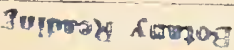


discos (1)

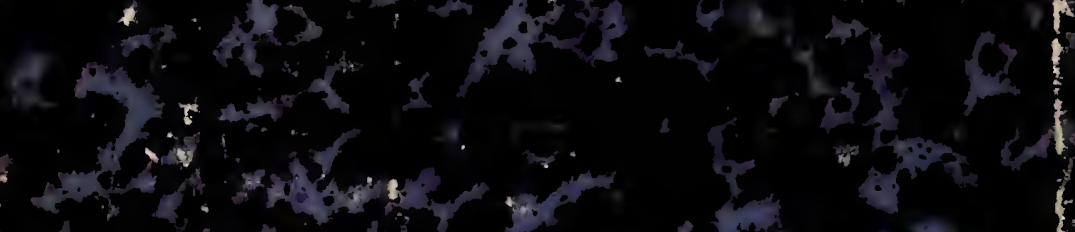

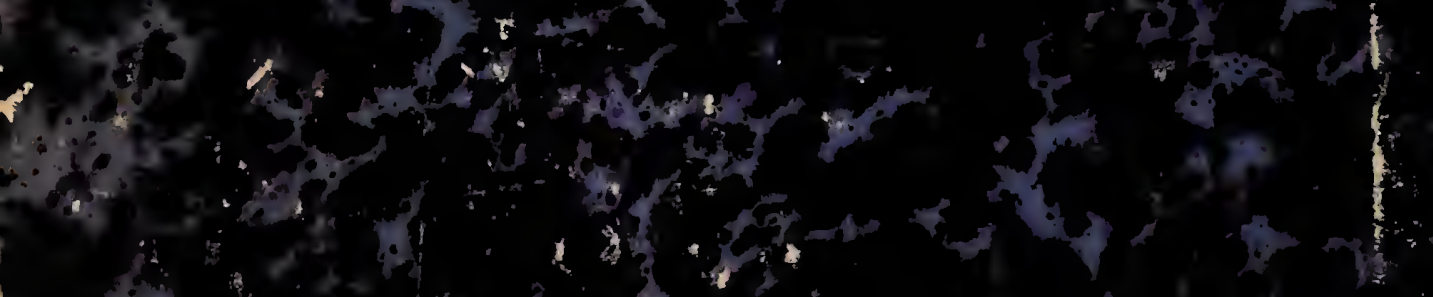

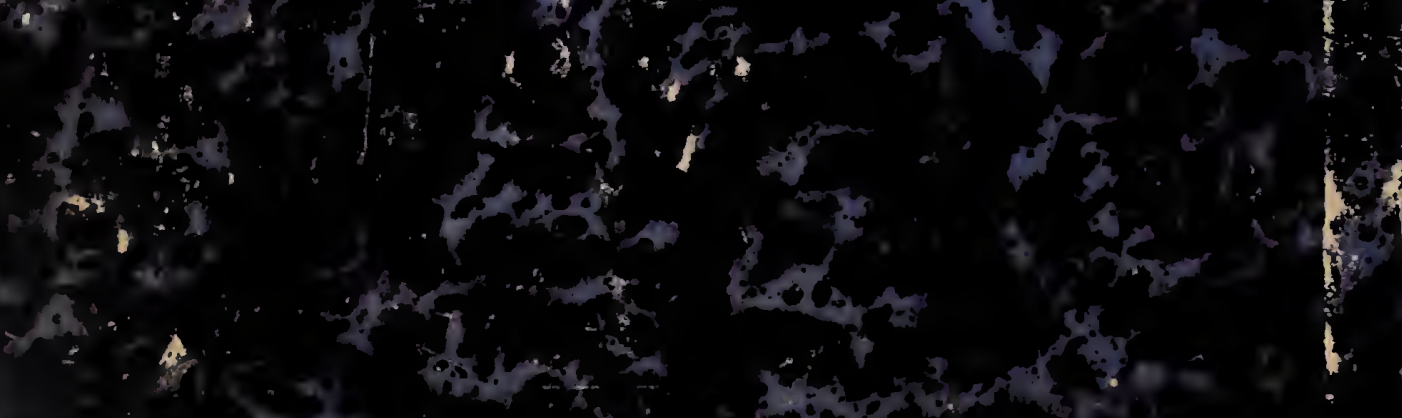

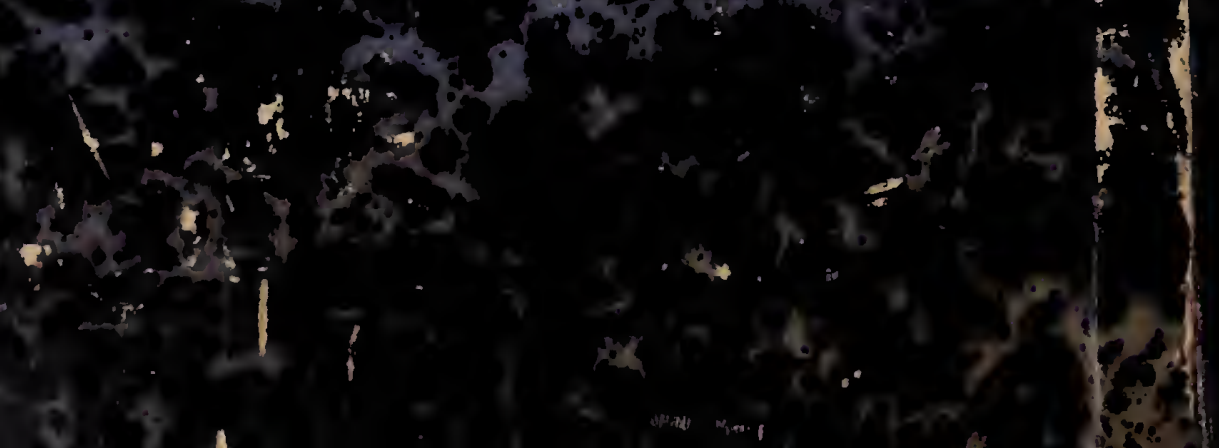

